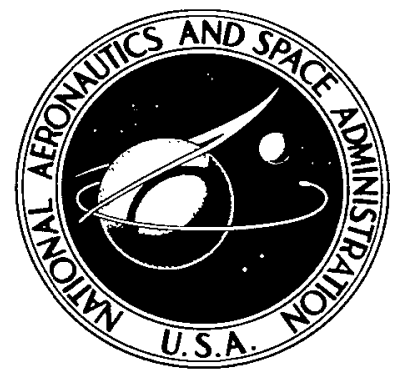

NASA IN 0.4527 C.I

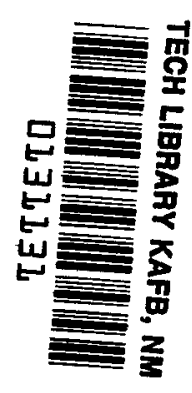

LOAN COPY: RETURN TO

\title{
THE GEOMAGNETIC SECULAR VARIATION
} $1900-1965$

by Joseph C. Cain and Shirley J. Hendricks

Goddard Space Flight Center

Greenbelt, Md.

NATIONAL AERONAUTICS AND SPACE ADMINISTRATION • WASHINGTON, D. C. • APRIL 1968 
THE GEOMAGNETIC SECULAR VARIATION

$$
1900-1965
$$

By Joseph C. Cain and Shirley J. Hendricks

Goddard Space Flight Center

Greenbelt, Md.

NATIONAL AERONAUTICS AND SPACE ADMINISTRATION

For sale by the Clearinghouse for Federal Scientific and Technical Information

Springfield, Virginio 22151 - CFSTI price $\$ 3.00$ 


\begin{abstract}
The GSFC (12/66) model of the main geomagnetic field uses linear and parabolic terms in time, to represent secular change over the interval 1900-1965. The predicted field is compared with observatory annual means to investigate systematic residuals. Deviations of the order of $100 \gamma$ occur for short spans of years and only in limited regions. Otherwise, the trends of the computed field parallel the observations. Secular-change charts agree well with those drawn by earlier analyses.

The westward drift is generally apparent in the vector representation of the harmonic coefficients, except that a few terms predominantly undergo an amplitude change. The components below $\left(g_{6}{ }^{6}, \mathrm{~h}_{6}{ }^{6}\right)$ that show a recognizable eastward drift are the $(3,2),(5,1)$, and $(5,2)$ terms.

Both dipole poles move smoothly northwestward over the interval, whereas the dipole position initially drifts eastward, reverses direction near 1920, and then moves westward at a rate up to about 0.07 degrees per year. Its 1965 position is found to be $78.8^{\circ} \mathrm{N}, 70.0^{\circ} \mathrm{W}$.
\end{abstract}


CONTENTS

Abstract............................ ii

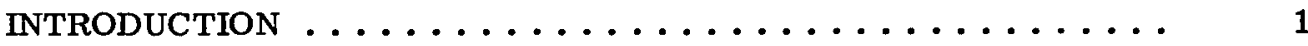

COMPARISON WITH OBSERVATORY ANNUAL MEANS ....... 2

COMPARISON WITH EARLIER ISOPORIC CHARTS ......... 5

THE GEOMAGNETIC SECULAR VARIATION FIELD IN $1965 \ldots \ldots$

DRIFT OF HARMONIC COMPONENTS ............... 6

CHANGES IN SURFACE FEATURES ............... 7

POSITION OF POLES ...................... 8

DECREASE IN MAGNETIC MOMENT OF DIPOLE ......... 8

CONCLUSIONS ......................... 9

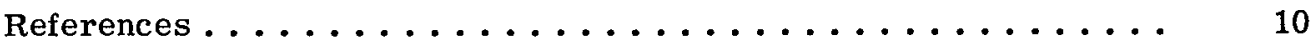

Appendix A-Comparison of Observatory Annual Mean Values 1900-1965 With Elements Computed From

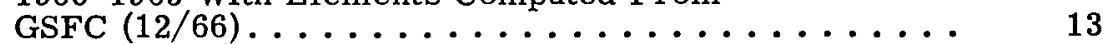

Appendix B-Comparison of Isoporic Charts (1912-1942) From GSFC (12/66) With Those From Vestine et al. (1947). . . 157

Appendix C-Main Field Component and Isoporic Charts Computed From GSFC (12766) for 1965.0 at the Earth's Surface . . 207 


\title{
THE GEOMAGNETIC SECULAR VARIATION $1900-1965^{*}$
}

\author{
by \\ Joseph C. Cain and Shirley J. Hendricks \\ Goddard Space Flight Center
}

\section{INTRODUCTION}

In the last few centuries over a hundred papers have been written concerning the main geomagnetic field and its secular variation. These research efforts have followed two main lines of approach: (1) the data from fixed observatories or relocatable positions (repeat stations) are compared quantitatively over a year or two and the differences by components contoured on charts. These secular-change, or isoporic, charts can be compared at intervals (e.g., decades) to attempt to learn how the patterns are changing with time. (2) Magnetic charts for given epochs are constructed, using survey observations reduced to the epoch of the chart. These charts are subjected to spherical-harmonic analysis and the results compared for several epochs (Mauersberger, 1952; McDonald and Gunst, 1967).

Recently we have chosen a different approach making a numerical fitting to all of the observational data available through the Magnetic Division of the United States Coast and Geodetic Survey for the period 1900-1964 plus some recent global satellite data acquired by the OGO-2 satellite. The result of this work, designated the GSFC(12/66) field model (Cain et al., 1967), is intended for use as an initial tool in evaluating time variations in the field observed by OGO-2. A set of 120 spherical harmonics of the internal potential were obtained, including their first and second time derivatives.

The accuracy of this expansion in matching the observational data was expressed in terms of the residuals of fit by type of data, component, and epoch. It was shown that the non-satellite data was scattered about the fit with a Gaussian distribution $(\sigma \sim 120 \gamma)$, apart from some higher-thanGaussian tails. Over half the data of a given component lay within $100 \gamma, 75$ percent within $200 \gamma$ and 95 percent within $500 \gamma$ of the fit. The distribution by component varied slightly, with the Gaussian "core" of the $\Delta z$ distribution being the widest at $210 \gamma$, whereas the total field distribution (with a $100 \gamma$ core) was the narrowest. Inspection of the data makes it clear that the large nonGaussian excursions of the survey data about the fitting surface are due to crustal anomalies.

\footnotetext{
*This paper was presented at the International Union of Geodesy and Geophysics 14th General Assembly St. Gall, Switzerland, September 30, 1967.
} 
(Considering the fact that the distributions were obtained without our making any selection of the observations, and no corrections were made for short period variations, it is remarkable that only 5 percent of the data fall outside the $500 \gamma$ limit.)

The satellite data are free from the influence of these crustal anomalies and depart by much less from the fitting surface. The OGO-2 total field data used were taken from a magnetically quiet period (October 29-November 15, 1965) and deviated with an almost Gaussian distribution whose constant was $12 \gamma$. The root-mean-square residuals of the survey data (those differing by more than $2000 \gamma$ were rejected) were of the order of $180-260 \gamma$ for individual years over the interval 1906-1964, after decreasing from a peak of $320 \gamma$ in 1900. It was suggested in the previous paper that there may thus be systematic deviations of the secular change estimates from the fitting surface.

In creating the GSFC(12/66) field model, a deviation was made from previous practice. No special heavy weighting was given to the observatory data included in the fit. As explained in the discussion of the GSFC(12/66) derivation, the earlier evaluations (Cain et al., 1965; Hendricks and Cain, 1966; and Cain, 1966) used very heavy relative weights for the observatory data because these are more accurate than the field survey data. However, these analyses showed that the scatter of the observatory data was not appreciably different from that of the rest of the observations; the main disturbing factor is the presence of crustal anomalies and not measurement inaccuracies. The observatory annual means were thus entered into the fit with the same relative weights as the other surface data.

In past work on secular change, displays of comparisons between the observational data and the results of analysis have been surprisingly few. This paper shows how the parabolic series for the spherical harmonic coefficients matches the field variations measured at selected magnetic observatories, and points out how some features of secular change compare with those reported in past papers.

\section{COMPARISON WITH OBSERVATORY ANNUAL MEANS}

Appendix A, consisting of a map (Figure A1) and 212 graphs (Figures A2 through A213) shows the results of comparing the field components computed from the GSFC(12/66) model with annual means observed at a selection of magnetic observatories. (Figure A1 shows the location of most of the observatories.) The graphs (plotted automatically) are arranged alphabetically by observatory name. An observatory is omitted only if it offers less than five annual means. Under each observatory's name is its latest location, given by geodetic longitude and latitude in decimal degrees (positive east and north) and its altitude in kilometers, if known and above 100 meters. The vertical scales, arranged from left to right, show $\mathrm{H}$ and $\mathrm{Z}$ in gammas with $1000 \gamma$ between abscissa ( $Z$ positive down), and $D$ in degrees (positive eastward) at 2-degree intervals. The computed values are traced by the solid lines and are labeled on the right side according as they are $\mathrm{H}, \mathrm{D}$, or $z$. There is a break in the computed curves if the observatory was moved. The calculations are made as appropriate to the site of observation. 
The observed annual means are plotted as $\oplus$ for $H, \odot$ for $D$, and $\square$ for $Z$. In reproduction, these symbols are not always clear but may appear as filled circles or squares. (The symbols $\mathrm{H}$, $\mathrm{D}$, or $\mathrm{Z}$ also appear before the first hourly mean for each graph, as appropriate.) The computed values are fed to the cathode-ray-tube plotter for each year for which there are observations of a component. The plotter beam is left on between points and traces out a straight line. The continuous curves thus appear lighter for those years for which observed means are missing, since the beam moves more quickly; and, whereas a continuous set of points seems to give a smooth curve, large gaps in the data (e.g., Chelyuskin, Hel) result in a straight line connecting the points.

One feature of the plots is that the observed data occasionally disappear from the top or bottom of the plots. This problem arose in imperfections in the computer algorithm which was computed in order to give a scale that would suit all graphs. Since only a few plots were affected and the algorithm was already quite complex, it was decided to omit the worst offenders and keep the rest. Thus in a few instances (e.g., Dombas $z$ before 1928) there are more observed data than appear on the graphs. The fact that observed and measured data often parallel each other with up to a few hundred gammas displacement (e.g., Alibag) suggests that the absolute differences are due to crustal anomalies. This view is supported by such examples as Honolulu, where the observed values hopped from one side of the computed $\mathrm{D}$ and $\mathrm{H}$ curves when the station was moved, around 1947. The question then arises: does the total observed secular change represent that of the main field, or does it include a contribution from crustal matter with a "soft" permeability? Here we assume that the changes with time in the anomaly field are unimportant; they are probably of the order of the percentage secular change multiplied by the size of the anomaly. Thus, for the 95 percent of the data within $500 \mathrm{\gamma}$, variations of the anomaly field due to a change of the main field by a few percent would represent only a few gammas. The graphs indicate that the oscillation of the data from the fitting surface is more often of the order of $100 \gamma$.

Eleman (1966) has pointed out another factor regarding the influence of anomalies. If a constant anomaly causes the observed annual means $\mathrm{H}$ and $\mathrm{D}$ to deviate from the normal field $\mathrm{H}_{\mathrm{N}}$ and $\mathrm{D}_{\mathrm{N}}$, then a representation of secular change in terms of $\dot{\mathrm{H}}$ and $\dot{\mathrm{D}}$ can be erroneous. If $\delta=\mathrm{D}_{\mathrm{N}}-\mathrm{D}_{\mathrm{N}}$, the secular change of the normal field is given by

$$
\begin{aligned}
& \dot{\mathrm{D}}_{\mathrm{N}} \approx\left(\mathrm{H} / \mathrm{H}_{\mathrm{N}}\right) \dot{\mathrm{D}}-\left(\dot{\mathrm{H}} / \mathrm{H}_{\mathrm{N}}\right) \delta, \\
& \dot{\mathrm{H}}_{\mathrm{N}}=\dot{\mathrm{H}}+\dot{\mathrm{H}} \dot{ } \delta,
\end{aligned}
$$

provided that $\delta$ is sufficiently small, so that $\cos \delta \approx 1$ and $\sin \delta \approx \delta$. Eleman showed that for Kiruna (1954-1955) the second terms amount to about 1 minute per year for $\dot{D}$ and $4 \gamma$ per year for $\dot{H}$. A plot of the data in the orthogonal components $X, Y$, and $Z$ should eliminate any concern over this geometric interaction. We have chosen to make the comparison here in terms of the observed values, since at this stage such refinements are not essential.

If the displacement due to crustal anomalies is taken into account, curve trends can be profitably compared with the observations. Considering that the fit was made to a selection of all data 
without any corrections for storm variations or other transient effects such as the diurnal variations, the agreement is, in general, fairly good. For most observatories, the computea and measured $\mathrm{H}$ component trends not only are very nearly parallel but also show little absolute displacement. Declination trends agree somewhat less well. The vertical intensity curves show the largest displacements and the poorest agreement of the curves as a whole, and the largest scatter of individual points.

Significant discrepancies between predicted and observed data occur at the western edge of the Indian Ocean. Mauritius vertical-intensity and Tananarive declination curves have a smooth parabolic shape that differs considerably from the computed curves. Alibag vertical intensity, after tracking very well for the first 40 years, now shows an increasing deviation from computed values.

For most of the other graphs, the deviations from the computed curves must be real because they exceed any possible errors of measurement; but generally they can be regarded as secondorder perturbations from the main trend of secular change. These deviations can matter seriously when the field model is used to compute a reference field, particularly when extrapolating beyond 1965.

A relationship may exist between the earth rotation rate and secular change (Dicke, 1966). In the period 1900-1920, for example, there may have been a short-lived reversal of the slowing of the earth's rotation rate that has otherwise appeared to be almost constant from 1800 through 1950 (Munk and MacDonald, 1960). The high residuals of fit from 1900 to 1910 noted in the previous paper (Cain et al., 1967) may have been related to this phenomena. In the absence of 18th-century survey data, it is uncertain that such an increase was not due to the numerical process of least squares, where the residuals are sometimes largest near the fringes of the data set-particularly when the data distribution is relatively thin (as it is for 1900-1910).

However, the graphs in Appendix A do show a definite trend away from the parabolic curves for 1900-1910 for some components and stations. The curves for all English and European observatories (e.g., Bochum, Stonyhurst, Kew, DeBilt, Greenwich, etc.) show that the measured secular change in $\mathrm{H}$ is significantly more positive than that computed. Likewise, for the same area the secular change in declination is more negative than that predicted. The boundaries of this phenomenon are somewhat vague but it is clearly not present in the Pacific, South America, and Asia (e.g., Melbourne, Hong Kong, Kakioka, Christchurch, Kodaikanal, Huancayo, Santiago, Colaba, etc.). In the United States (Cheltenham, Baldwin, Sitka) and central Russia (Sverdlovsk) the higher observed secular change in $\mathrm{H}$ is evident, but not the corresponding disparity in declination. It is undoubtedly such irregularities that have led investigators (e.g., Chapman and Bartels, 1940 , p. 130) to conclude that secular variation is a regional phenomenon. Although the deviations seem to correlate for observing stations in a given region so that a very accurate mathematical model would require their inclusion in some way, it is apparent that the general character of secular change is well enough represented by this model. 


\section{COMPARISON WITH EARLIER ISOPORIC CHARTS}

Using the GSFC(12/66) coefficients it is possible to compute the secular change of the components at any epoch. This is a simple process for the orthogonal components (differentiating the expressions for those components and evaluating $-\nabla \dot{\mathrm{V}}$ ), but the representation of $\dot{\mathrm{H}}$, $\dot{\mathrm{D}}$, and $\dot{\mathrm{I}}$ requires special expansions. It is therefore simpler to compute the field for a small increment of time (e.g., 0.5 year) on either side of an epoch and take the difference. This procedure was carried out for the epochs 1912.5, 1922.5, 1932.5, and 1942.5 for the components $\mathrm{H}, \mathrm{I}, \mathrm{X}, \mathrm{Y}, \mathrm{Z}$, and $\mathrm{F}$ and isoporic charts drawn by means of an automatic contouring procedure similar to that described by Cain and Neilon (1963). These charts appear in Appendix B along with reproductions of the corresponding ones from Vestine et al. (1947). These charts may also be compared with those for 1922 by Fisk (Chapman and Bartels, 1940, p. 115-119).

Comparison with the earlier charts shows in all instances the same basic cell structure. The GSFC-map extreme values for the force components differ by a few tens of gammas per year from the values given by Vestine et al. and generally have a smaller absolute magnitude. For the inclination charts, the agreement with Vestine is within a few minutes per year for the center cells. Comparison with the diagrams by Fisk for 1922 also leads to the conclusion that the GSFC extreme values are of smaller absolute value than those on the earlier works. This suggests that the analysis using only 120 spherical harmonics may give too smooth a picture of the secular change patterns.

\section{THE GEOMAGNETIC SECULAR VARIATION FIELD IN 1965}

For those wishing to use the GSFC(12/66) model as a reference at current epochs, Appendix C presents a set of surface charts for 1965.0 (Figures $\mathrm{C} 1$ through C13). These closely agree with the U. S. World Magnetic Charts for the same epoch; although, as previously noted in the comparison with the earlier isoporic charts, the GSFC(12/66) patterns are slightly broader and less intense.

Comparing the computed rate of change since 1960 with that observed at various observatories shows some systematic deviations over certain areas of the earth. For example, the observed rate of change in the vertical component over South America is of the order of 40 gammas per year greater than the computed rate. Increasing the computed rate for the area by this amount would sharpen the low cell pattern to the northeast and bring the GSFC(12/66) model into closer agreement with the U. S. Charts. Also, for the region around the Caspian Sea, the observed change in the horizontal intensity is about $30 \gamma$ per year less than that computed. Changing the computed rate by this amount would again result in better agreement with the U. S. Charts. Other regional deviations since 1960 were noted. In Europe and North America, the observed change in $Z$ is about $15 \gamma$ per year less than that computed; in Europe and South America, the variation in $\mathrm{H}$ is about $15 \gamma$ per year greater than that computed; in Central America, the variation in $\mathrm{H}$ is about $30 \gamma$ per year less than that computed. The secular change in declination appears to be 1 to 2 
minutes per year less than that computed in Europe and most of Russia, 2 to 4 minutes per year less in South America, and up to 10 minutes per year less along the northern coast of Scandinavia and Russia.

Thus, the present model apparently produces patterns of secular change that may, in general, be smoother than the observed changes, but it would be hard to improve the representation realistically over the whole sphere, using the present sparse data set. However, these comparisons do suggest that the user of the GSFC(12/66) model as a reference beyond 1965 should be wary of possible deviations of the order of magnitude indicated above.

\section{DRIFT OF HARMONIC COMPONENTS}

Figure 1, a plot of $\mathrm{g}$ and $\mathrm{h}$ harmonic vectors, displays one aspect of secular change. The trace of the individual components is given from 1900 to 1970 , with the arrow at the later date, for the components $\left(\mathrm{g}_{1}{ }^{1}, \mathrm{~h}_{1}{ }^{1}\right)$ through $\left(\mathrm{g}_{6}{ }^{6}, \mathrm{~h}_{6}{ }^{6}\right)$. The scale is in gammas and must be divided by 5 for the $\left(g_{5}{ }^{1}, h_{5}{ }^{1}\right)$ through $\left(g_{6}{ }^{6}, h_{6}{ }^{6}\right)$ traces. Also, the scale is broken for the large $h_{1}{ }^{1}$ component. This figure is very similar to one that Cain and Hide (1966) show for the results of an earlier analysis. A single curved arrow is used for the whole interval without indicating the location of the points for the years between 1900 and 1970; however, a detailed inspection of the data revealed that the years fall almost uniformly along each path.

Consideration of the westward drift in terms of harmonic components was first discussed by Carlheim-Gyllenskolld, who deduced that the harmonic components of the first few terms drifted westward at an increasing rate according to the degree of the expansion. Bartels disagreed with this deduction on the basis of his analysis of data from the period 1902-1920 (cf. Chapman and Bartels, 1940, p. 666). Phase changes for the spherical harmonics are also discussed in several later works (cf. Nagata, 1962) which conclude that all components up to $(4,4)^{*}$ drift westward with the exception of $(3,2)$.

Figure 1 supports the general pattern of westward drift as indicated by the number of components moving clockwise about the origin. The components predominantly moving westward are $(2,1),(2,2),(3,3),(4,1),(4,2),(4,3),(5,4),(6,1),(6,2),(6,3)$; those predominantly moving eastward are $(3,2),(5,1)$ and $(5,2)$. The others tend to be special cases. For example, $(3,1)$ and $(4,4)$ and $(6,5)$ show a large amplitude change and move predominantly westward; $(5,3)$ and $(6,4)$ show a large amplitude change and move predominantly eastward. The dipole term $(1,1)$ is drawn with a bar across at the 1900 starting point. It traces out from 1900 to about 1920 in an increasingamplitude, eastward direction and then suddenly reverses and overlays itself with a slight westward motion. As pointed out earlier, it would be unwise to infer too much from this reversal before a systematic analysis is performed that includes pre-1900 data.

*The notation $(n, m)$ is used here to denote the components $\left(g_{n}^{m}, h_{n}^{m}\right)$. 


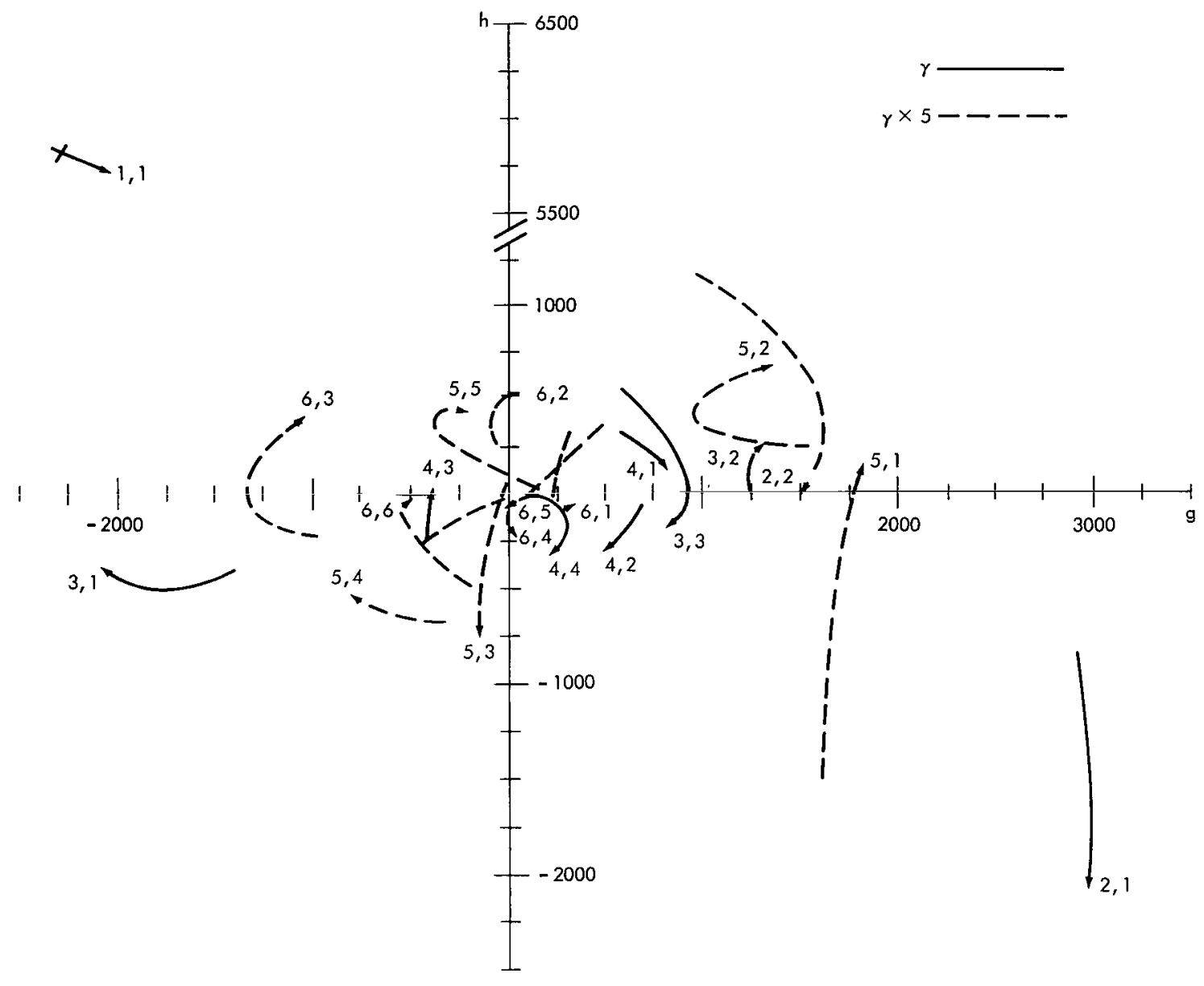

Figure 1-GSFC(12/66) coefficients 1900 to 1970.

The more constant and characteristic feature of this diagram, which was also discussed by Cain and Hide $(1966)$, is that-with the exception of the $(6,1)$ and $(5,3)$ traces-both eastward- and westward-moving components have a clockwise curl.

\section{CHANGES IN SURFACE FEATURES}

Bullard et al. (1950) treated the question of westward drift by considering the "non-dipole" field. This they defined by vectorially subtracting the eccentric-dipole field from a real field. This subtraction is commonly performed because the dipole contribution is so much larger than the others, appears to change differently, and thus may have a different physical basis. However, the absolute change in the $(1,1)$ component is not disproportionate to that in the other harmonic terms (Figure 1). The small angular change in its phase is due to its relatively large amplitude and a reversal of trend. At this juncture we shall discuss features pertaining to the whole field. 
A cursory inspection of some of the surface features confirms the general westerly motion of the field depicted by our model. The 0.23-degree-per-year drift of the Brazilian minimum in total field for this model has already been discussed (Cain, Langel, and Hendricks, 1967). The Siberian high in $\mathrm{F}$ at the surface is estimated by the model to be located at $61.8^{\circ} \mathrm{N}, 107.6^{\circ} \mathrm{E}$ in 1960 and moving at a rate of 0.03 degree per year north in latitude and 0.1 degree per year west in longitude. The Canadian high is also moving north from its 1960 position of $56.7^{\circ} \mathrm{N}, 98.0^{\circ} \mathrm{W}$ at a rate of 0.08 degree per year, but has an easterly drift of about 0.03 degree per year.

\section{POSITION OF POLES}

The GSFC(12/66) model shows both the north and south dip poles moving northwesterly. The change in position of these two points for the period of the data is shown in Table 1.

The 1965 latitude values agree exactly with those adopted for the U. S. (Hurwitz et al., 1966) and for the U. K. (Leaton, Malin, and evans, 1965) World Magnetic Charts but the longitude values differ by a few tenths of a degree.

Although the positions of the computed dipoles varied smoothly over the period 1900-1965, the direction of motion of the dipole appeared to reverse, as already indicated in Figure 1. The positions of the boreal point are given in Table 2. After the reversal near 1920 , the pole began to move westward at a current rate of about 0.07 degree per year.

The 1965 location given here can be compared with the $78.6^{\circ} \mathrm{N}, 70.4^{\circ} \mathrm{W}$ position given by Leaton, Malin, and Evans (1965) and the $78.6^{\circ} \mathrm{N}, 70.0^{\circ} \mathrm{W}$ position given by Hurwitz et al. (1966).

\section{DECREASE IN MAGNETIC MOMENT OF DIPOLE}

The first three terms of the expansion can be used to compute an equivalent dipole moment and equatorial field (Chapman and
Table 1

Drift of Dip Poles-GSFC(12/66) Model.

\begin{tabular}{|c|cc|cc|}
\hline Date & \multicolumn{2}{|c|}{$\begin{array}{c}\text { North Dip Pole } \\
\text { (degrees) }\end{array}$} & \multicolumn{2}{|c|}{$\begin{array}{c}\text { South Dip Pole } \\
\text { (degrees) }\end{array}$} \\
\hline 1900 & $71.2 \mathrm{~N}$, & $96.9 \mathrm{~W}$ & $72.3 \mathrm{~S}$, & $153.2 \mathrm{E}$ \\
1930 & $72.6 \mathrm{~N}$, & $99.0 \mathrm{~W}$ & $68.8 \mathrm{~S}$, & $144.7 \mathrm{E}$ \\
1960 & $75.1 \mathrm{~N}$, & $100.7 \mathrm{~W}$ & $66.7 \mathrm{~S}$, & $140.7 \mathrm{E}$ \\
1965 & $75.5 \mathrm{~N}$, & $101.0 \mathrm{~W}$ & $65.5 \mathrm{~S}$, & $140.3 \mathrm{E}$ \\
\hline
\end{tabular}

Table 2

North Dipole Location - GSFC(12/66) Model.

\begin{tabular}{|c|c|c|c|}
\hline Date & $\begin{array}{c}\text { Latitude } \\
\text { (degrees) }\end{array}$ & $\begin{array}{c}\text { Longitude } \\
\text { (degrees) }\end{array}$ & $\begin{array}{c}\text { Westward } \\
\text { Drift Rate } \\
\text { (degrees/year) }\end{array}$ \\
\hline 1900 & $79.0 \mathrm{~N}$ & $69.0 \mathrm{~W}$ & -0.03 \\
1910 & $78.8 \mathrm{~N}$ & $68.6 \mathrm{~W}$ & -0.01 \\
1920 & $78.7 \mathrm{~N}$ & $68.5 \mathrm{~W}$ & 0.01 \\
1930 & $78.7 \mathrm{~N}$ & $68.6 \mathrm{~W}$ & 0.02 \\
1940 & $78.7 \mathrm{~N}$ & $68.8 \mathrm{~W}$ & 0.04 \\
1950 & $78.7 \mathrm{~N}$ & $69.2 \mathrm{~W}$ & 0.05 \\
1960 & $78.7 \mathrm{~N}$ & $69.7 \mathrm{~W}$ & 0.07 \\
1965 & $78.8 \mathrm{~N}$ & $70.0 \mathrm{~W}$ &..- \\
\hline
\end{tabular}


Bartels, 1940, p. 642). With a value of $a=$ $6.3712 \times 10^{8} \mathrm{~cm}$ for a mean radius, the value of $M$ and $H_{0}$ are given in Table 3. Since field reversals are believed to have occurred in geological times (Cox et al., 1967), it has recently become popular (Leaton and Malin, 1967; McDonald and Gunst, 1967) to speculate on the demise of the main-field dipole (about 3700-4000 A.D.) by extrapolating a linear trend from such data as the above. Note, however, the tendency toward a reduction in the rate of decrease. Since our analysis included data for a time spanduring which there is only a 3-percent change in $M$, extrapolations to zero are most untrustworthy.

\section{CONCLUSIONS}

Since the GSFC(12/66) field analysis was performed on survey data without correcting them for short-period fluctuations such as Dst and $\mathrm{Sq}$, it is remarkable that the main patterns of secular change represented agree so closely with earlier analyses in which the data were subjected to a careful screening and correction process. The main defects of the model result from the irregular regional changes superimposed on the general trends and the use of a parabolic representation over too long an interval. Therefore, extrapolation of the model to epochs beyond the last data used (1965.8) will be increasingly in error-by as much as a few tens of gammas per year, in some areas. This deviation may seem large, but better forecasts can hardly be made until recent satellite survey data are evaluated over a year or more, to allow for a more accurate global estimate of secular change. This work does indicate that there is no special need for fixed repeat stations for monitoring the secular change. Although data from such stations were indeed a valuable addition to the data set, the analysis ignored the fact that they remained in one location. It may later be possible to monitor the main field using only satellite data corrected for time variations as derived from the fluctuations observed at the surface observatories.

The westward motion of most of the spherical-harmonic vectors confirms earlier observations. The clockwise curvature pattern for almost all components is noted for the first time as a curious and unexplained fact. The sudden reversal of the eastward drift of the dipole poles near 1920 may be due to inaccuracies in the analysis resulting partly from the poor distribution of data. On the other hand, the change may be connected with the 1900-1920 anomalous increase of the earth's rate of rotation. The slight slowing of the rate of decrease of the moment of the earth's main dipole suggests that the field is not beginning a cycle of reversal. To check such suggestions requires subjecting a much longer span of magnetic-field observations to a consistent analysis.

\footnotetext{
Goddard Space Flight Center

National Aeronautics and Space Administration

GreenbeIt, Maryland, November 22, 1967

841 - 12-02-06-51
} 


\section{REFERENCES}

1. Bullard, E. C., C. Freedman, H. Gellman, and J. Nixon, "The Westward Drift of the Earth's Magnetic Field," Phil. Trans. Roy. Soc., 243A, 67-92, 1950.

2. Cain, J. C., and J. R. Neilon, "Automatic Mapping of the Geomagnetic Field," J. Geophys. Res., 68, 4689-4698, 1963.

3. Cain, J. C., W. E. Daniels, S. J. Hendricks, and D. C. Jensen, "An Evaluation of the Main Geomagnetic Field, 1940-1962," J. Geophys. Res., 70, 3647-3674, 1965.

4. Cain, J. C., and R. Hide, "The Secular Change of the Geomagnetic Field (abstract)," Trans. Am. Geophys. Union, 47, 57, 1966.

5. Cain, J. C., "Models of the Earth's Magnetic Field," in Radiation Trapped in the Earth's Magnetic Field, edited by D. Reidel, p. 1, 1966.

6. Cain, J. C., S. J. Hendricks, R. A. Langel, and W. V. Hudson, "A Proposed Model for the International Geomagnetic Reference Field," Goddard Space Flight Center Document X-61267-173, 1967.

7. Cain, J. C., R. A. Langel, and S. J. Hendricks, "Magnetic Chart of the Brazilian Anomaly A Verification," Goddard Space Flight Center Document, X-612-67-373, 1967.

8. Chapman, S., and J. Bartels, Geomagnetism, Oxford University Press, London, 1940.

9. Cox, A., G. B. Dalrymple, and R. R. Doell, "Reversals of the Earth's Magnetic Field," Sci. Am., 216, 44, 1967.

10. Dicke, R. H., "The Secular Acceleration of the Earth's Rotation and Cosmology," in The Earth Moon System, p. 141, Plenum Press, New York, 1966.

11. Eleman, F., "Time Variations of Geomagnetic $\mathrm{H}$ and $\mathrm{D}$ at Disturbed Stations," Nature, 209, 1120-1121, 1966.

12. Hendricks, S. J., and J. C. Cain, "Magnetic Field Data for Trapped Particle Evaluations," J. Geophys. Res., 71, 346, 1966.

13. Hide, R., "Free Hydromagnetic Oscillations of the Earth's Core and the Theory of the Geomagnetic Secular Variation," Phil. Trans. Royal Soc., A259, 615-647, 1966.

14. Hurwitz, L., D. G. Knapp, J. H. Nelson, and D. E. Watson, "Mathematical Model of the Geomagnetic Field," J. Geophys. Res., 71, 2373, 1966.

15. Leaton, B. R., S. R. C. Malin, and M. J. Evans, "An Analytical Representation of the Estimated Geomagnetic Field and Its Secular Change for the Epoch 1965.0," J. Geomag. Geoelec., 17, 187-194, 1965.

16. Leaton, B. R., and S. R. C. Malin, 'Recent Changes in the Magnetic Dipole Moment of the Earth," Nature, 213, 1110, 1967.

17. Mauersberger, P., "A Discussion of the Variation with Time of the Parameters of the Geomagnetic Field Based on the Existing Potential Analysis, NASA TT-F-8443, 1963. 
18. McDonald, K. L. and R. H. Gunst, "An Analysis of the Earth's Magnetic Field from 1835 to 1965," ESSA Tech. Rept. IER 46-IES 1, 1967.

19. Munk, W. H., and G. J. F. MacDonald, The Rotation of the Earth, University Press, Cambridge [England], 1960.

20. Nagata, T., "Two Main Aspects of Geomagnetic Secular Variation-Westward Drift and NonDrifting Components," Benedum Earth's Magnetism Symposium, U. of Pittsburgh Press, 1962.

21. Vestine, E. H., I. Lange, L. Laporte, and W. E. Scott, "The Geomagnetic Field, Its Description and Analysis," Carnegie Institution of Washington, Publication 580, 1947. 
Appendix A

Comparison of Observatory Annual Mean Values 1900 - 1965

With Elements Computed From GSFC $[12 / 66)$ 


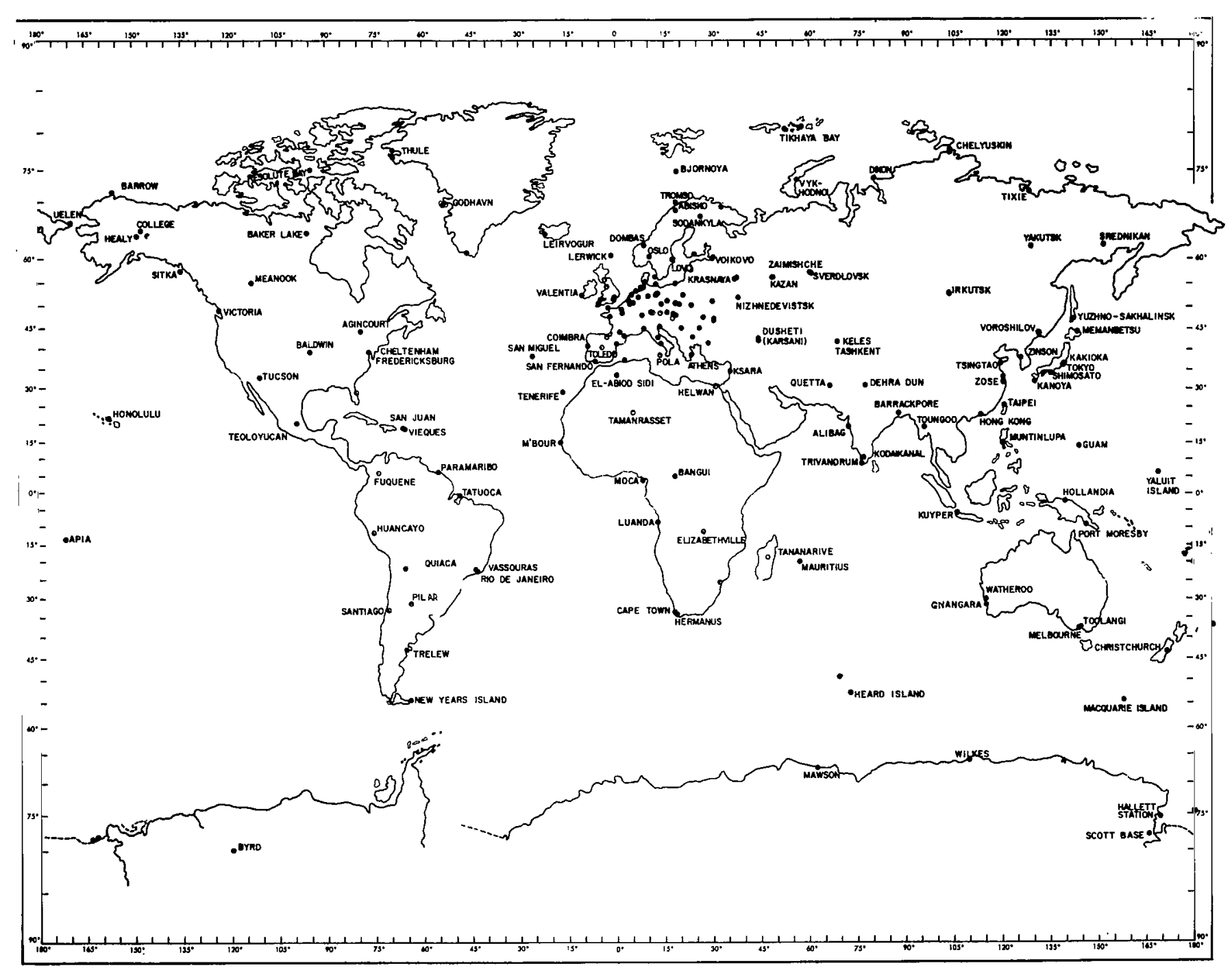

Figure A] 


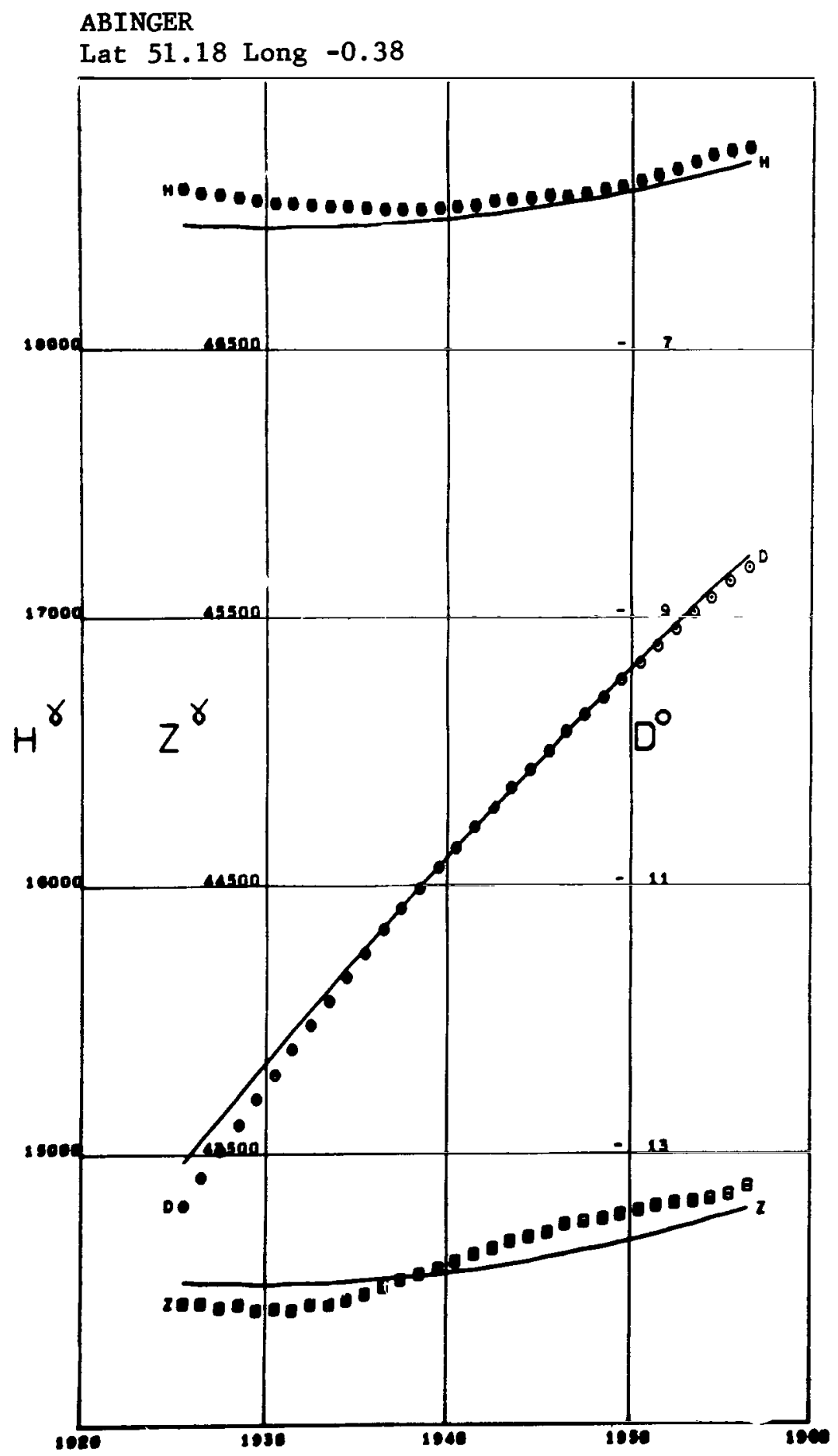

Figure A2 


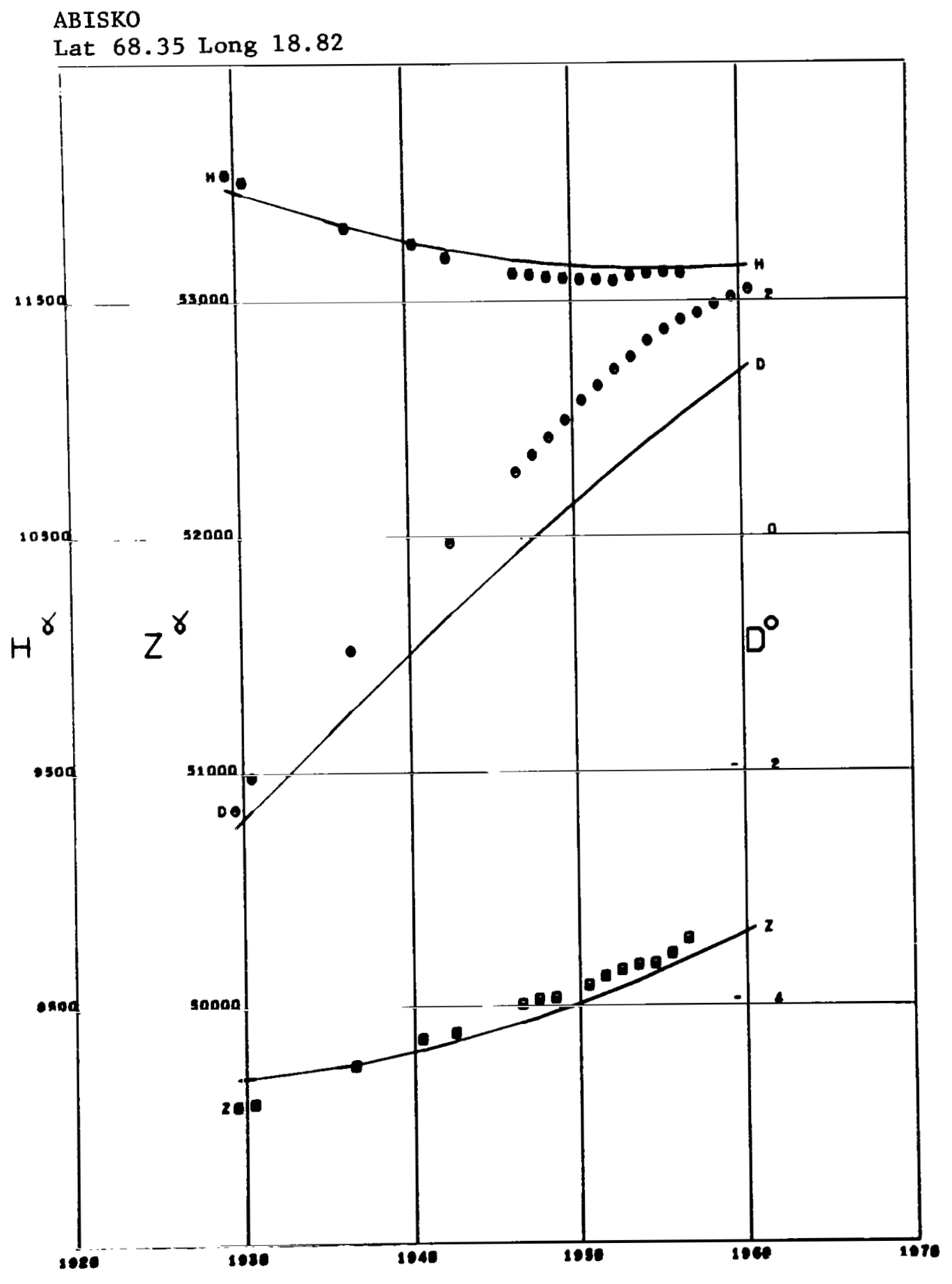

Figure A3 


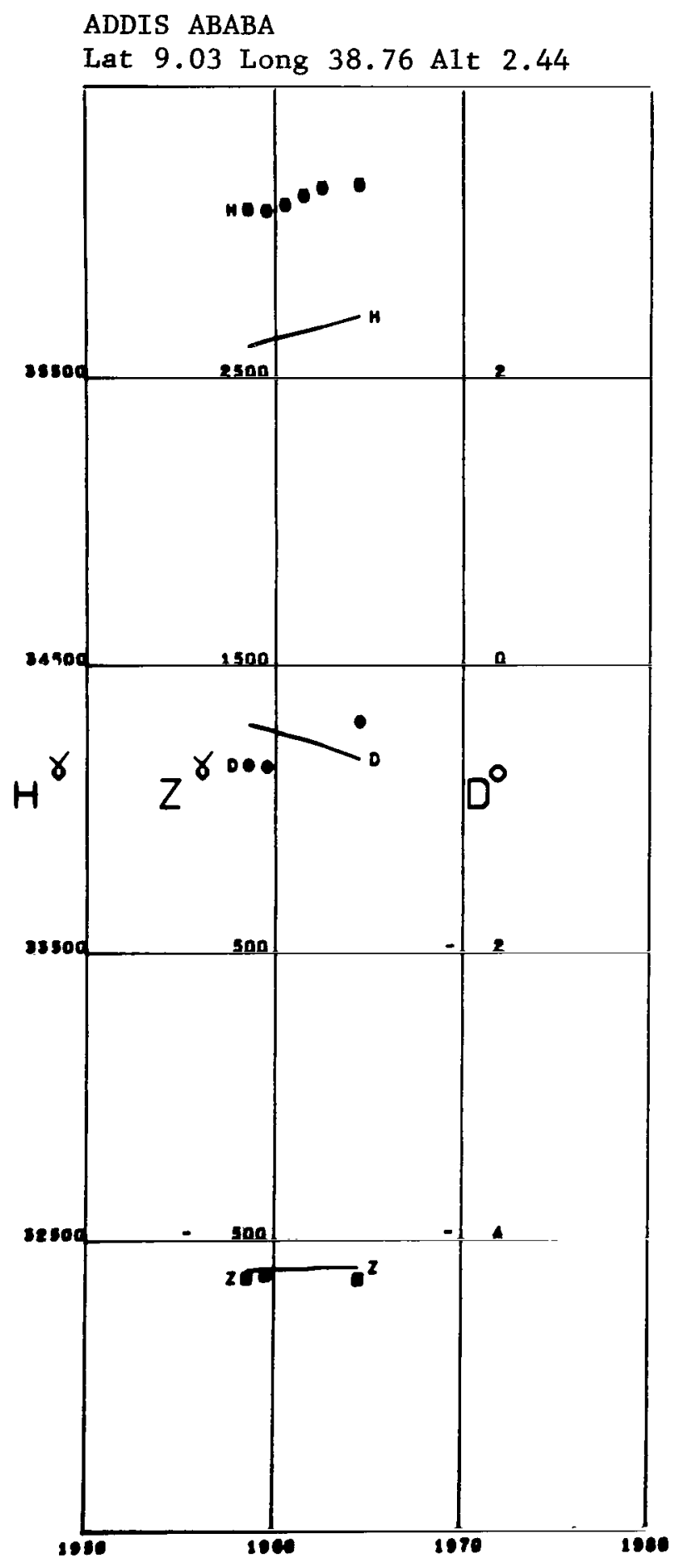

Figure A4 


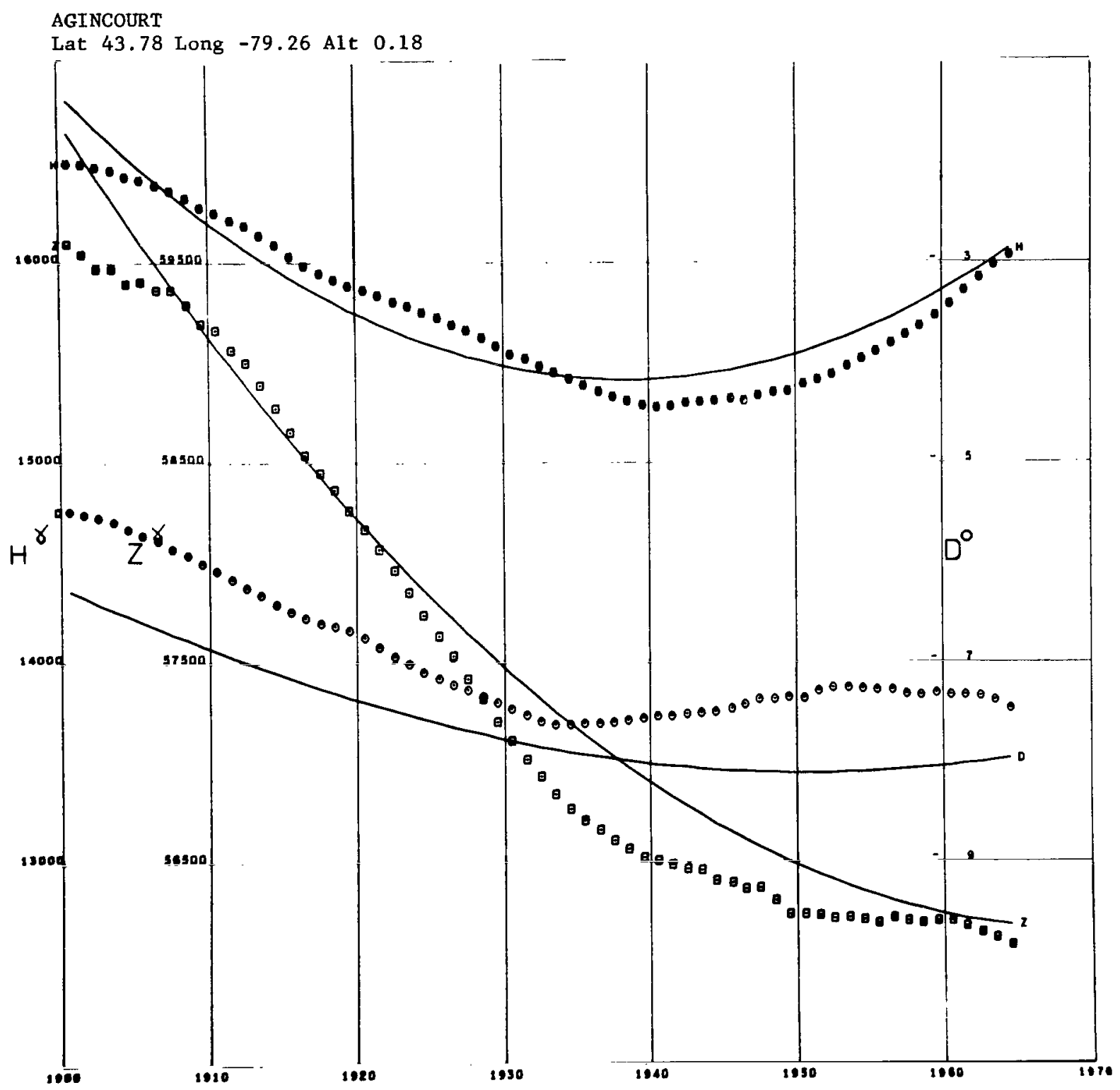

Figure A5 
ALIBAG

Lat 18.63 Long 72.87 A1t 0.01

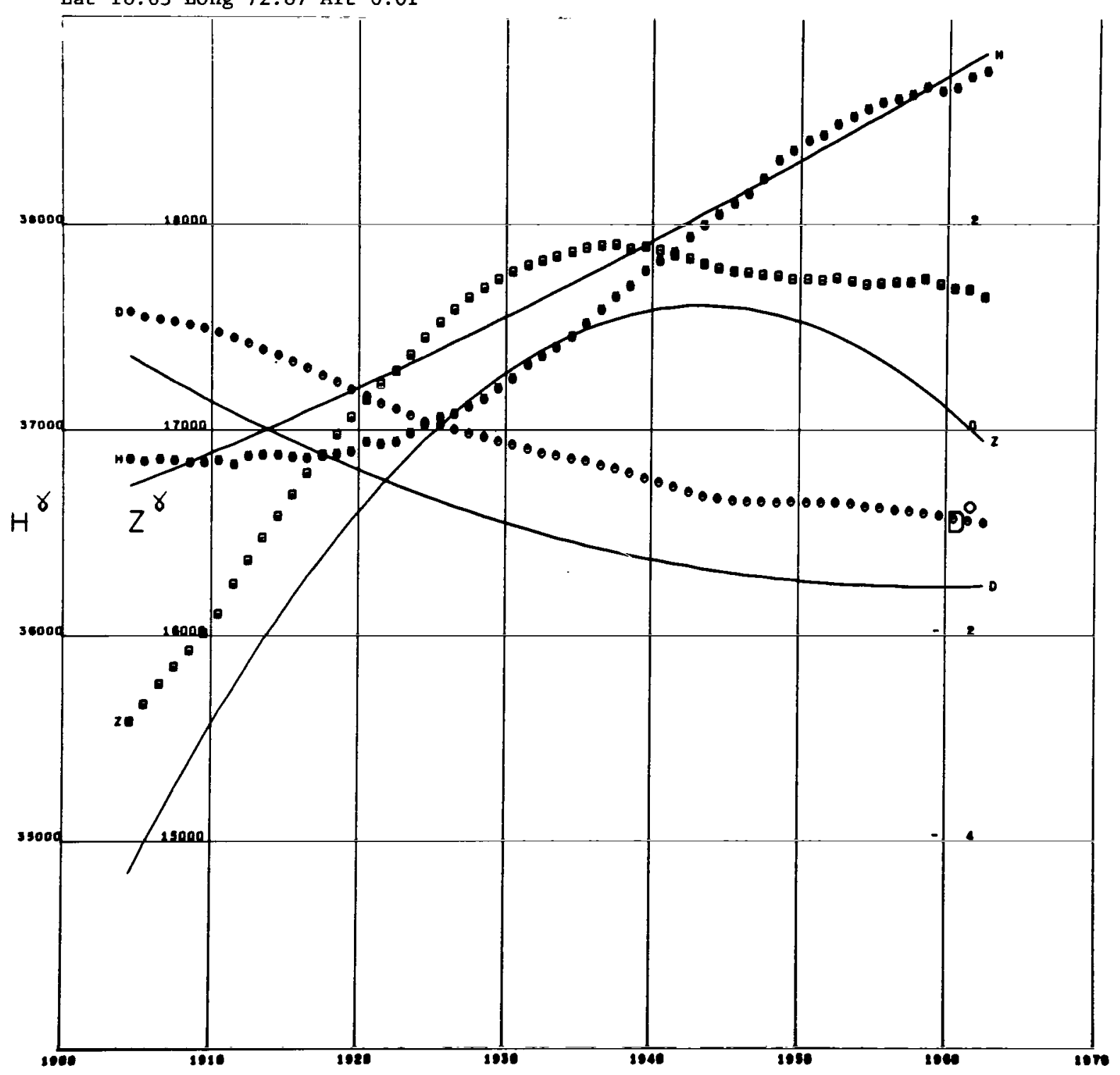

Figure $A 6$ 


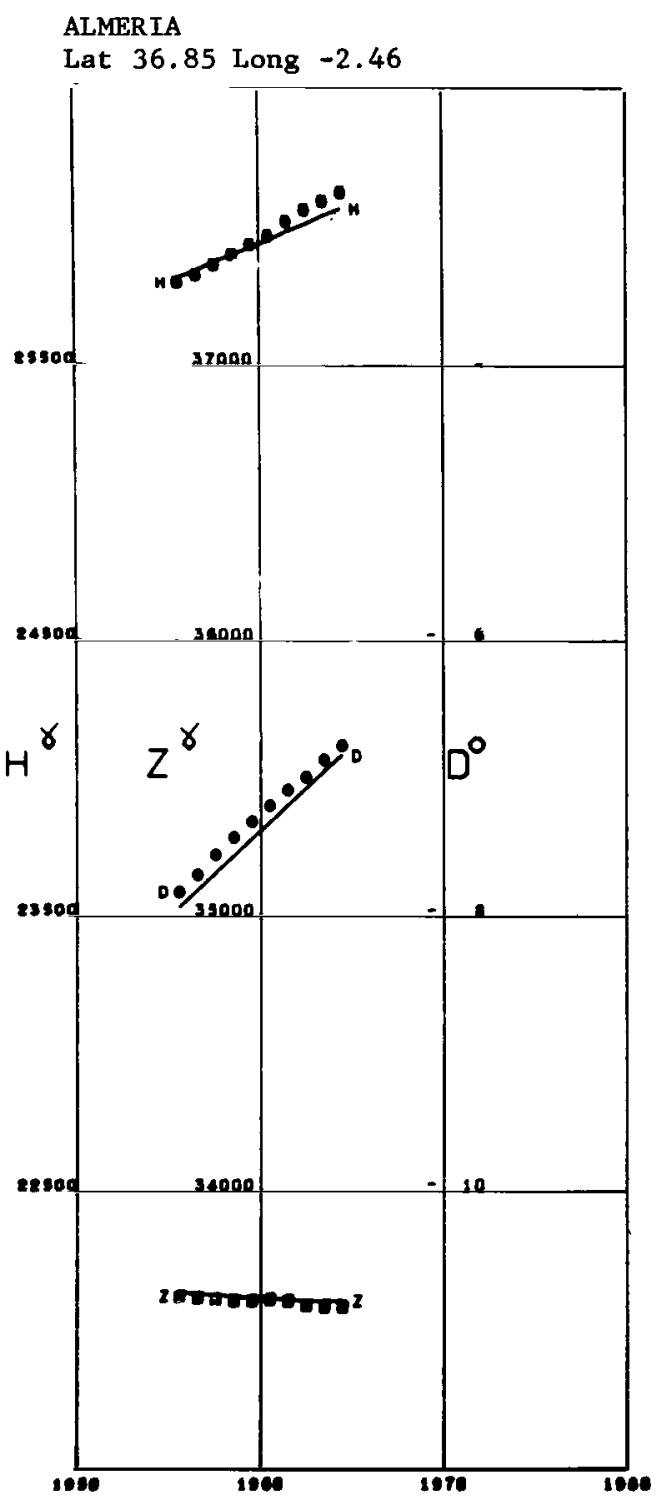

Figure A7

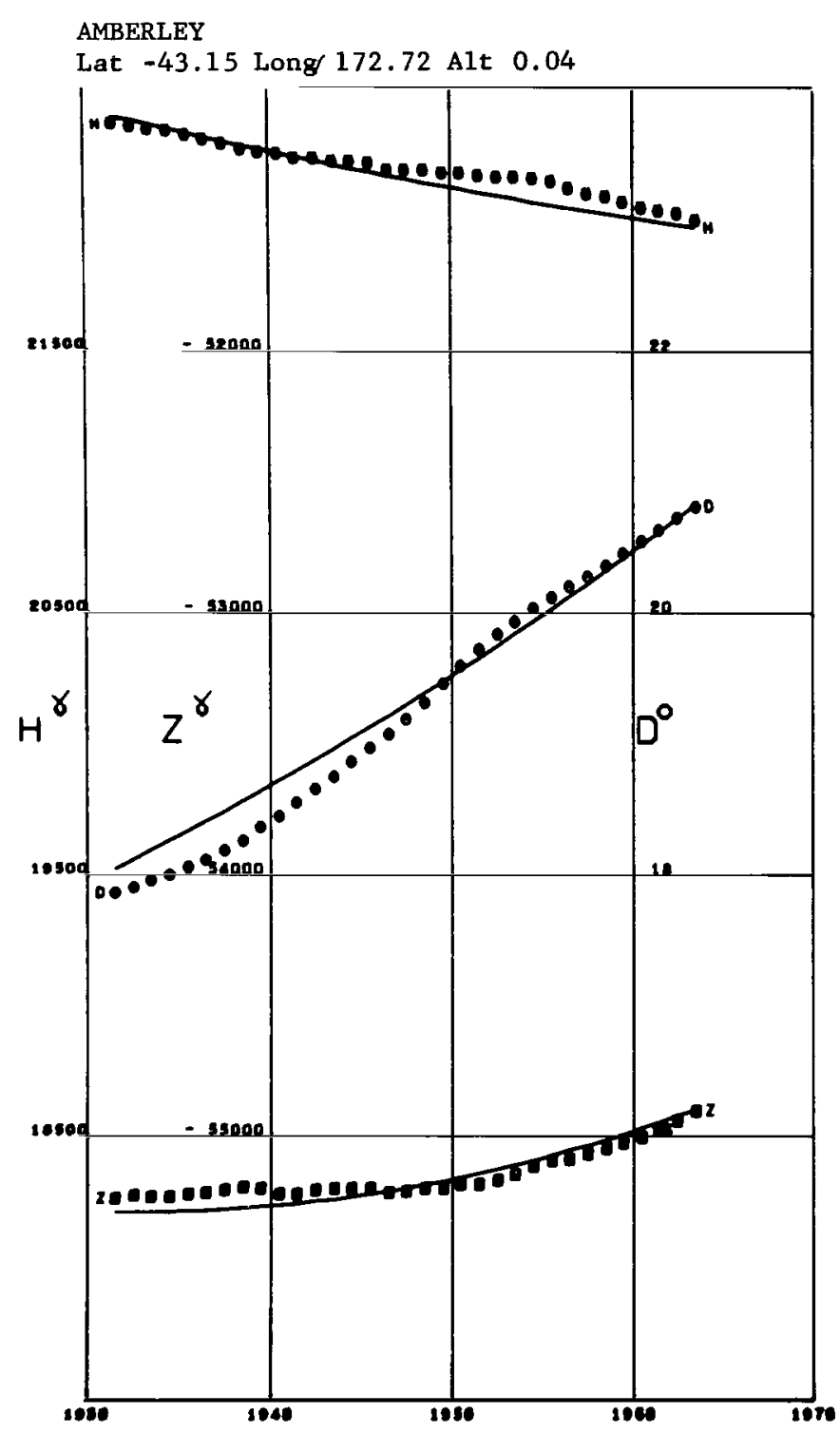

Figure $A B$ 


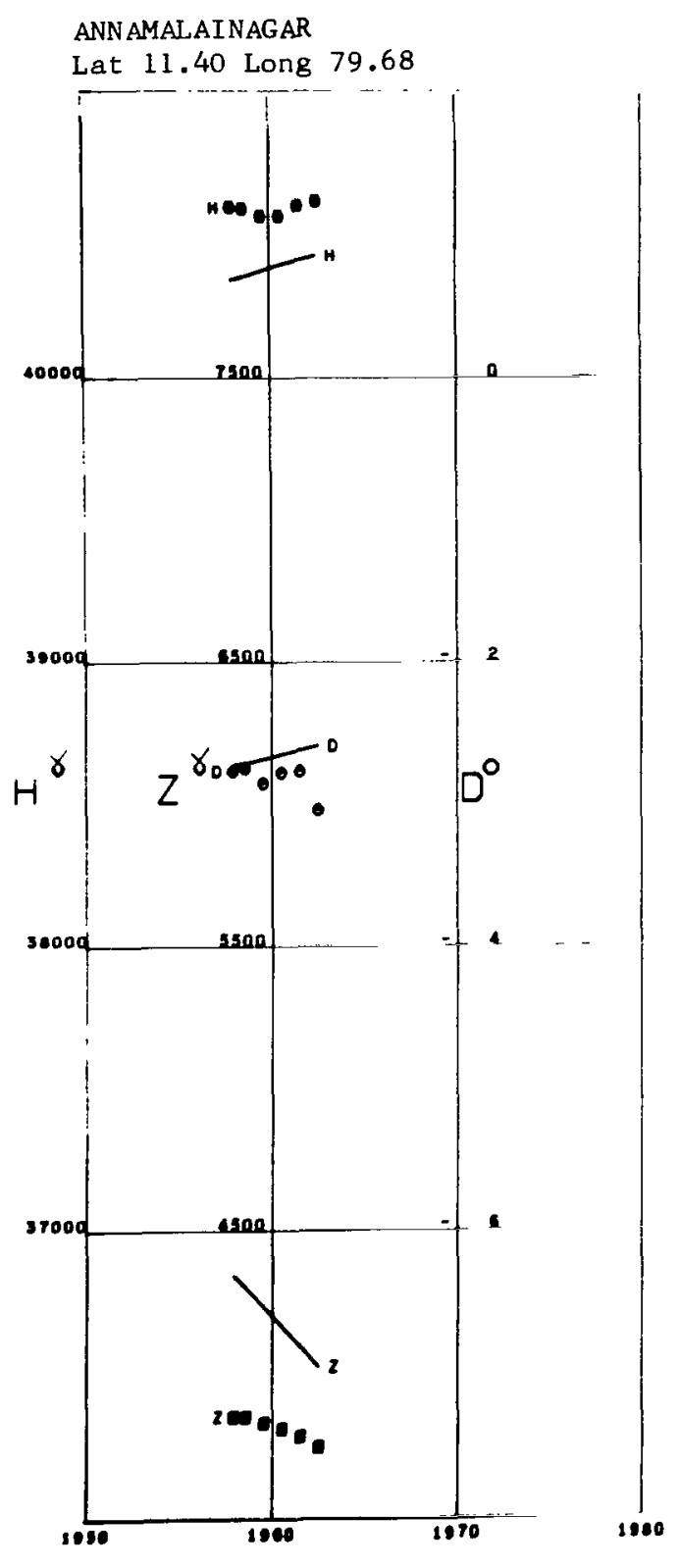

Figure A9

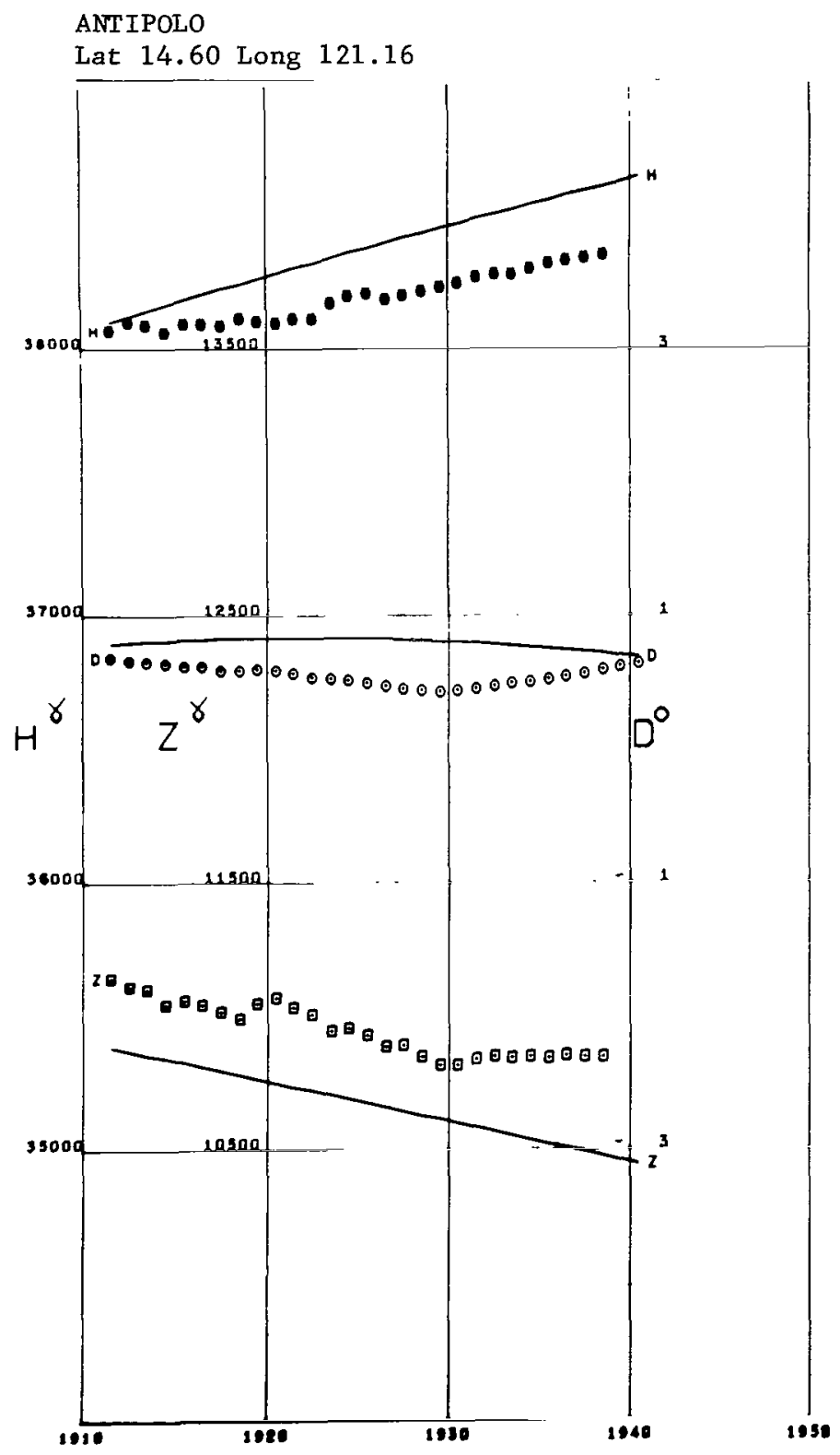

Figure A10 
APIA

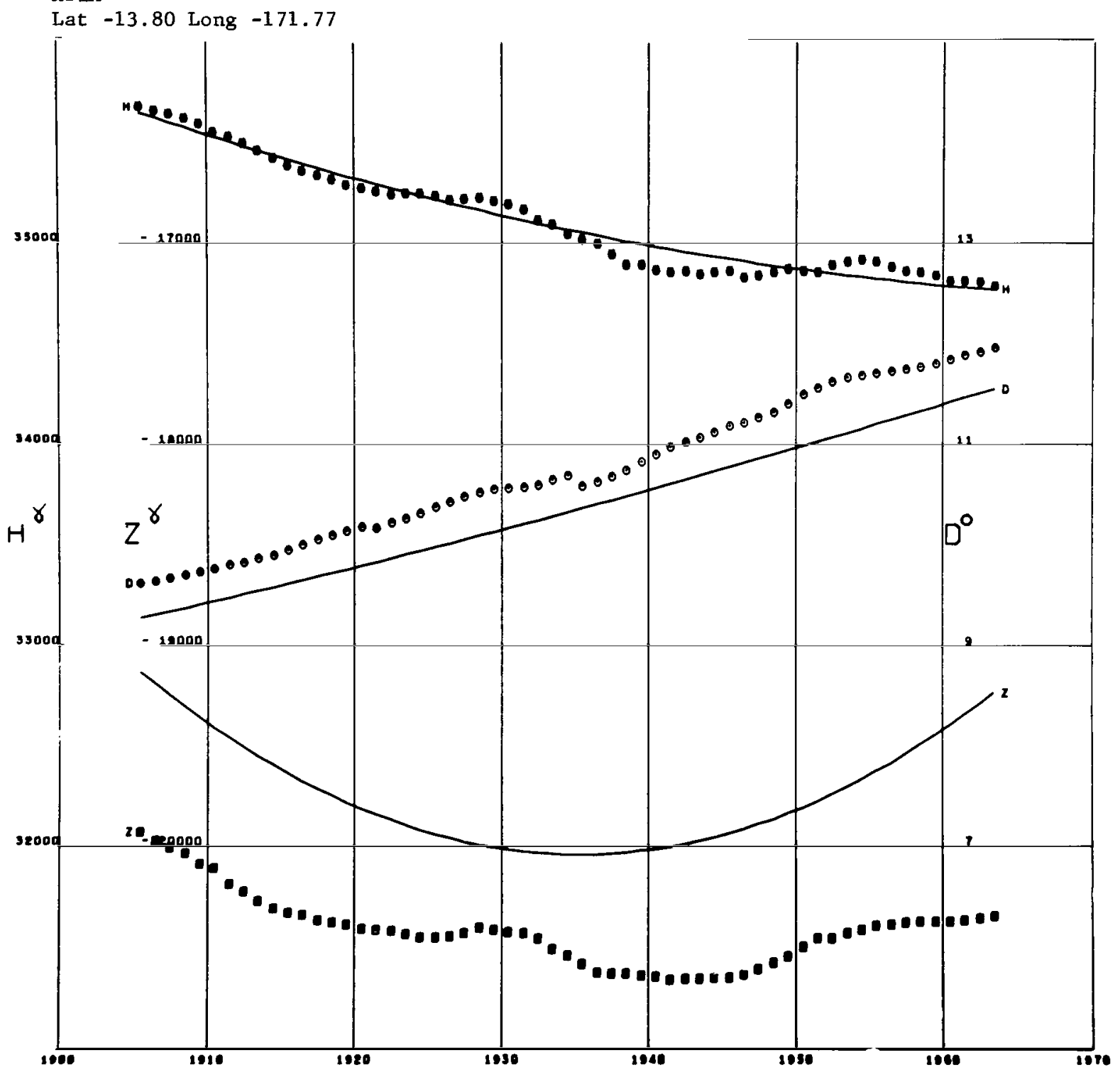

Figure All 
AQUILA

Lat 42.38 Long 13.31

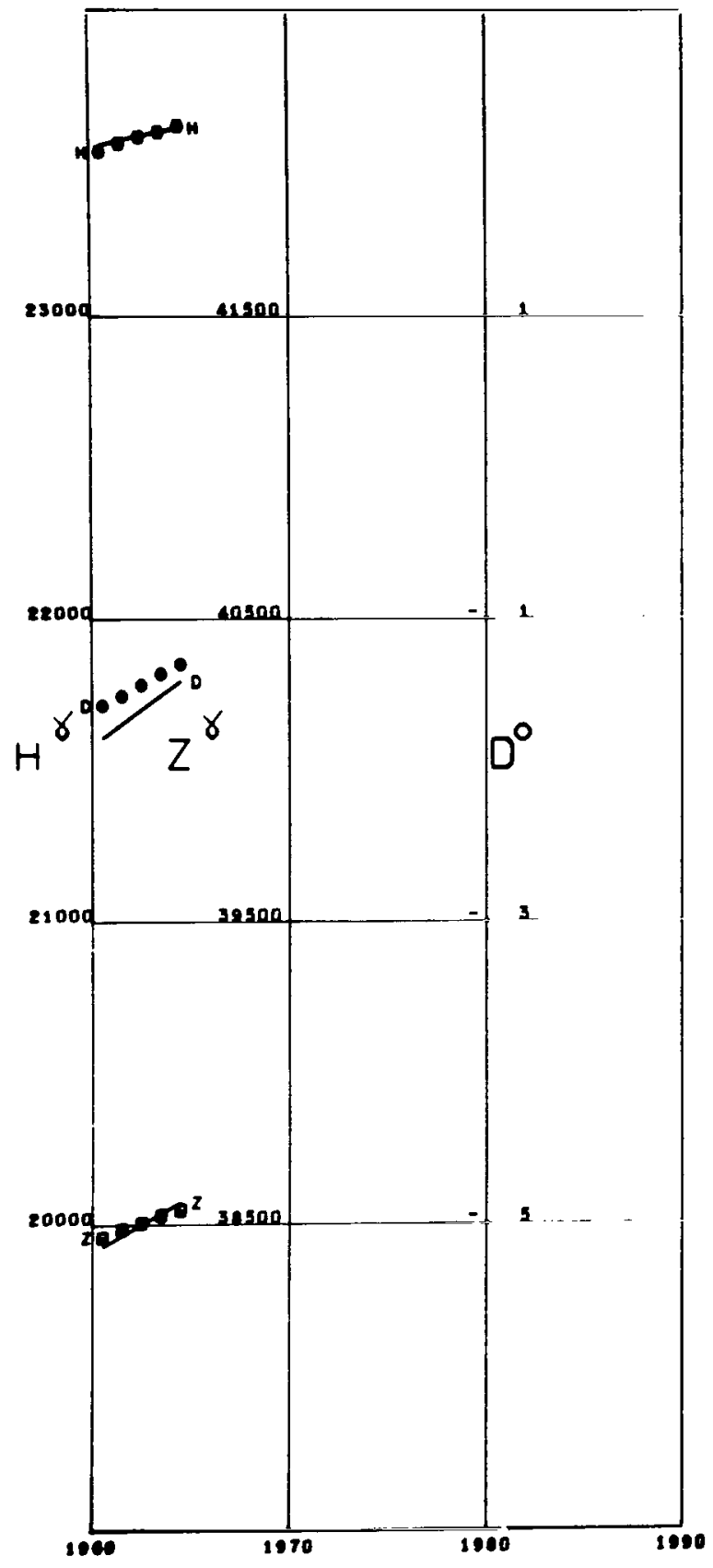

Figure A12

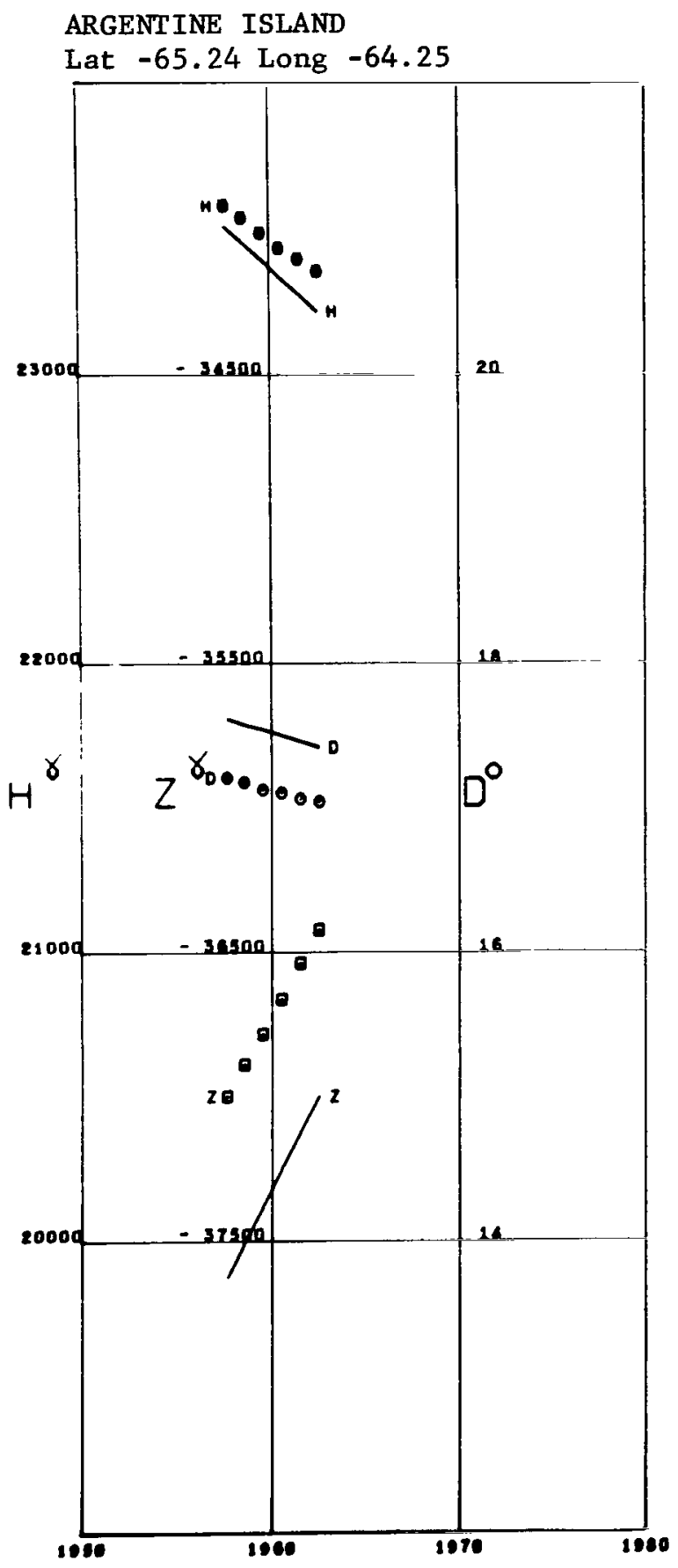

Figure A13 
ATHENS

Lat 37.97 Long 23.72

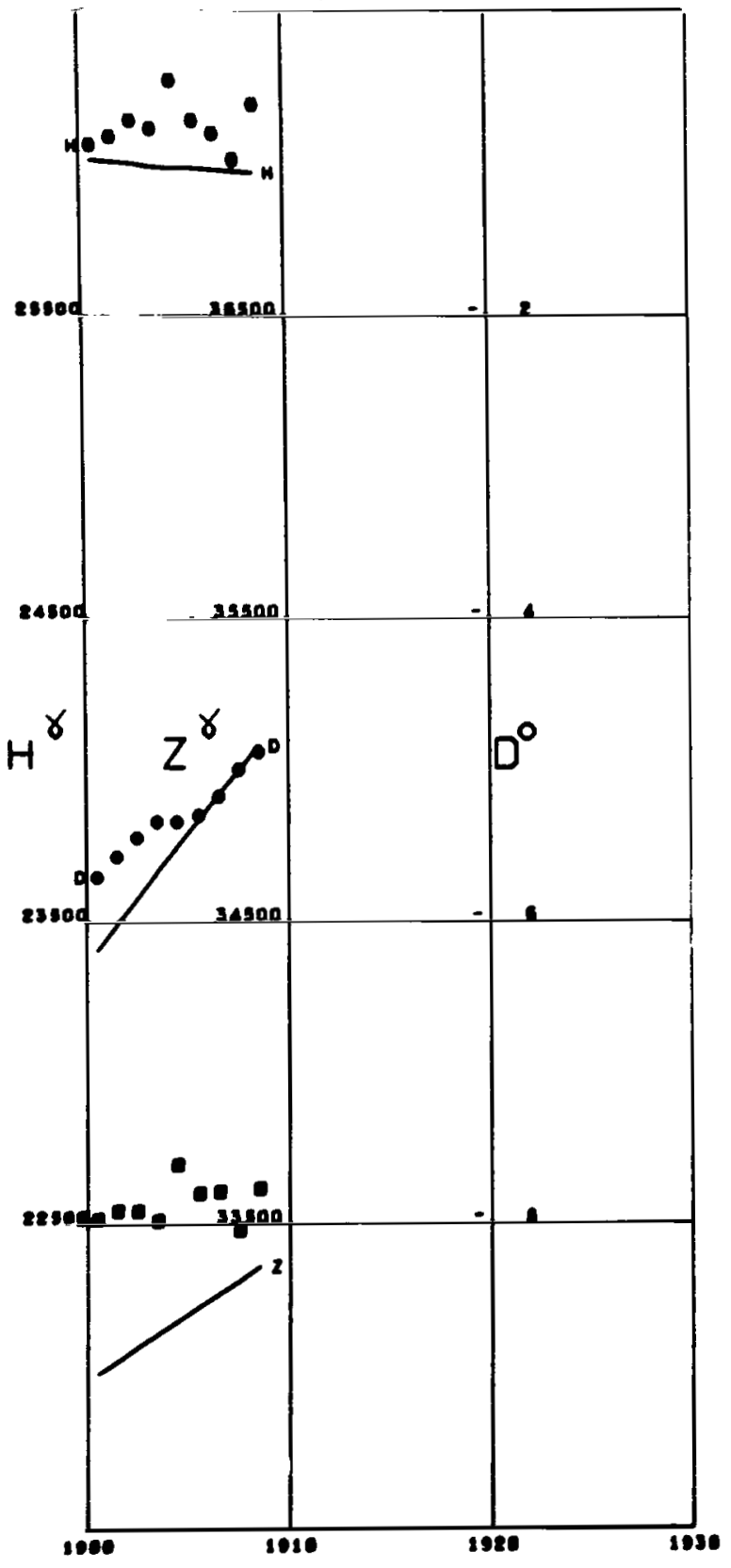

Figure A14
AU TAU

Lat 22.44 Long 114.04

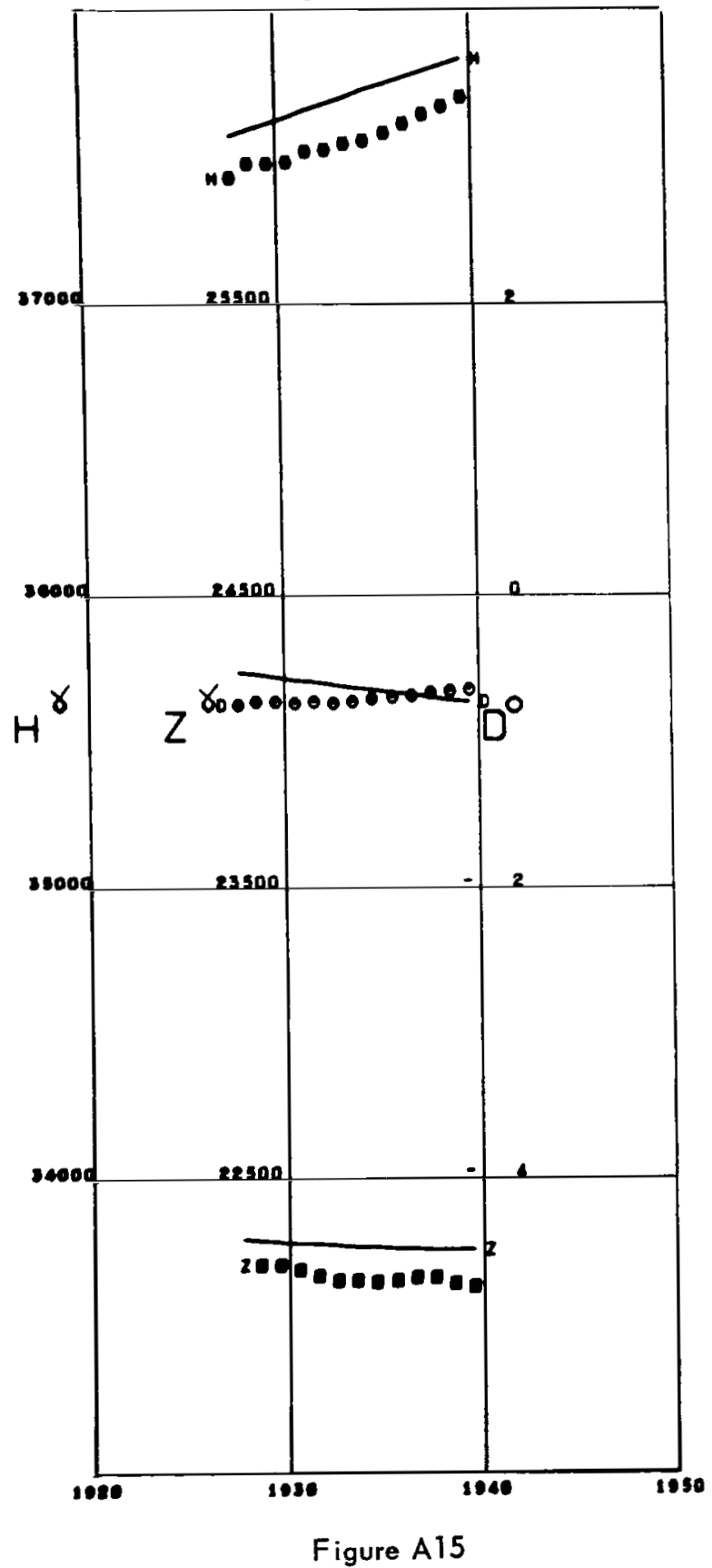




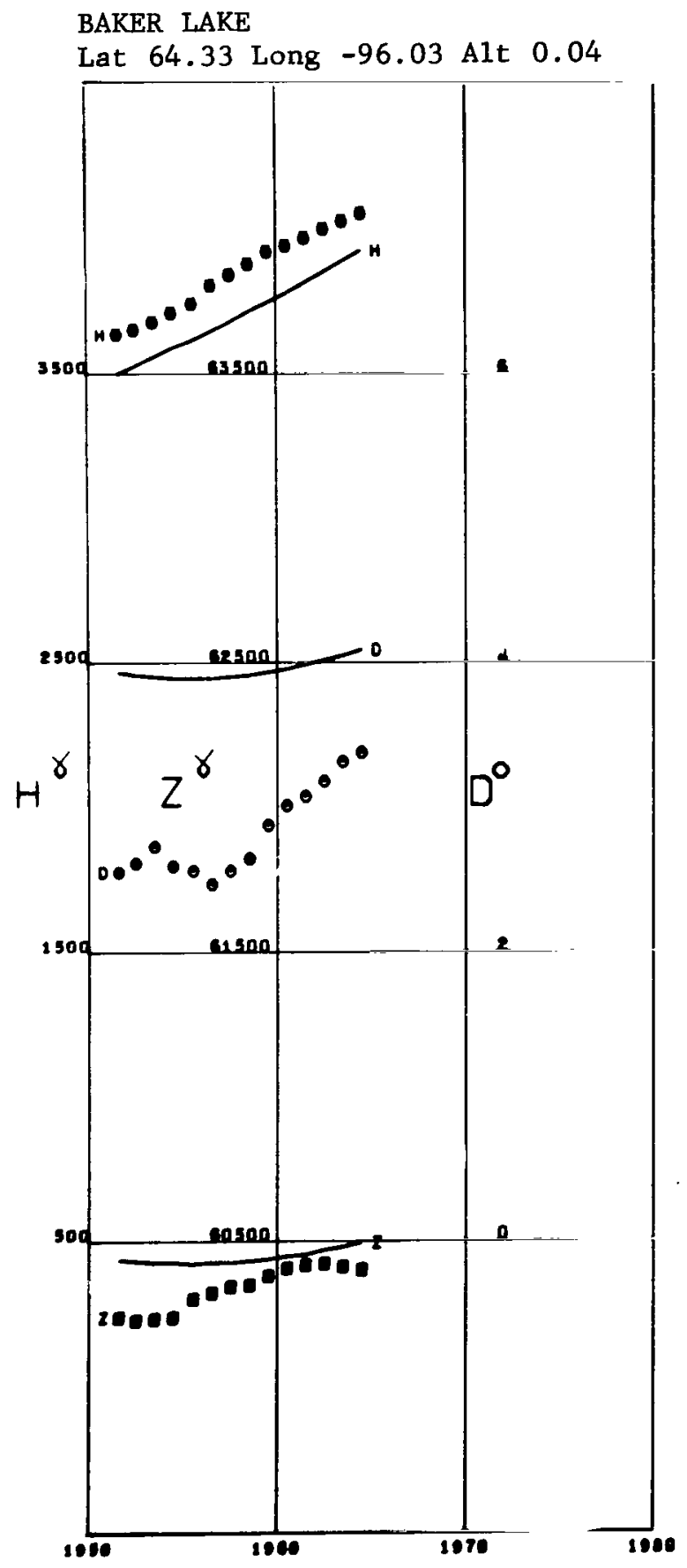

Figure A16

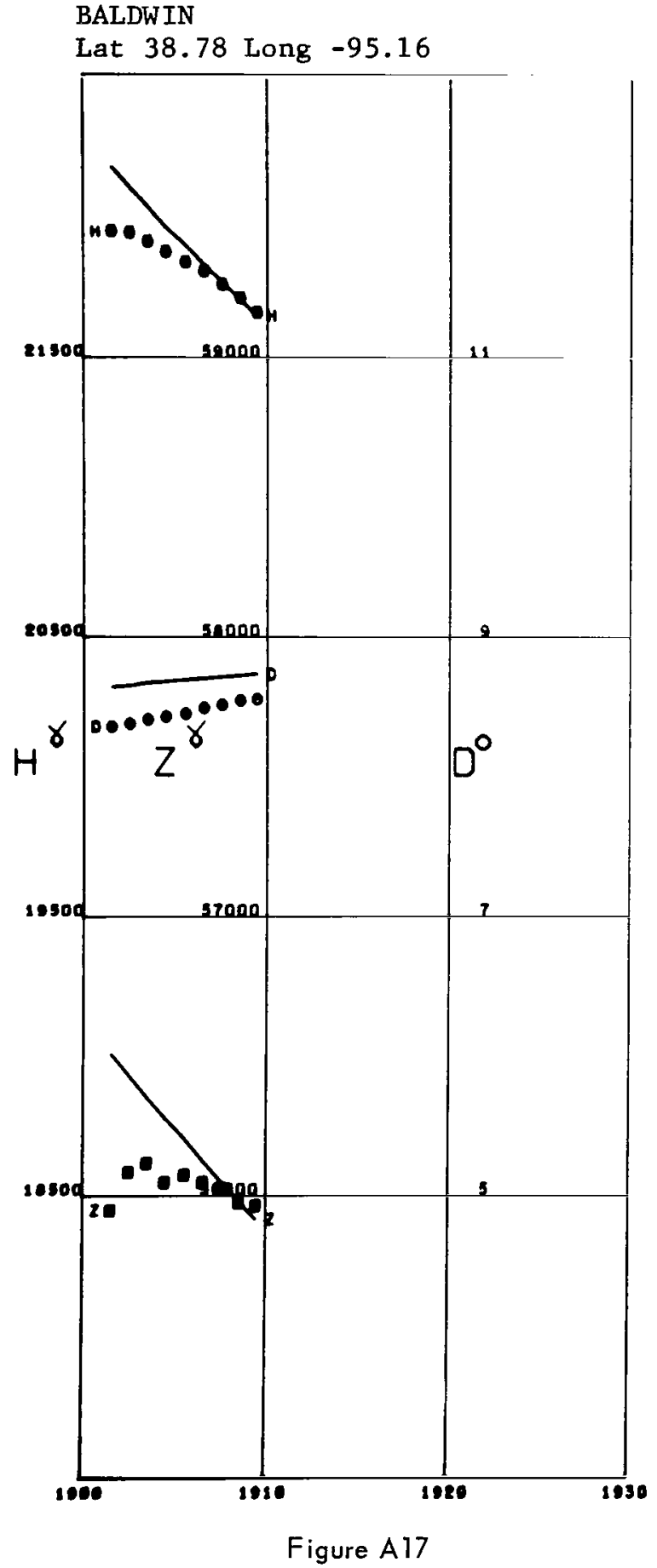

BALDW IN

at 38.78 Long -95.16 


\section{BANGUI}

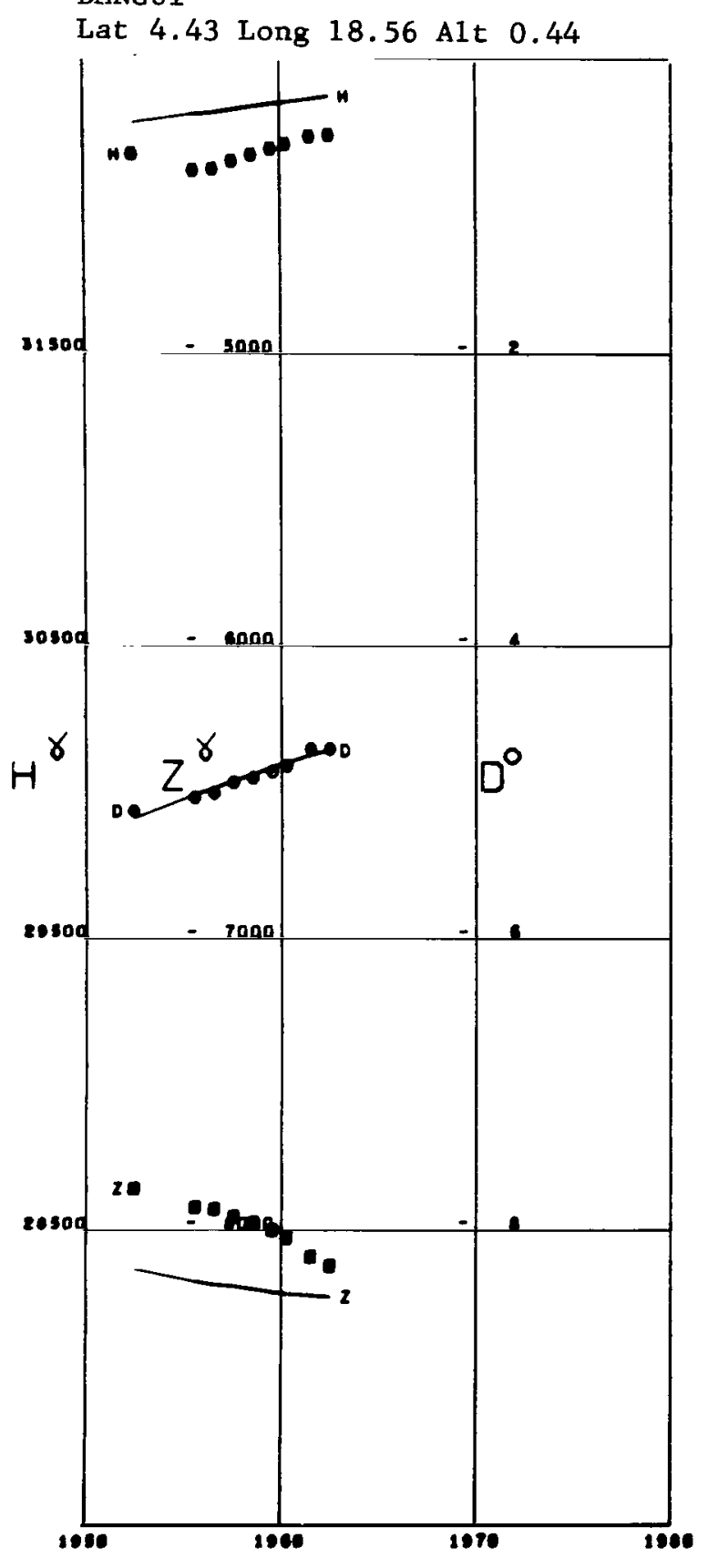

Figure A18
BARRACKPORE

Lat 22.77 Long 88.36

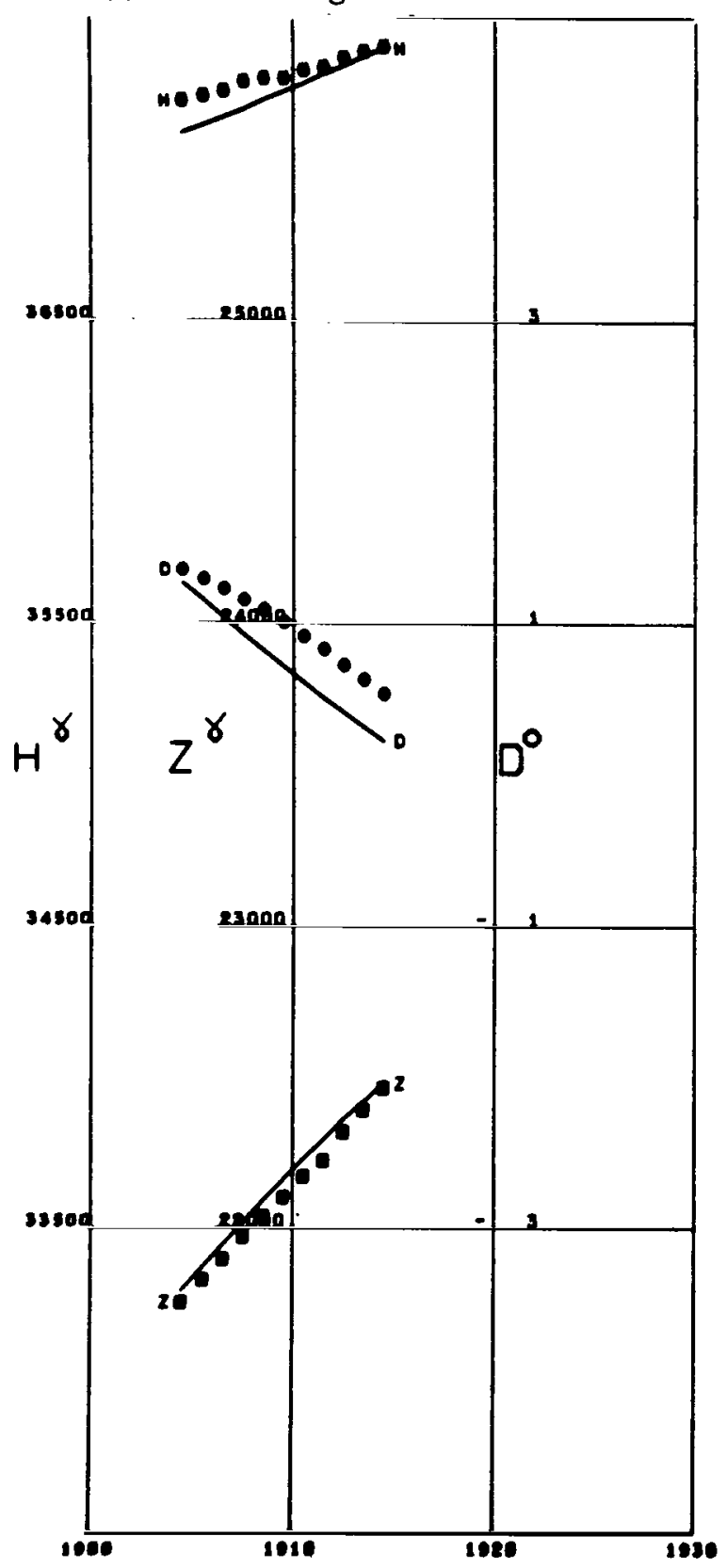

Figure A19 
BARROW

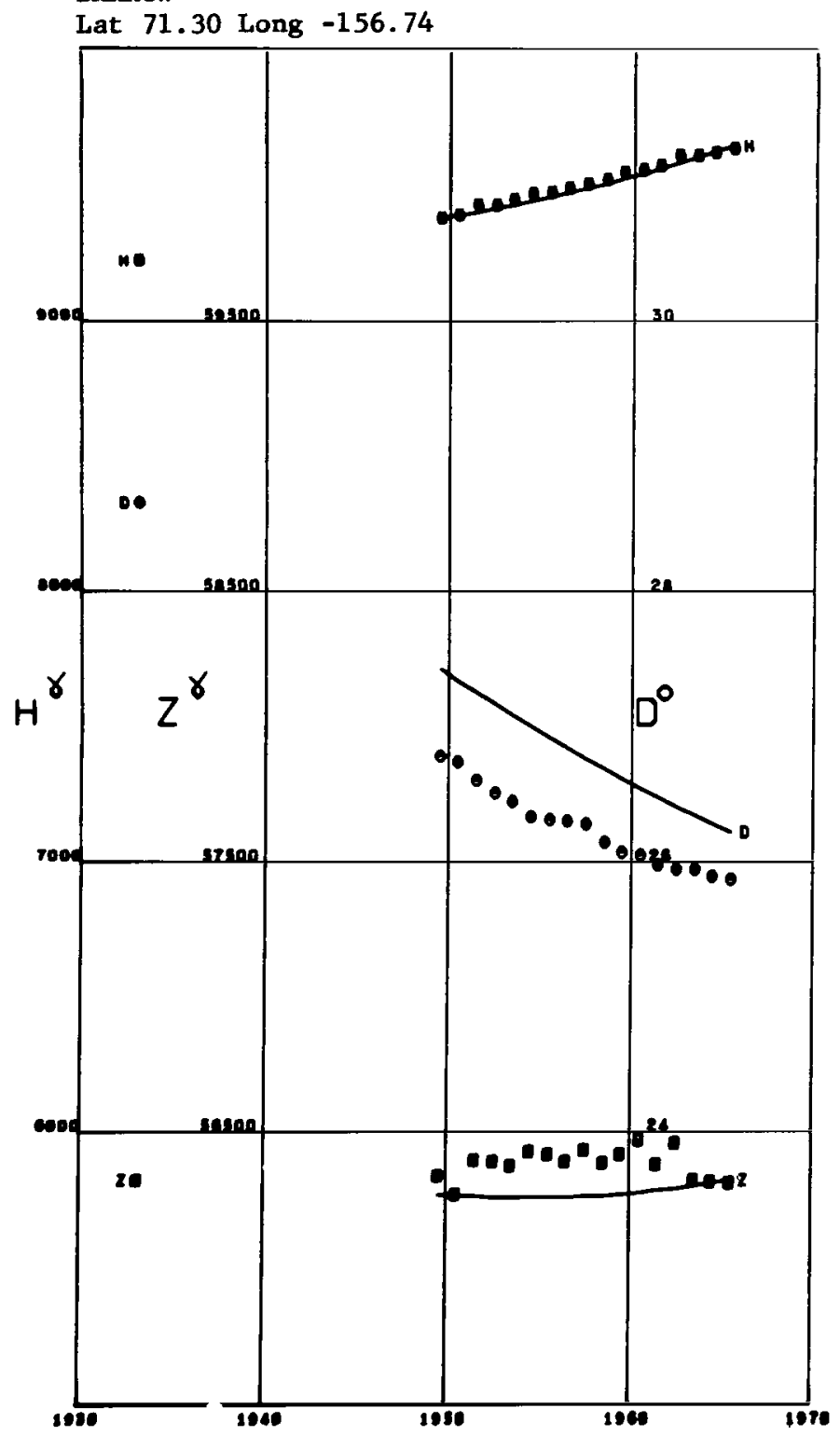

Figure A20
BATAVIA

Lat -6.18 Long 106.83

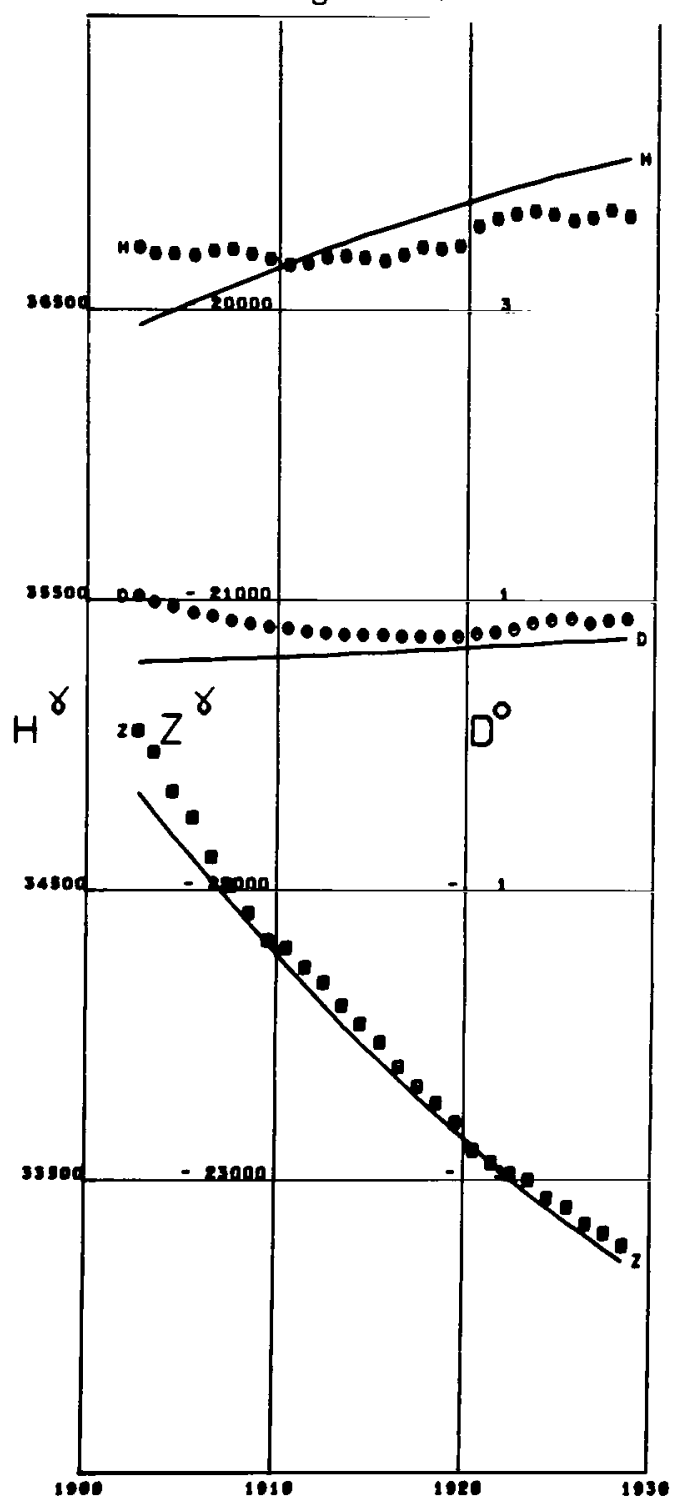

Figure A2I 


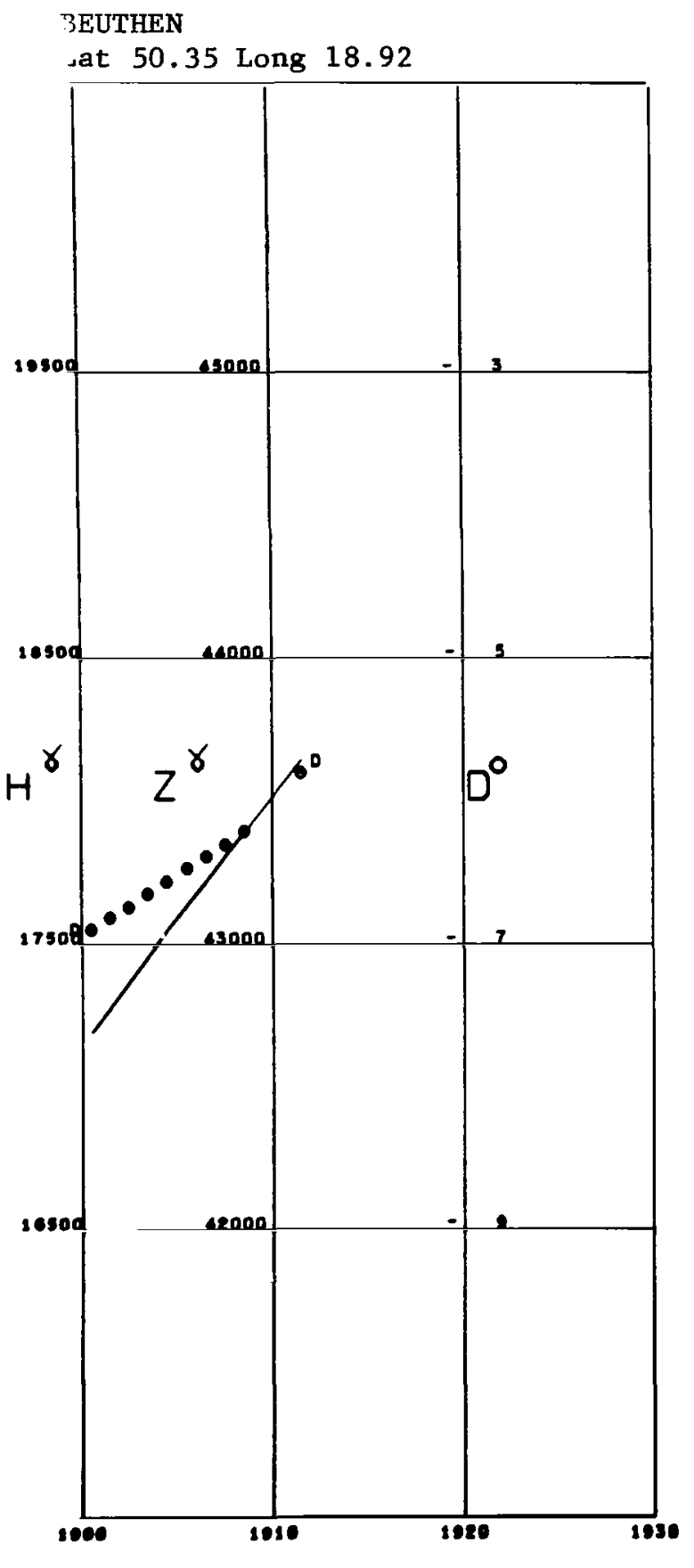

Figure A22
BEUTHEN MIKILOW

Lat 50.15 Long 18.90

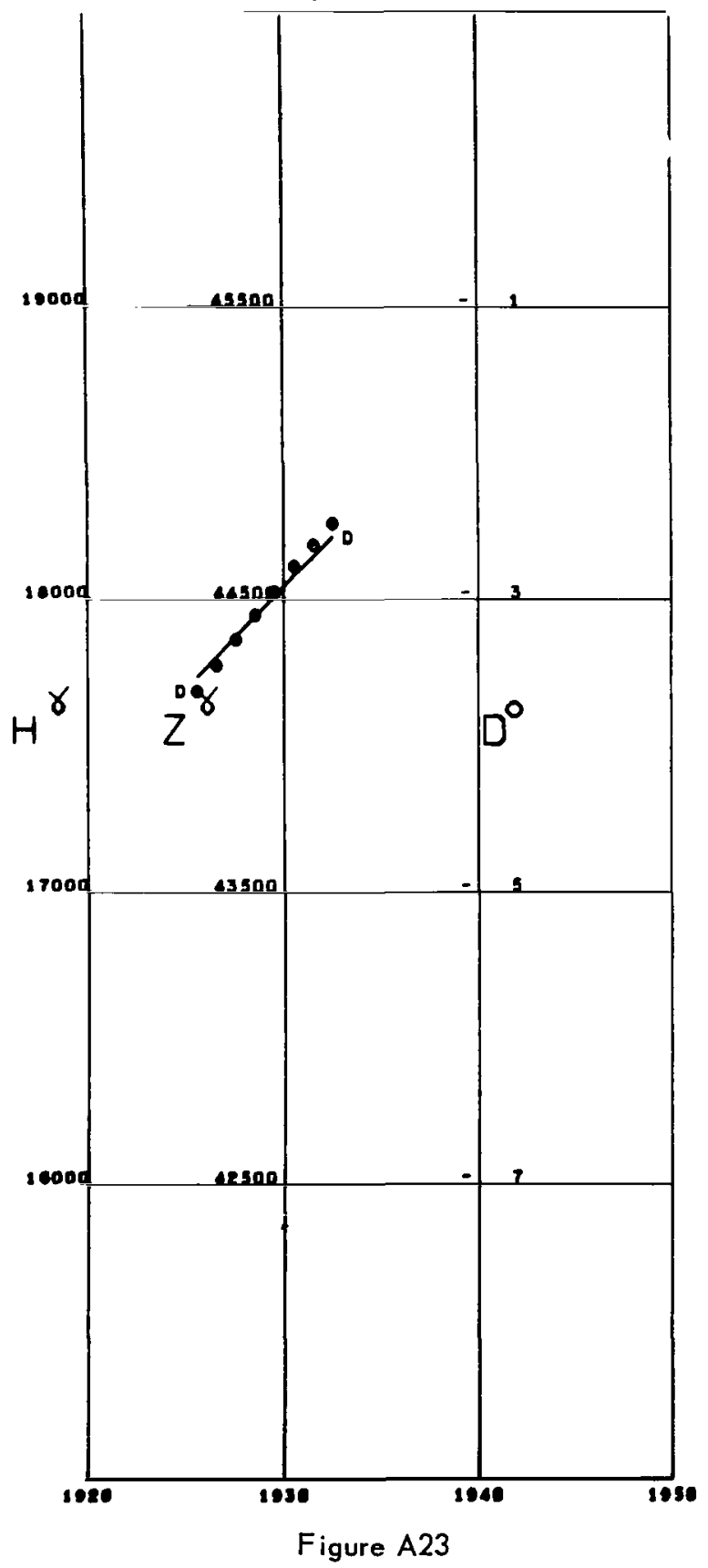


BJORNOYA

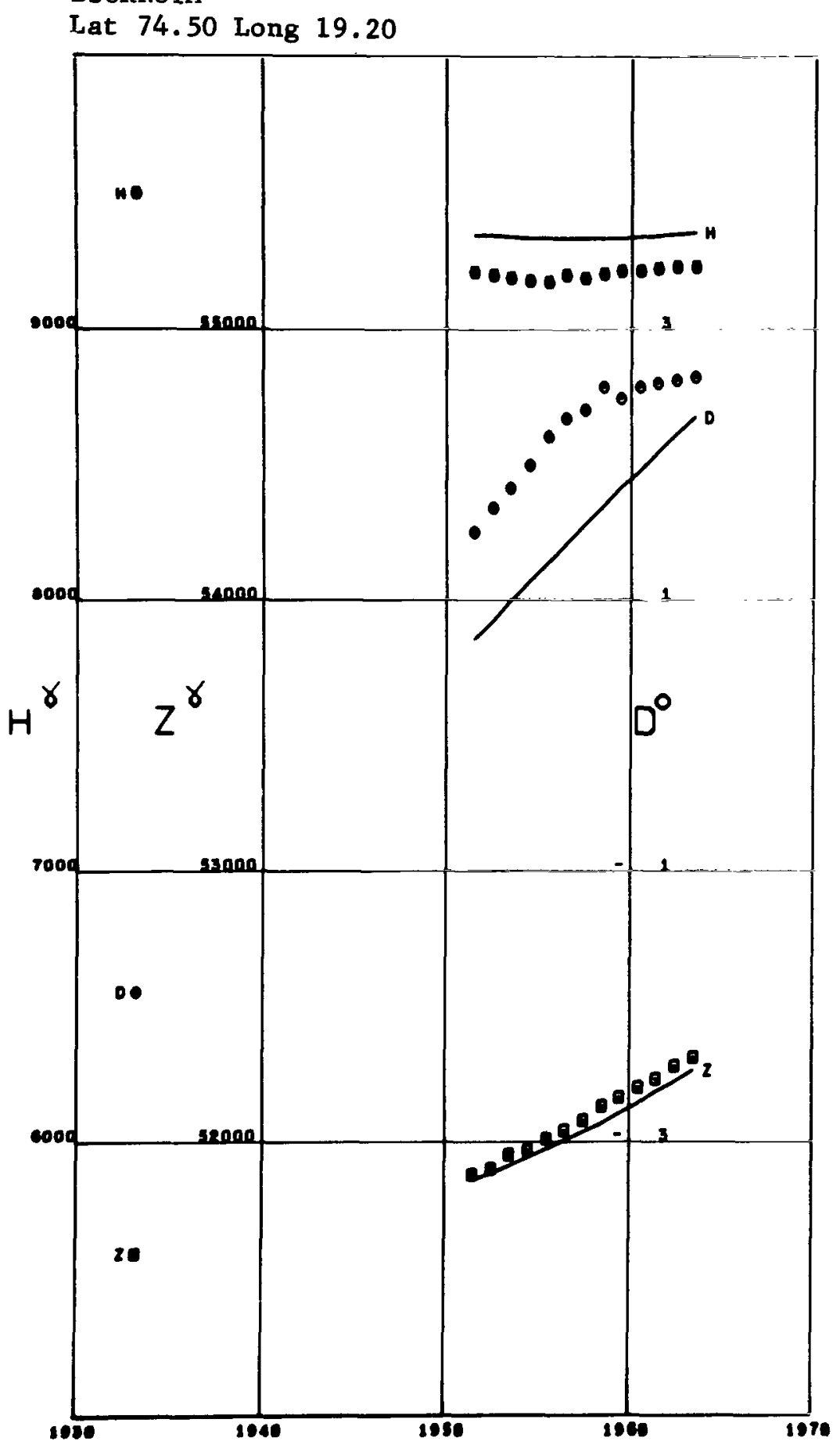

Figure A24 


\section{BOCHUM}

Lat 51.49 Long 7.23

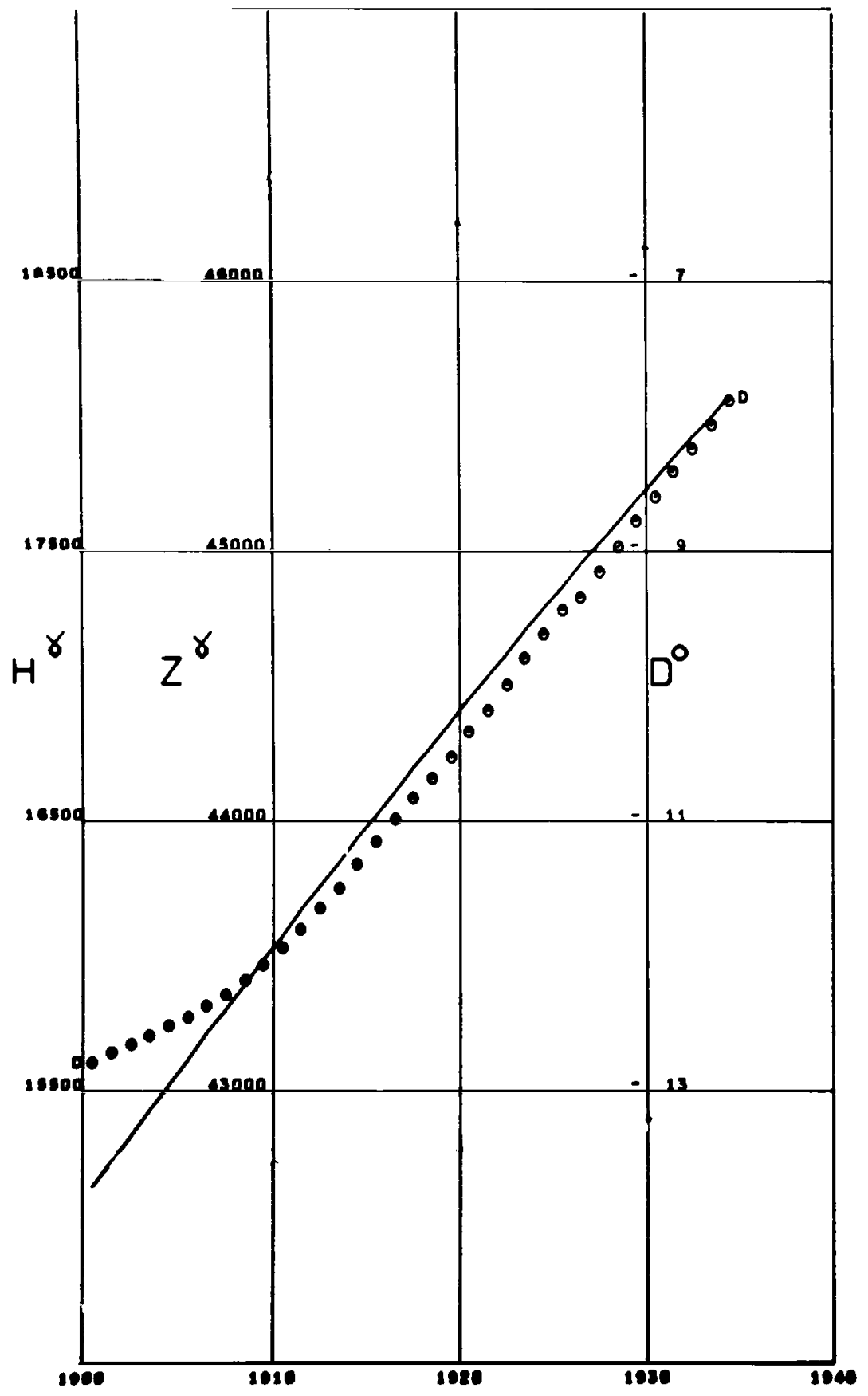

Figure A25 


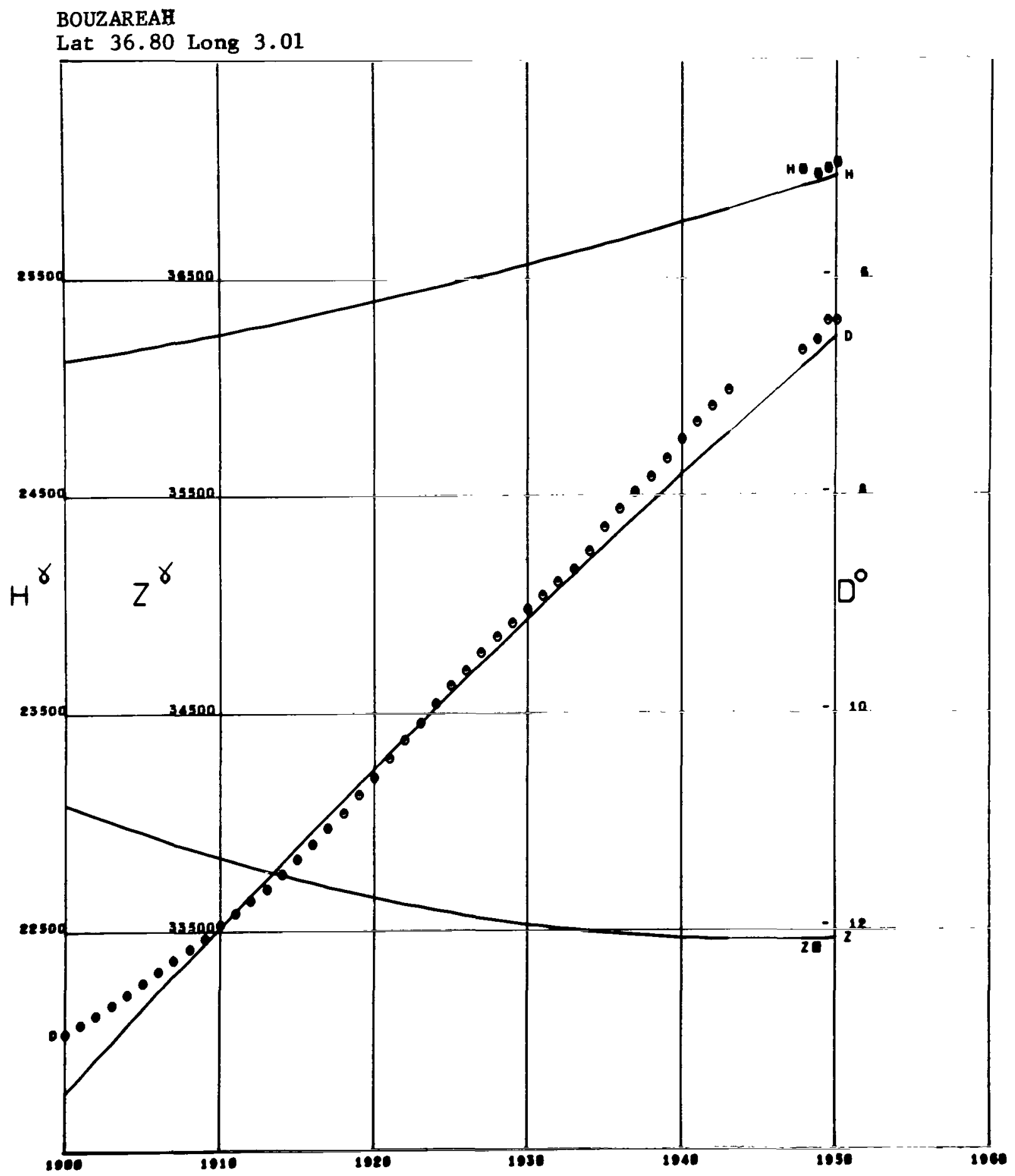

Figure A26 


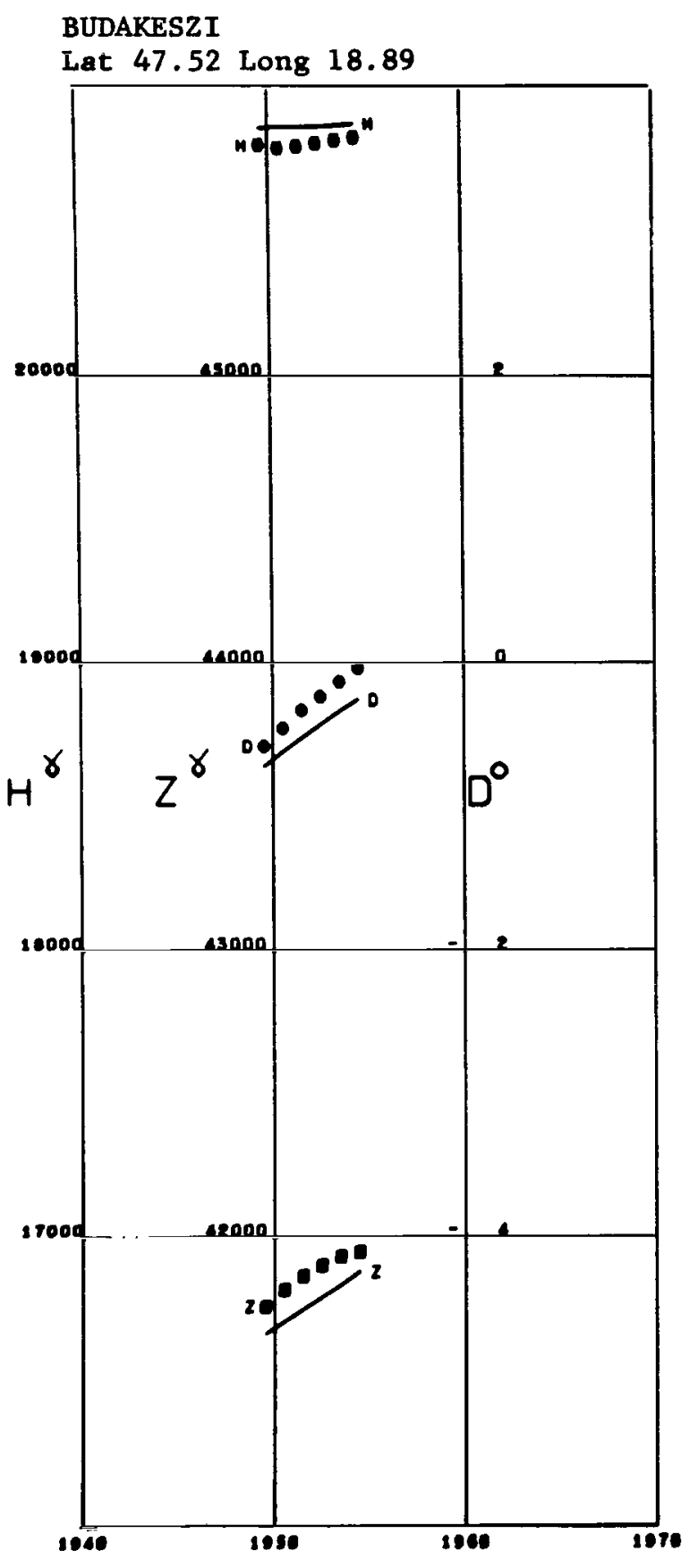

Figure A27

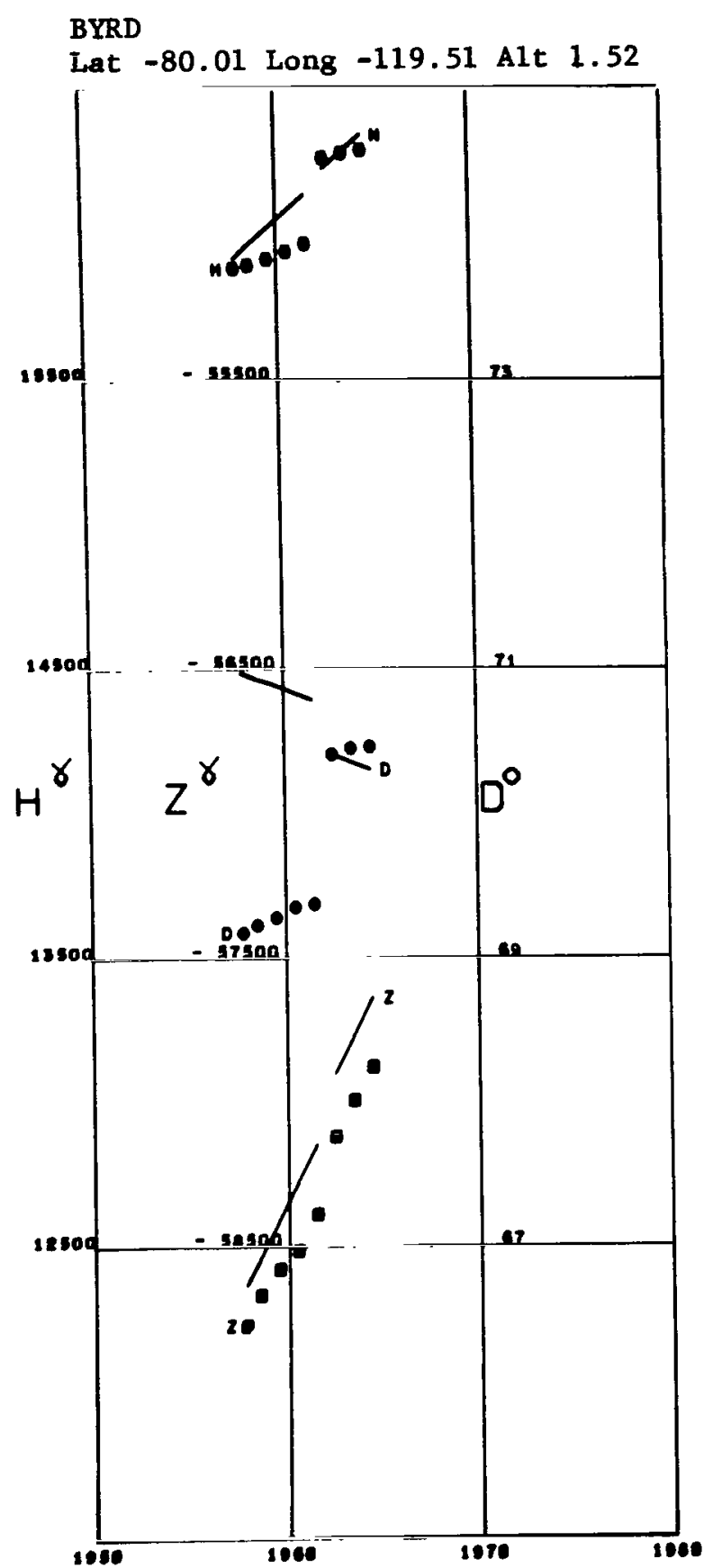

Figure A28 


\section{CAPETOWN}

Lat $\mathbf{- 3 3 . 9 5}$ Long 18.46

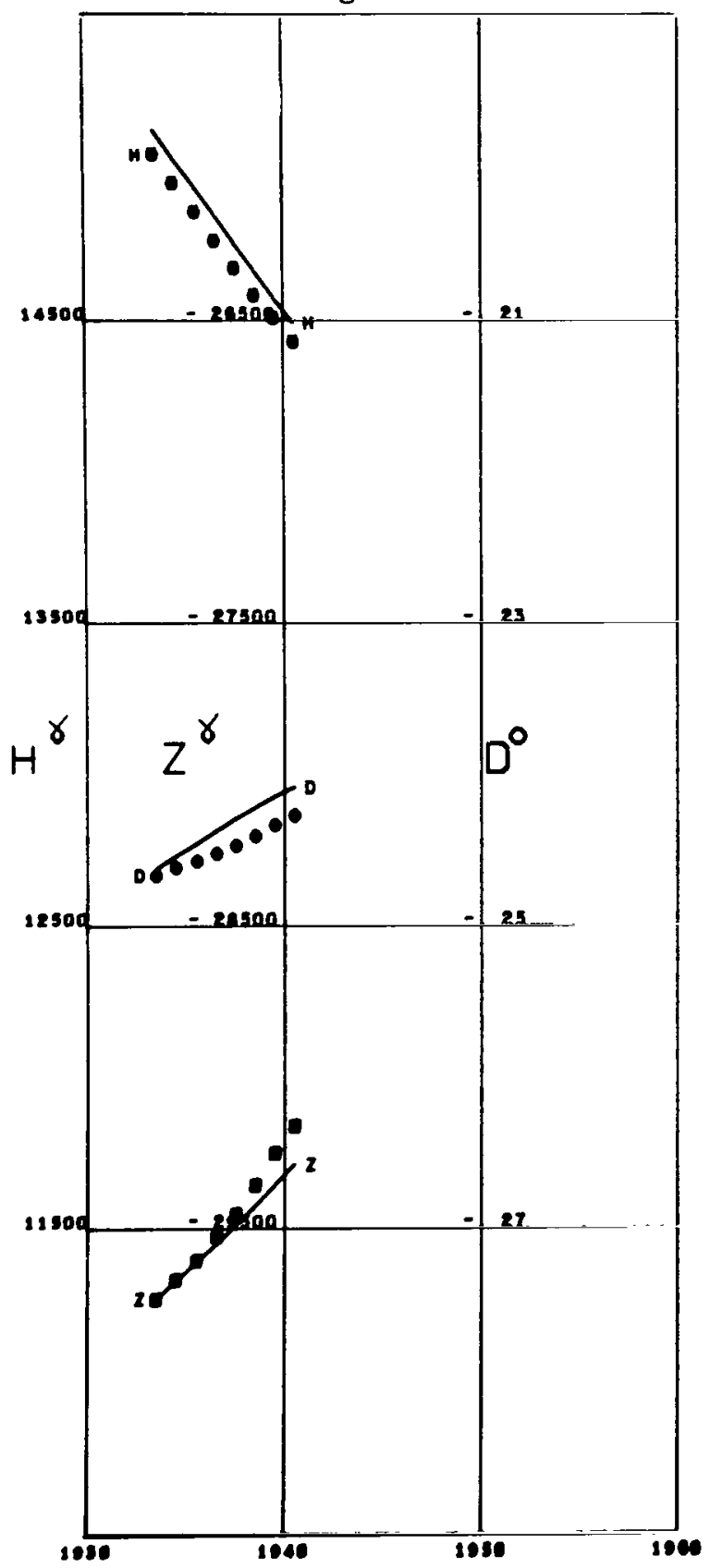

Figure A29
CAPODIMONTE

Lat 40.86 Long 14.25

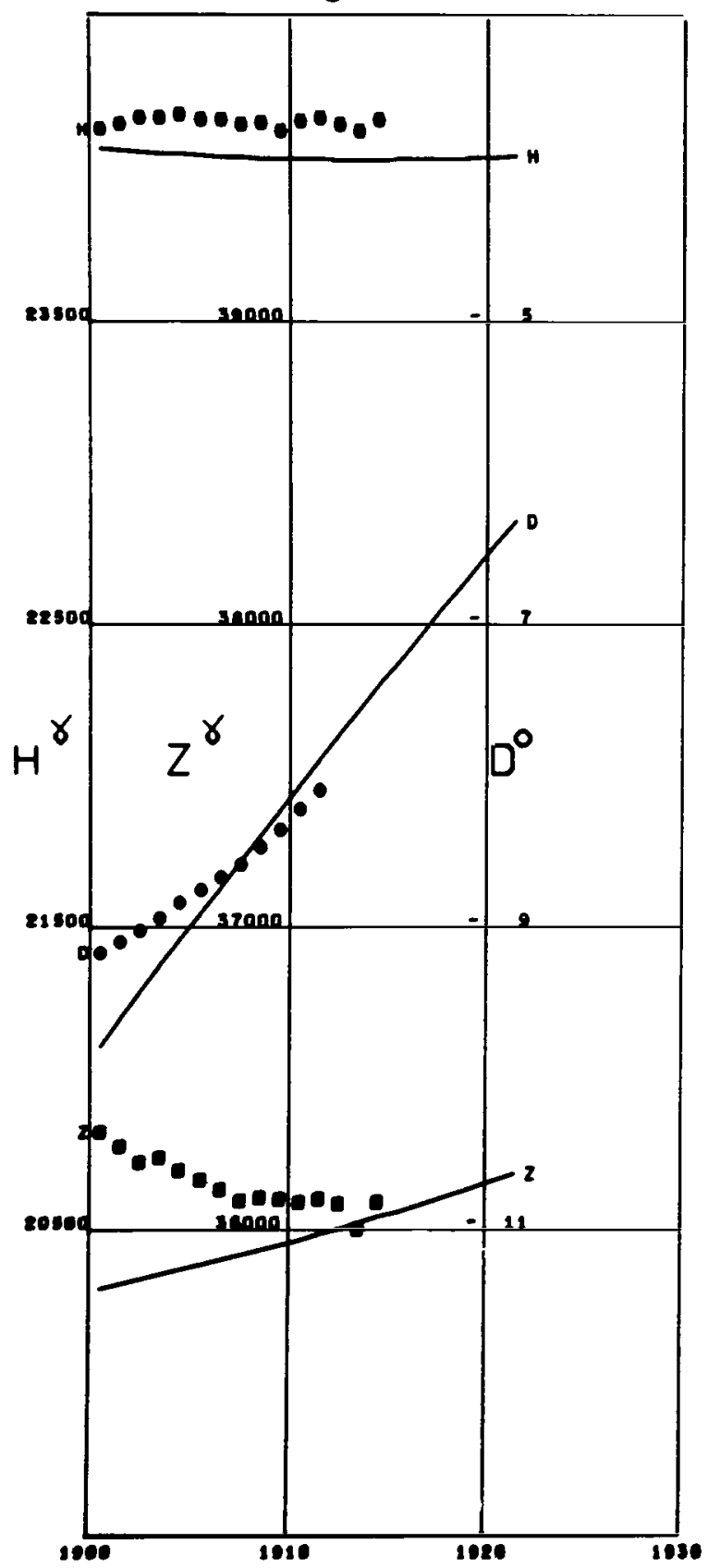

Figure A30 
CASTELLACC 10

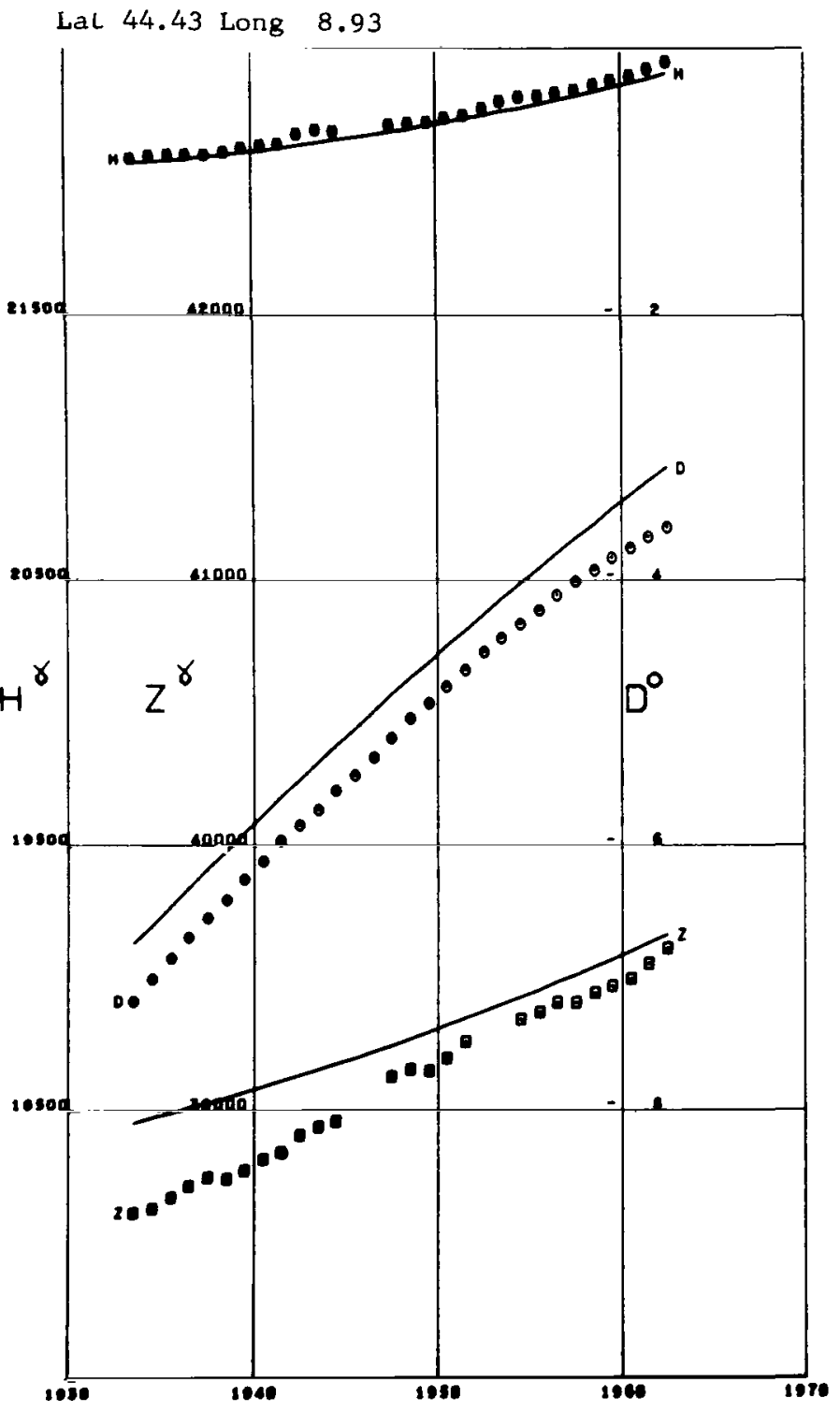

Figure A31
CHA PA

Lat 22.35 Long 103.83

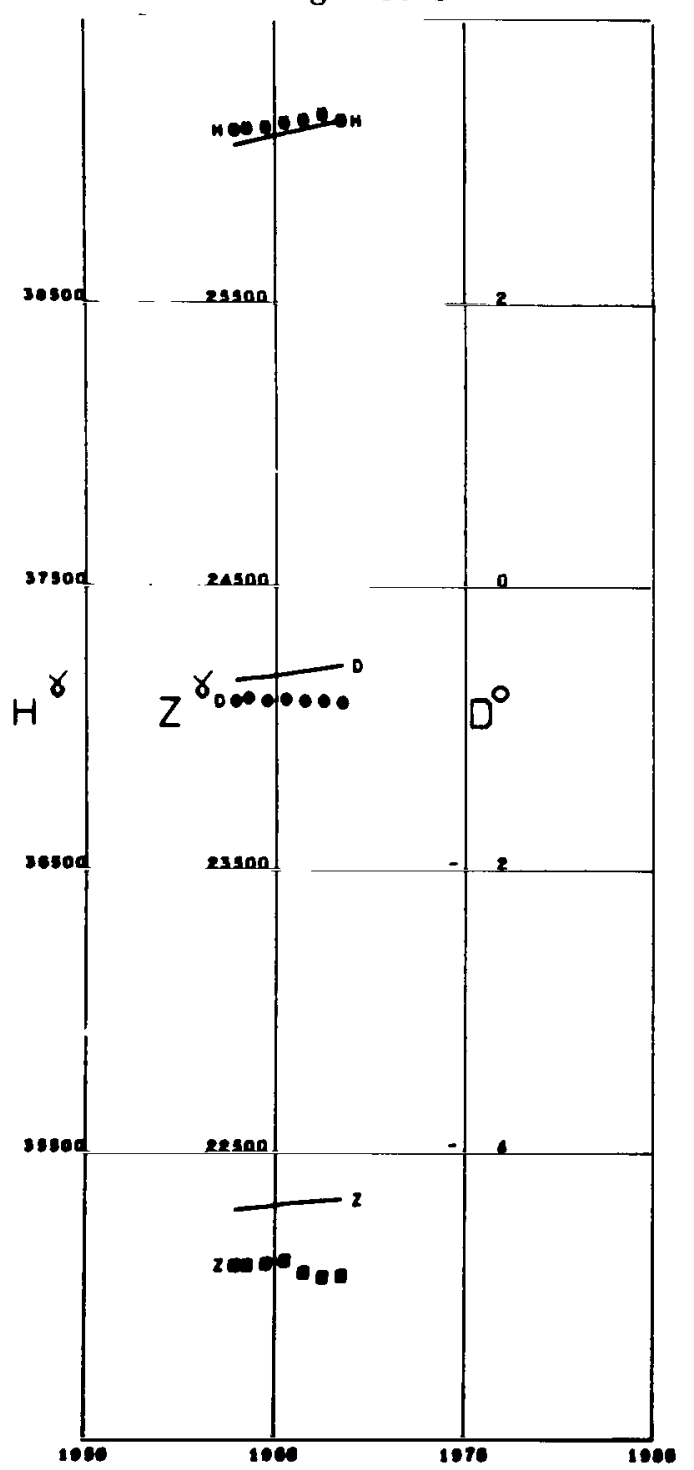

Figure A32 
CHAMBON-LA -F ORET

Lat 48.02 Long 2.26

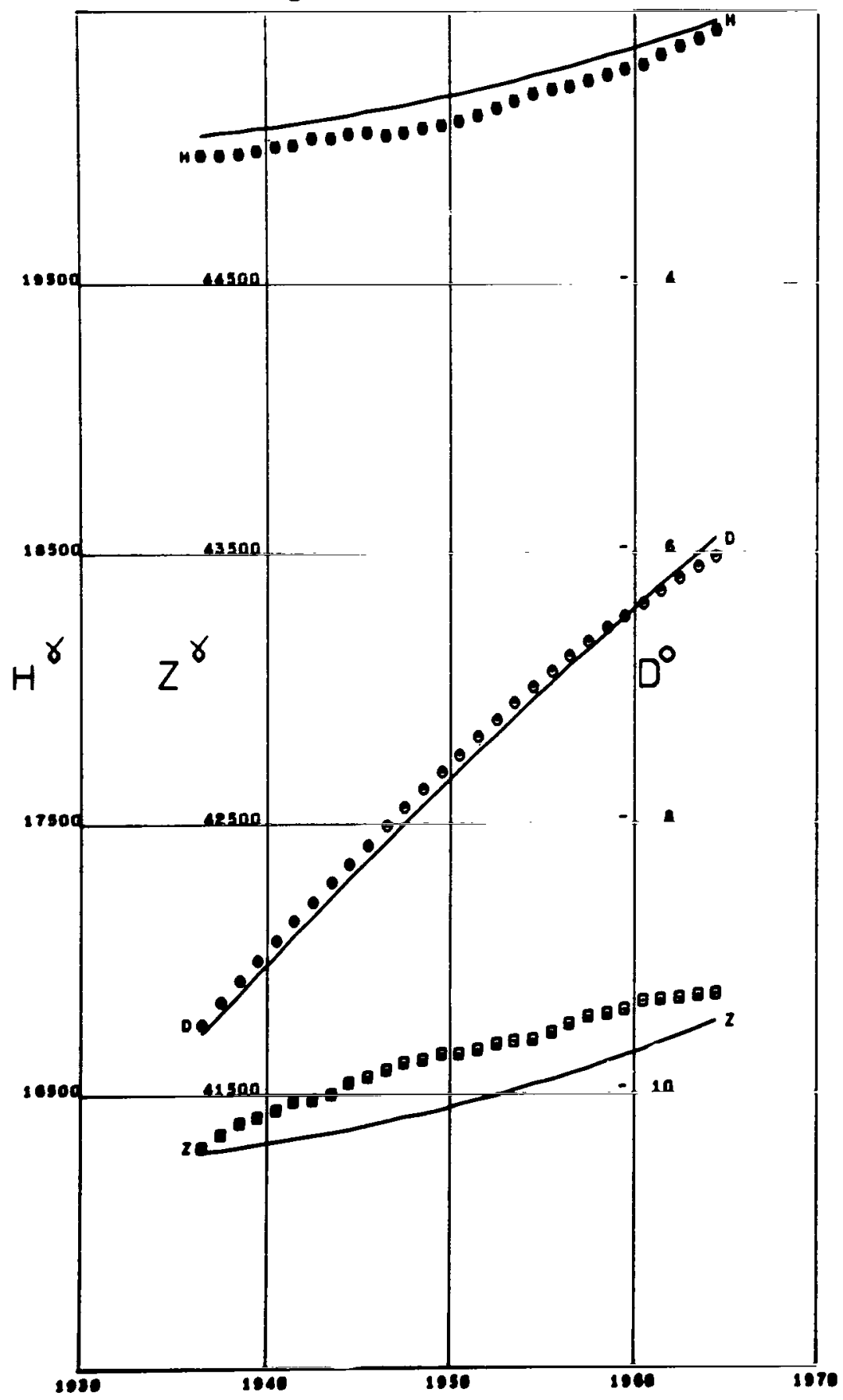

Figure A33 


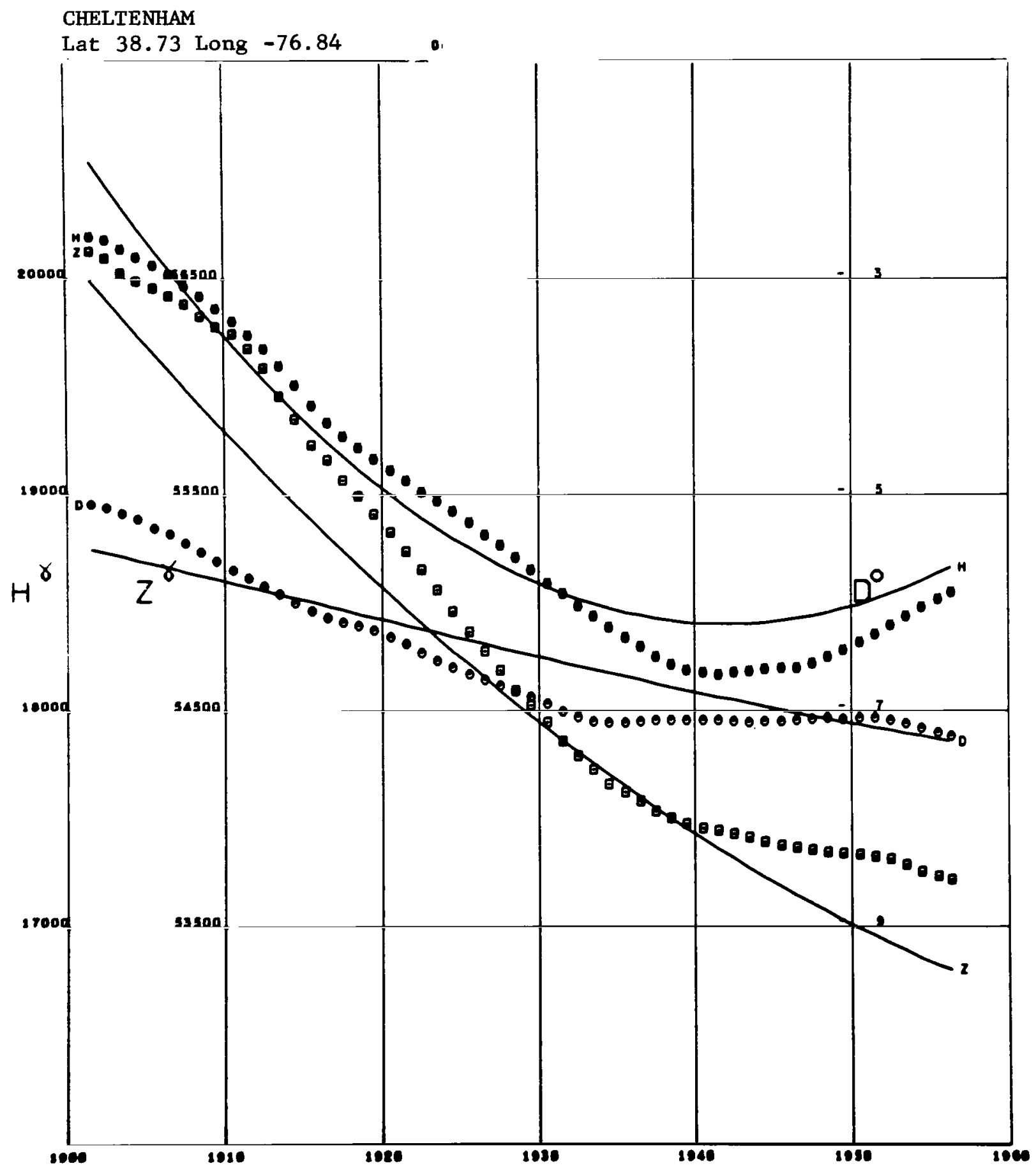

Figure A34 


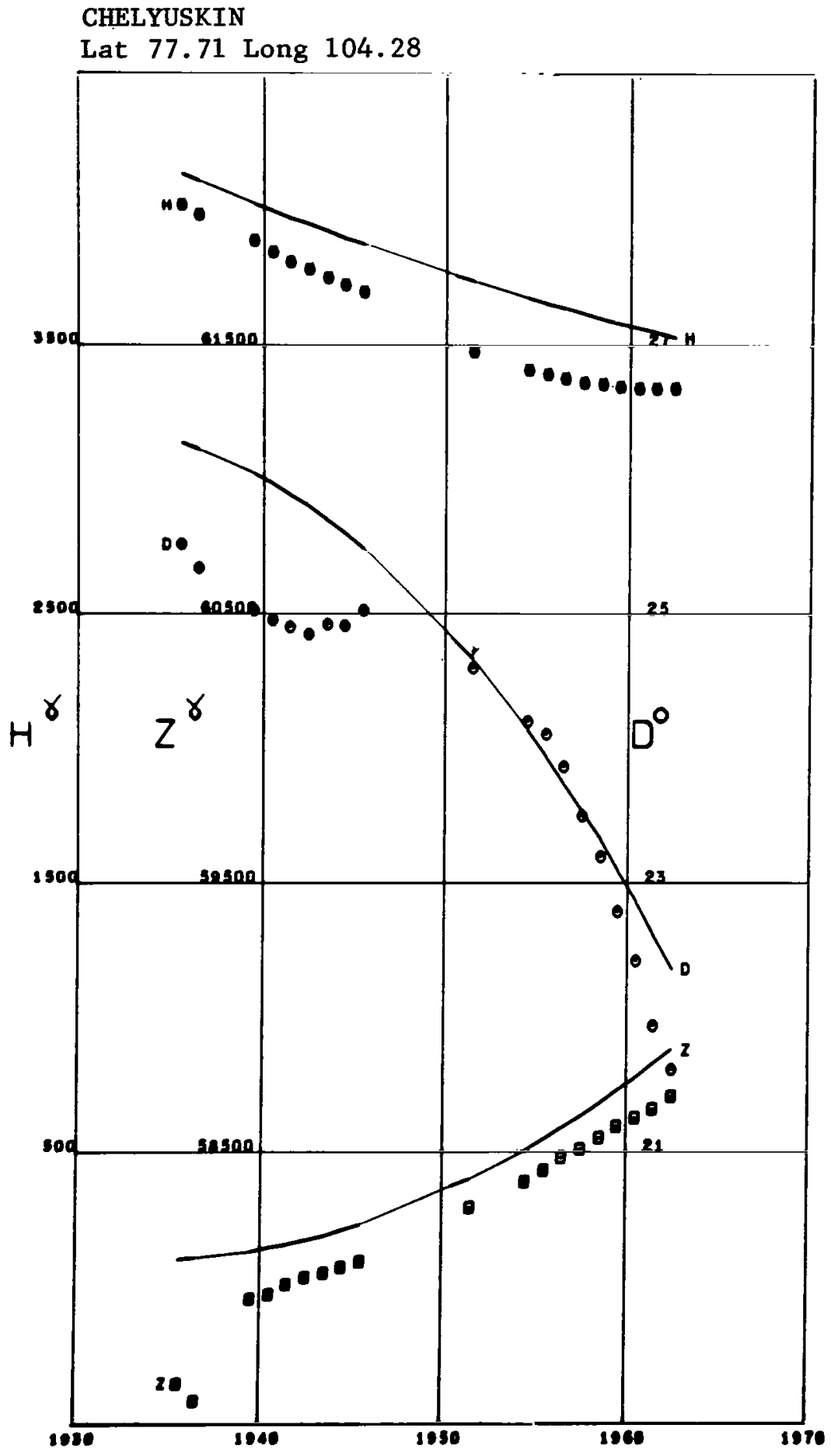

Figure A35 
CHR ISTCHURCH

Lat -43.53 Long 172.62

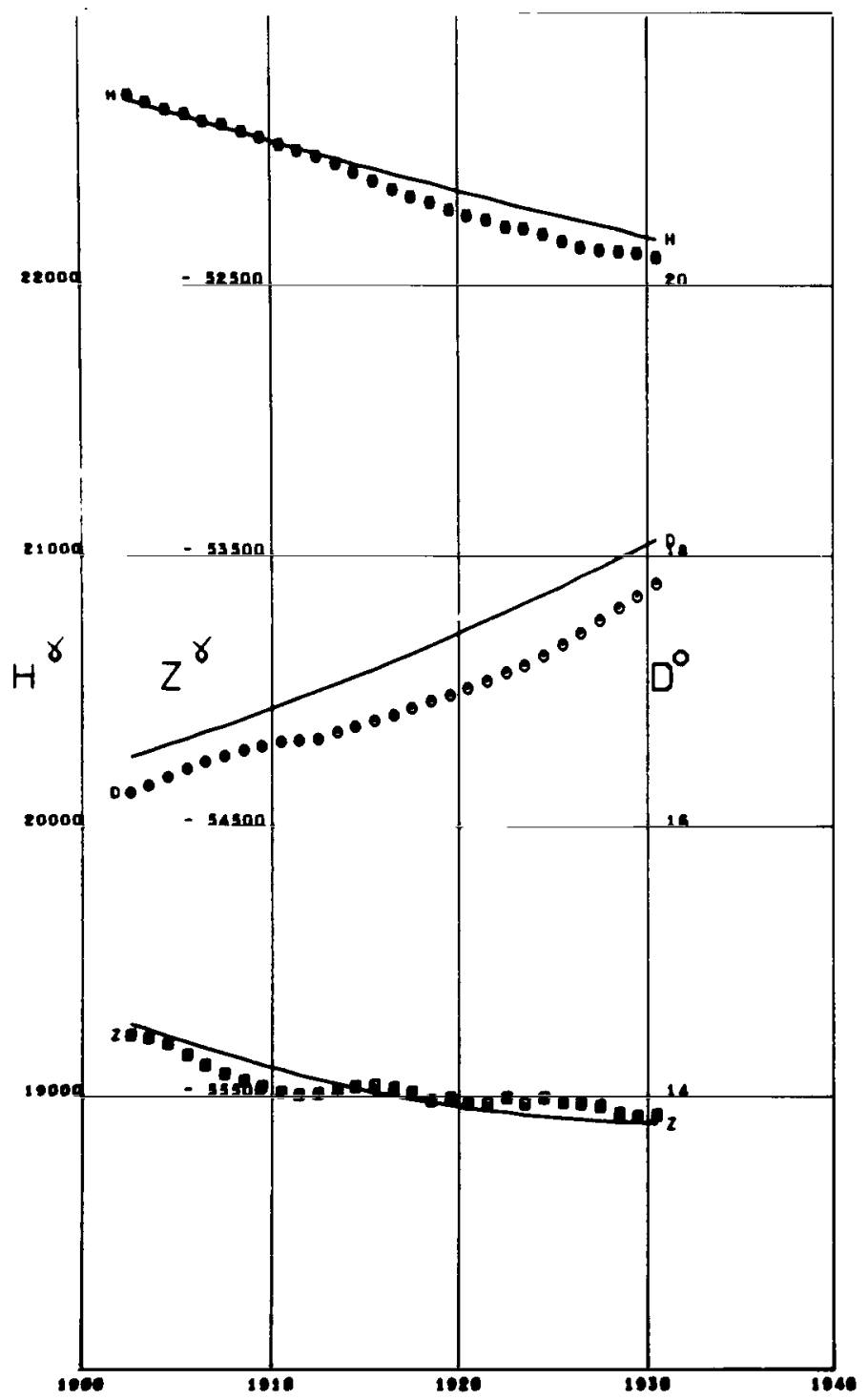

Figure A36
CLAUSTHAL

Lat 51.80 Long 10.33

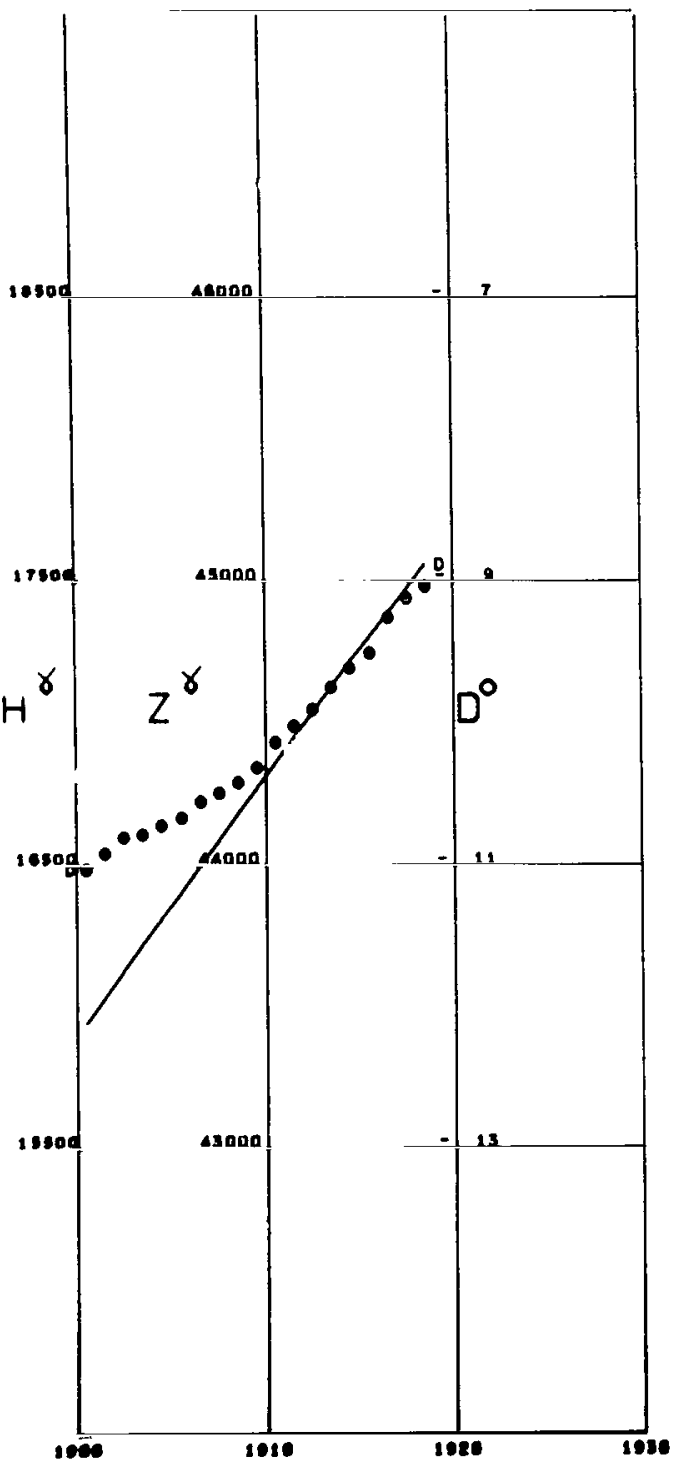

Figure A37 


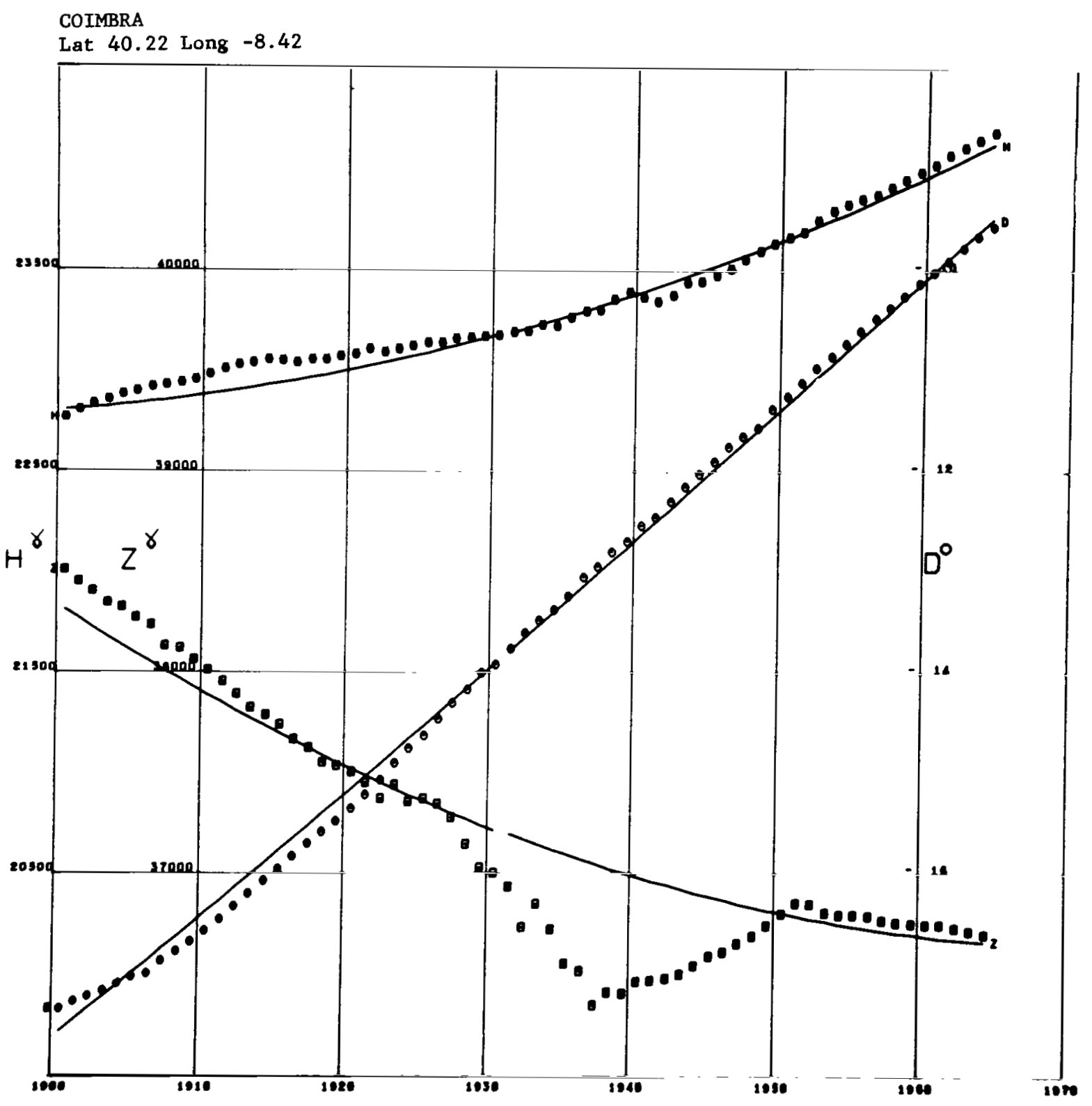

Figure A38 
COLABA

Let 18.89 Long 72.81

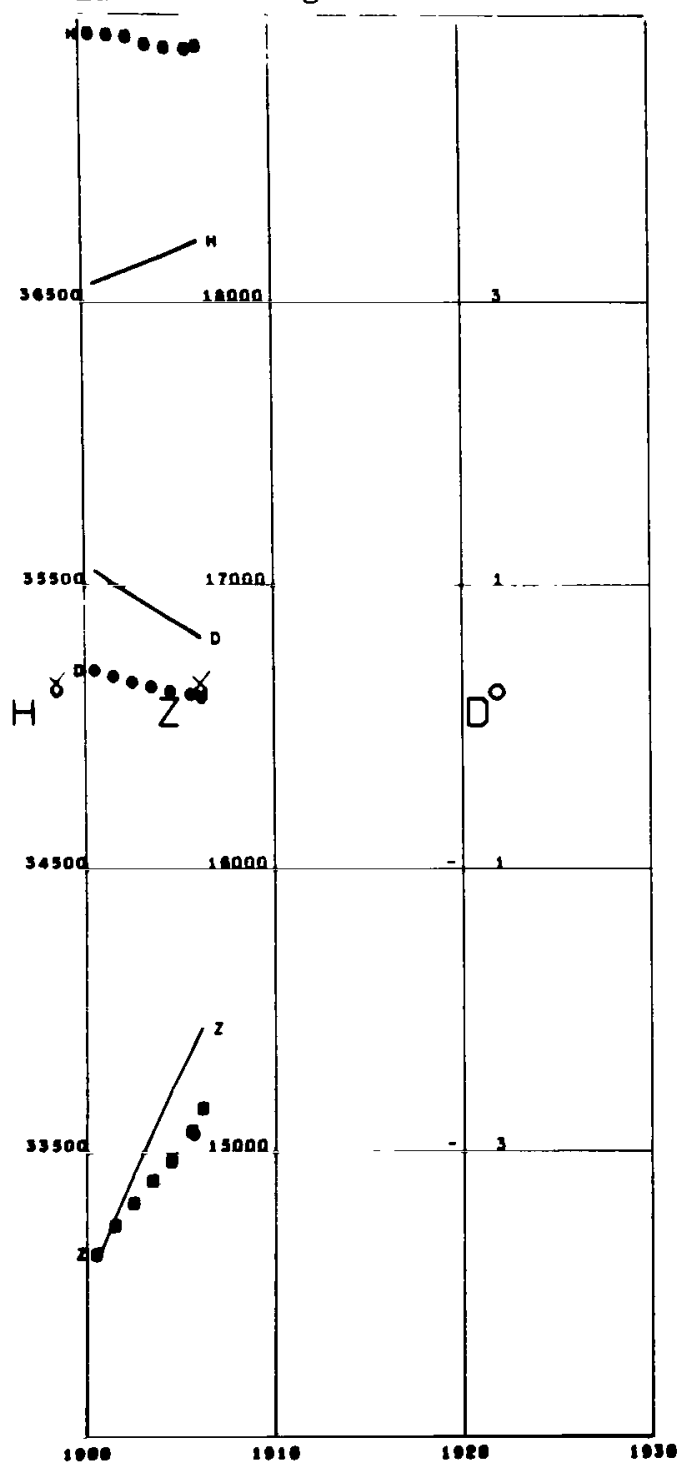

Figure A39

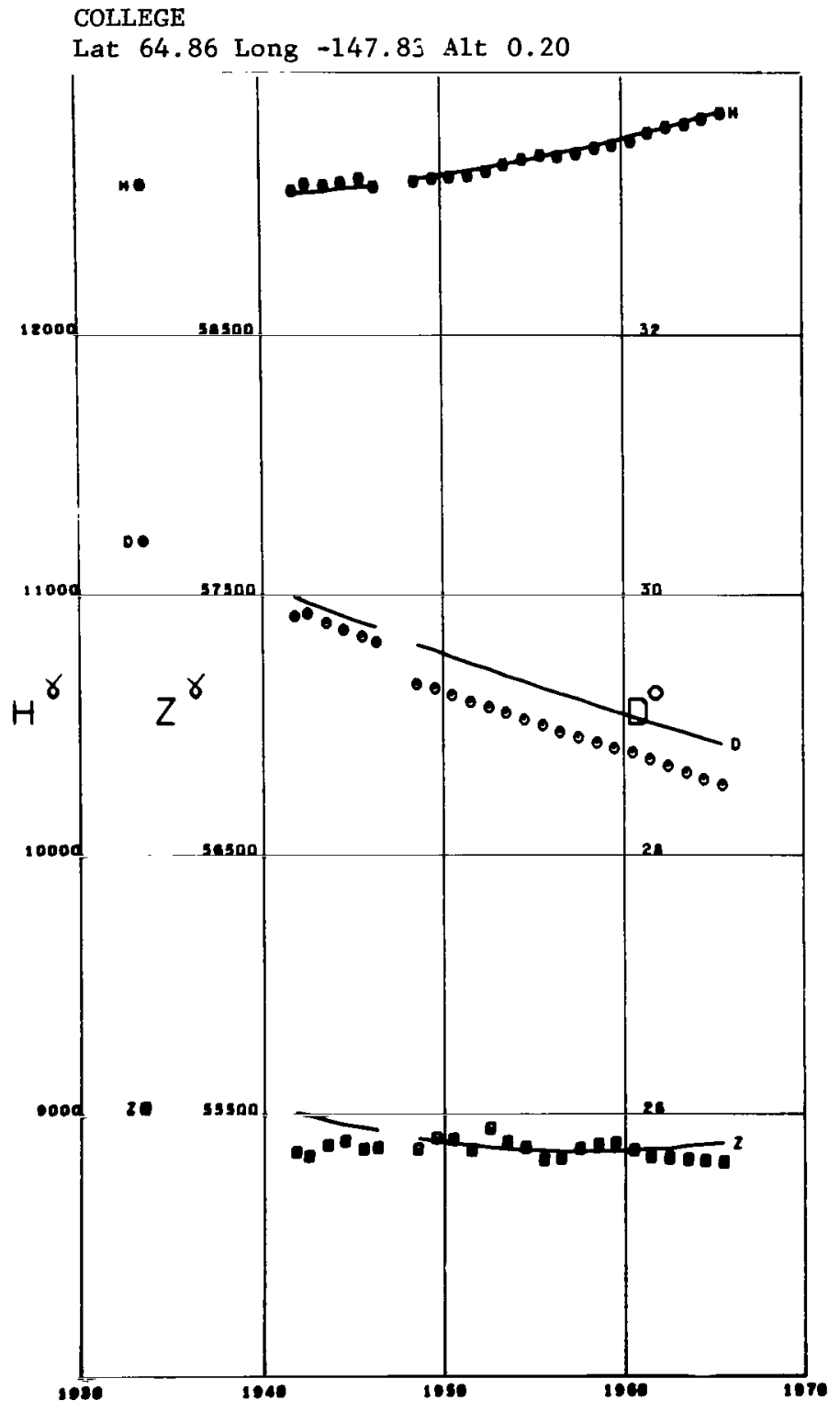

Figure A40 


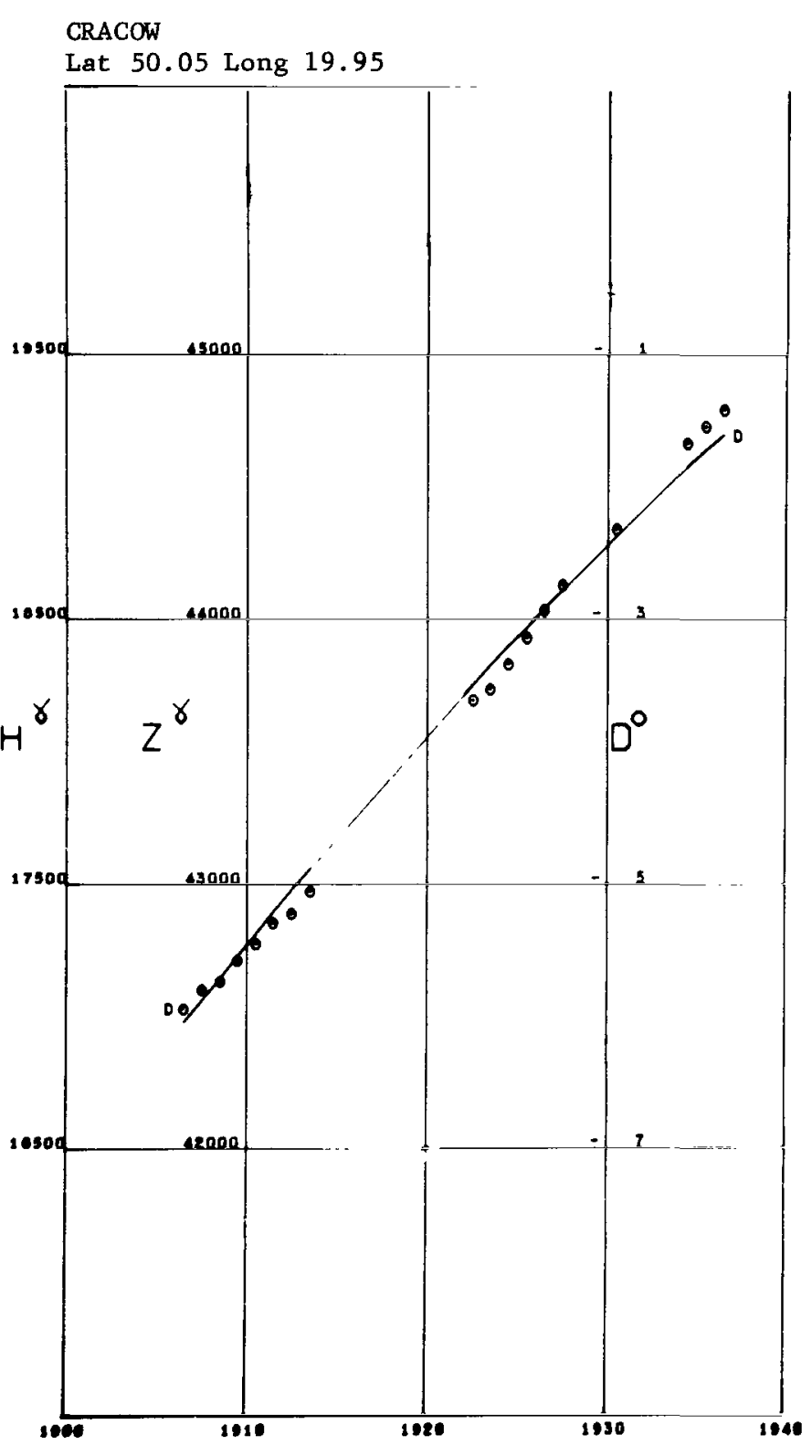

Figure A41
CUAJIMALPA

Lat 19.37 Long -99.28

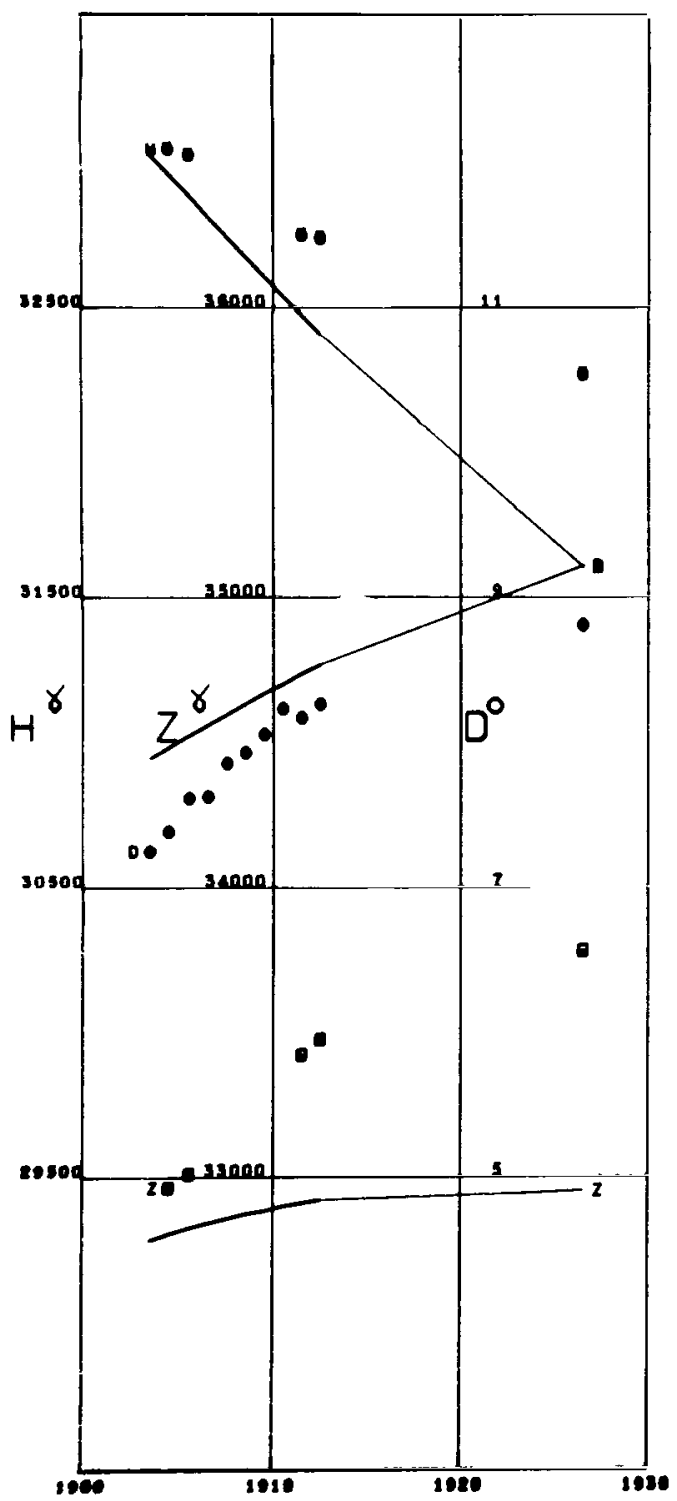

Figure $\mathrm{A} 42$ 


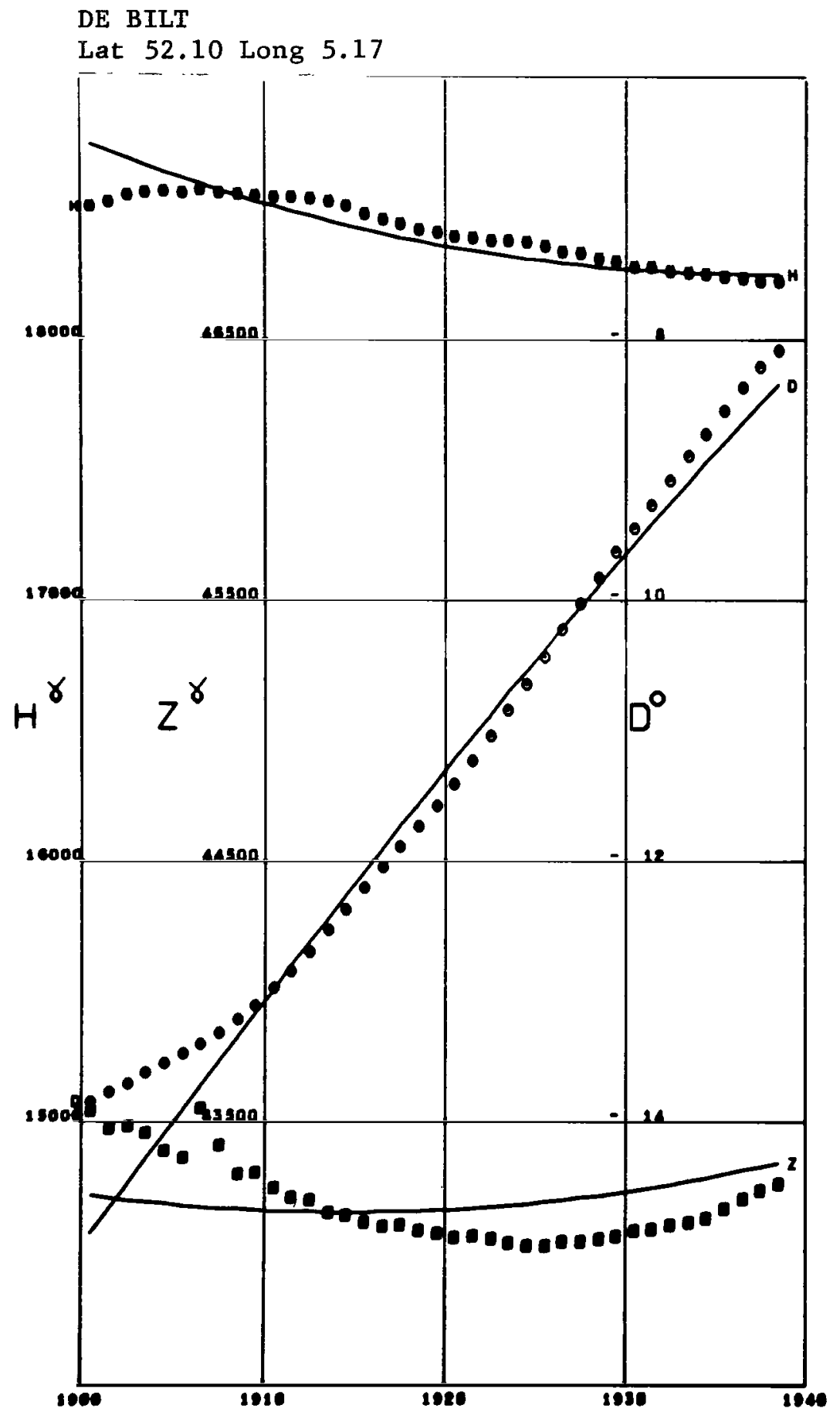

Figure A43 
DEHRA DUN

Lat 30.32 Long 78.05

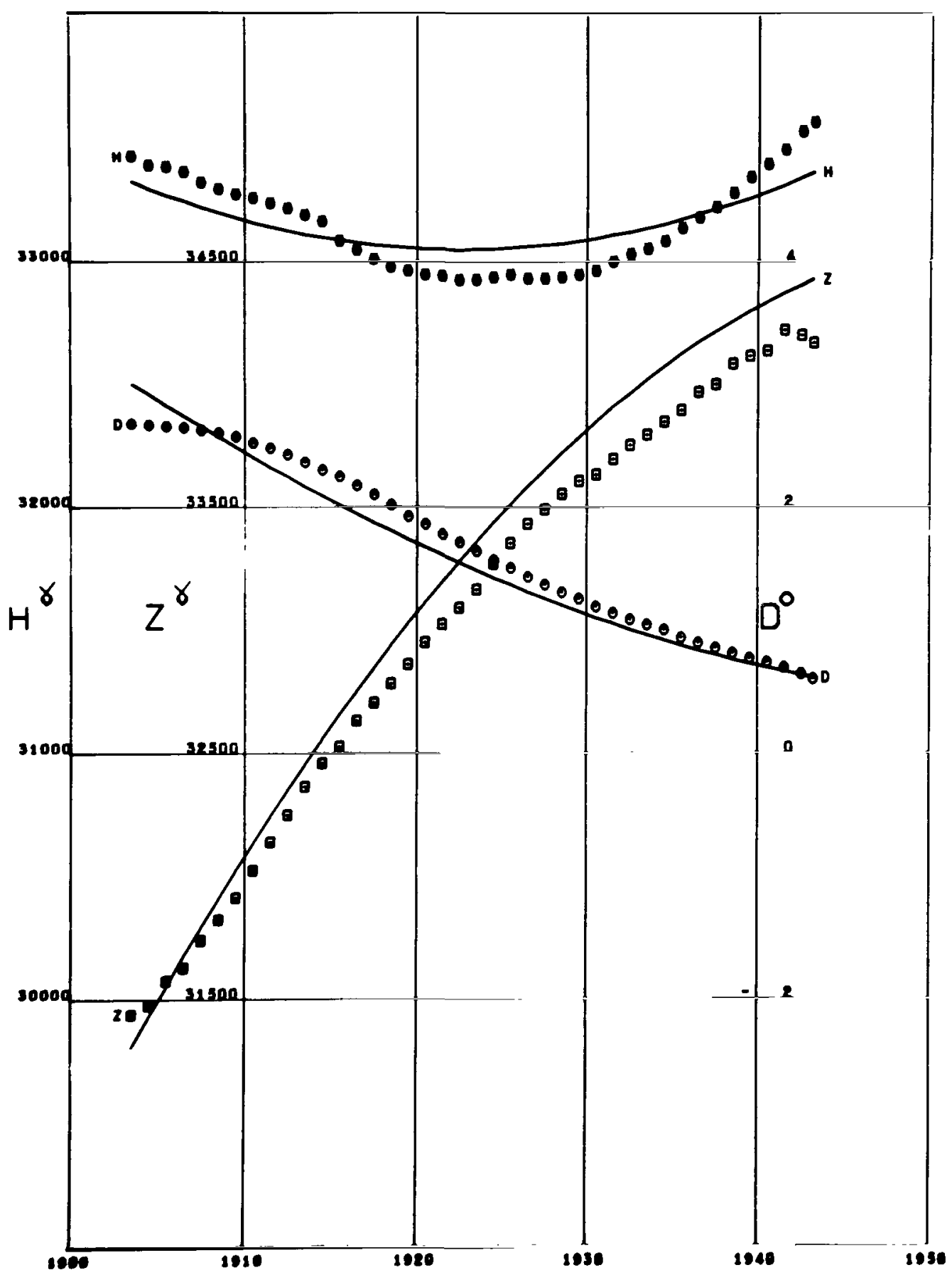

Figure A44 
๘KELEIA

Lat 38.10 Long 23.77

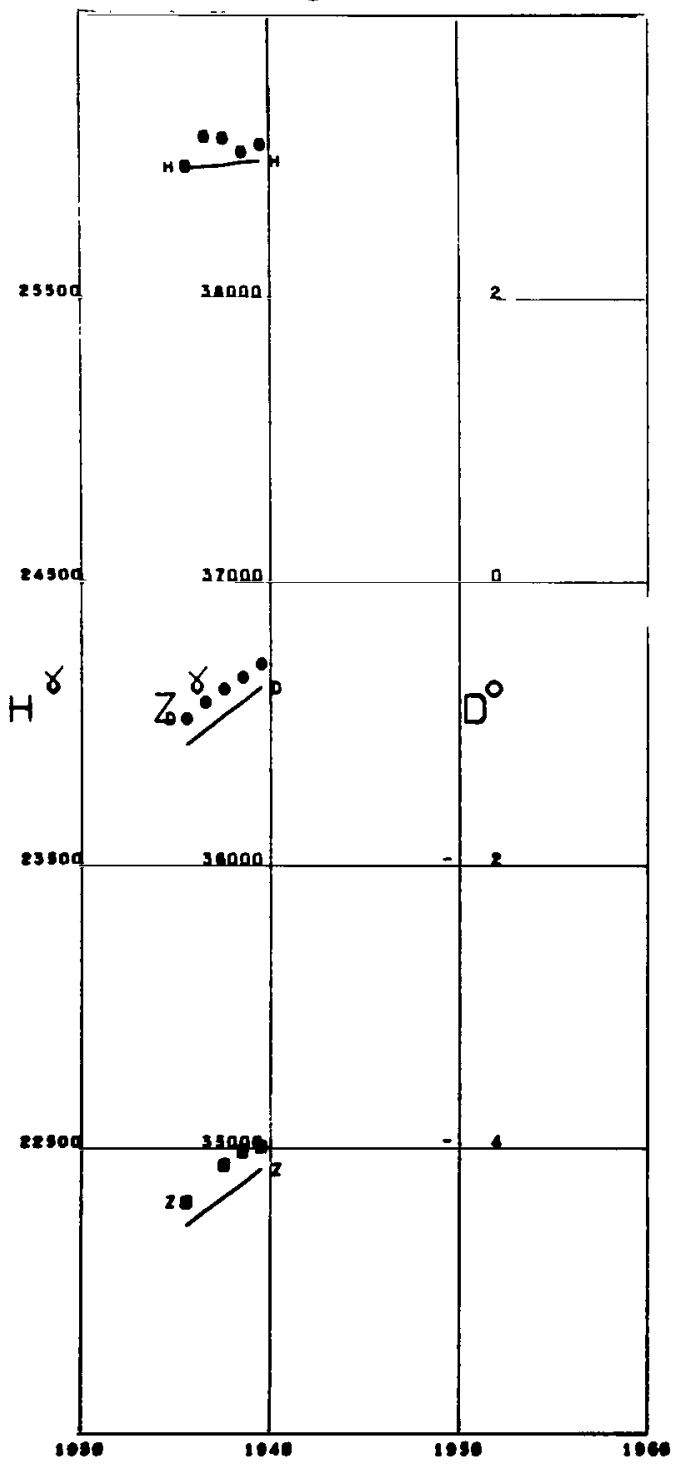

DIKSON

Lat 73.54 Long 80.56

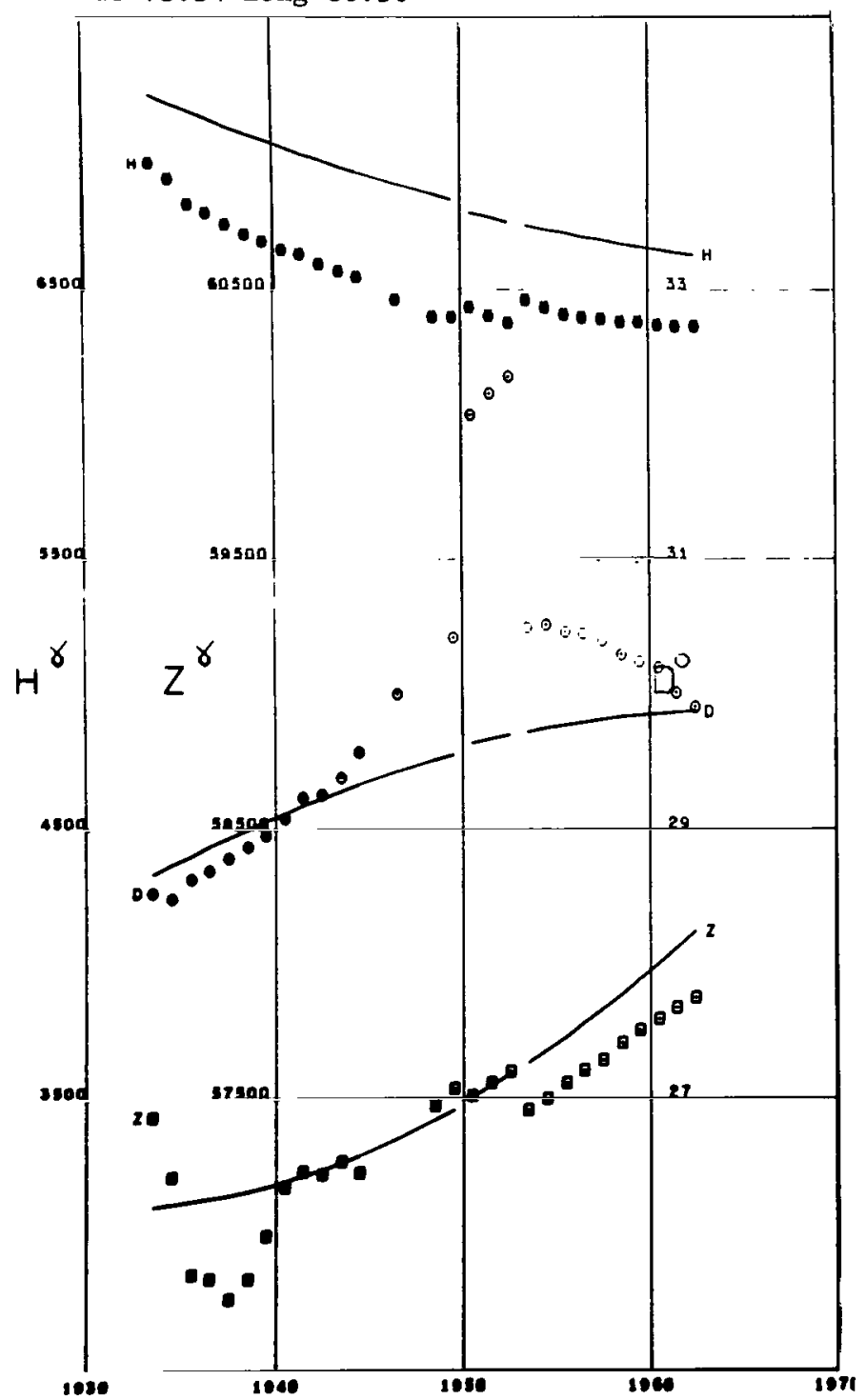

Figure A45

Figure A46 


\section{DOMBAS}

Lat 62.07 Long 9.11

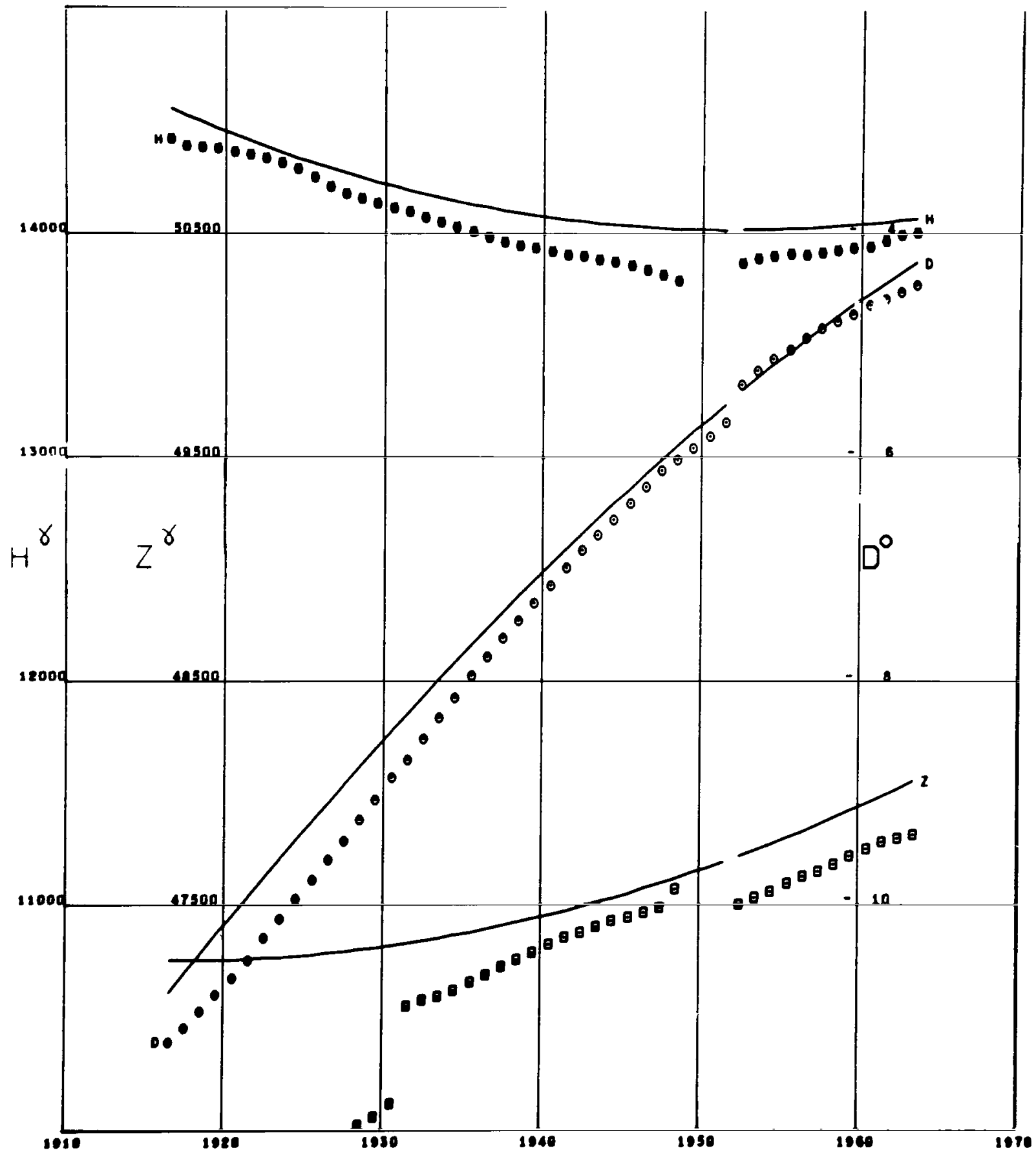

Figure A47 
DOURBES

Lat 50.09 Long 4.59

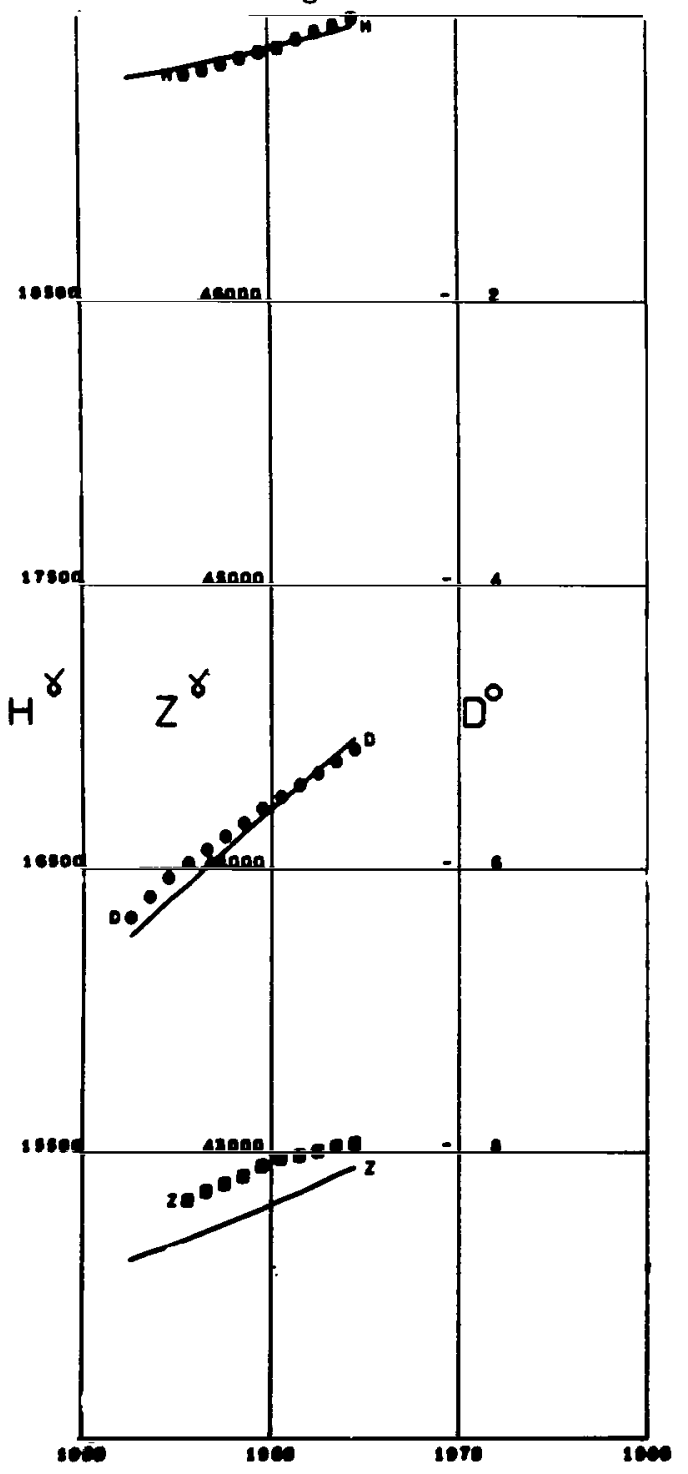

Figure A48
DUSHETI

Lat 42.09 Long 44.70

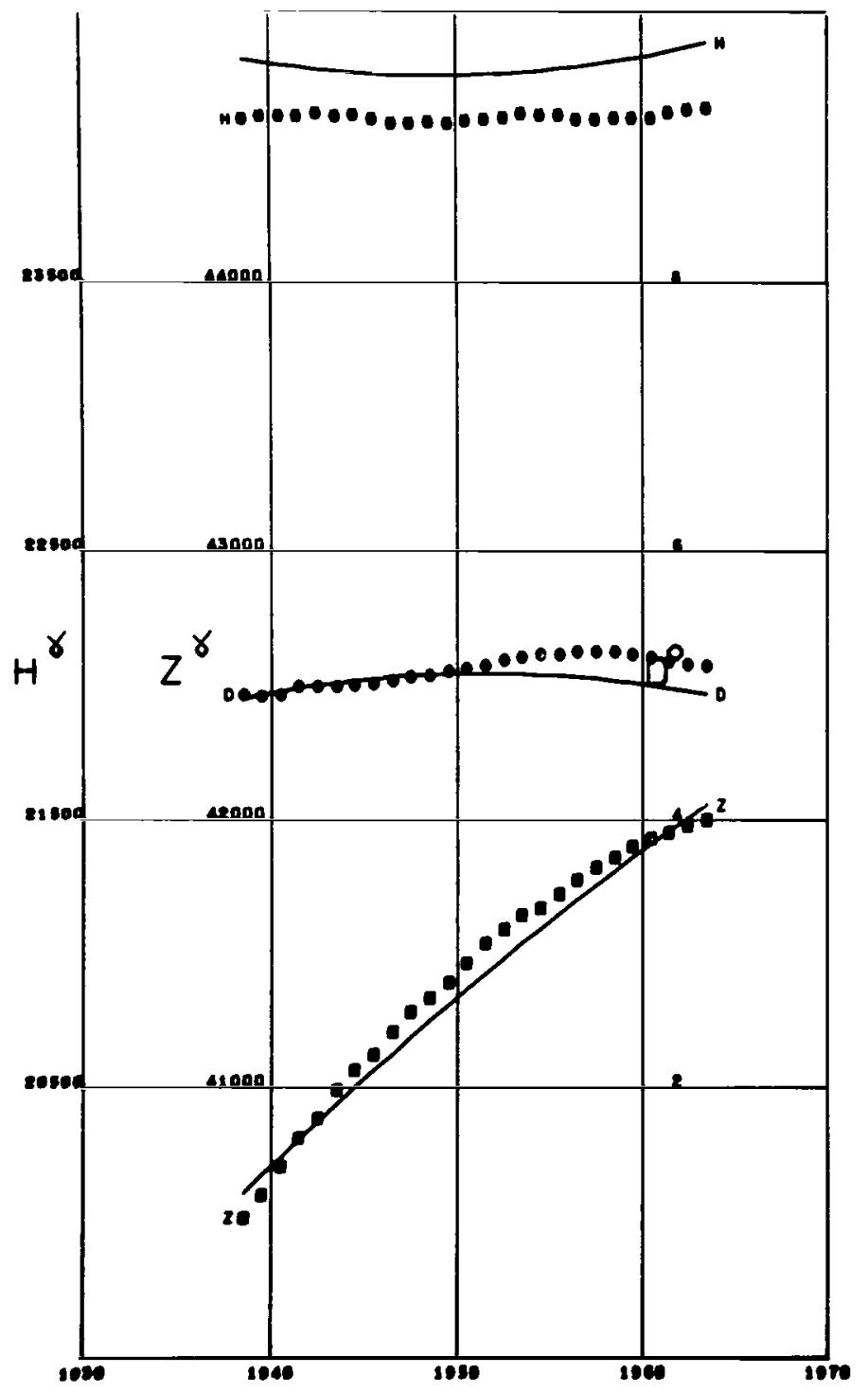

Figure A49 
EBRO

Lat 40 Long $0.49 \mathrm{Alt} 0.05$

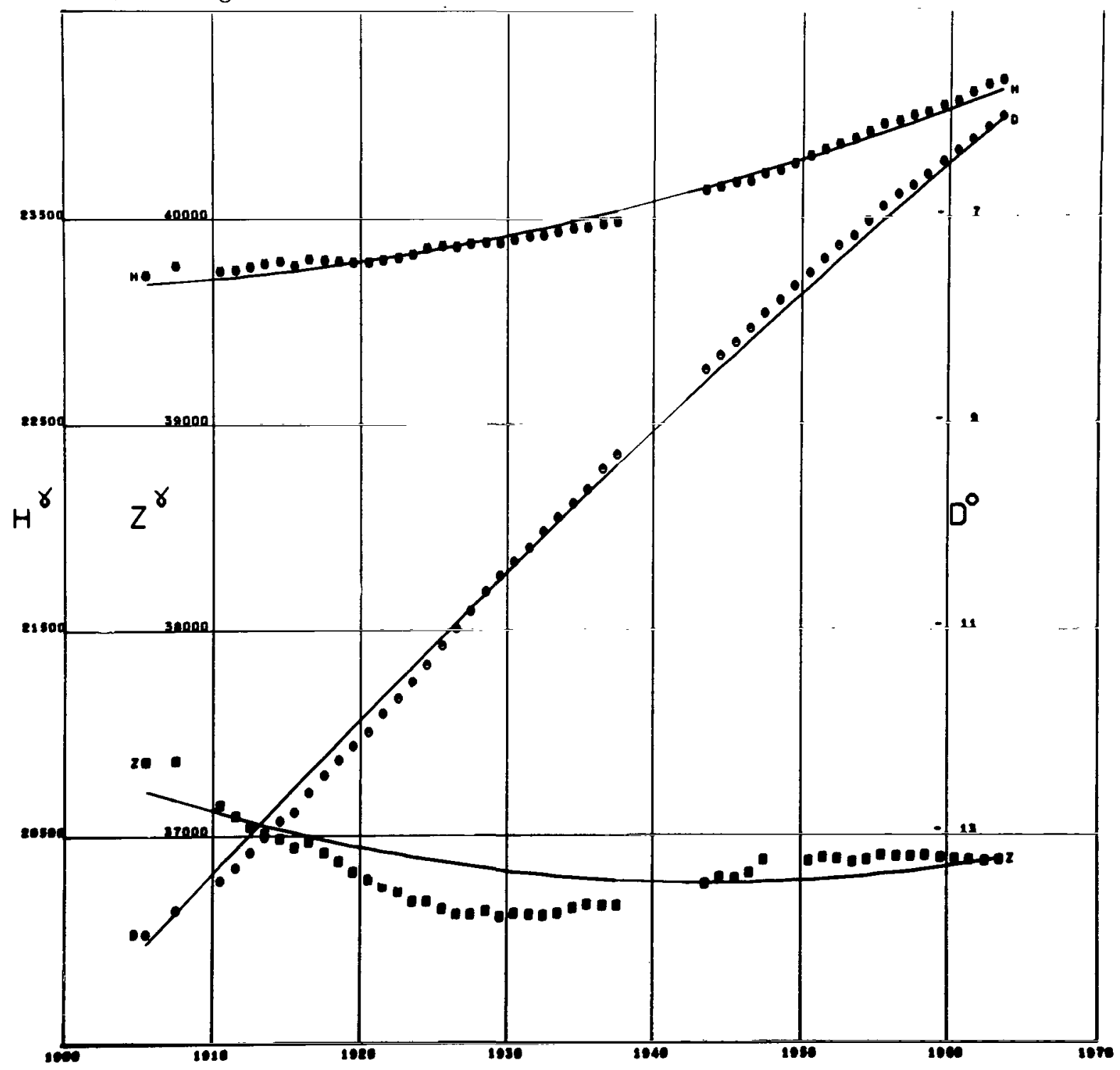

Figure A50 
EL ABIOD SIDI

Lat 32.90 Long 0.55

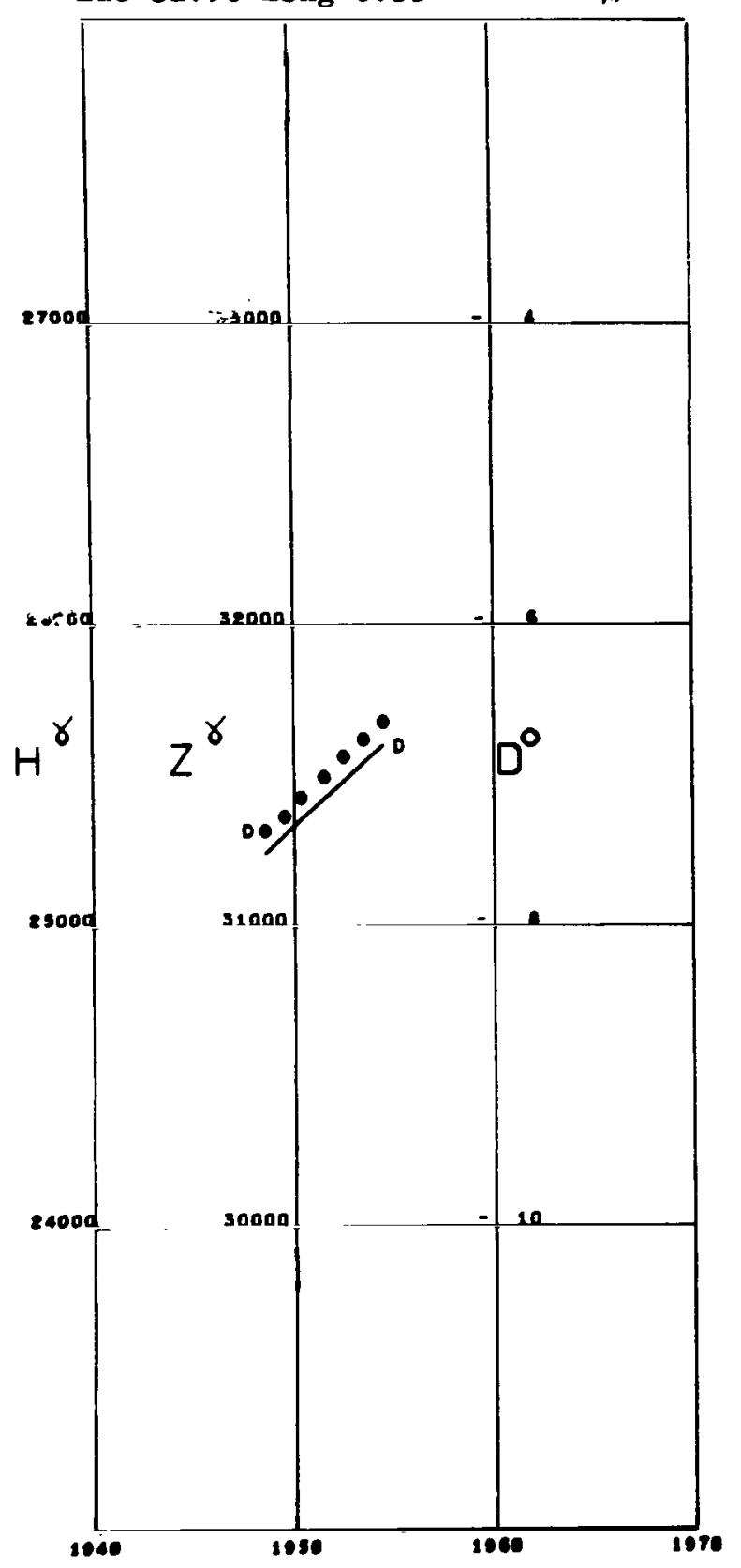

ELISABETHVILLE

Lat -11.65 Long 27.46

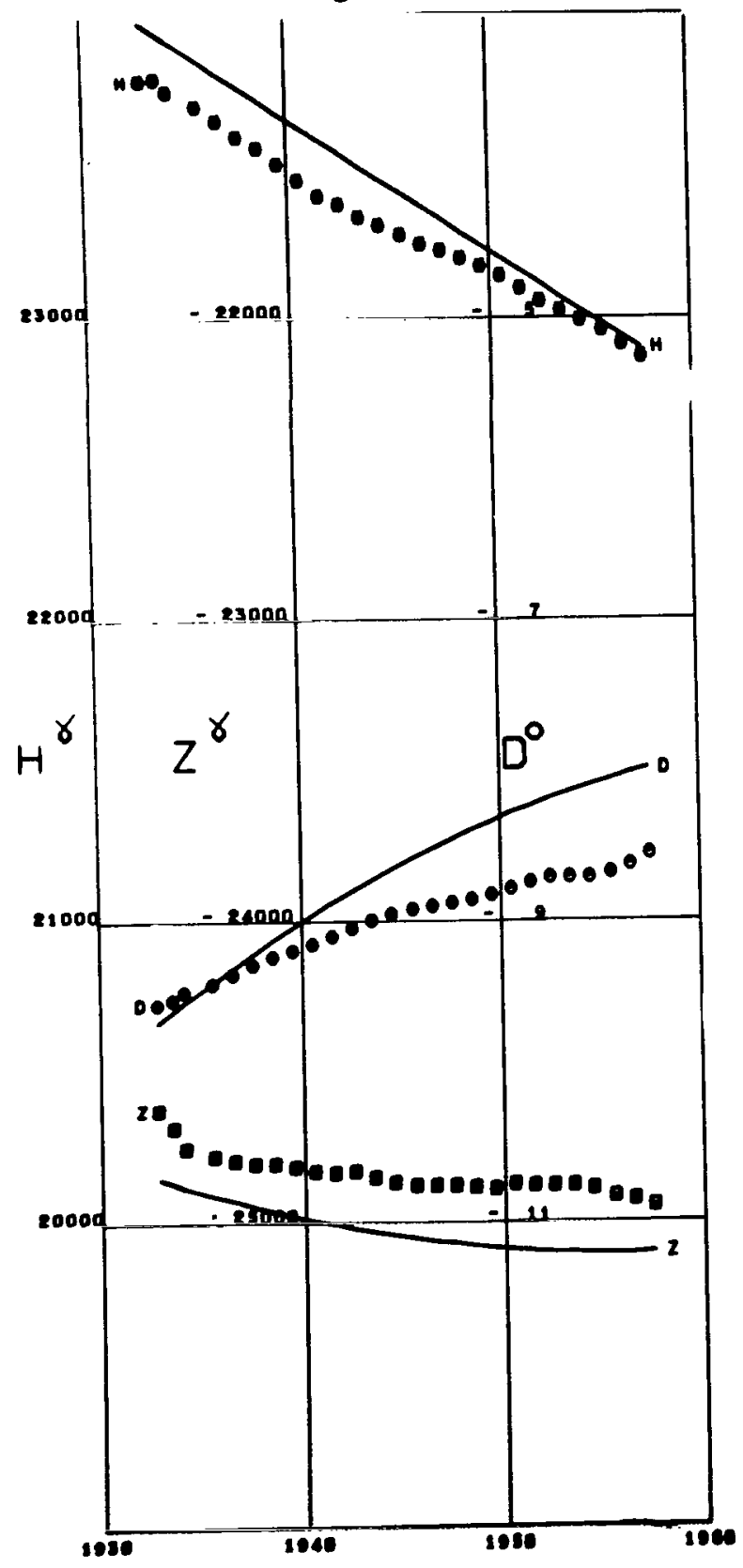

Figure A51 
ESKDALEMUIR

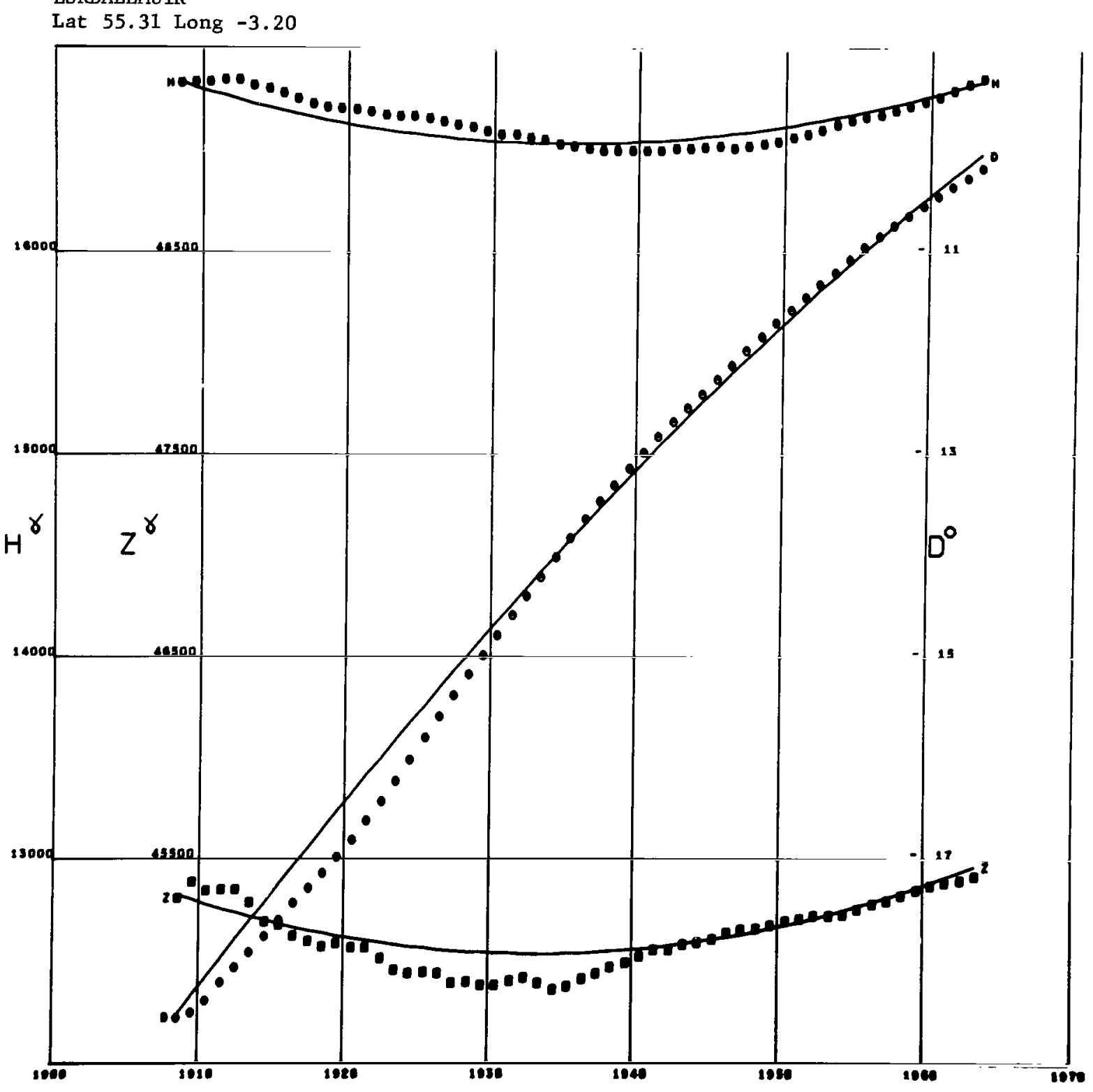

Figure A53 


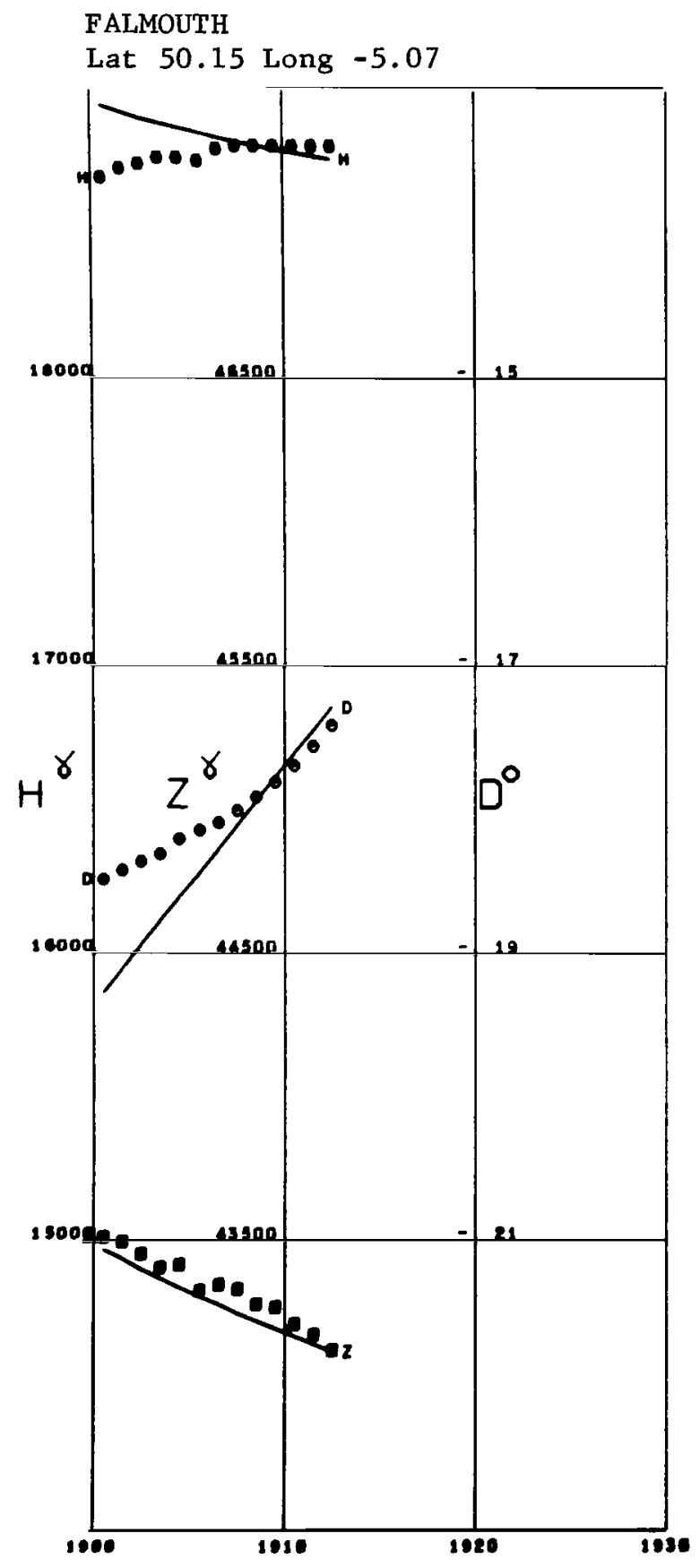

Figure A54

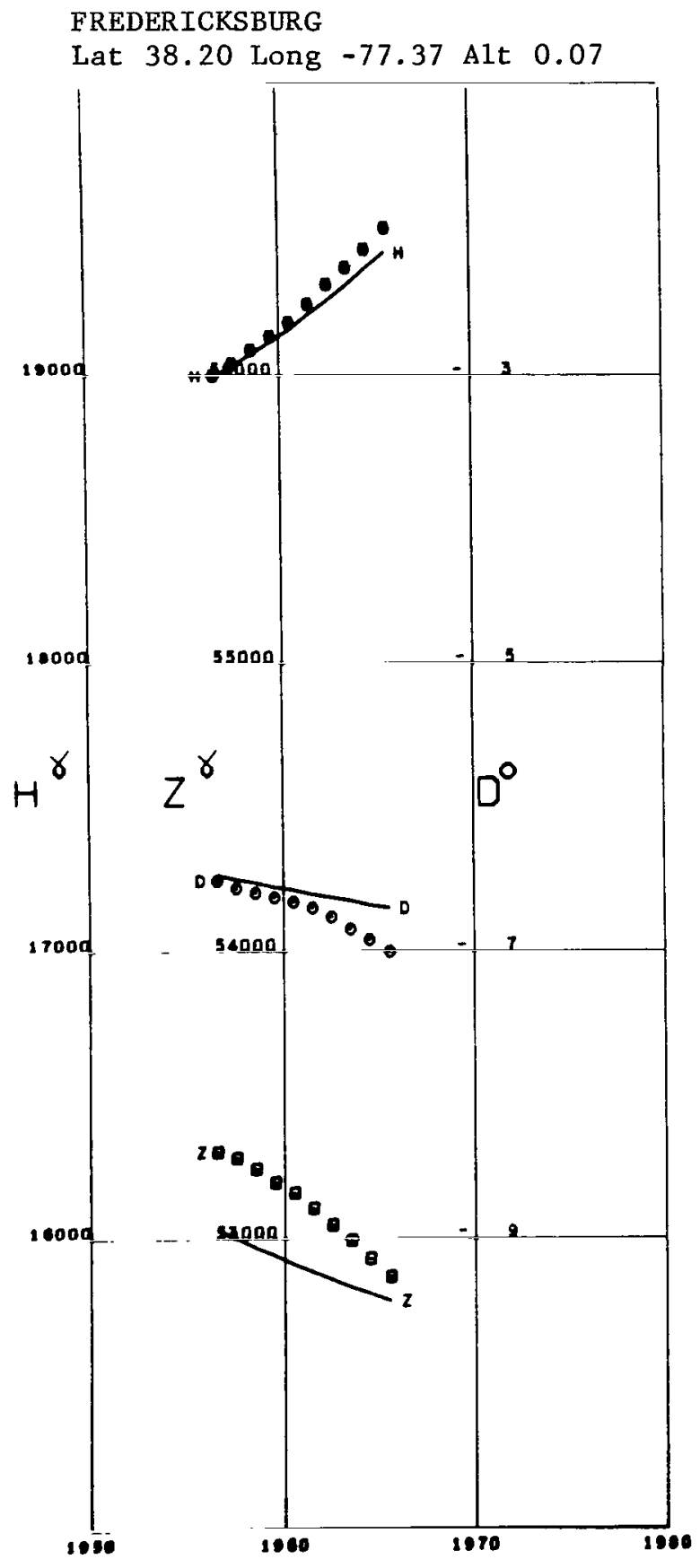

Figure A55 


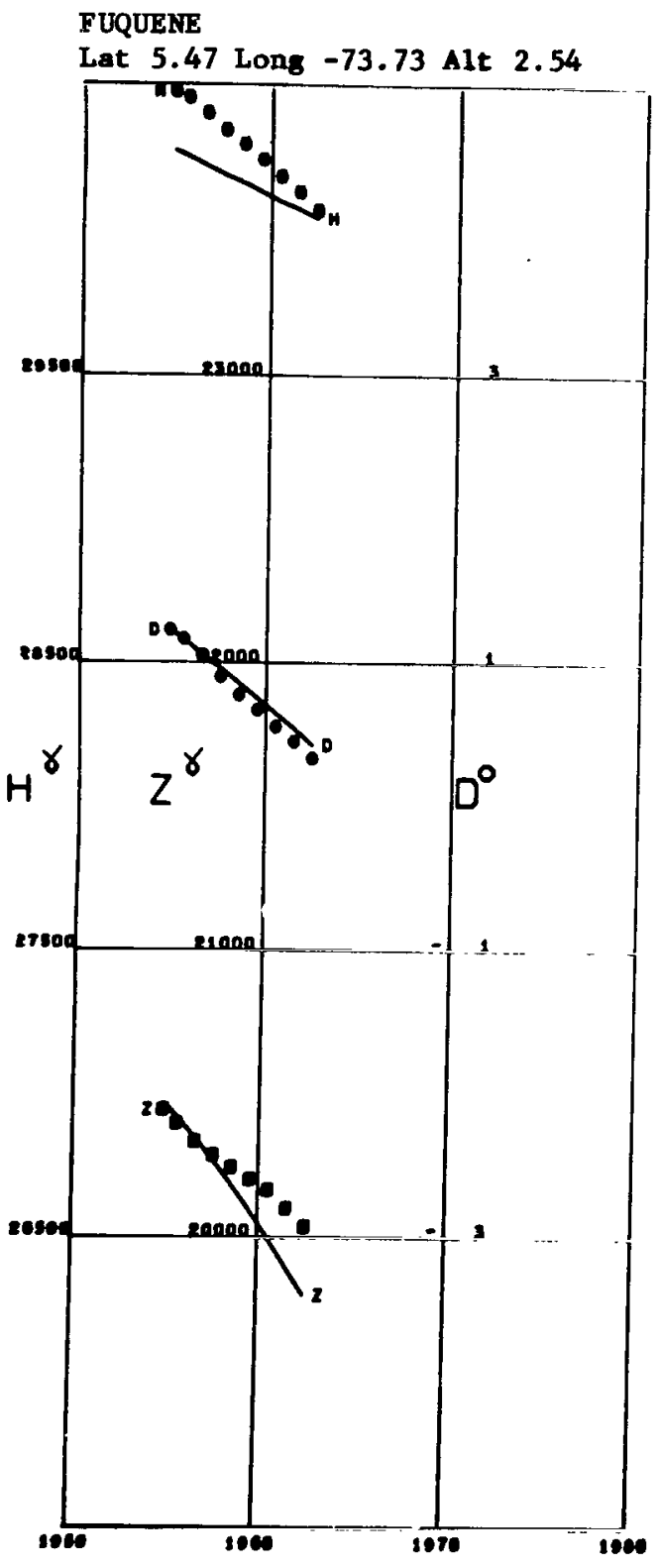

Figure A56

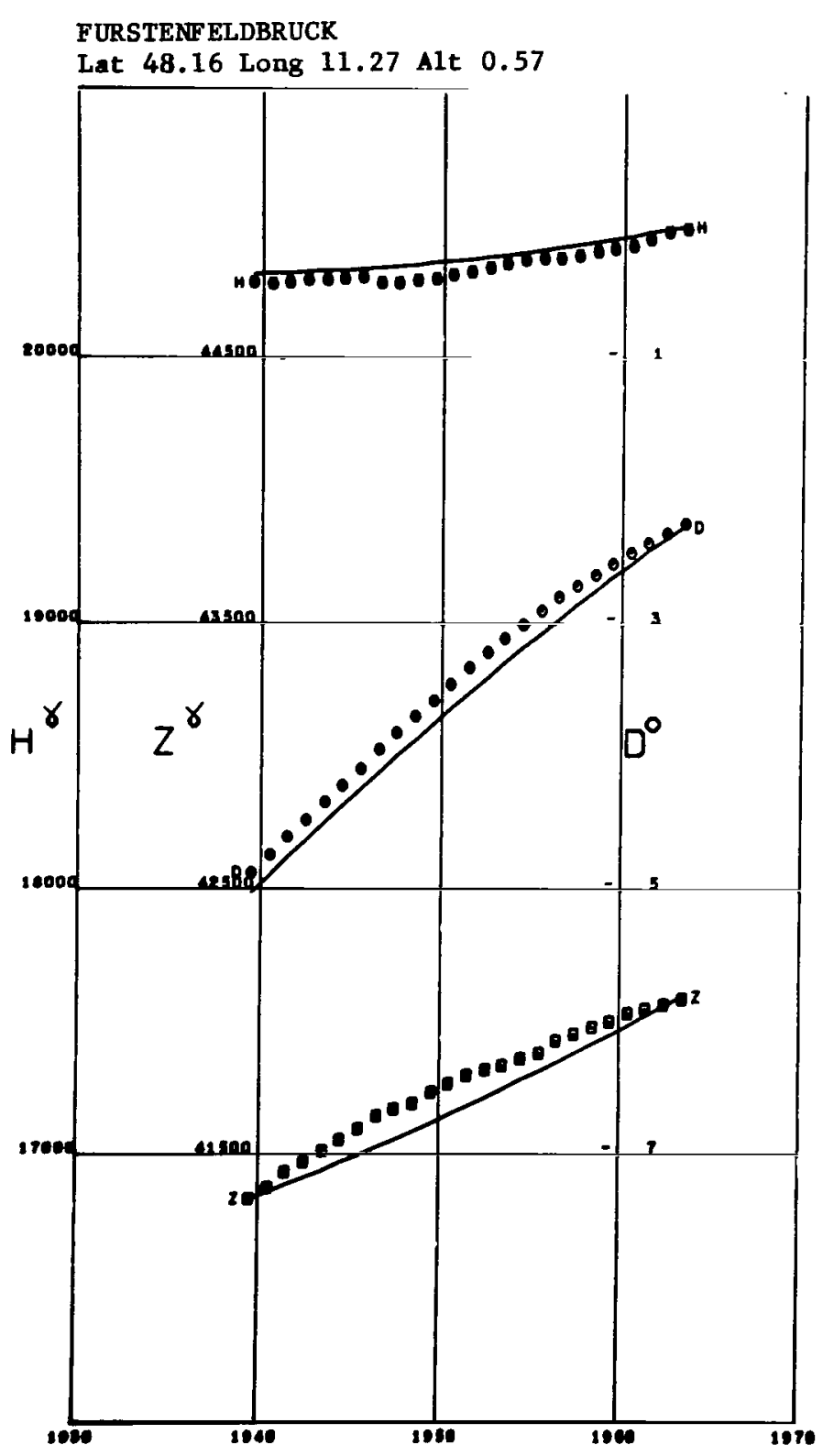

Figure A57 
GNANGARA

Lat -31.78 Long 115.95 Alt 0.06

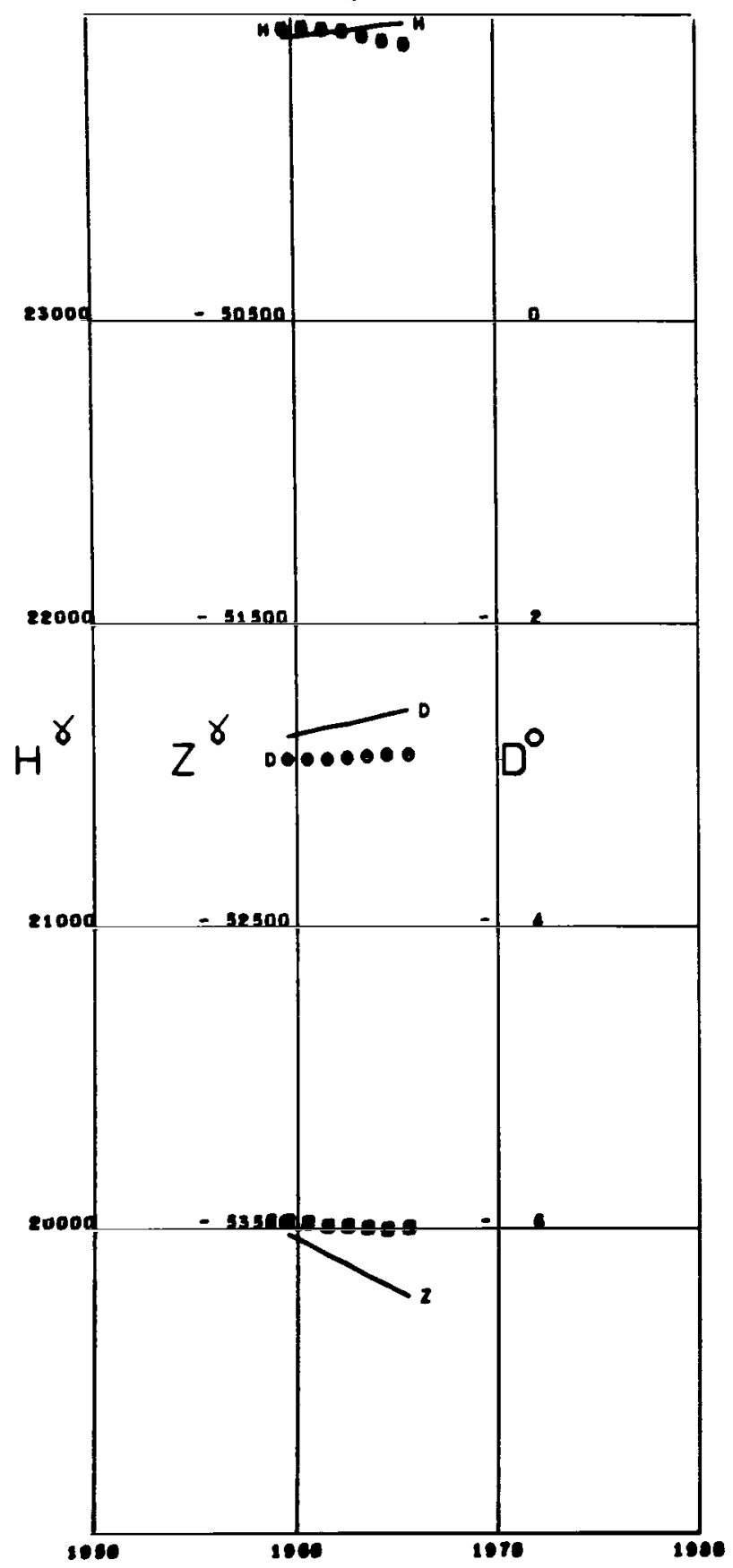

Figure A58 


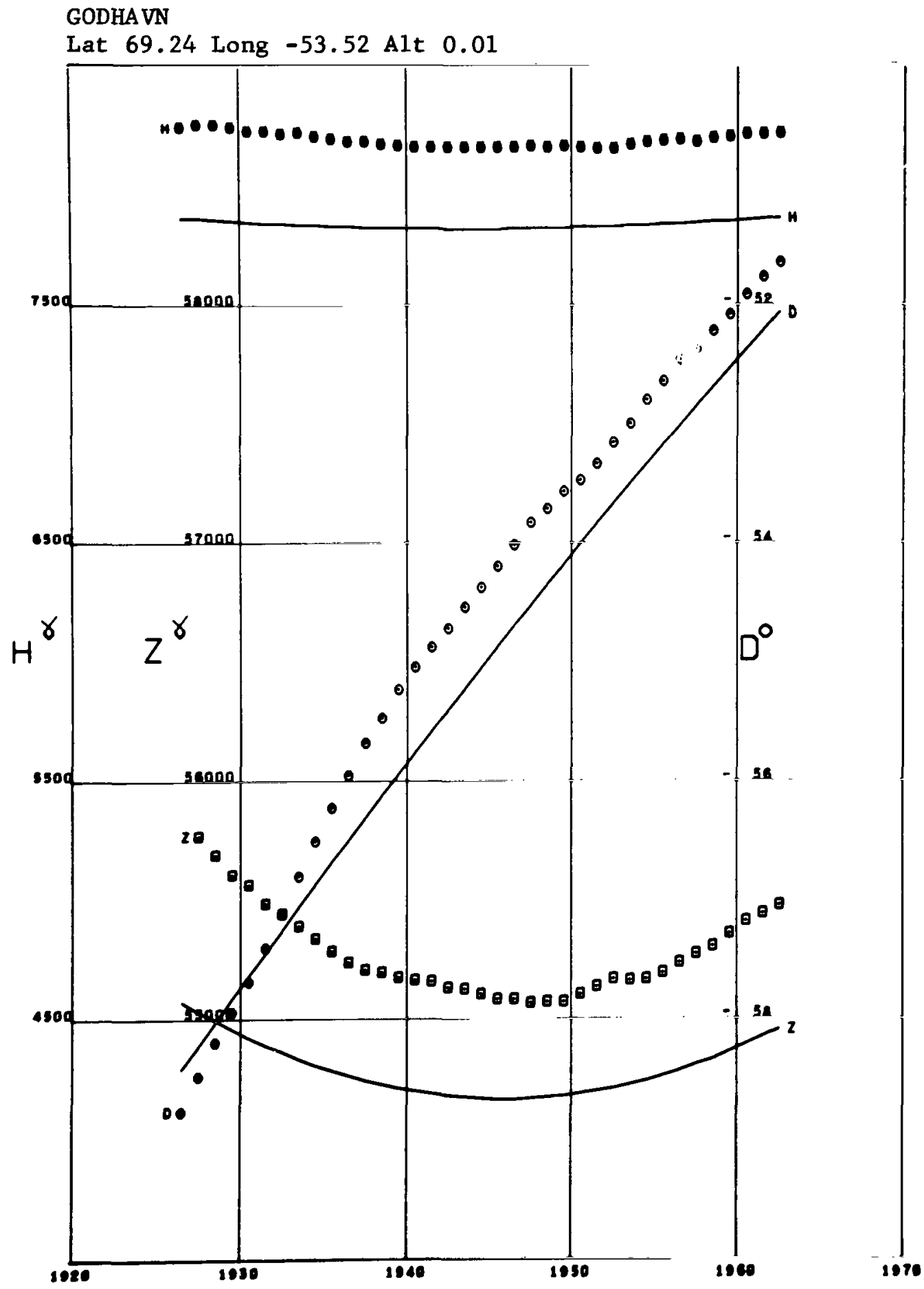

Figure A59 


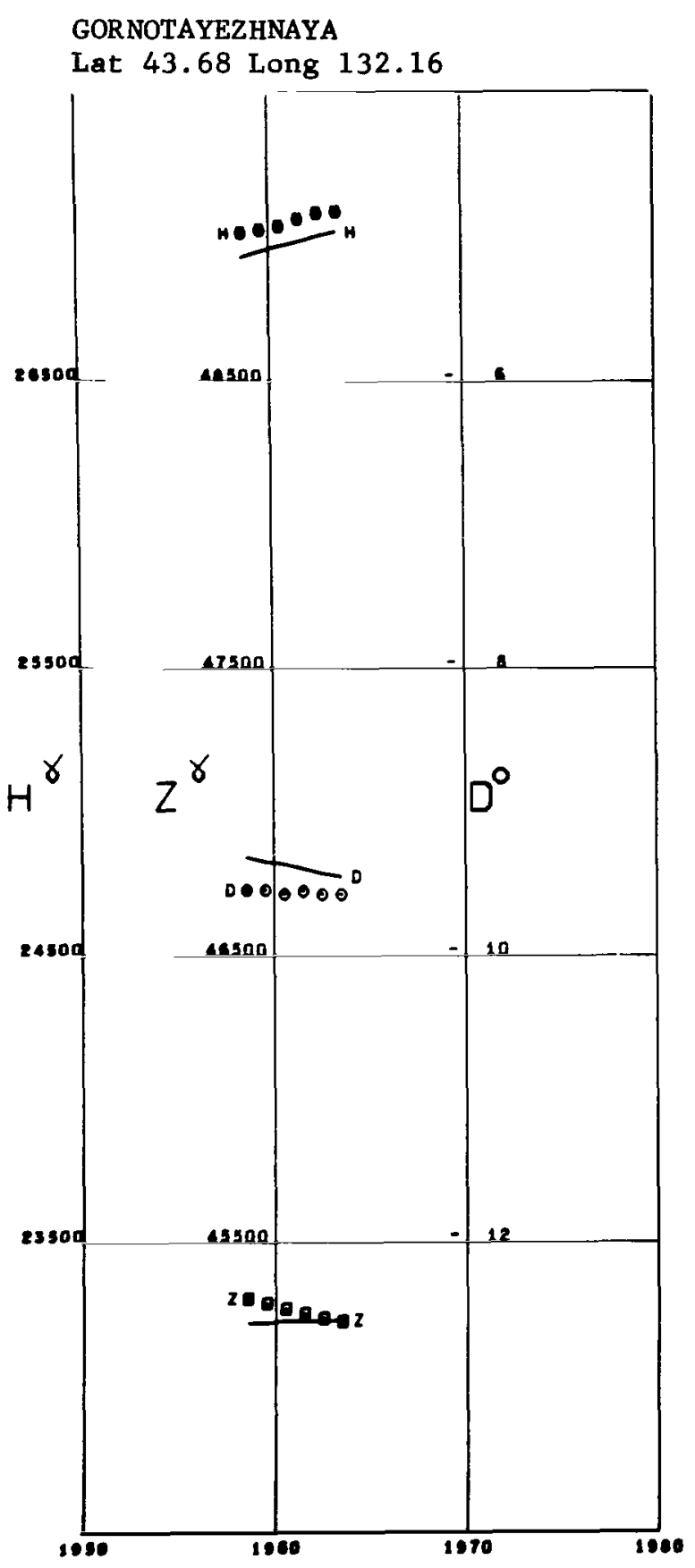

Figure A60

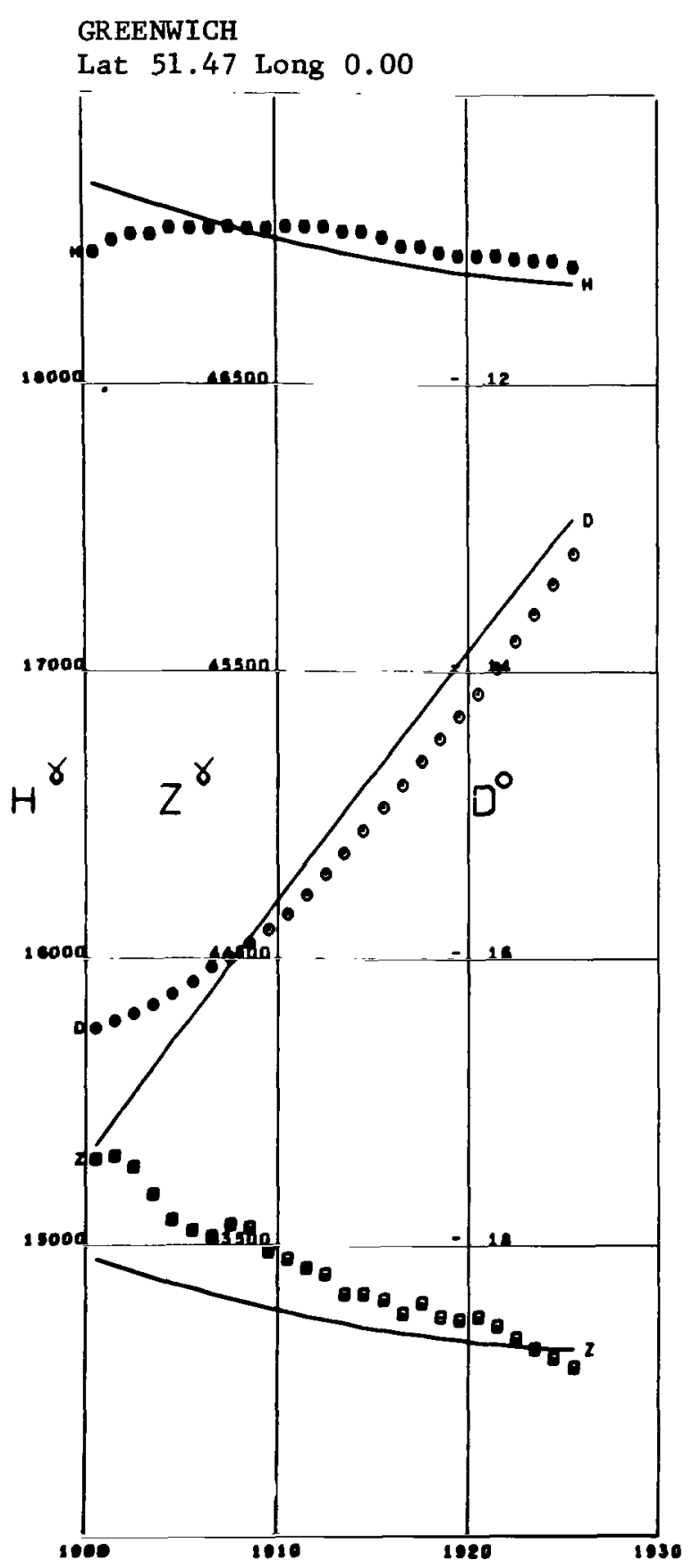

Figure A61 
GROCKA

Lat 44.63 Long 20.76

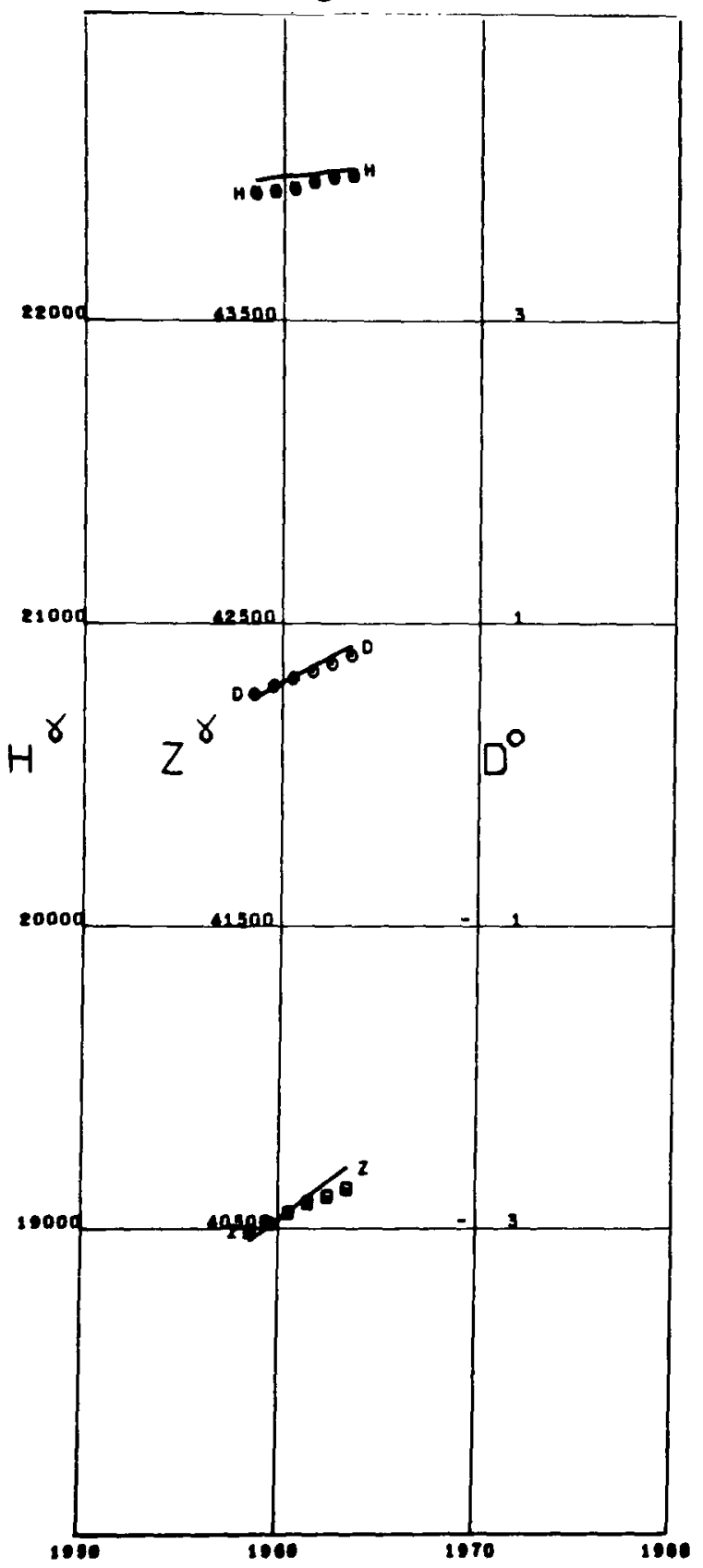

GUAM

Lat 13.58 Long 144.87 Alt 0.15

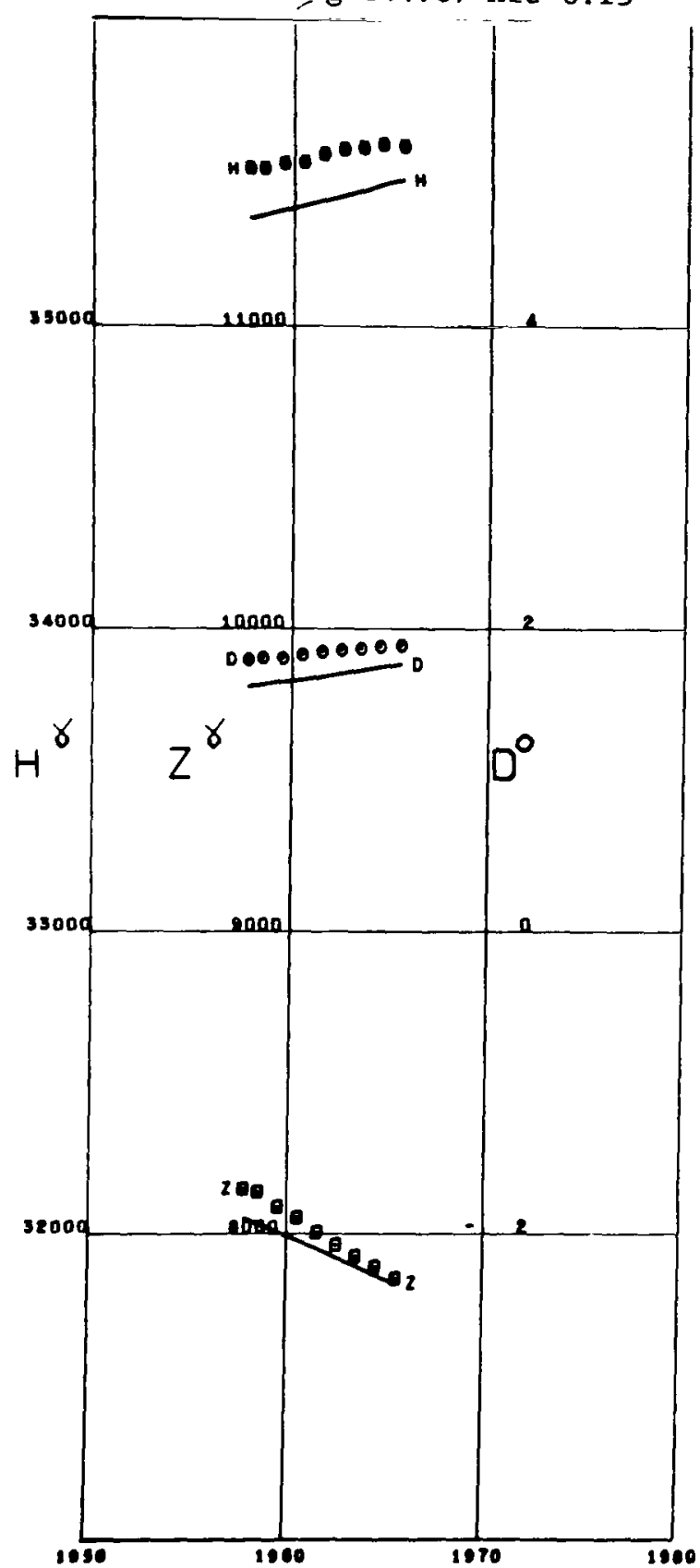

Figure A63 


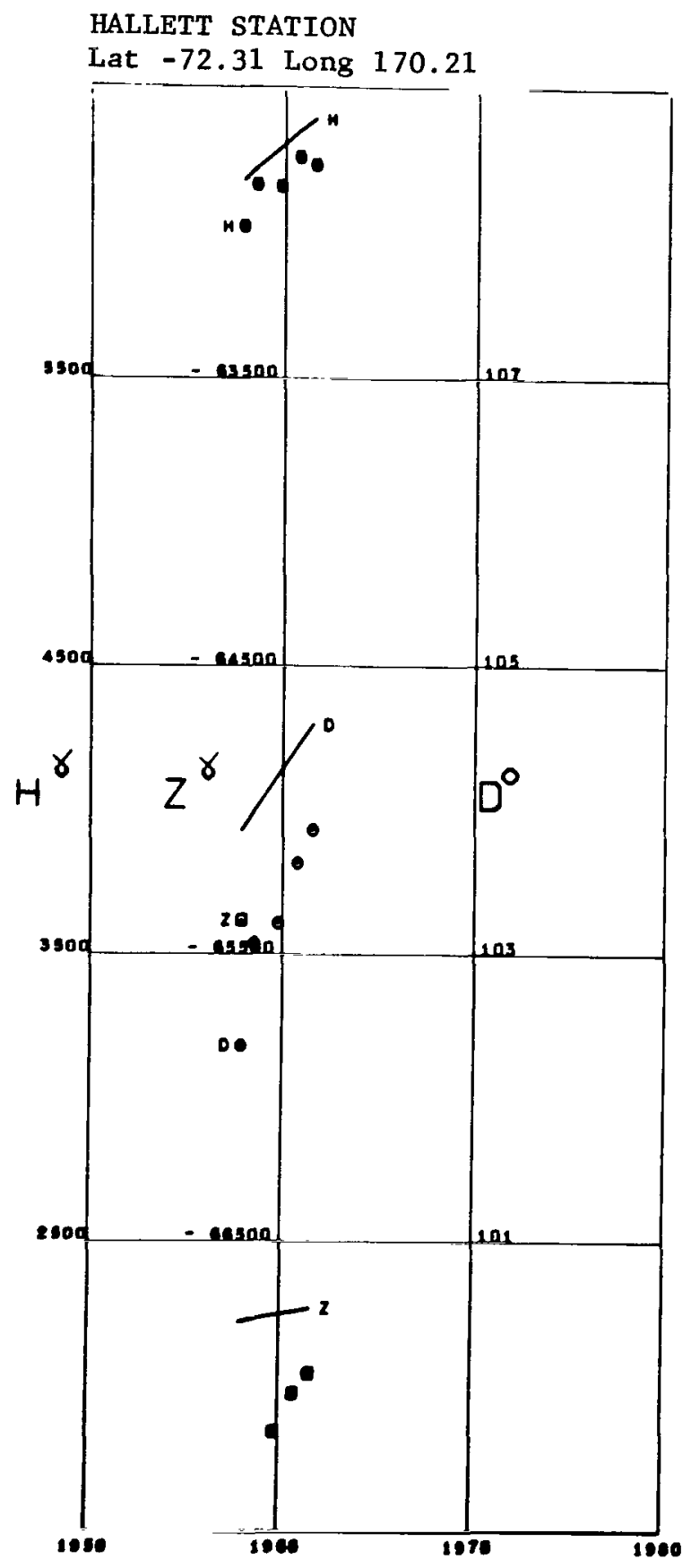

Figure A64

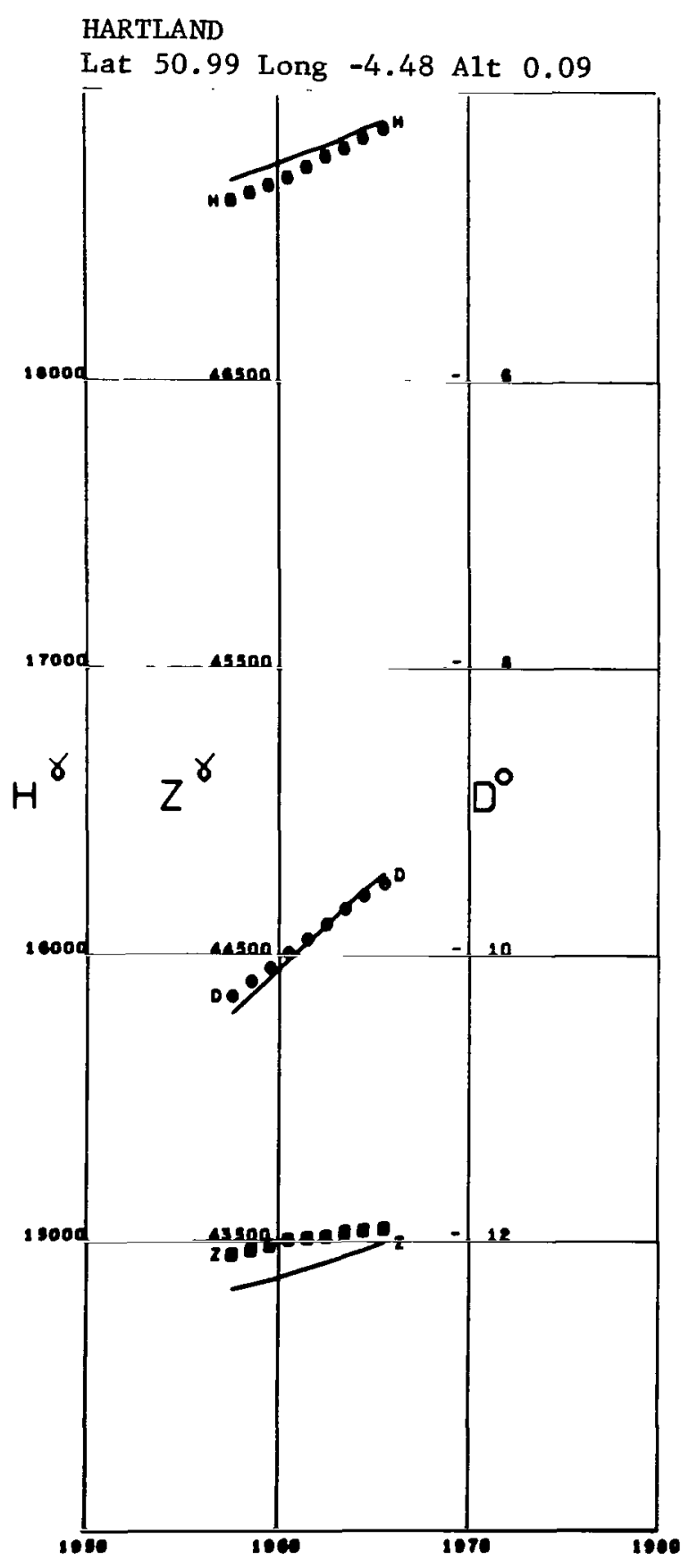

Figure A65 
HEARD ISLAND

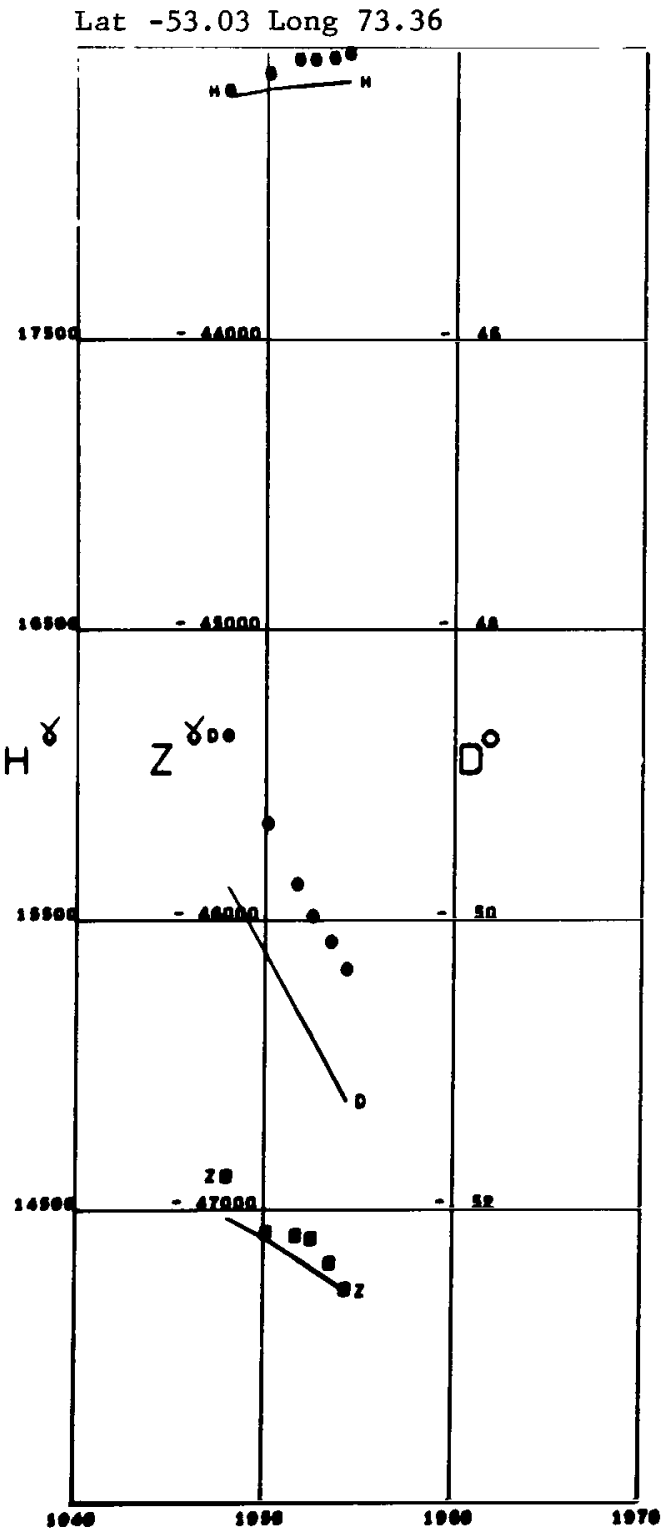

Figure A66
HEL

Lat 54.60 Long 18.81

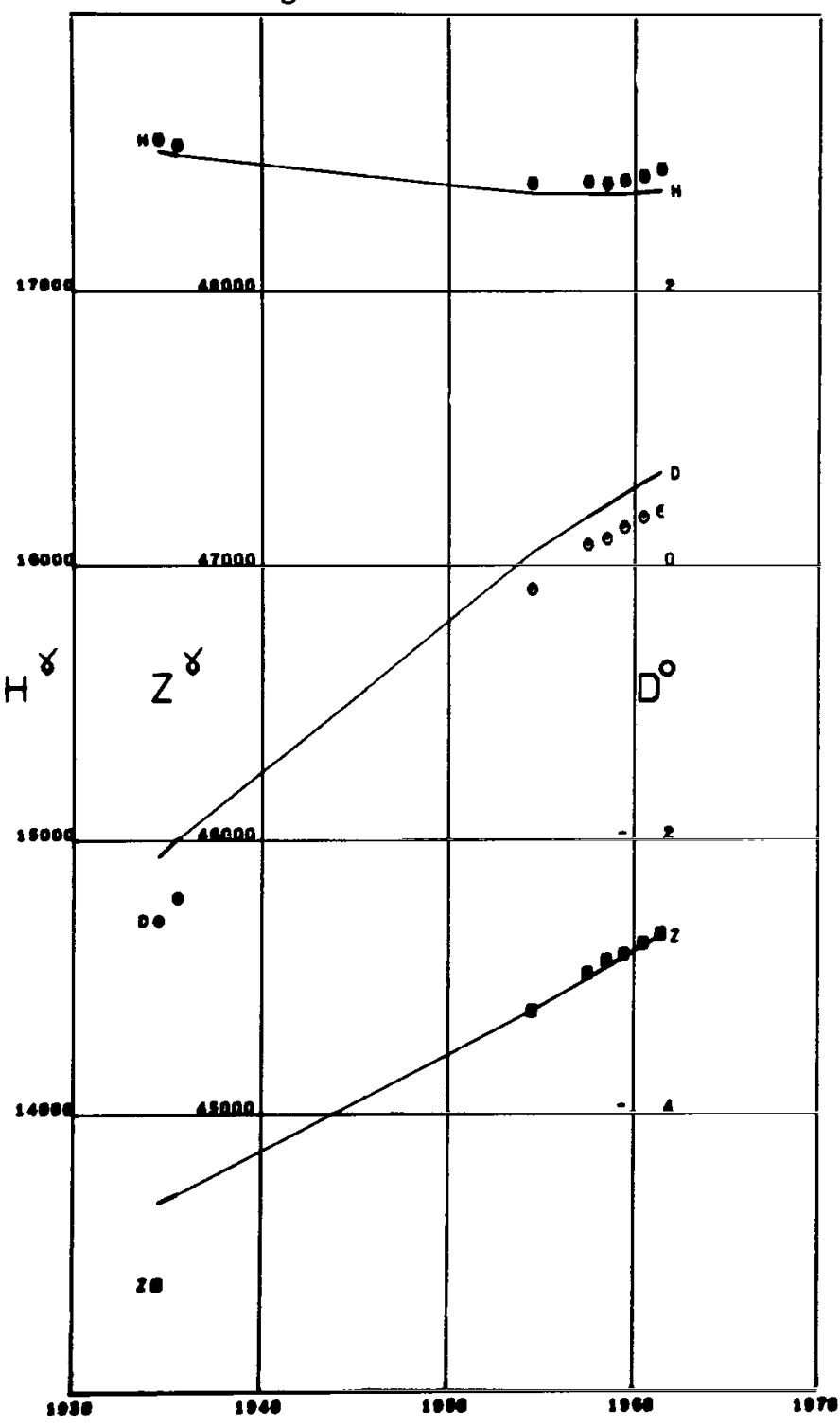

Figure A67 
HELWAN

Lat 29.85 Long 31.34

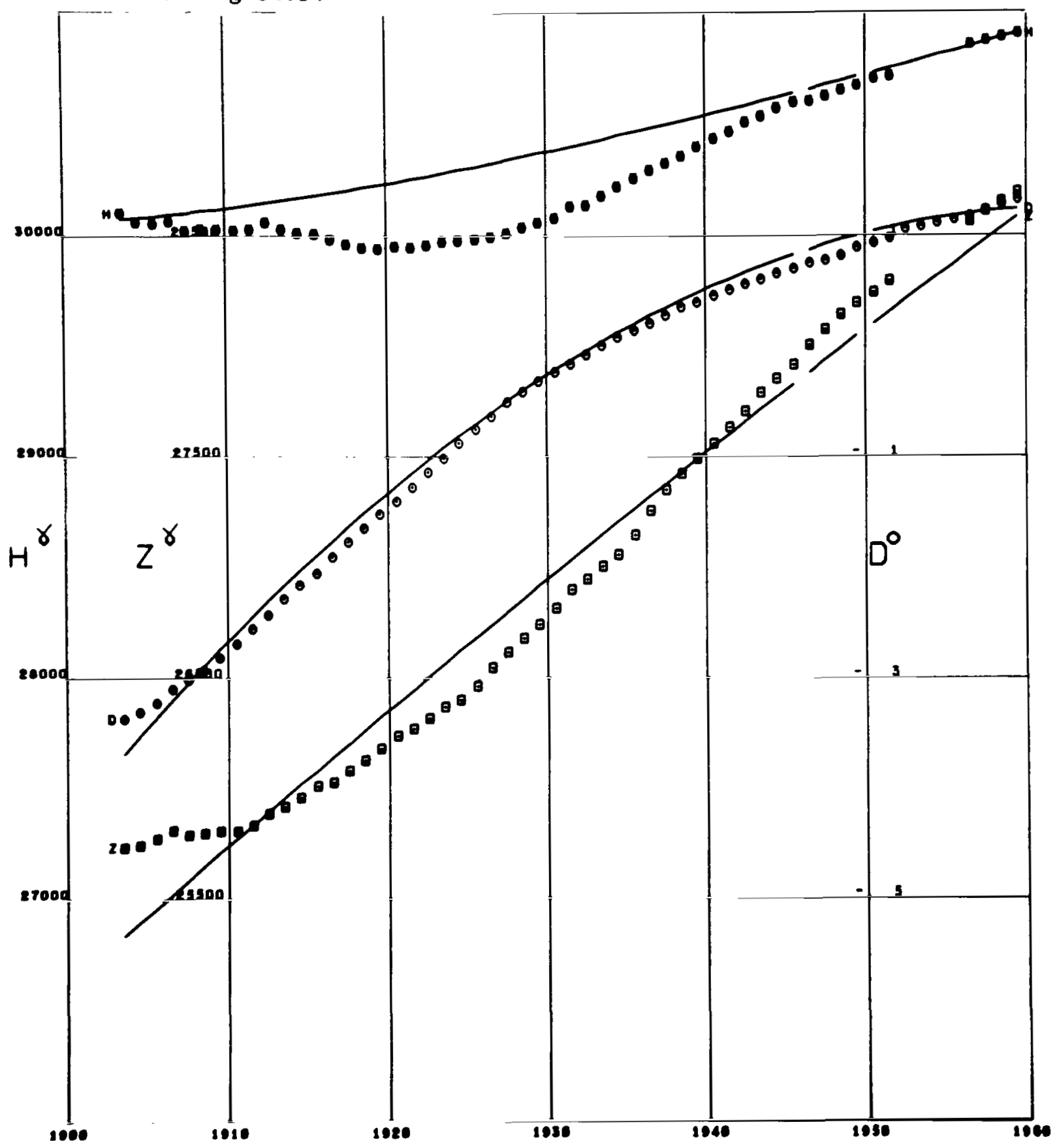

Figure A68 


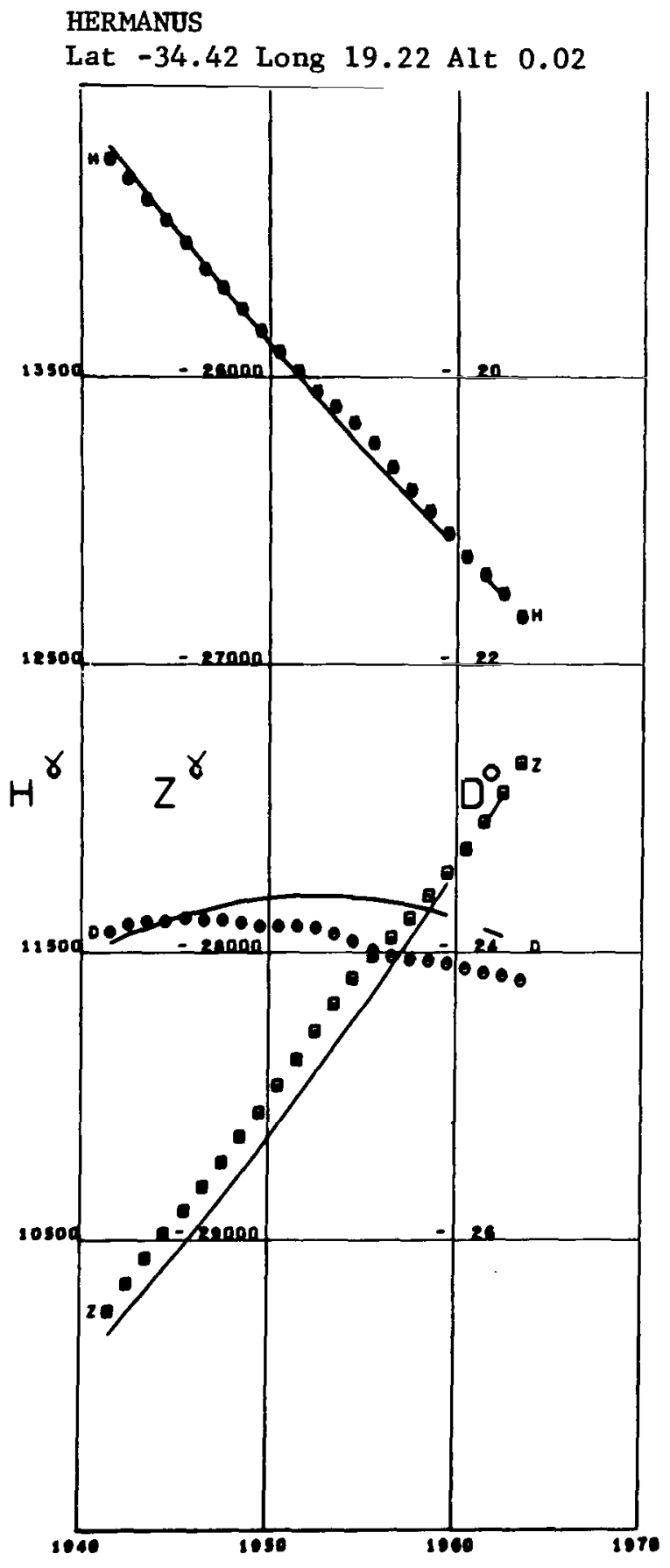

Figure A69

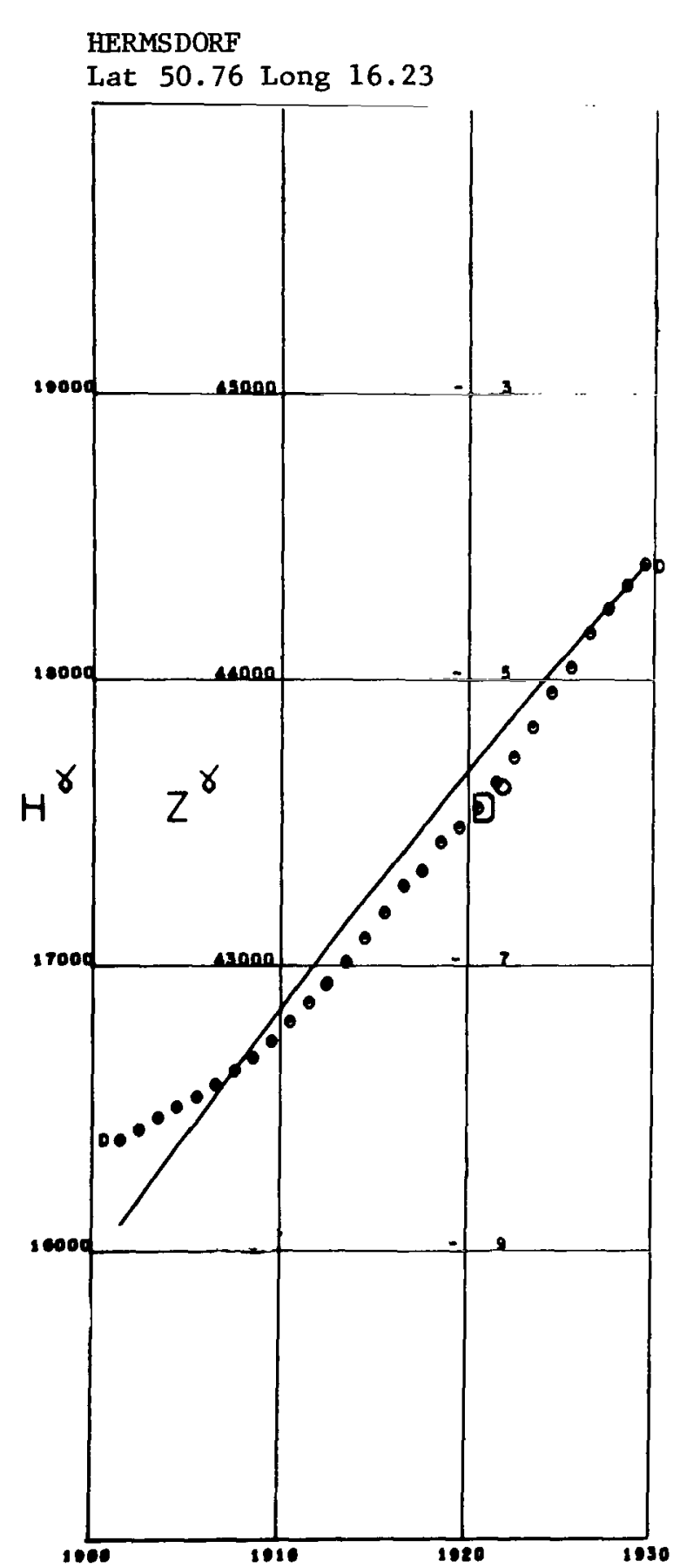

Figure $A 70$ 


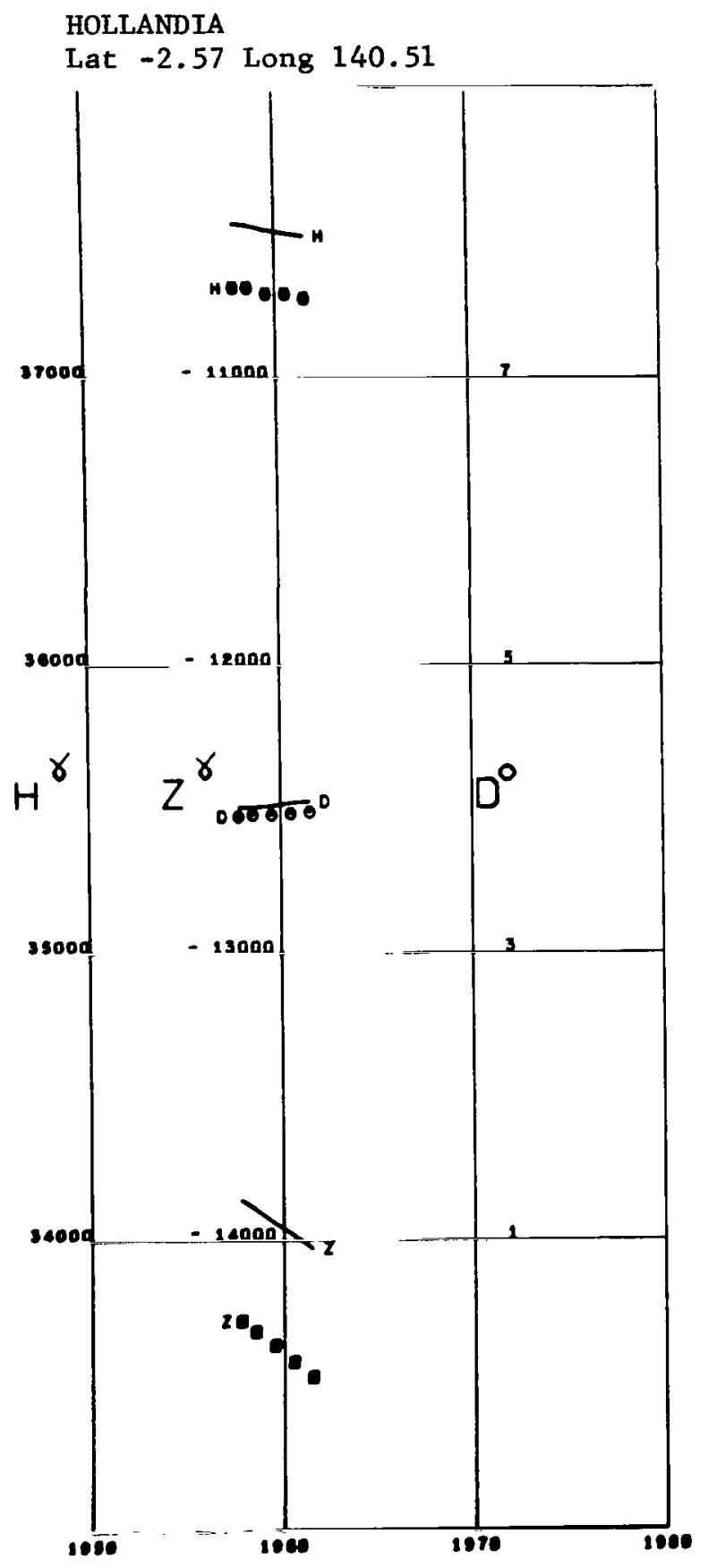

Figure A71

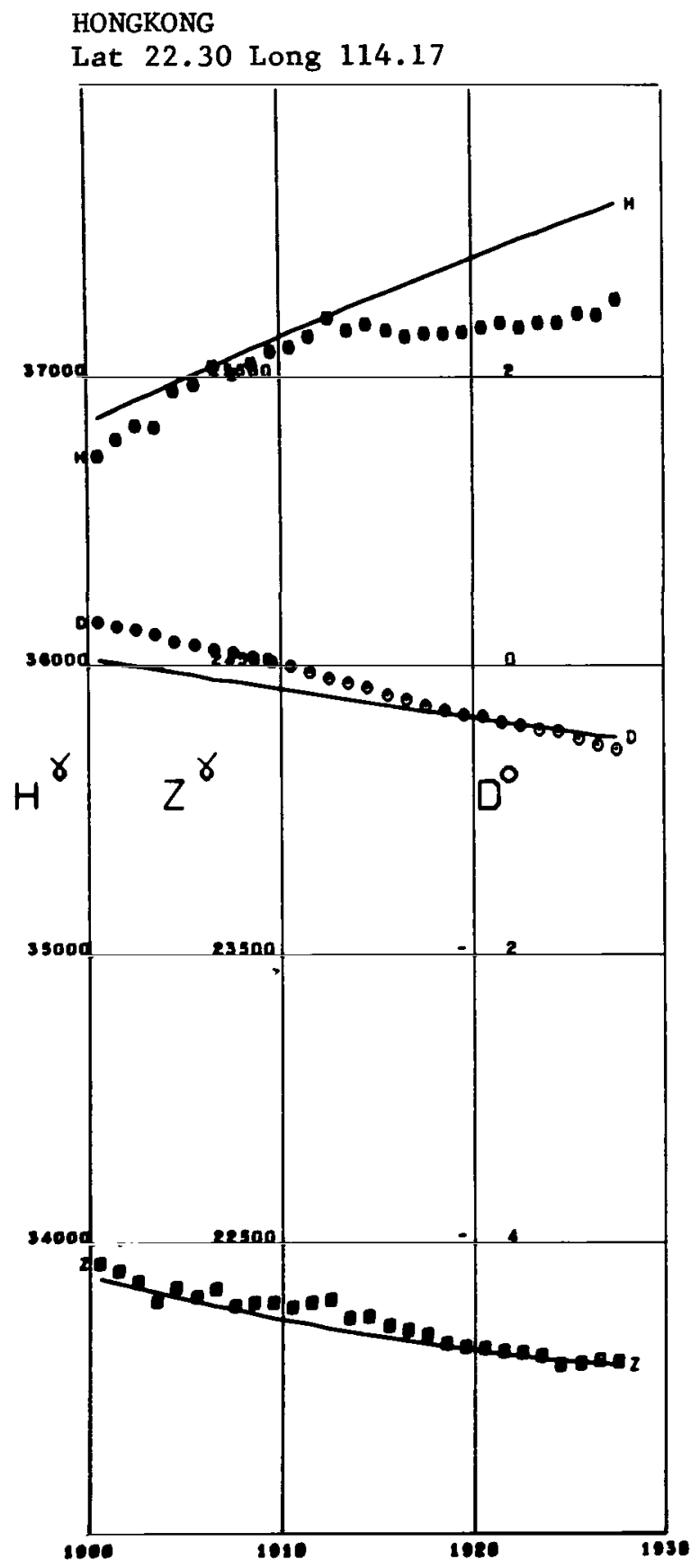

Figure A72

61

$\|$ 


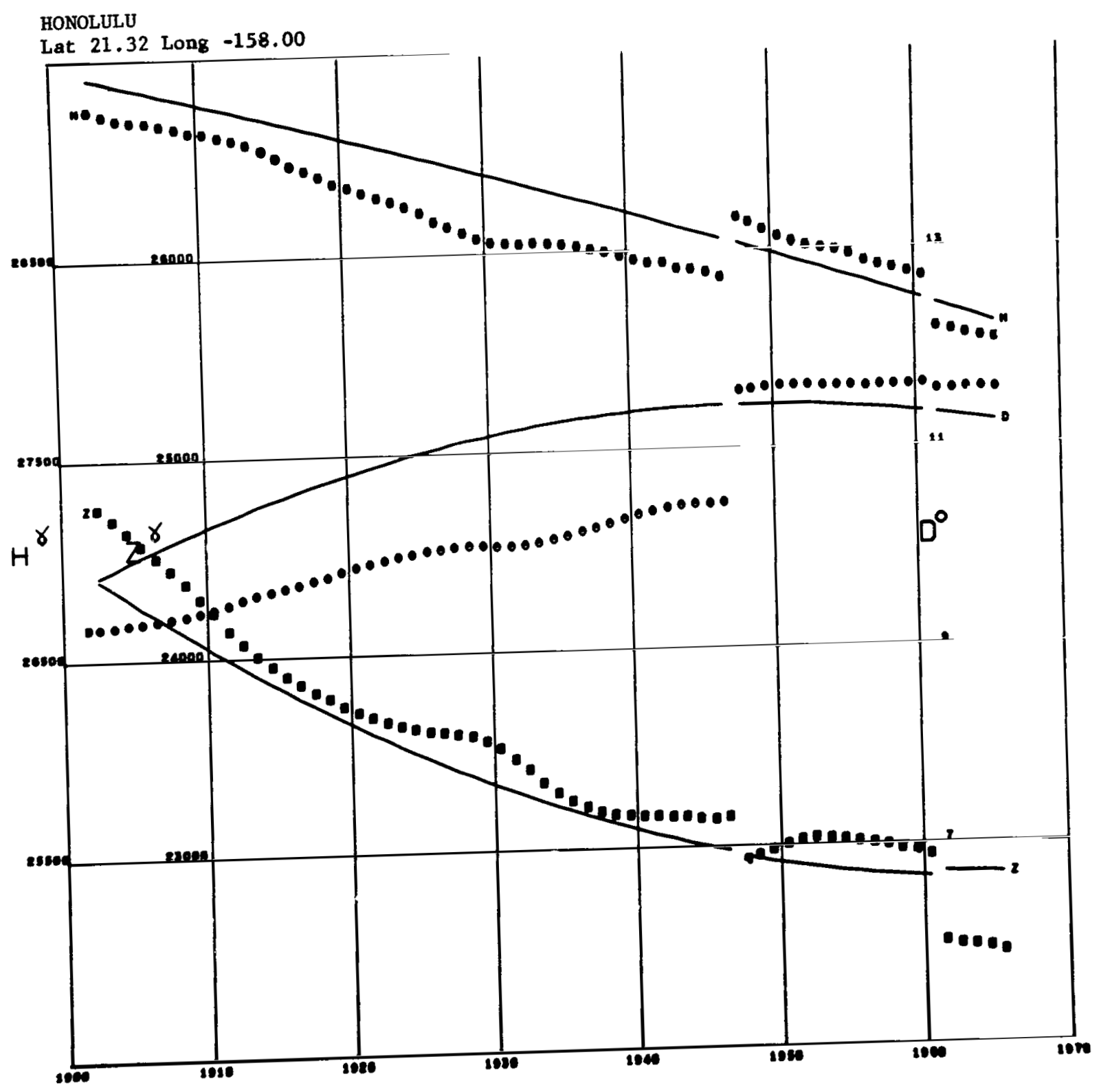

Figure A73 
HUANCAYO

Lat -12.04 Long -75.34 A1t 3.35

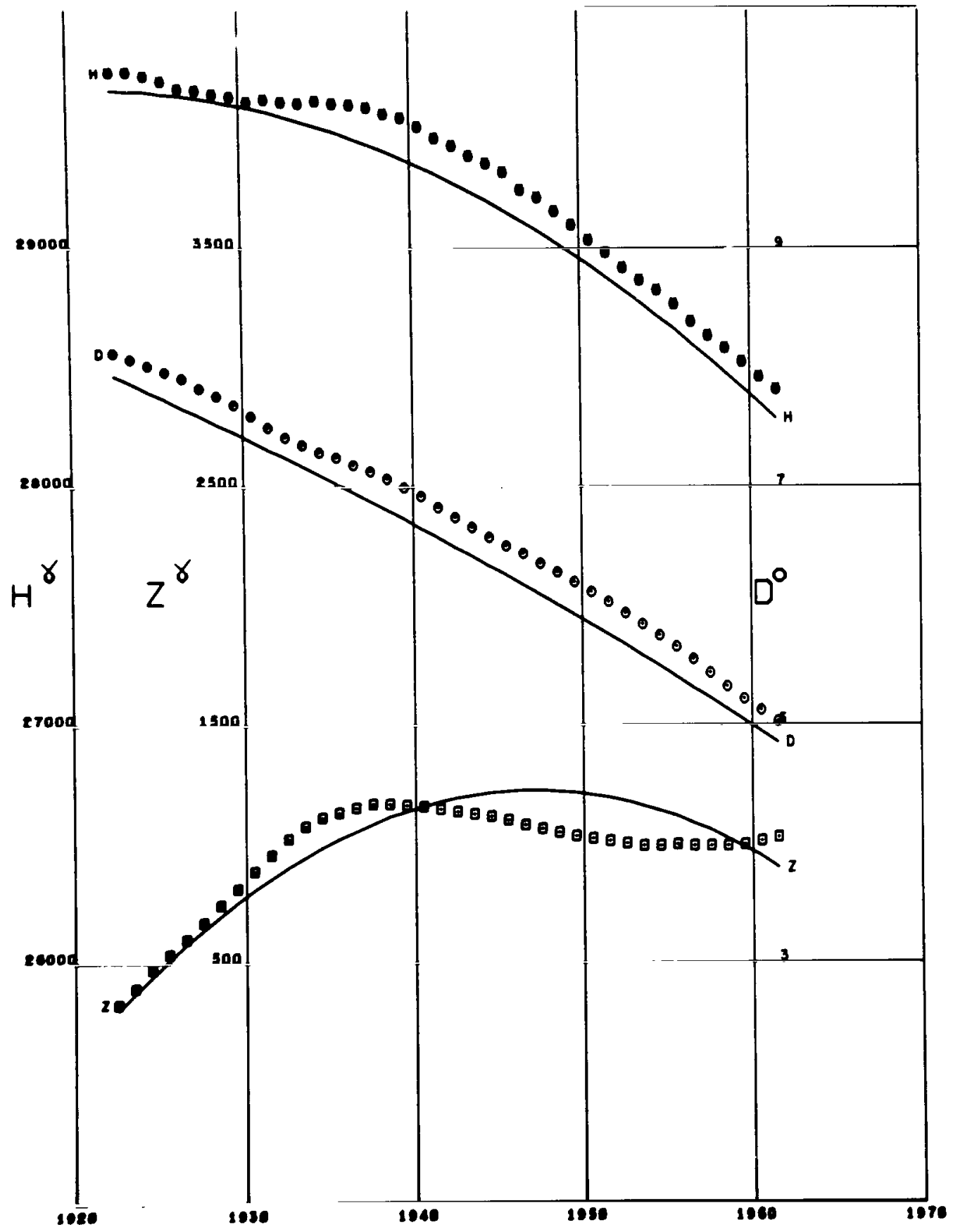

Figure A74 
HURBANOVO

Lat 47.87 Long 18.19

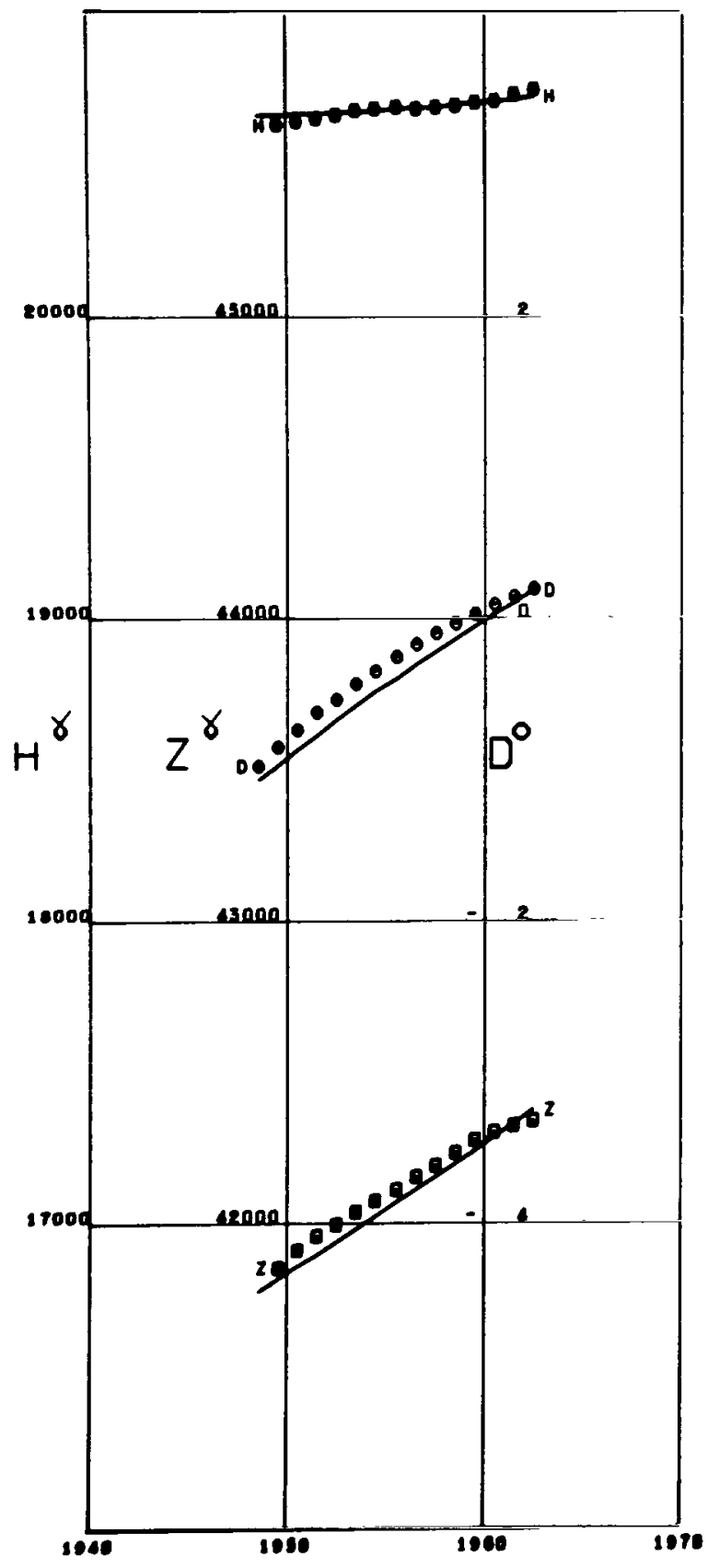

Figure A75
IBADAN

Lat 7.43 Long 3.90

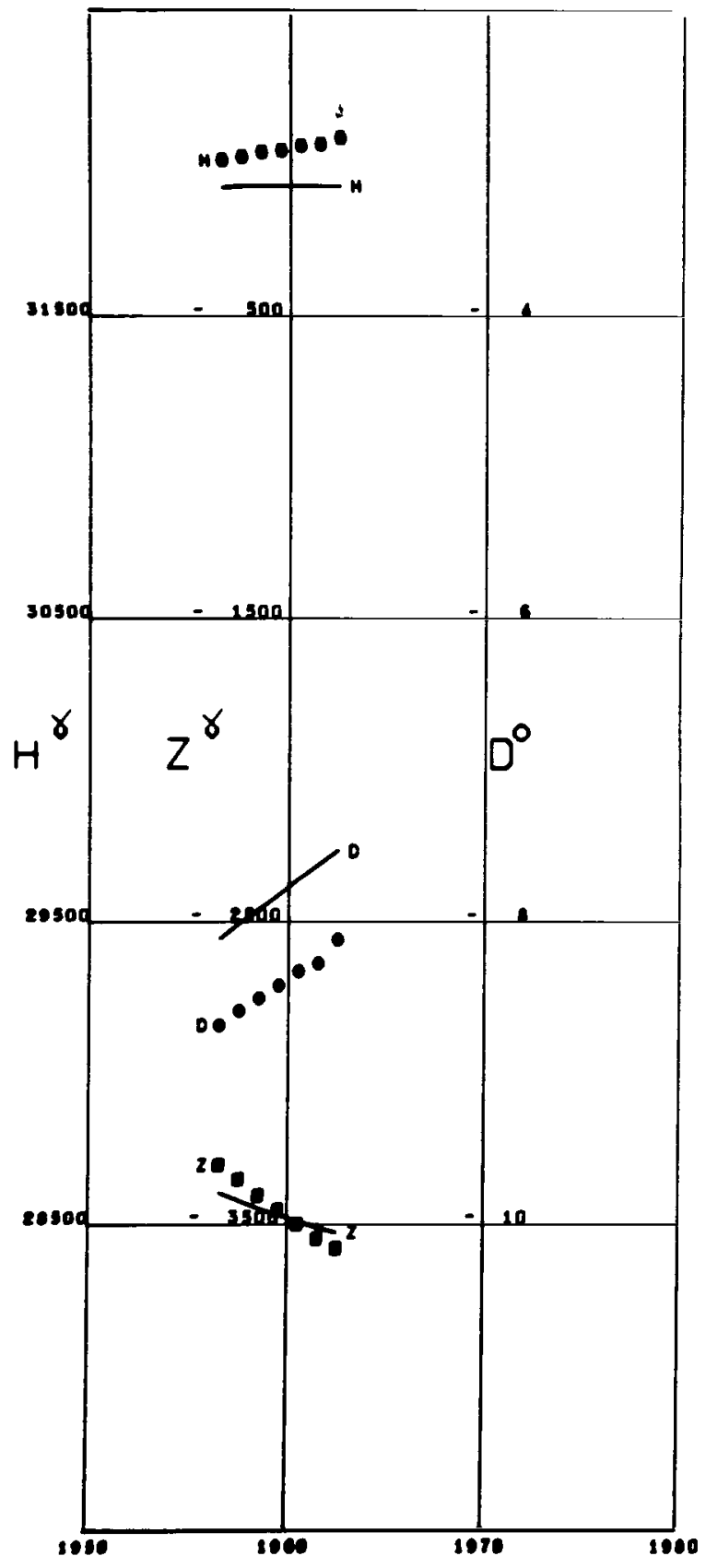

Figure A76

64 


\section{IRKUTSK}

Lat 52.26 Long 104.26

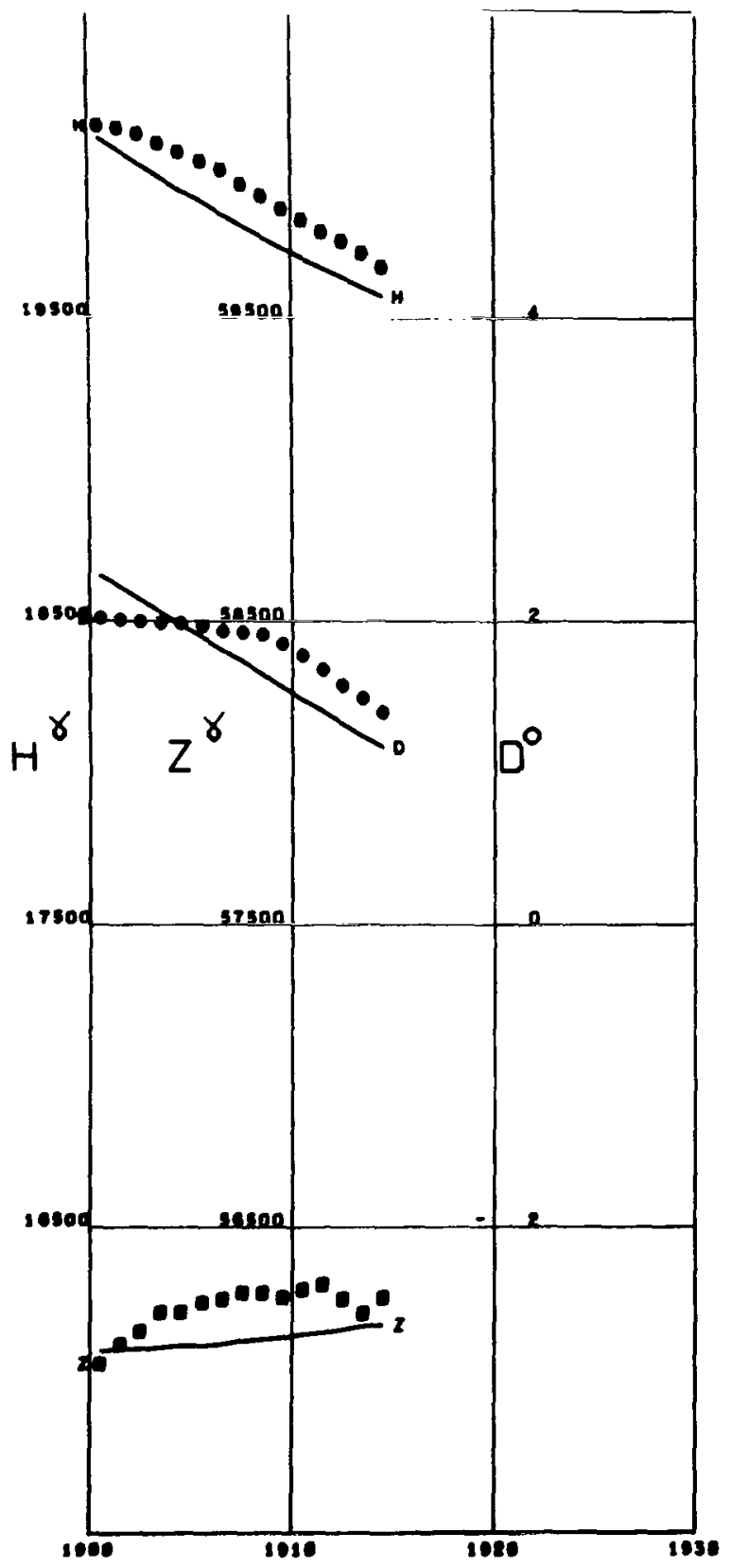

Figure A77
ISTANBUL KANDILLI

Lat 41.06 Long 29.06

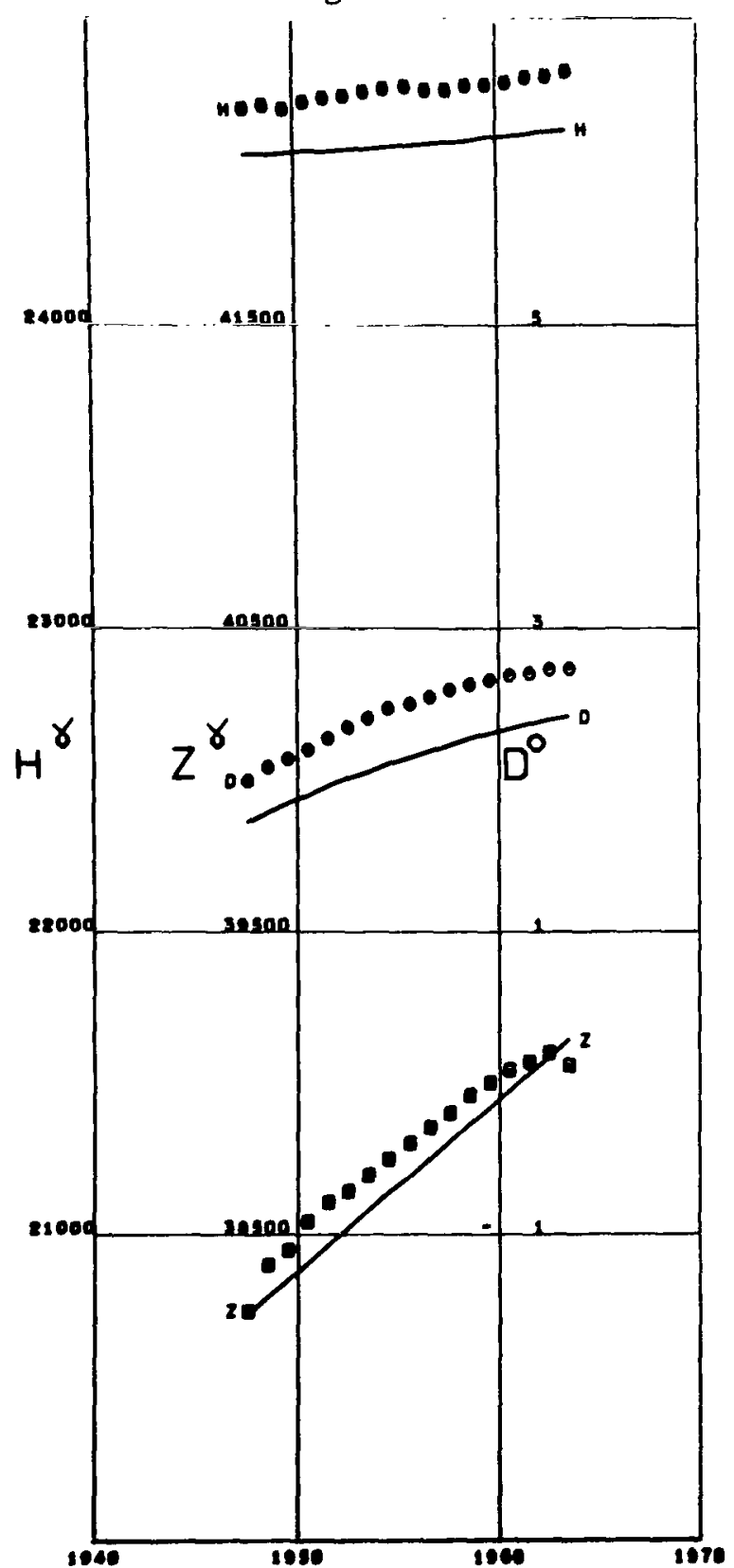

Figure A78 


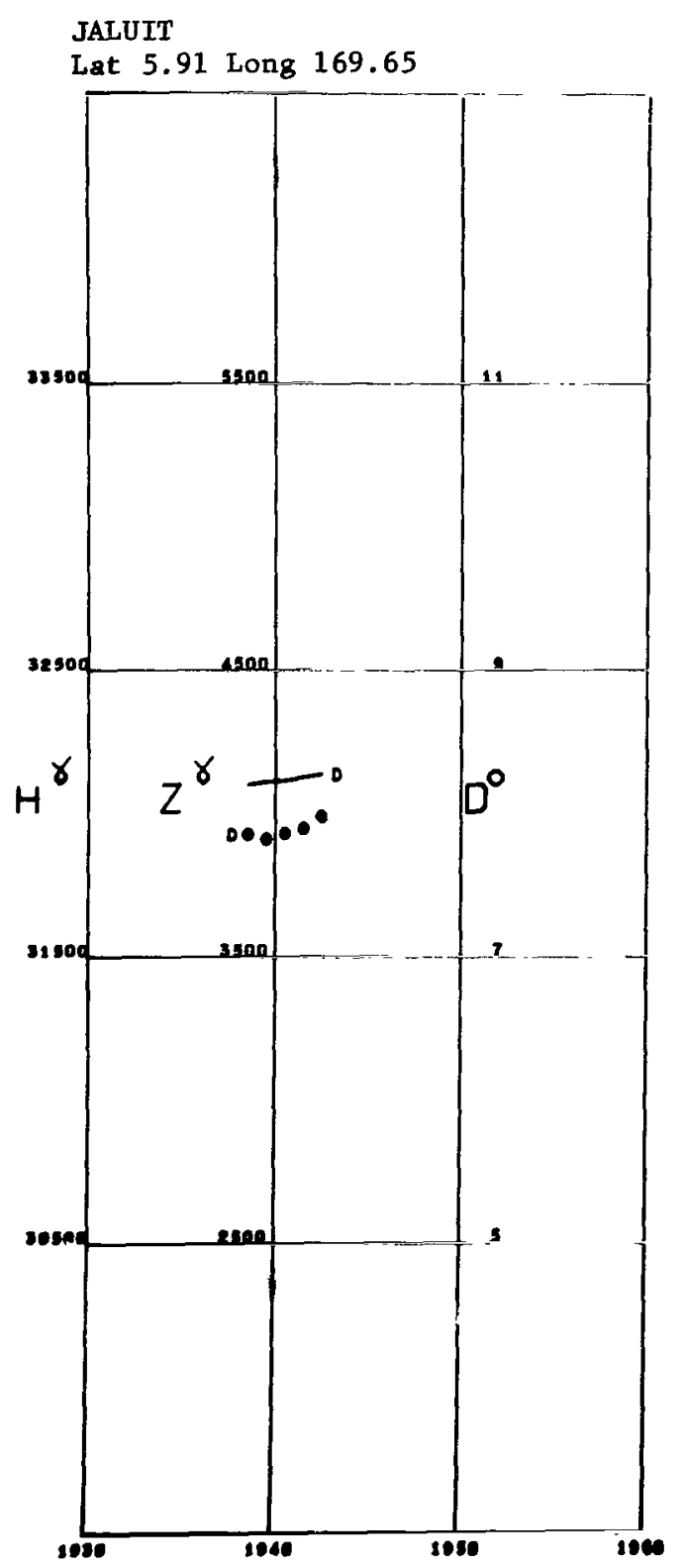

Figure A79
JASSY

Lat 47.18 Long 27.53

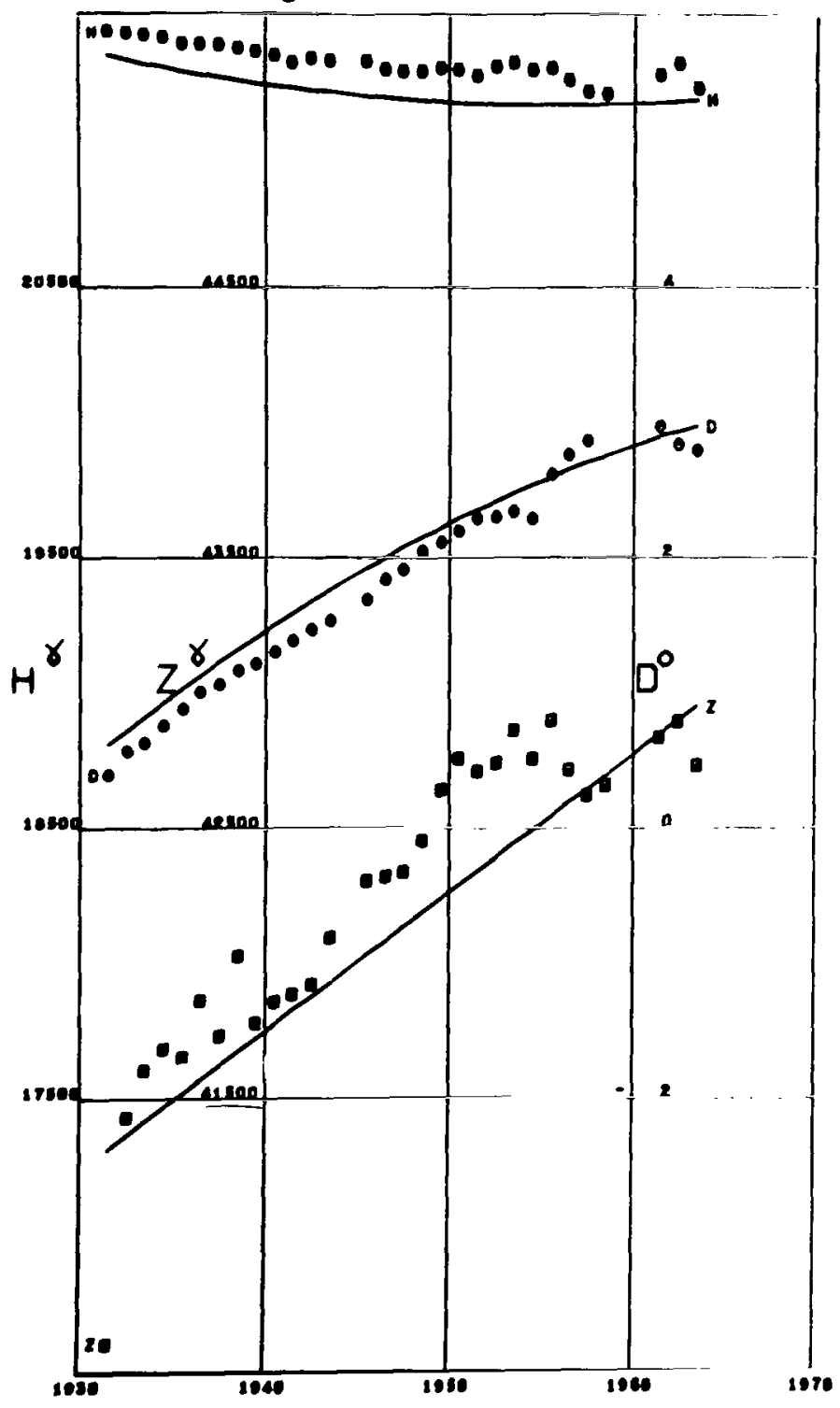

Figure $A 80$ 


\section{KAKIOKA}

Lat 36.23 Long 140.19 A1t 0.03

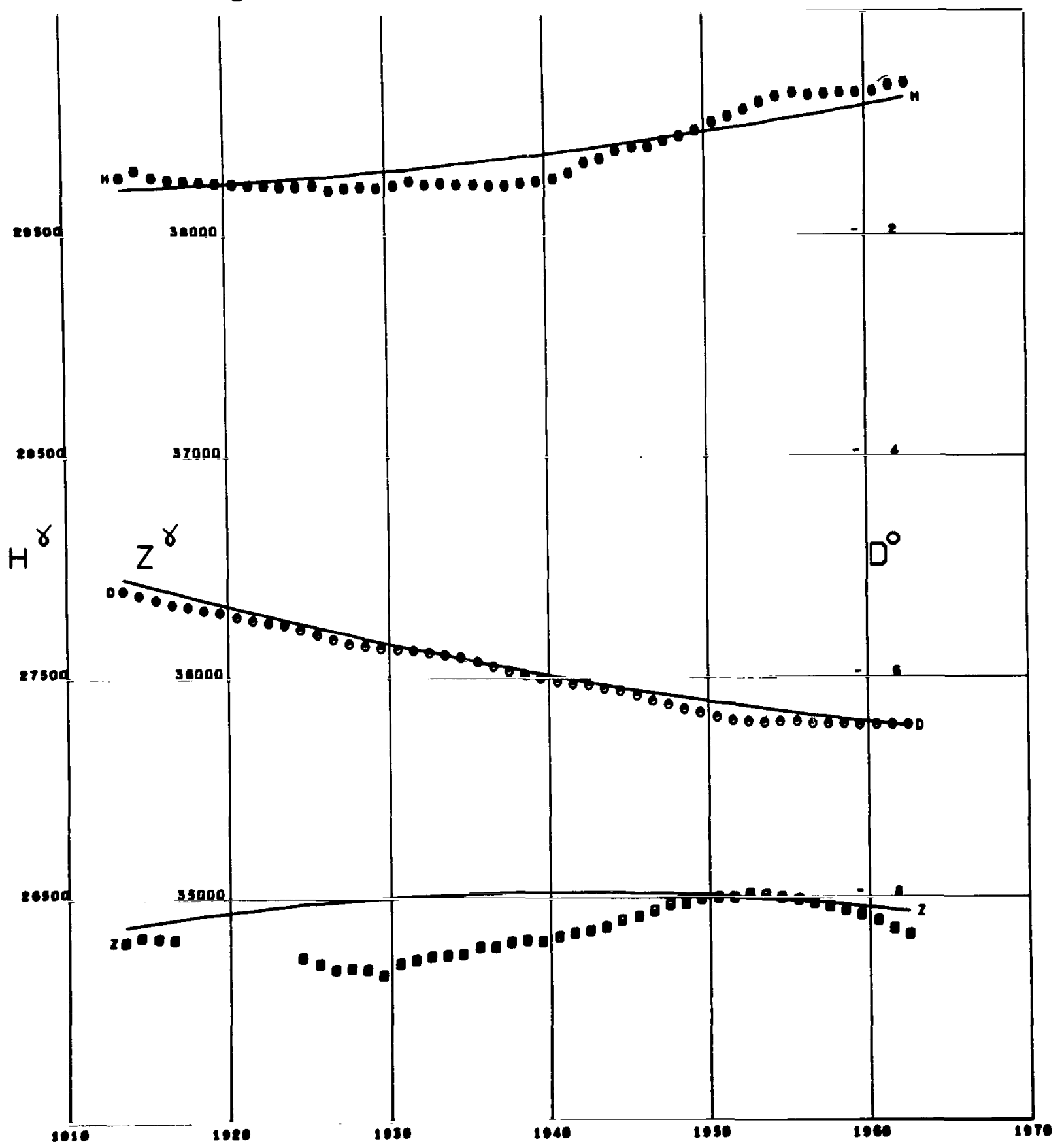

Figure $A 81$ 


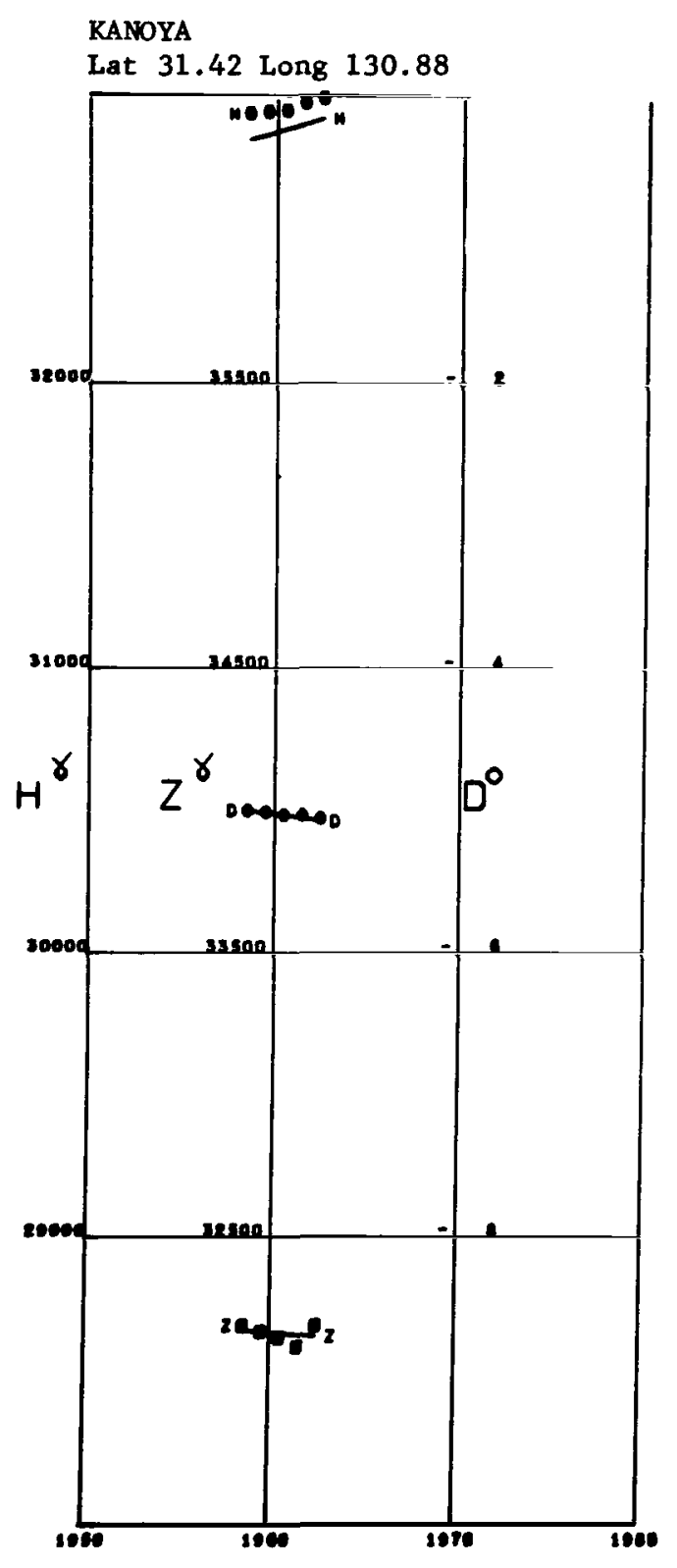

Figure A82

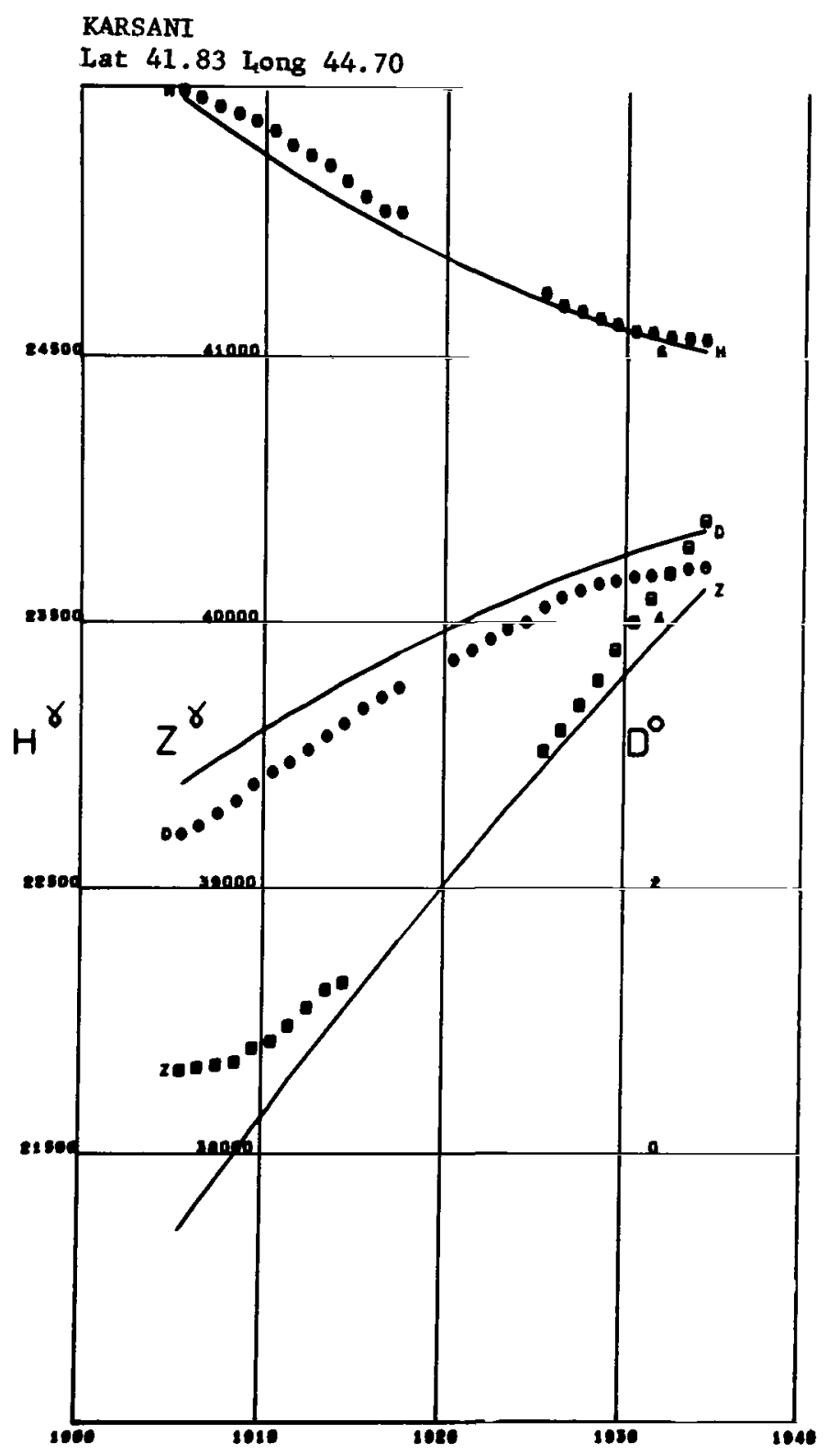

Figure $A 83$ 
KATUURA

Lat 33.63 Long 135.94

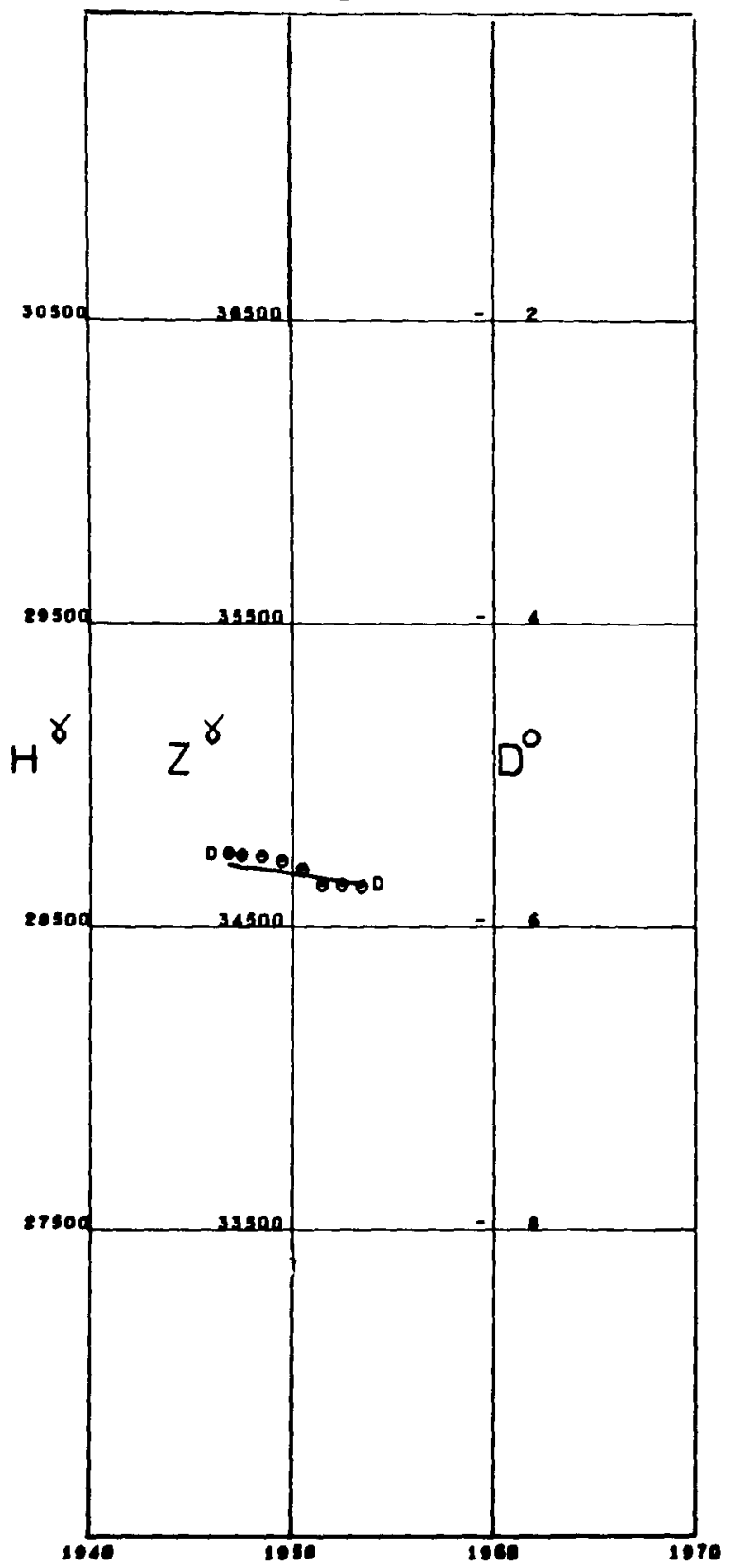

Figure $\mathrm{A} 84$
KAZAN

Lat 55.78 Long 49.13

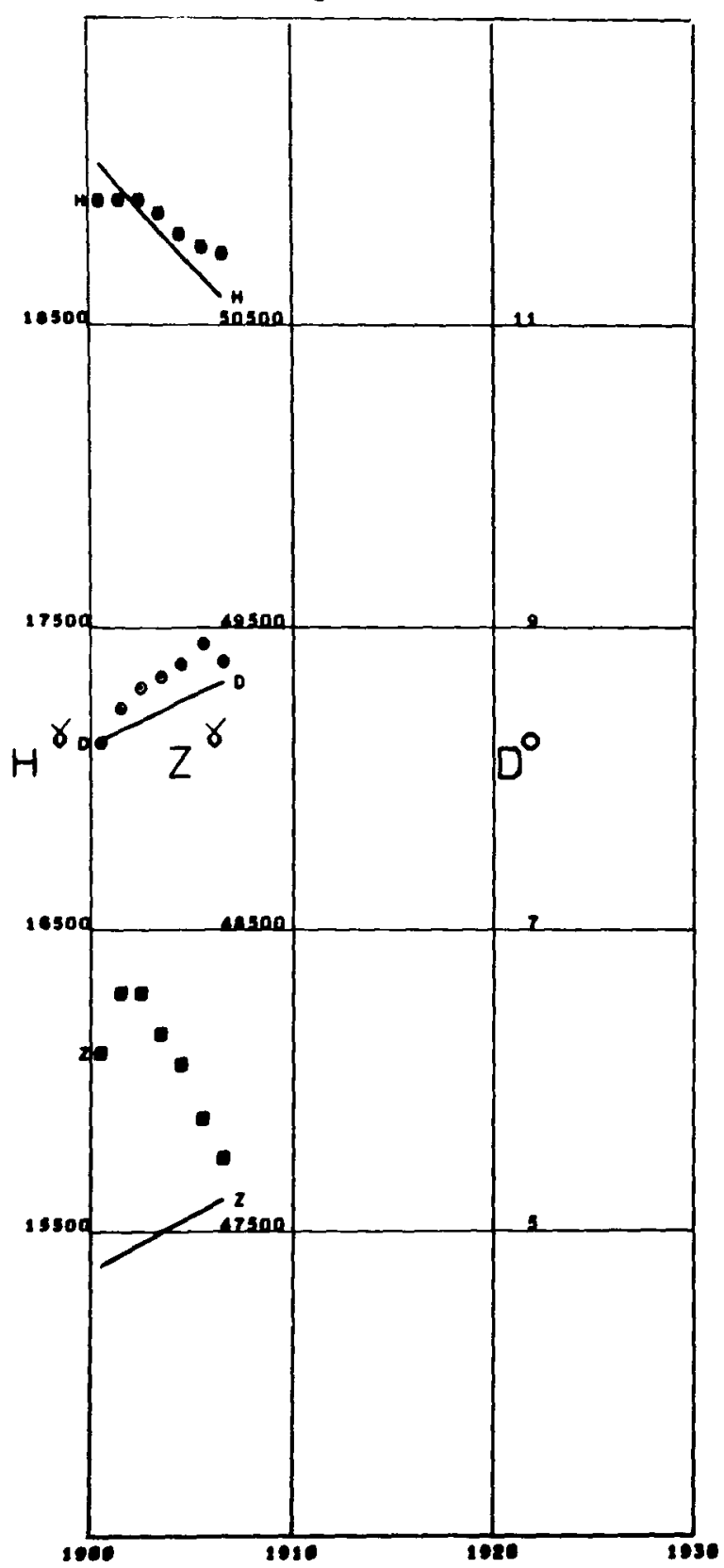

Figure A85 
KELES

Lat 41.42 Long 69.20

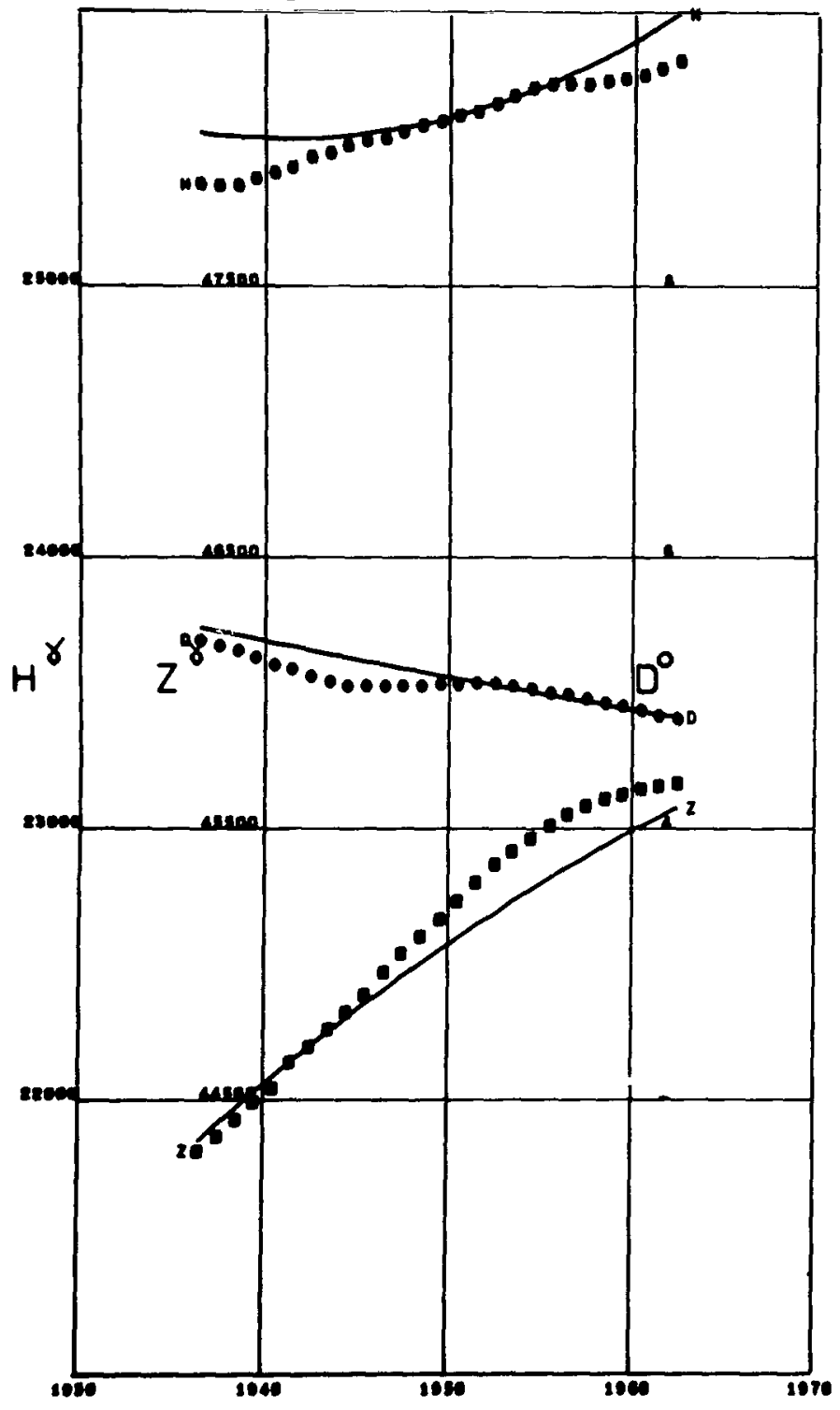

Figure A86
KERGUELEN

Lat -49.35 Long 70.20

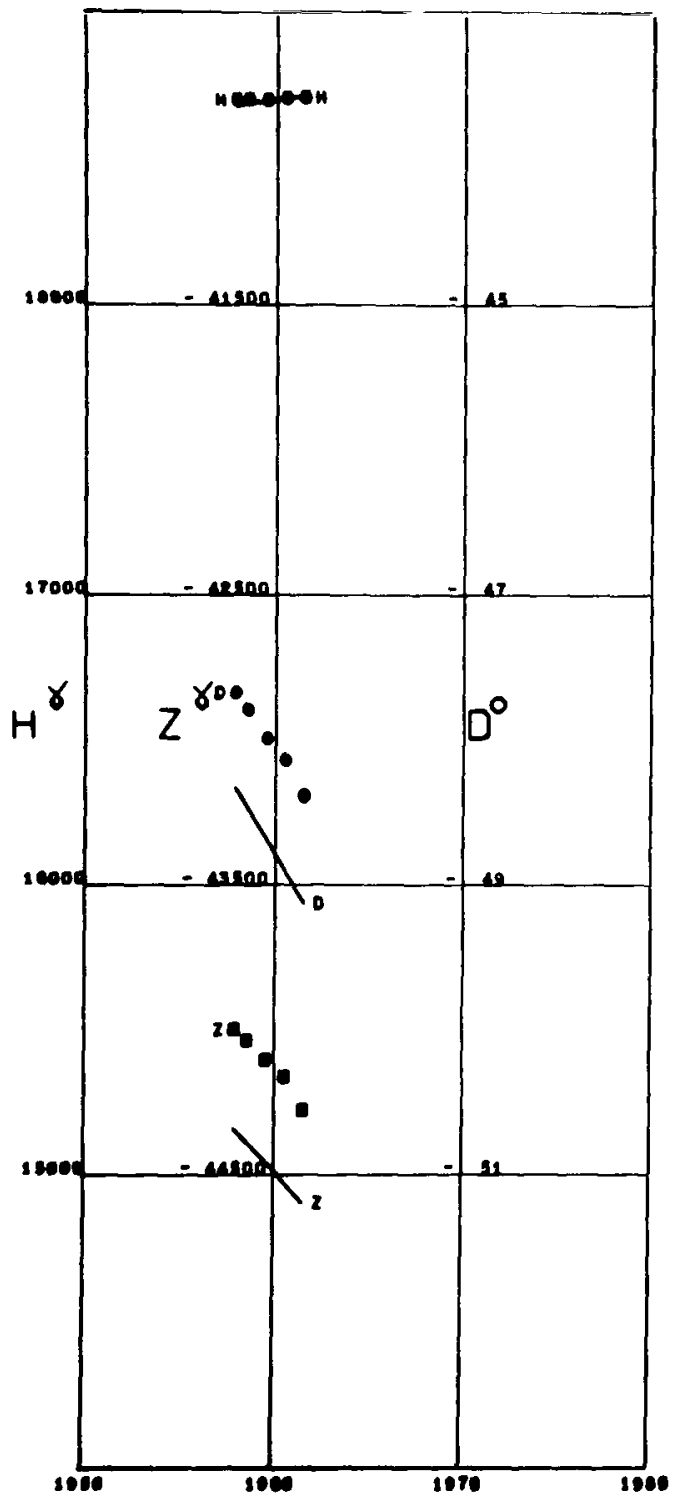

Figure $\mathrm{A} 87$ 


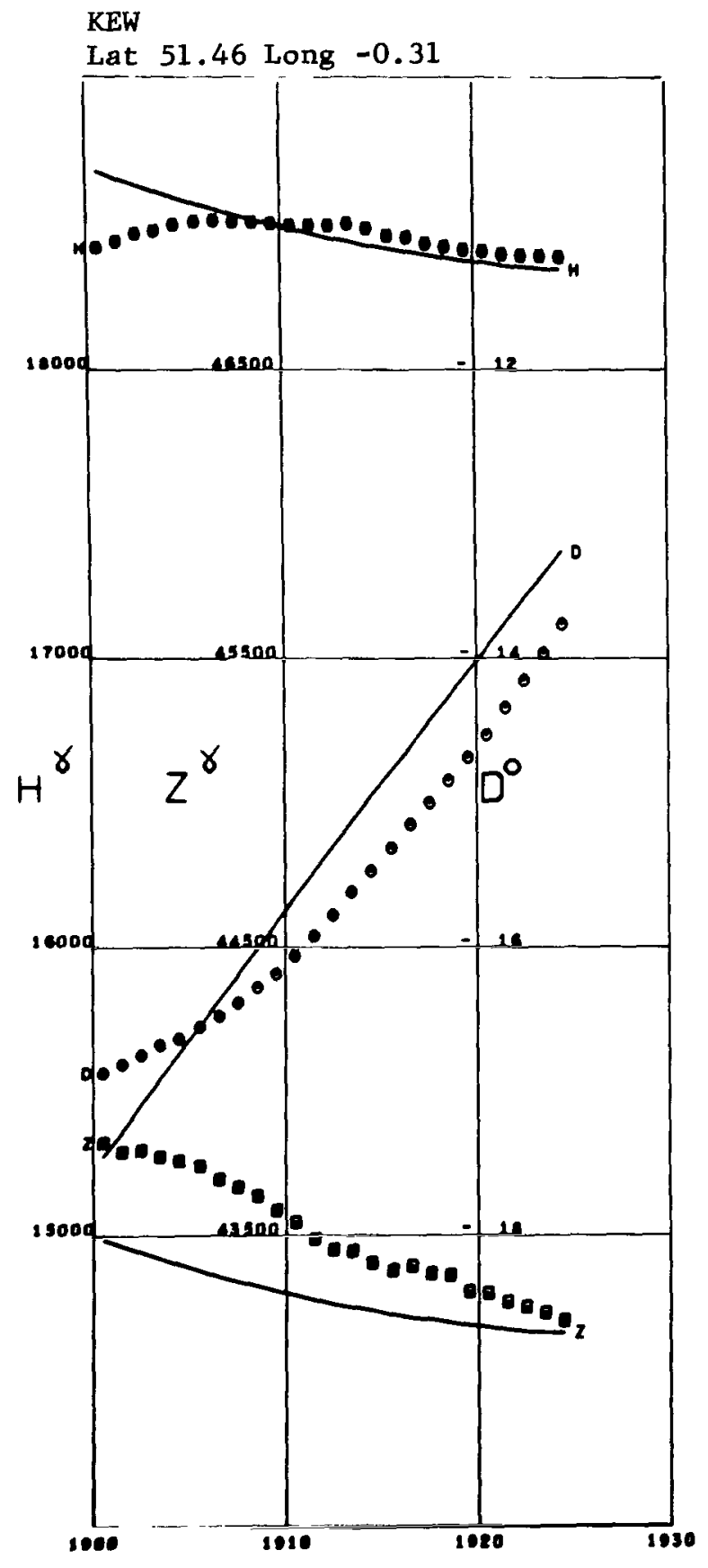

Figure A88

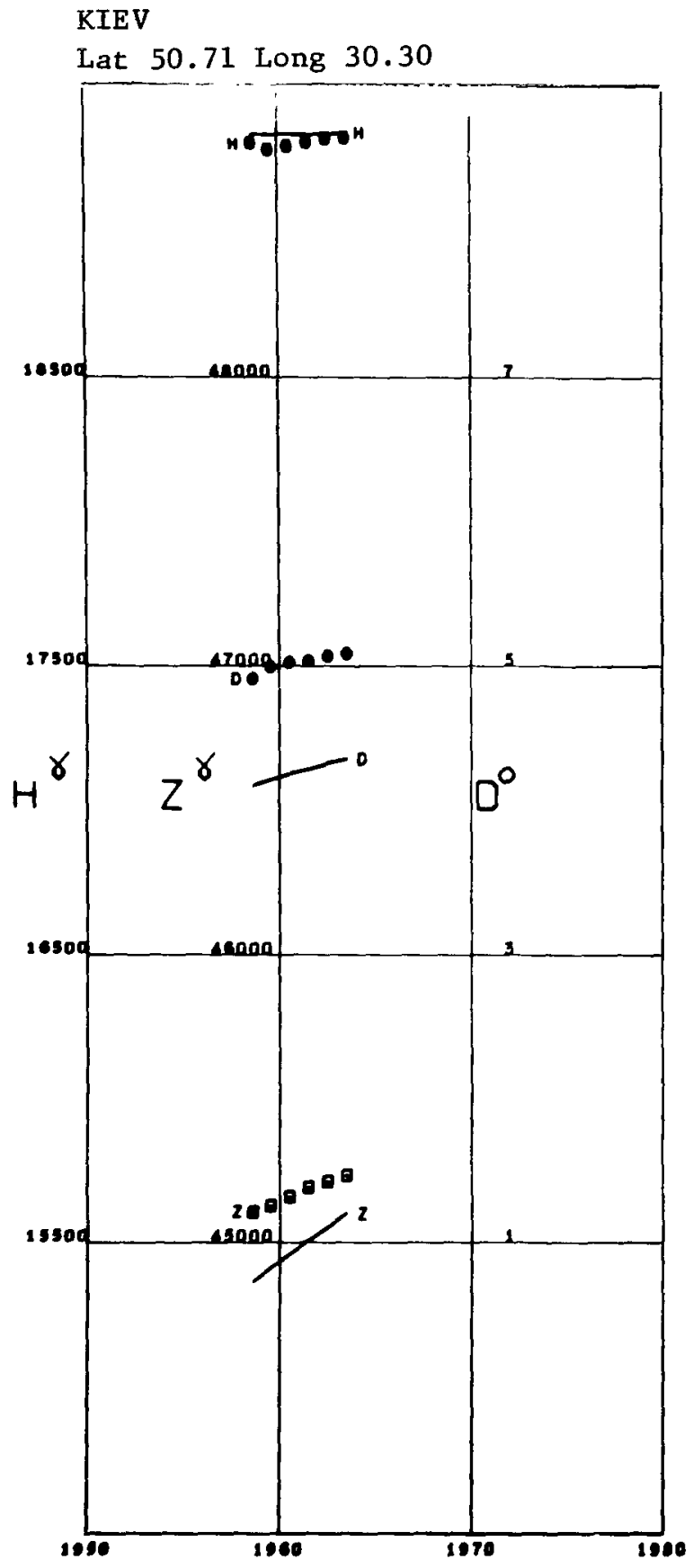

Figure A89 
KODAIKANAI

Lat 10.23 Long 77.46

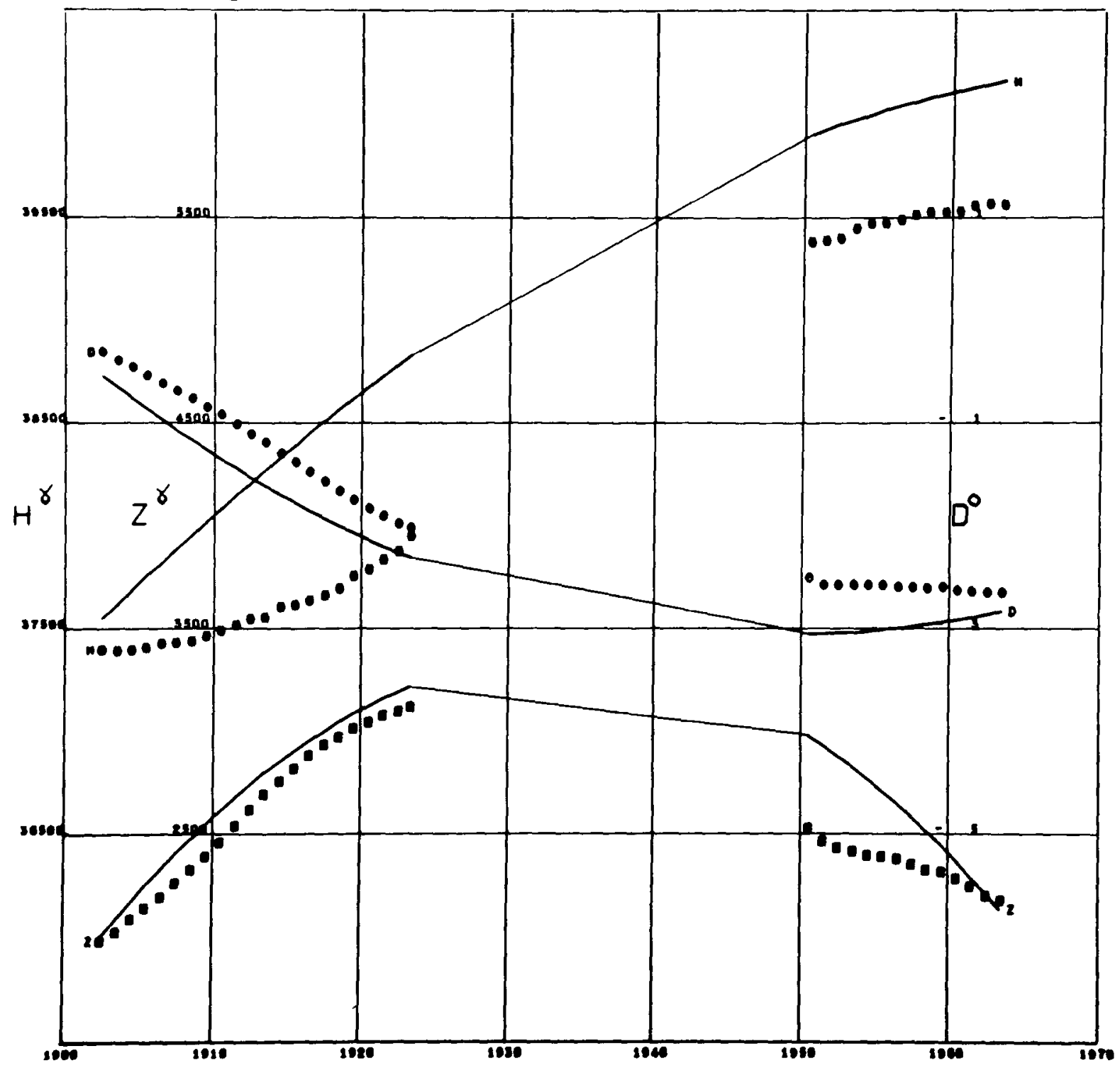

Figure A90 
KRASNAYA PAKHRA

Lat 55.47 Long 37.31

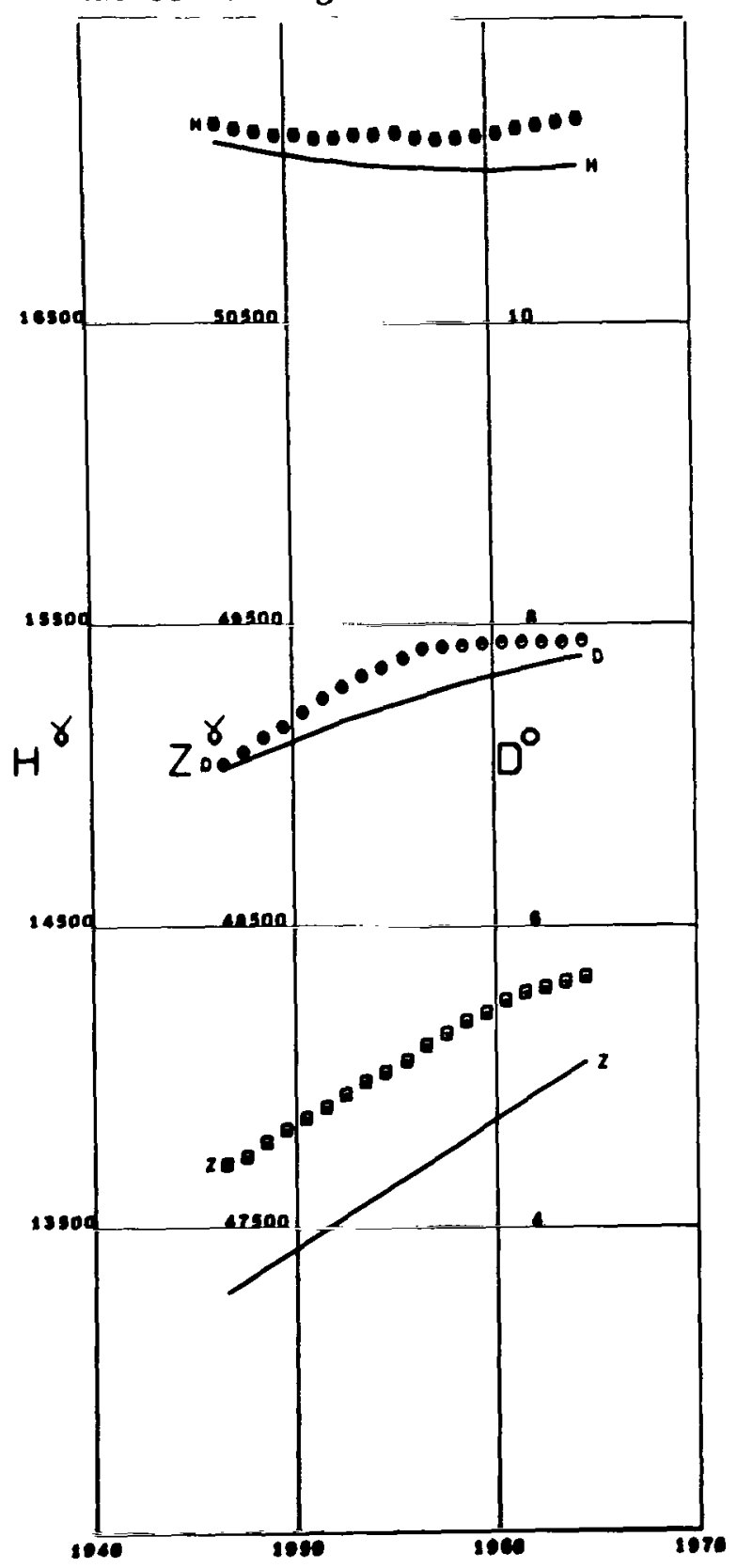

Figure A9]
KREMSMUNSTER

Lat 48.05 Long 14.13

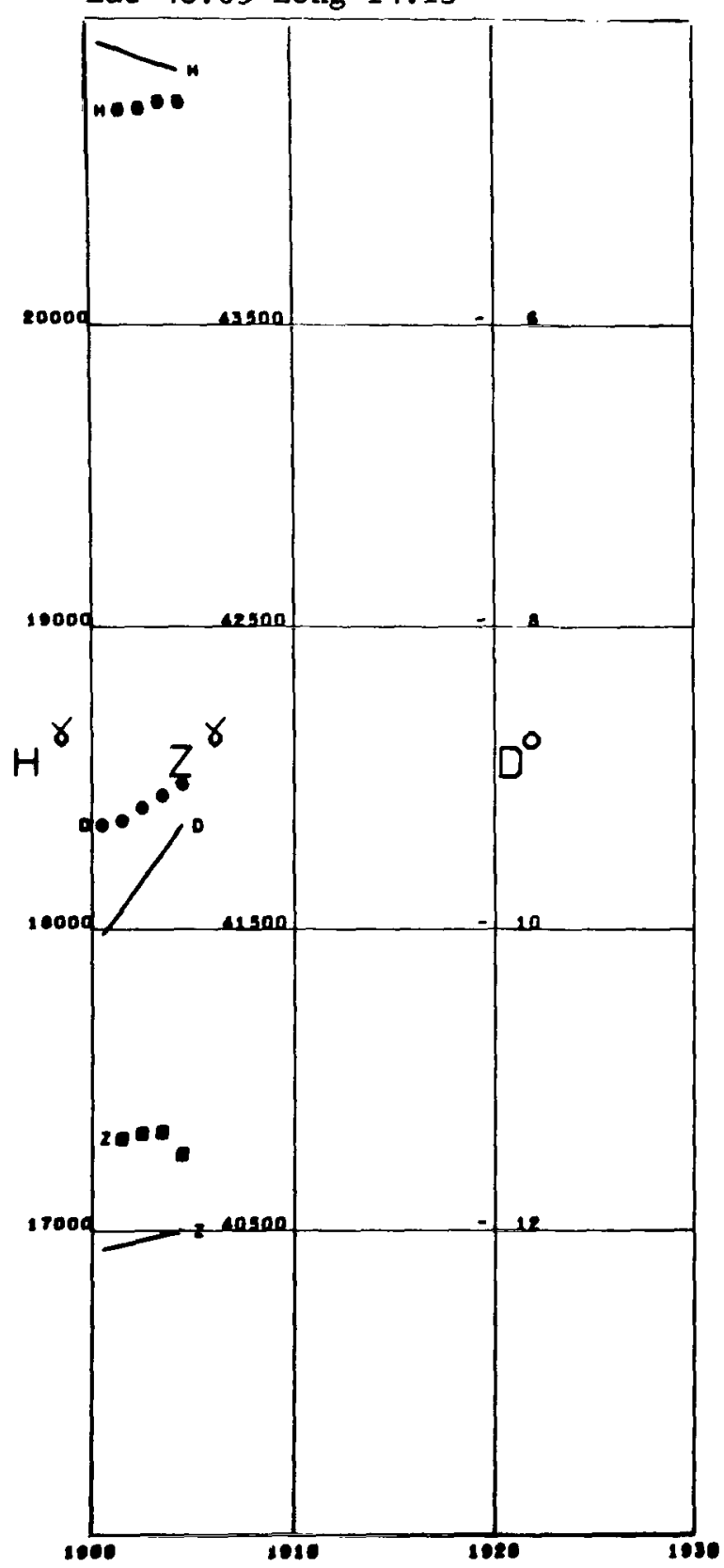

Figure A92 
KSARA

Lat 33.82 Long 35.88

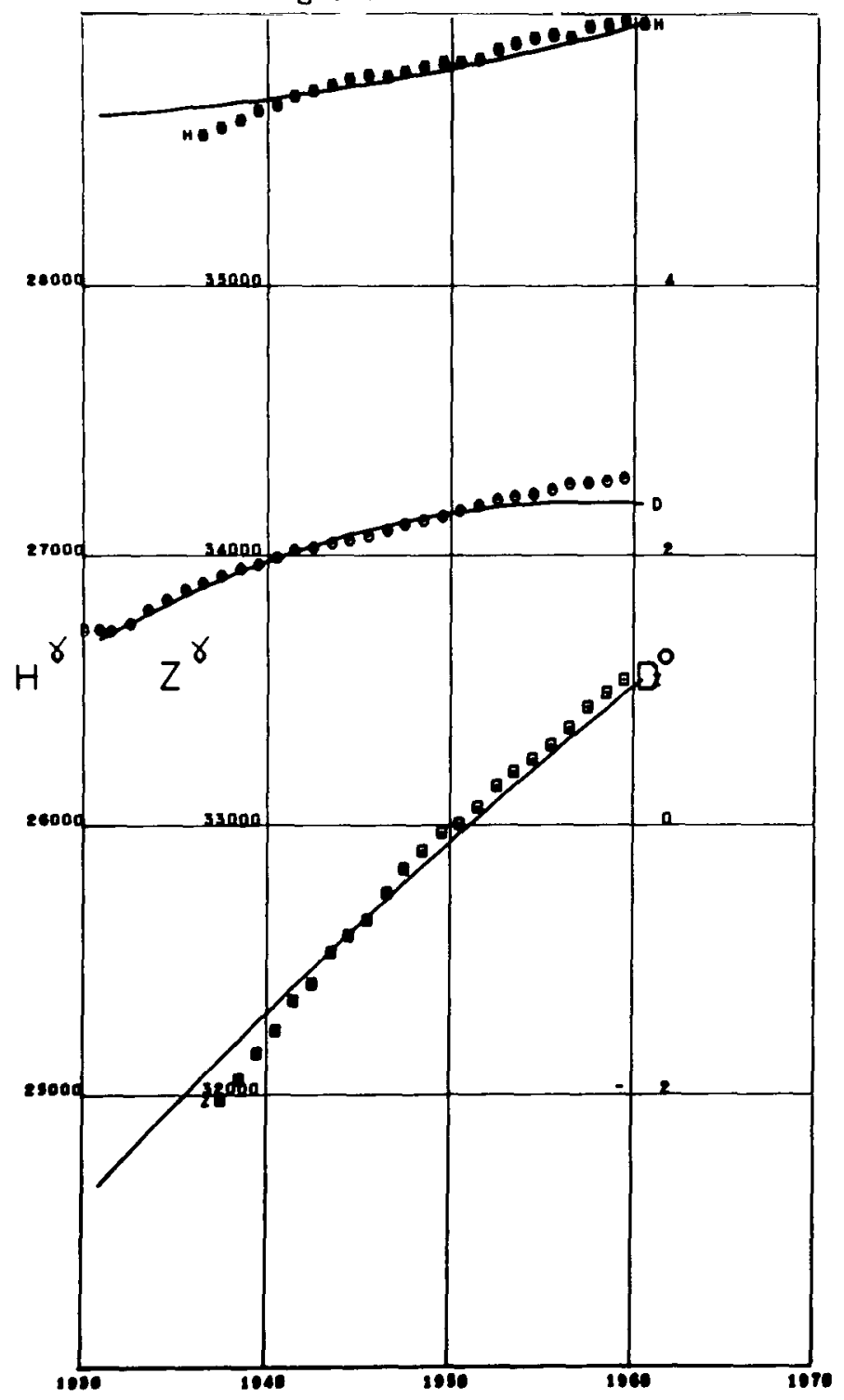

Figure $\mathrm{A93}$
KUTSCHINO

Lat 55.76 Long 37.96

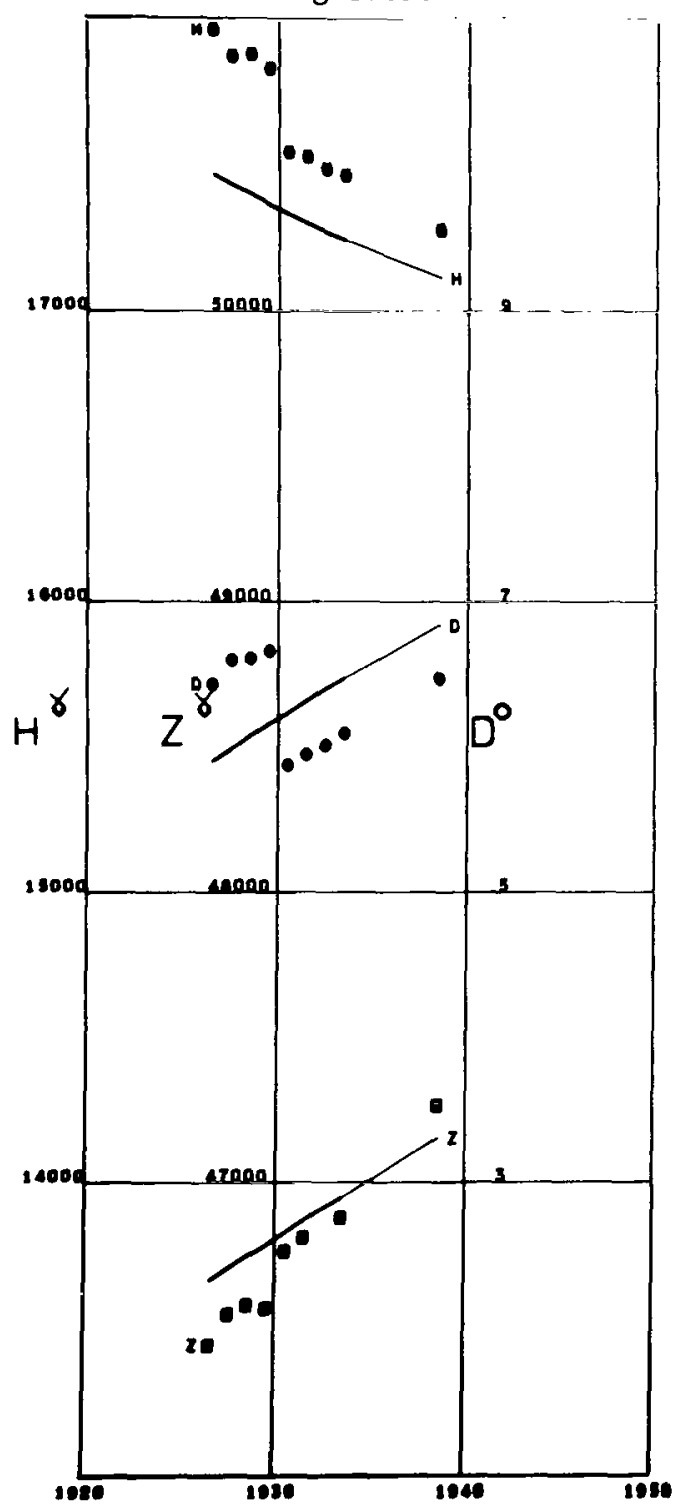

Figure A94 
KUYPER

Lat -6.03 Long 106.73

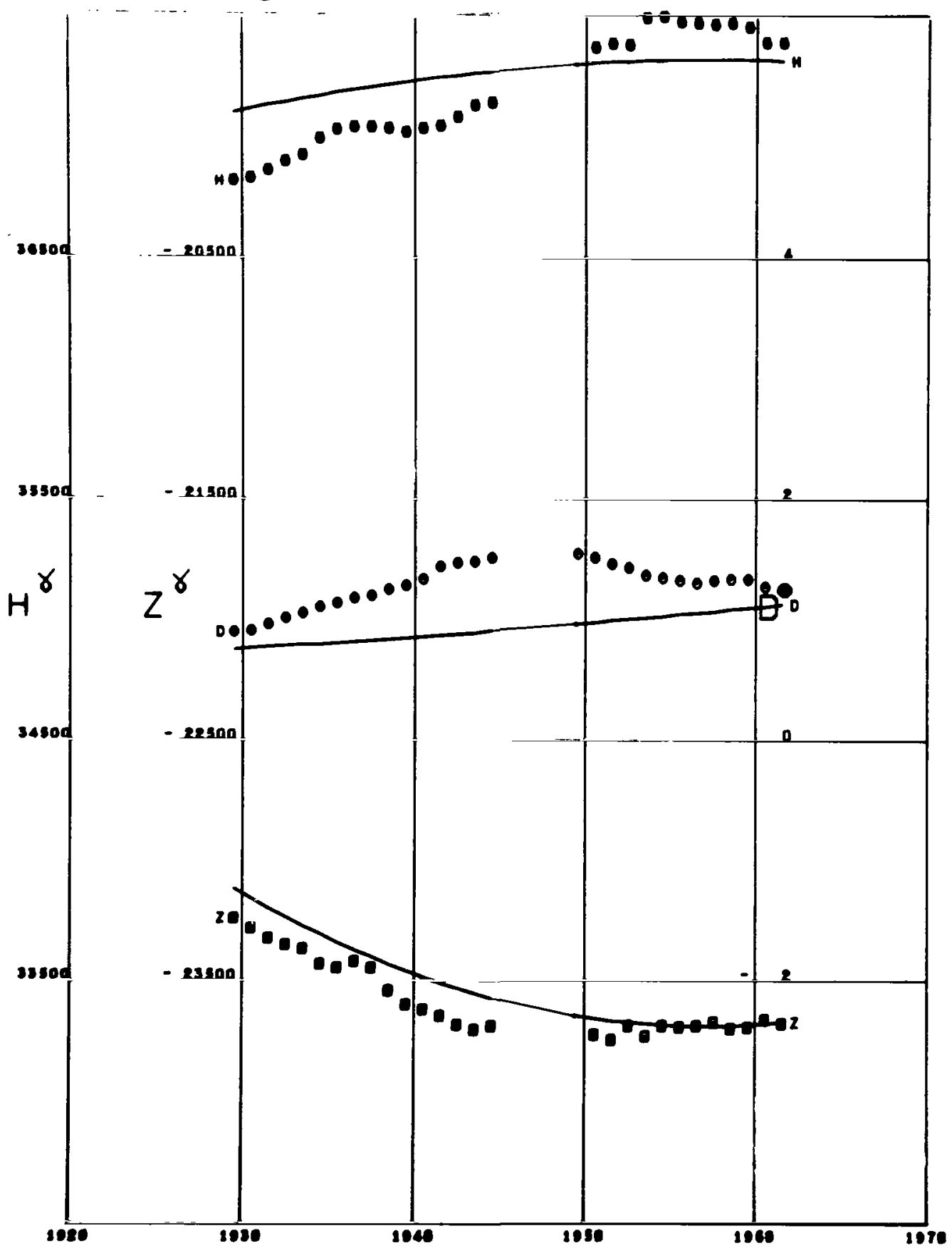

Figure A95 


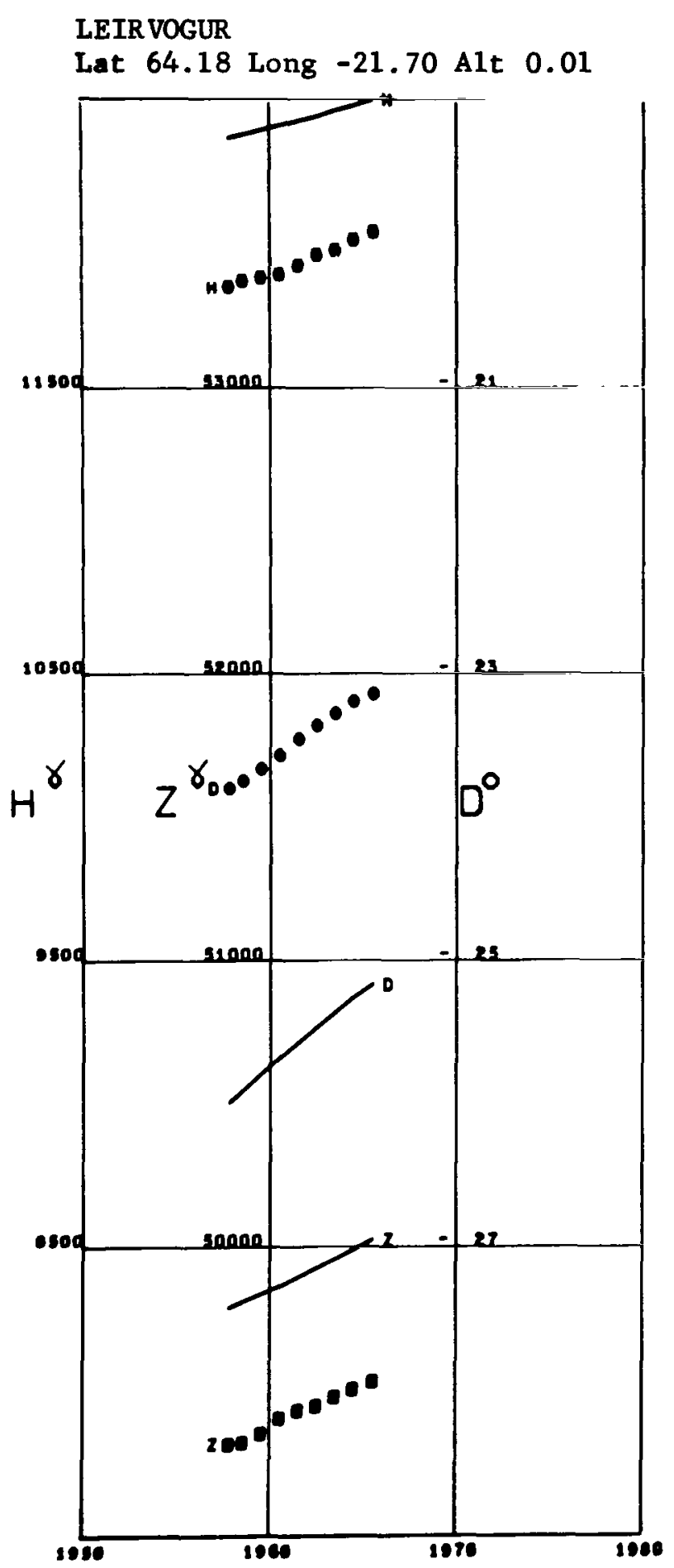

Figure A96 
LERWICK

Lat 60.13 Long -1.18

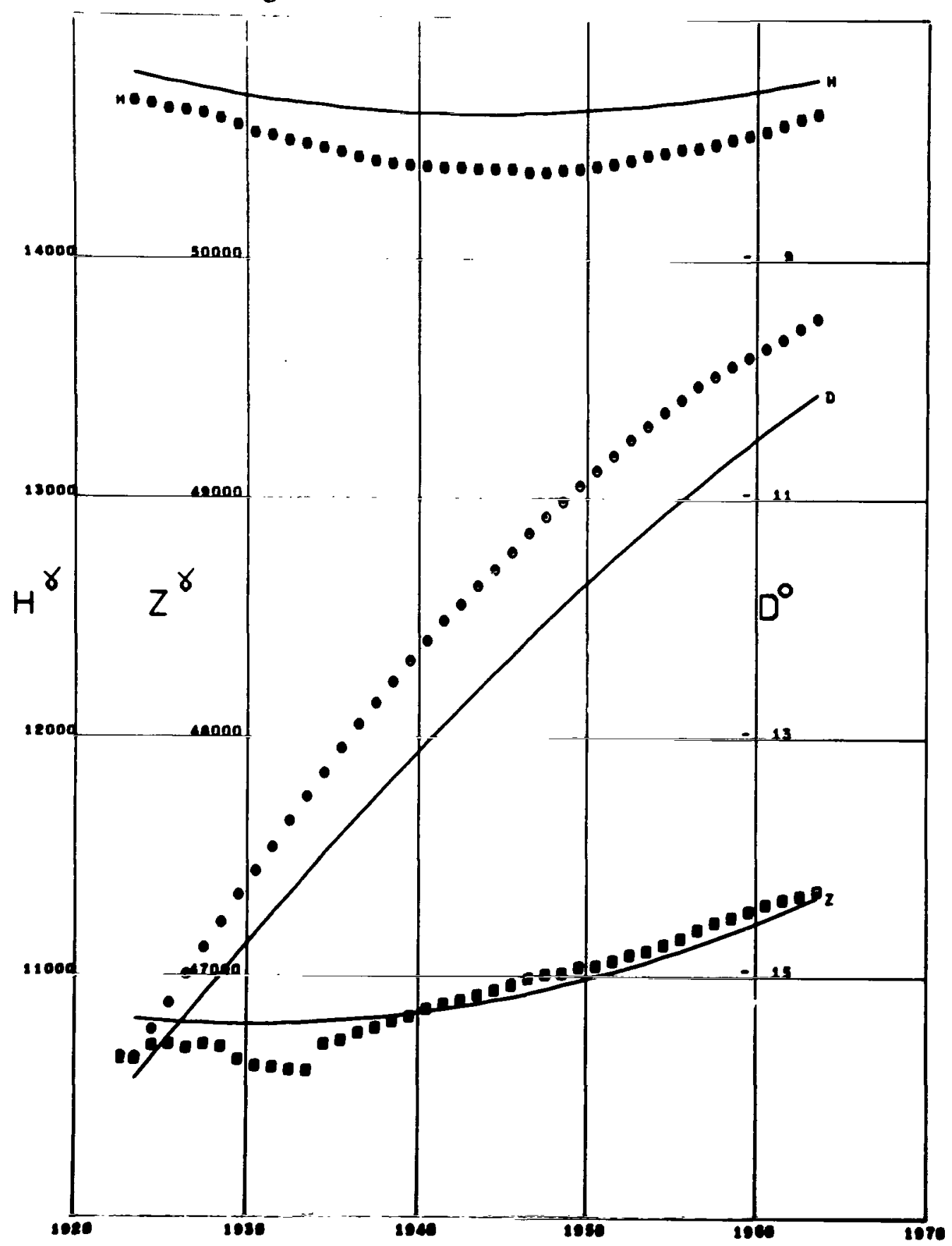

Figure A97 


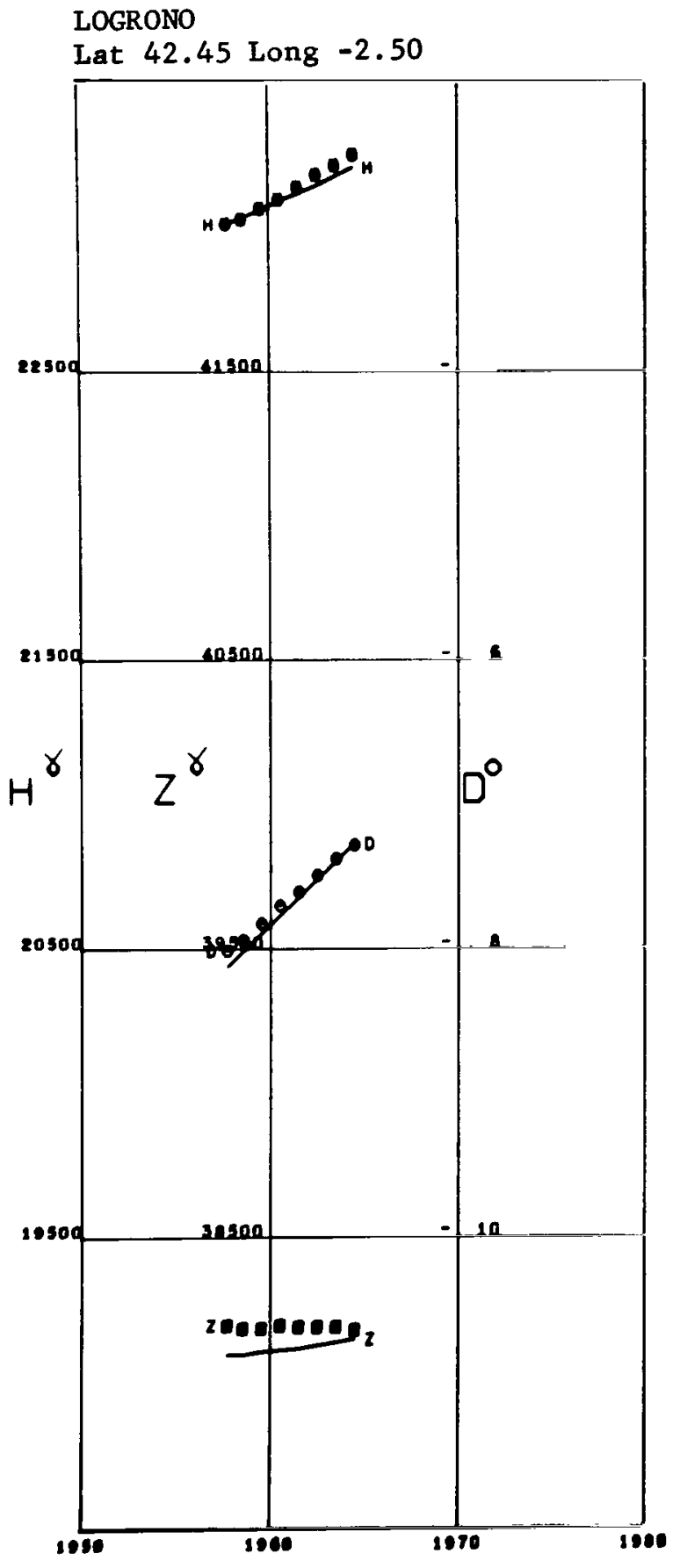

Figure A98

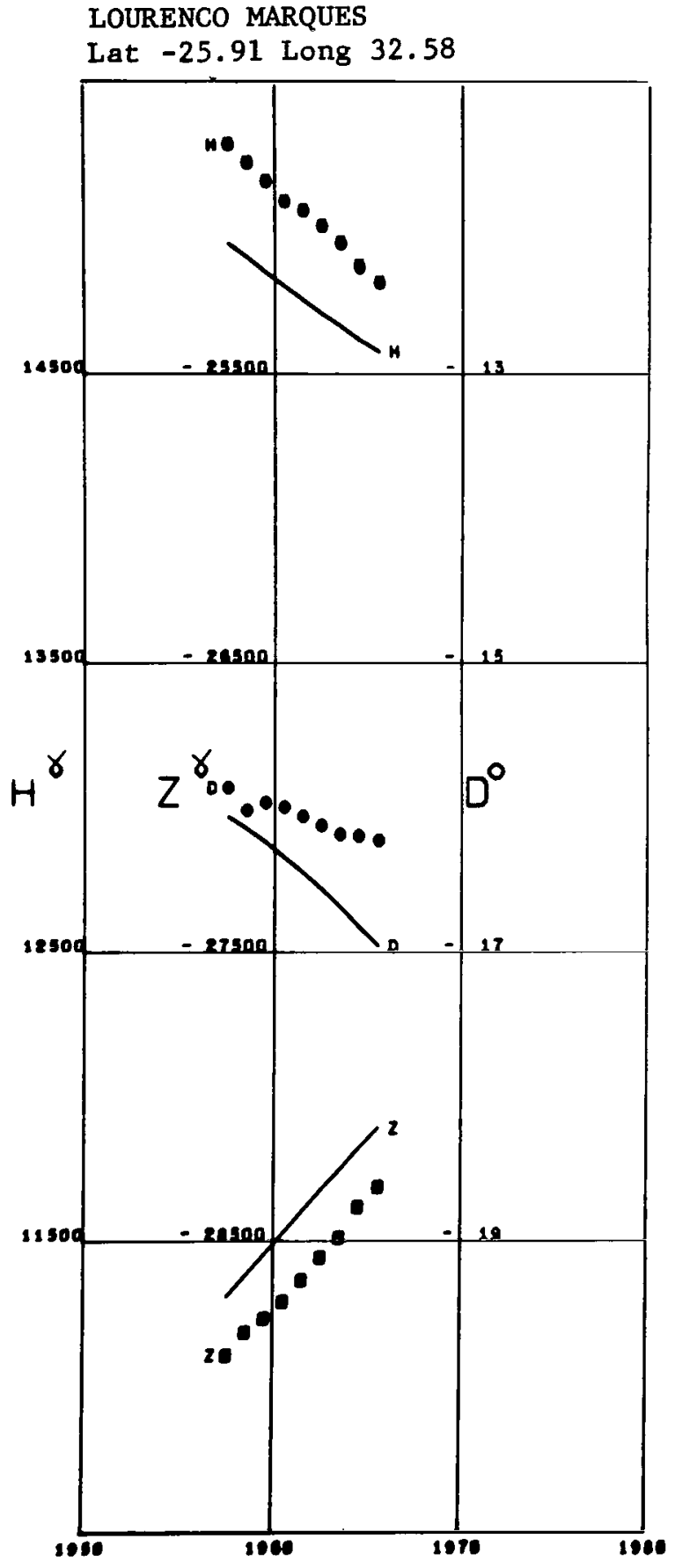

Figure A99 
Lowo

Lat 59.34 Long 17.82 Alt 0.02

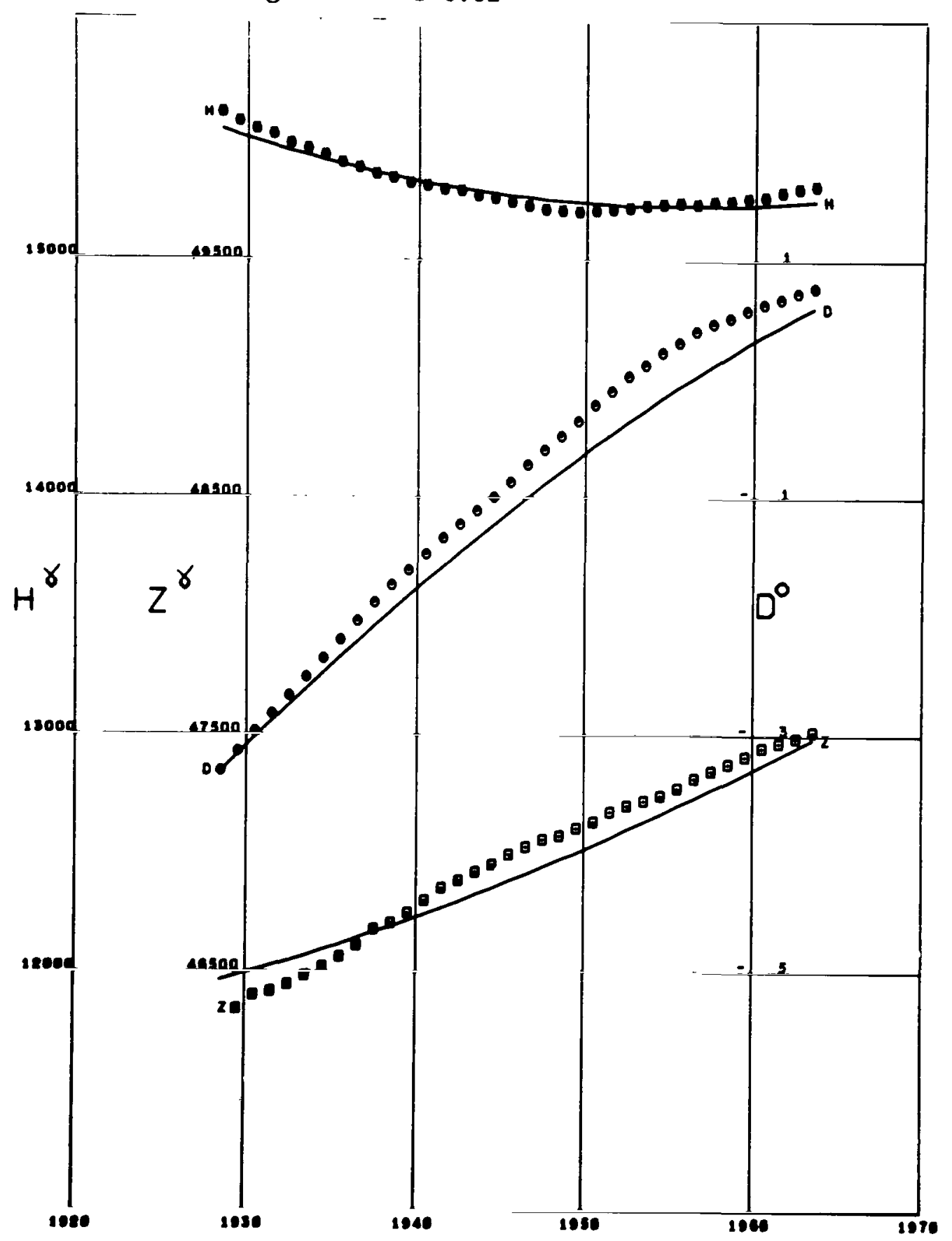

Figure A 100 


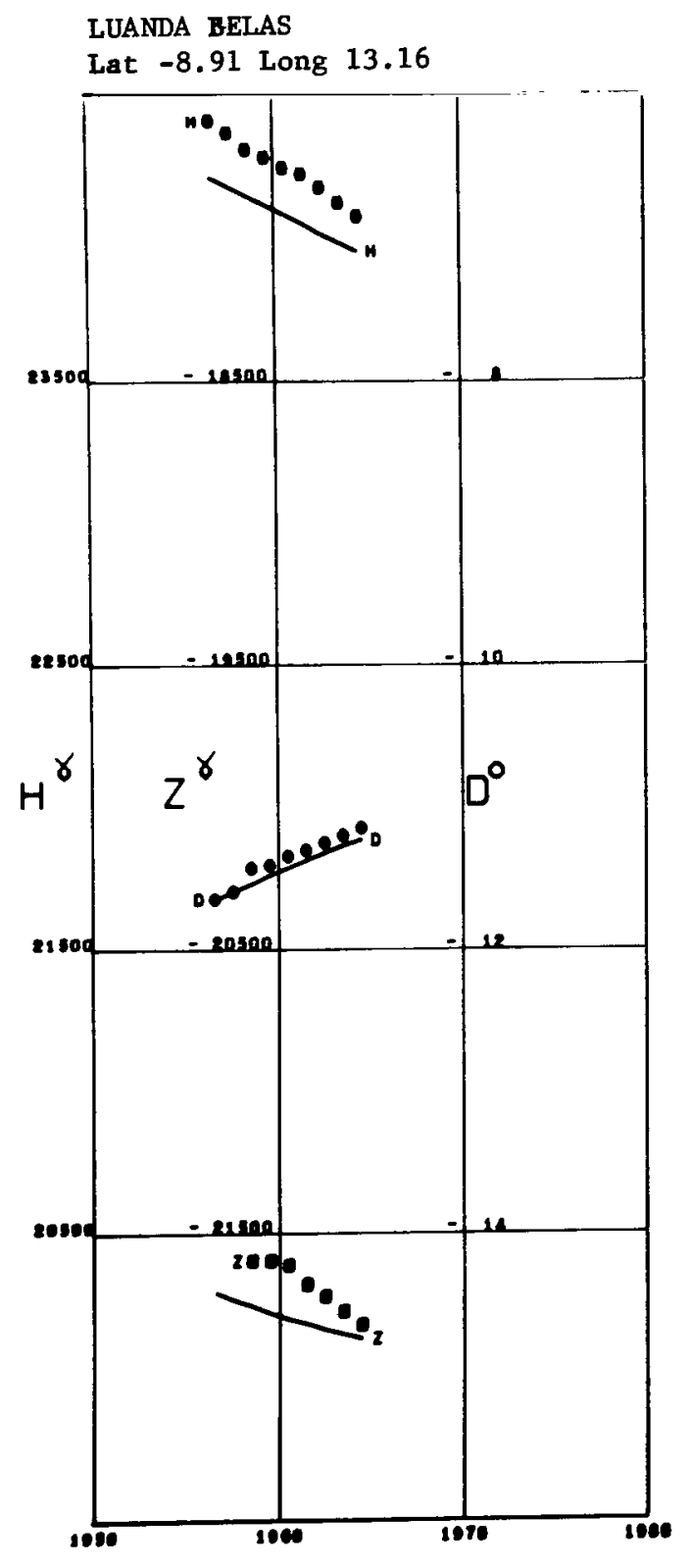

Figure A101

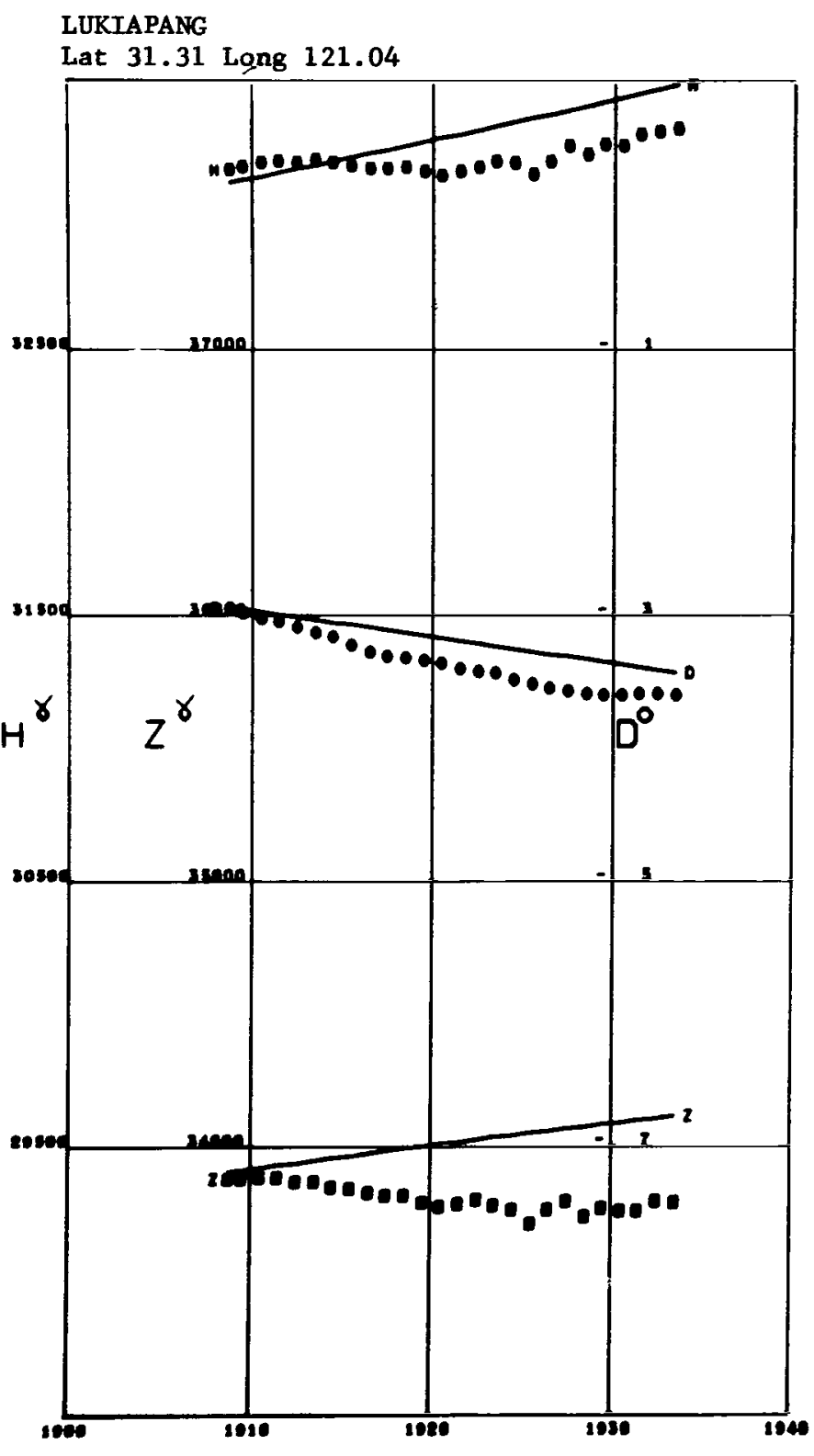

Figure A102 
LVOV

Lat 49.90 Long 23.75

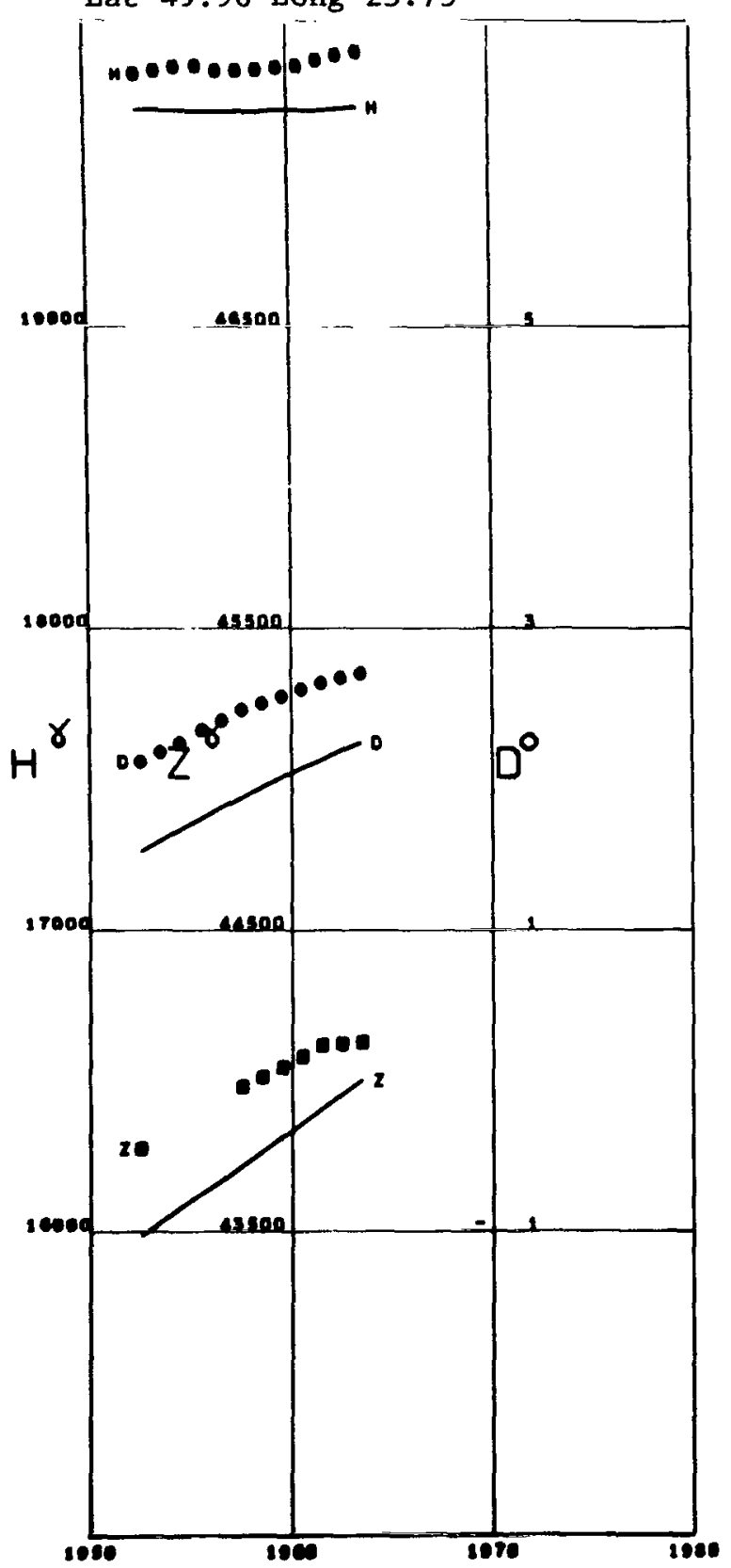

Figure Al03
M'BOUR

Lat 14.39 Long $>16.95$ A1t 0.01

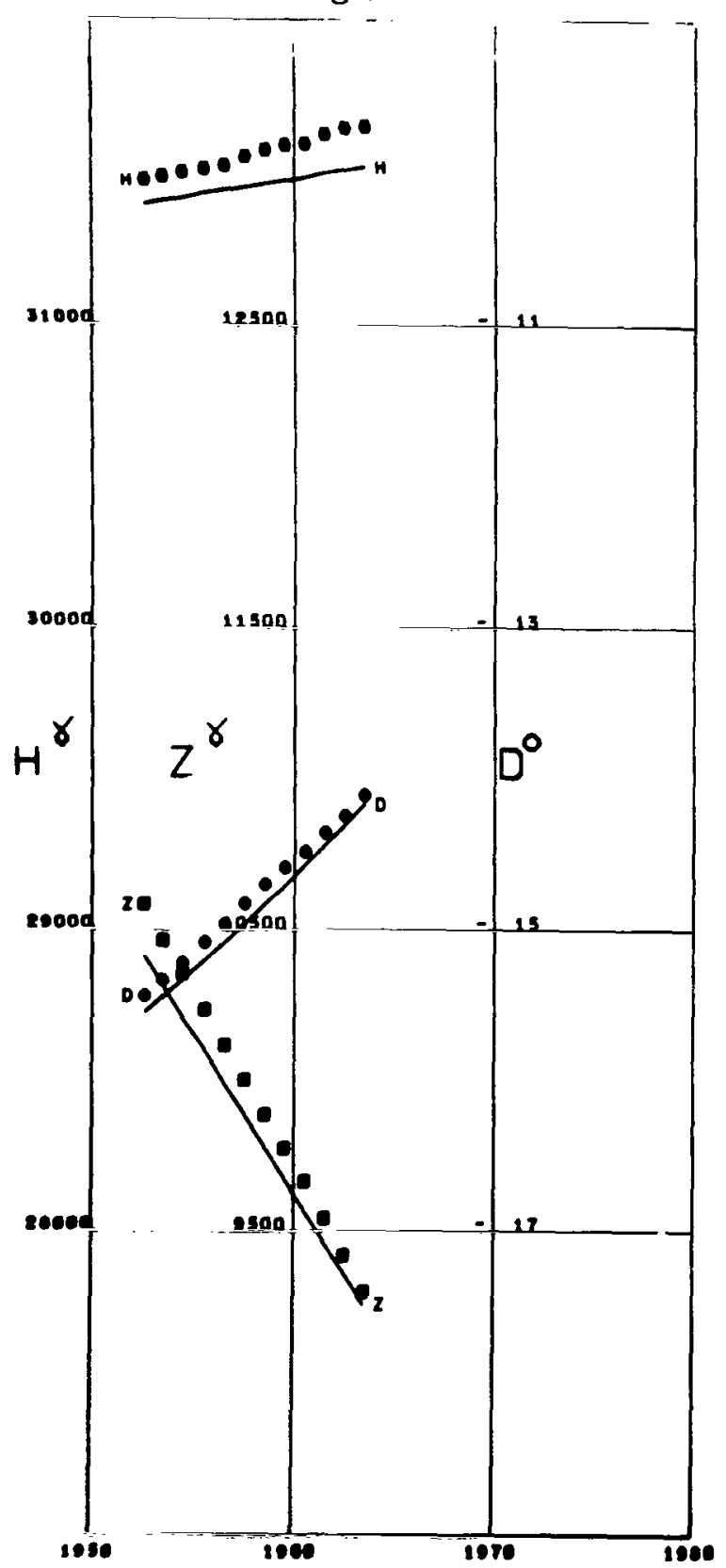

Figure A 104 


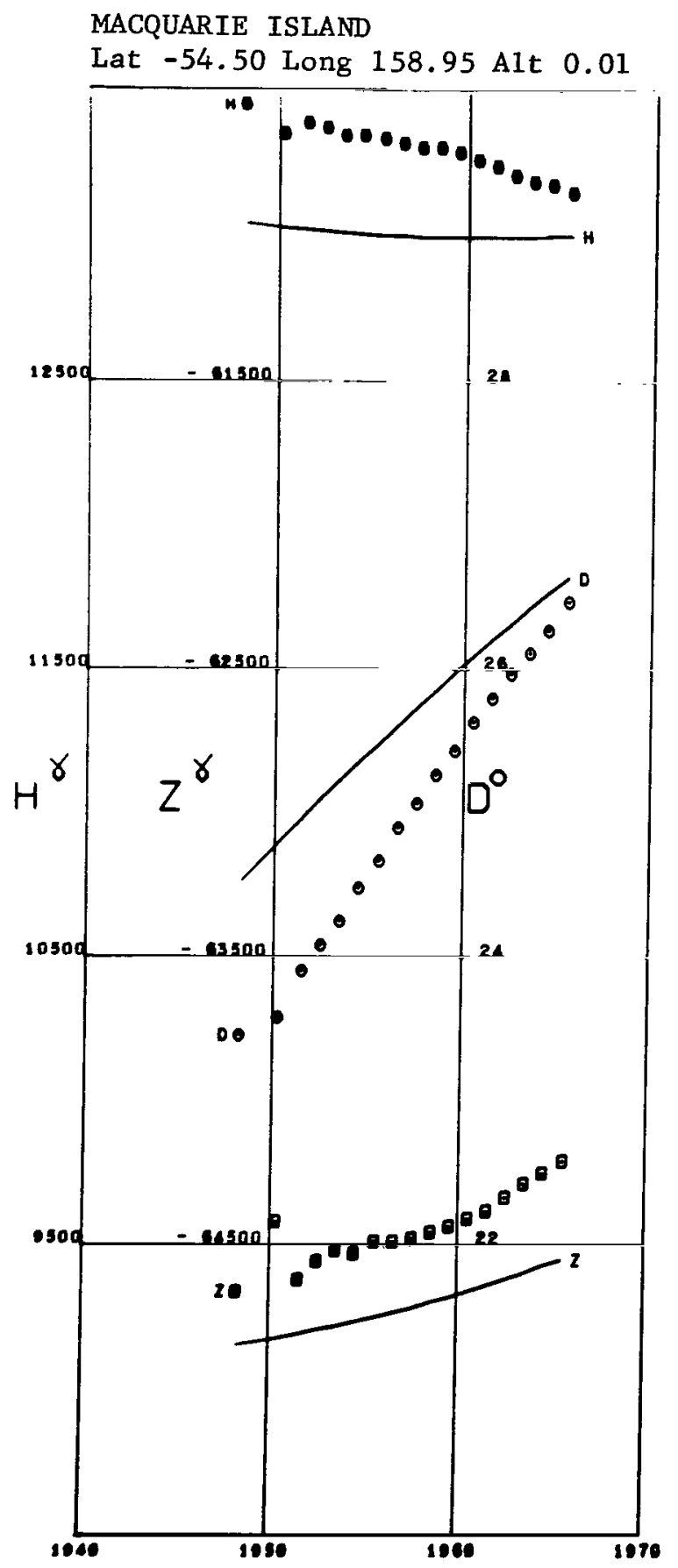

Figure A105

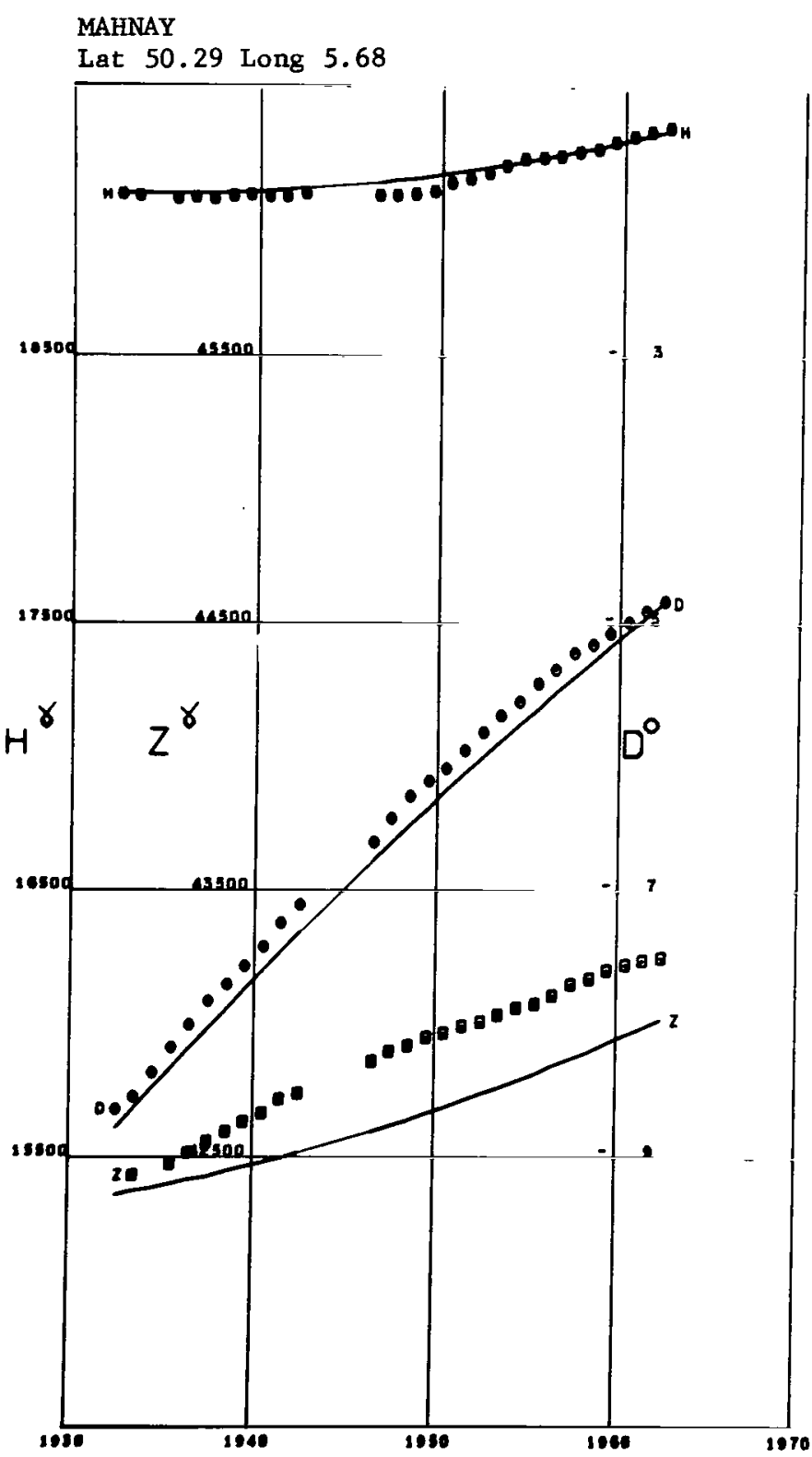

Figure A106 


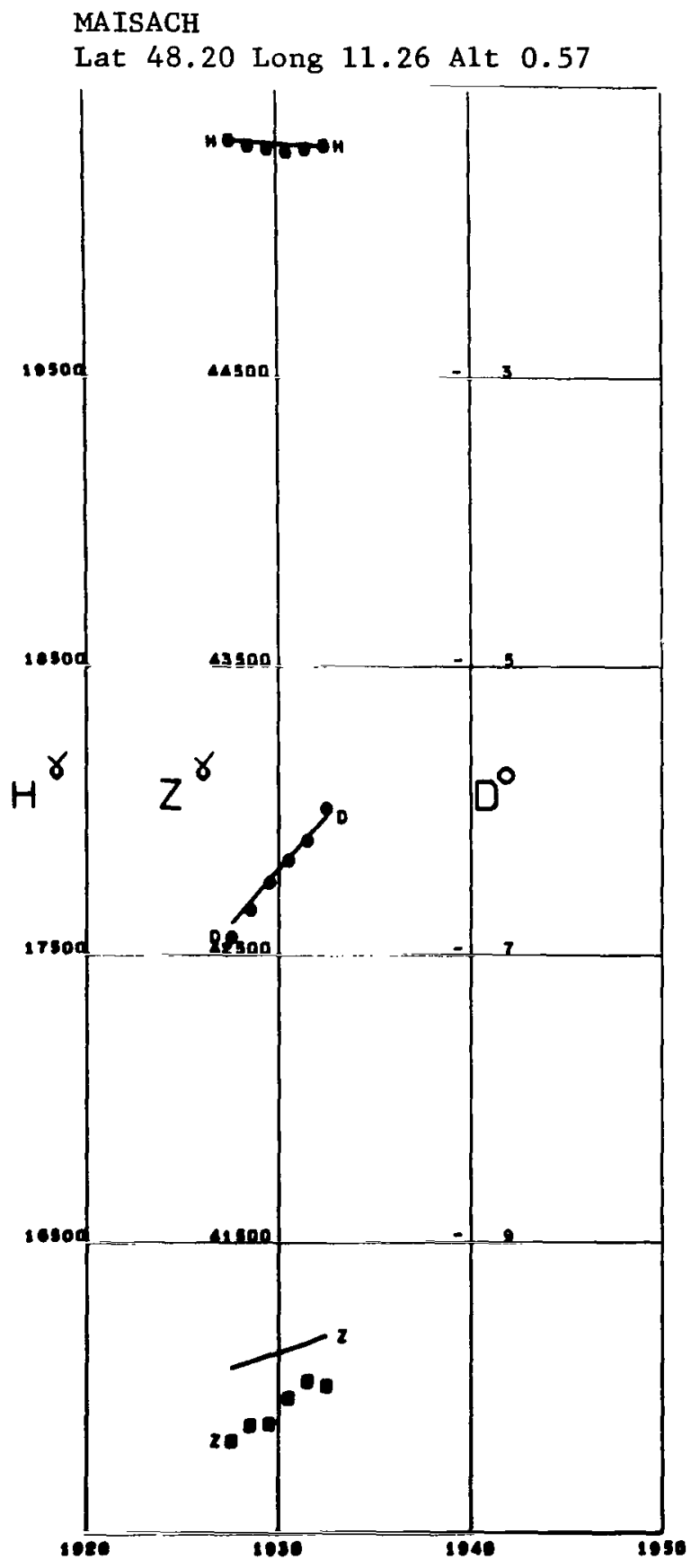

Figure A107

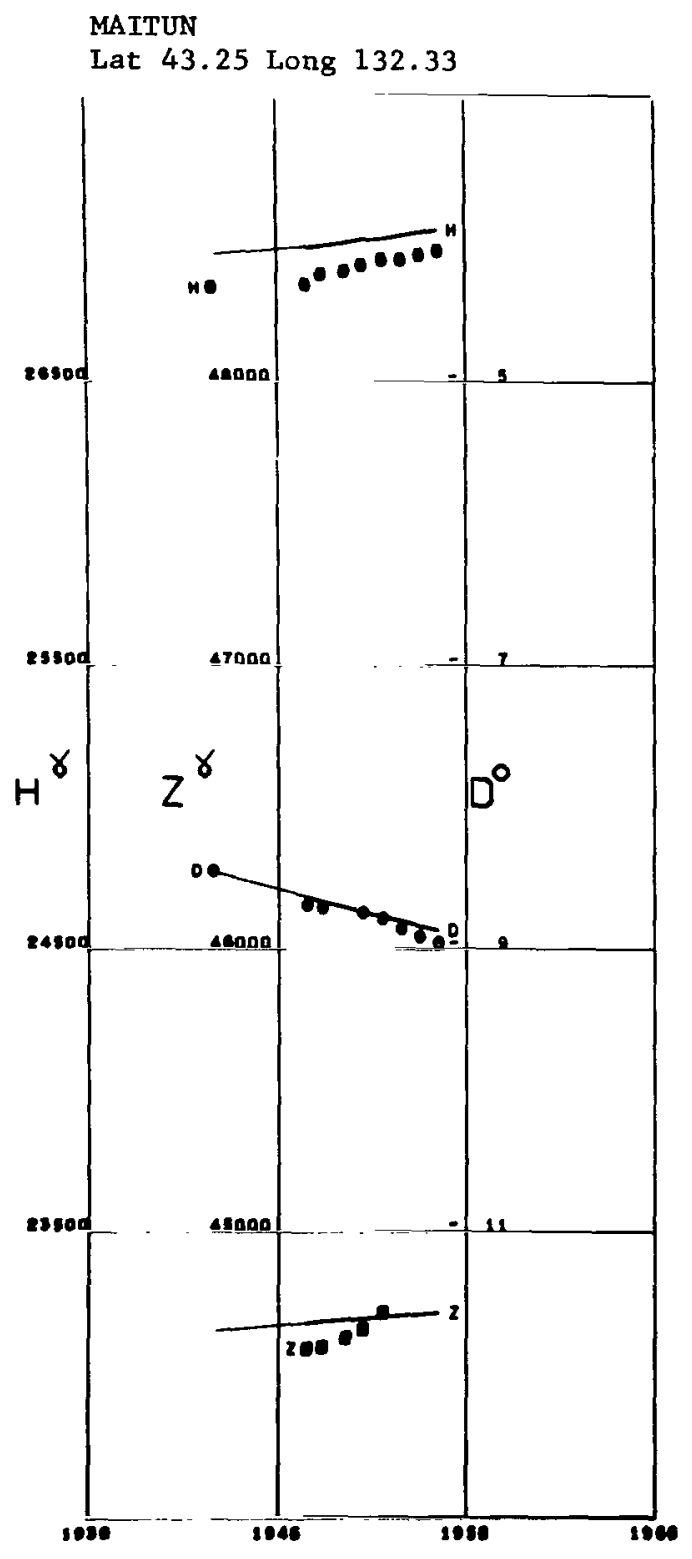

Figure A108 
MANILA

Lat 14.57 Long 120.97

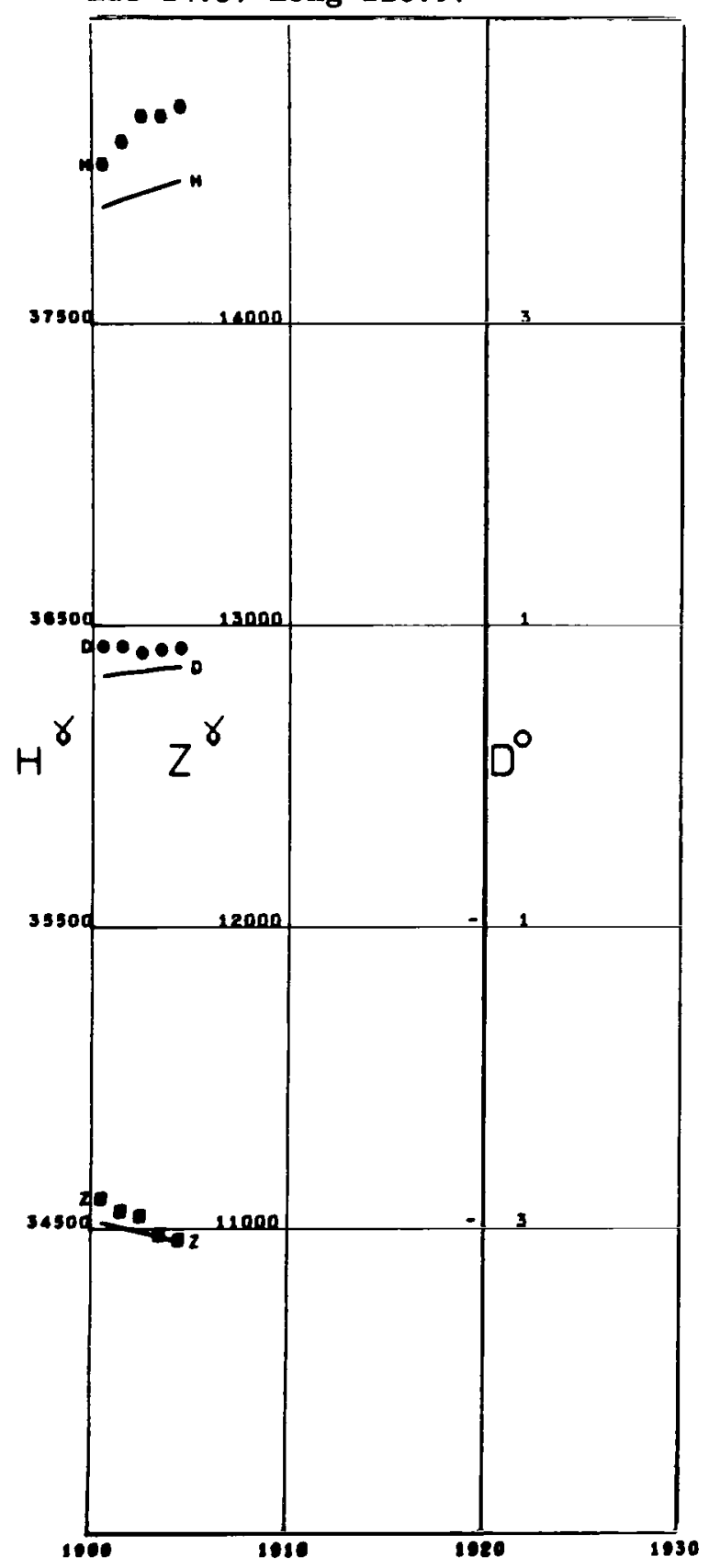

Figure A109

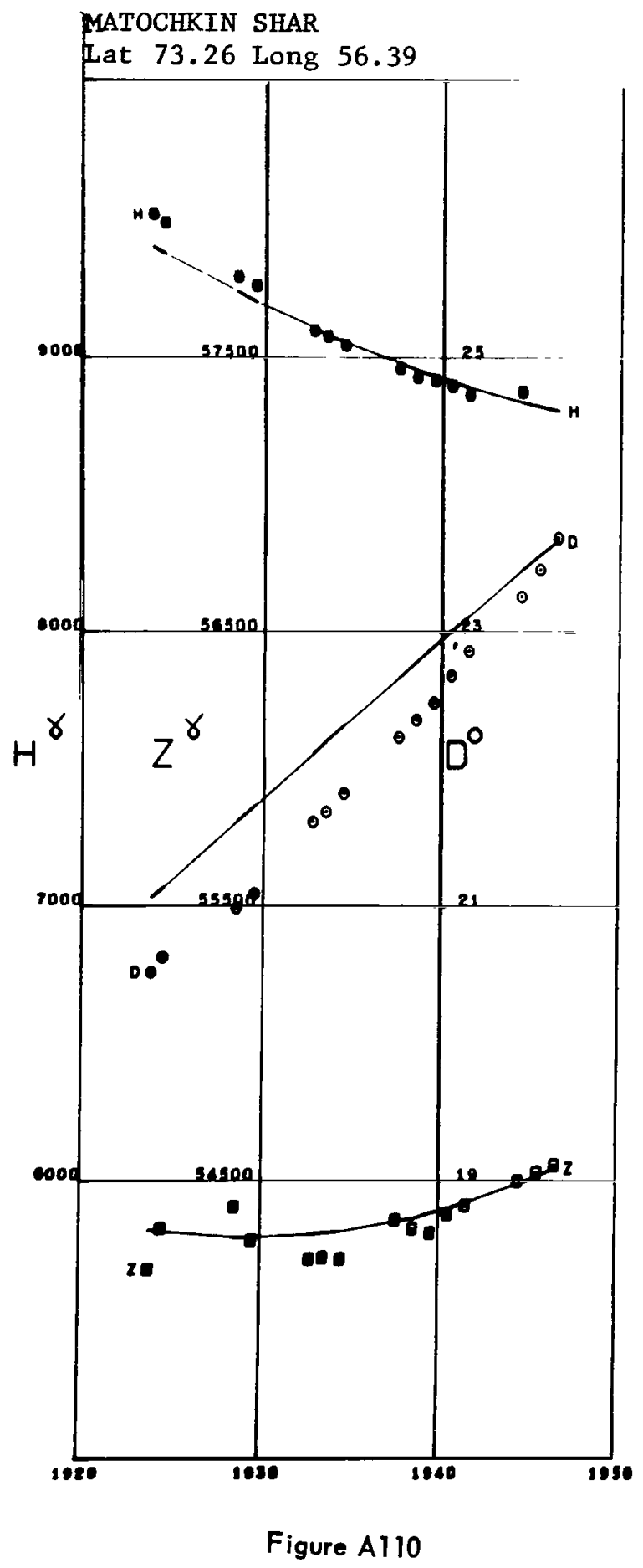

Figure Al10 
Lat -20.09 Long 57.55

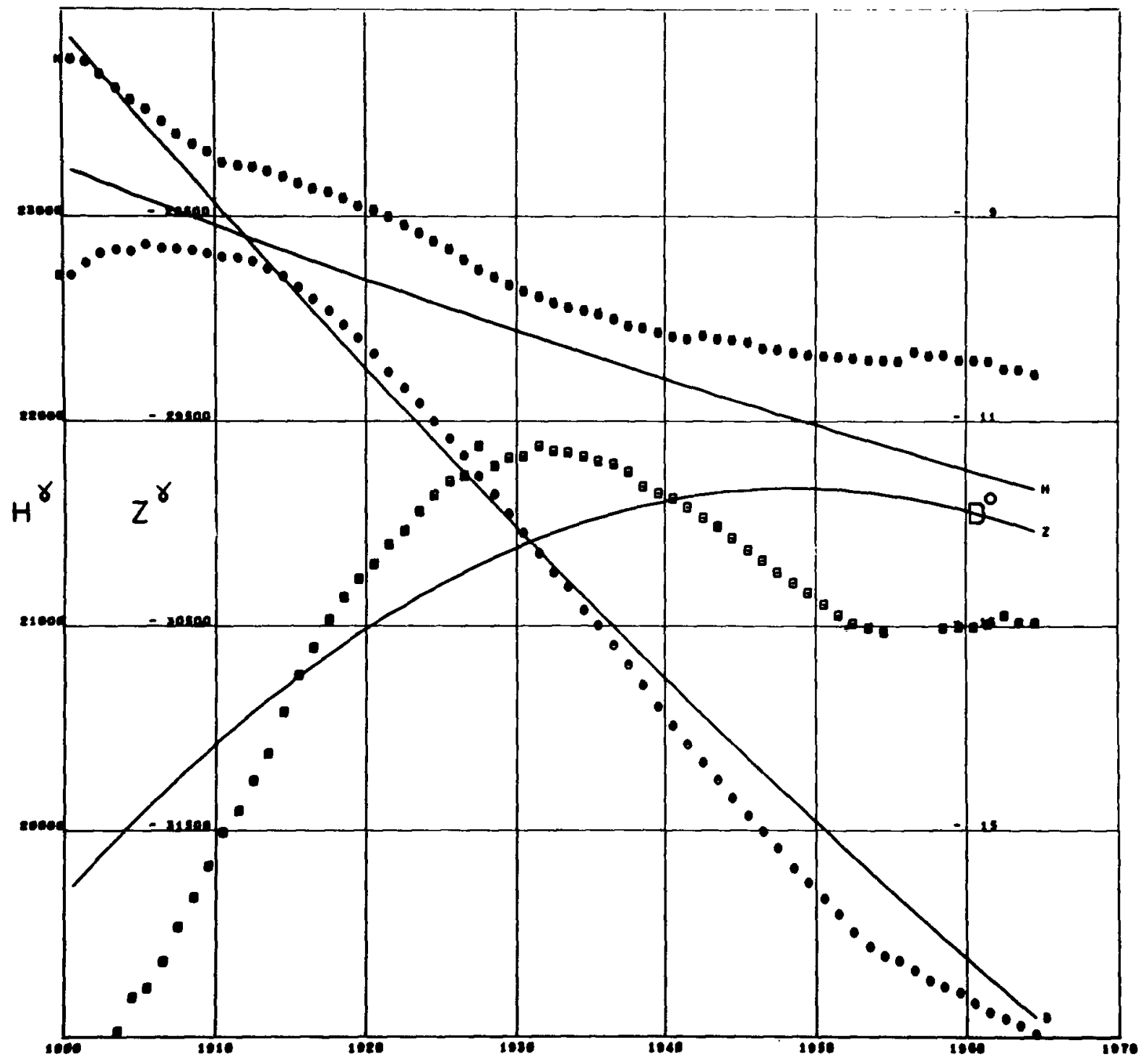

Figure All1 


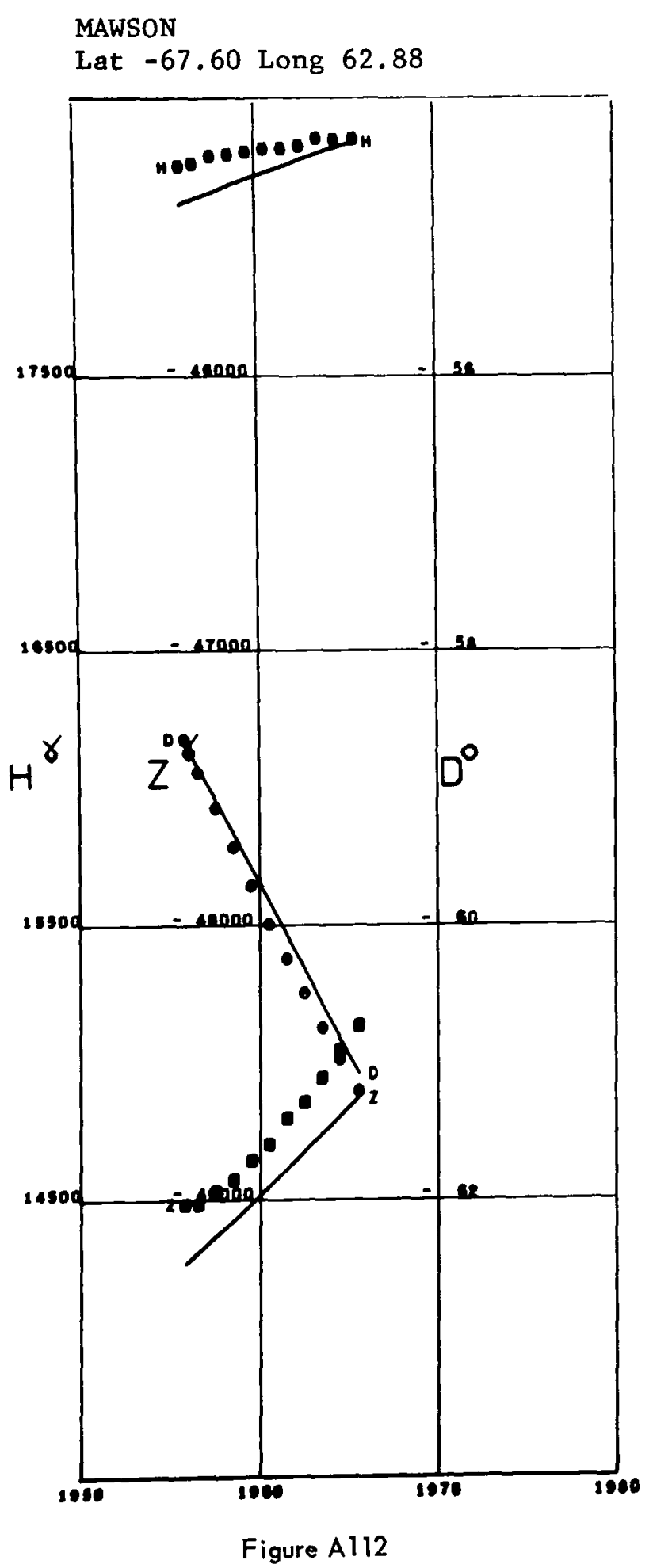




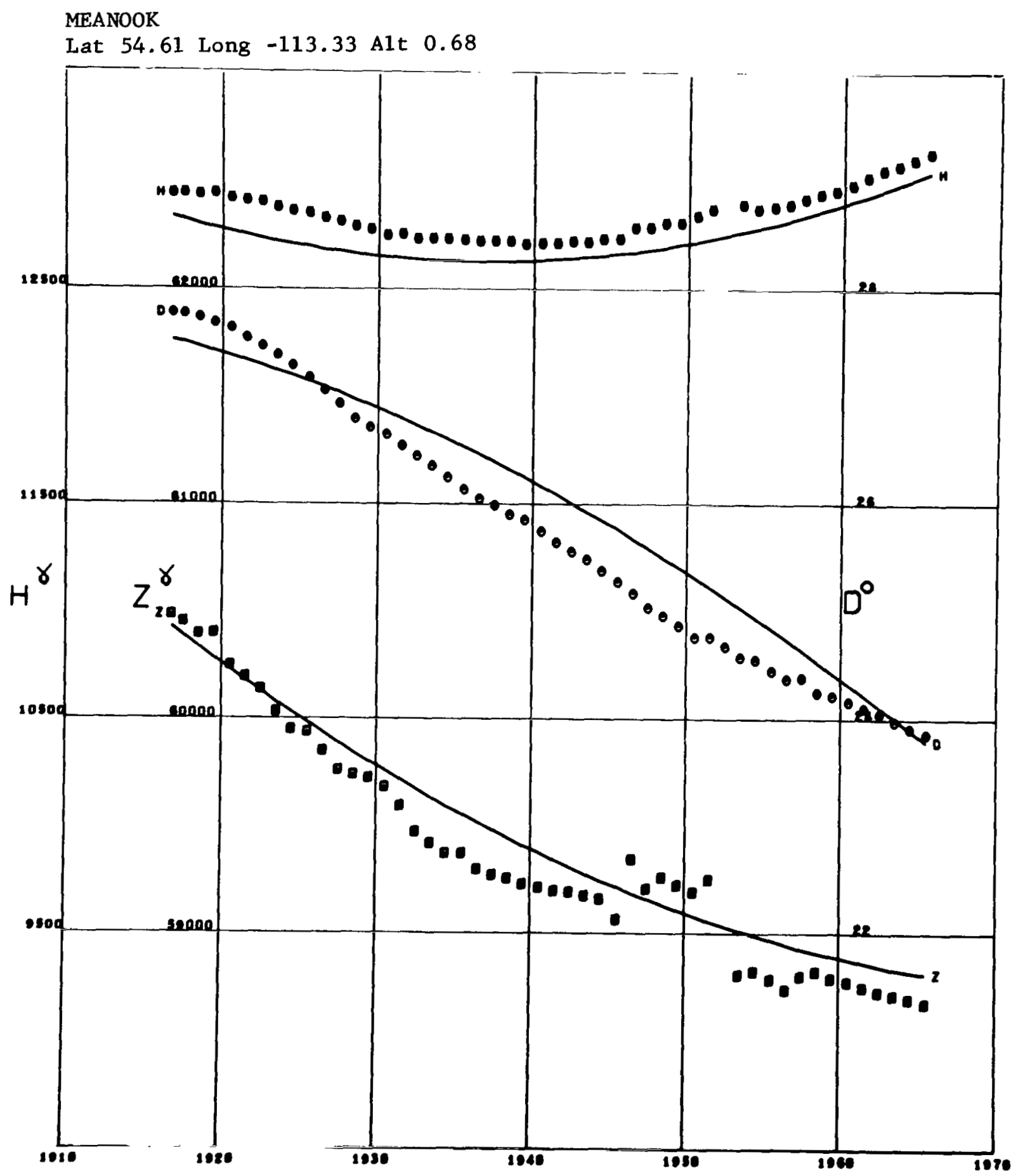

Figure A113 
MELBOURNE

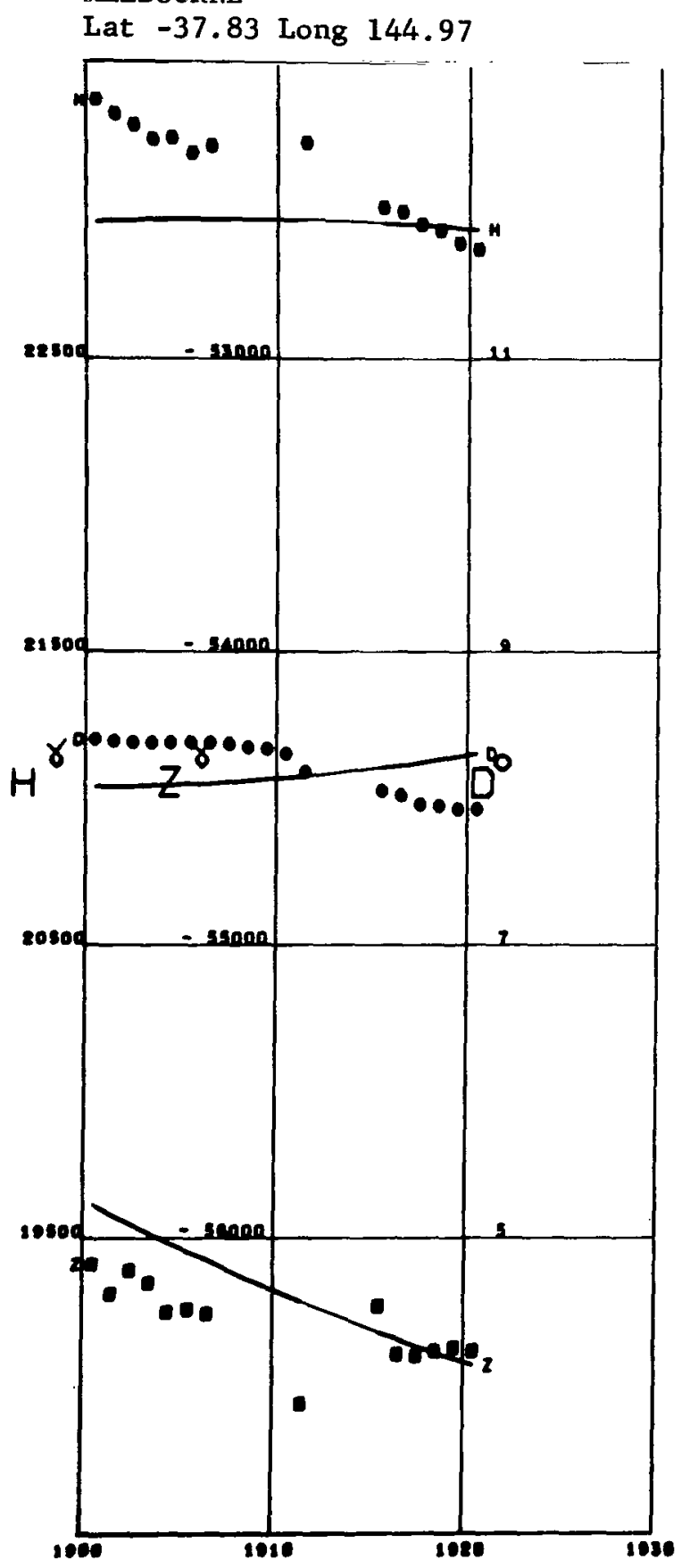

Figure A114
MEMAMBETSU

Lat 43.90 Long 144.19 Alt 0.04

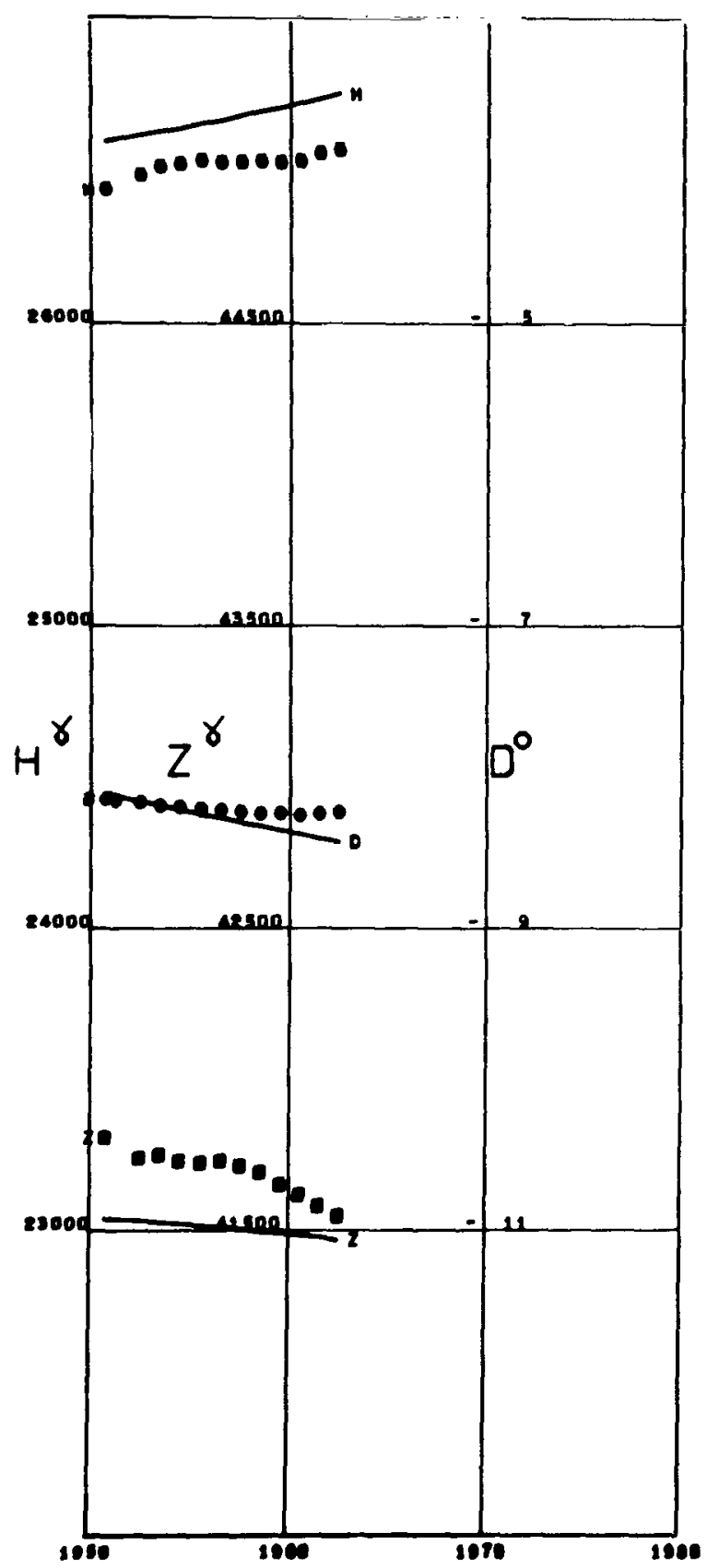

Figure A115 
MIRNYY

Lat -66.55 Long 93.01

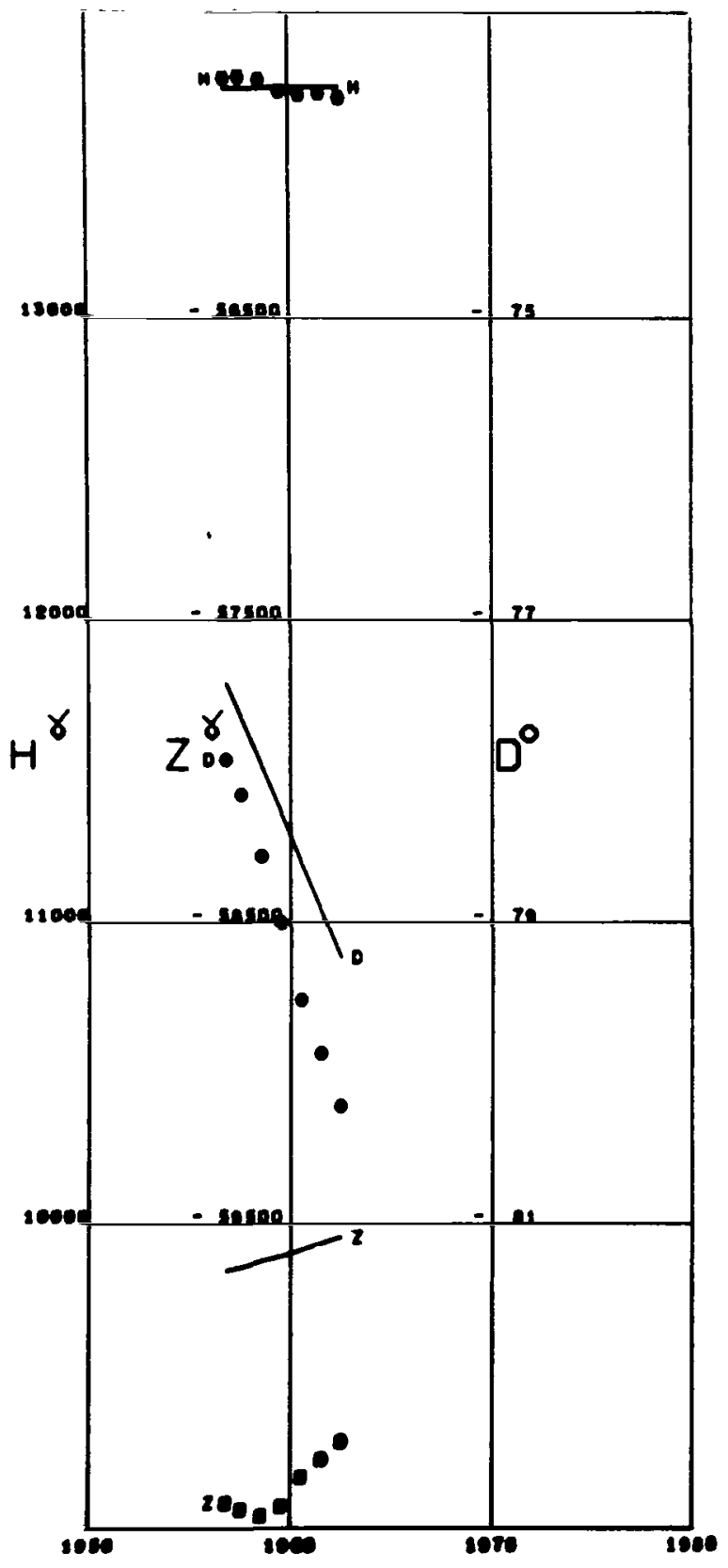

Figure Al16
MISALLAT

Lat 29.51 Long 30.89 Alt 0.12

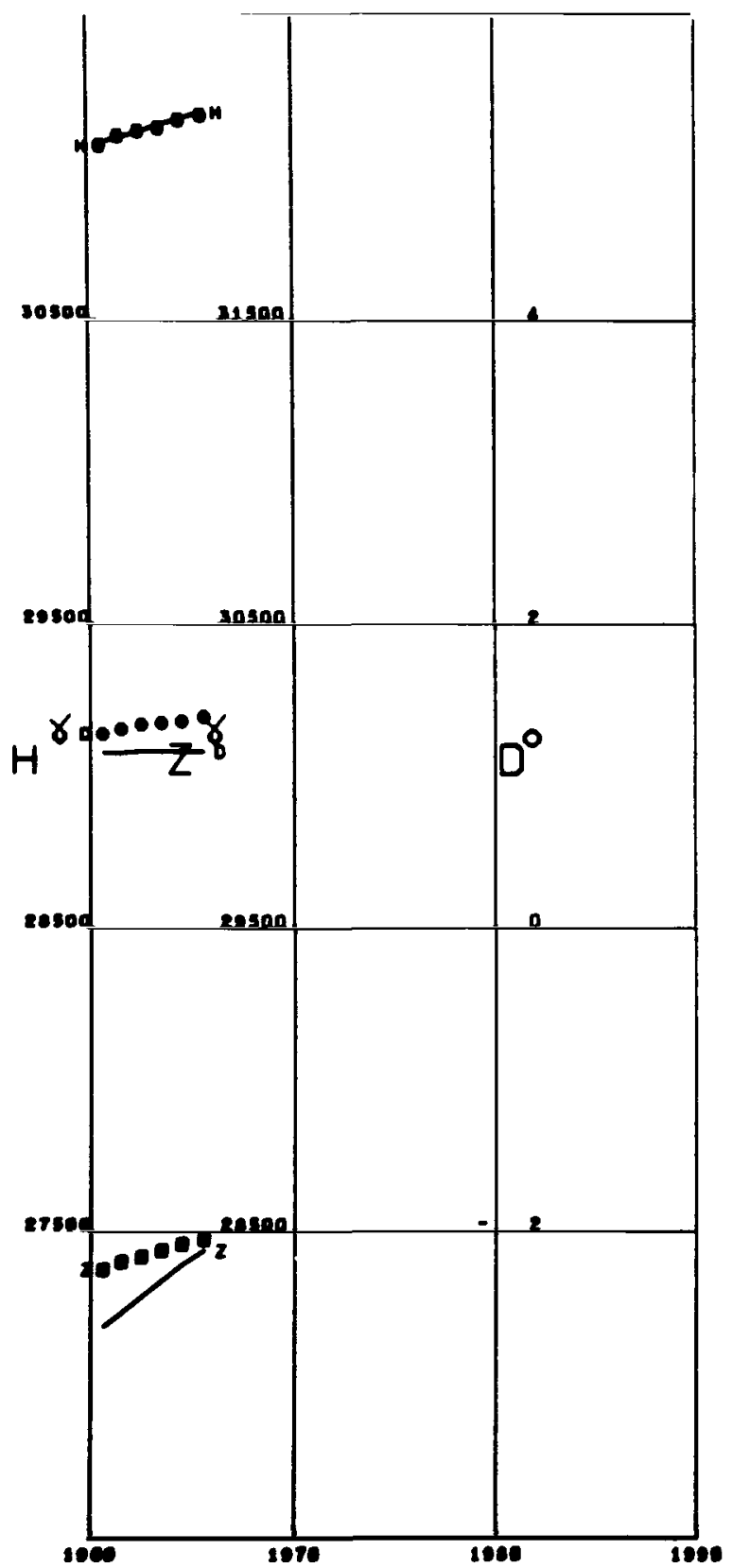

Figure Al17 


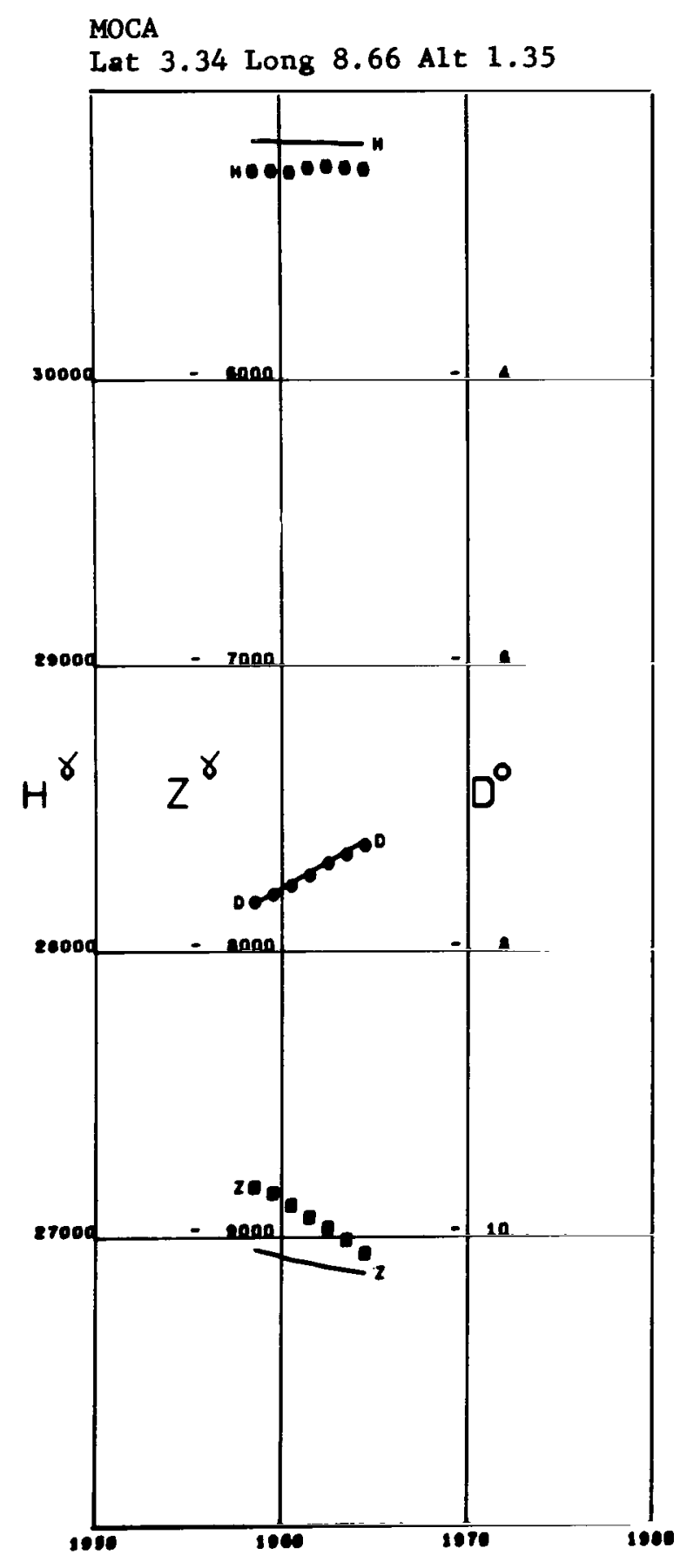

Figure A118

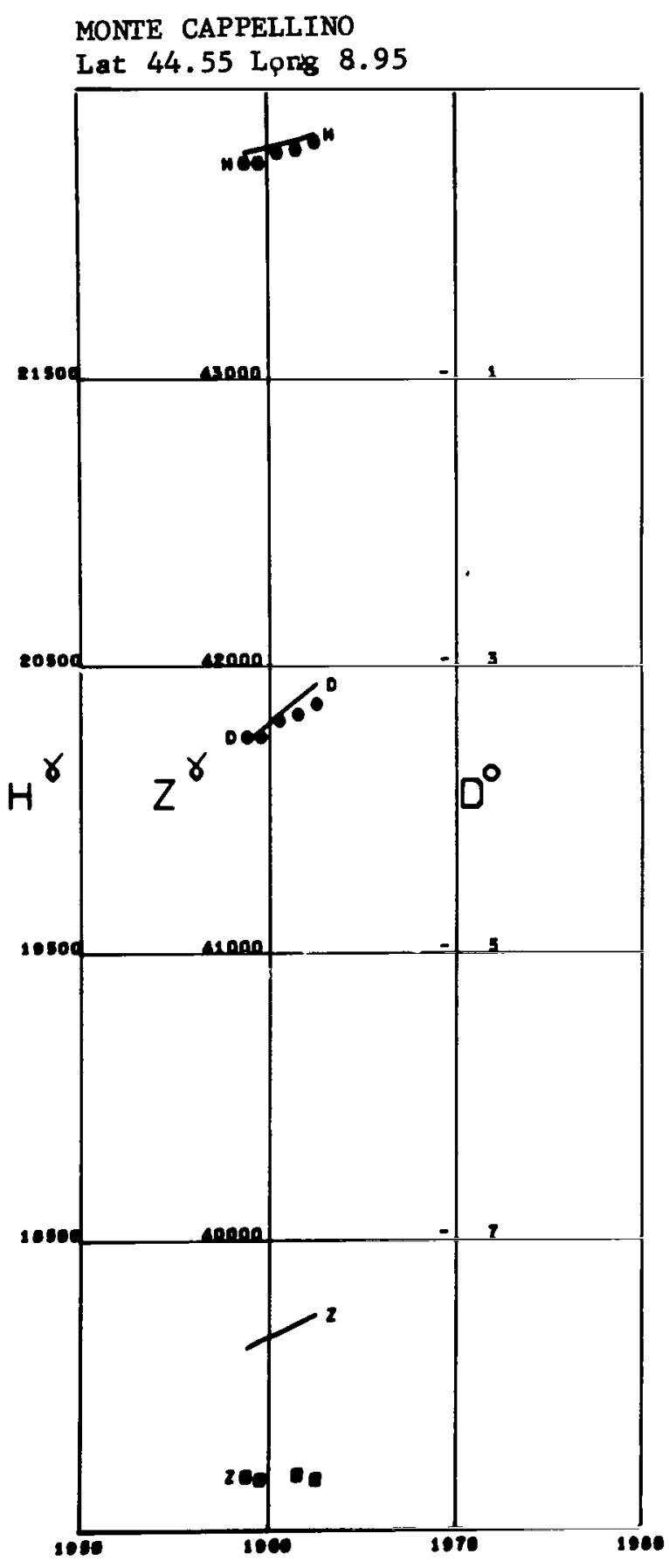

Figure Al19 
MUNICH

Lat 48.14 Long 11.60

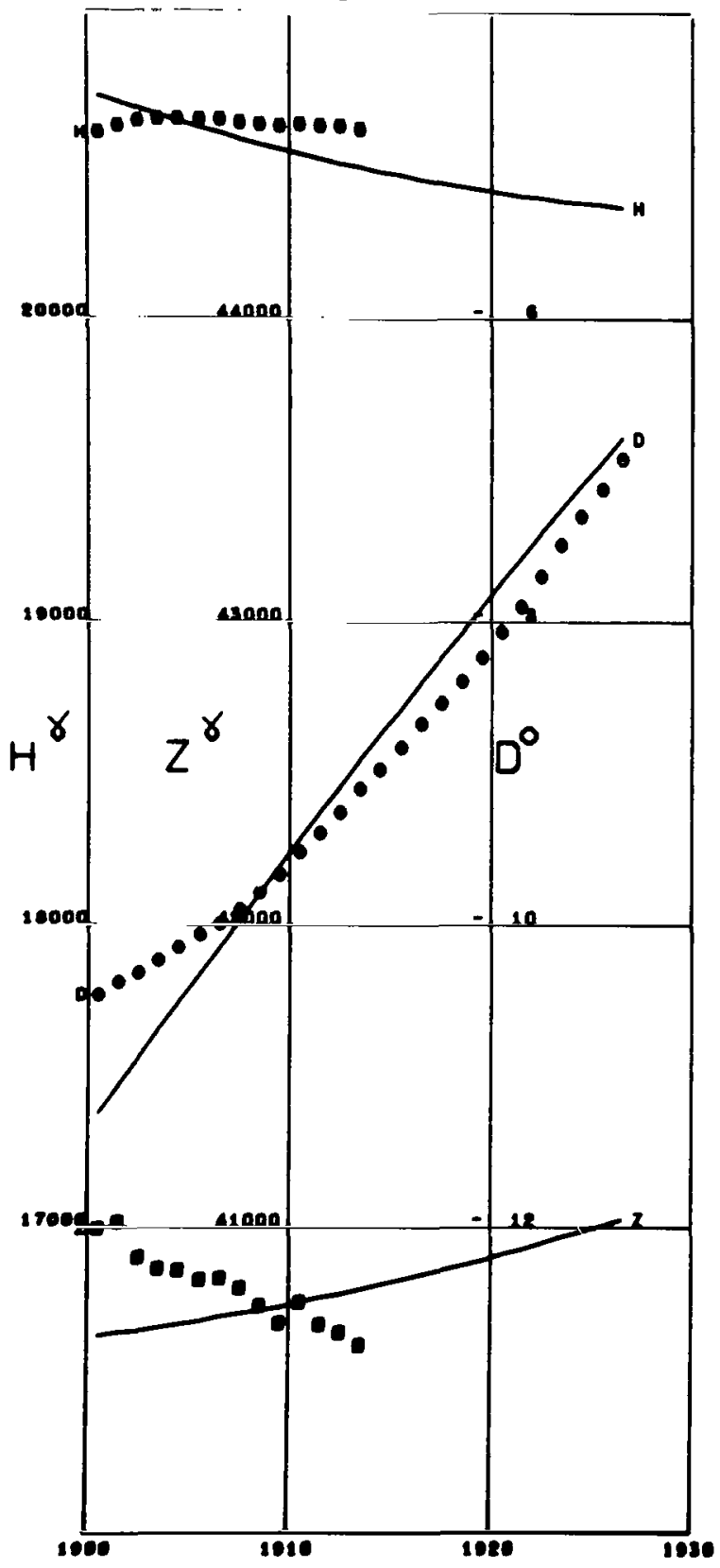

Figure A 120
MUNT INLUPA

Lat 14.37 Long 121.01 Alt 0.06

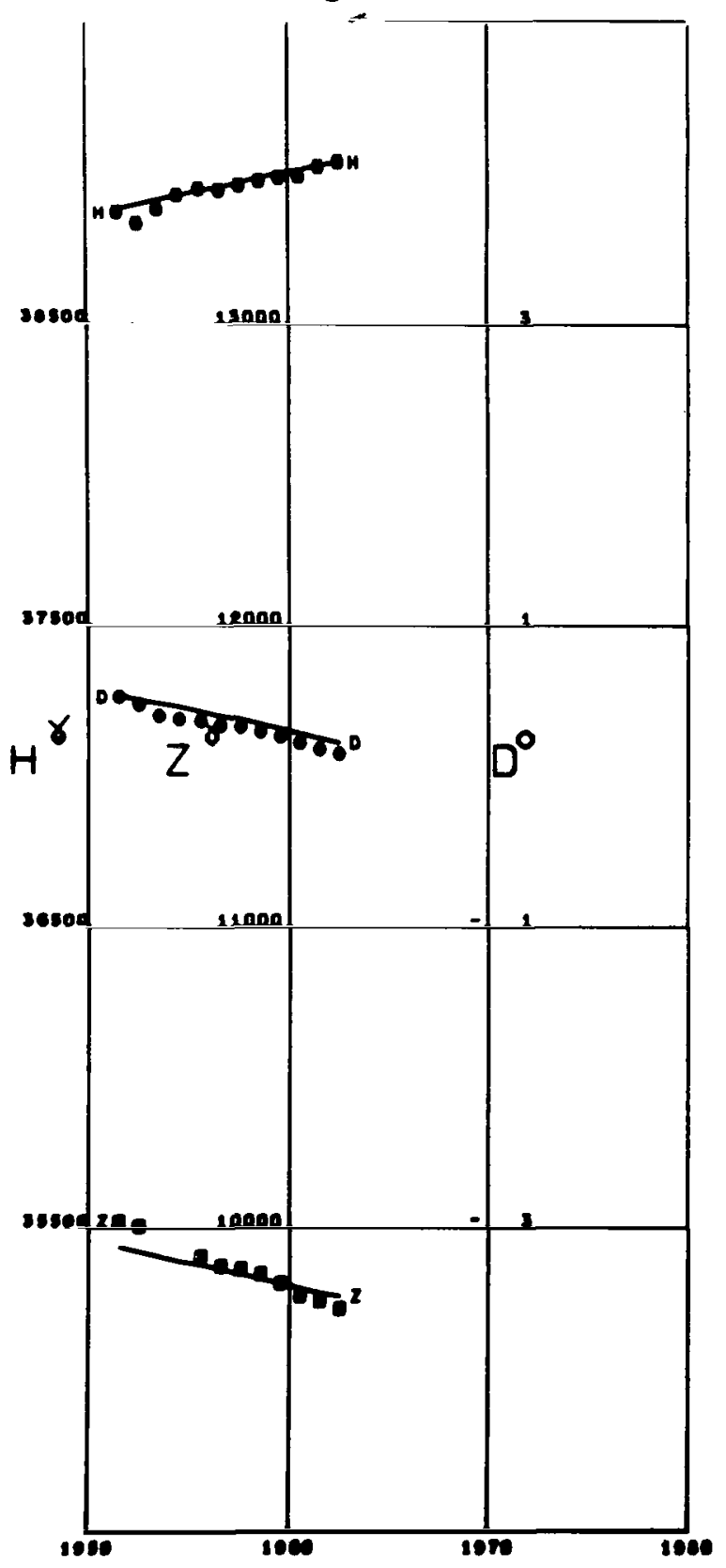

Figure A121 


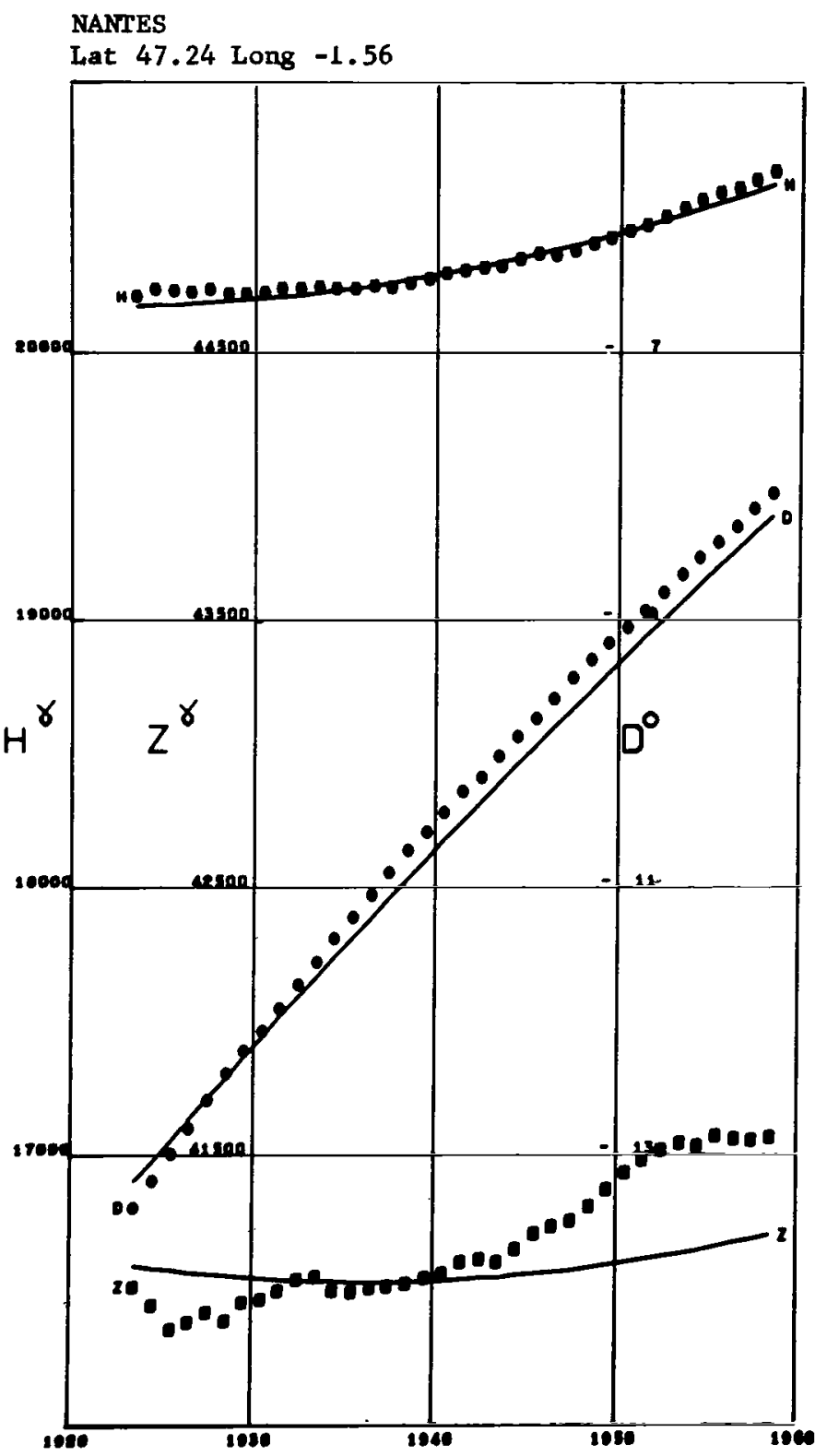

Figure A122
NEW YEARS ISLAND

Lat -54.65 Long -64.15

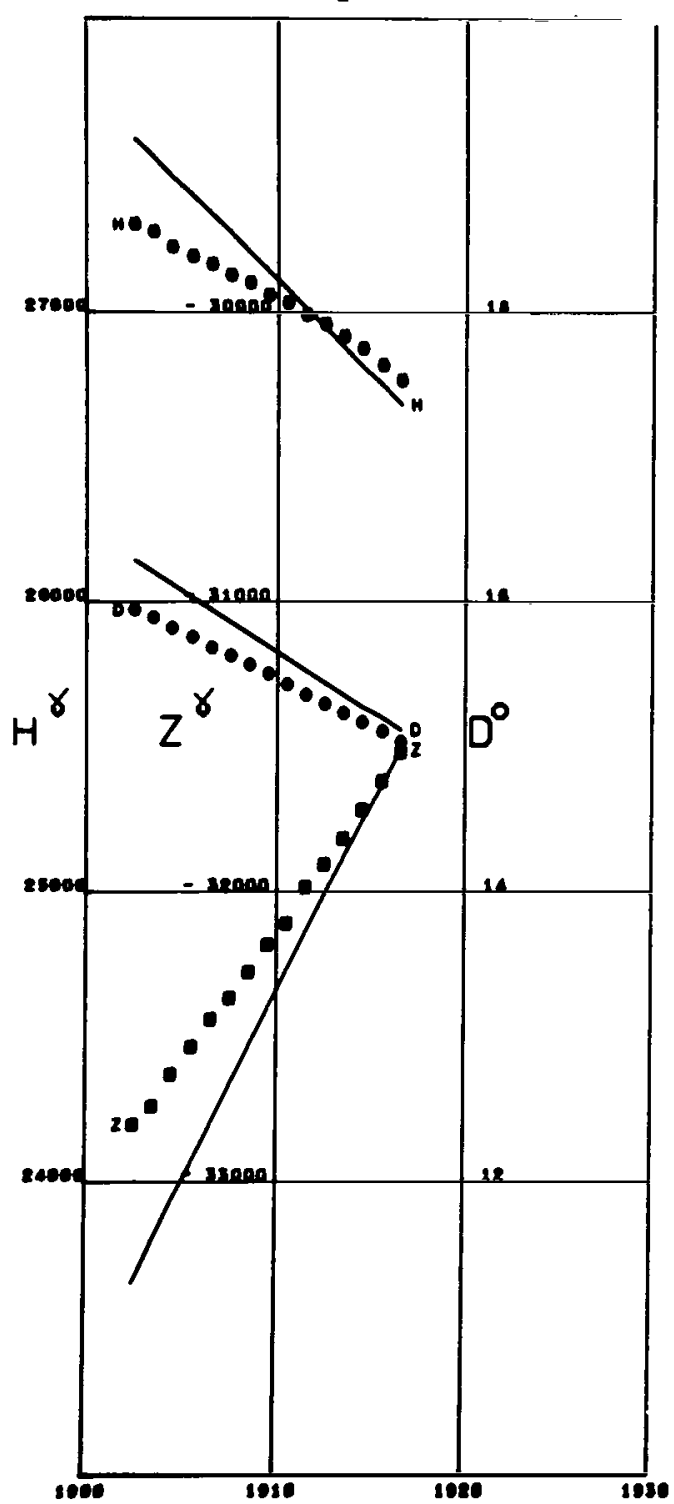

Figure A 123 


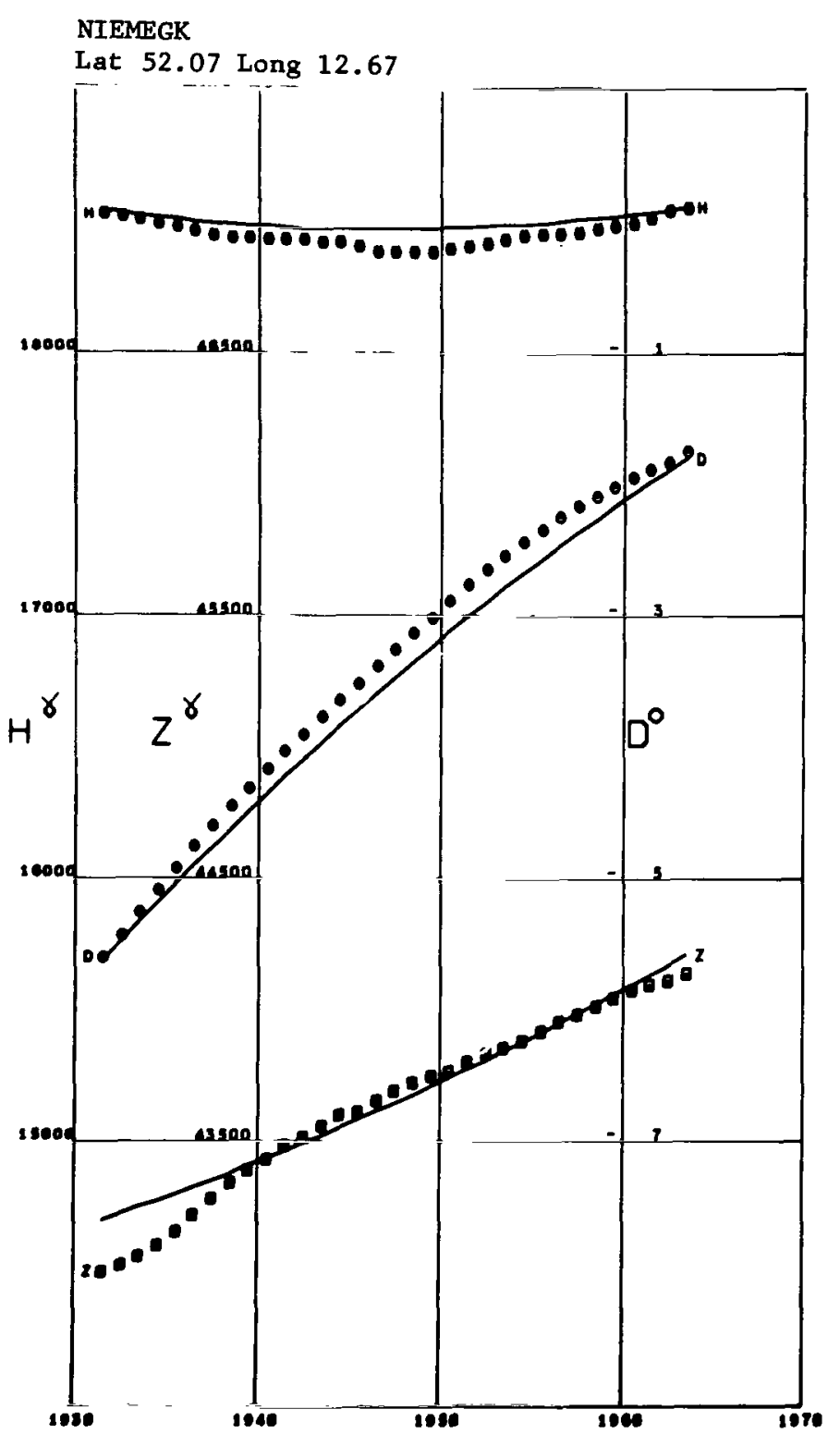

Figure A 124

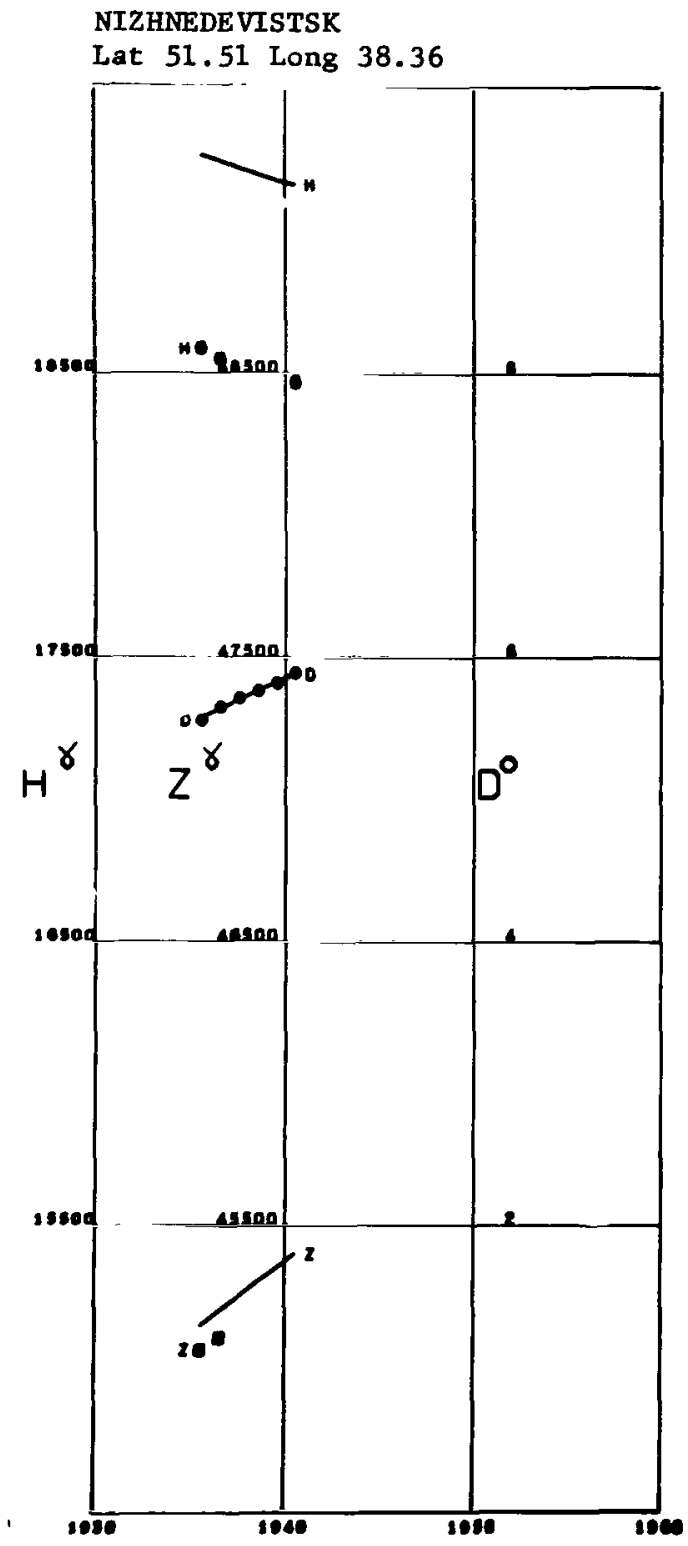

Figure A125 


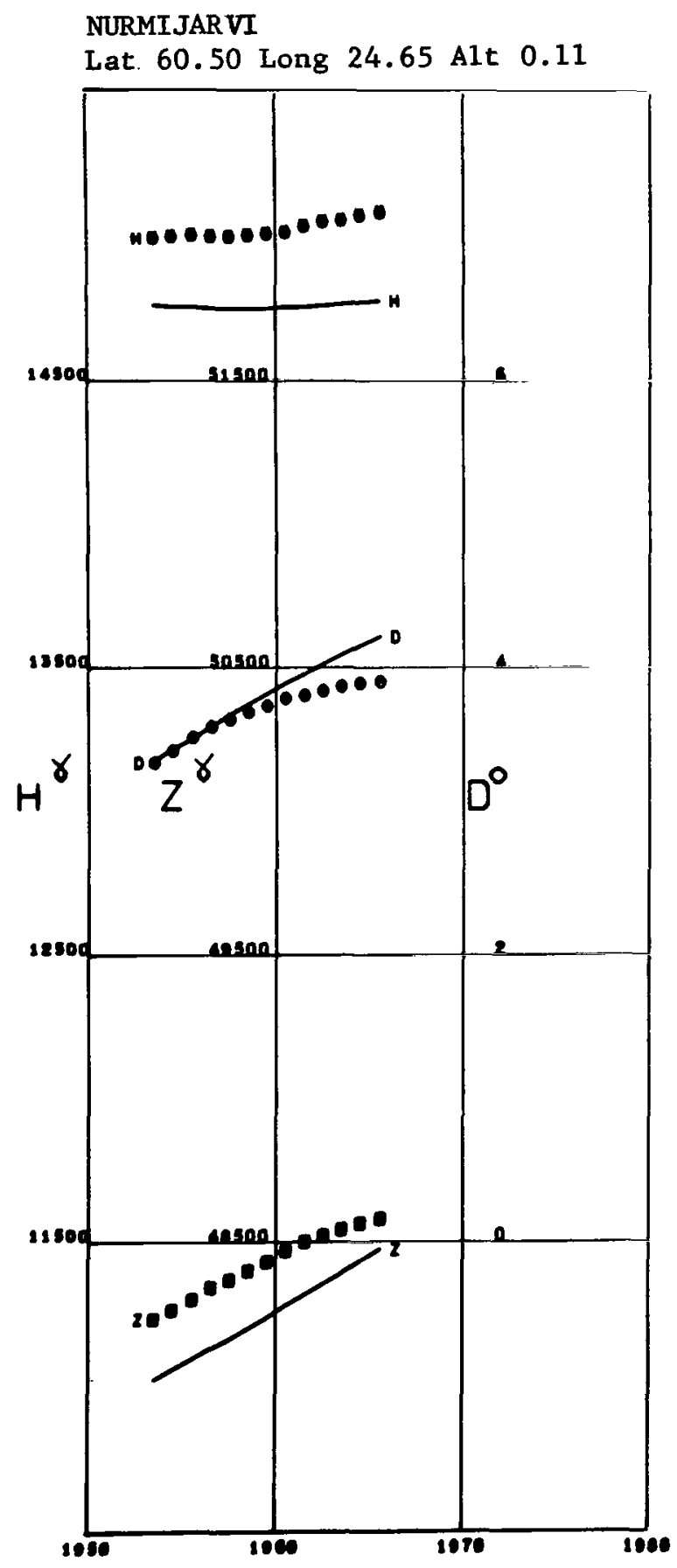

Figure A126
0 GYALLA PESTH

Lat 47.87 Long 18.19

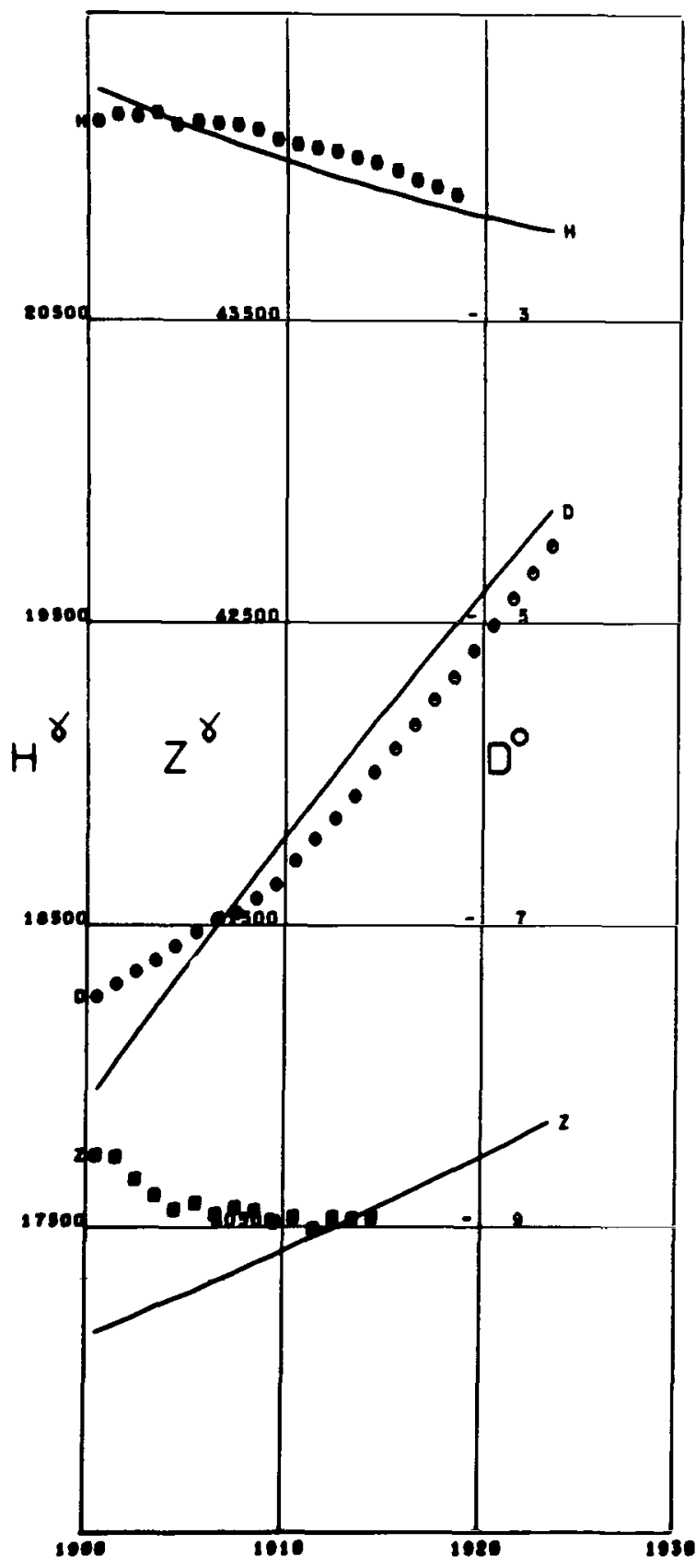

Figure A127 


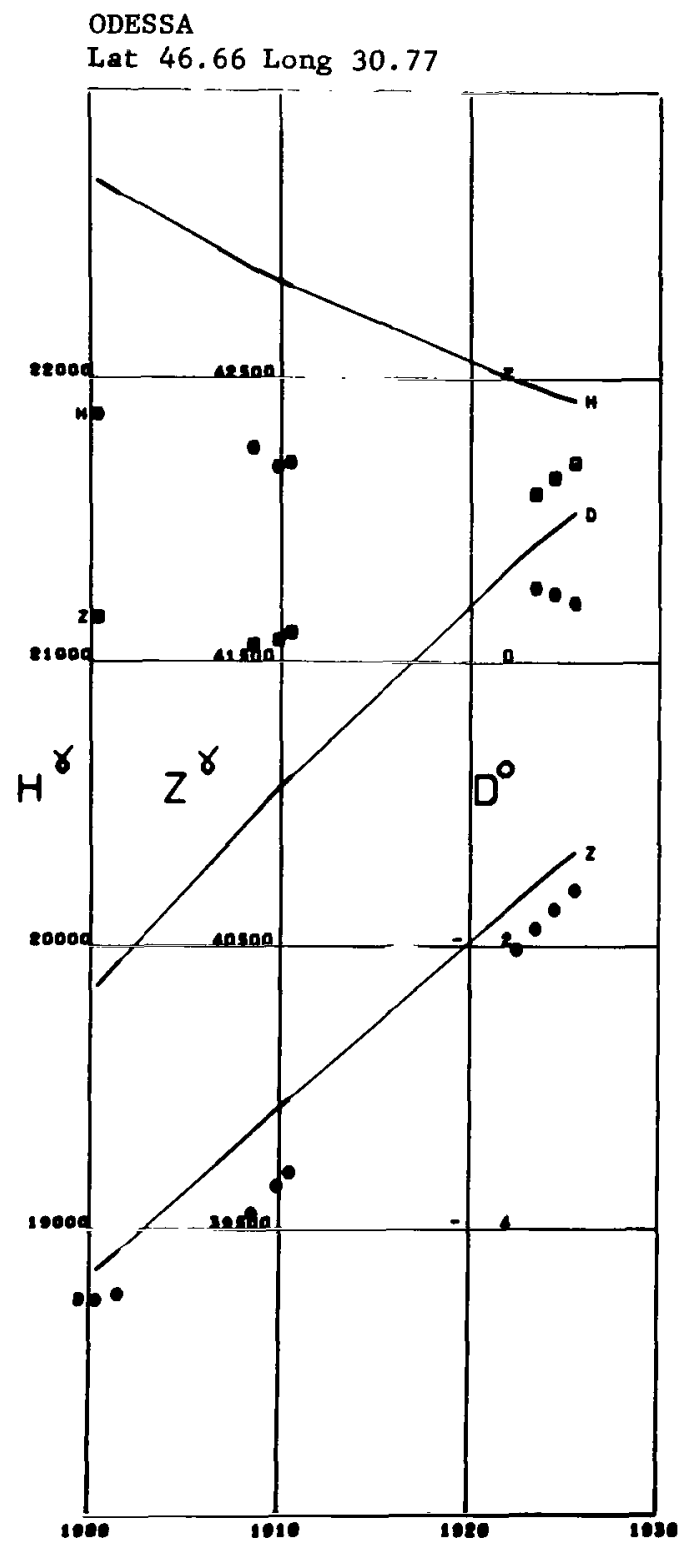

Figure A128

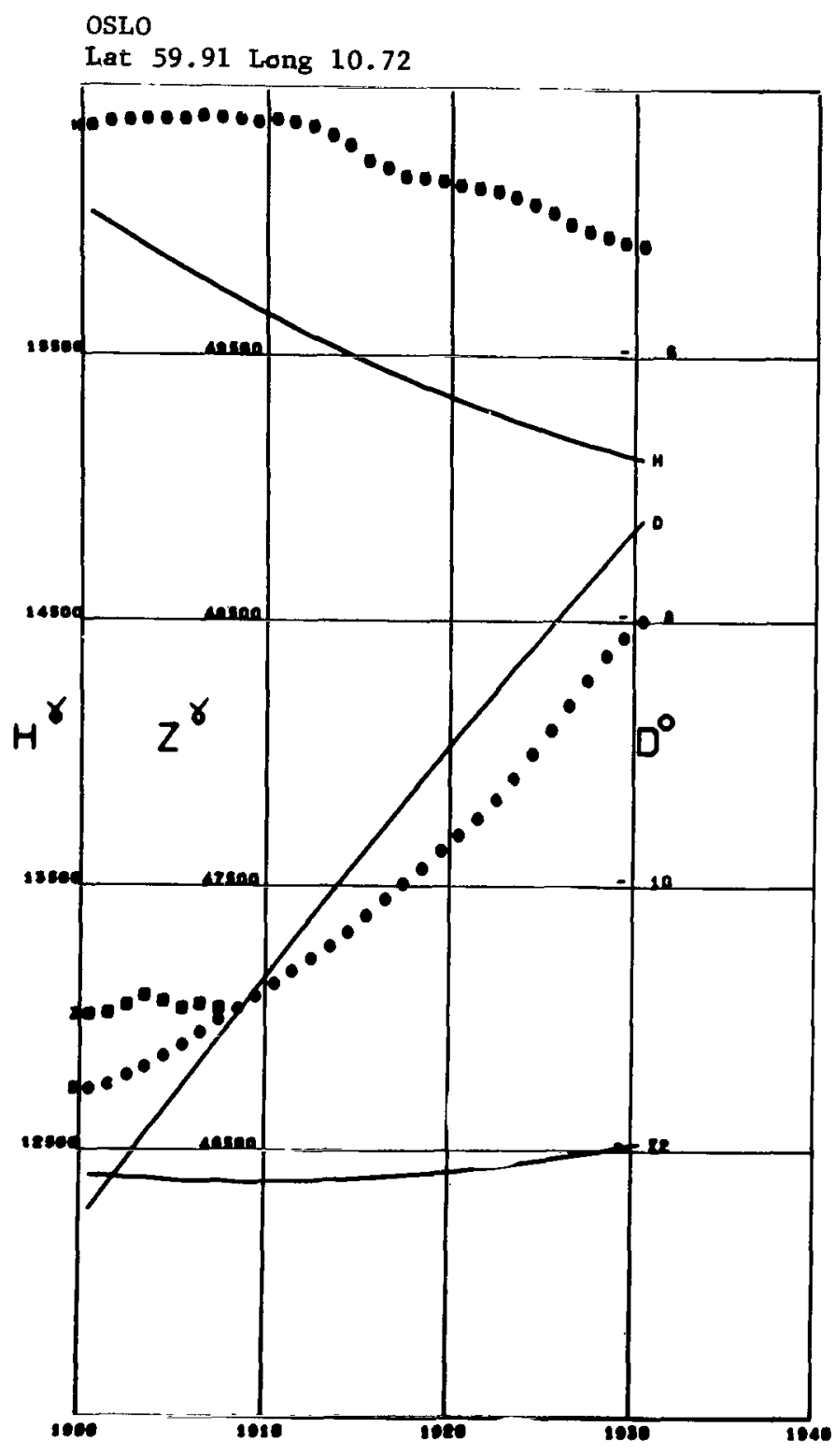

Figure A129 


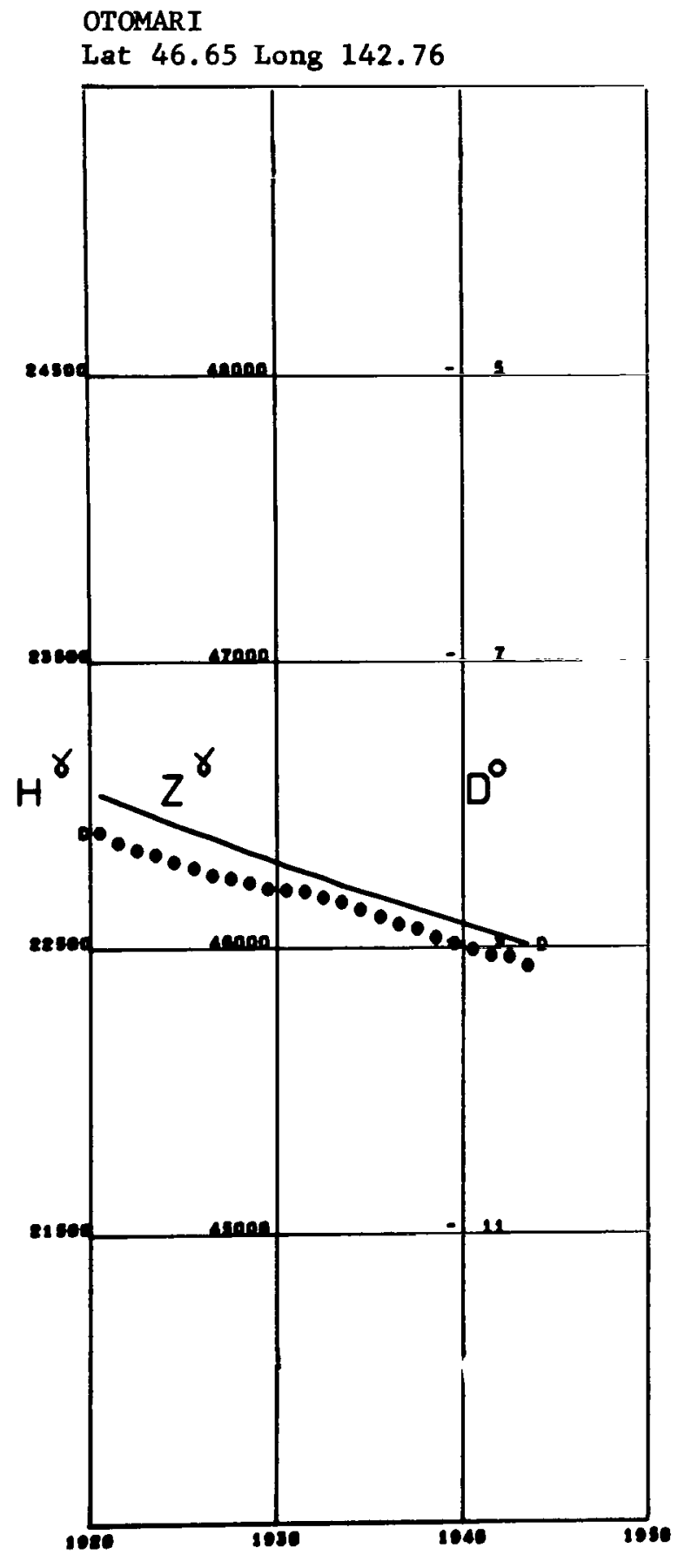

Figure $A 130$
PALAU

Lat 7.33 Long 134.48

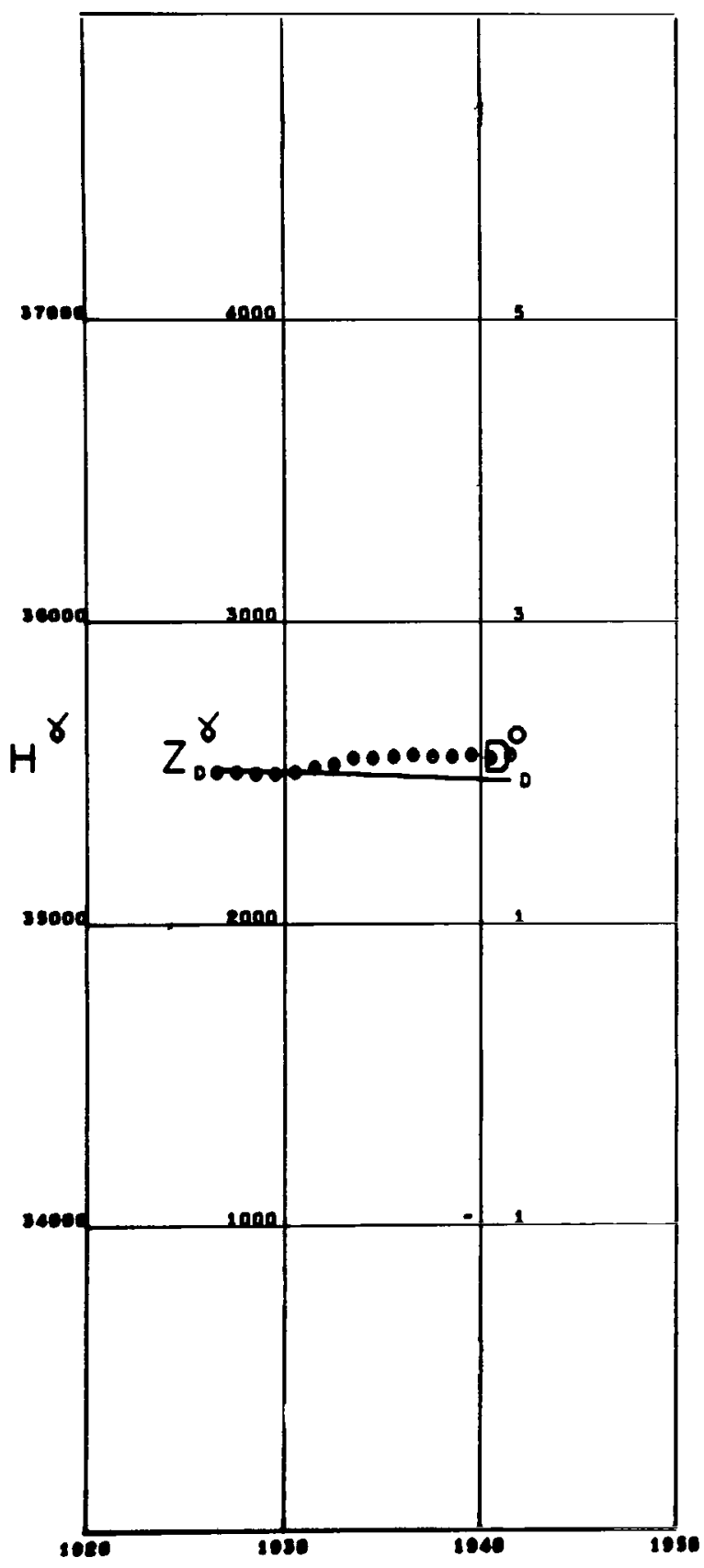

Figure A131 
PANAGYURISHTE

Lat 42.51 Long 24.18

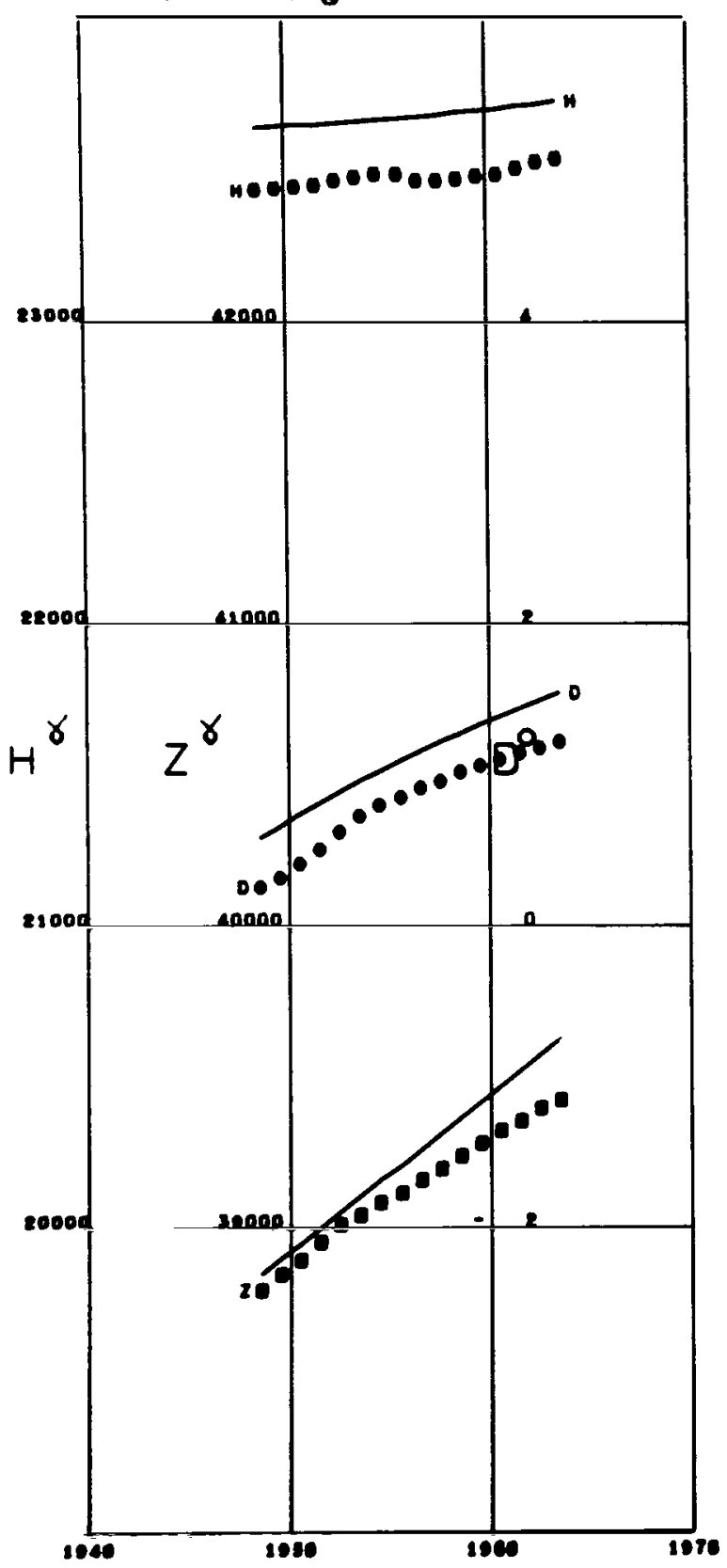

Figure A132
PARAMARIBO

Lat 5.81 Long -55.22 Alt 0.10

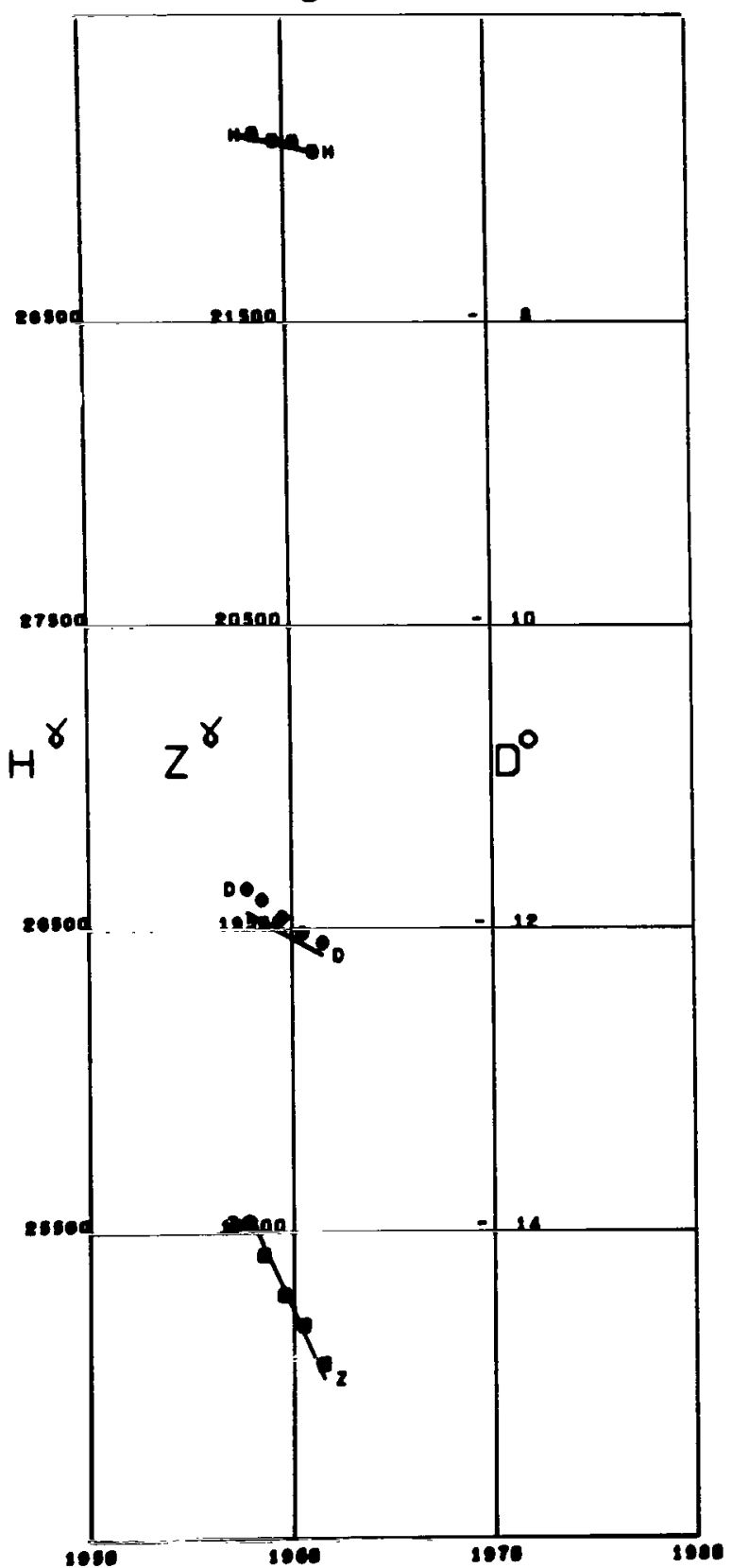

Figure A133 


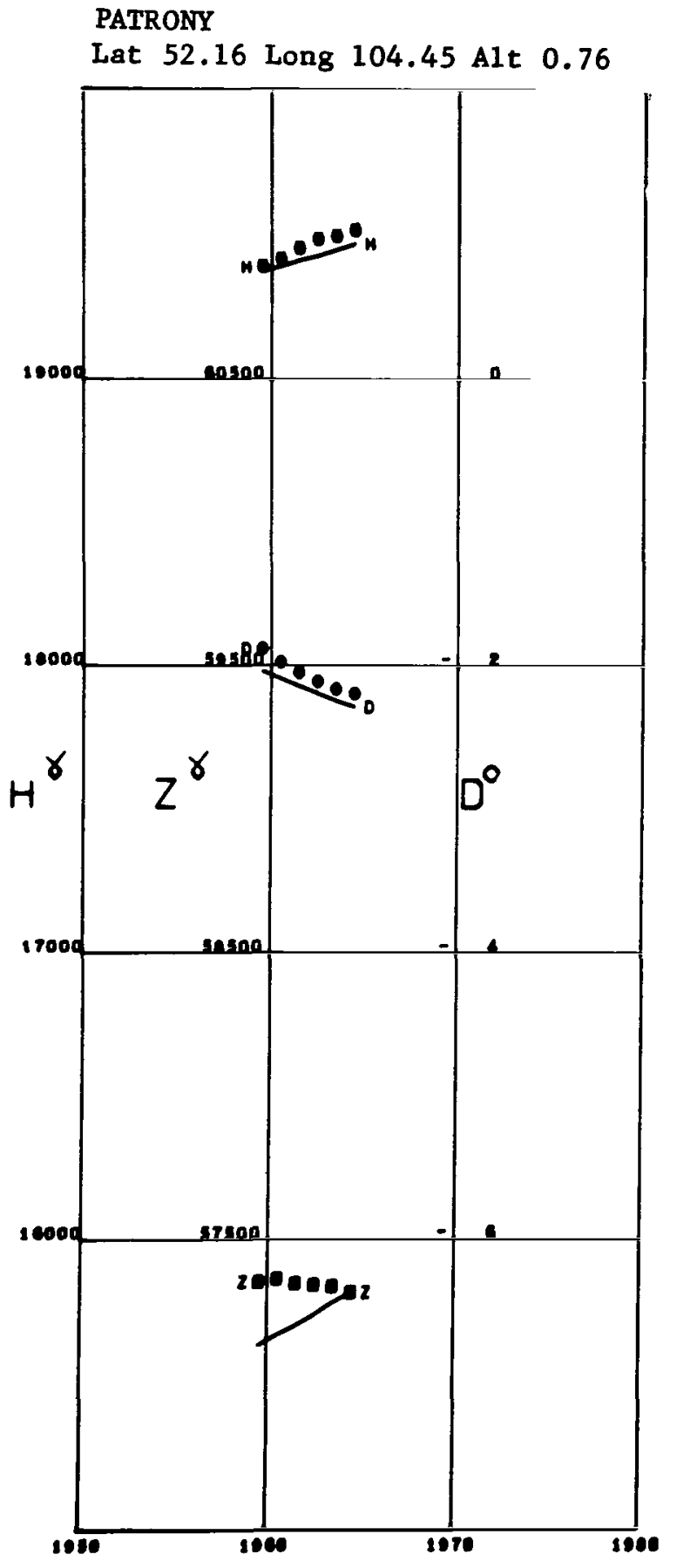

Figure A134
PER PIGNAN

Lat 42.70 Long 2.88

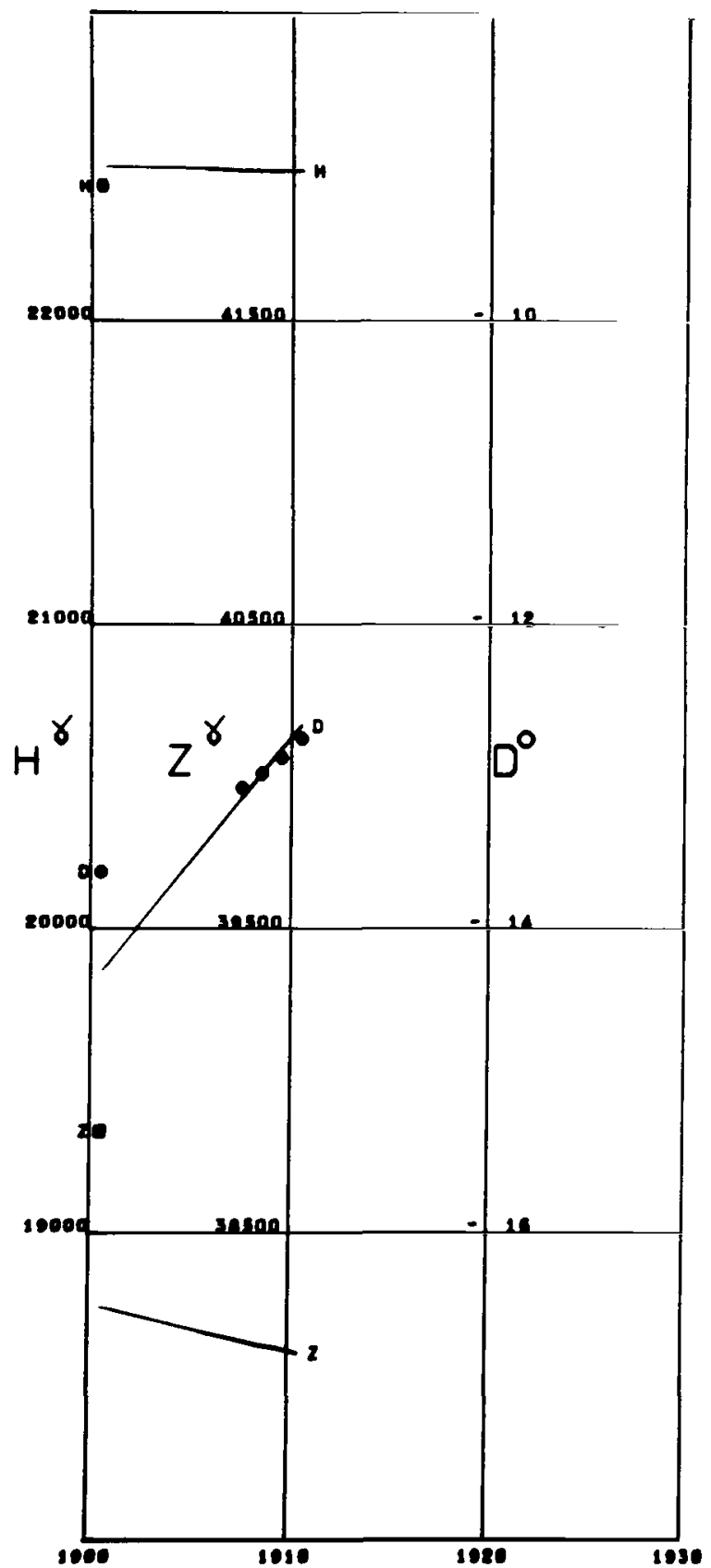

Figure A135 


\section{PILAR}

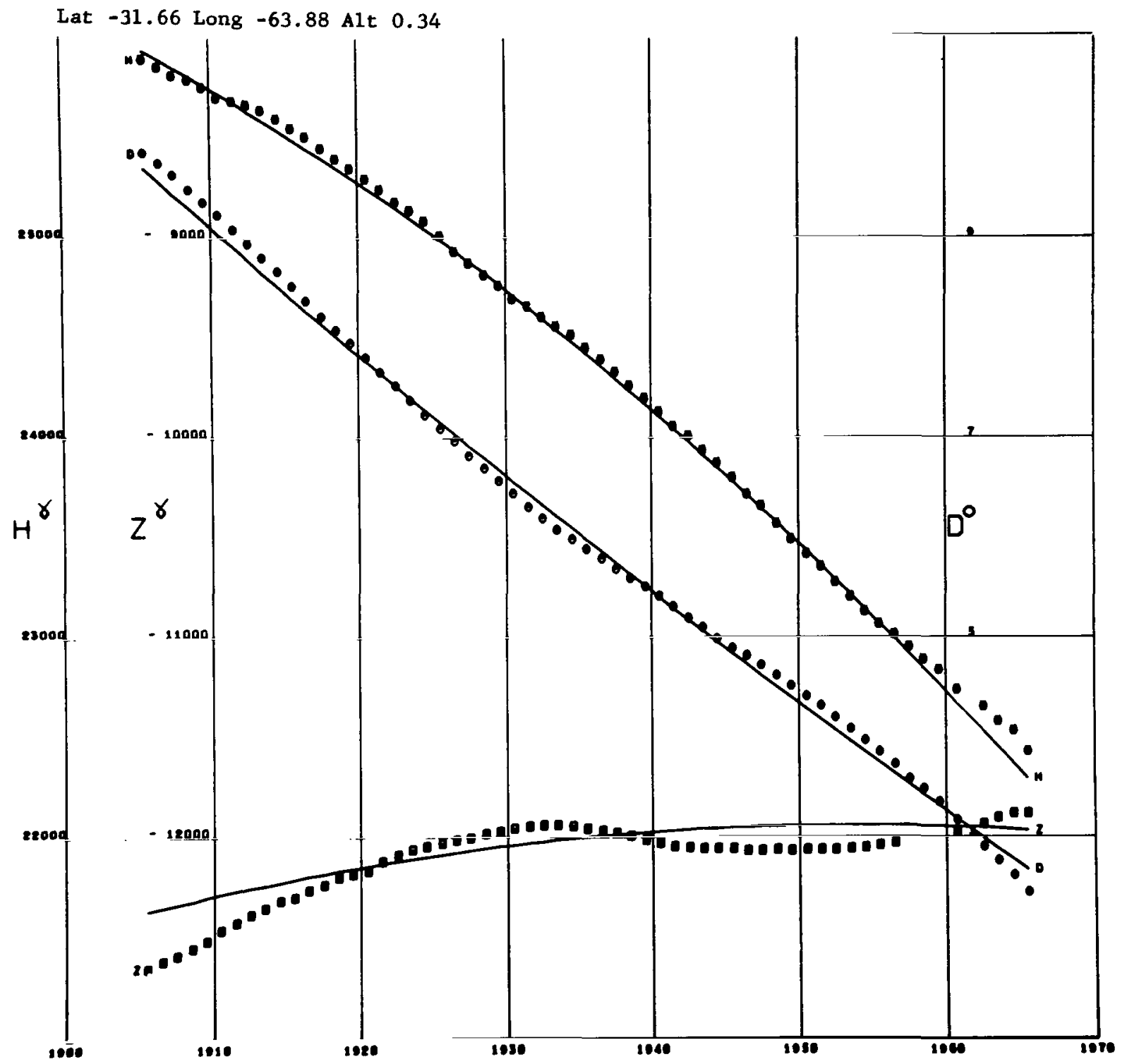

Figure A136 


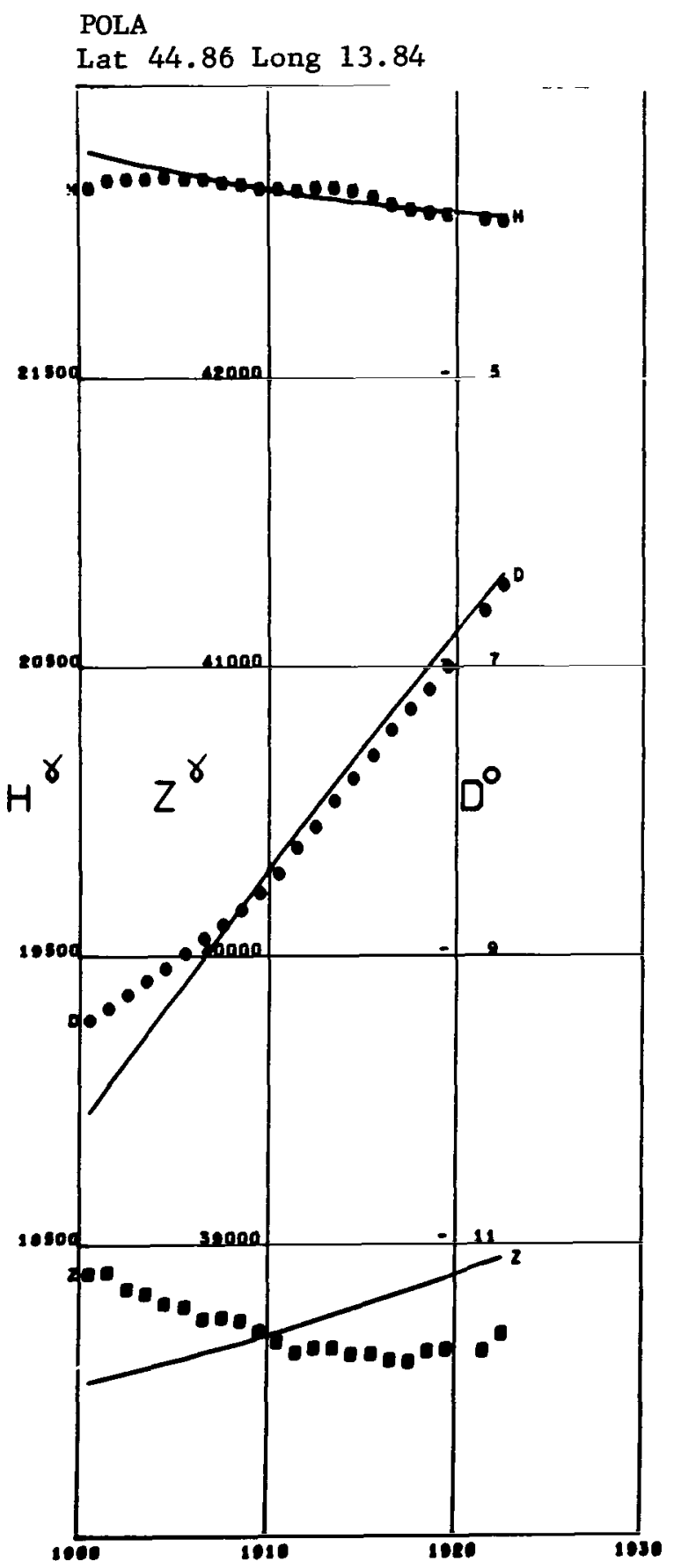

Figure A137

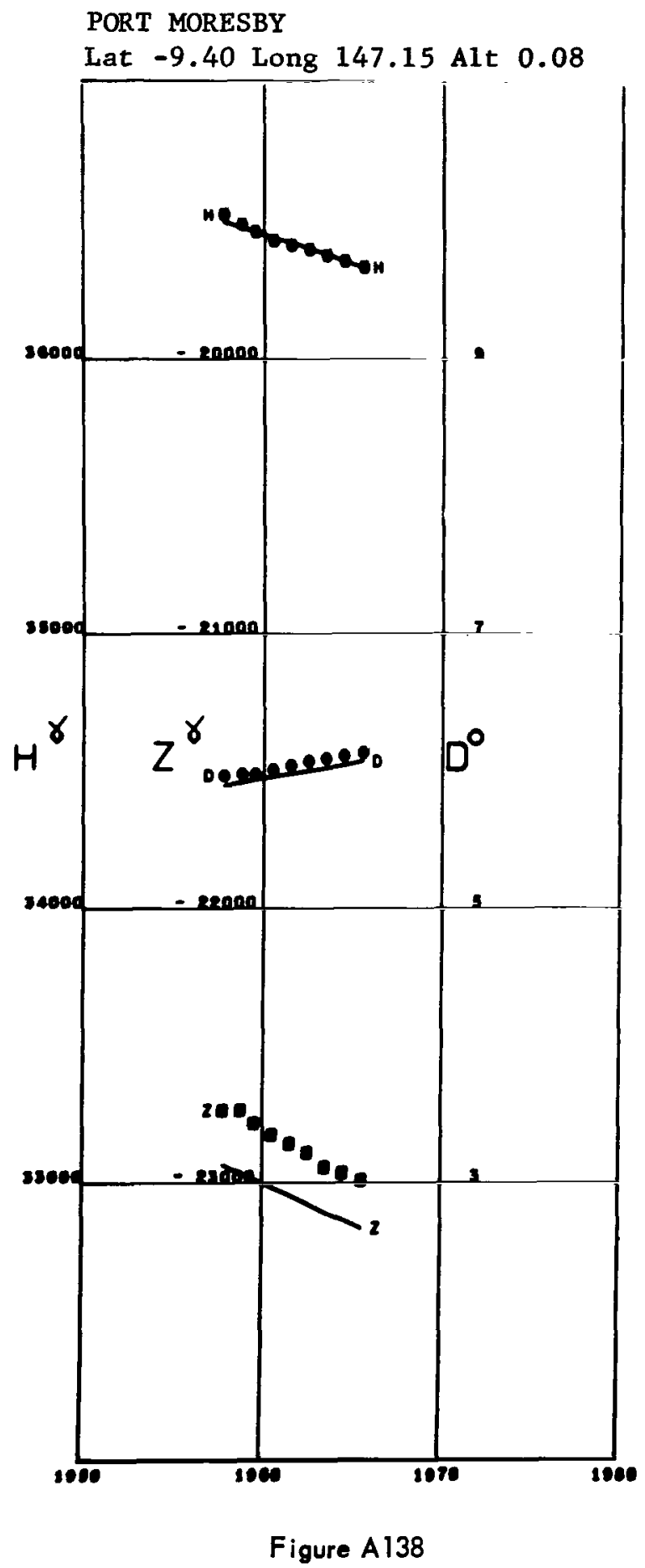

PORT MORESBY 
POTSDAM

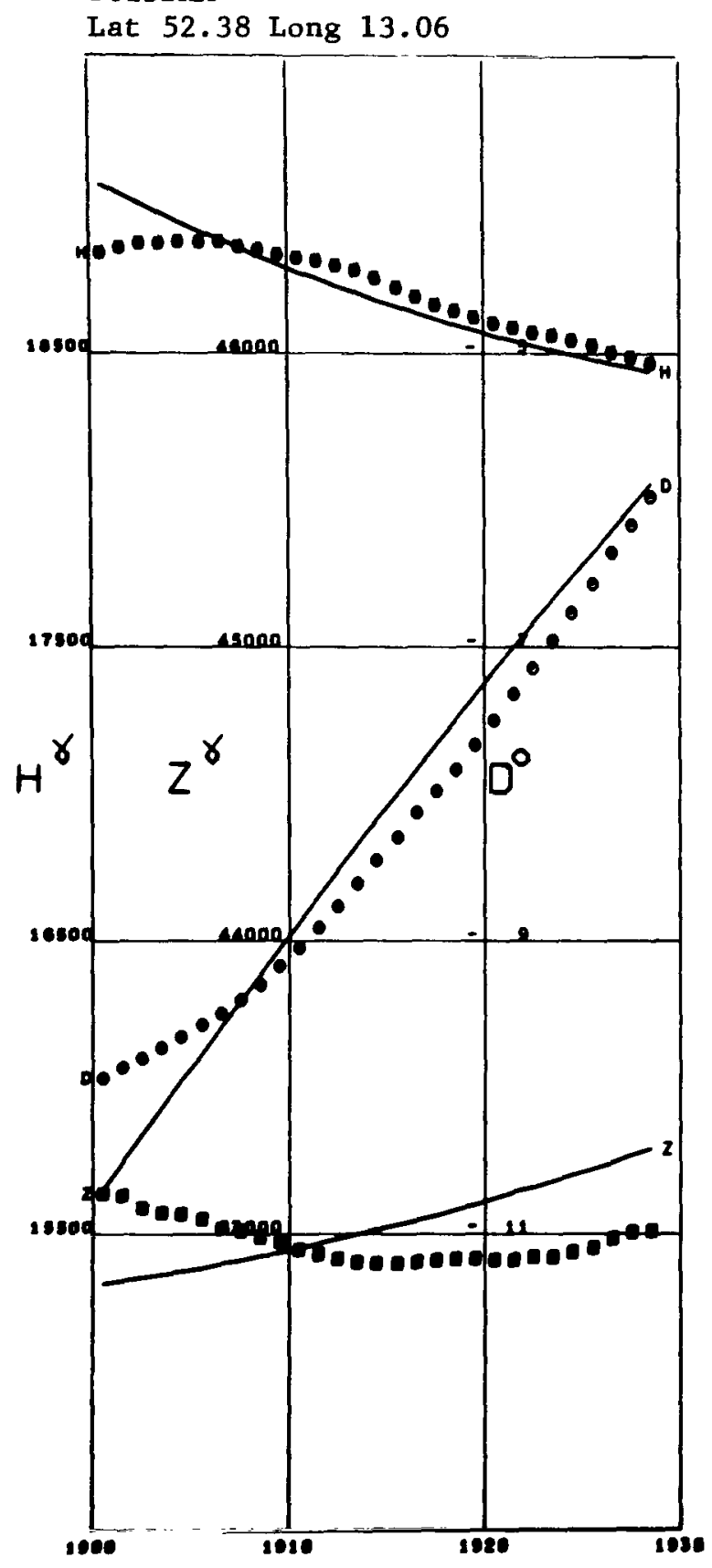

Figure A139
PRAGUE

Lat 50.08 Long 14.41

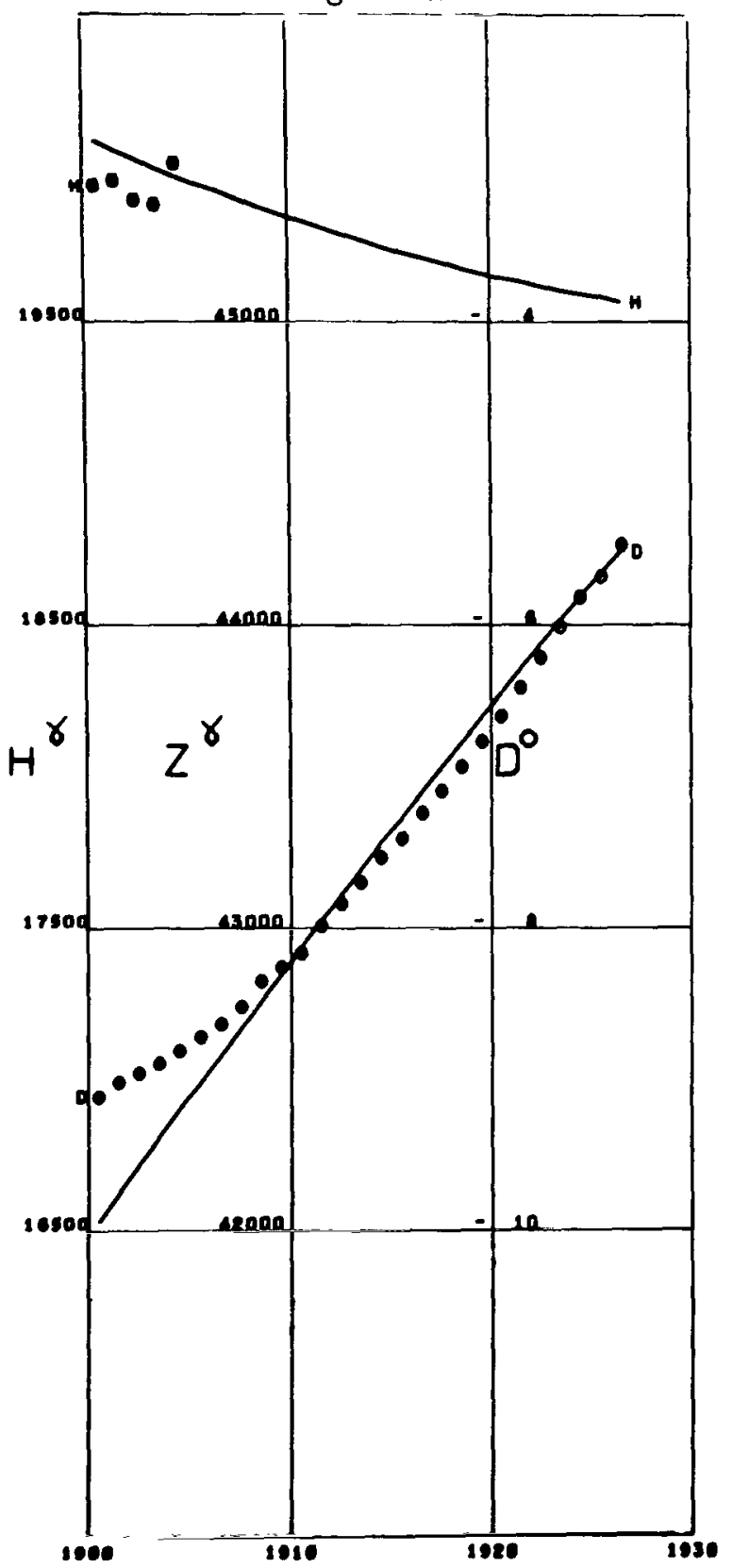

Figure A140 
PRUHONICE

Lat 49.99 Long 14.54

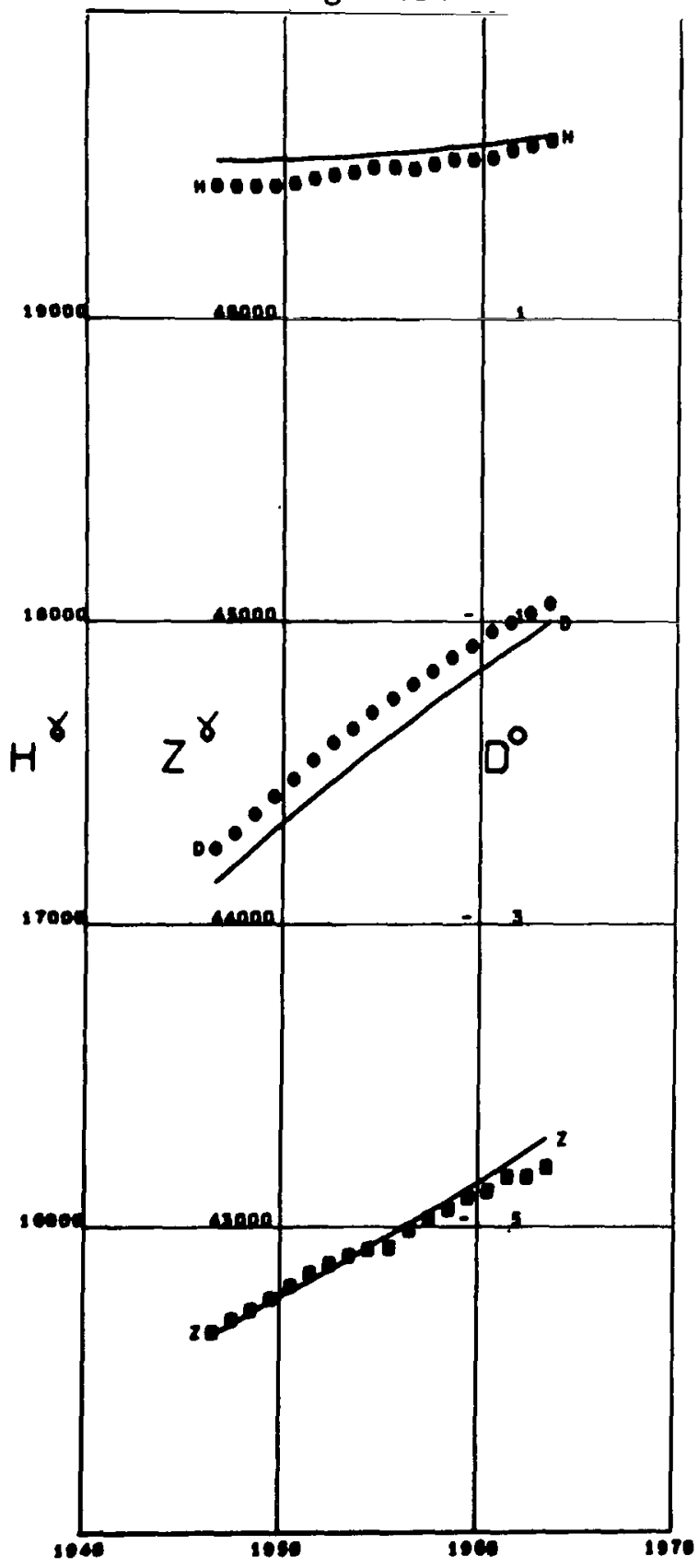

Figure A141
QUETTA

Lat 30.18 Long 66.95

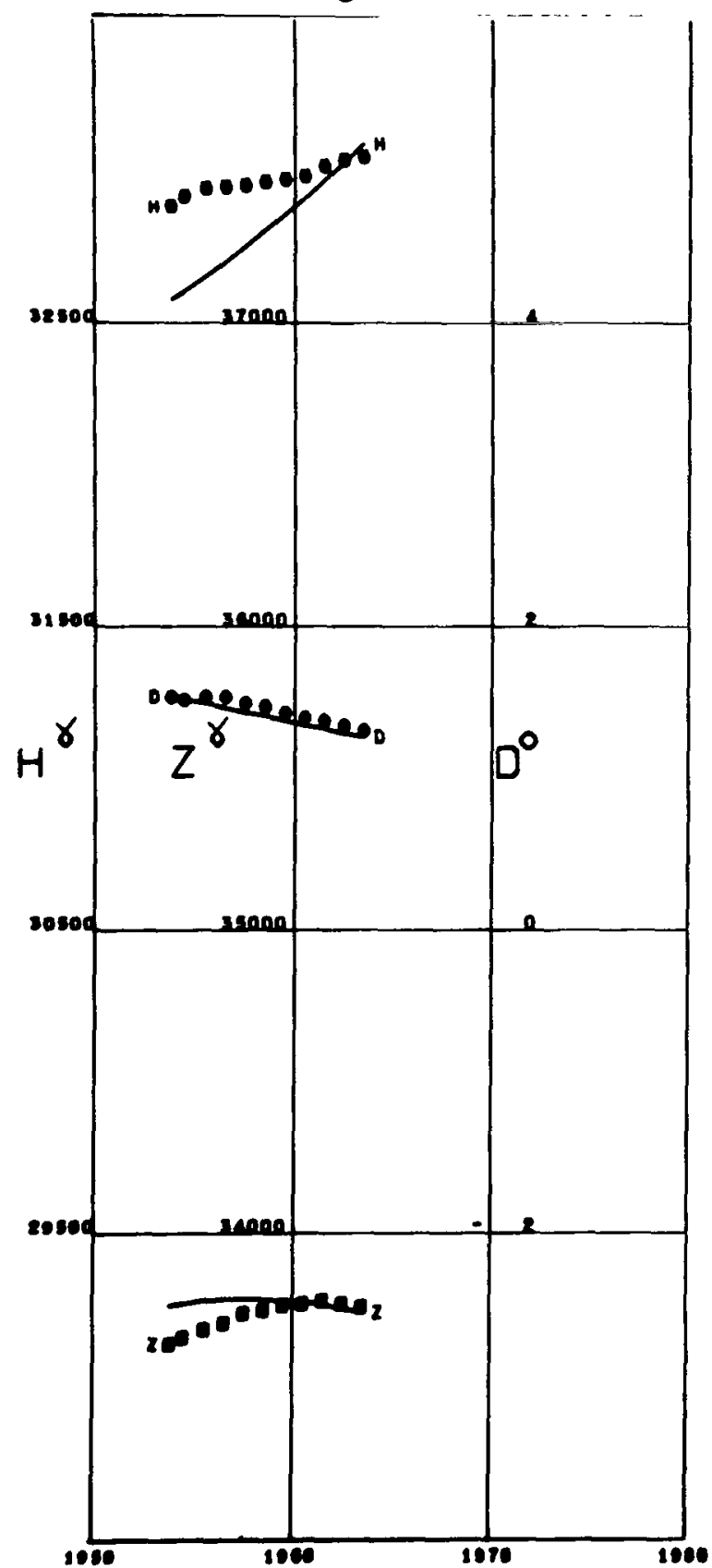

Figure A142 


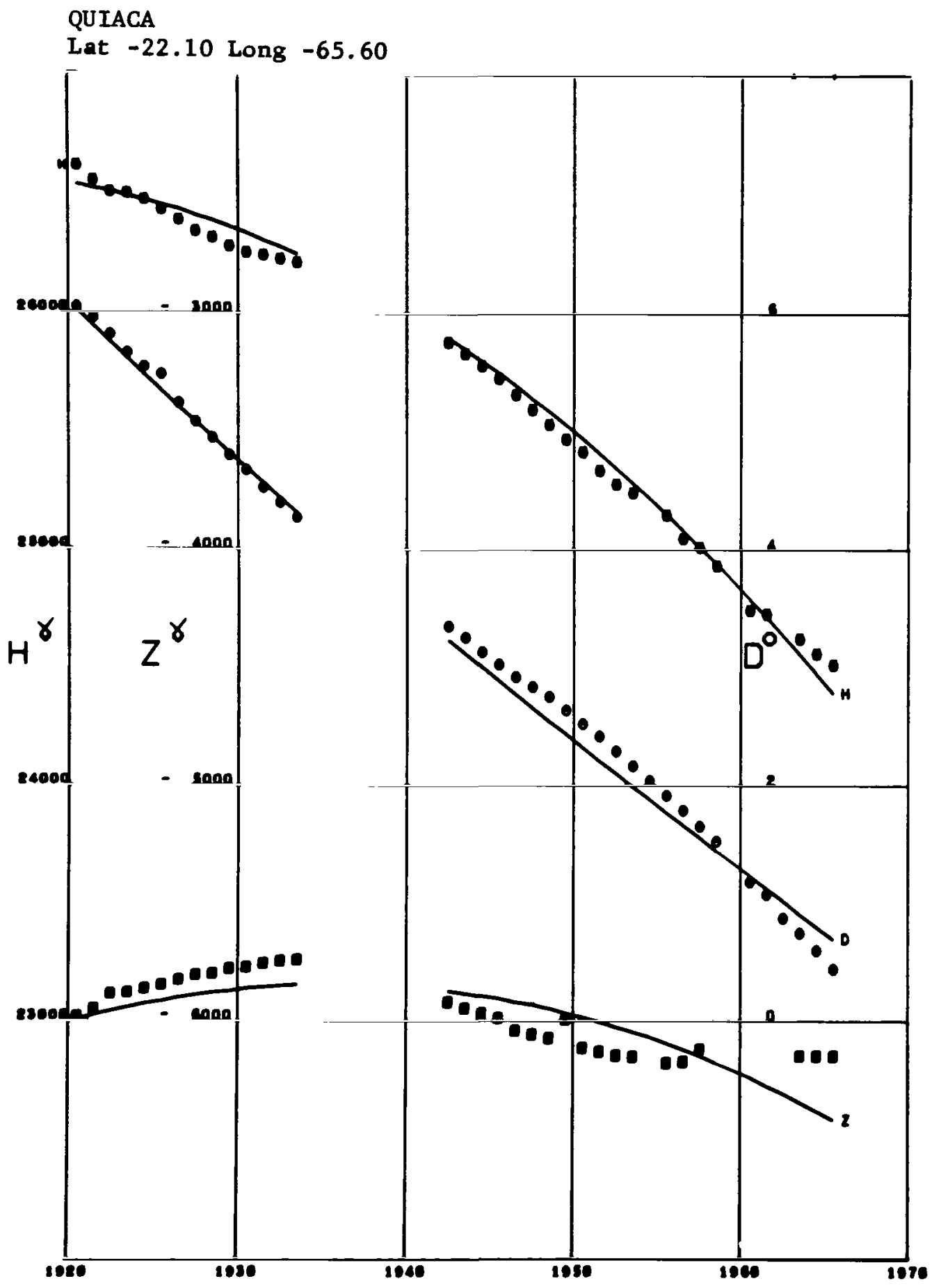

Figure A143 


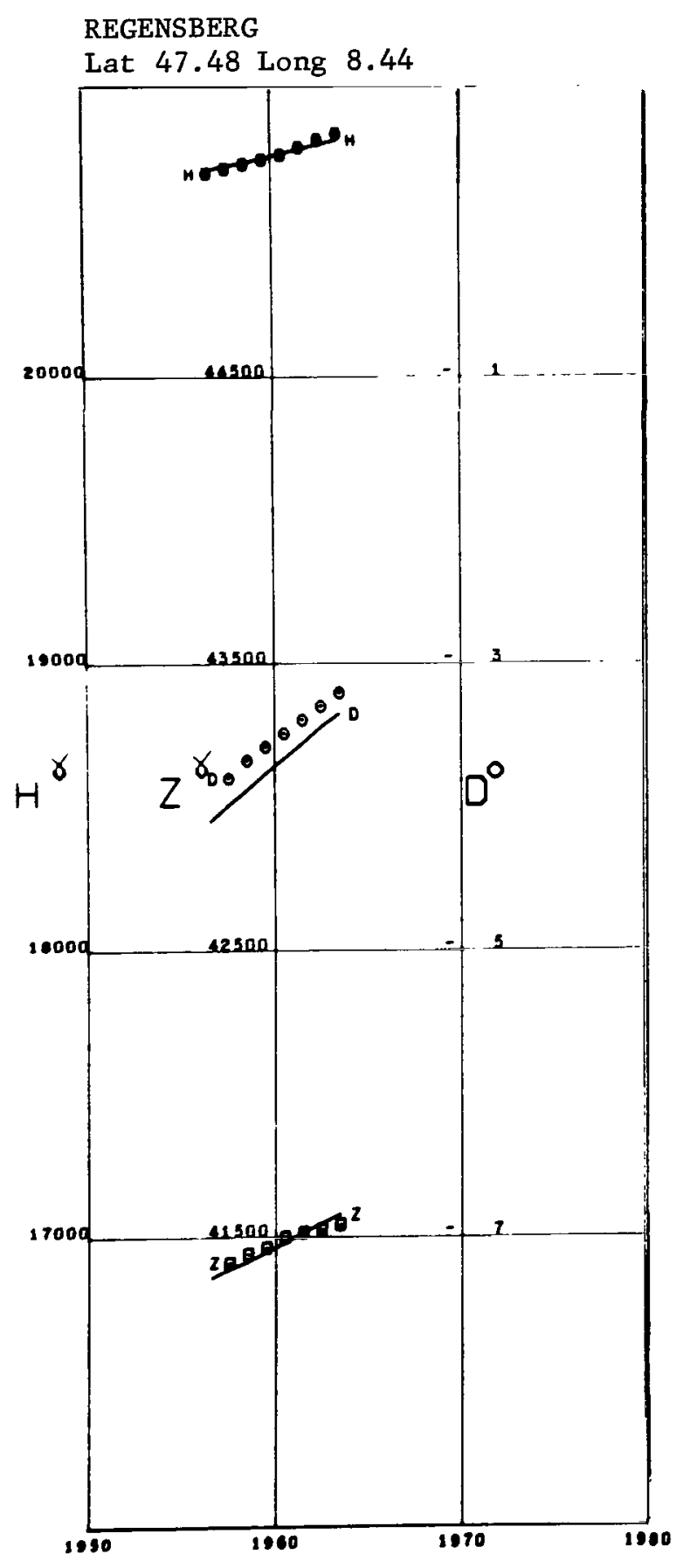

Figure A144

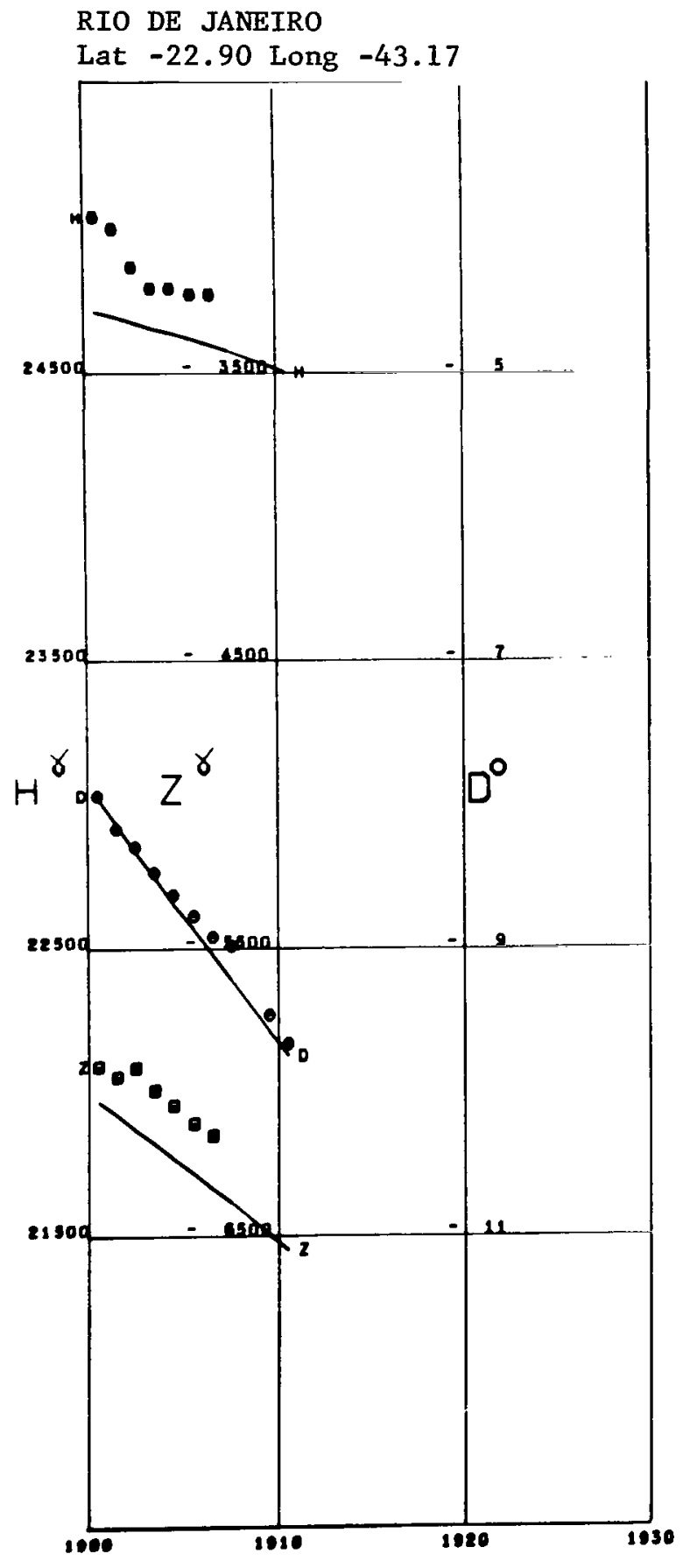

Figure A145 


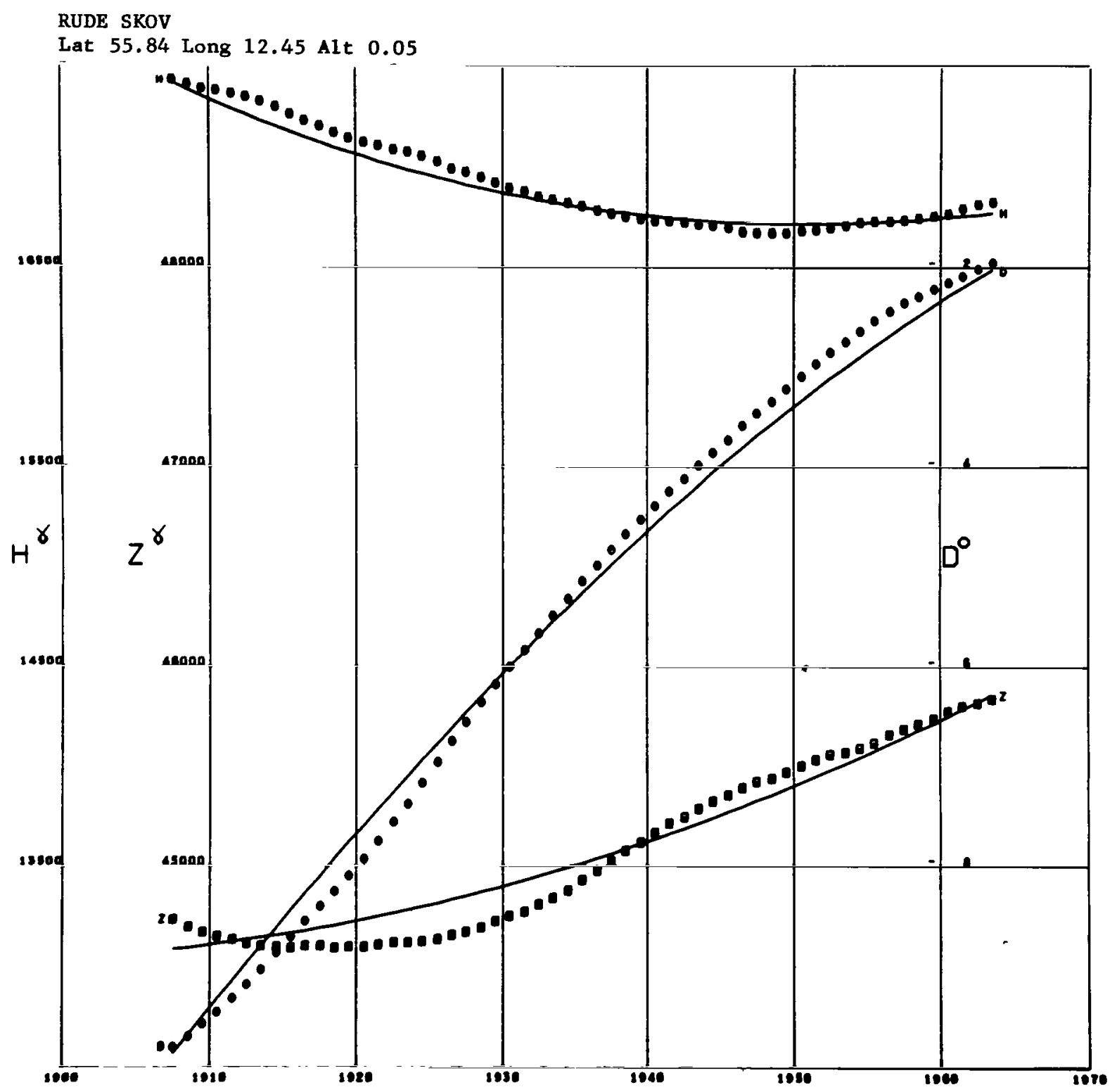

Figure A146 


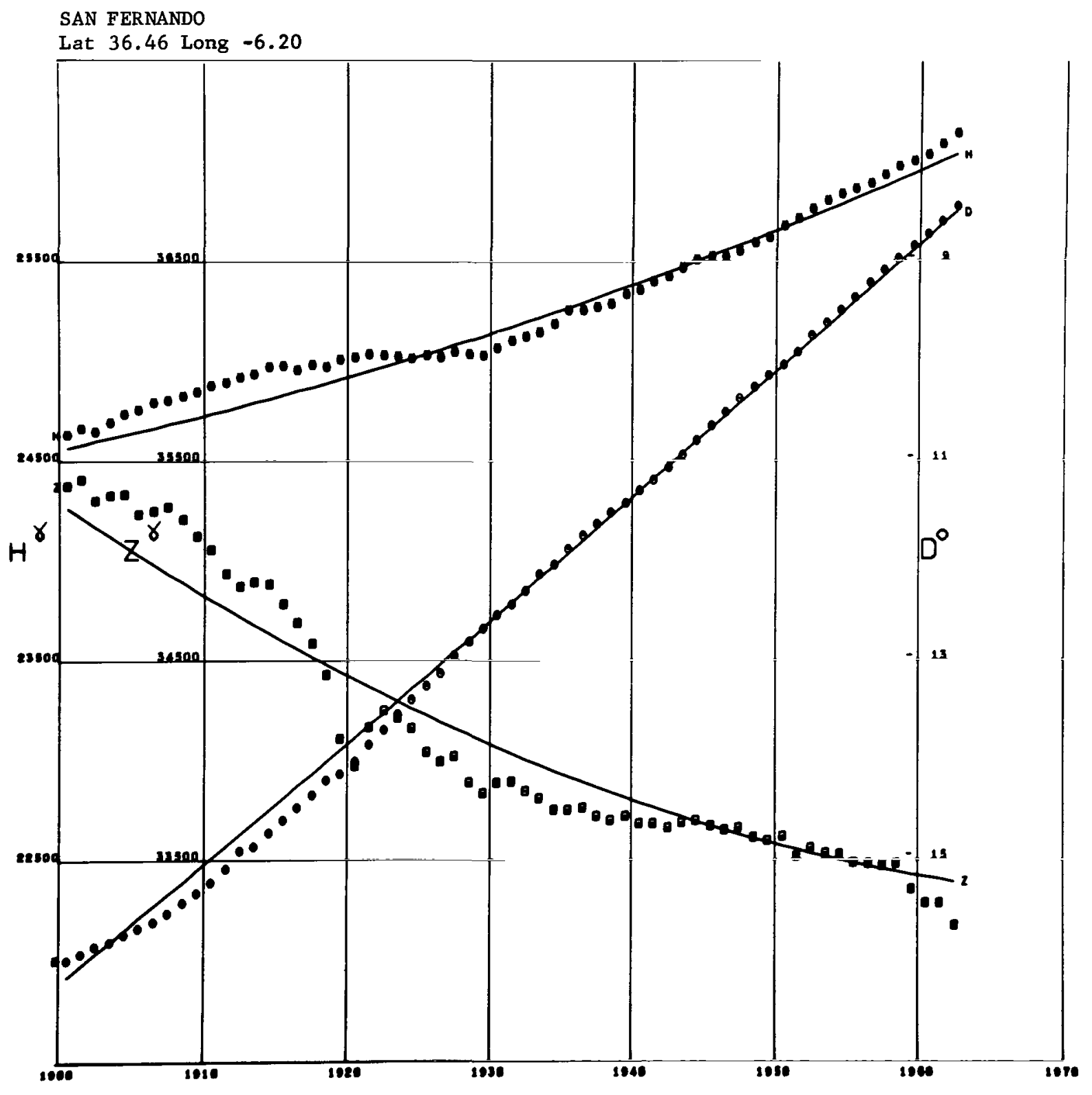

Figure A147 
SAN JUAN

Lat 18.11 Long -66.15 Alt 0.40

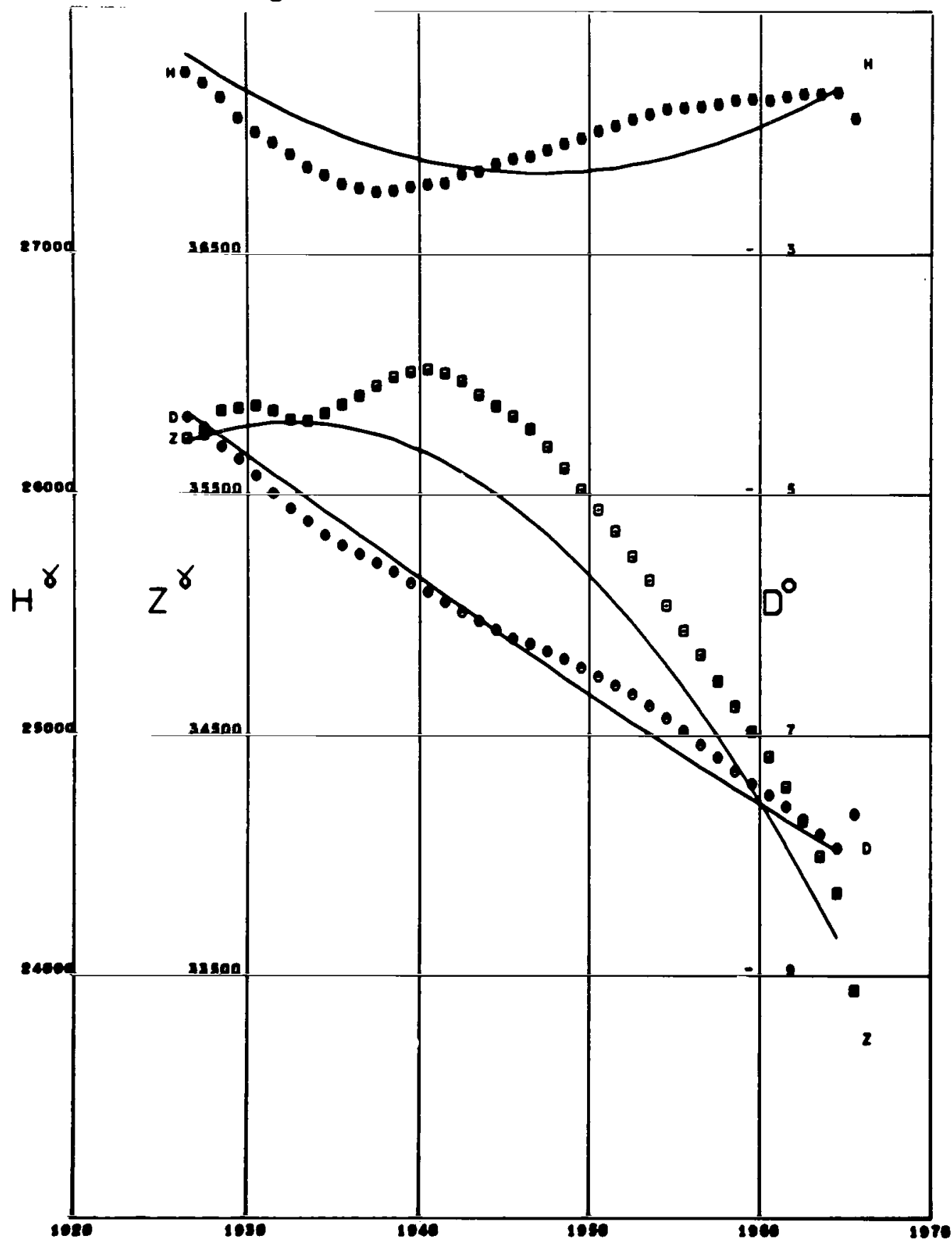

Figure A148 
SAN MIGUEL

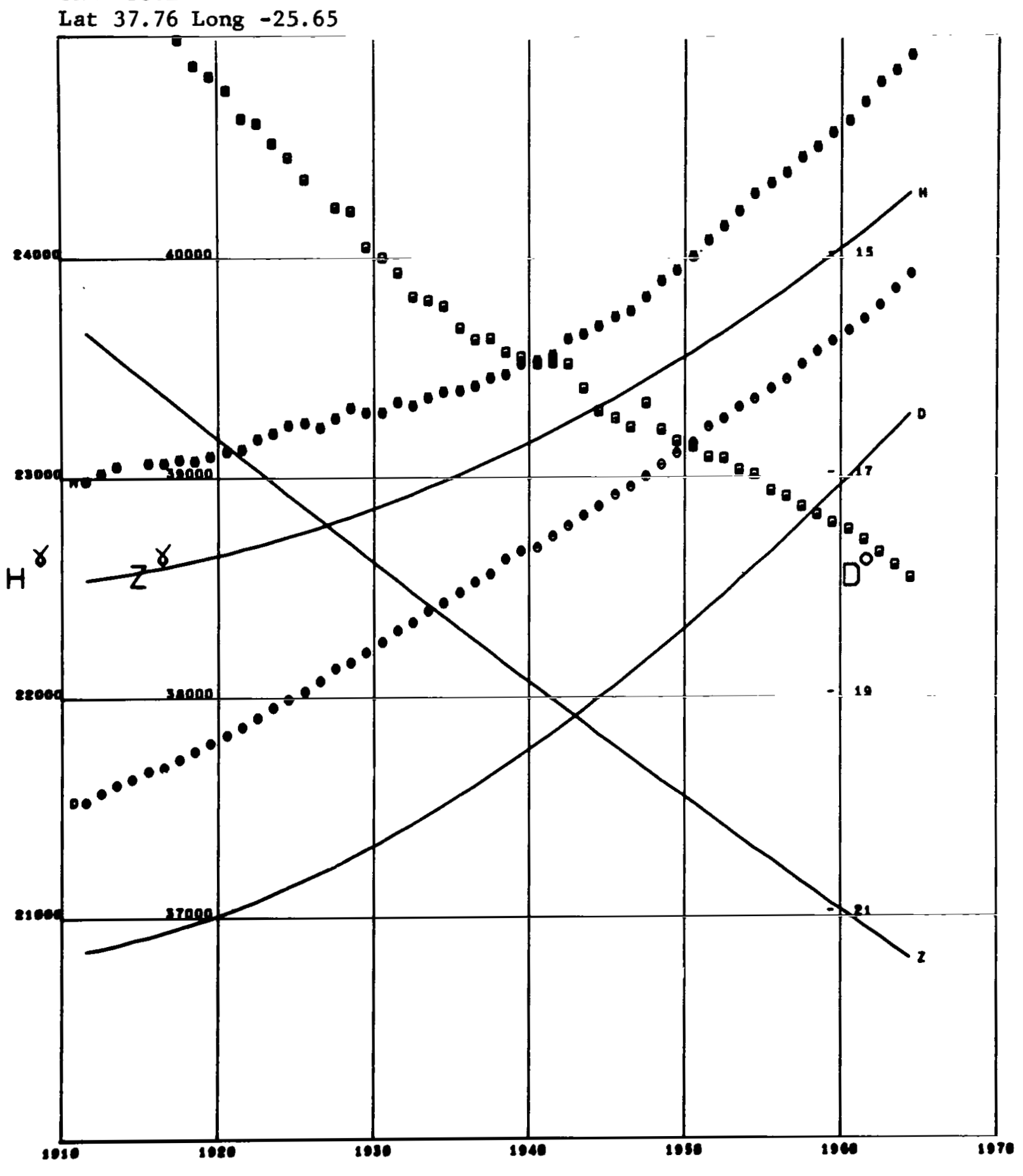

Figure A 149 


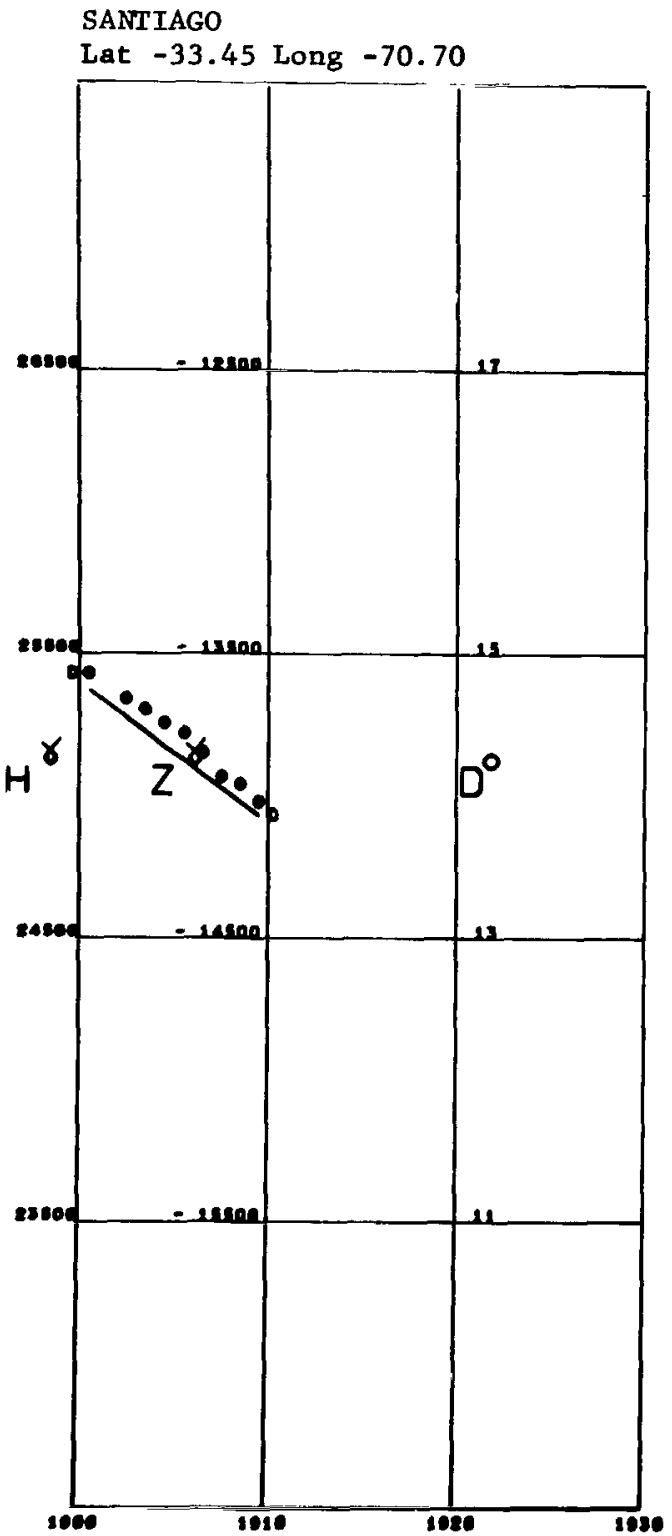

Figure A150
SEDDIN

Lat 52.27 Long 13.01

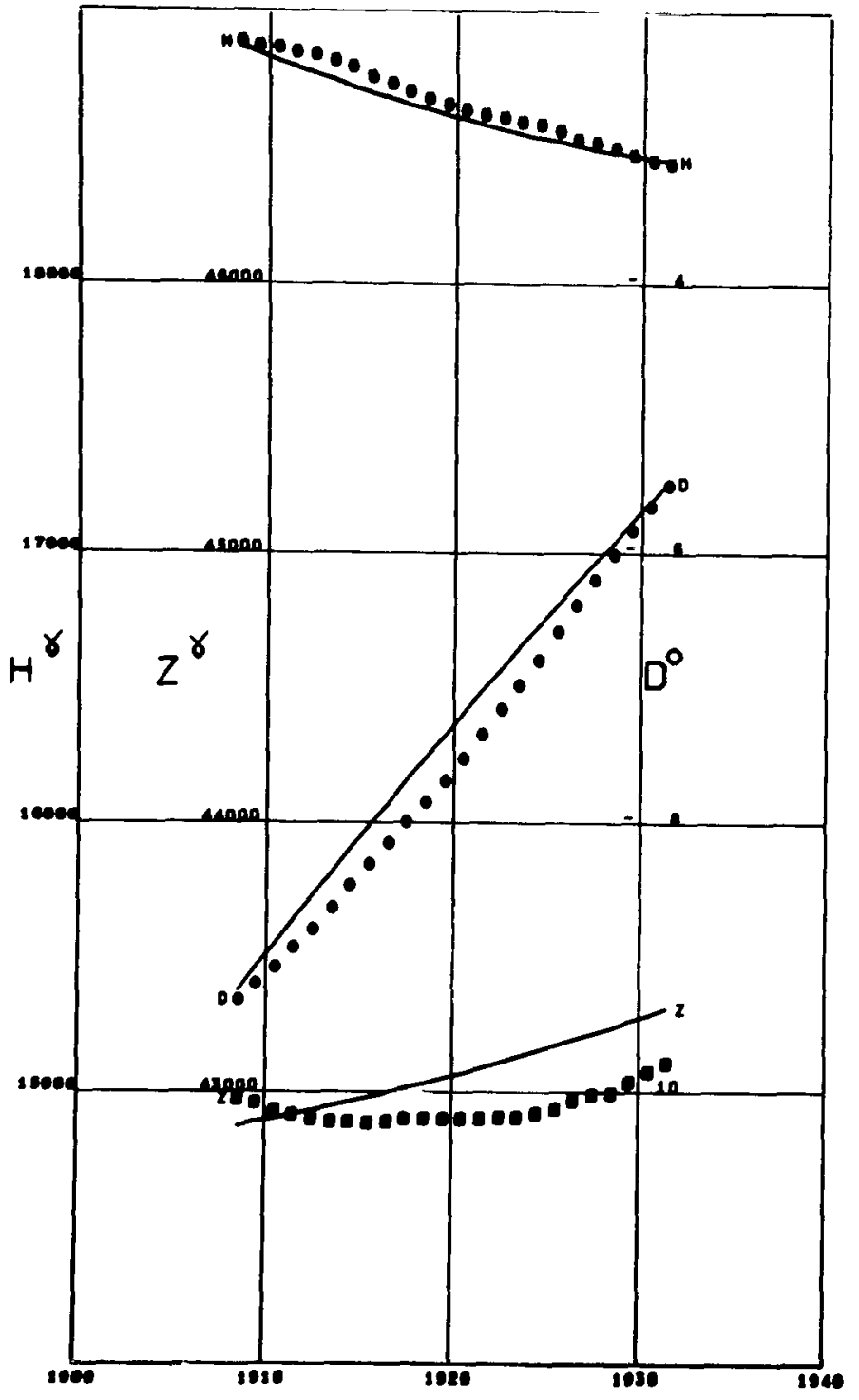

Figure A151 


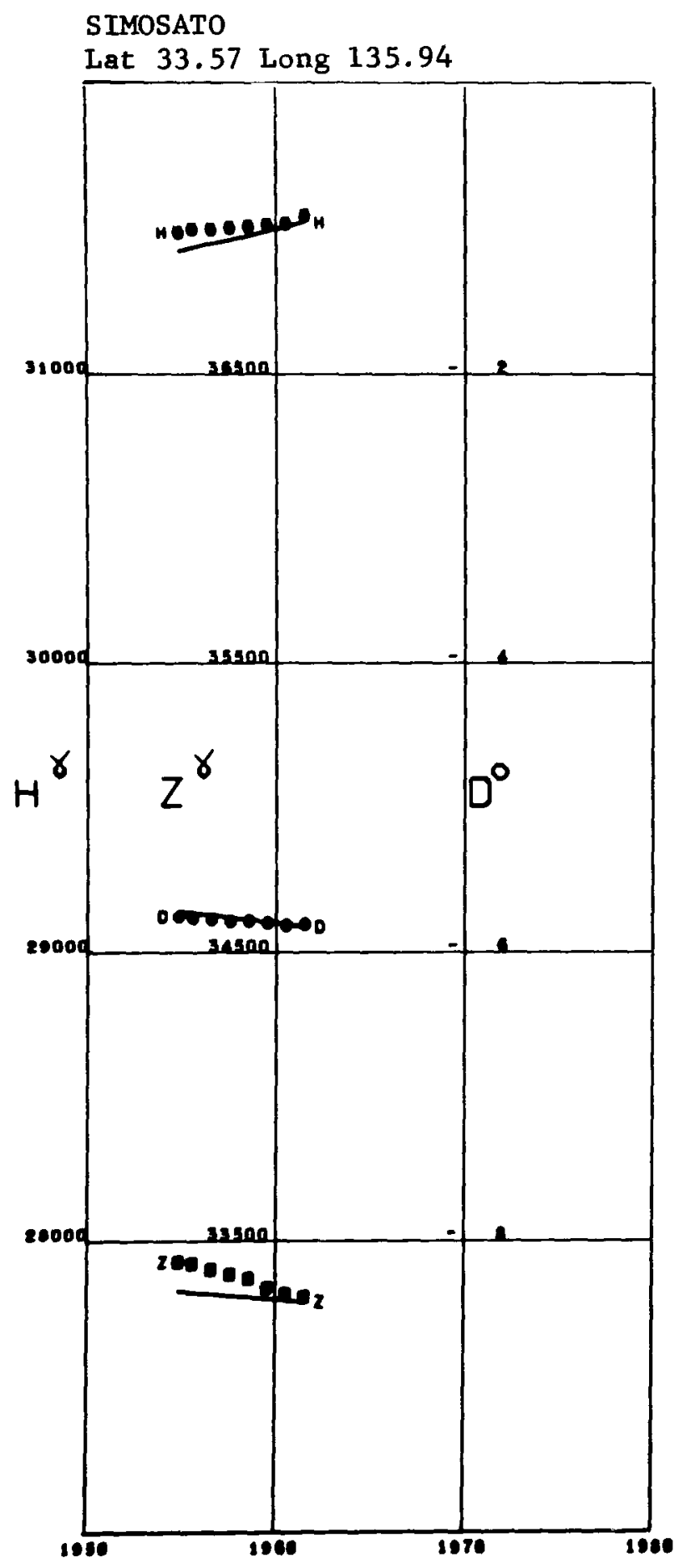

Figure A152 


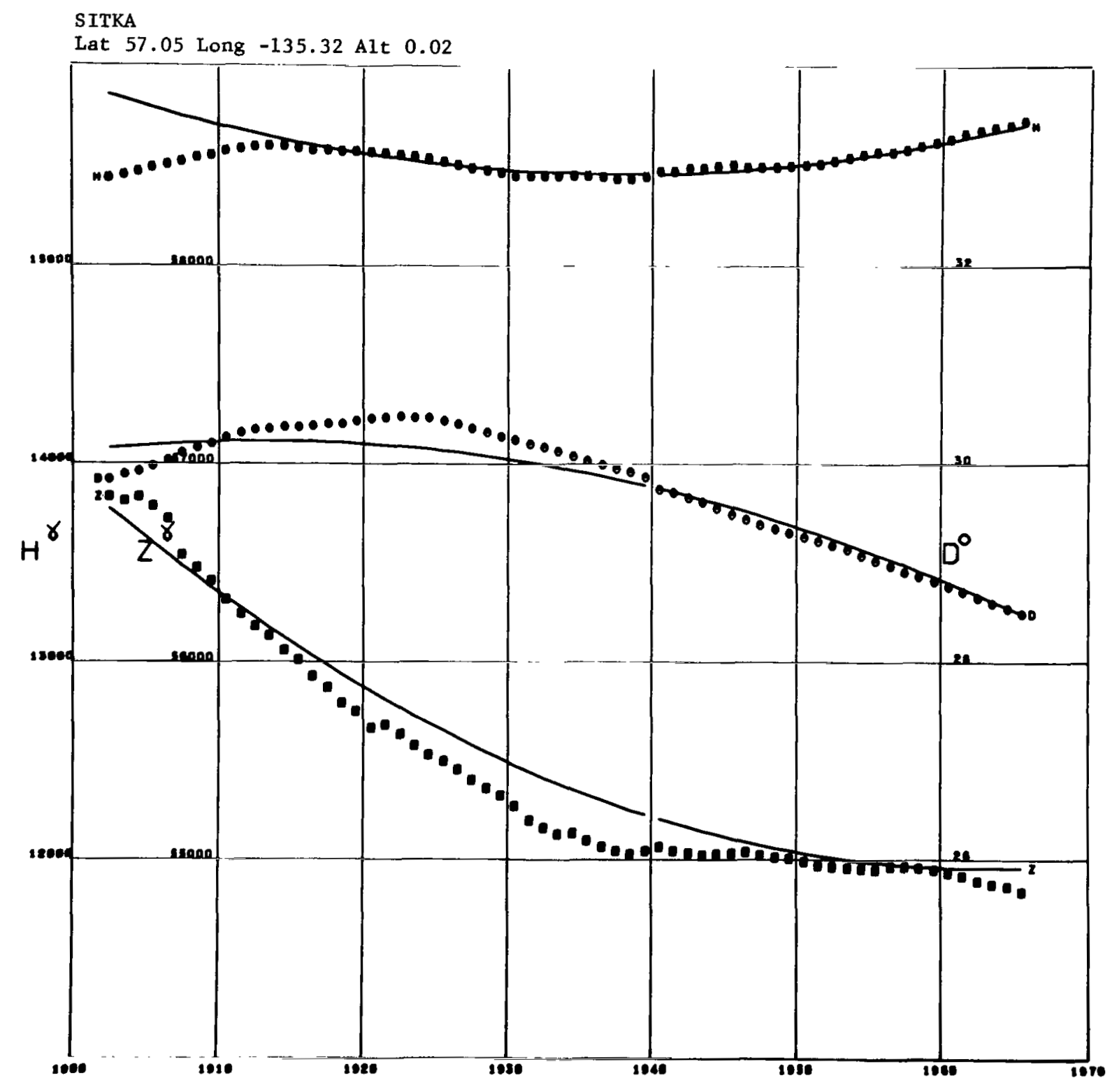

Figure A153 


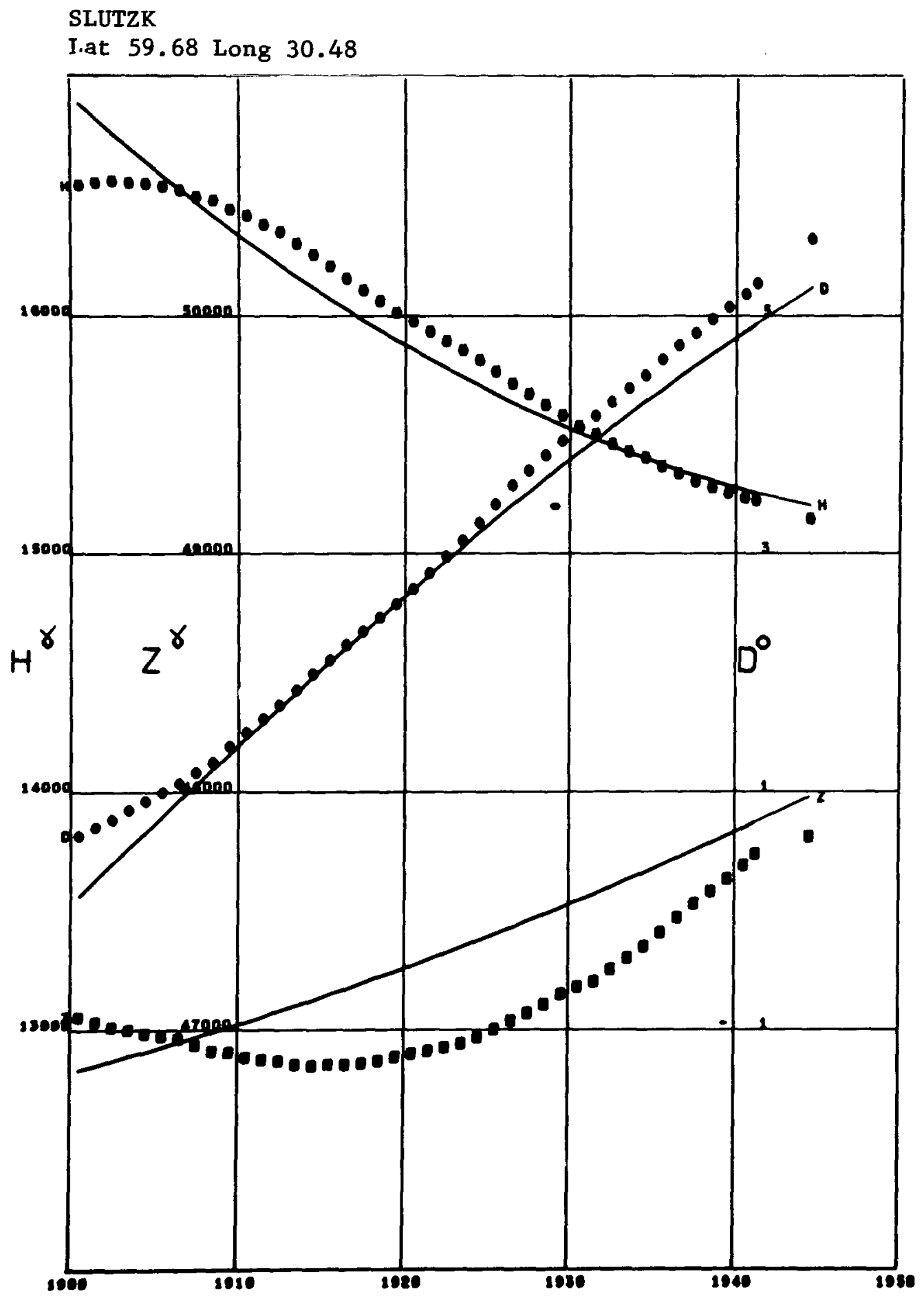

Figure A154 
SODANKYLA

Lat 67.36 Long 26.63

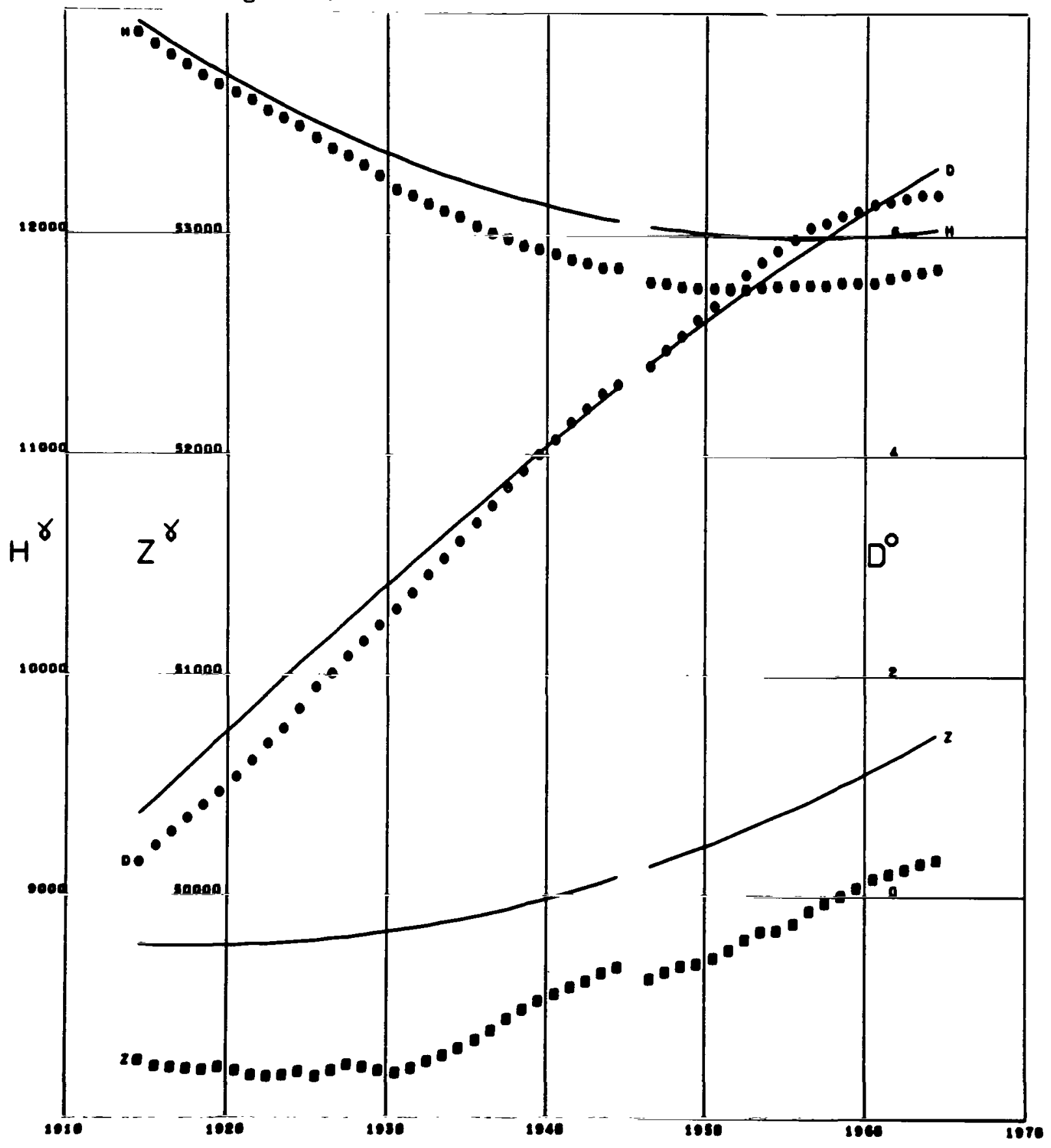

Figure A155 


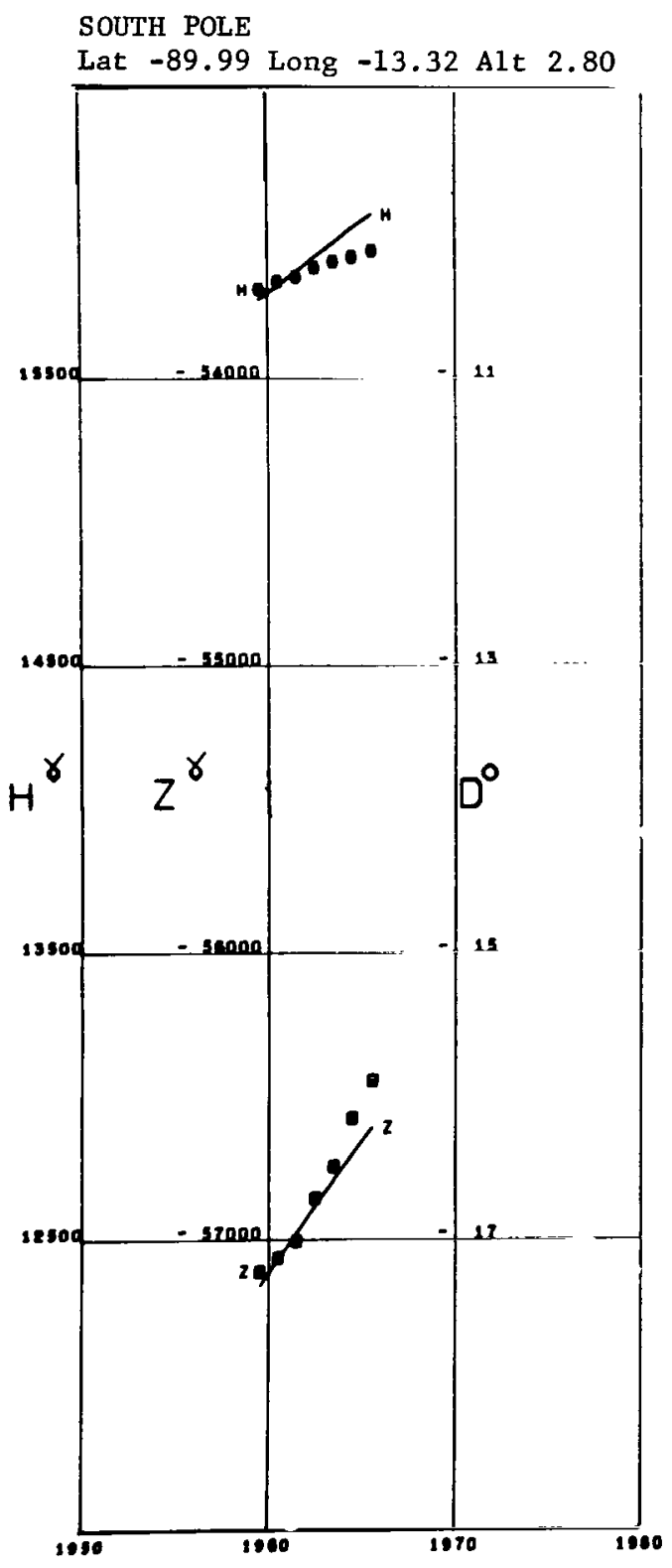

Figure A 156
SREDNIKAN

Lat 62.44 Long 152.31

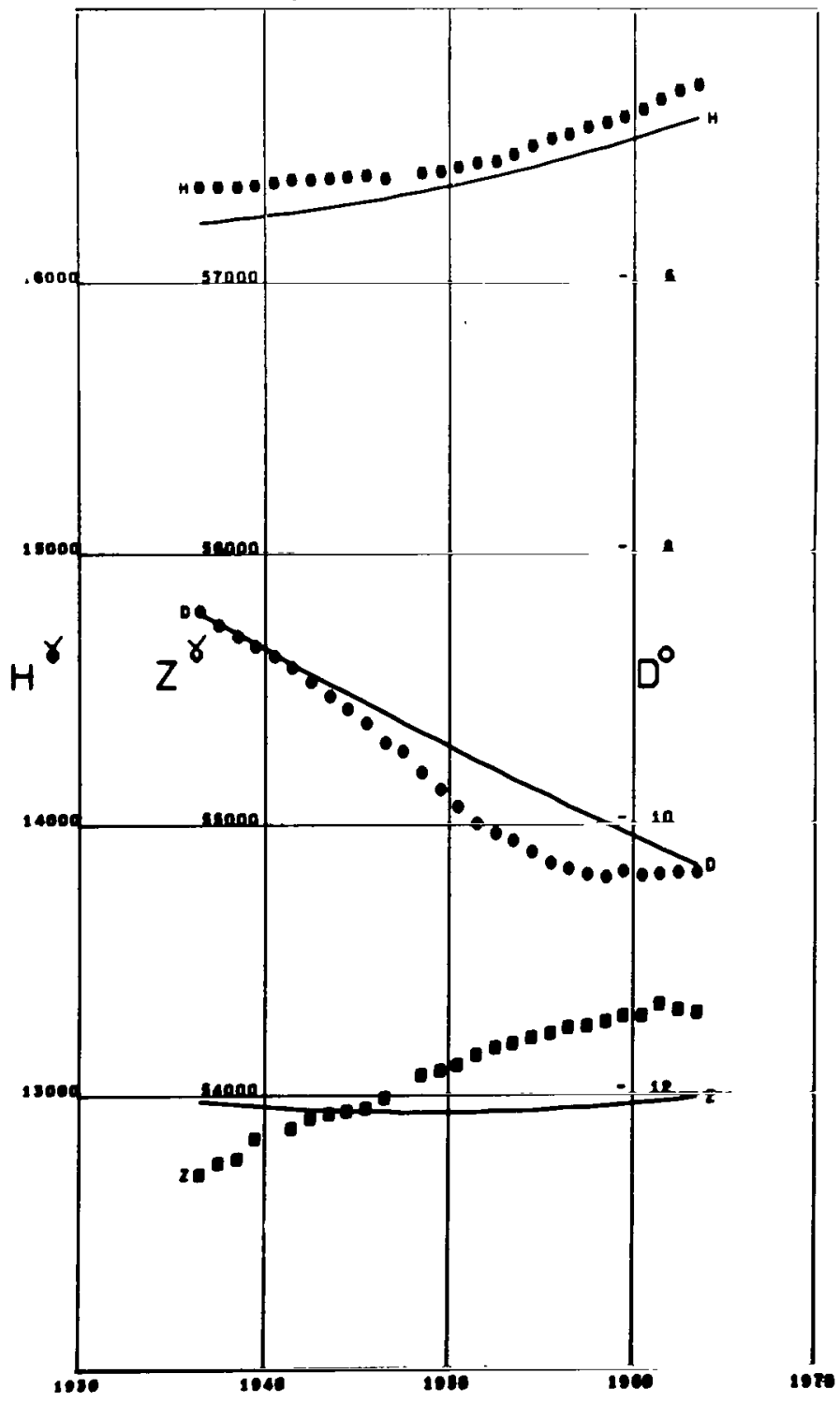

Figure A157 
ST . HELIER

Lat 49.19 Long-2.09

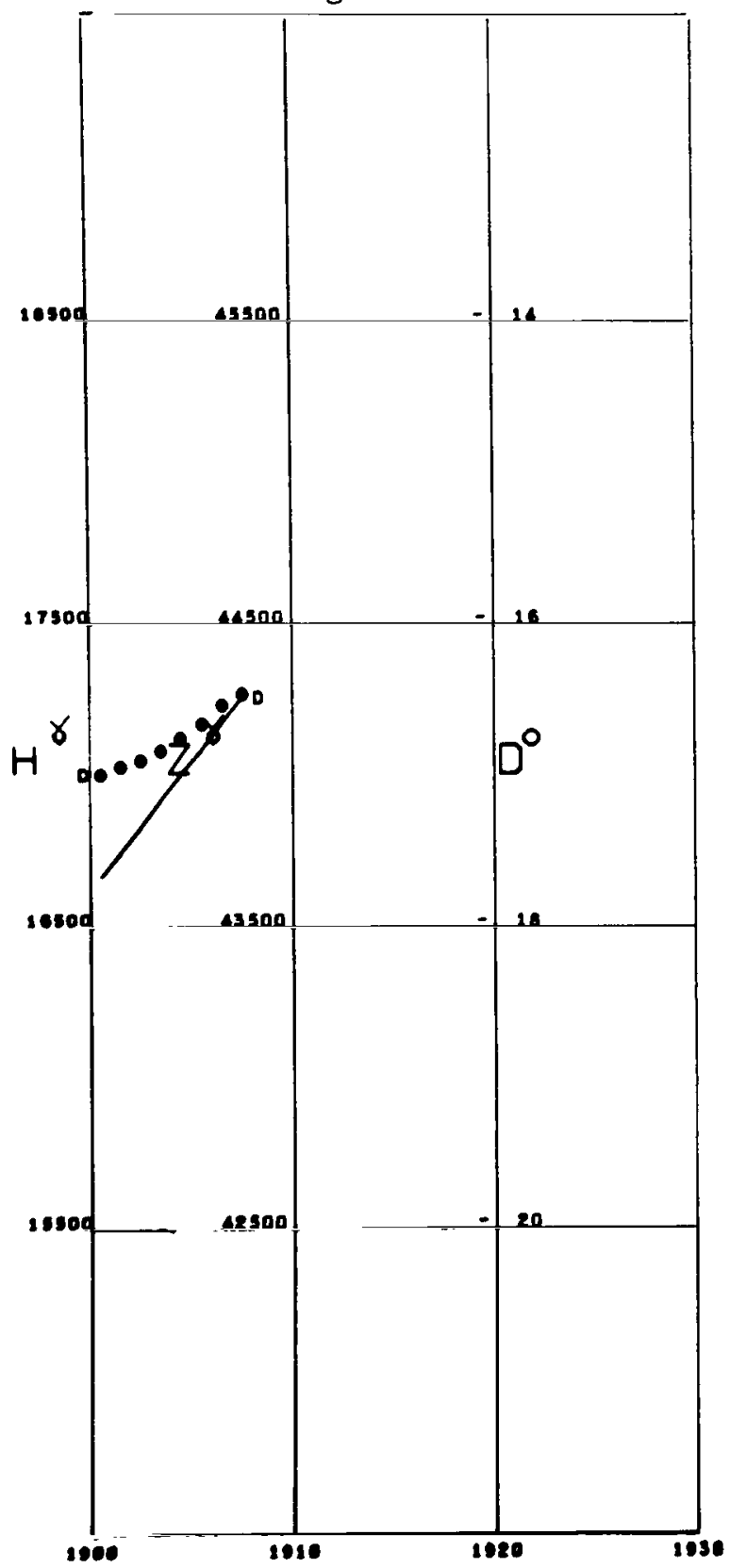

STARA DALA

Lat 47.87 Long 18.19

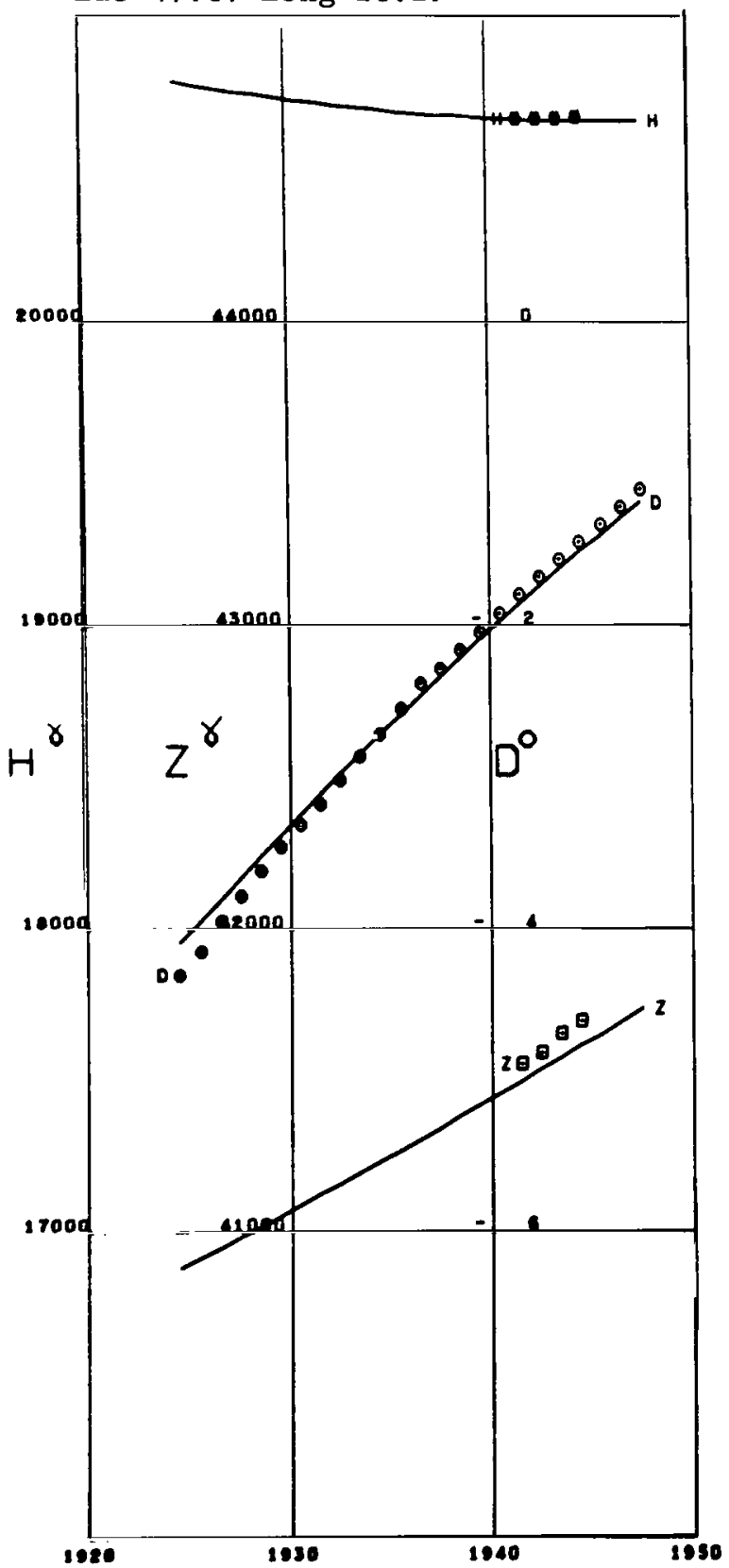

Figure A159

Figure A158 


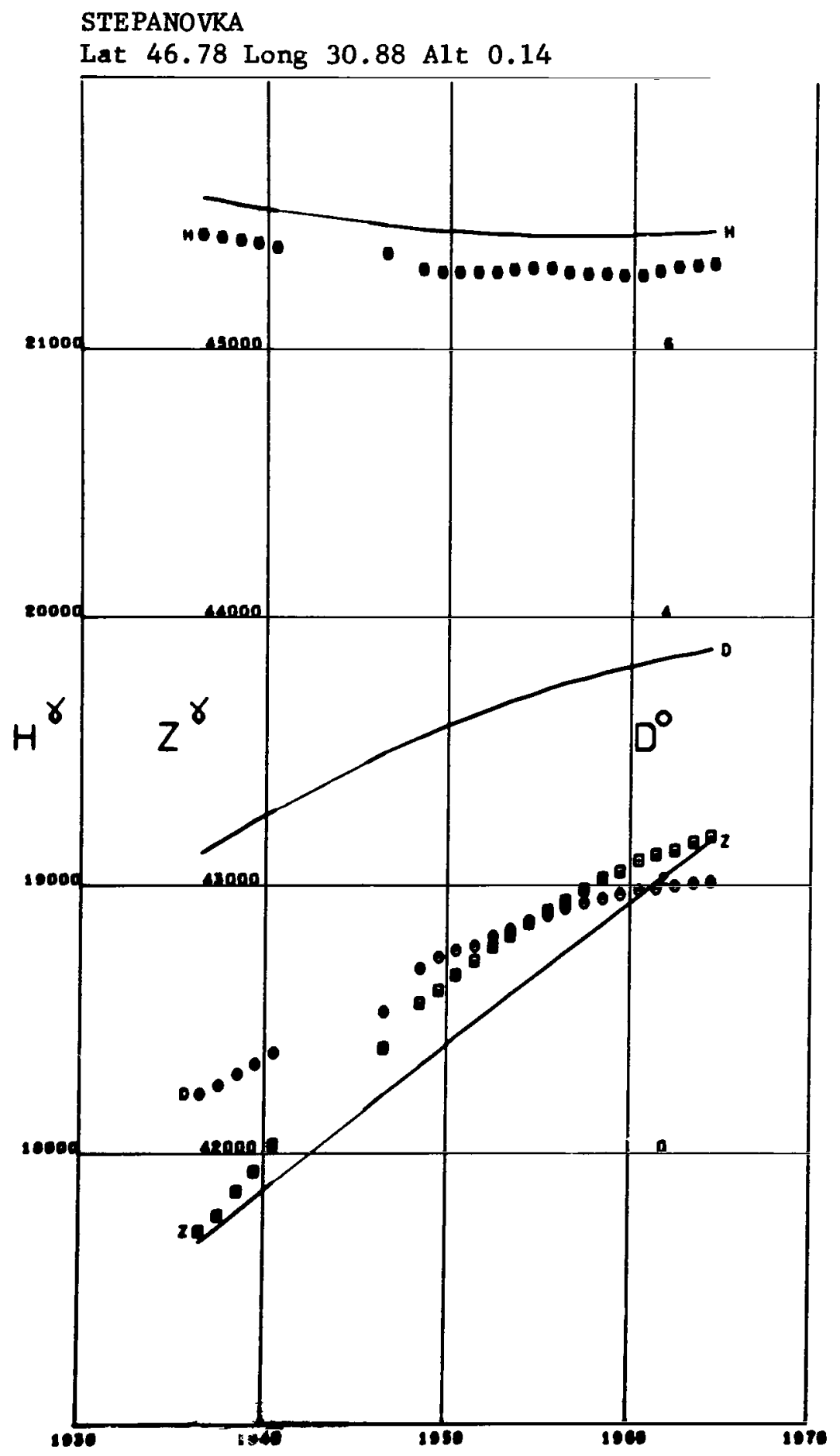

Figure A160 


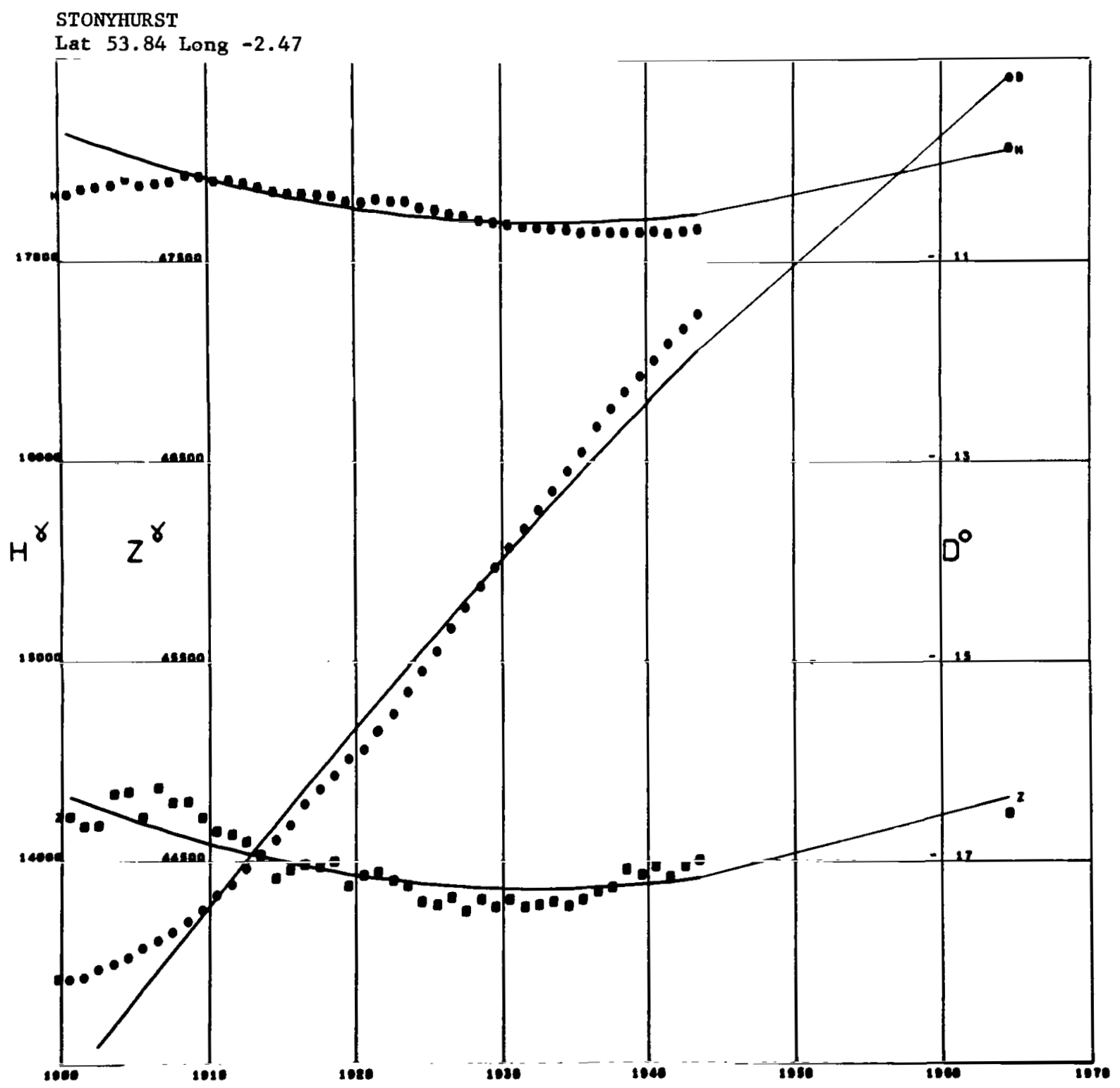

Figure A 161 


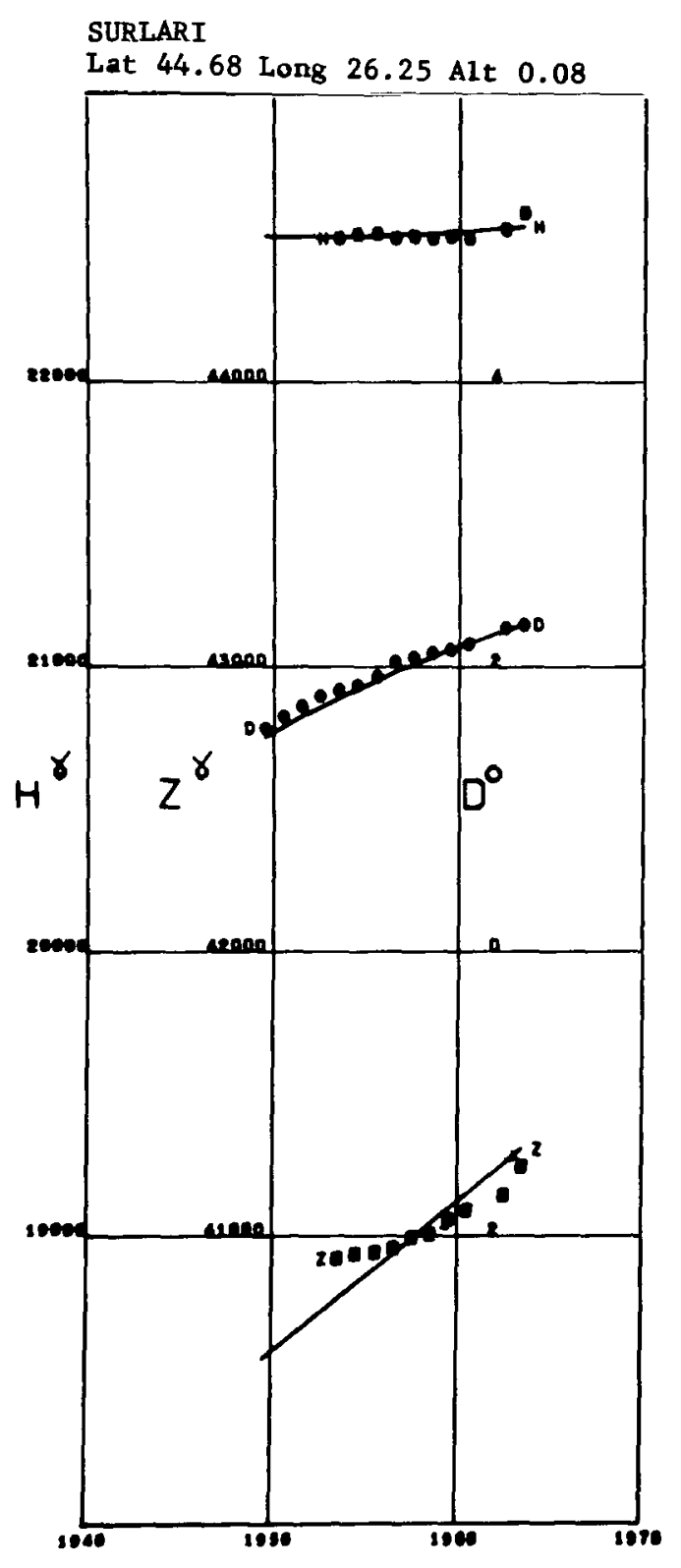

Figure A162

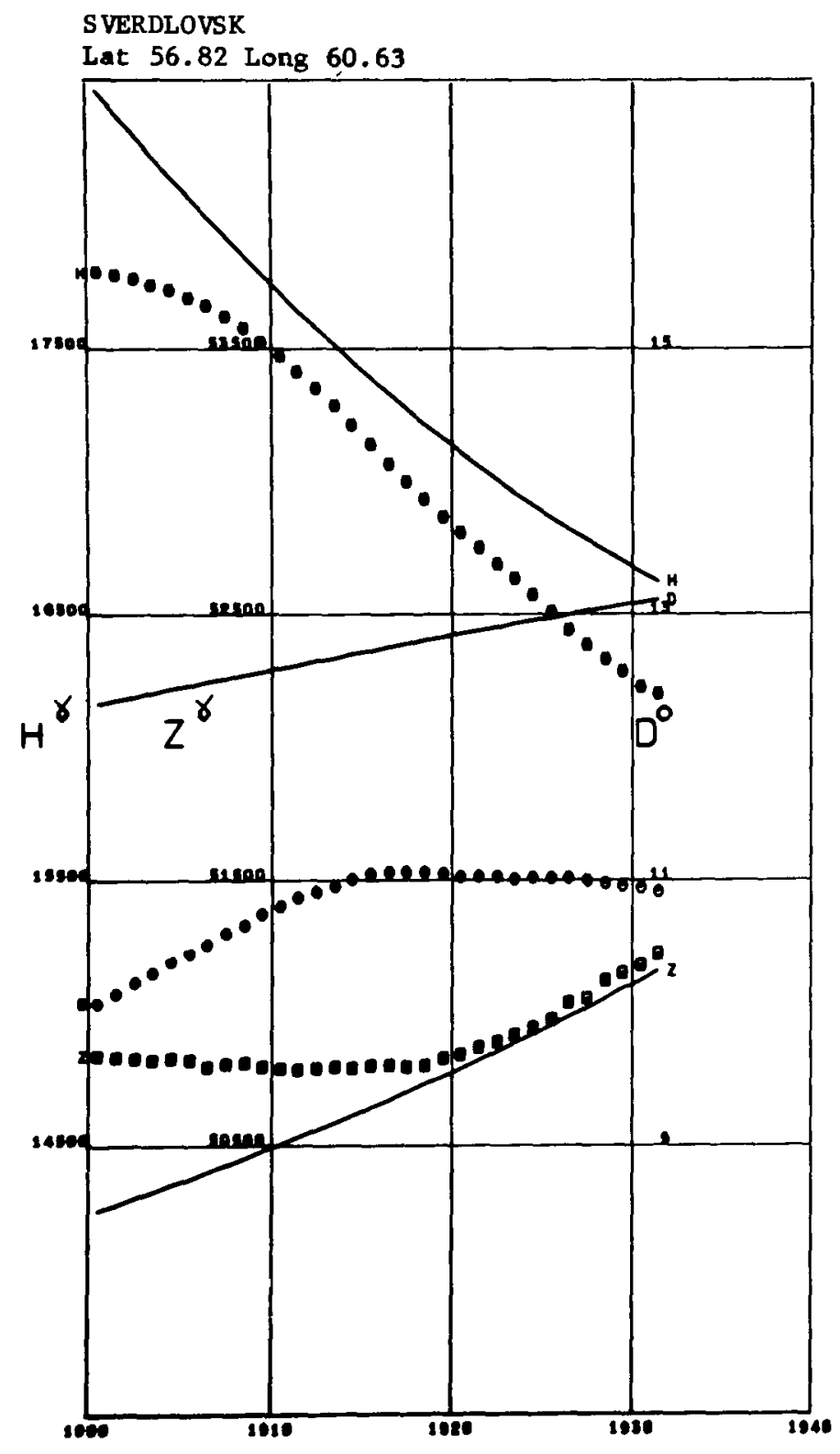

Figure A 163 


\section{SWIDER}

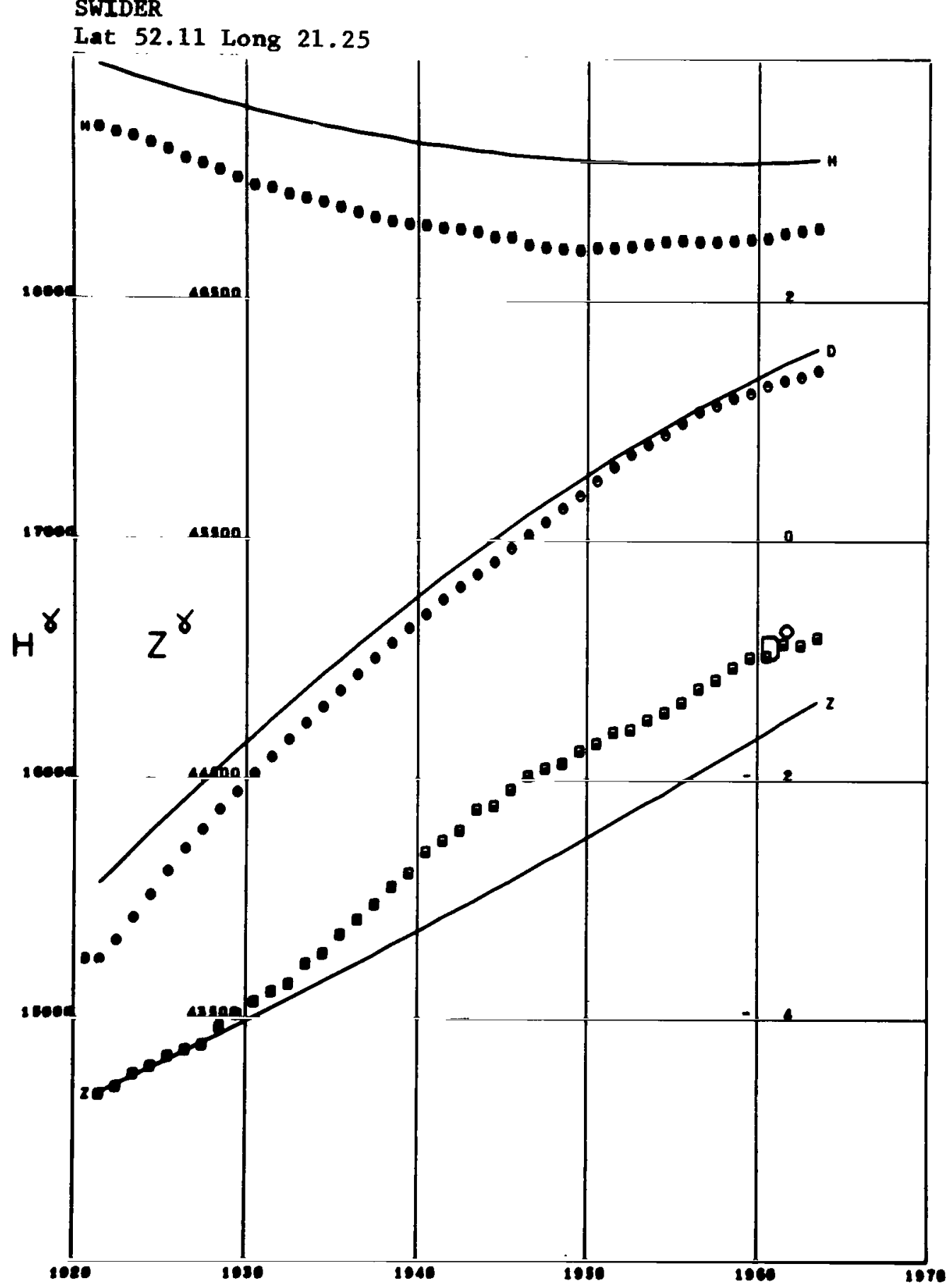

Figure A164 
TAIPEI

Lat 25.03 Long 121.51

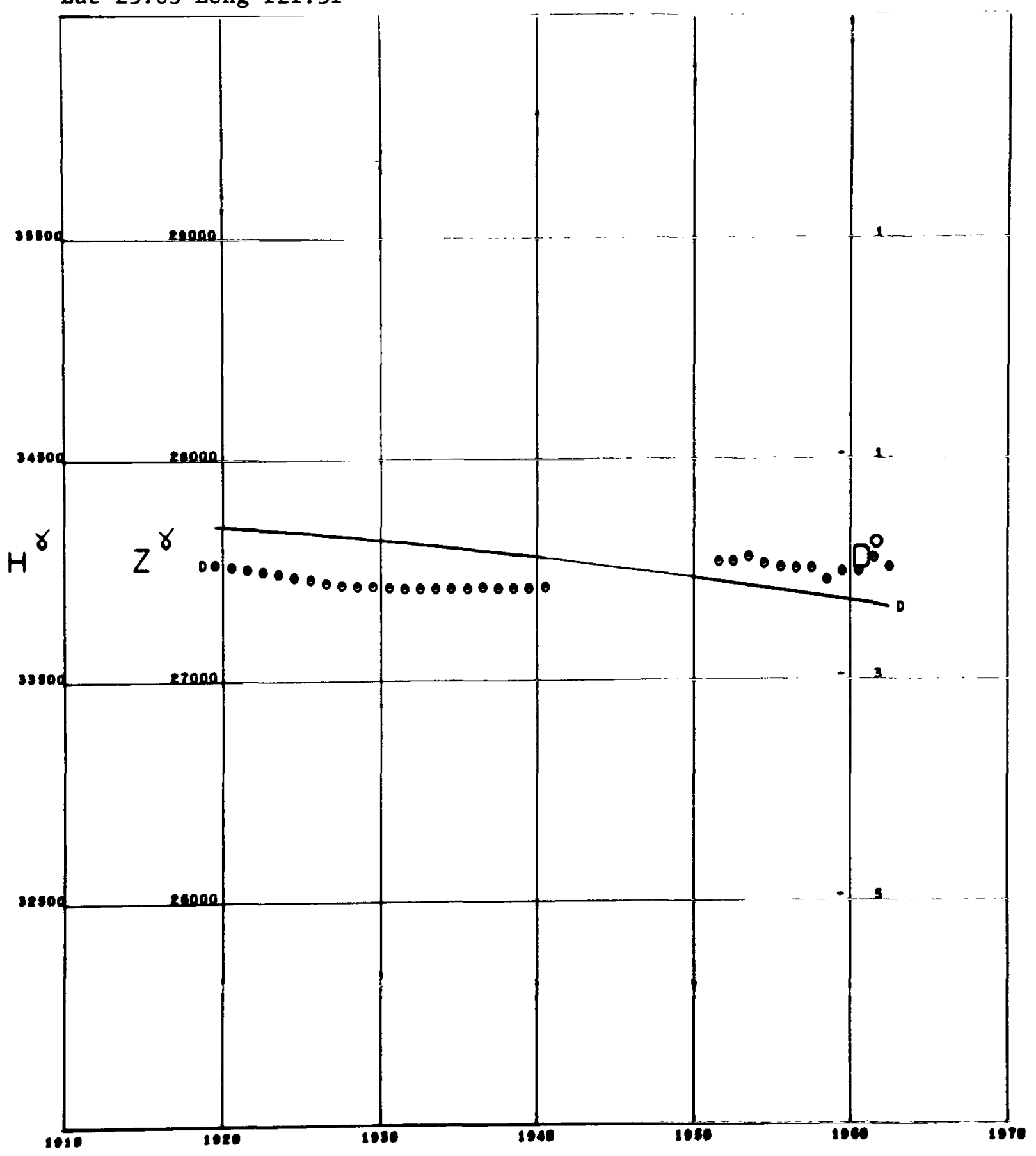

Figure A 165 


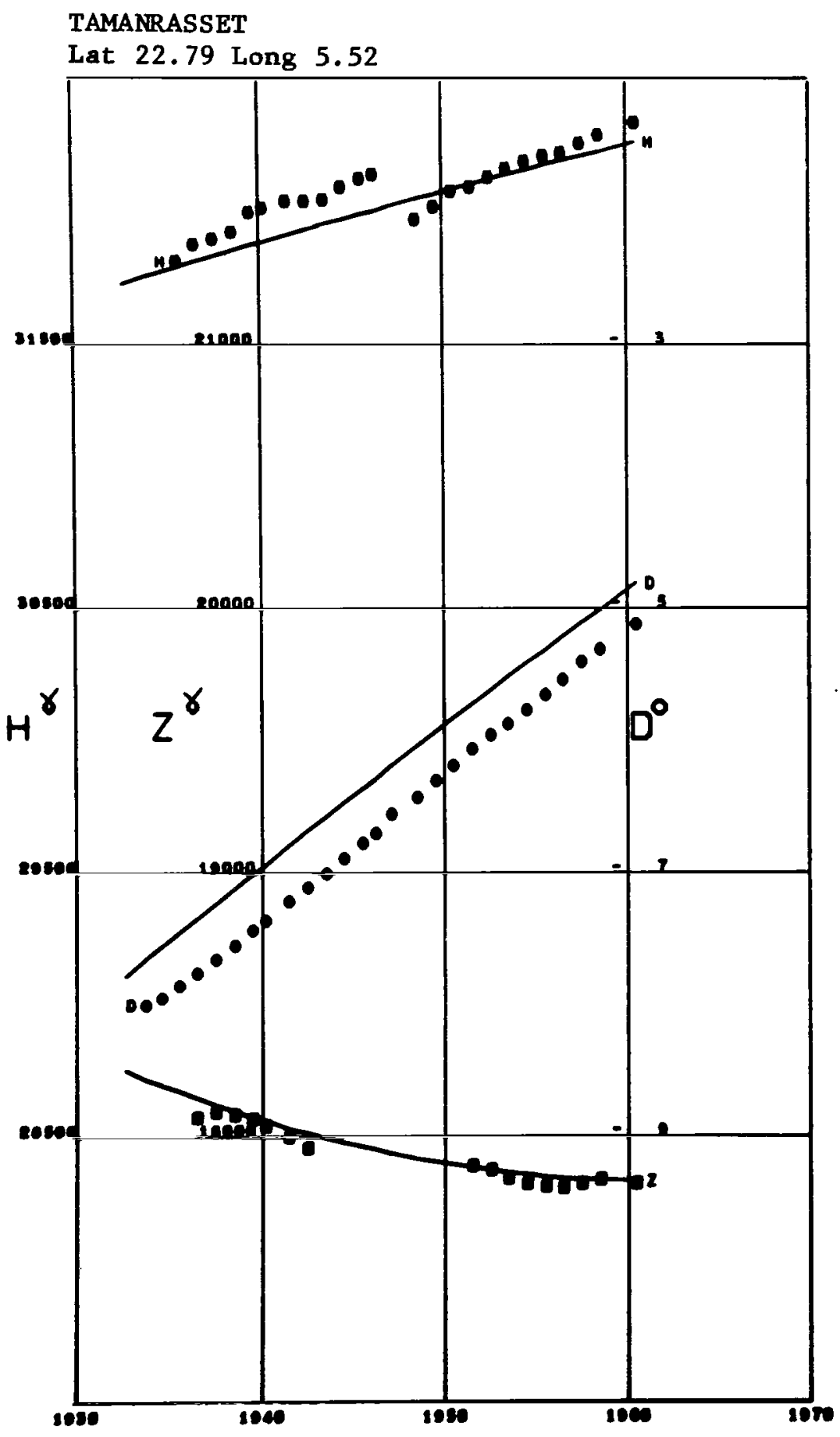

Figure A166 


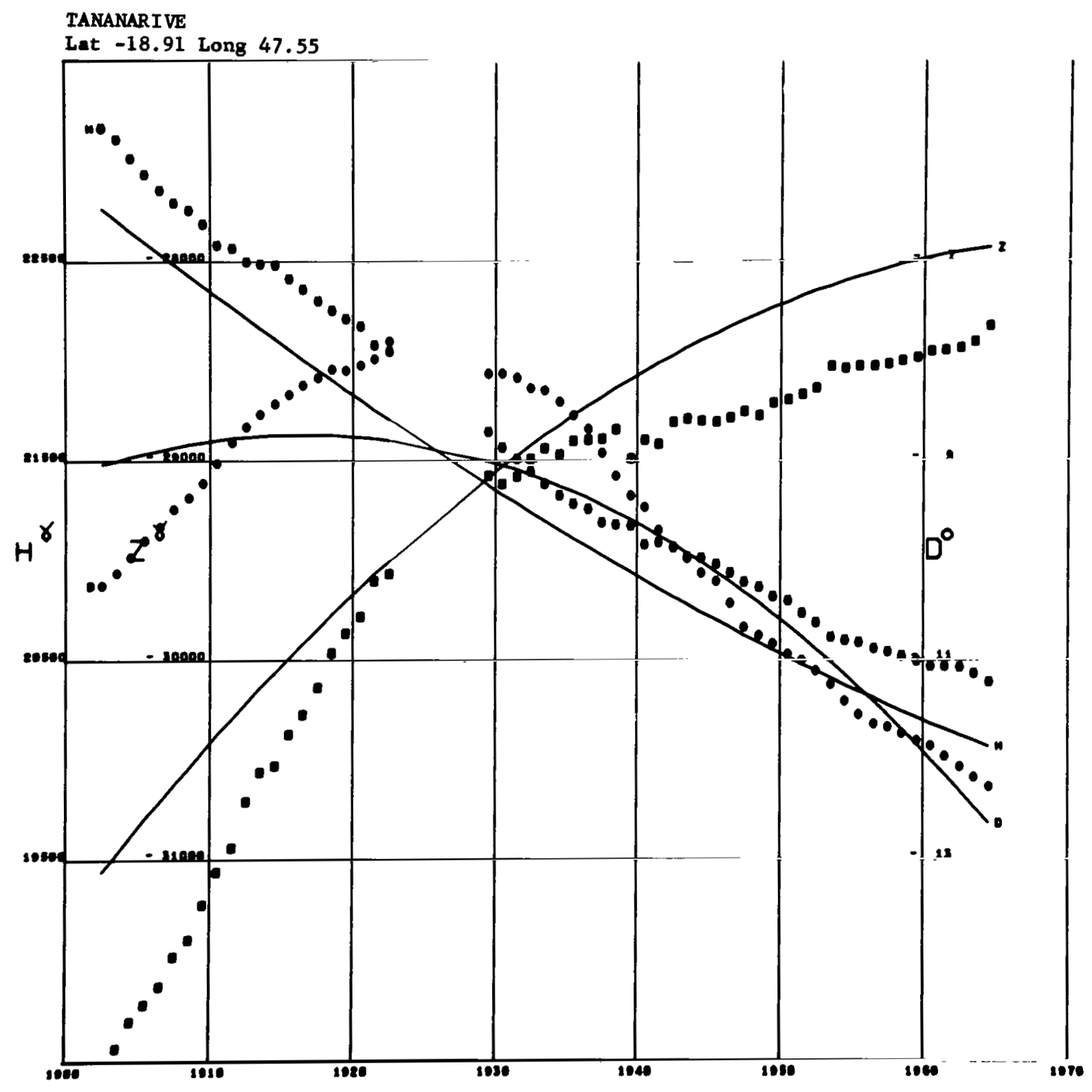

Figure A 167 


\section{TASHKENT}

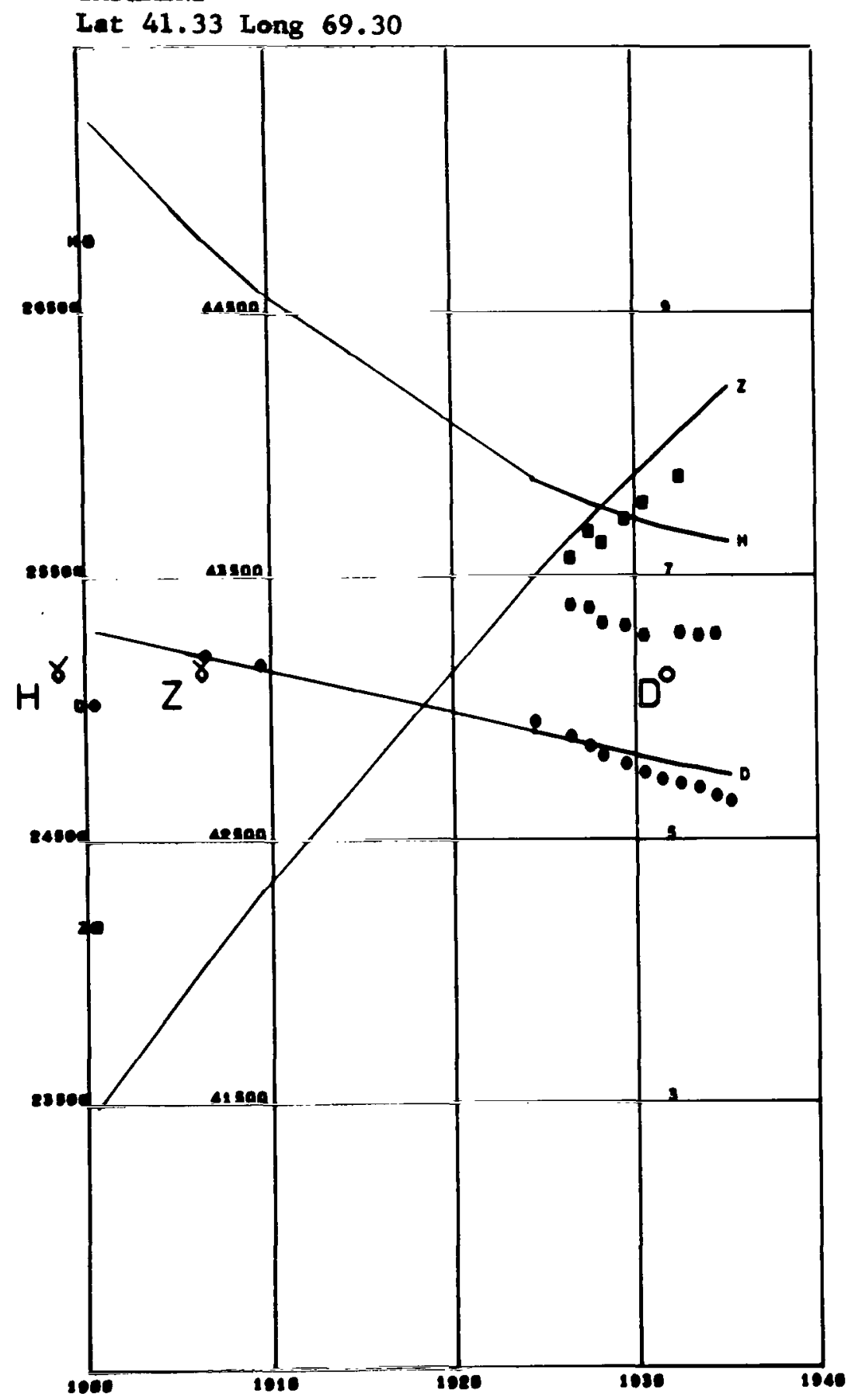

Figure Al68 


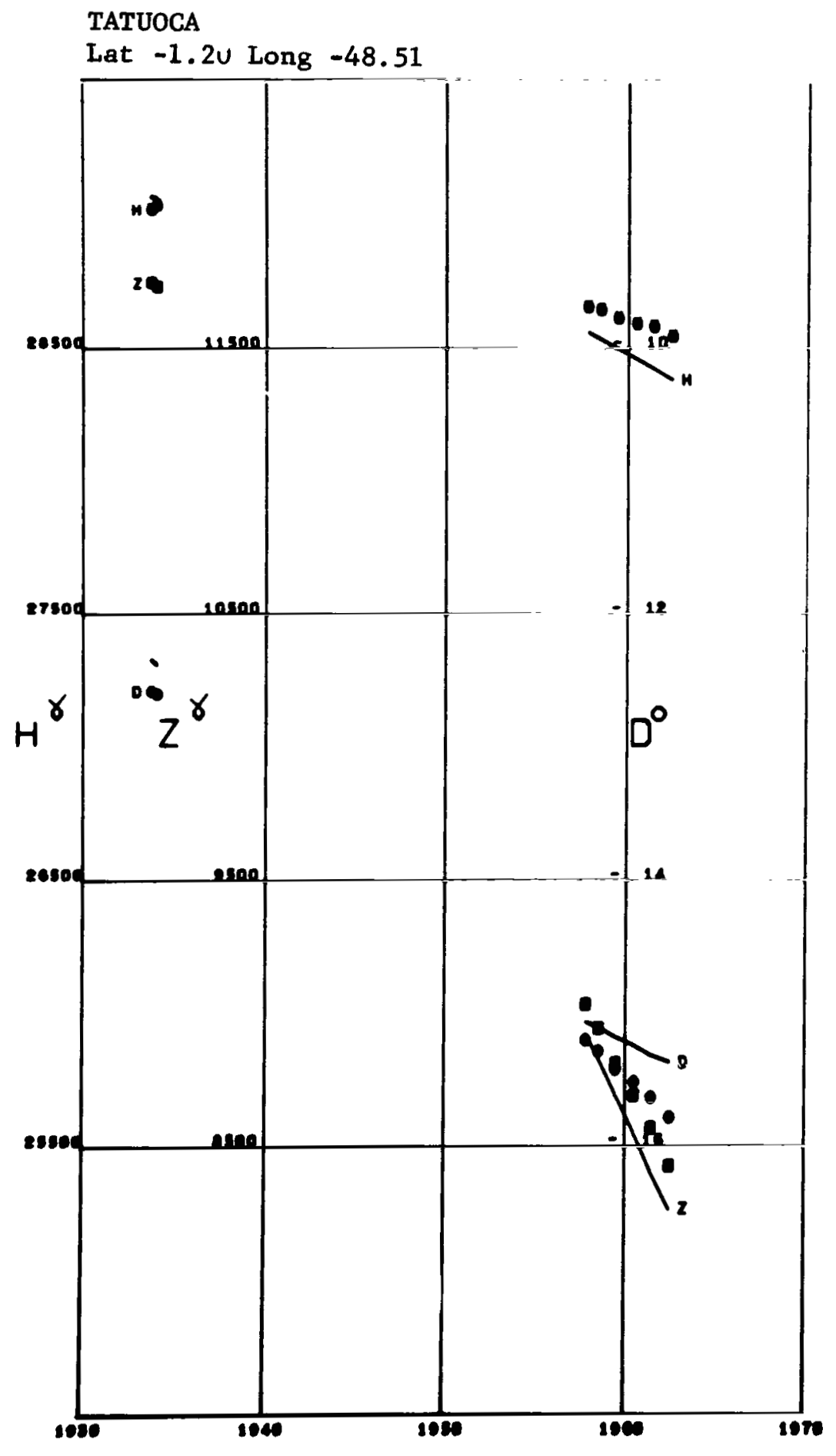

Figure A169 
TBILISI

Lat 41.71 Long 44.79

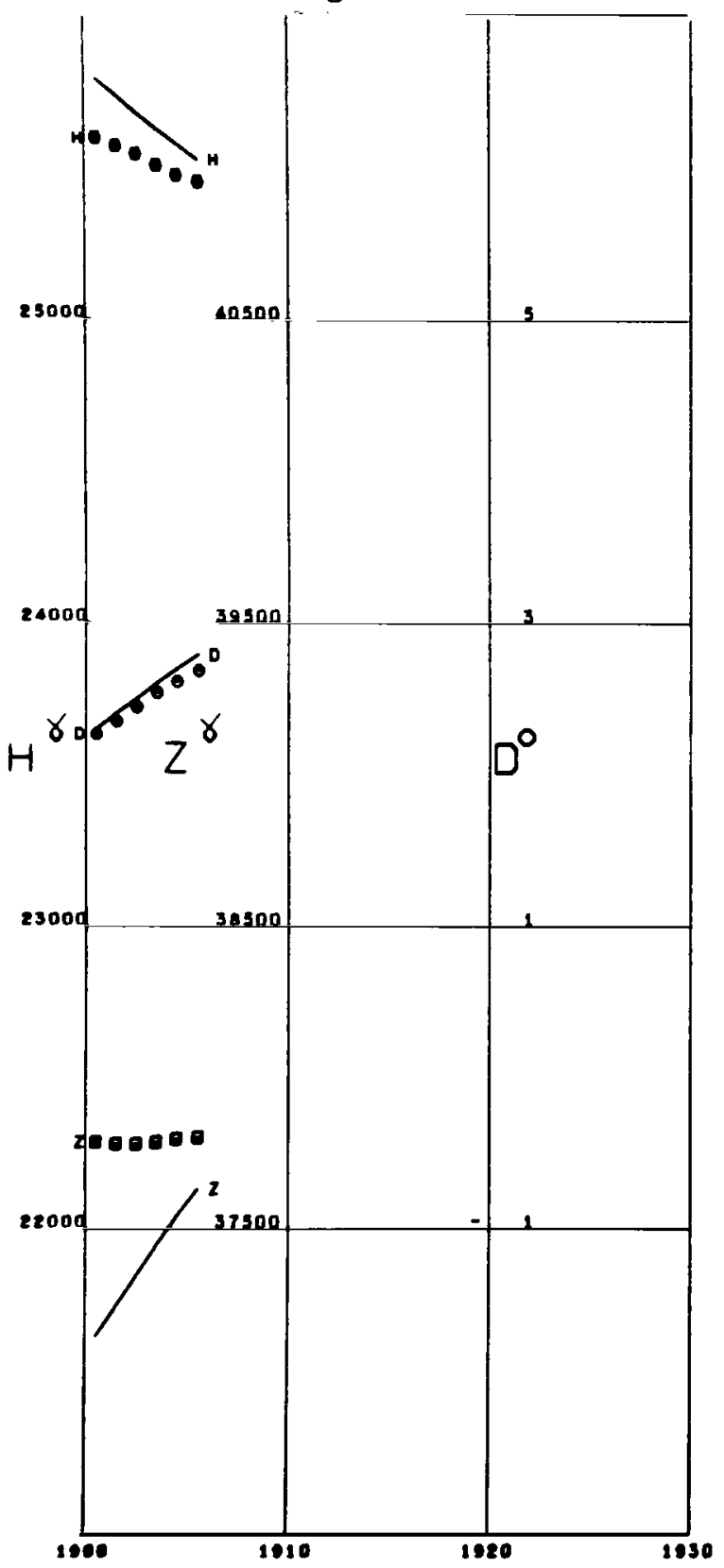

Figure A 170
TEHRAN

Lat 35.73 Lopg 51.38

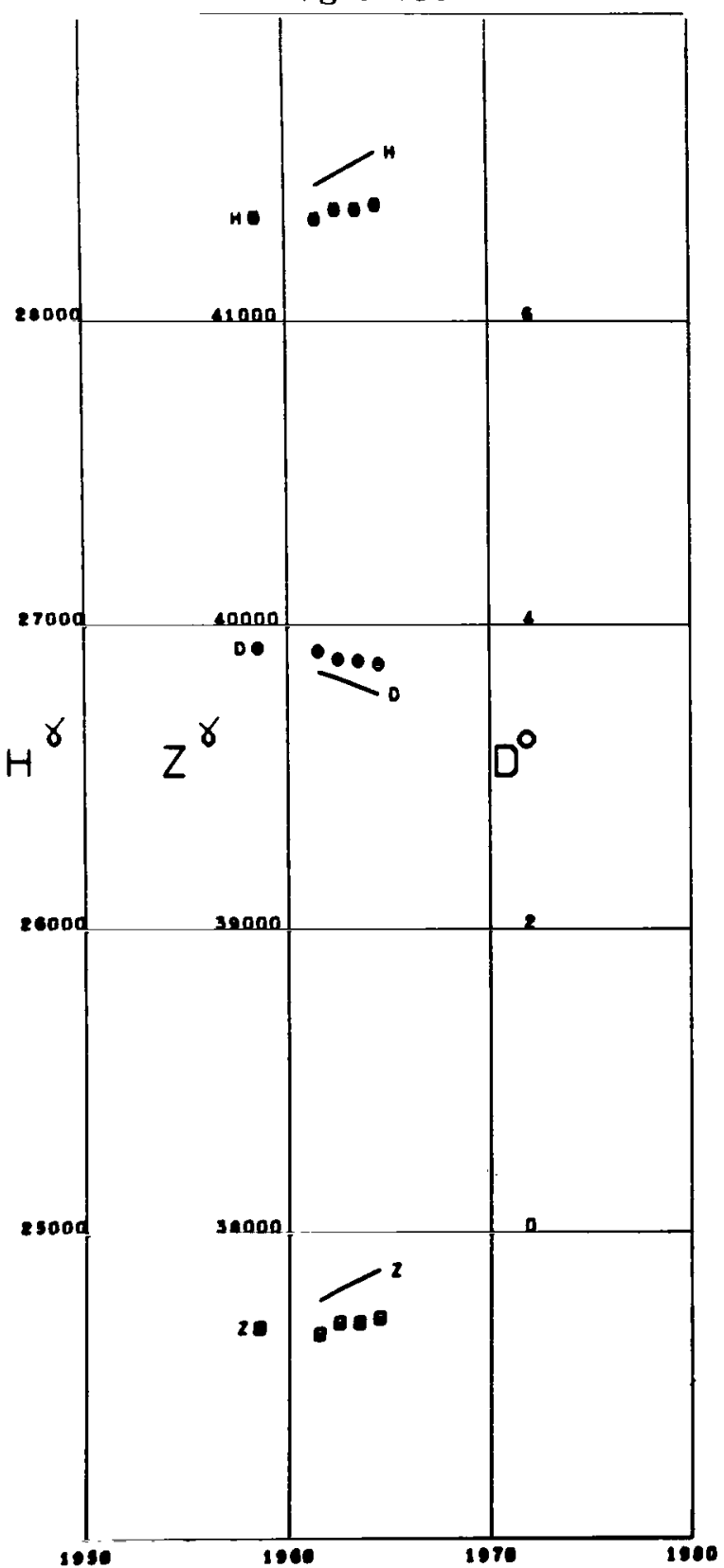

Figure A171 
TENER IFE

Lat 28.47 Long -16.27 Alt 0.40

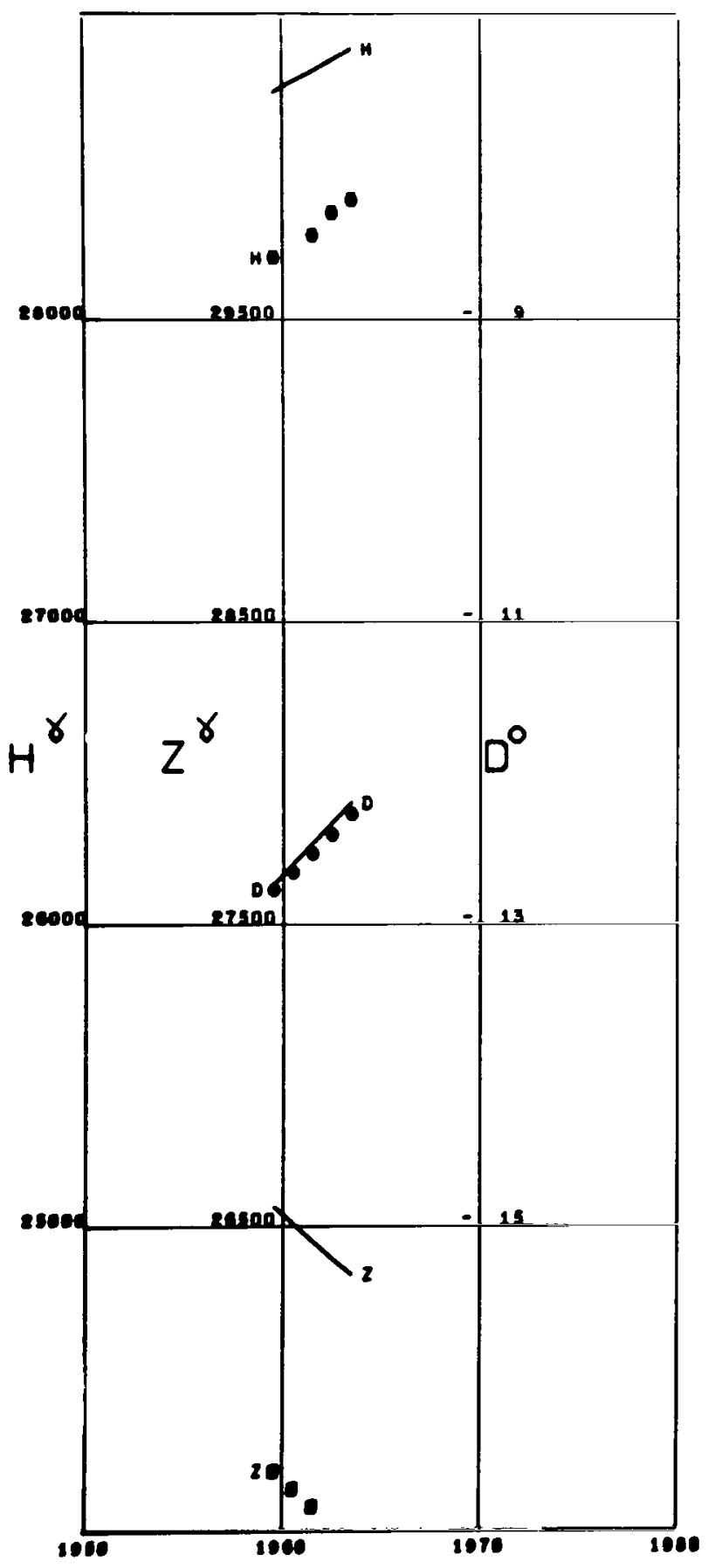

Figure A 172 
TEOLOYUCAN

Lat 19.74 Long -99.18

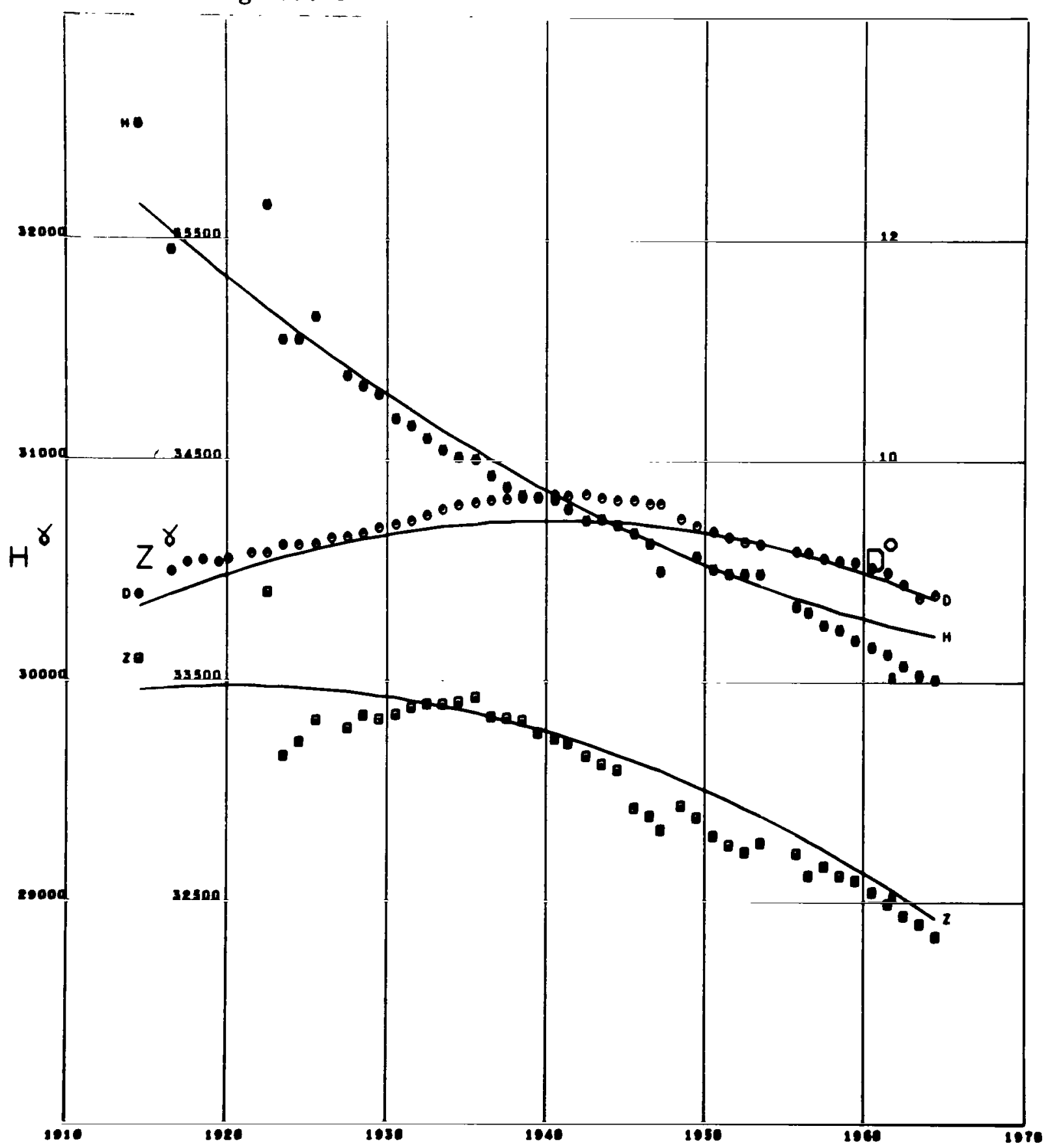

Figure A173 
THULE II

Lat 77.48 Long -69.16

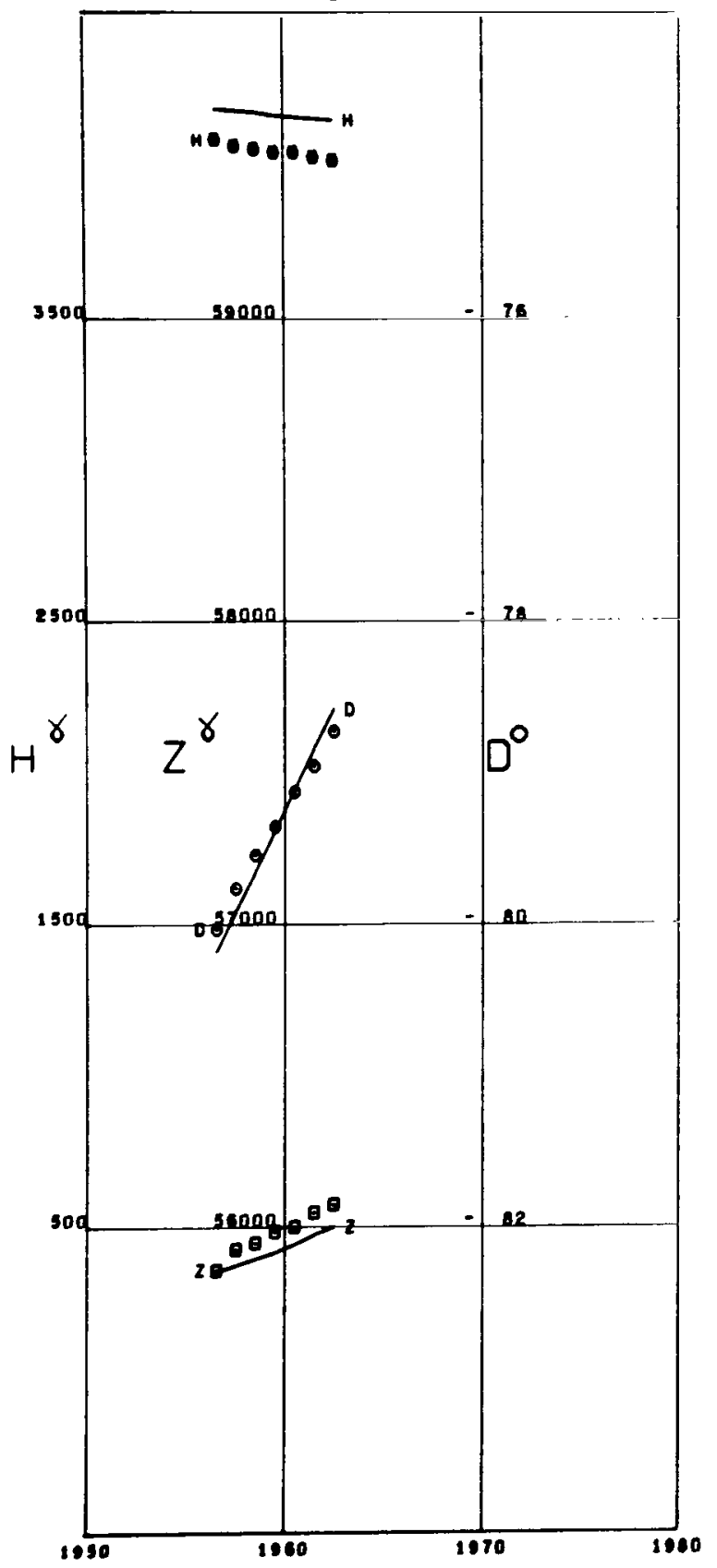

Figure A174
TIHANY

Lat 46.90 Long 17.89

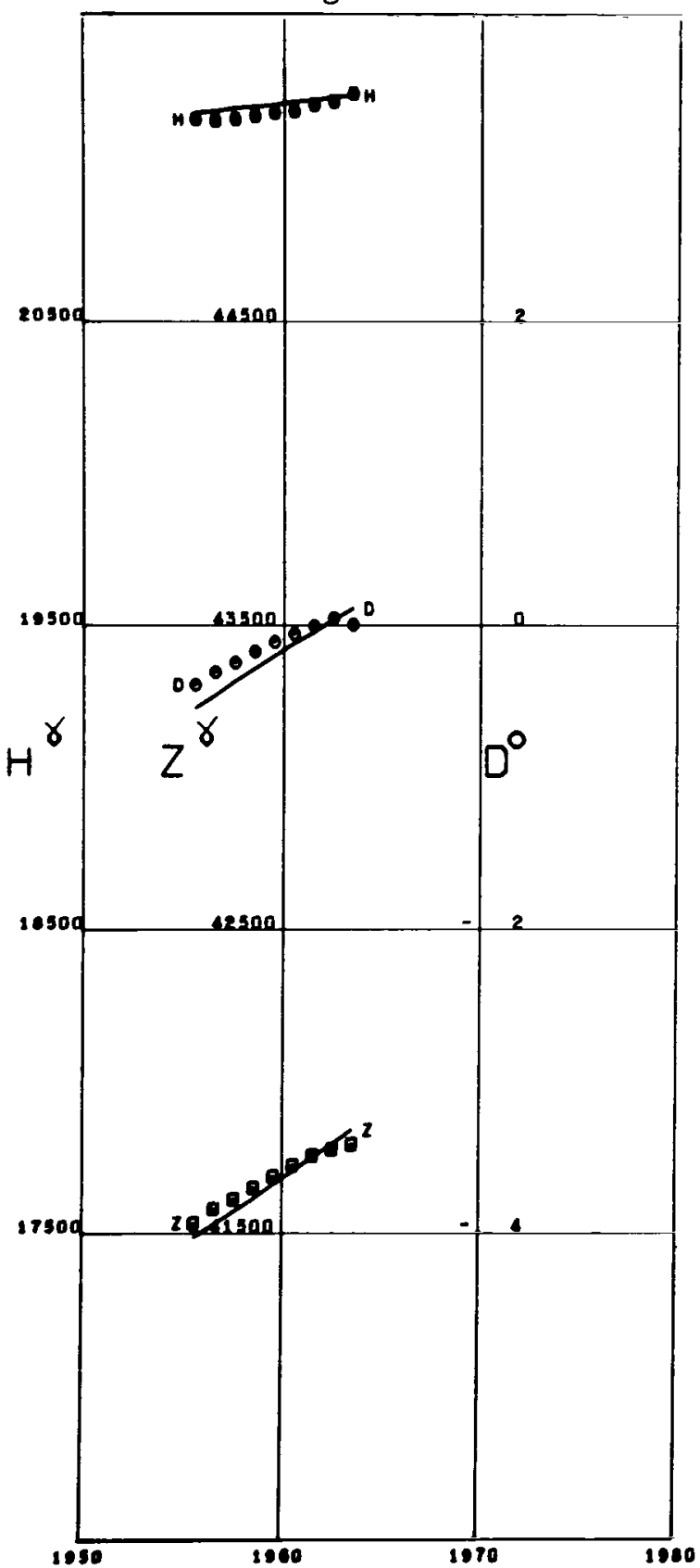

Figure A175 
TIKHAYA BAY

Lat 80.33 Long 52.80

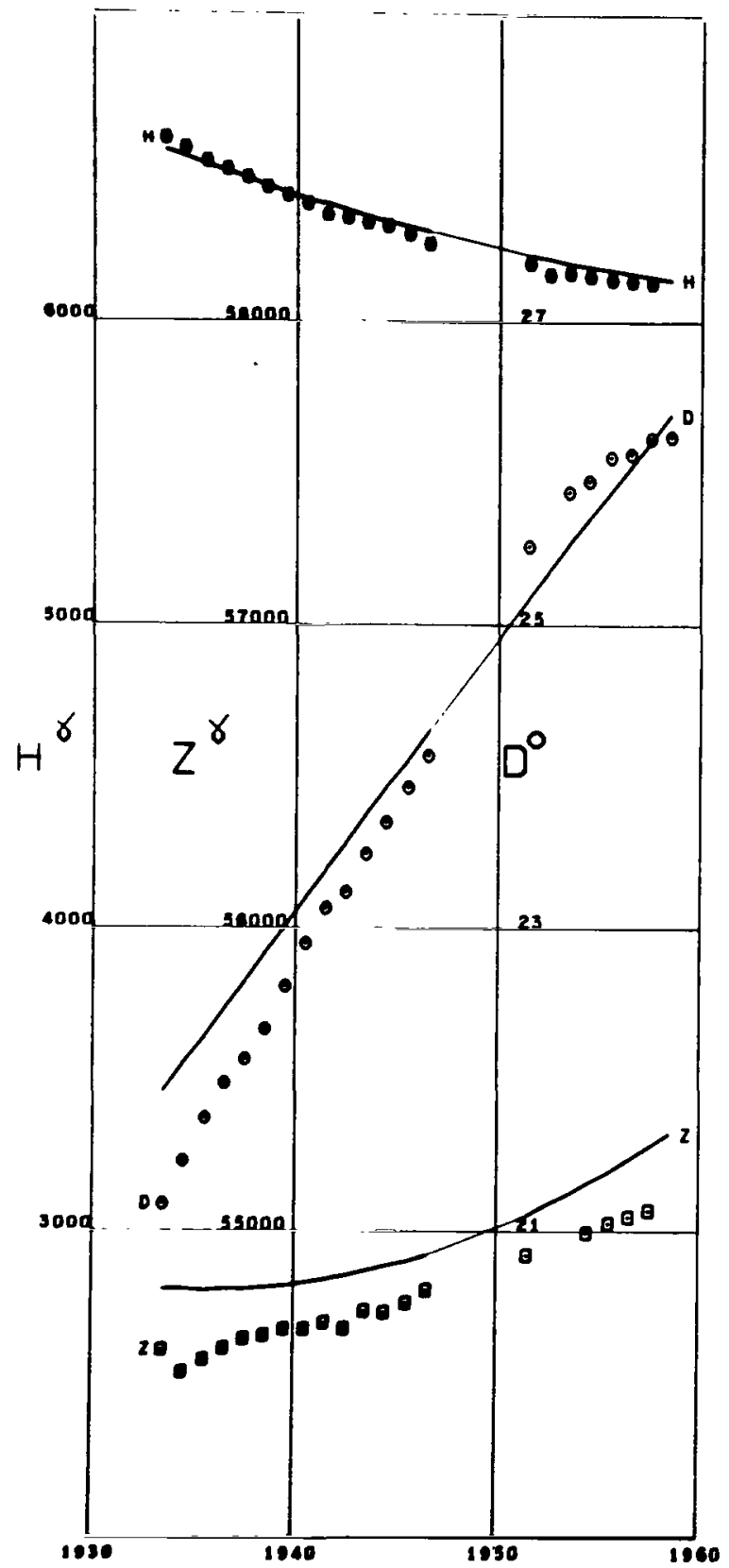

Figure A176

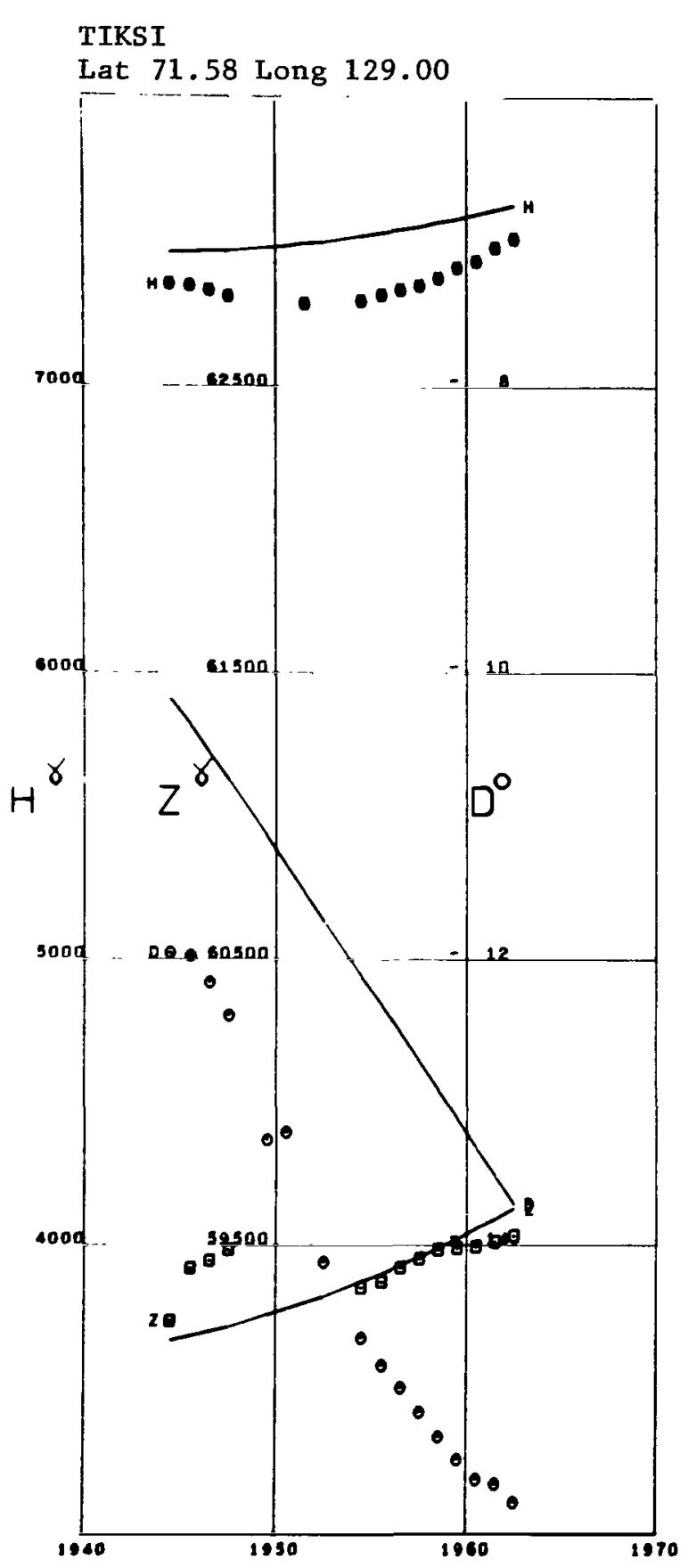

Figure A 177 
TOKYO

Lat 35.68 Long 139.75

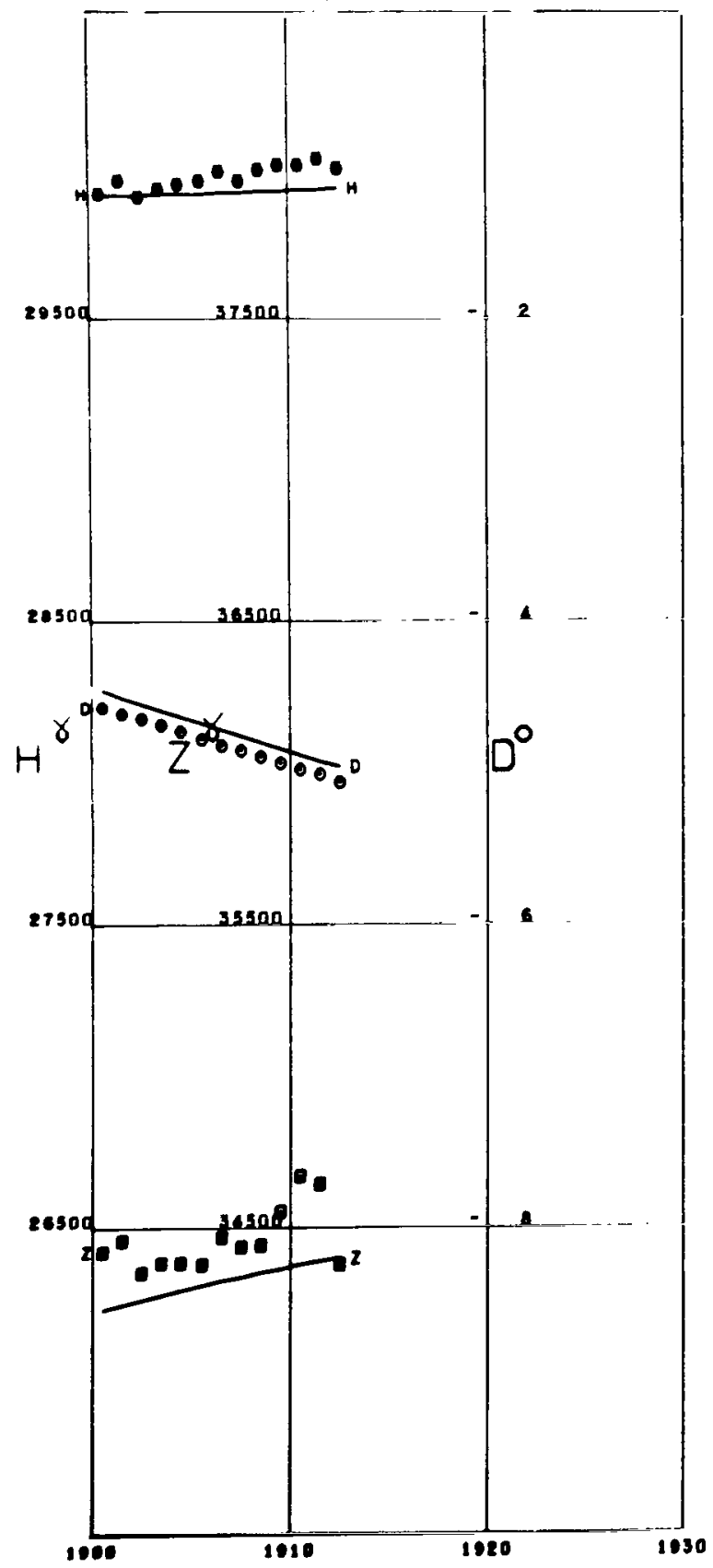

Figure A178
TOLEDO

Lat 39.88 Long -4.04 Alt 0.50

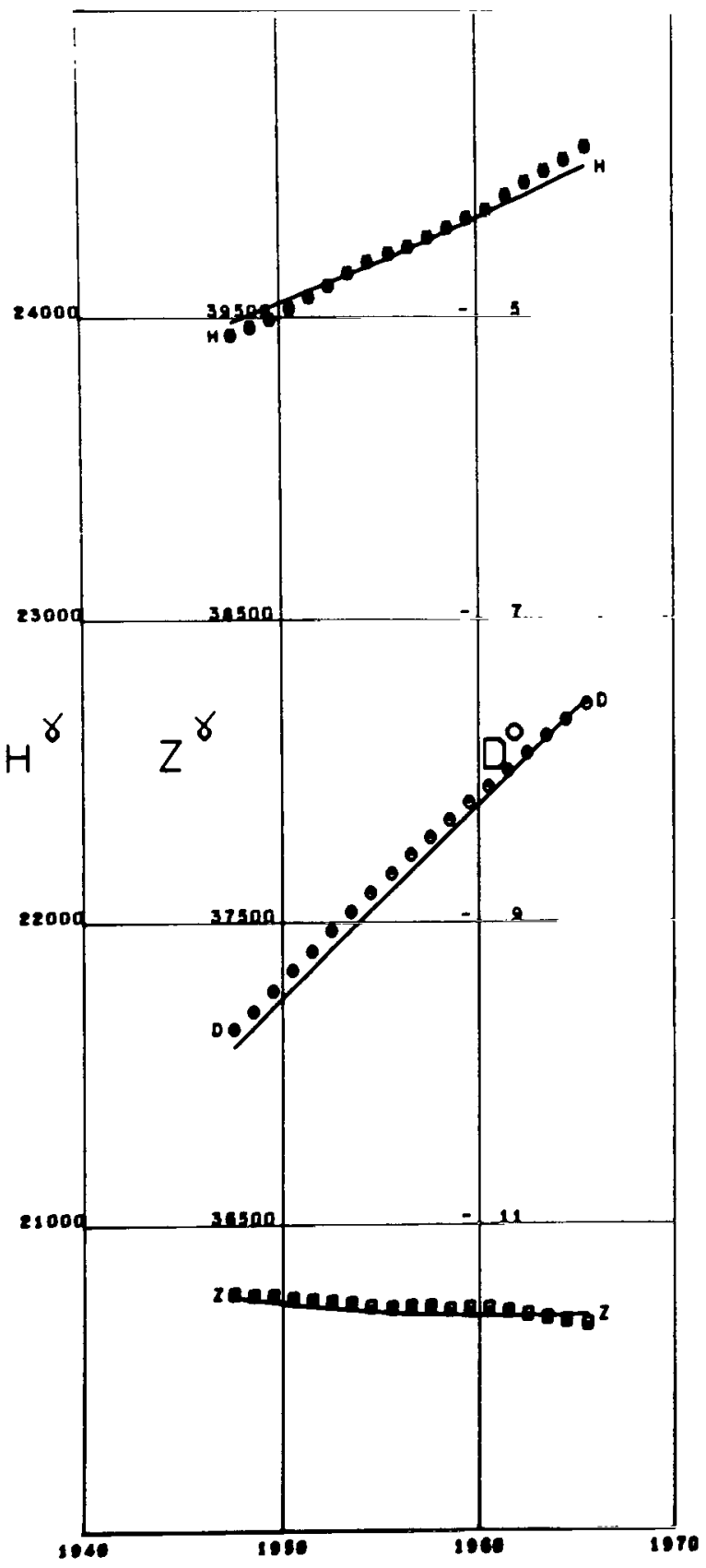

Figure A179 
TOOLANGI

Lat -37.53 Long 145.46 A1t 0.48

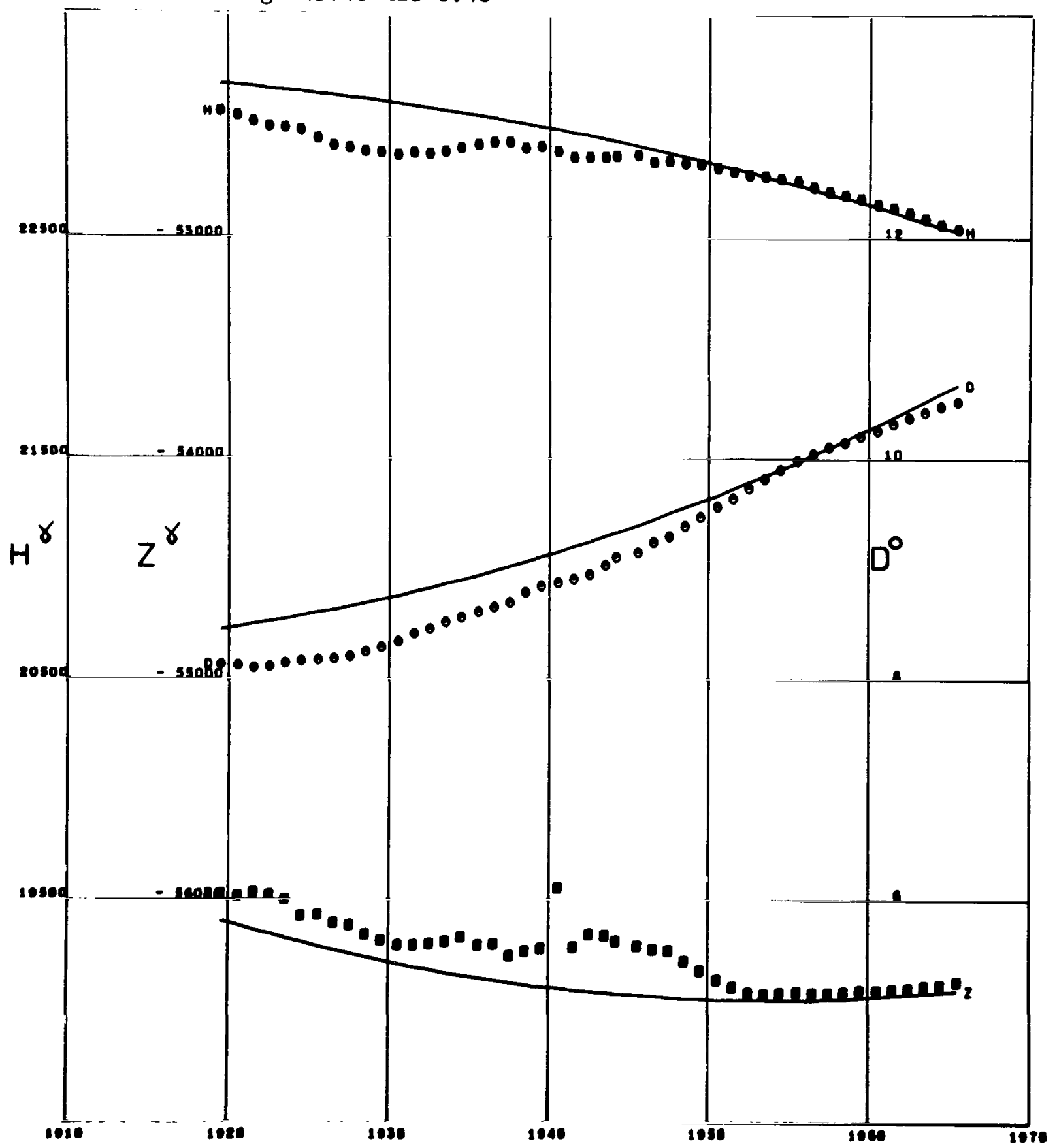

Figure A 180 


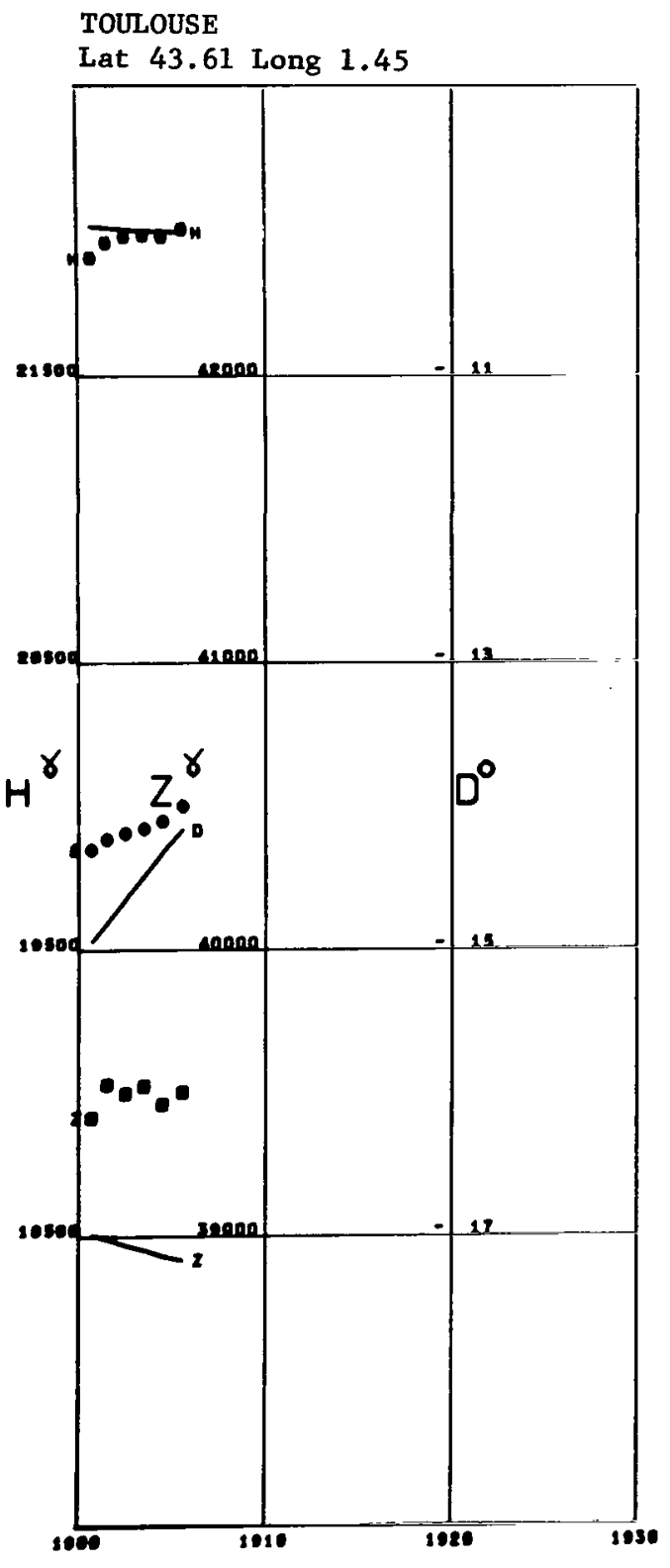

Figure A181

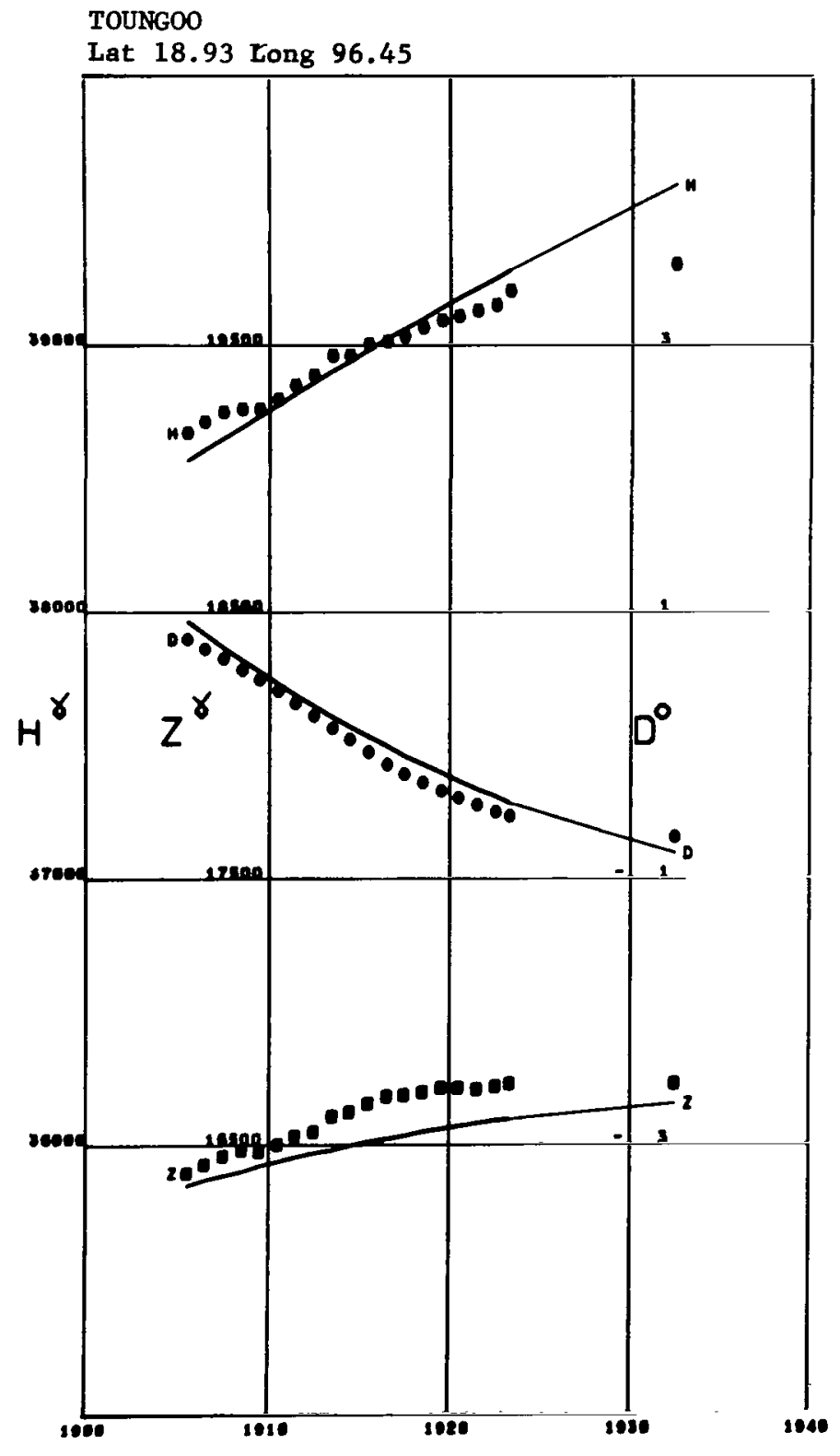

Figure A 182 
TOYOHARA

Lat 46.94 Long 142.74

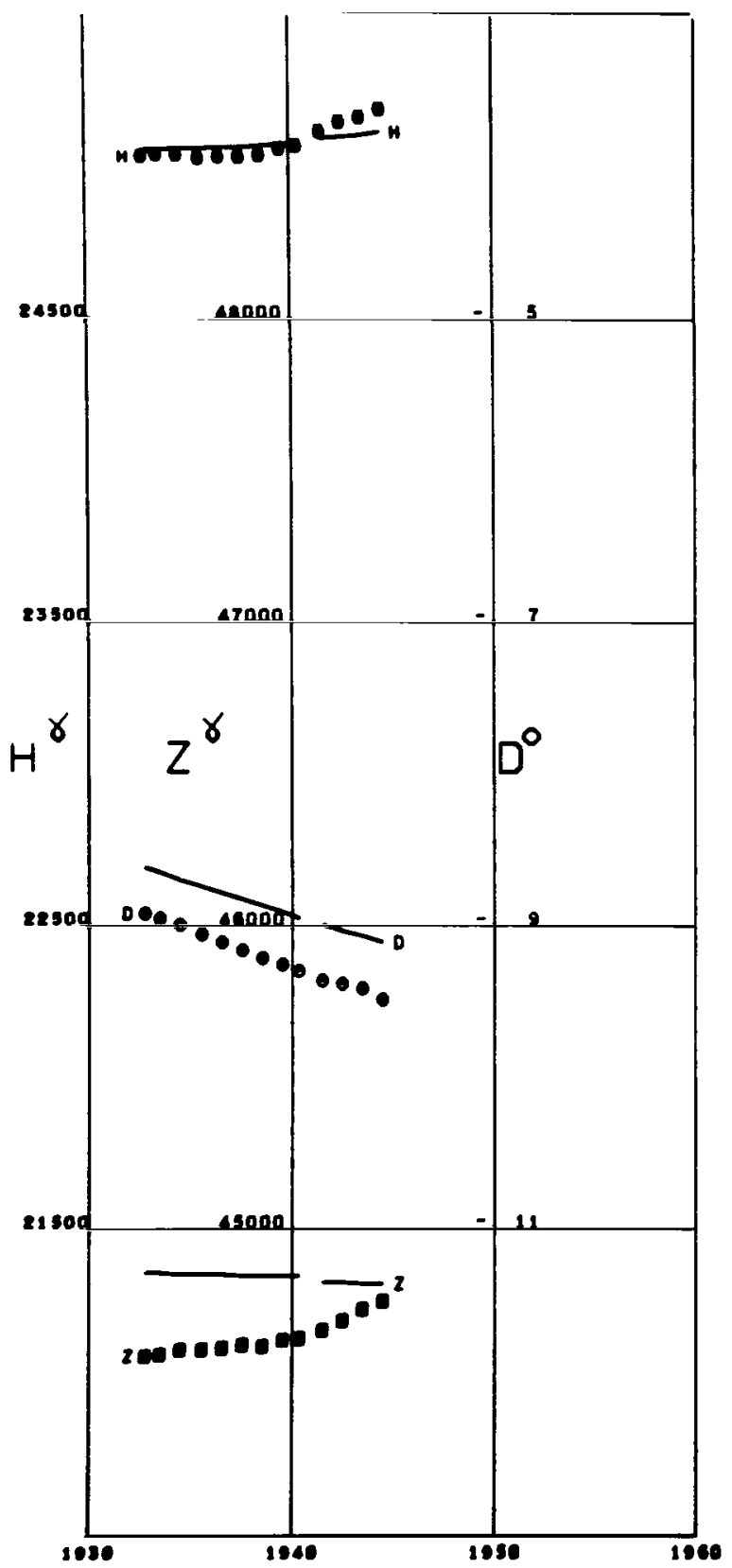

Figure A 183
TRELEW

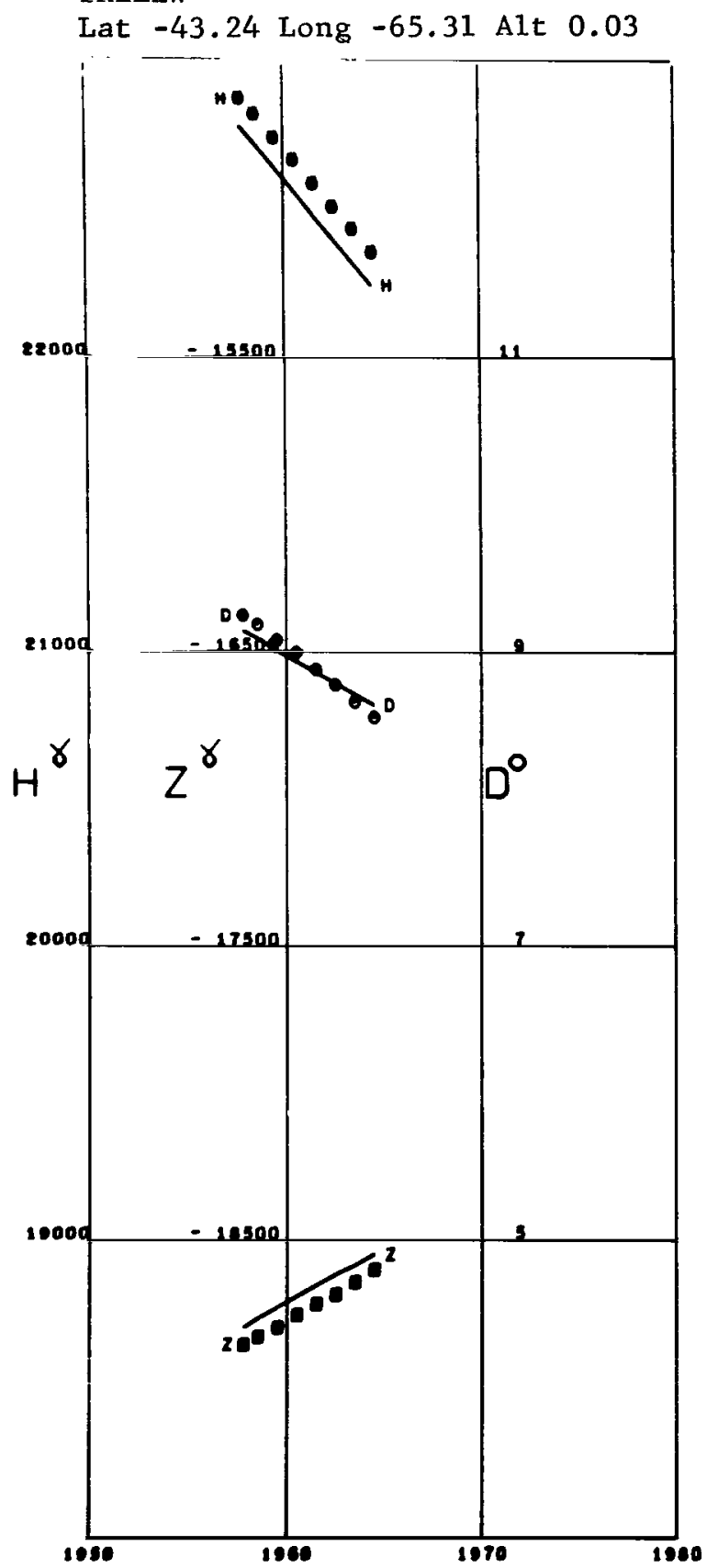

Figure A184 


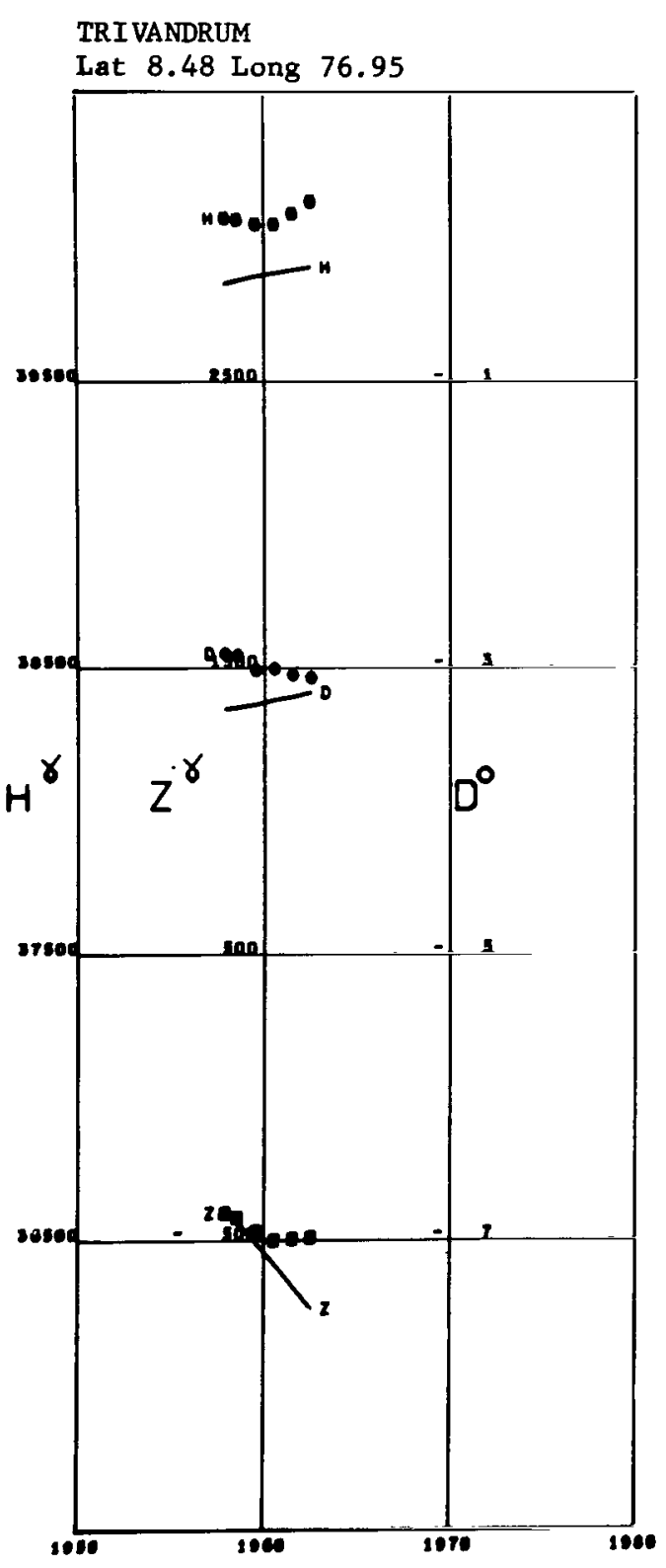

Figure A185
TROMSO

Lat 69.66 Long 18.94

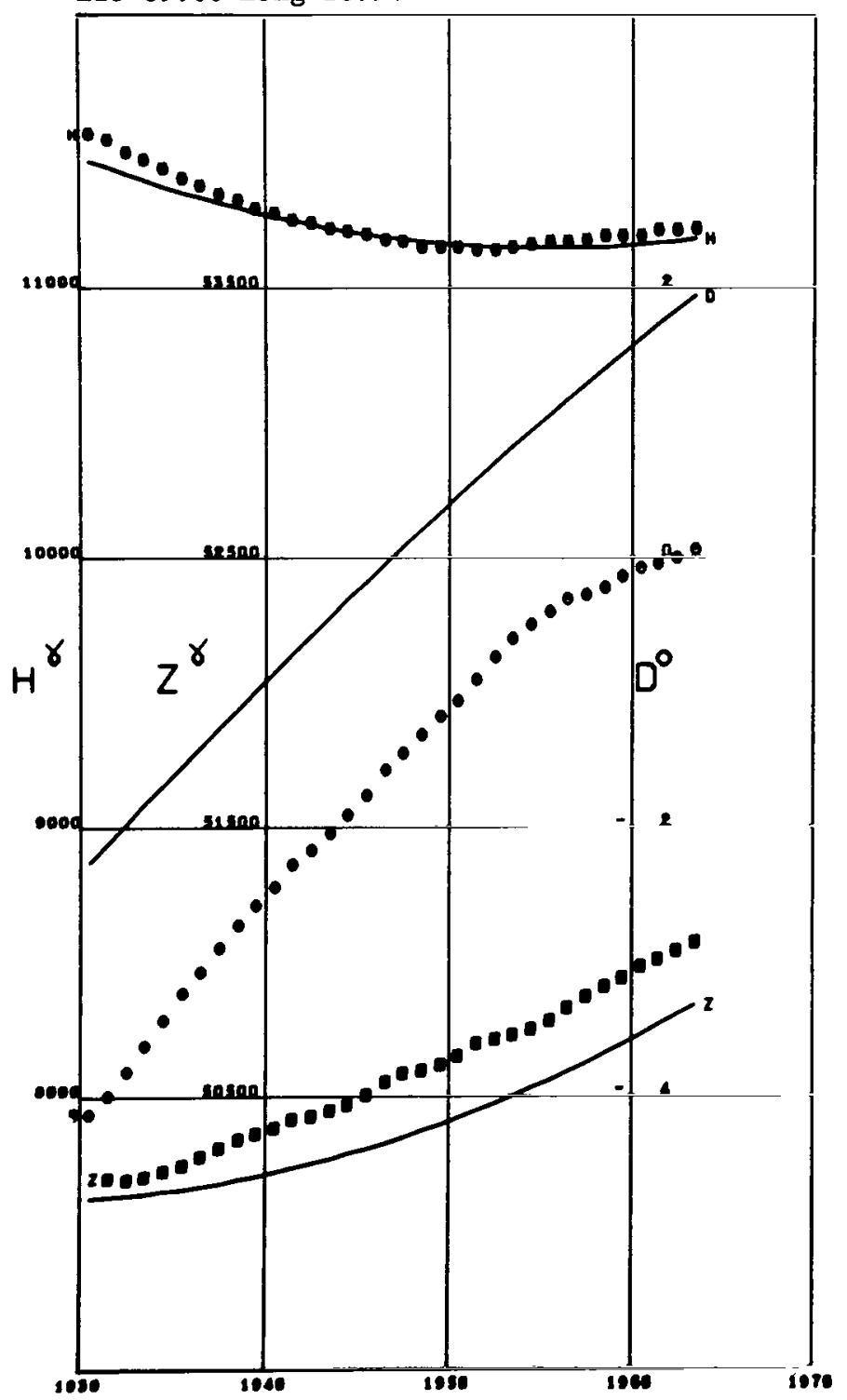

Figure A186 
TSINGTAO

Lat 36.07 Long 120.32

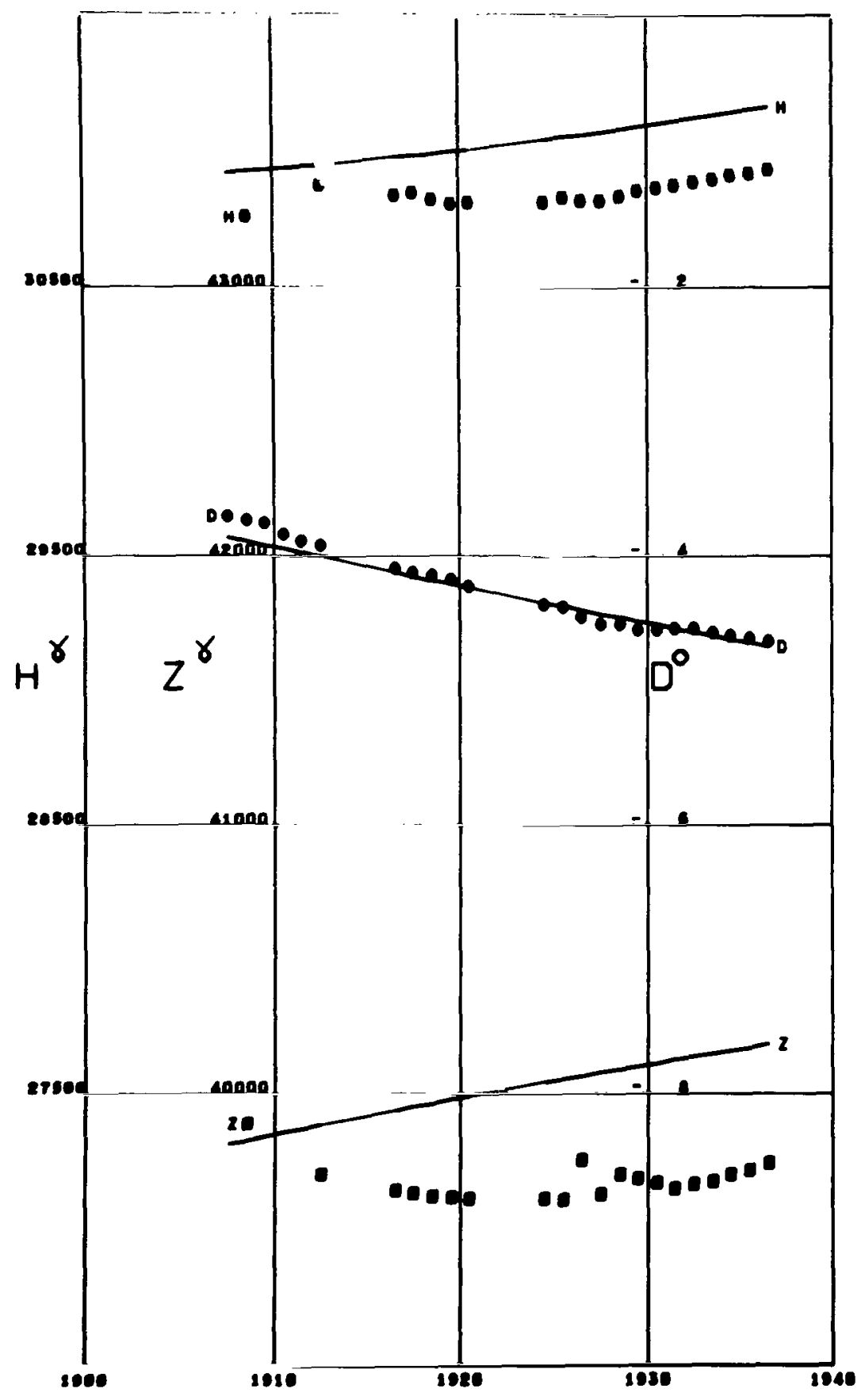

Figure A187 


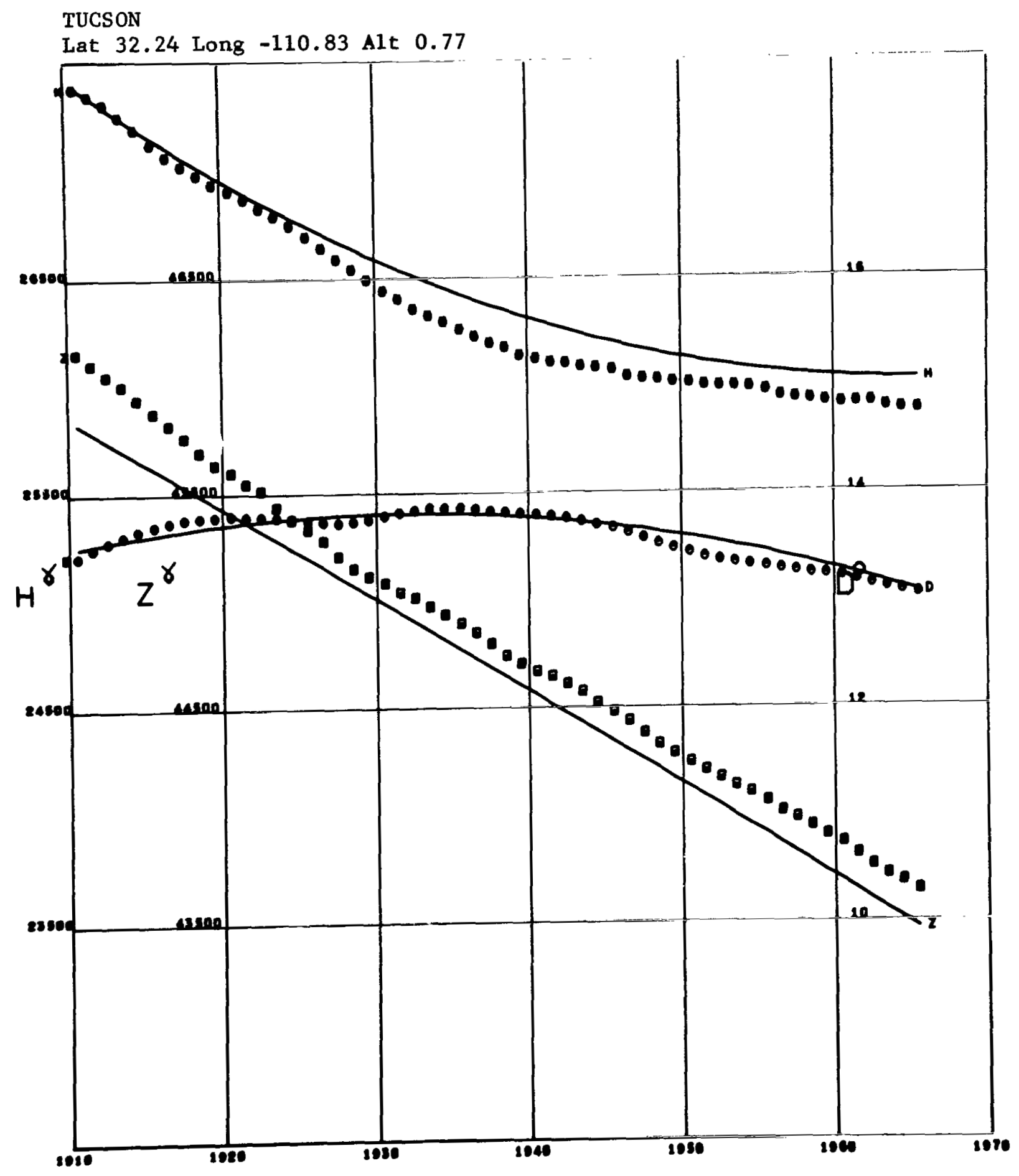

Figure A188 


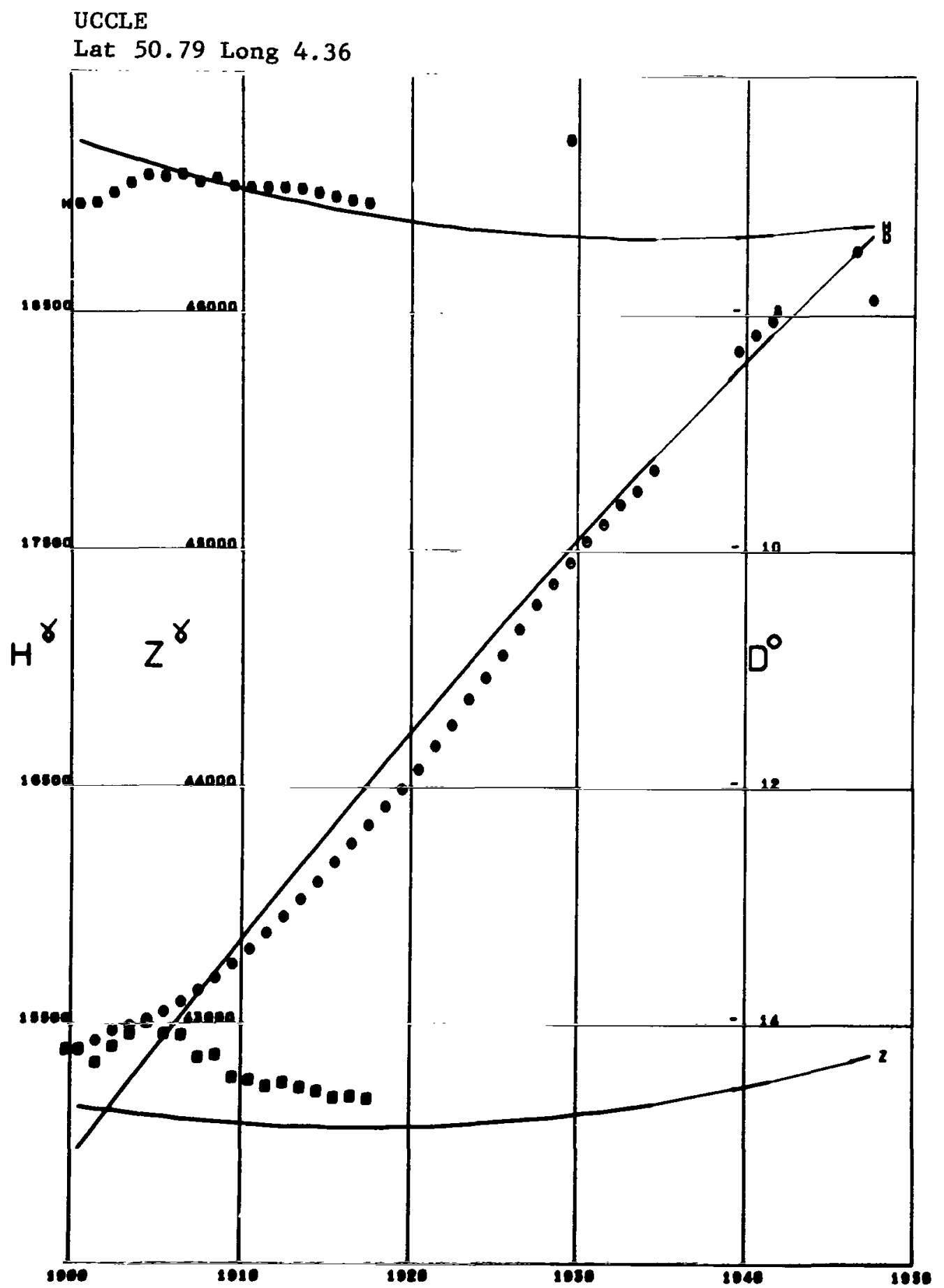

Figure A189 


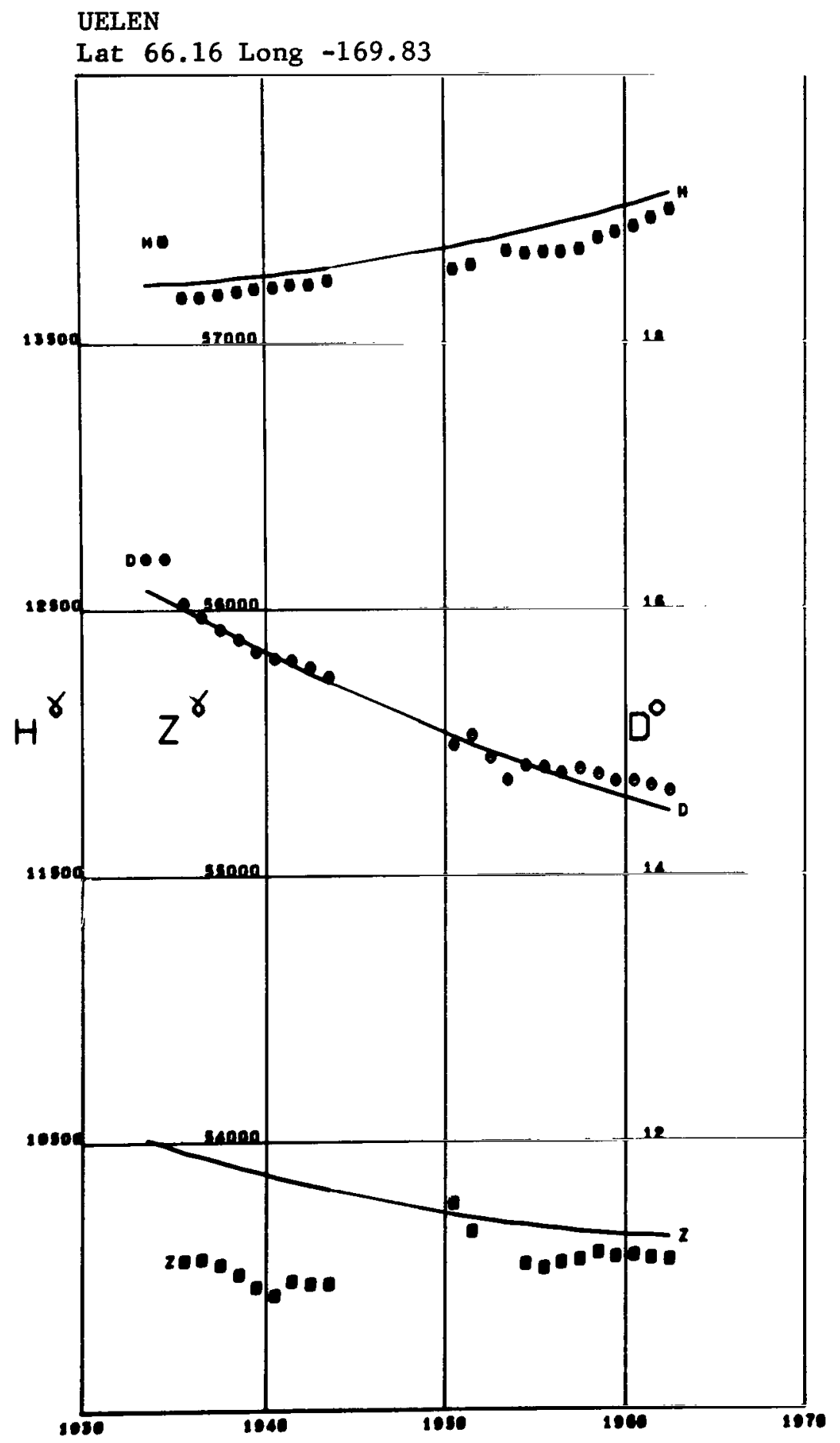

Figure A190 


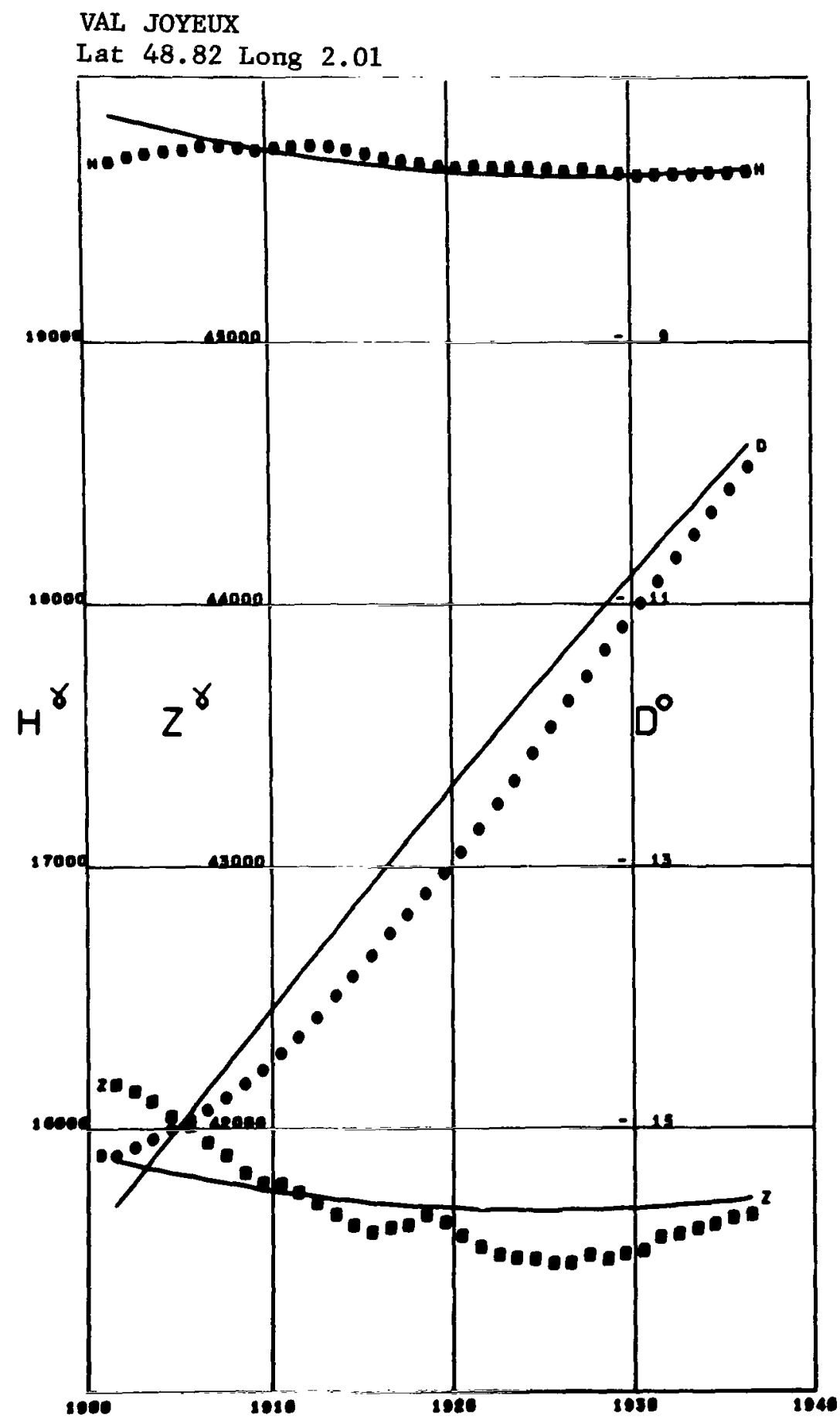

Figure A191 
VALENTIA

Lat 51.93 Long -10.25

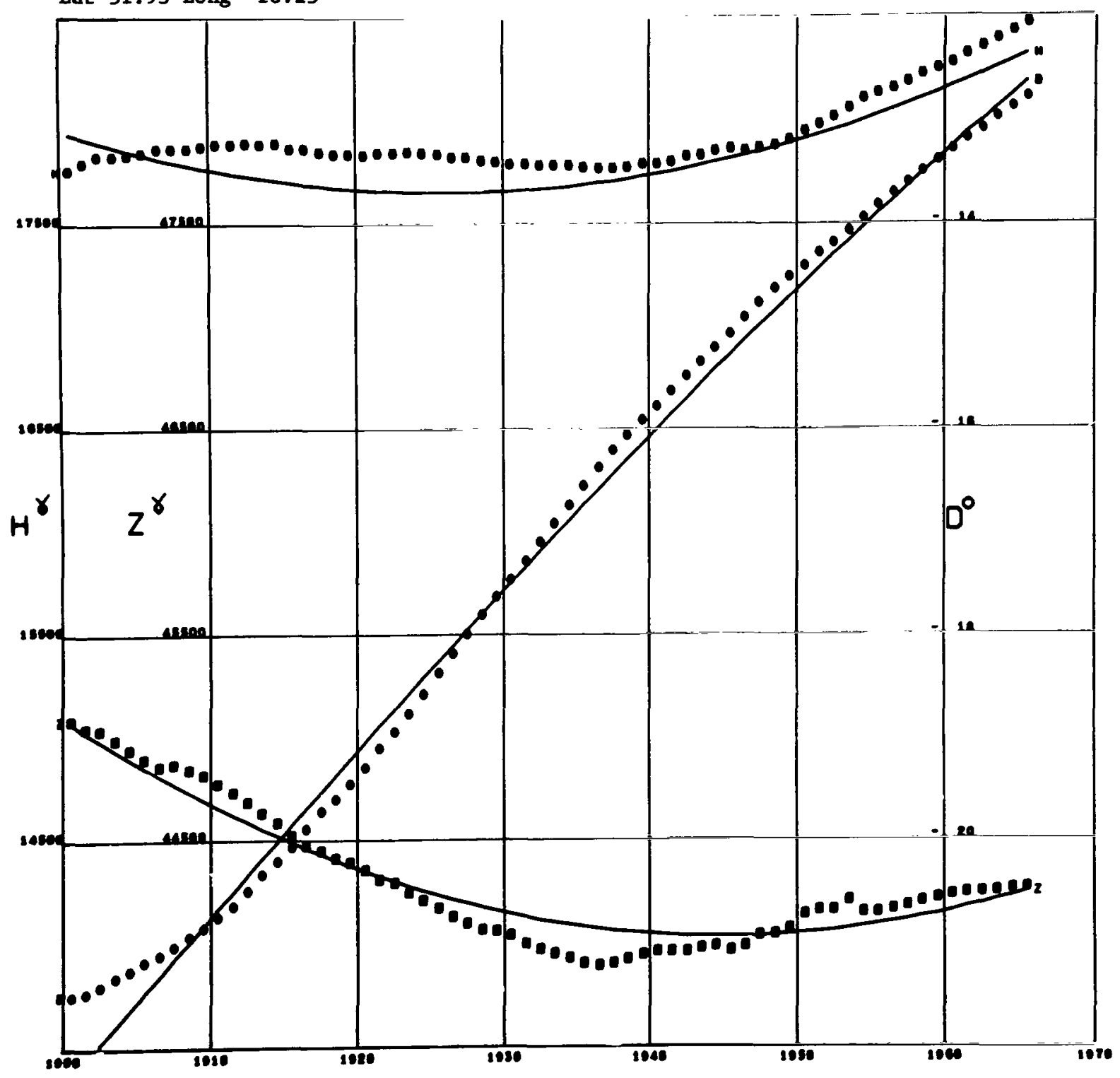

Figure A192 


\section{VASSOURAS}

Lat -22.40 Long -43.65 Alt 0.46

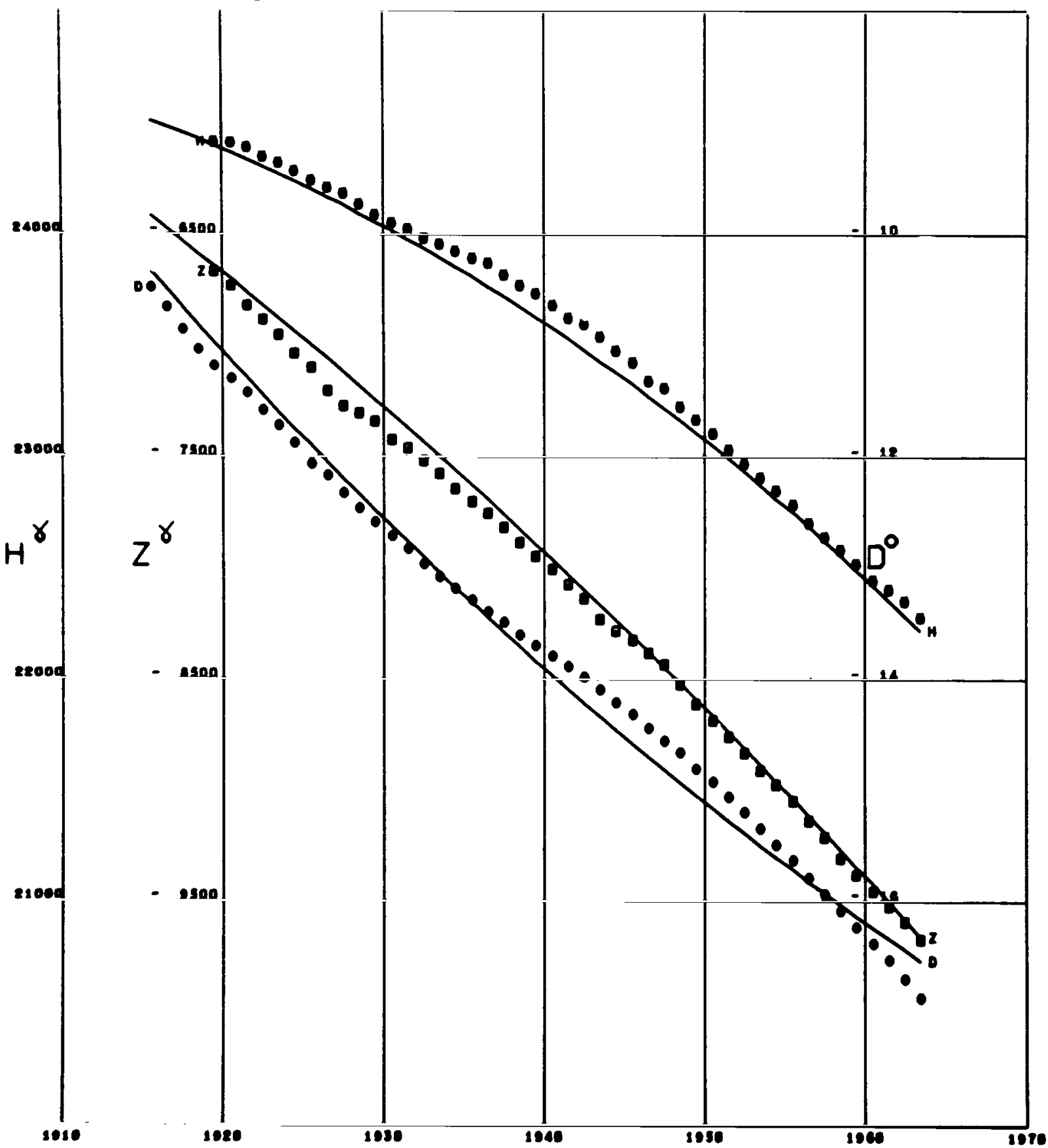

Figure A193 


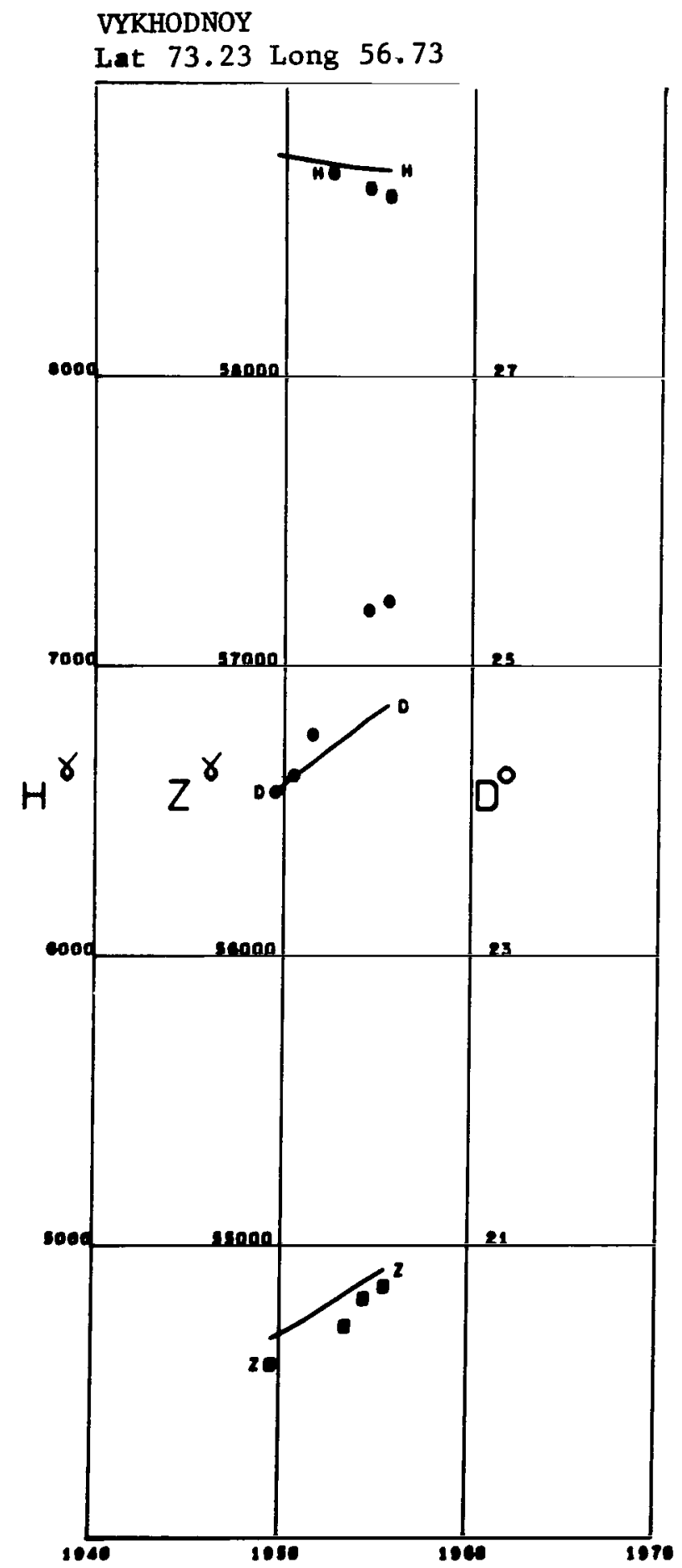

Figure A198 
VYSOKAYA DUBRAVA

Lat 56.73 Long 61.06 Alt 0.29

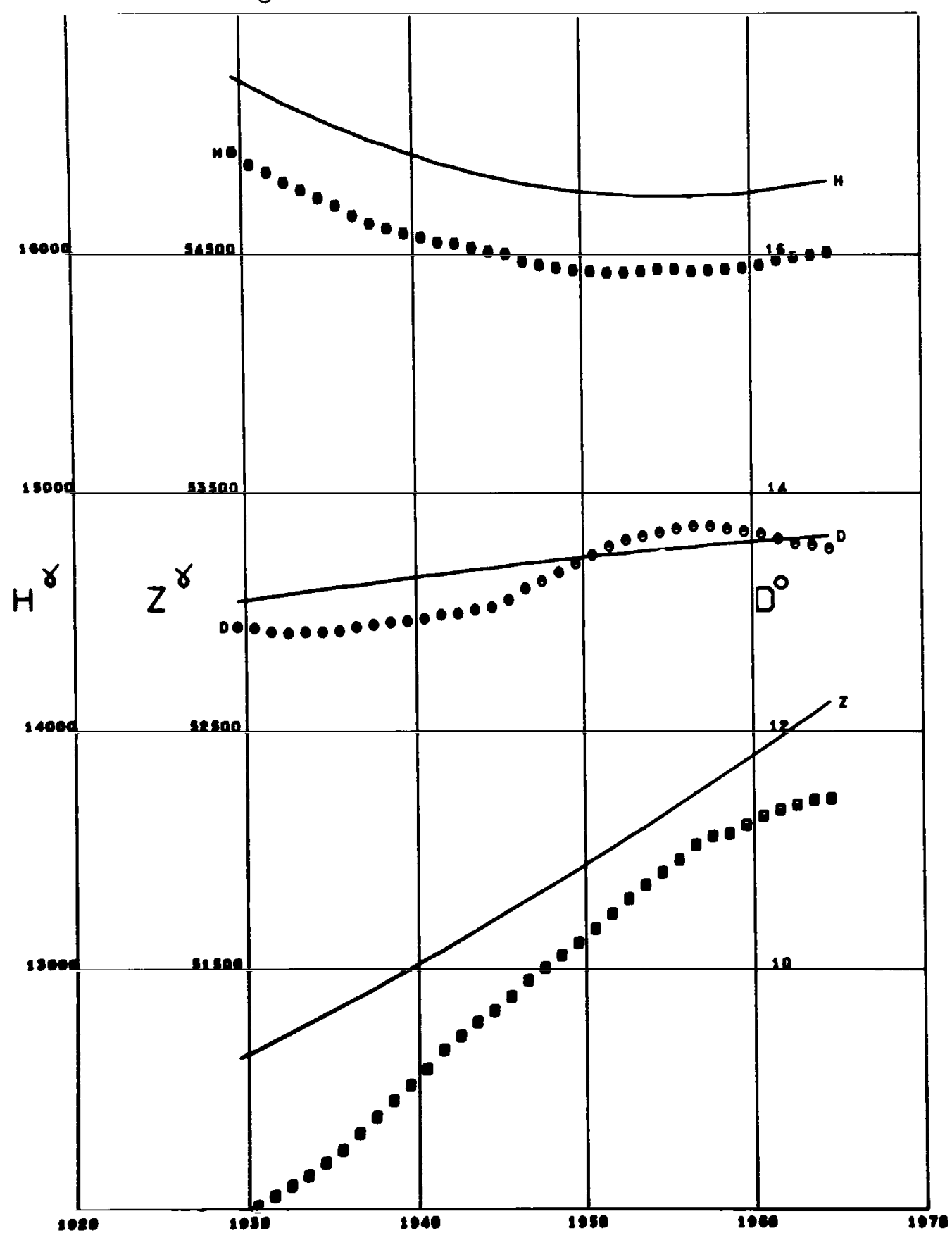

Figure A199 


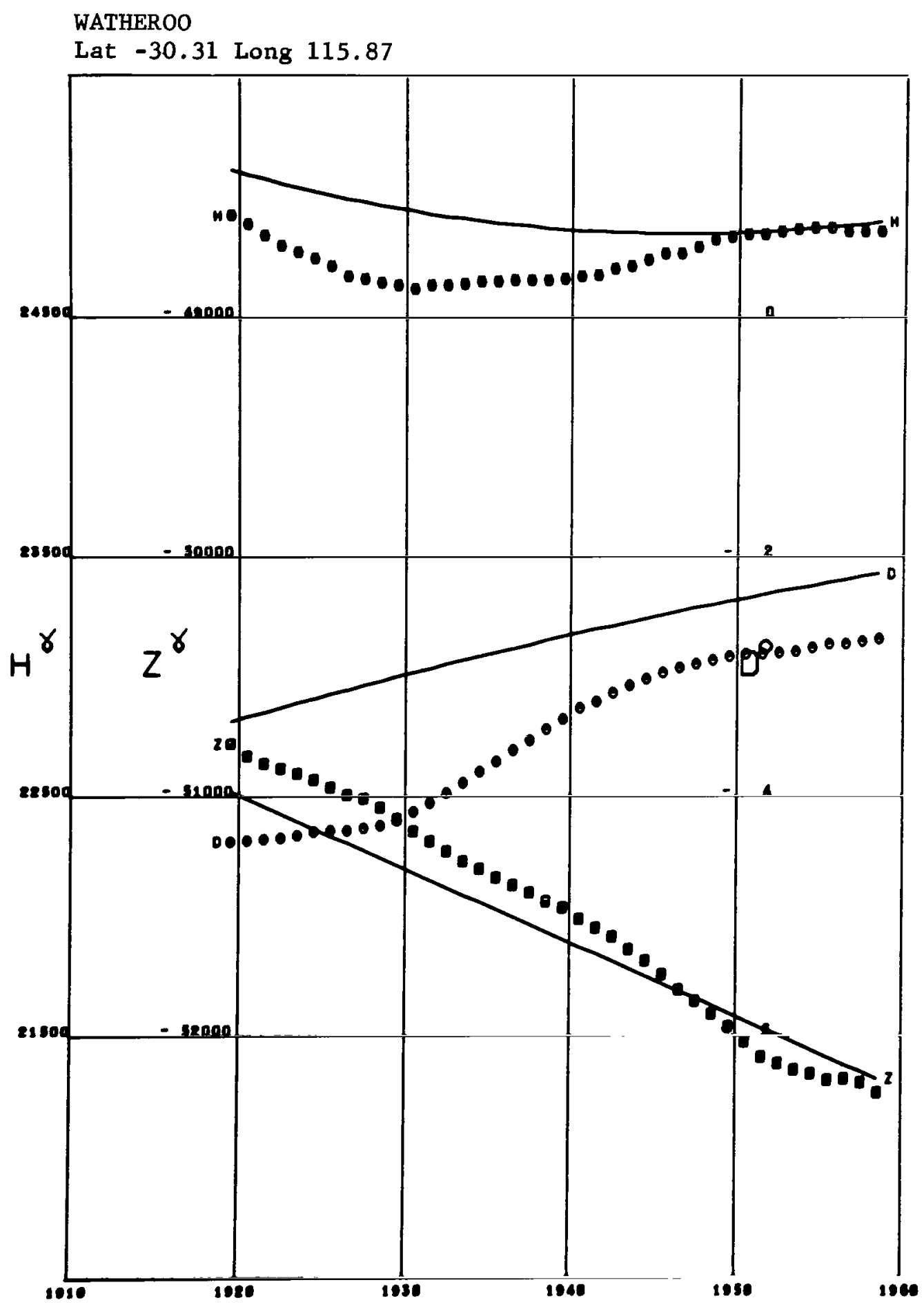

Figure A200 
WIEN AUHOF

Lat 48.20 Long 16.23

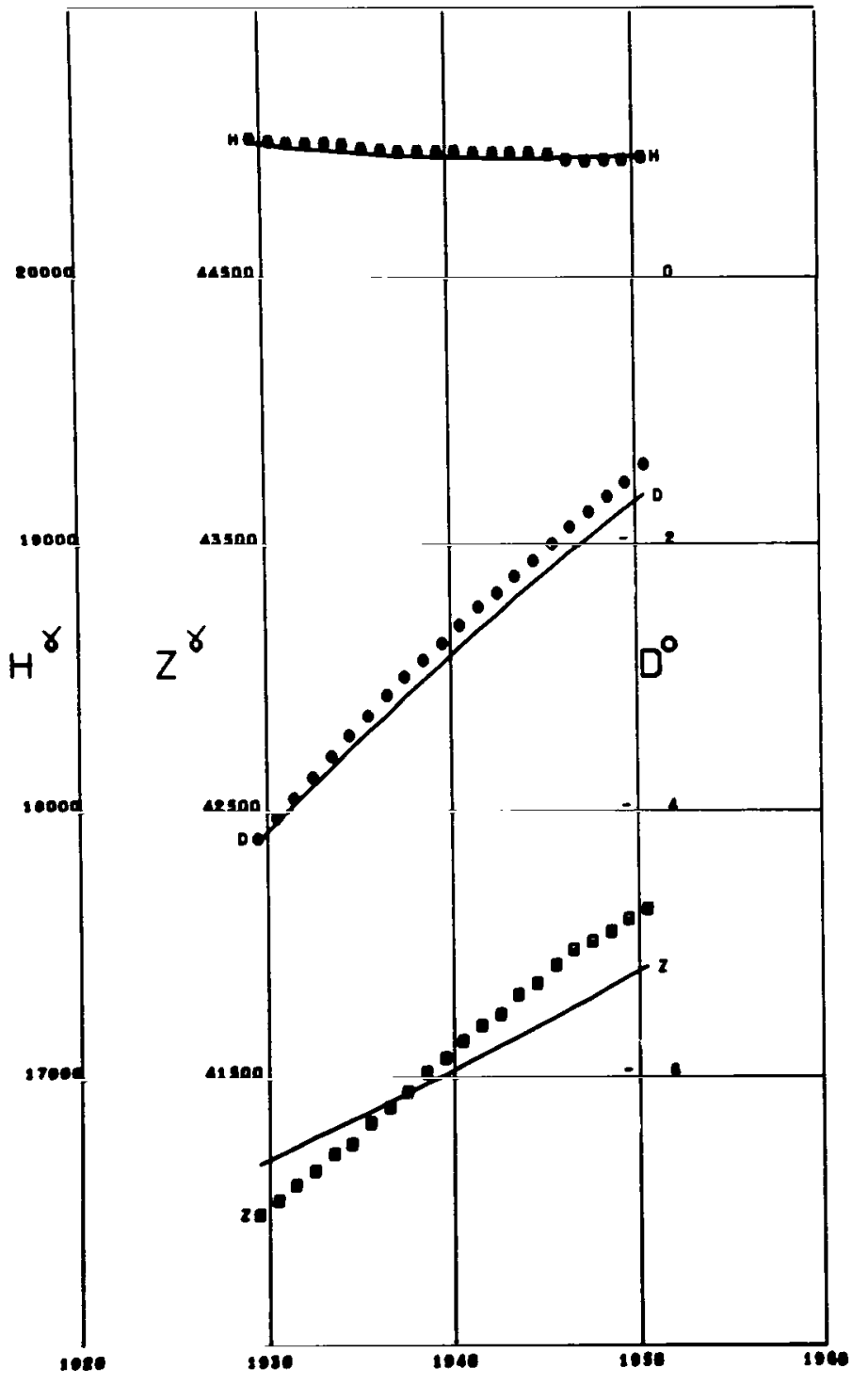

Figure A201
WIEN KOBENZL

Lat 48.26 Long 16.31

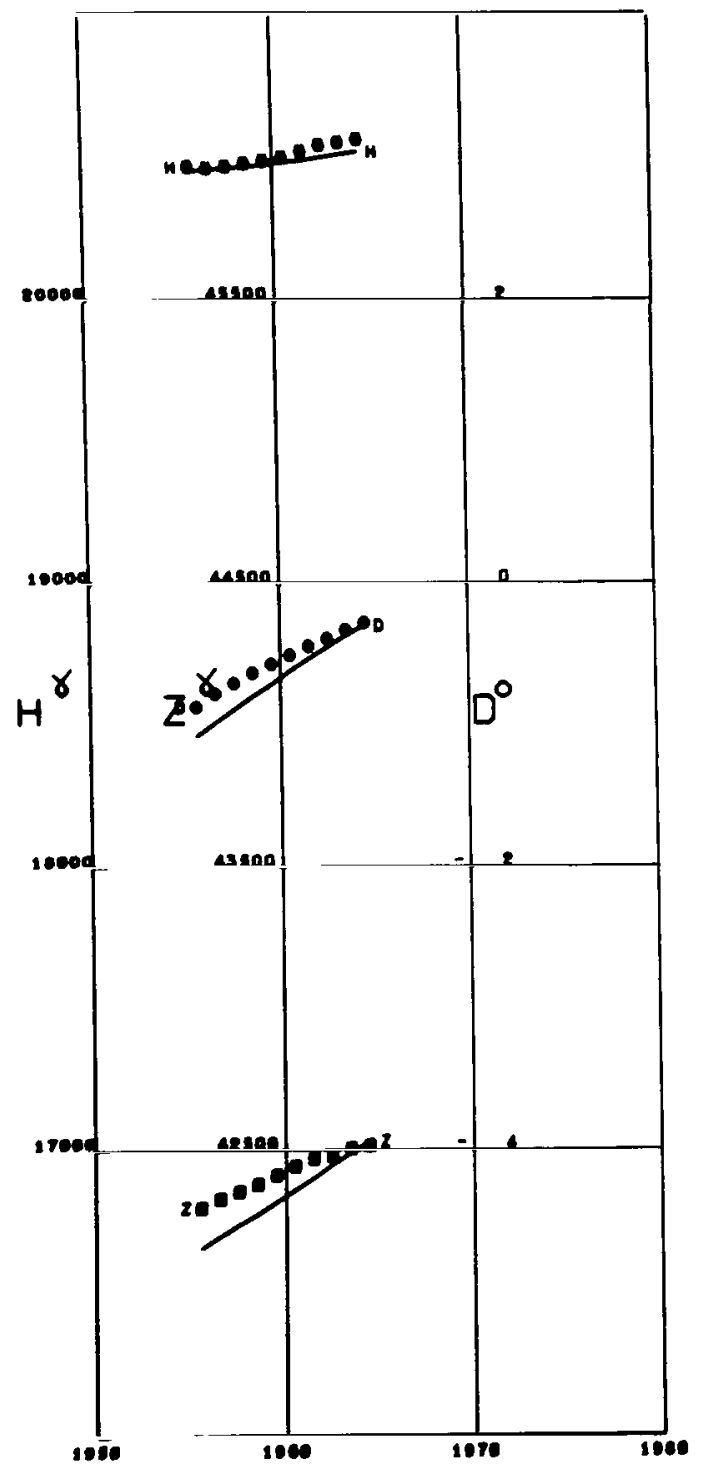

Figure A202 
WILHELMSHA VEN

Lat 53.53 Long 8.14

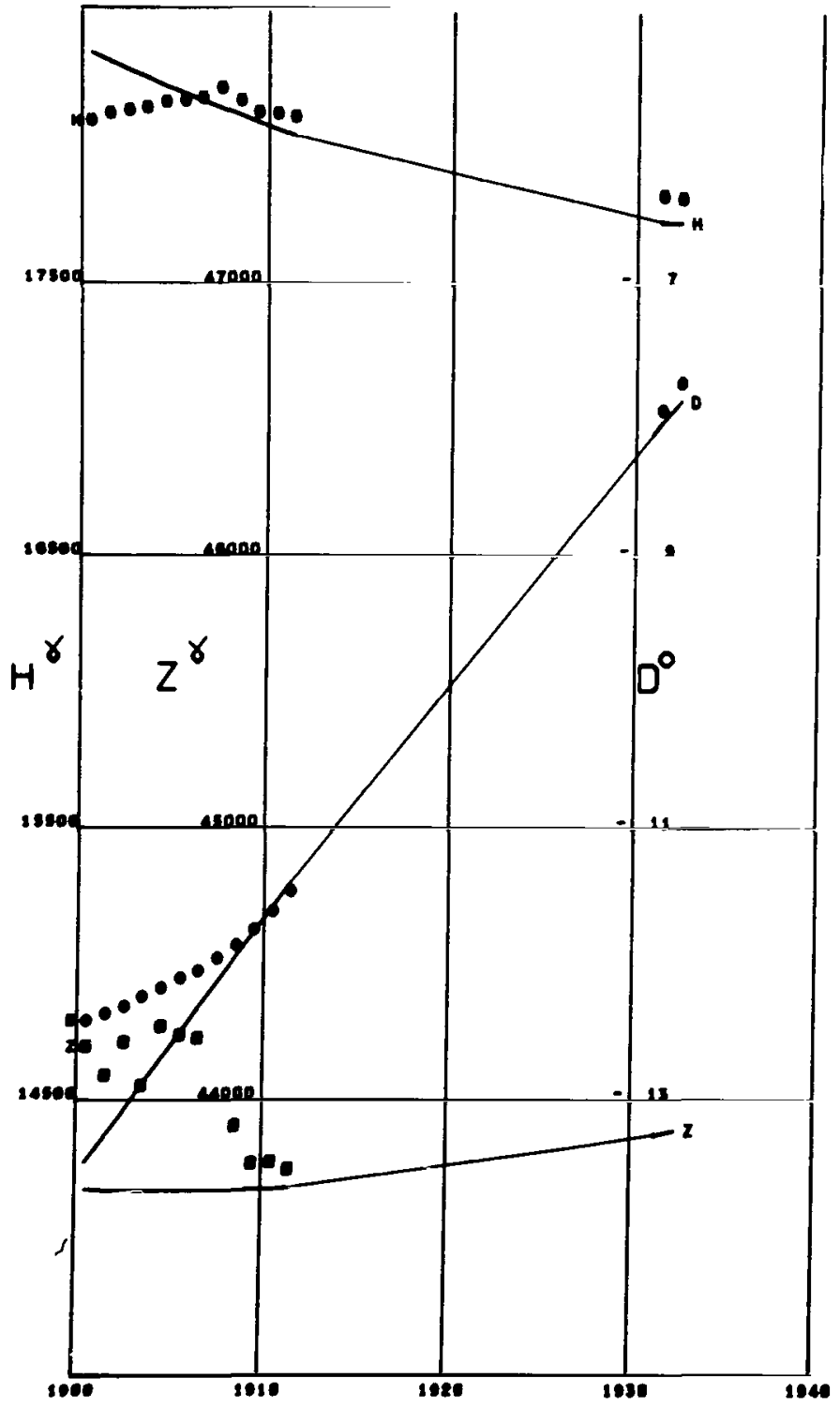

Figure A203
WILKES

Lat -66.25 Long 110.58 A1t 0.01

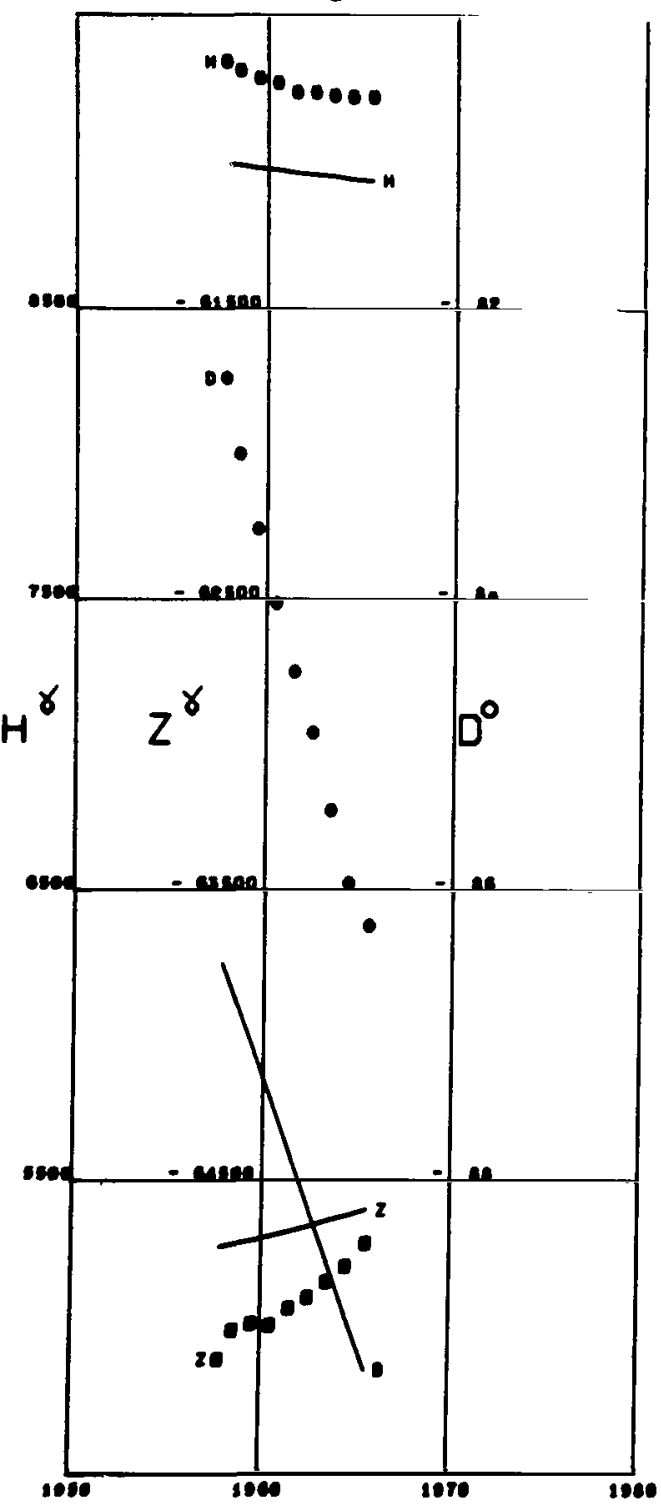

Figure A204 


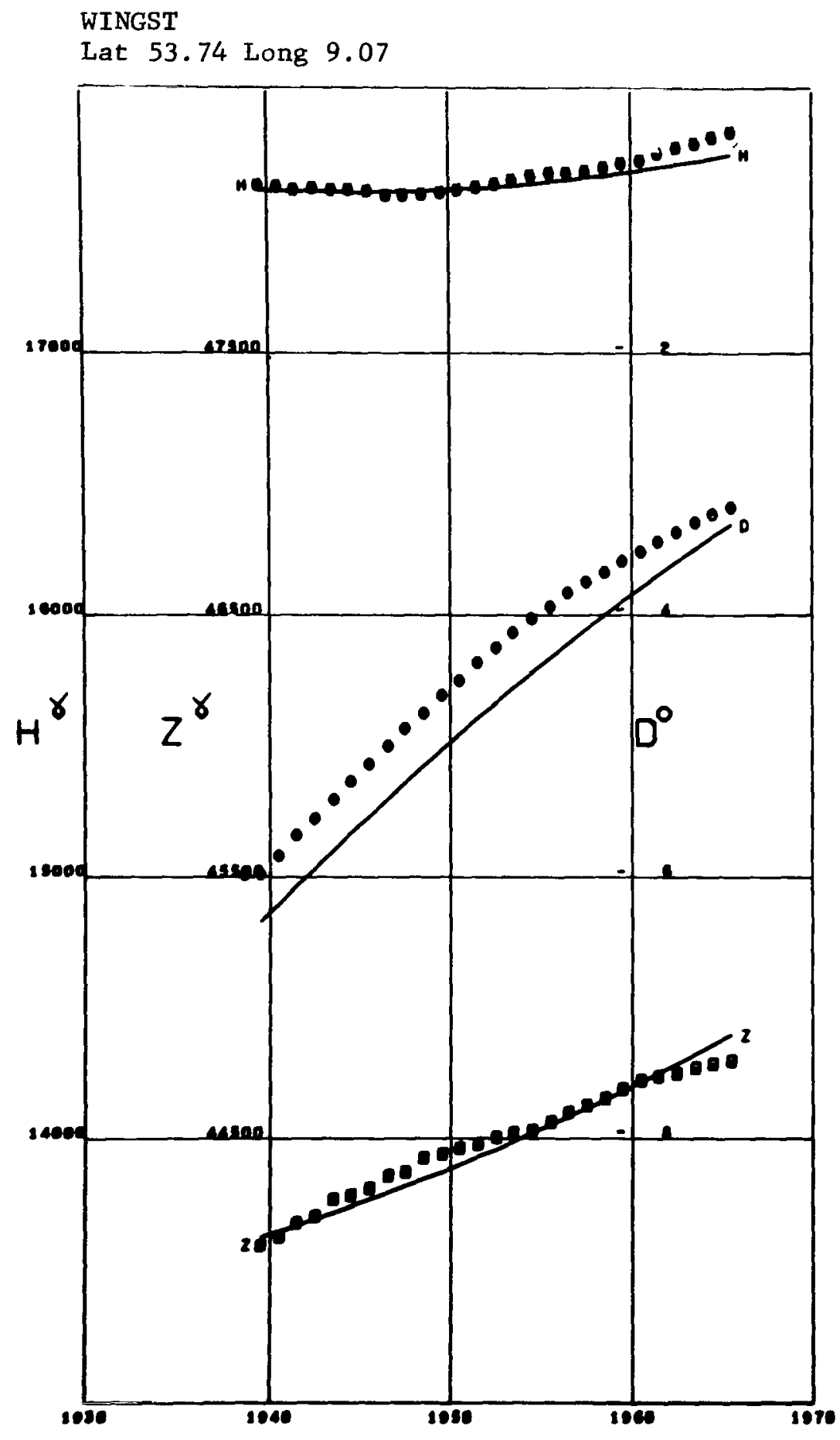

Figure A205 


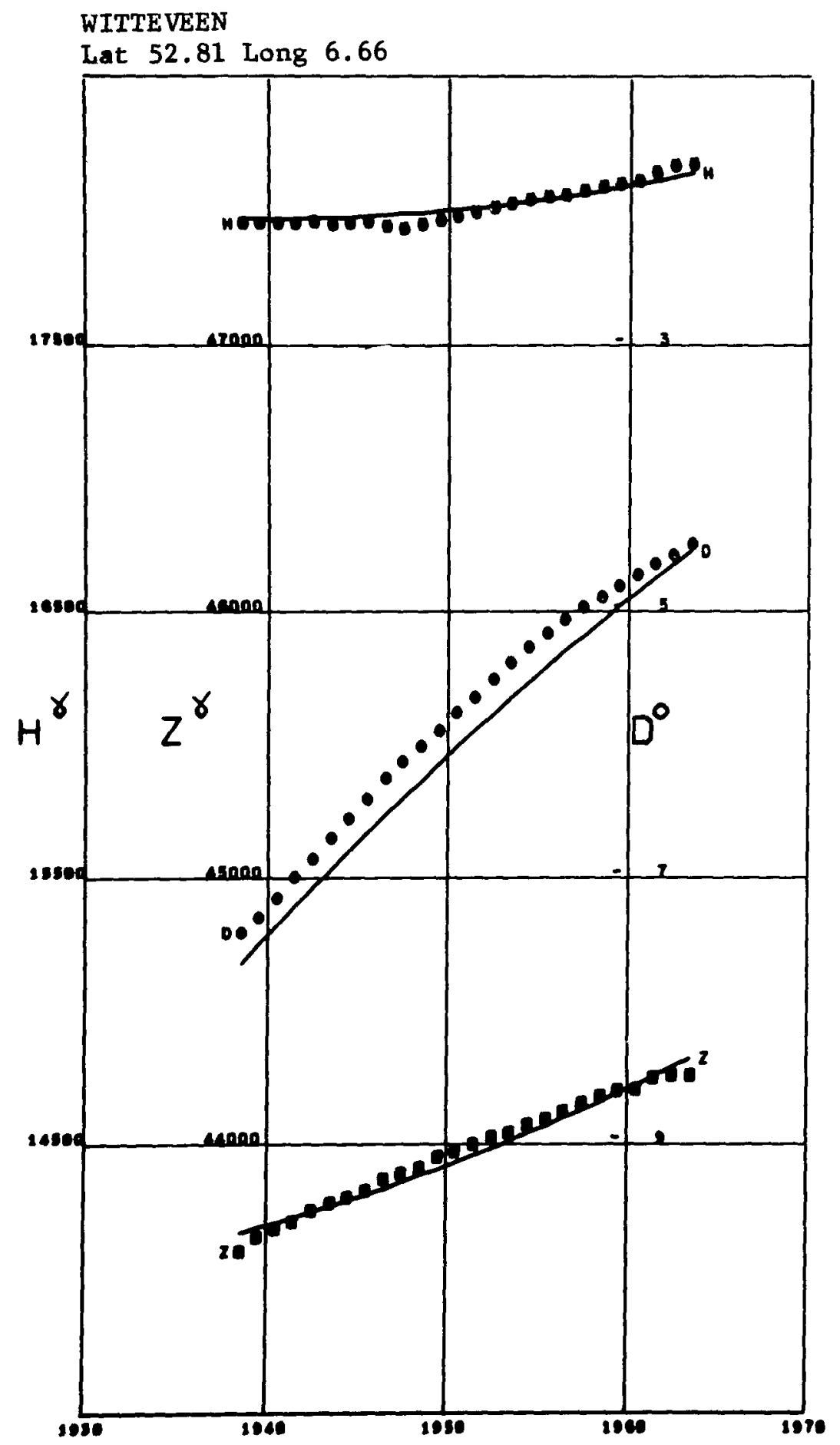

Figure A206 
YAKUTSK

Lat 62.01 Long 129.71 Alt 0.10

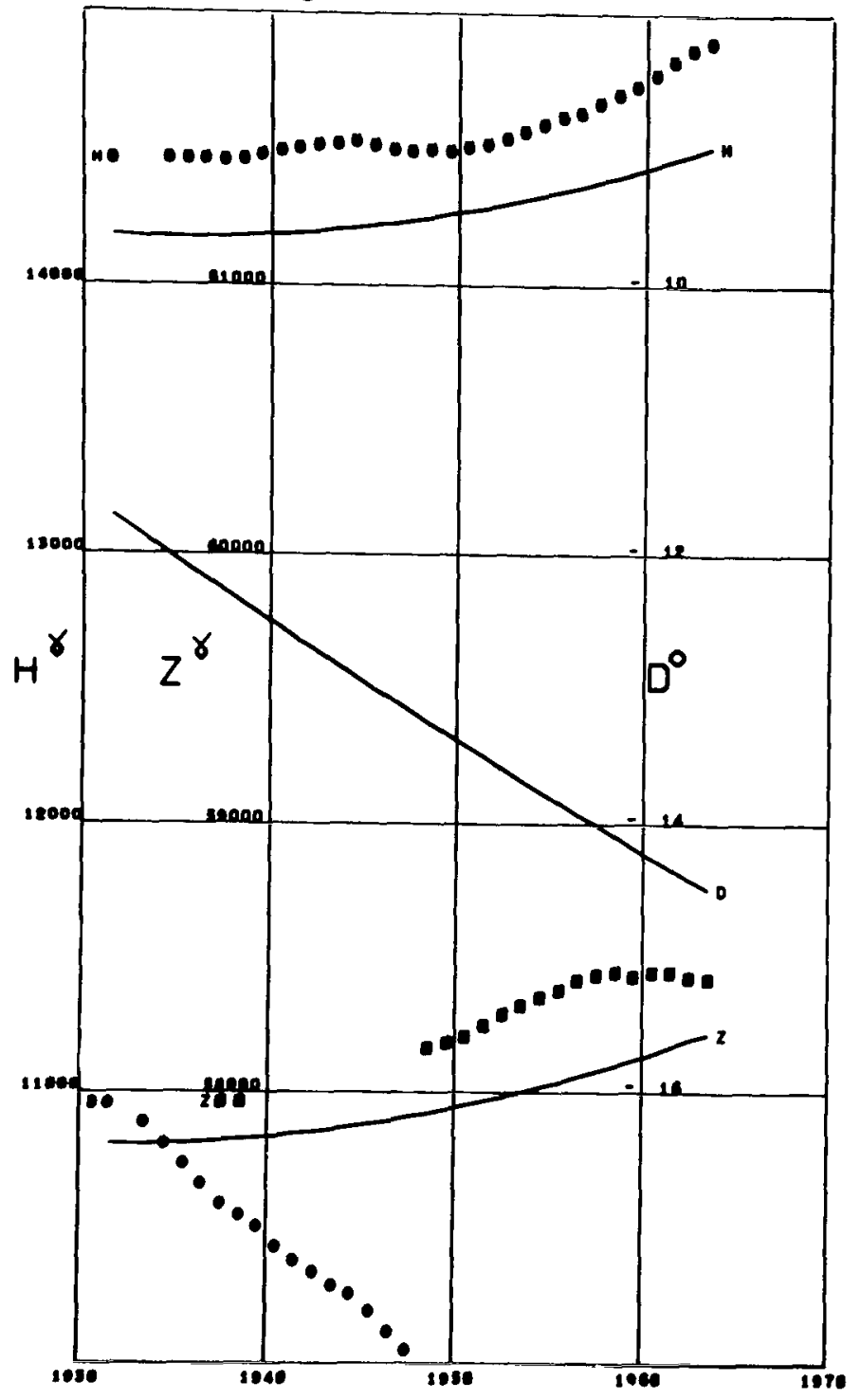

Figure A207
YUZHNO SAKHALINSK

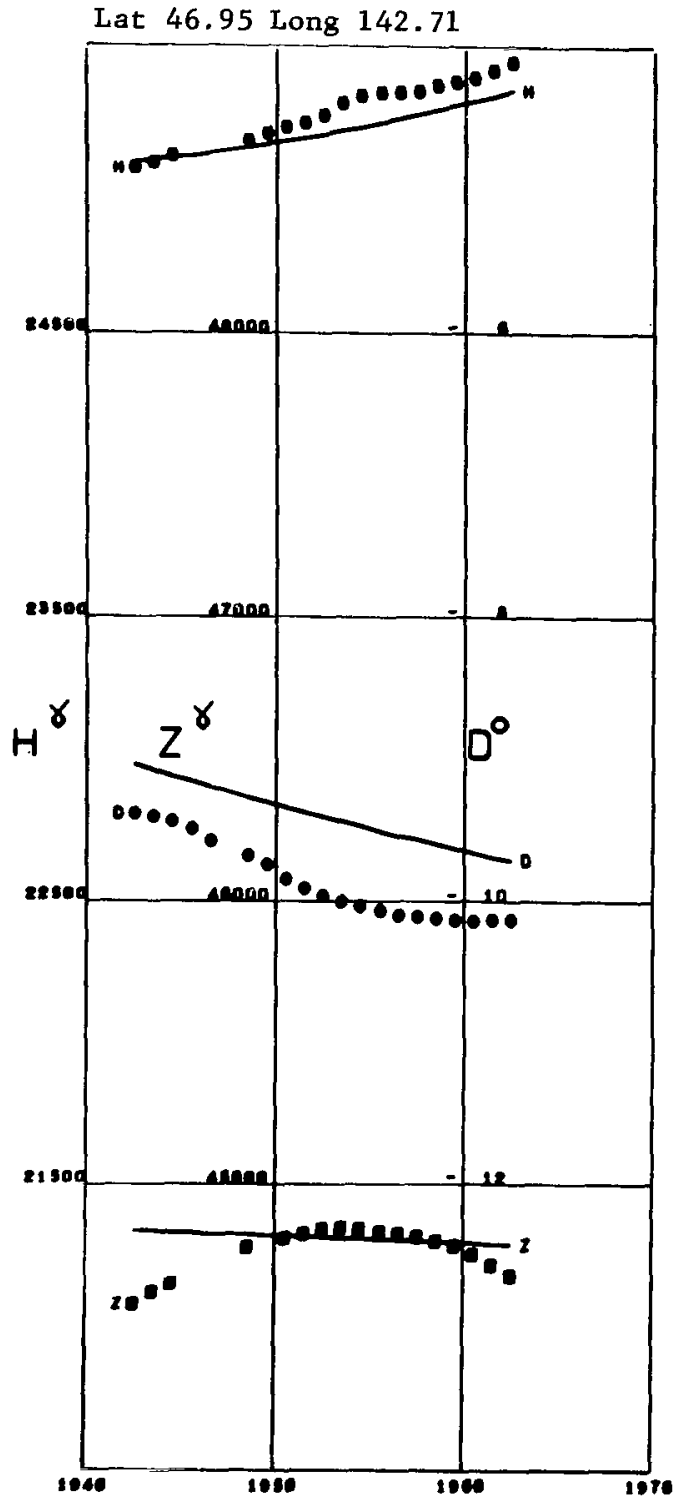

Figure A208 
ZAYMISHCHE

Lat 55.83 Long 48.85

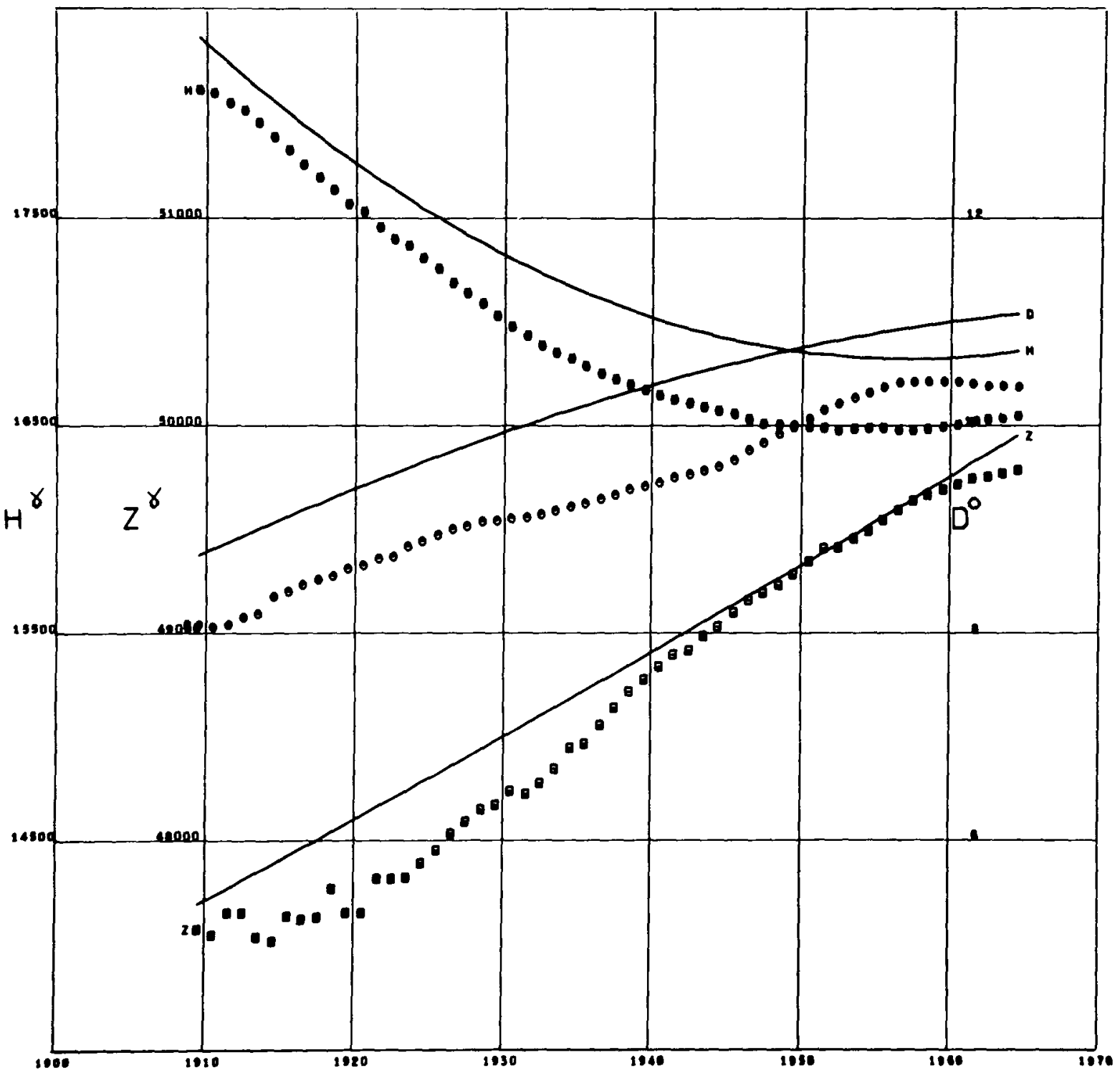

Figure A209 


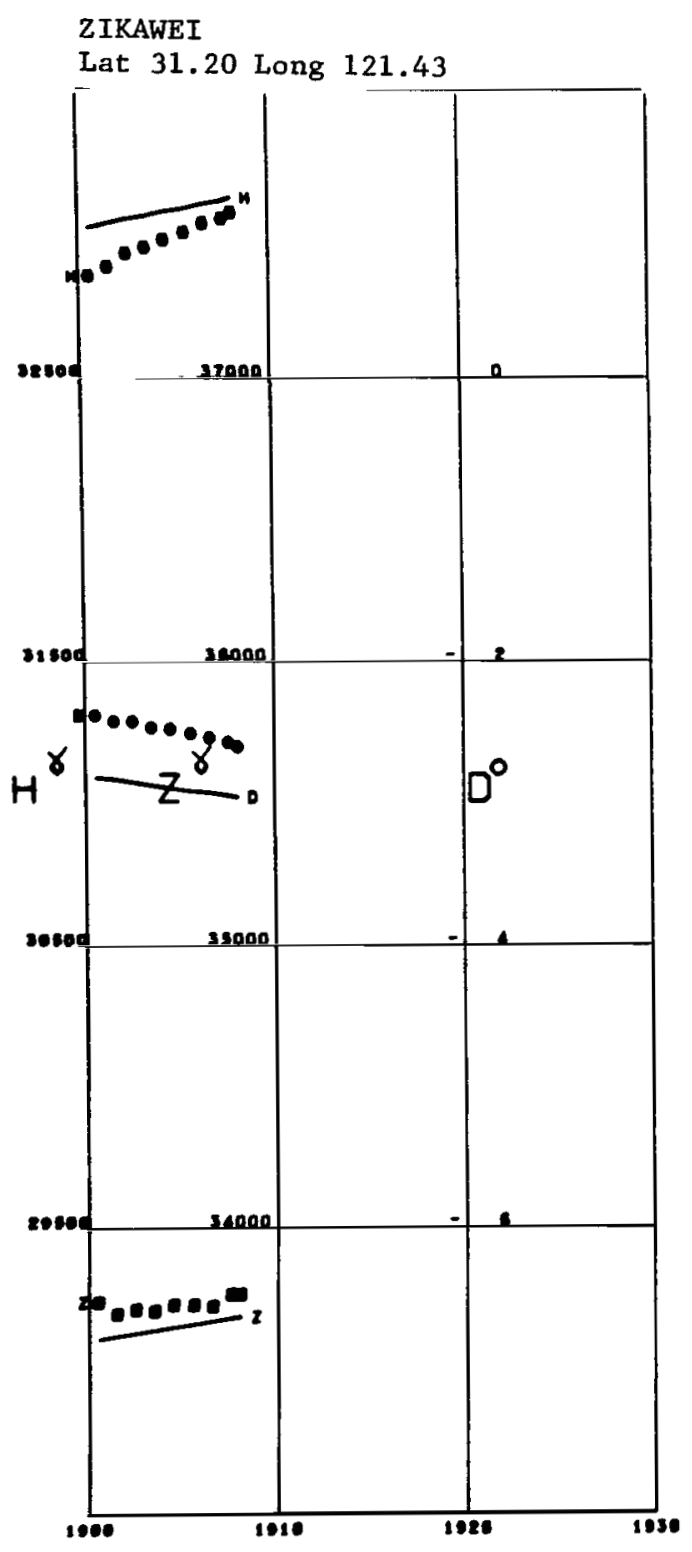

Figure A2 10

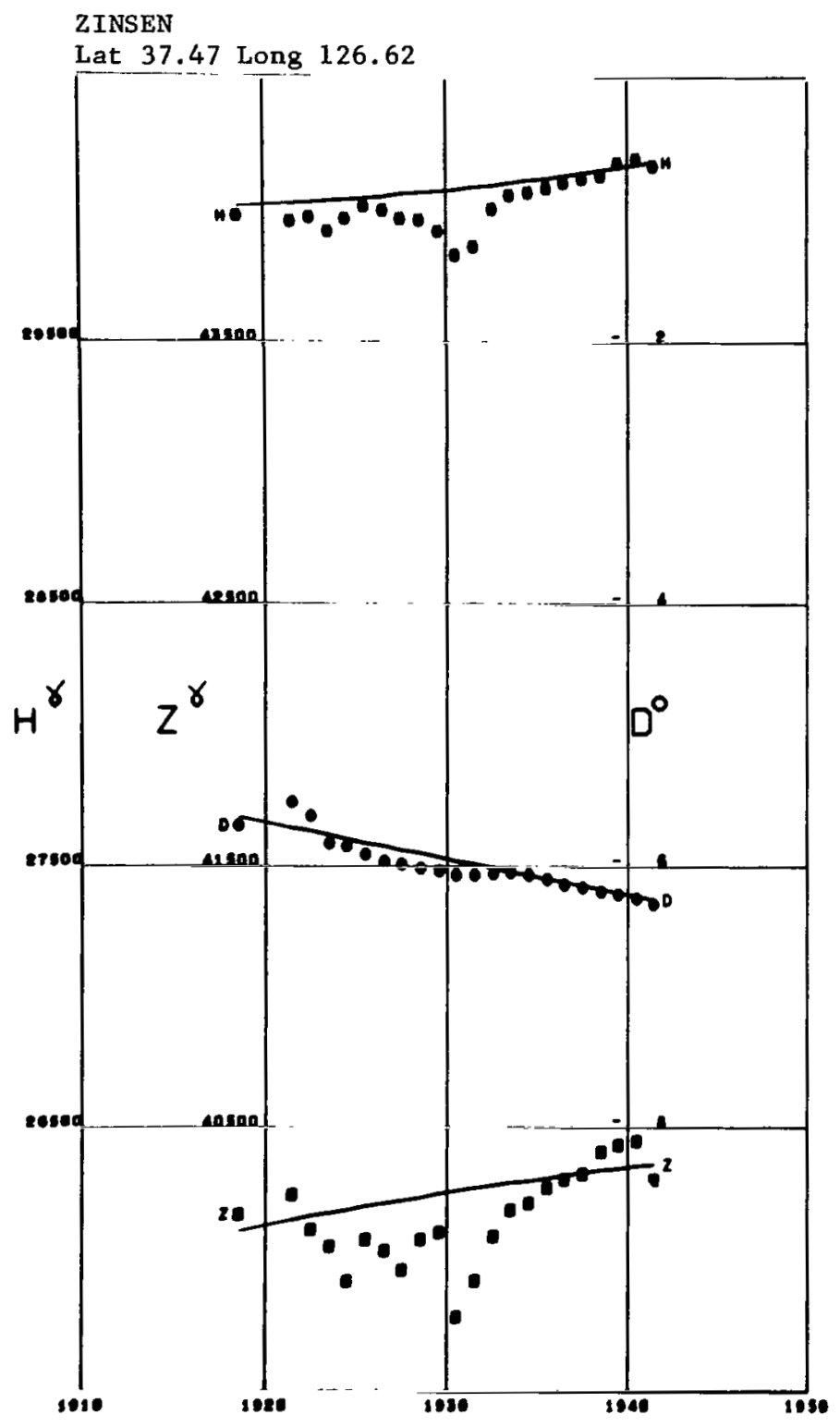

Figure A211 


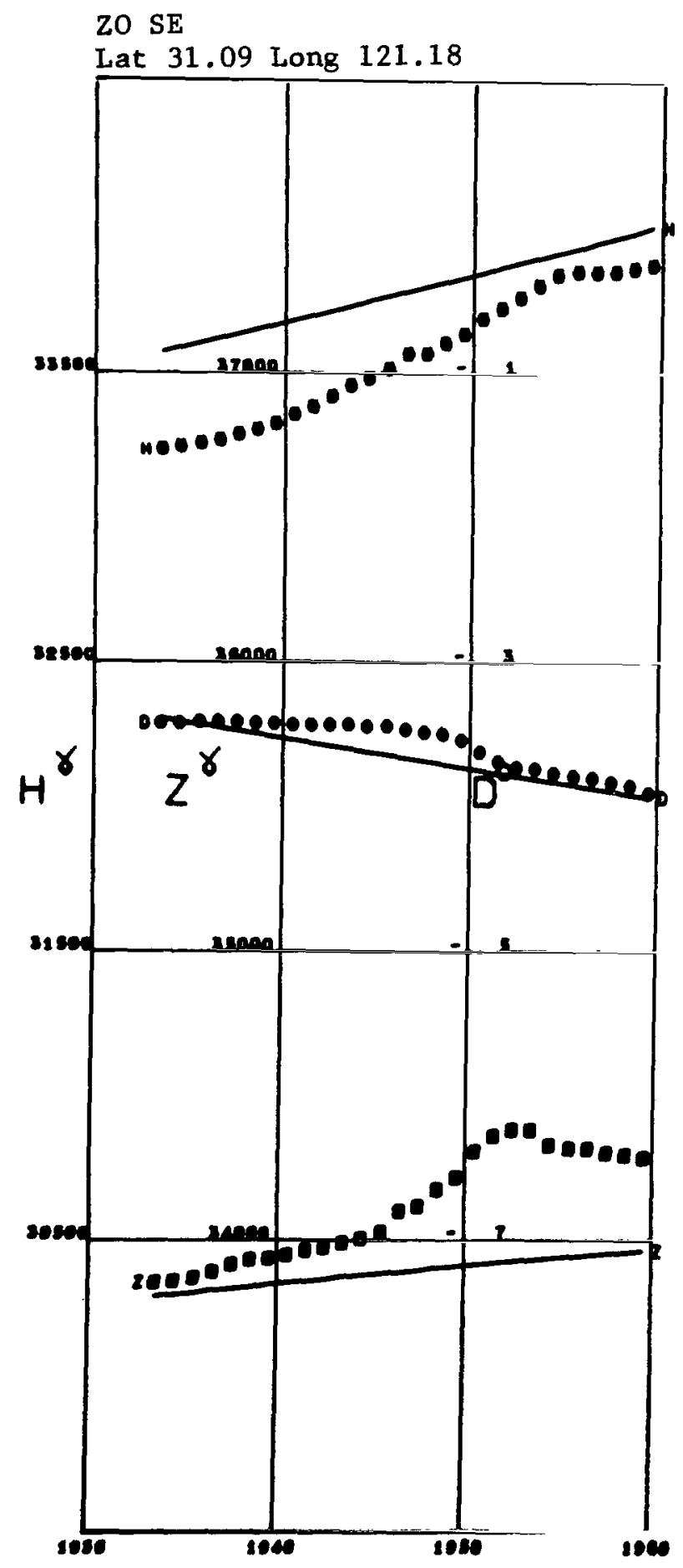

Figure A212 


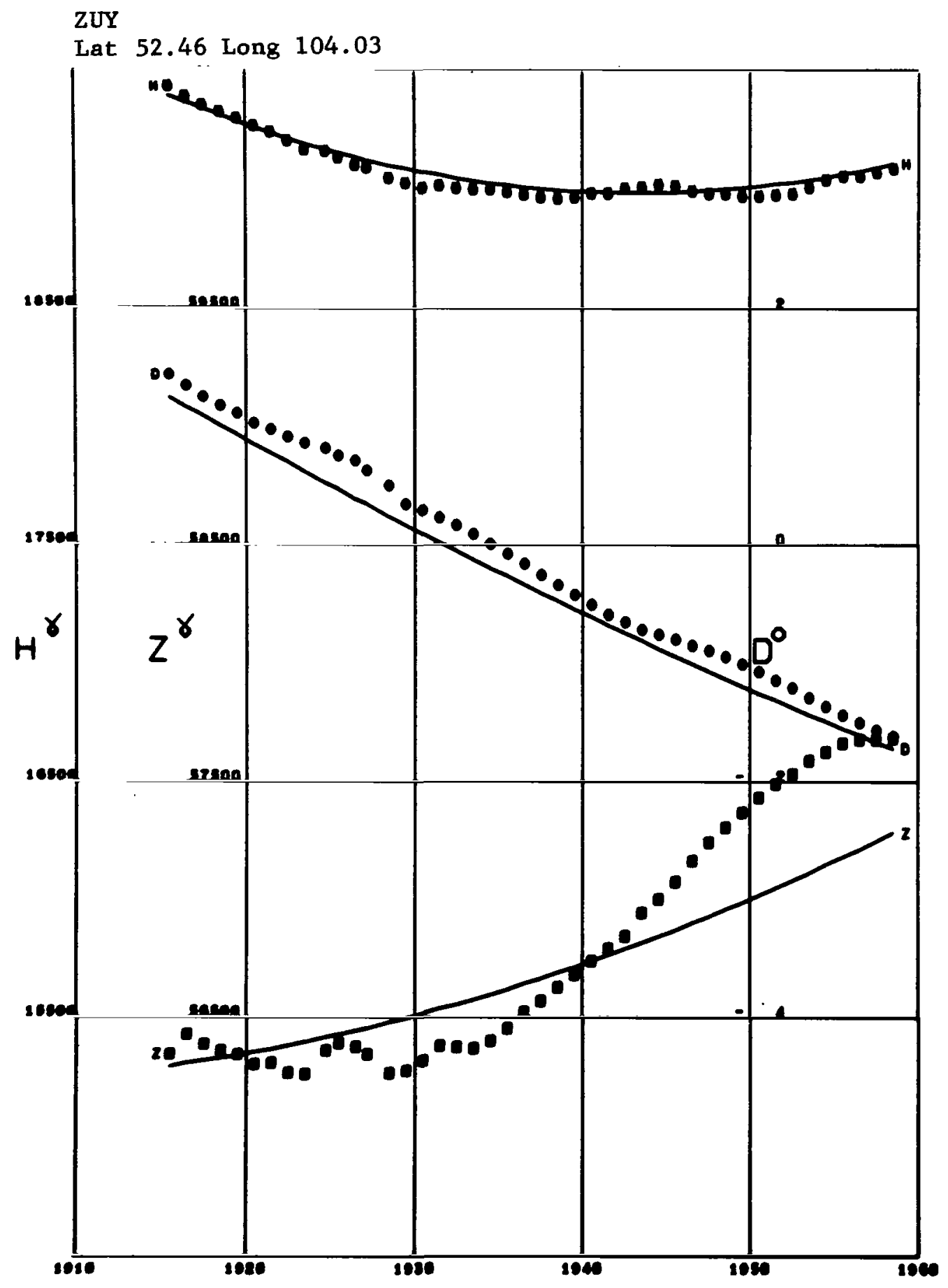

Figure A213 


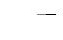


Appendix B

Comparison of Isoporic Charts (1912-1942) From GSFC (12/66) With Those From Vestine et al. (1947) 
夰

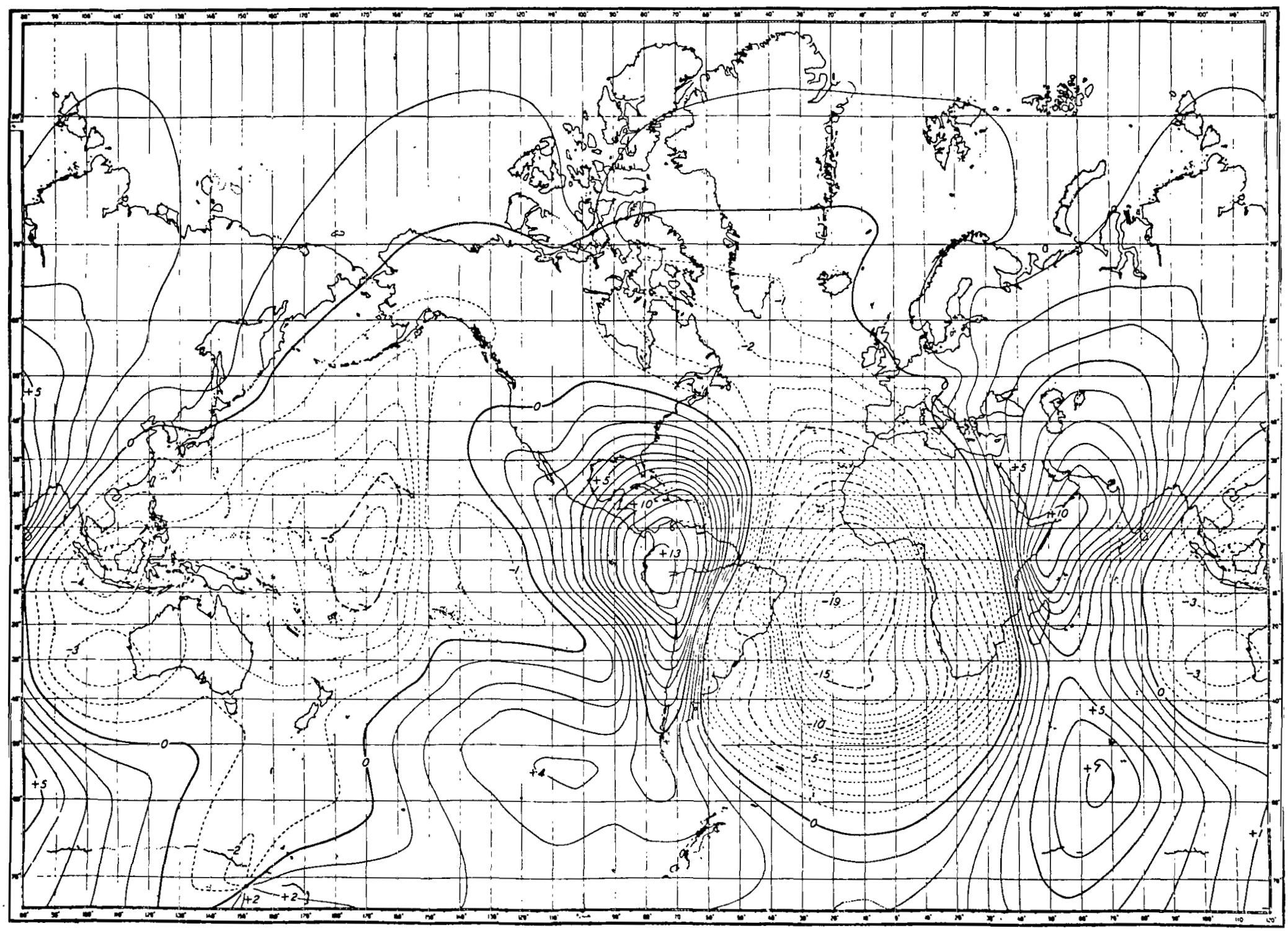

Figure BI-Geomagnetic secular change in minutes per year, inclination, epoch 1912.5. Vestine et al. (1947). 


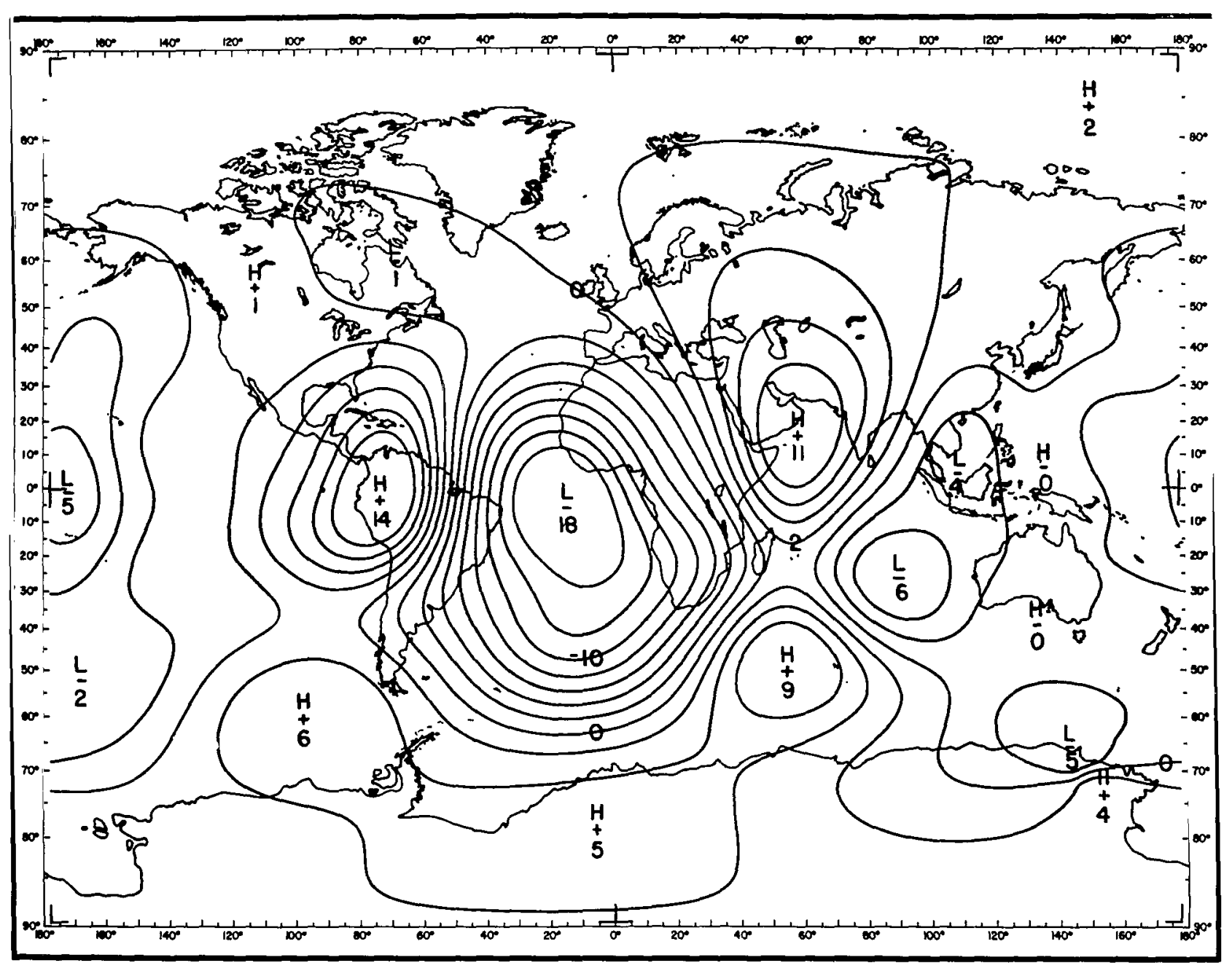

Figure B2-Geomagnetic secular change in minutes per year, inclination, epoch 1912.5. GSFC (12/66). 


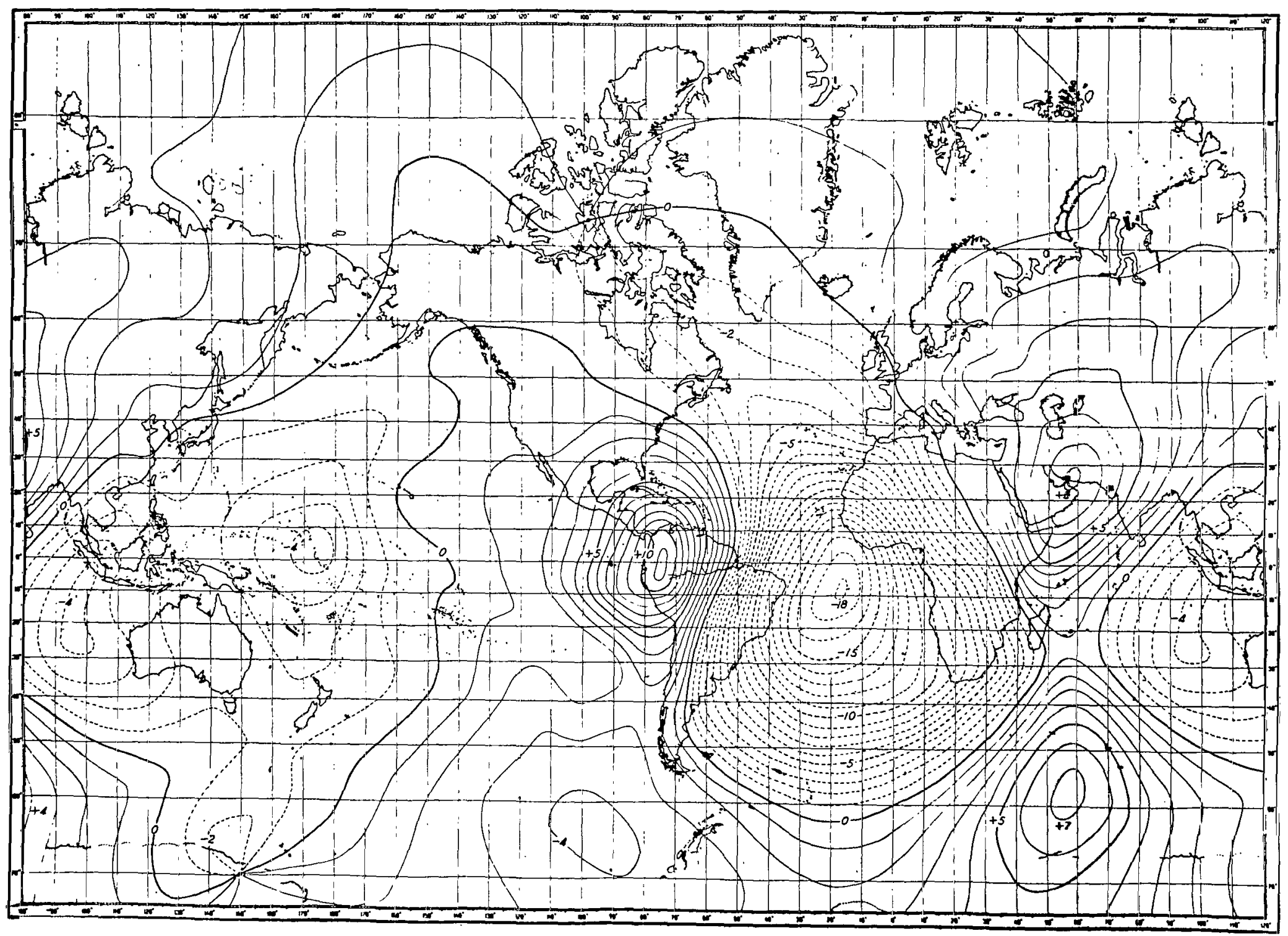

Figure B3-Geomagnetic secular change in minutes per year, inclination, epoch 1922.5. Vestine et al. (1947). 


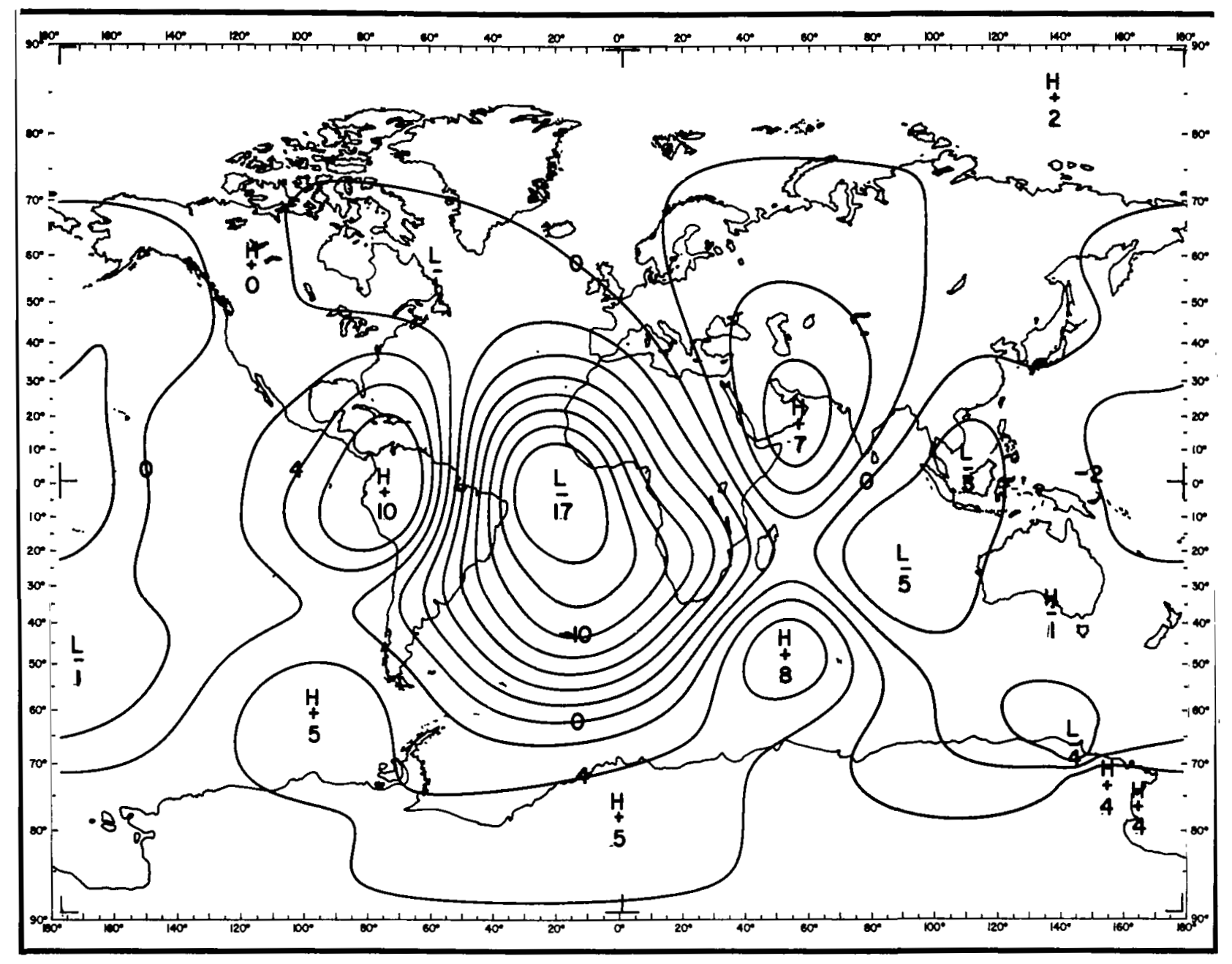

Figure B4-Geomagnetic secular change in minutes per year, inclination, epoch 1922.5. GSFC (12/66). 
옹

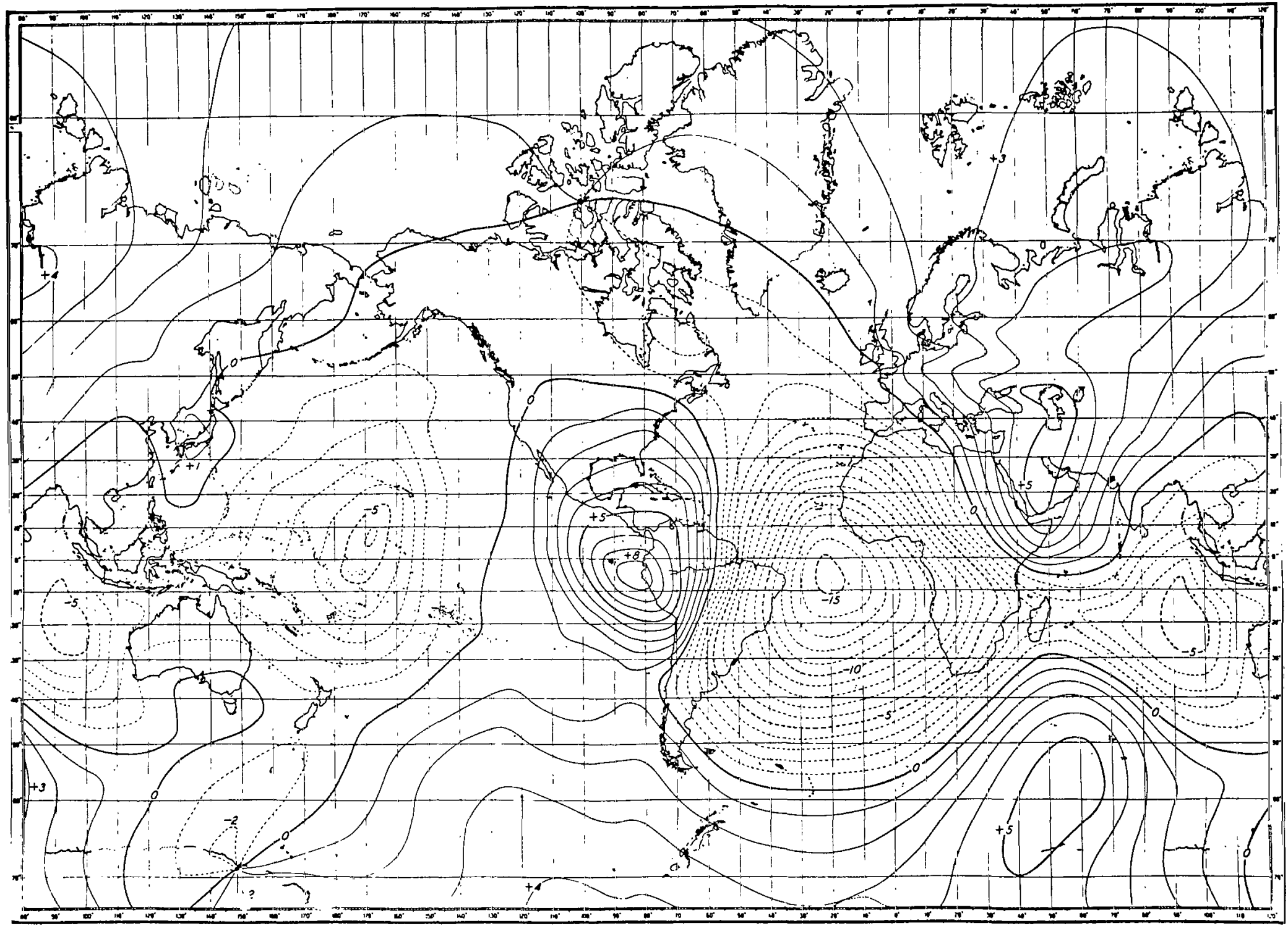

Figure B5-Geomagnetic secular change in minutes per year, inclination, epoch 1932.5. Vestine et al. (1947). 


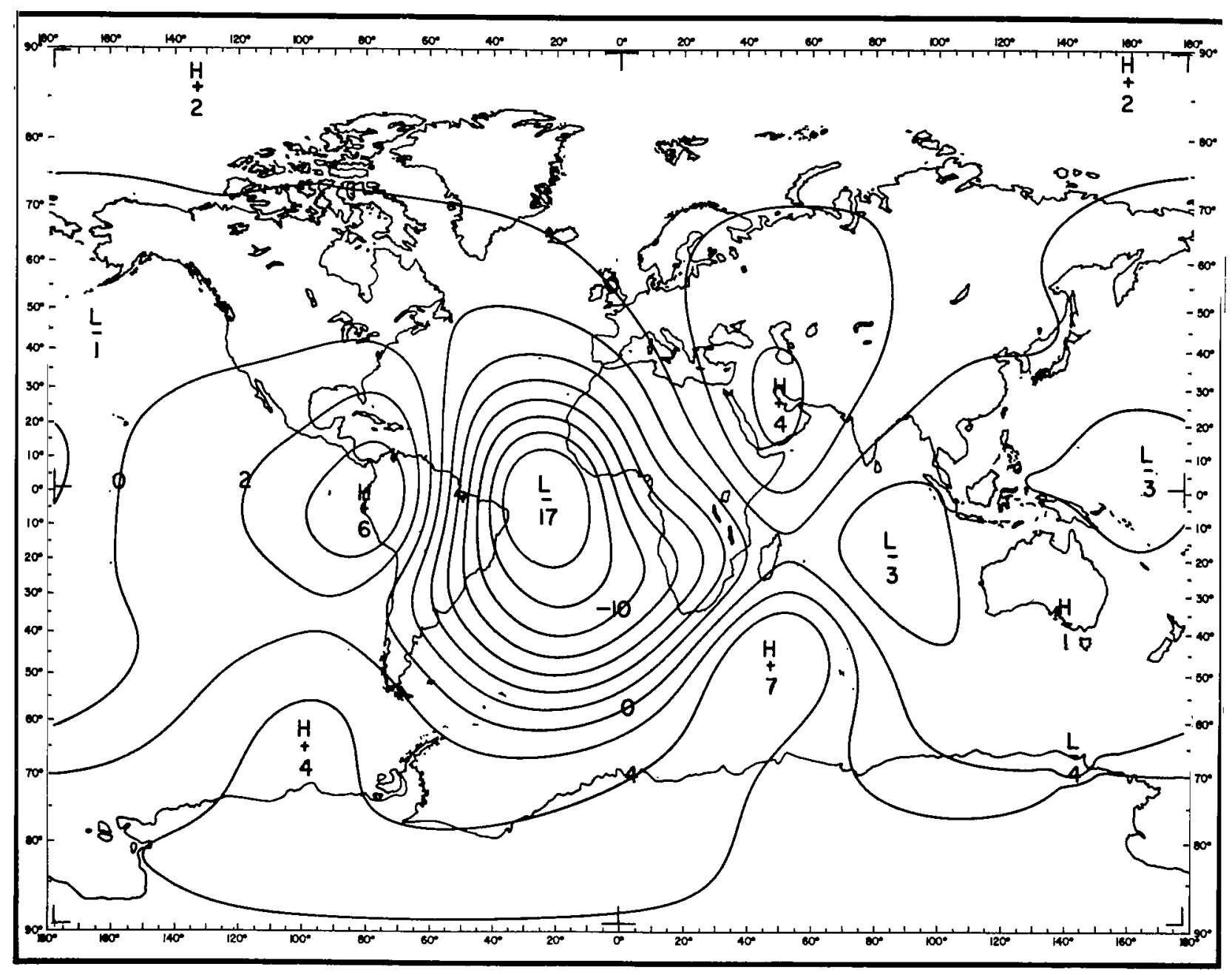

Figure B6-Geomagnetic secular change in minutes per year, inclination, epoch 1932.5. GSFC $(12 / 66)$. 
草

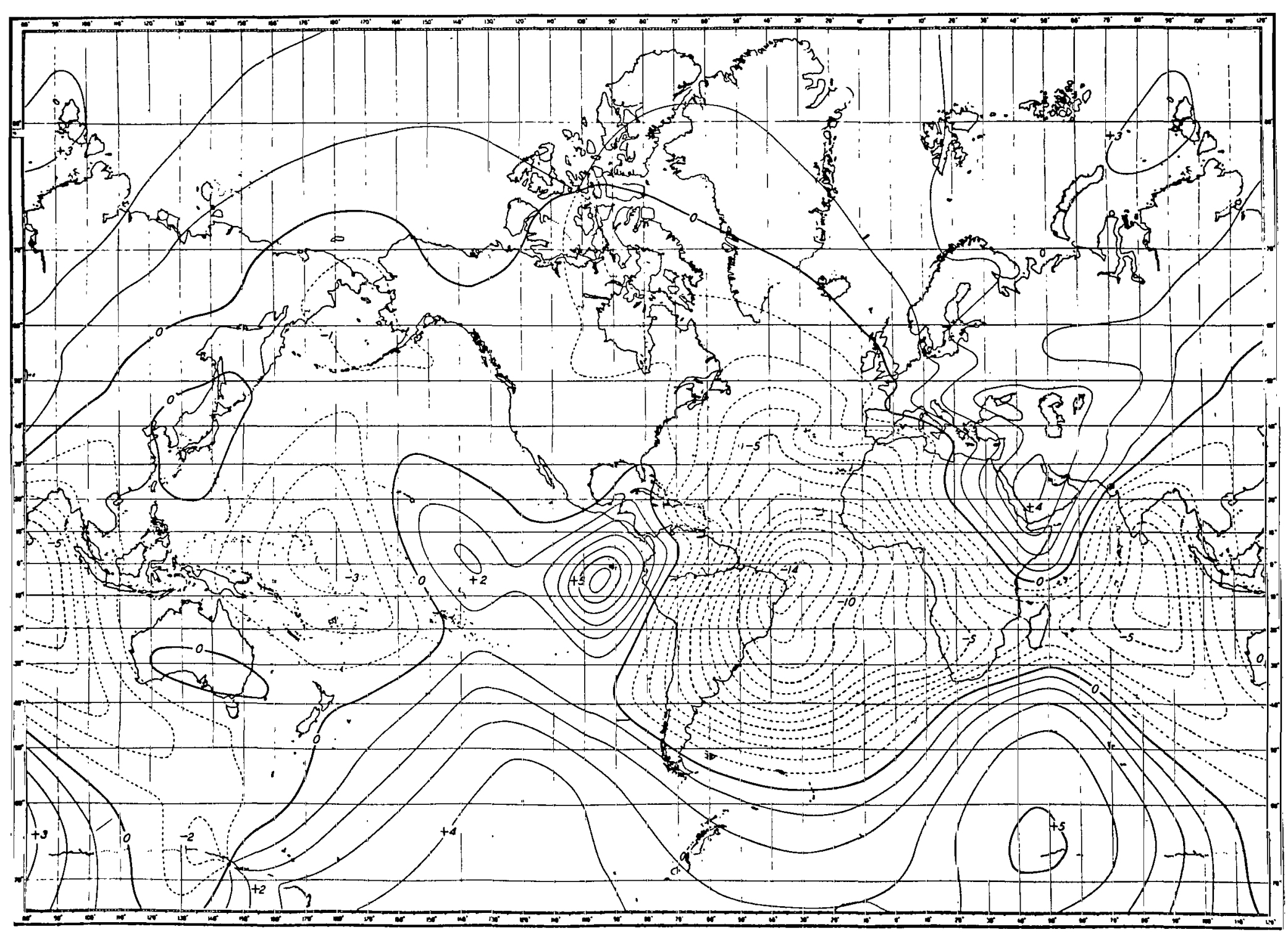

Figure B7-Geomagnetic secular change in minutes per year, inclination, epoch 1942.5. Vestine et al. (1947). 


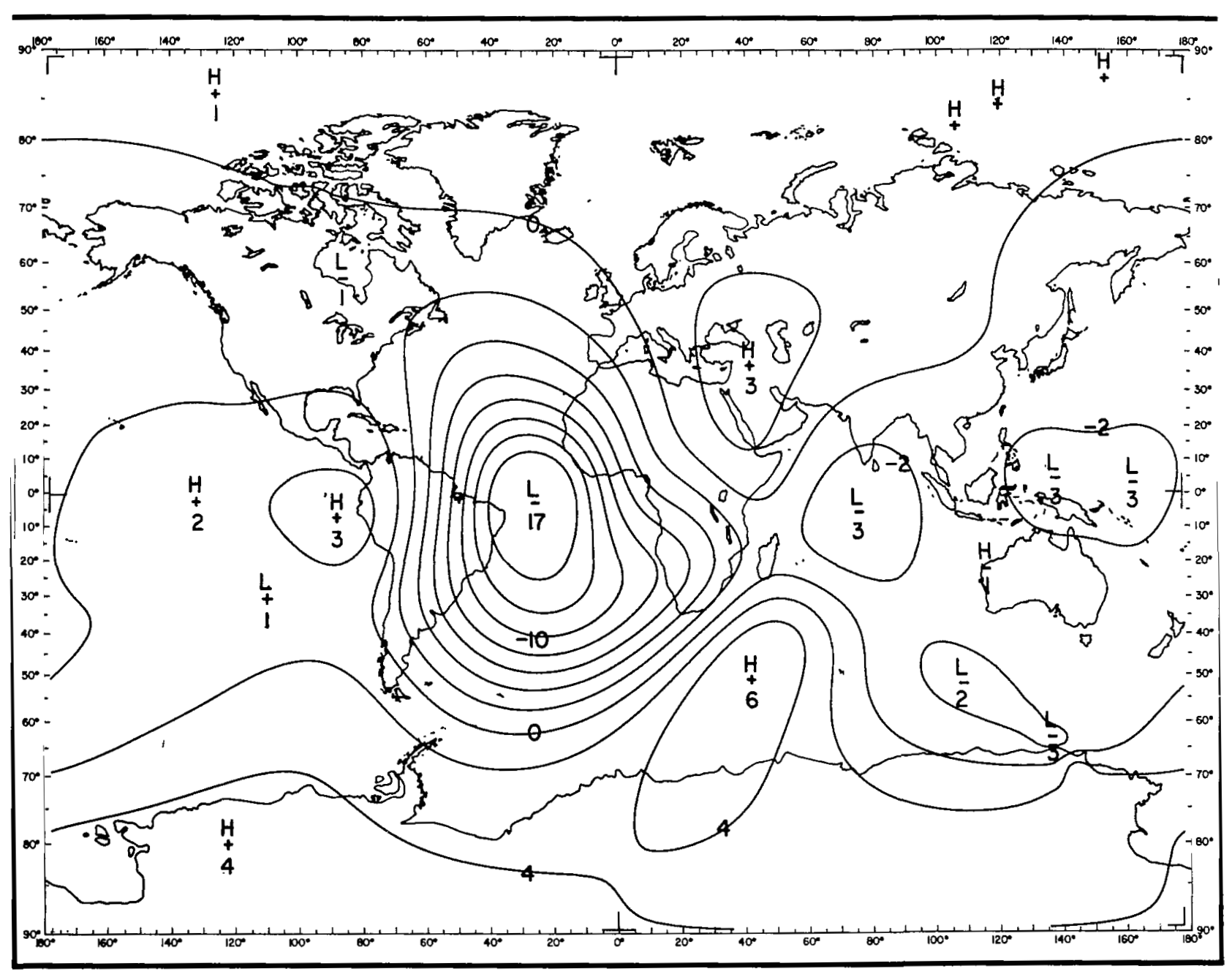

Figure B8-Geomagnetic secular change in minutes per year, inclination, epoch 1942.5. GSFC (12/66). 


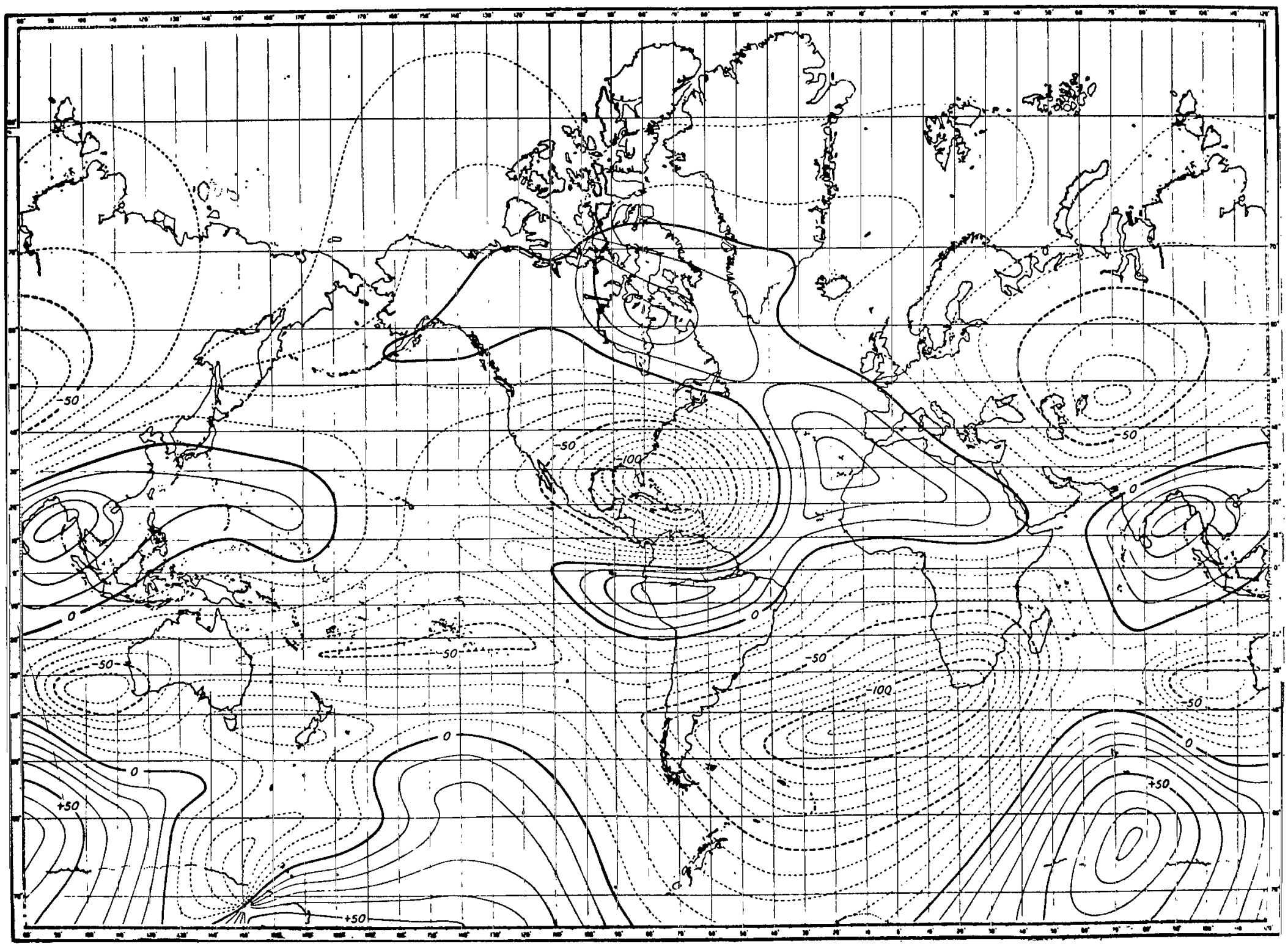

Figure B9-Geomagnetic secular change in gammas per year, horizontal component, epoch 1912.5. Vestine et al. (1947). 


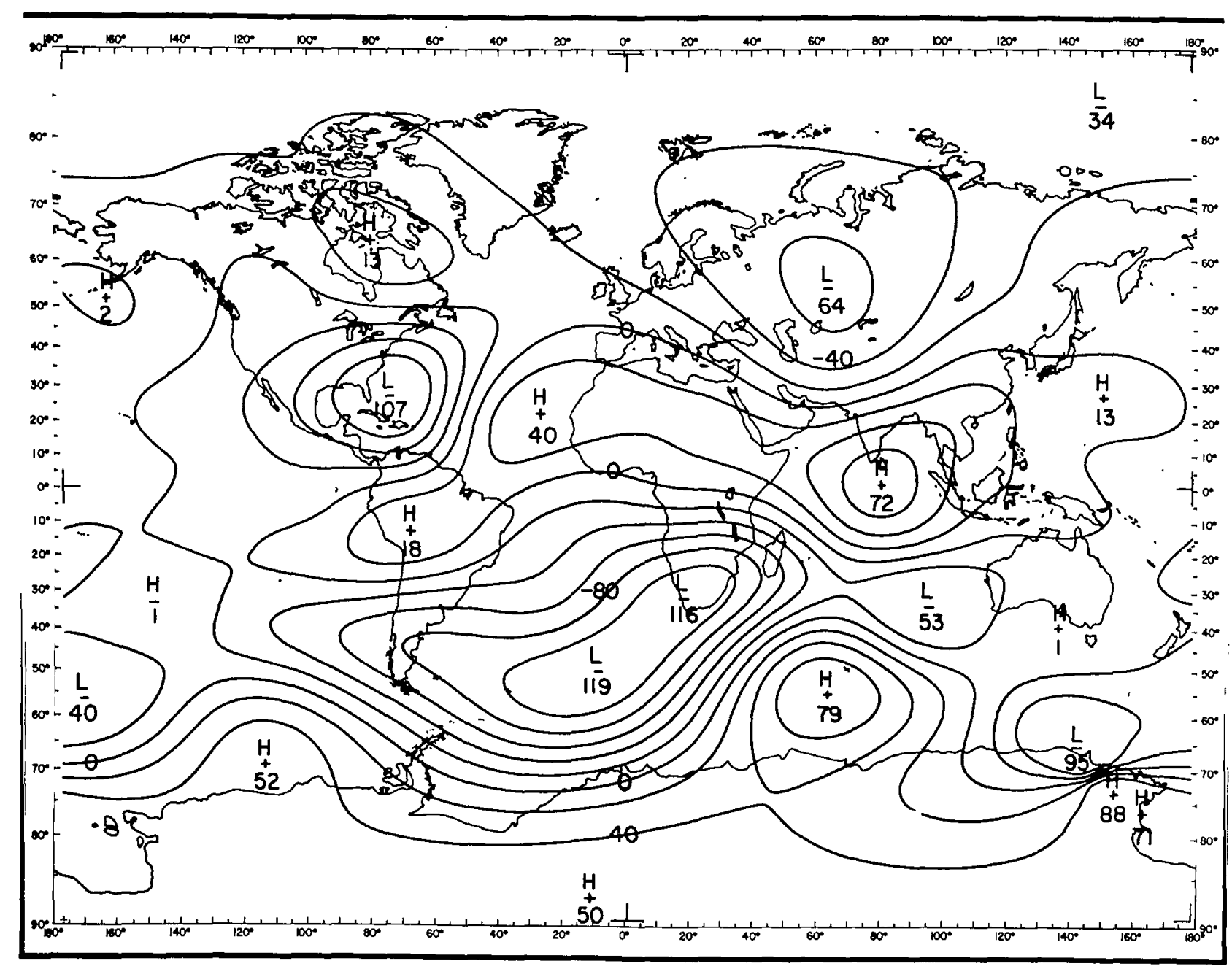

Figure B10-Geomagnetic secular change in gammas per year, horizontal component, epoch 1912.5. GSFC (12/66). 


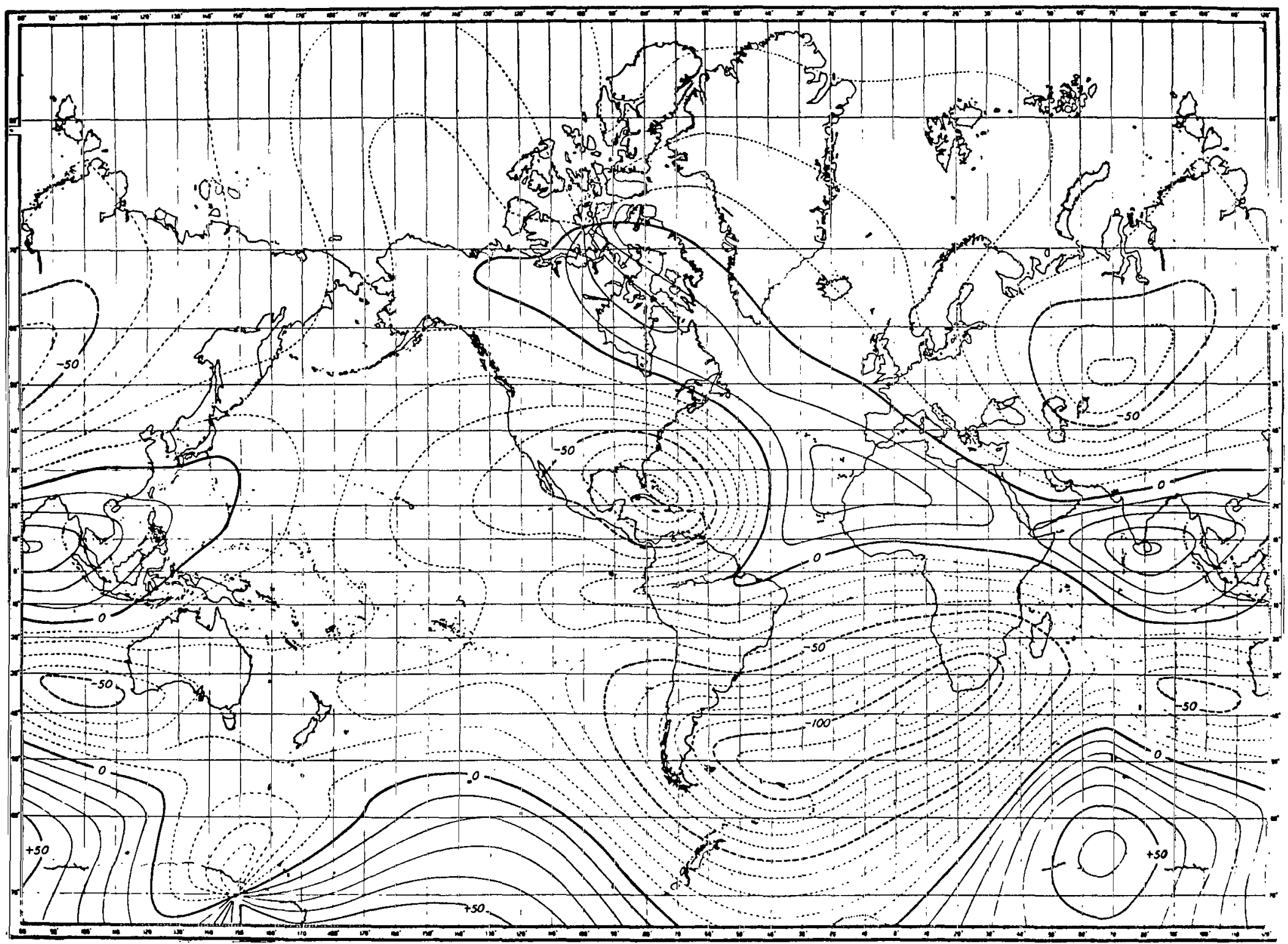

Figure Bll-Geomagnetic secular change in gammas per year, horizontal component, epoch 1922.5. Vestine et al. (1947). 


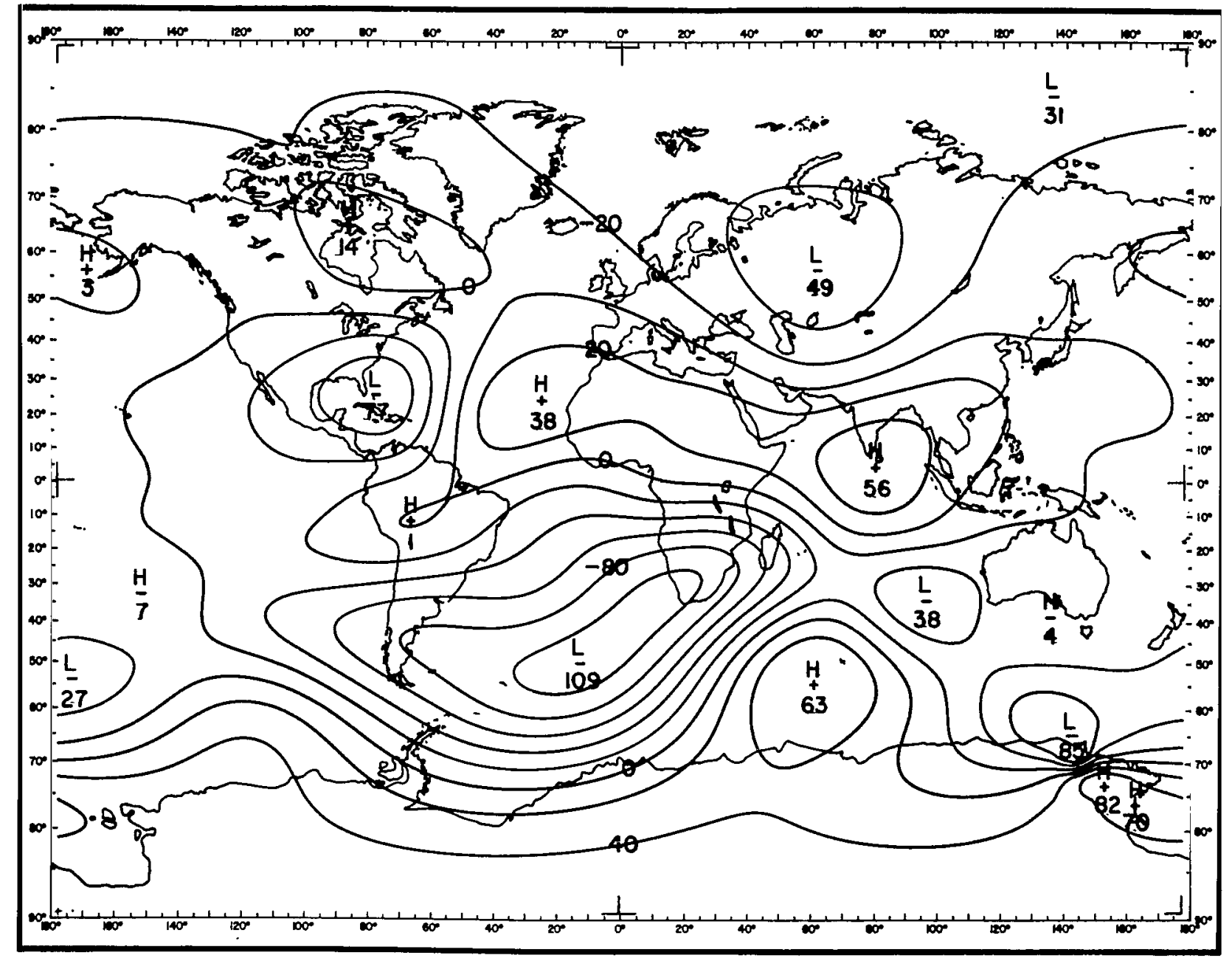

Figure B12-Geomagnetic secular change in gammas per year, horizontal component, epoch 1922.5. GSFC (12/66). 


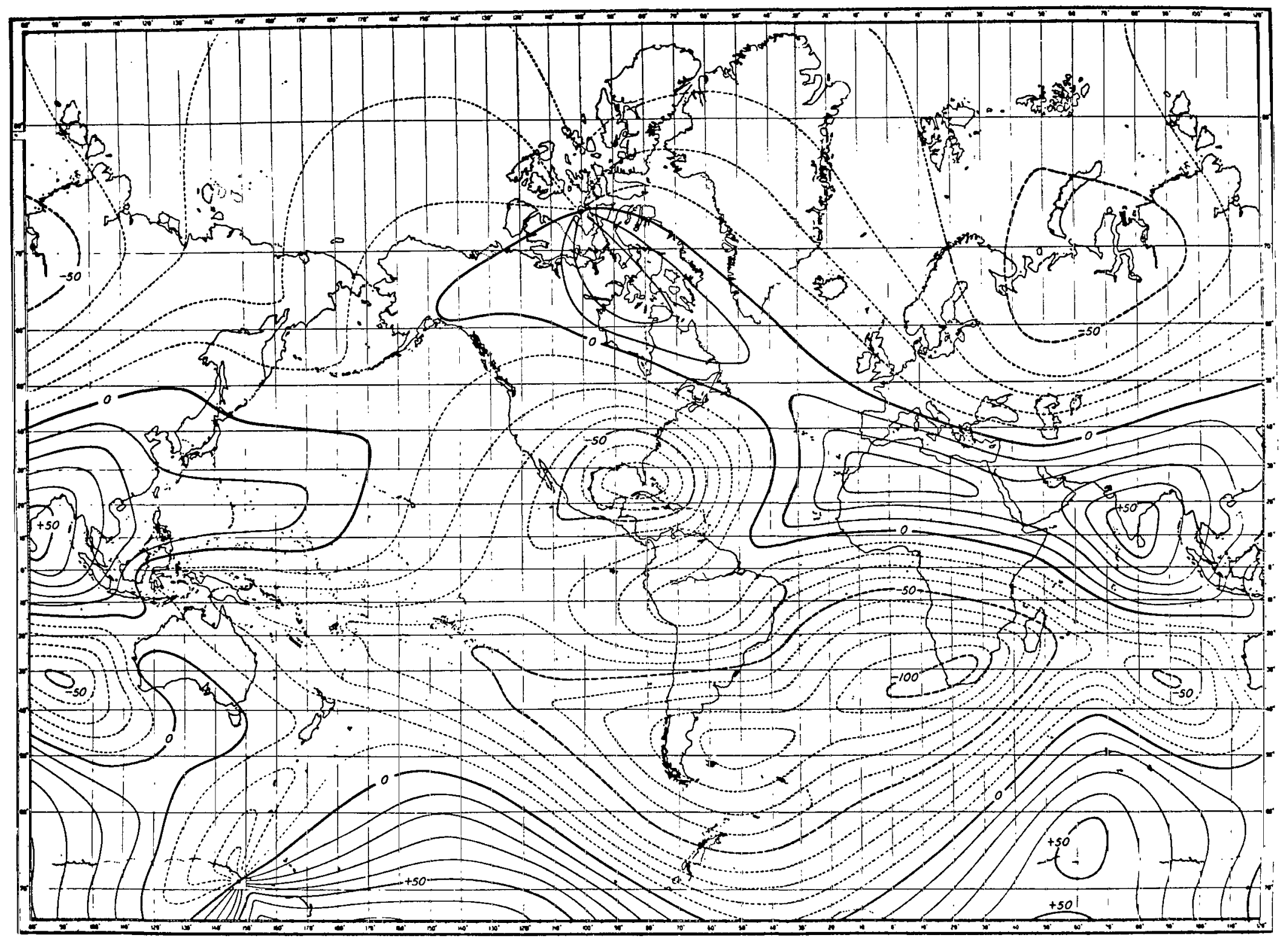

Figure B13-Geomagnetic secular change in gammas per year, horizontal component, epoch 1932.5. Vestine et al. (1947). 


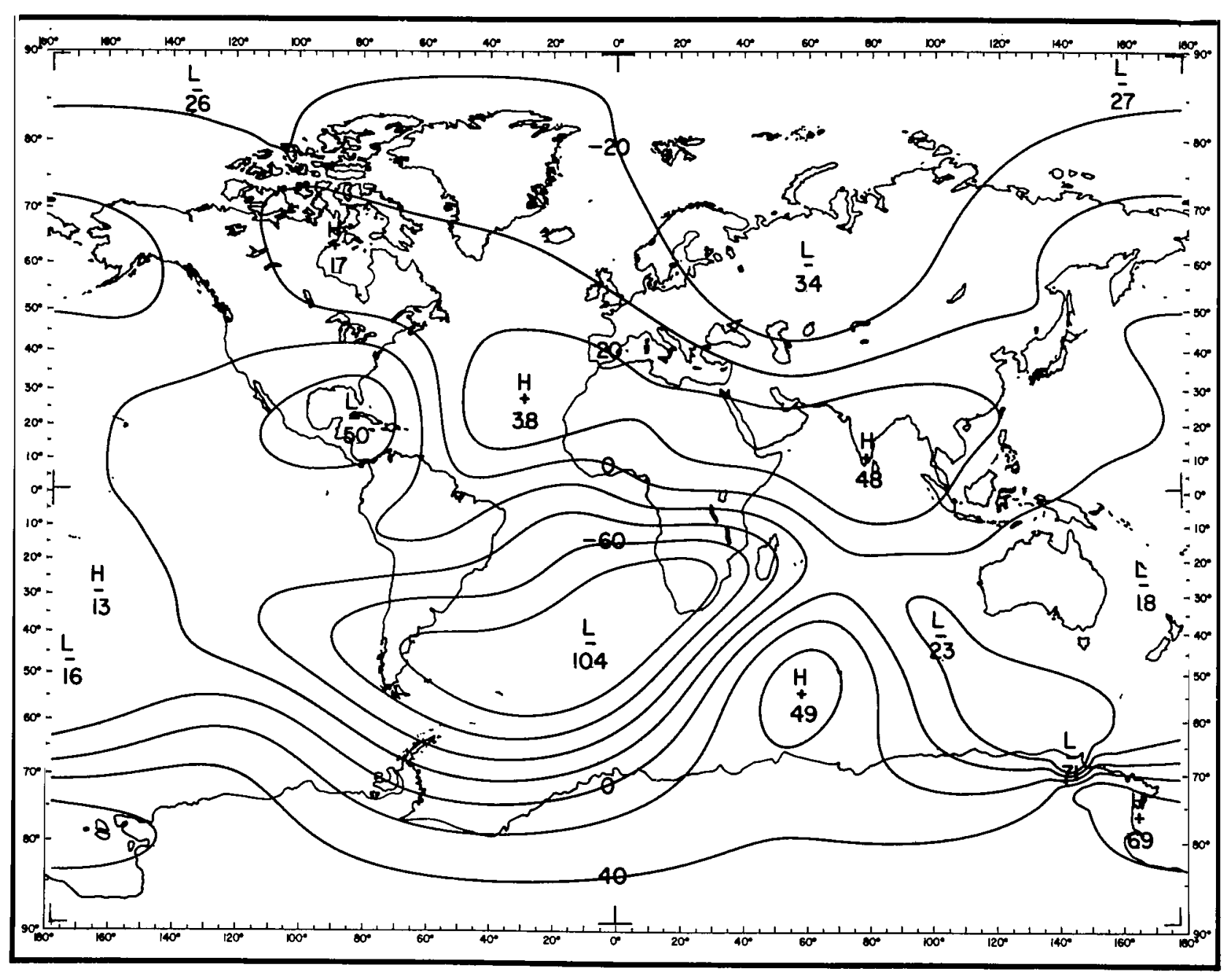

Figure B14-Geomagnetic secular change in gammas per year, horizontal component, epoch 1932.5. GSFC (12/66). 
N

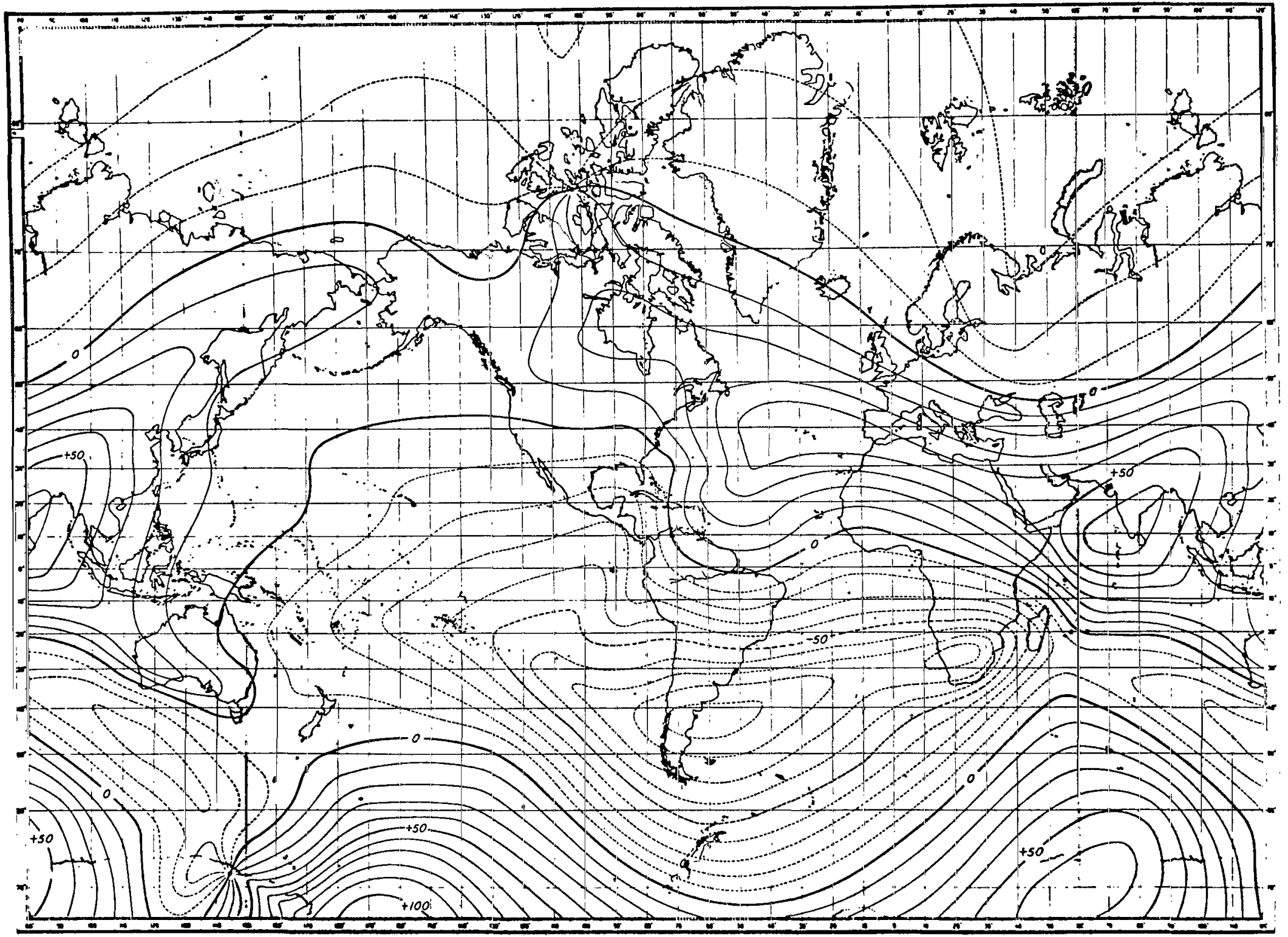

Figure B15-Geomagnetic secular change in gammas per year, horizontal component, epoch 1942.5. Vestine et al. (1947). 


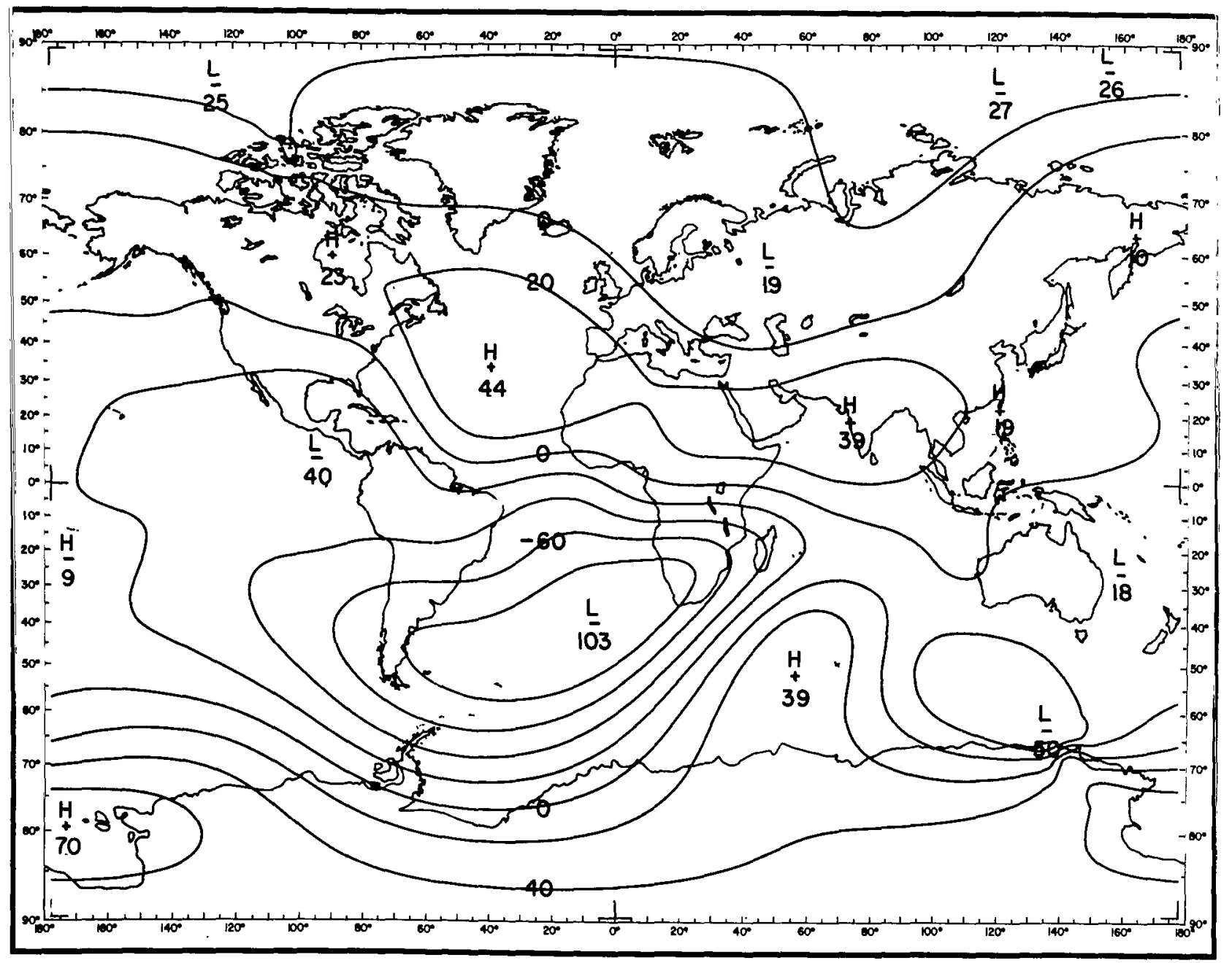

Figure B16-Geomagnetic secular change in gammas per year, horizontal component, epoch 1942.5. GSFC (12/66). 
㟔

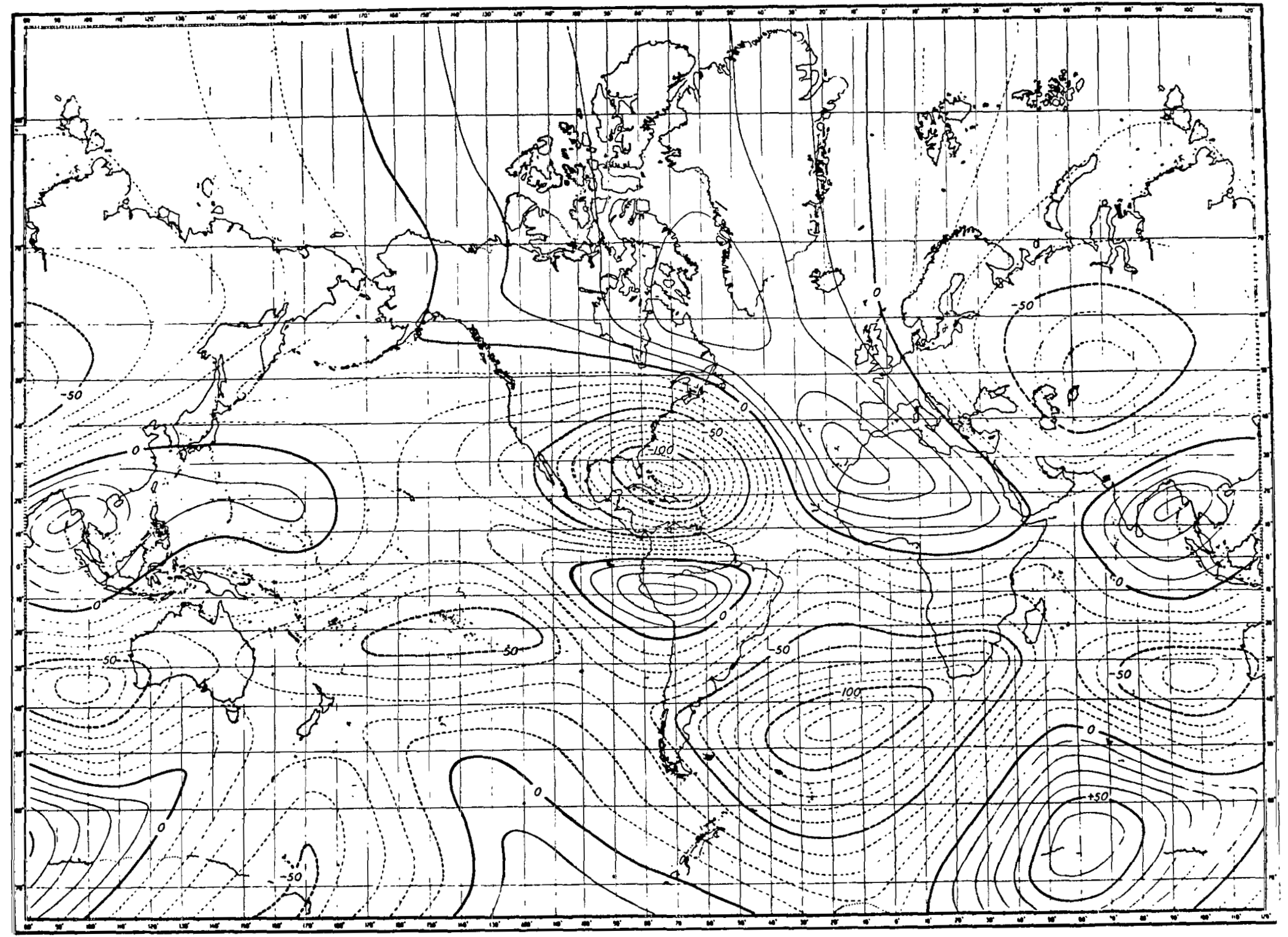

Figure B17-Geomagnetic secular change in gammas per year, north component, epoch 1912.5. Vestine et al. (1947). 


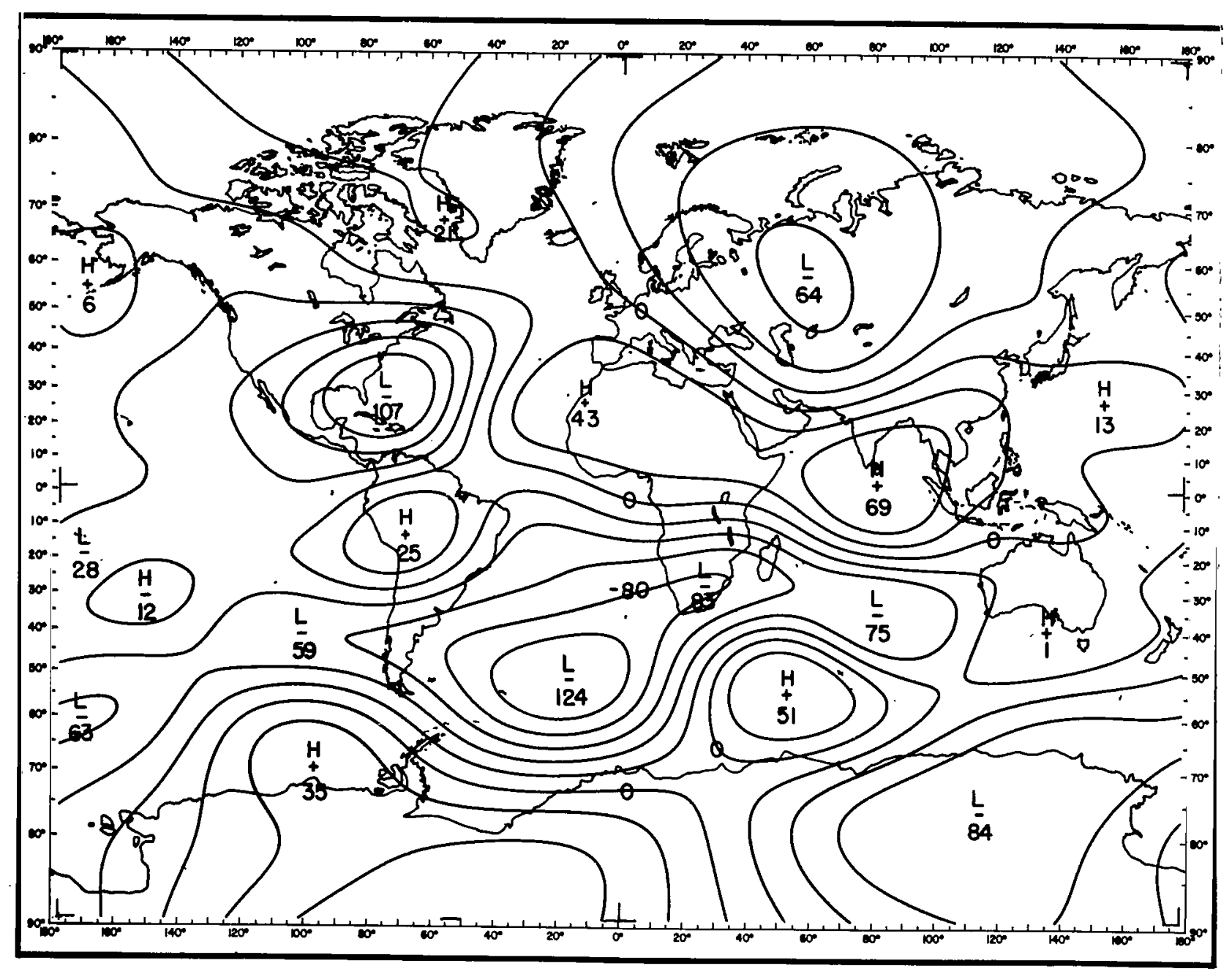

Figure B18-Geomagnetic secular change in gammas per year, north component, epoch 1912.5. GSFC (12/66). 


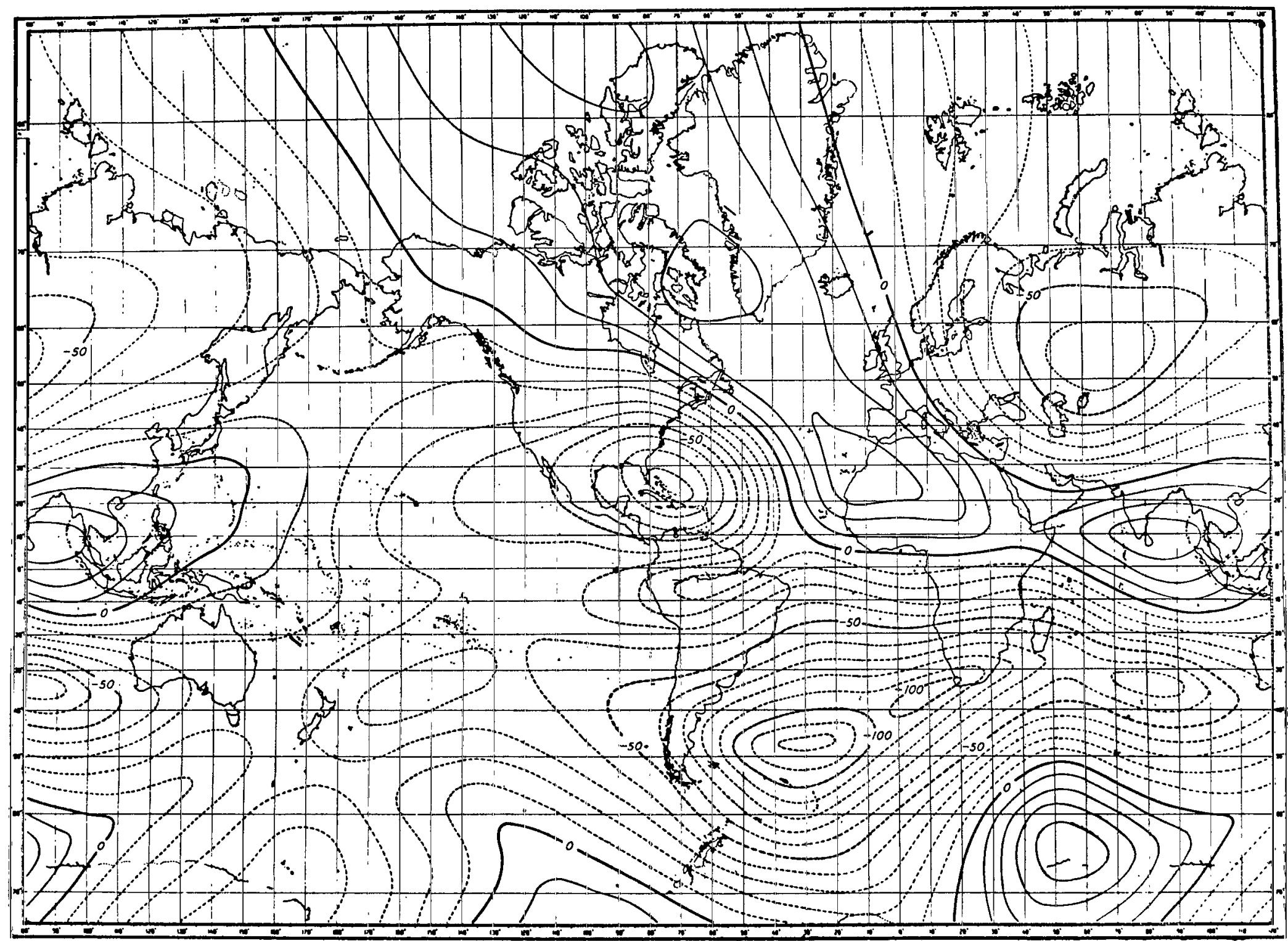

Figure B19-Geomagnetic secular change in gammas per year, north component, epoch 1922.5. Vestine et al. (1947). 


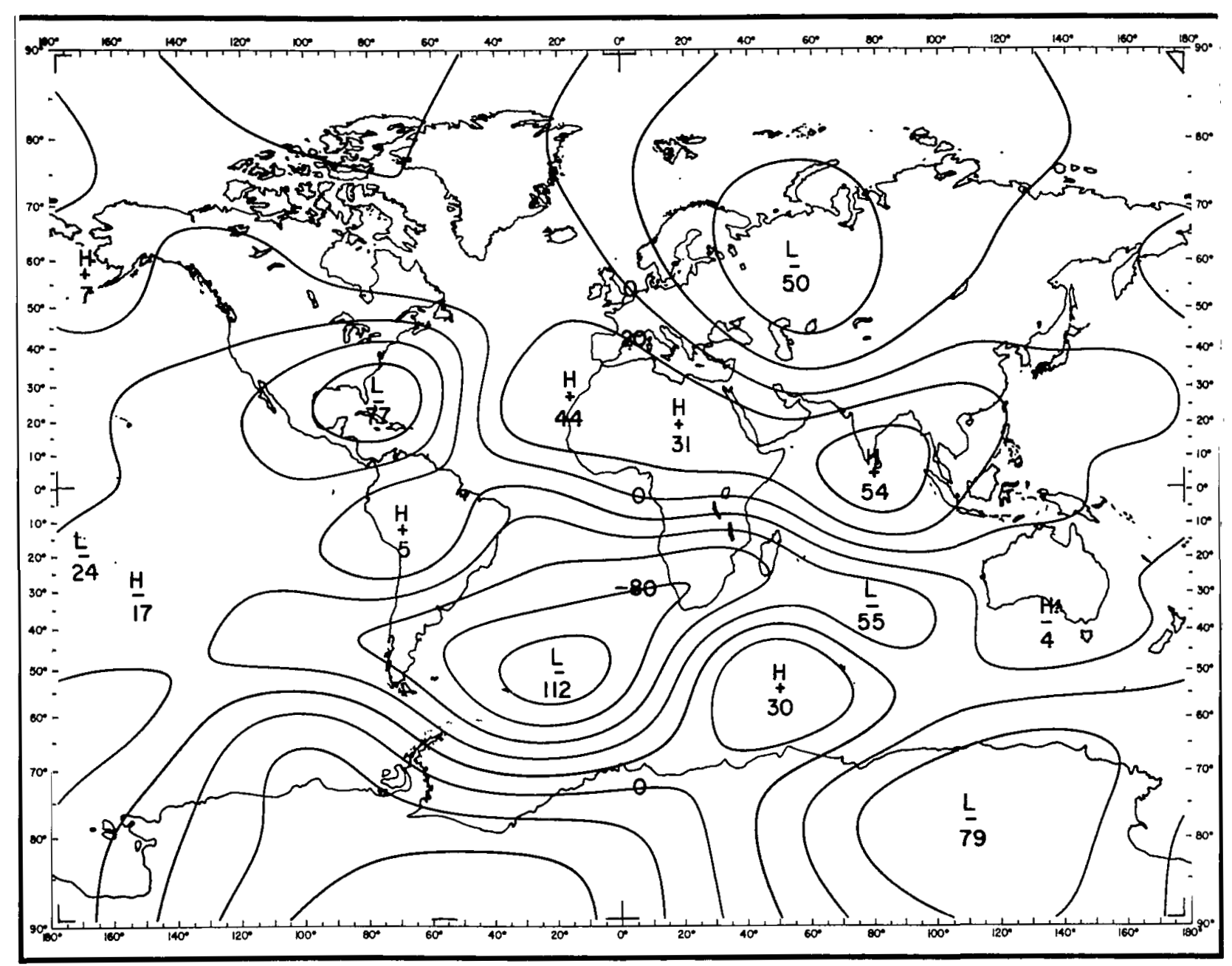

Figure B20-Geomagnetic secular change in gammas per year, north component, epoch 1922.5. GSFC $(12 / 66)$. 
$\stackrel{\leftrightarrow}{\rightarrow}$

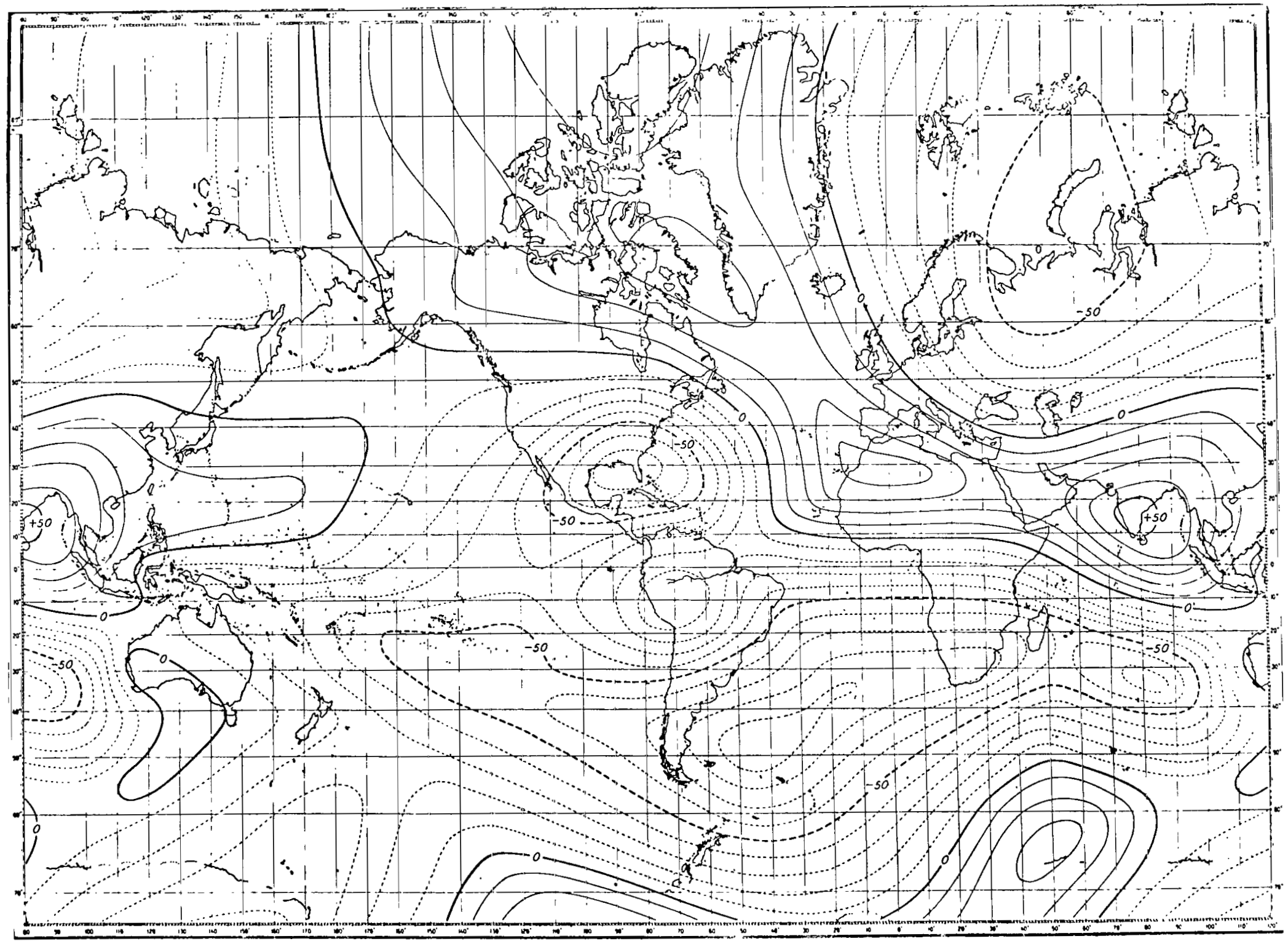

Figure B21-Geomagnetic secular change in gammas per year, north component, epoch 1932.5. Vestine et al. (1947). 


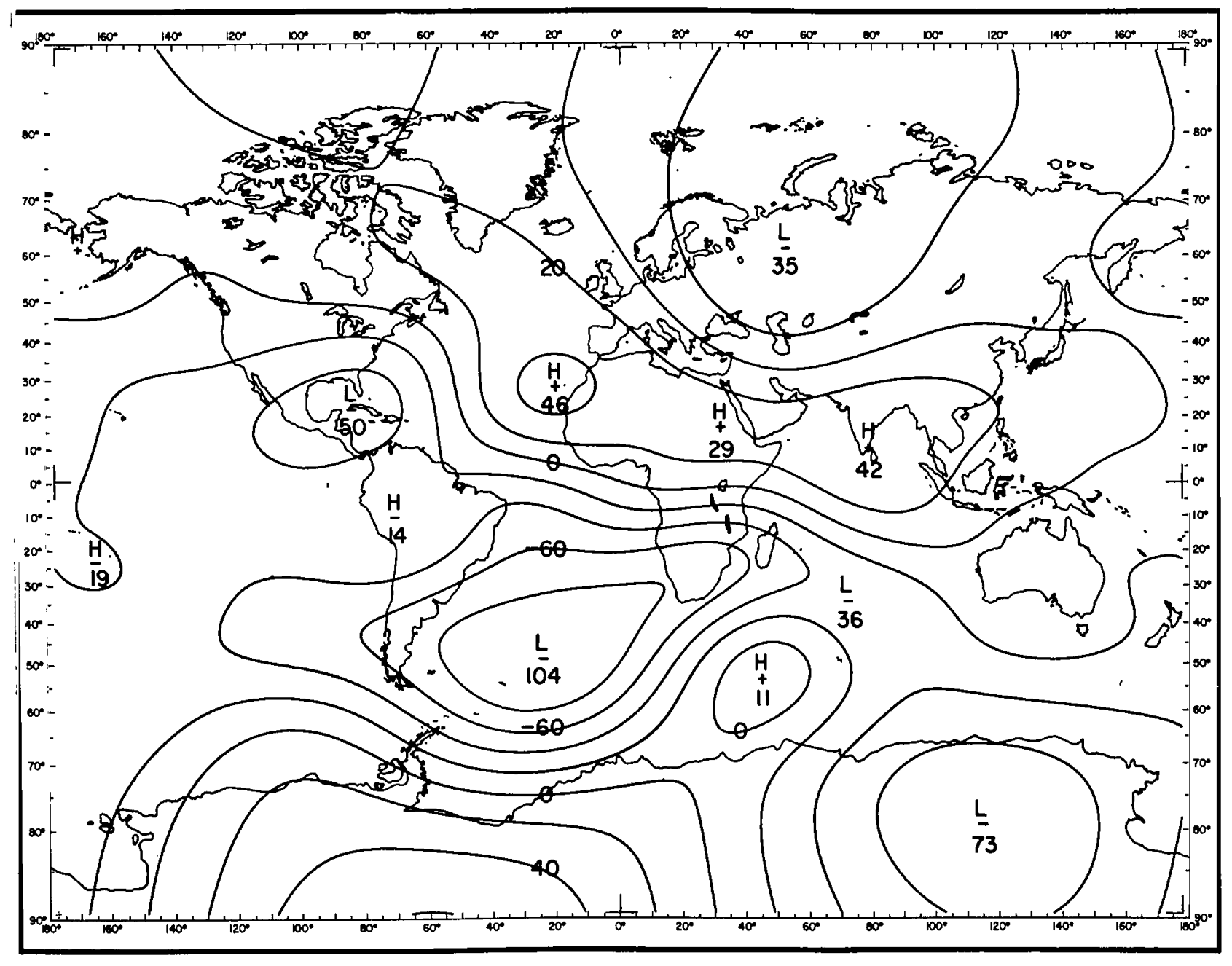

Figure B22-Geomagnetic secular change in gammas per year, north component, epoch 1932.5. GSFC (12/66). 


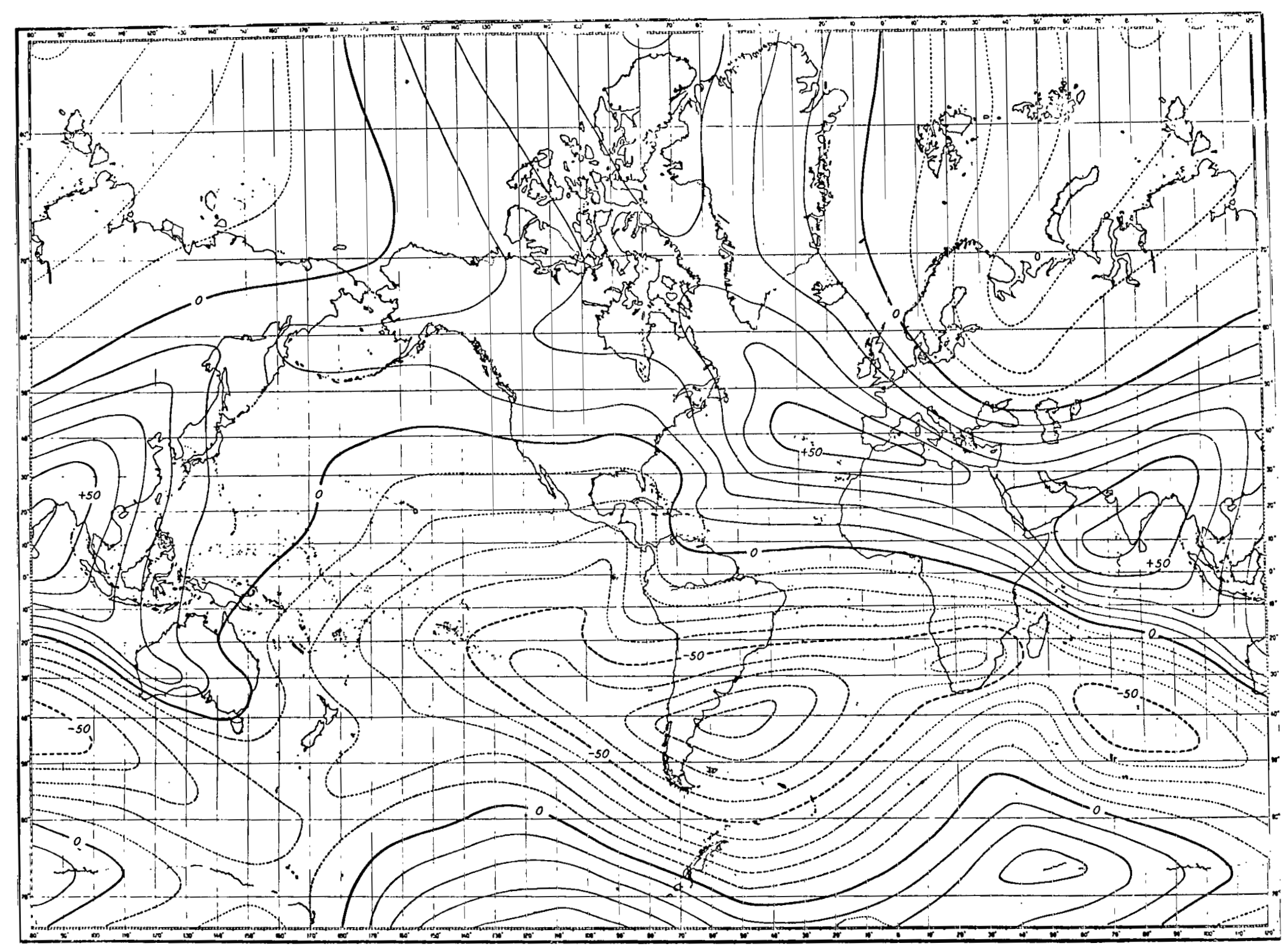

Figure B23-Geomagnetic secular change in gammas per year, north component, epoch 1942.5. Vestine et al. (1947). 


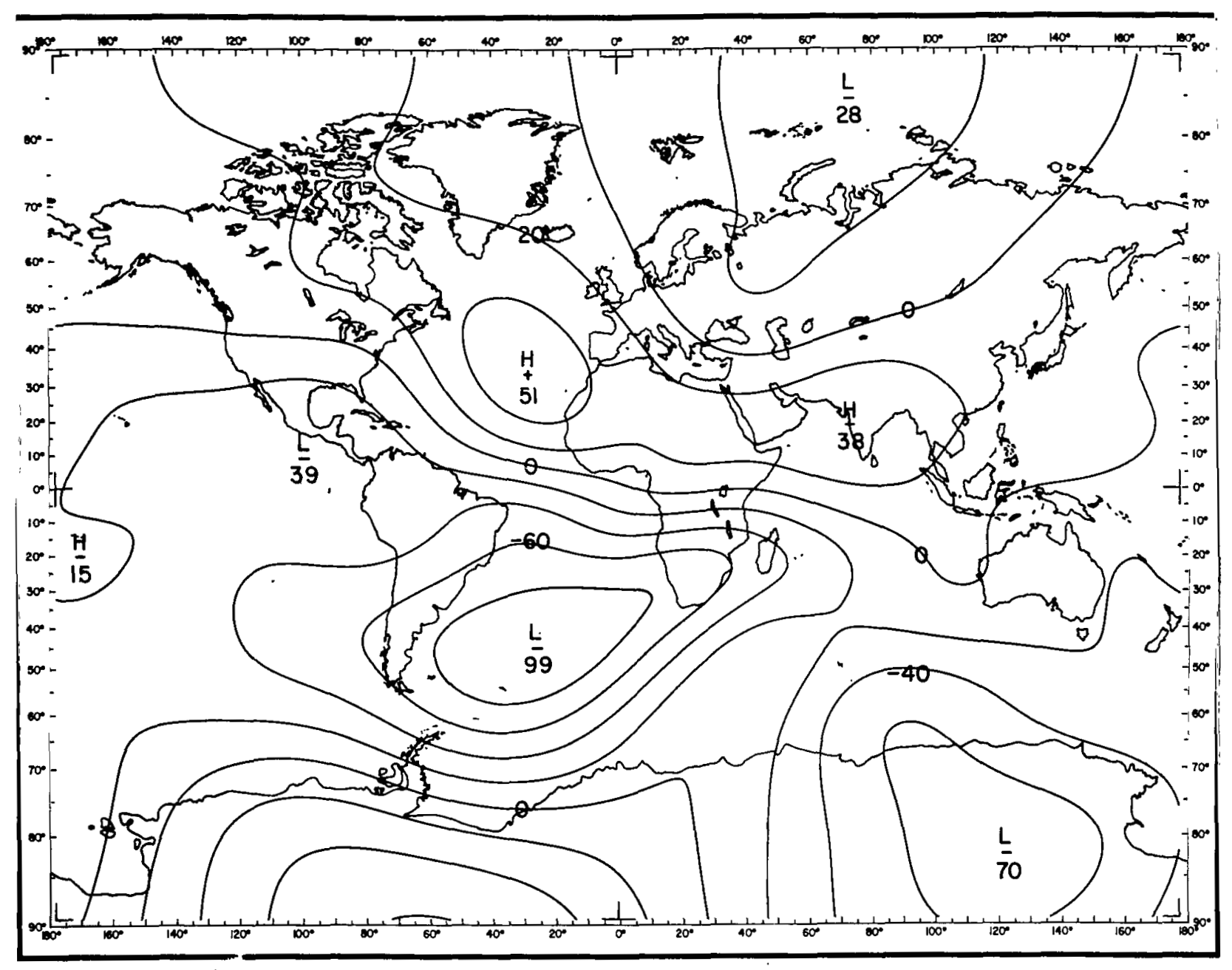

Figure B24-Geomagnetic secular change in gammas per year, north component, epoch 1942.5. GSFC (12/66). 
㐫

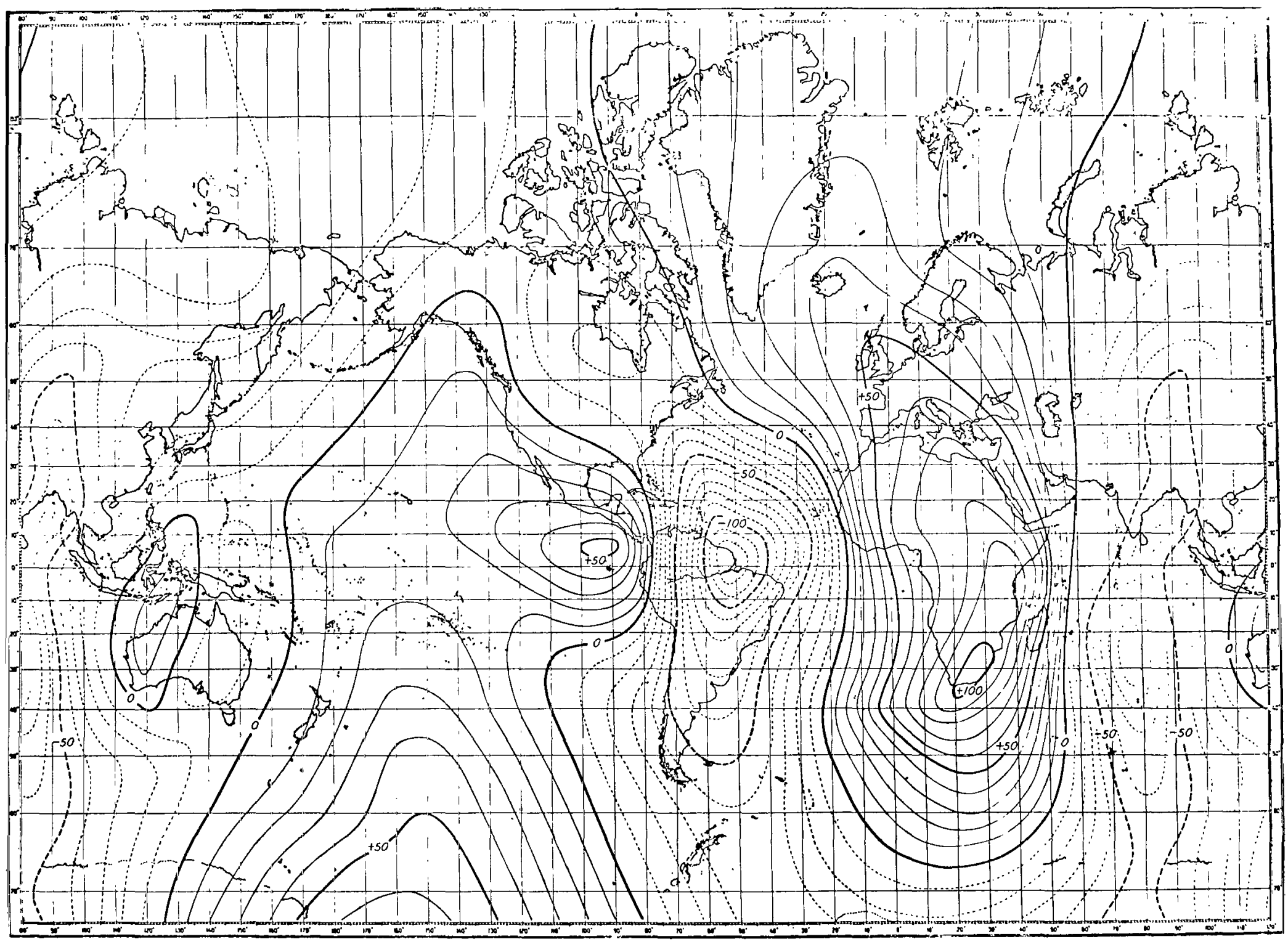

Figure B25-Geomagnetic secular change in gammas per year, east component, epoch 1912.5. Vestine ef al. (1947). 


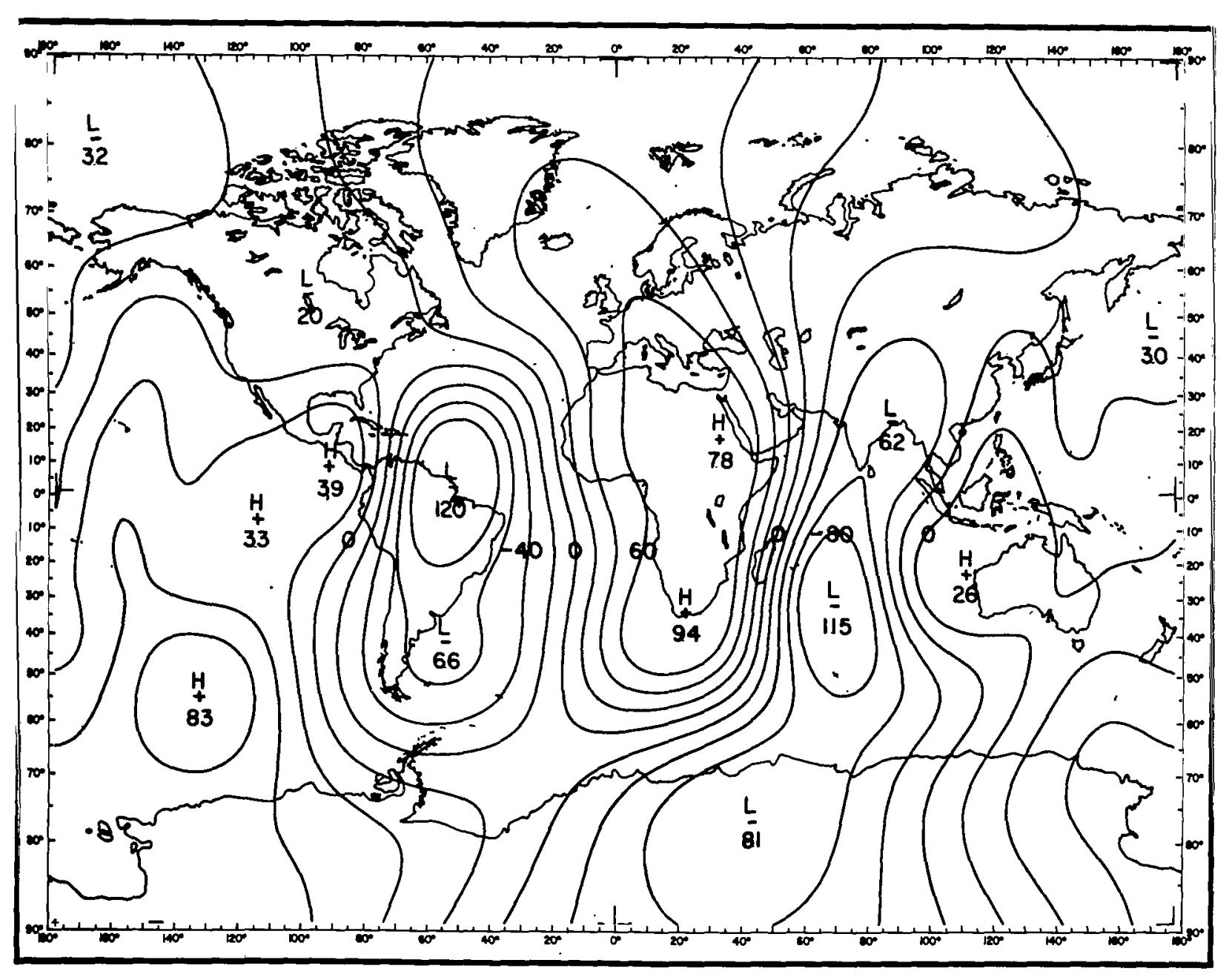

Figure B26-Geomagnetic secular change in gammas per year, east component, epoch 1912.5. GSFC (12/66). 


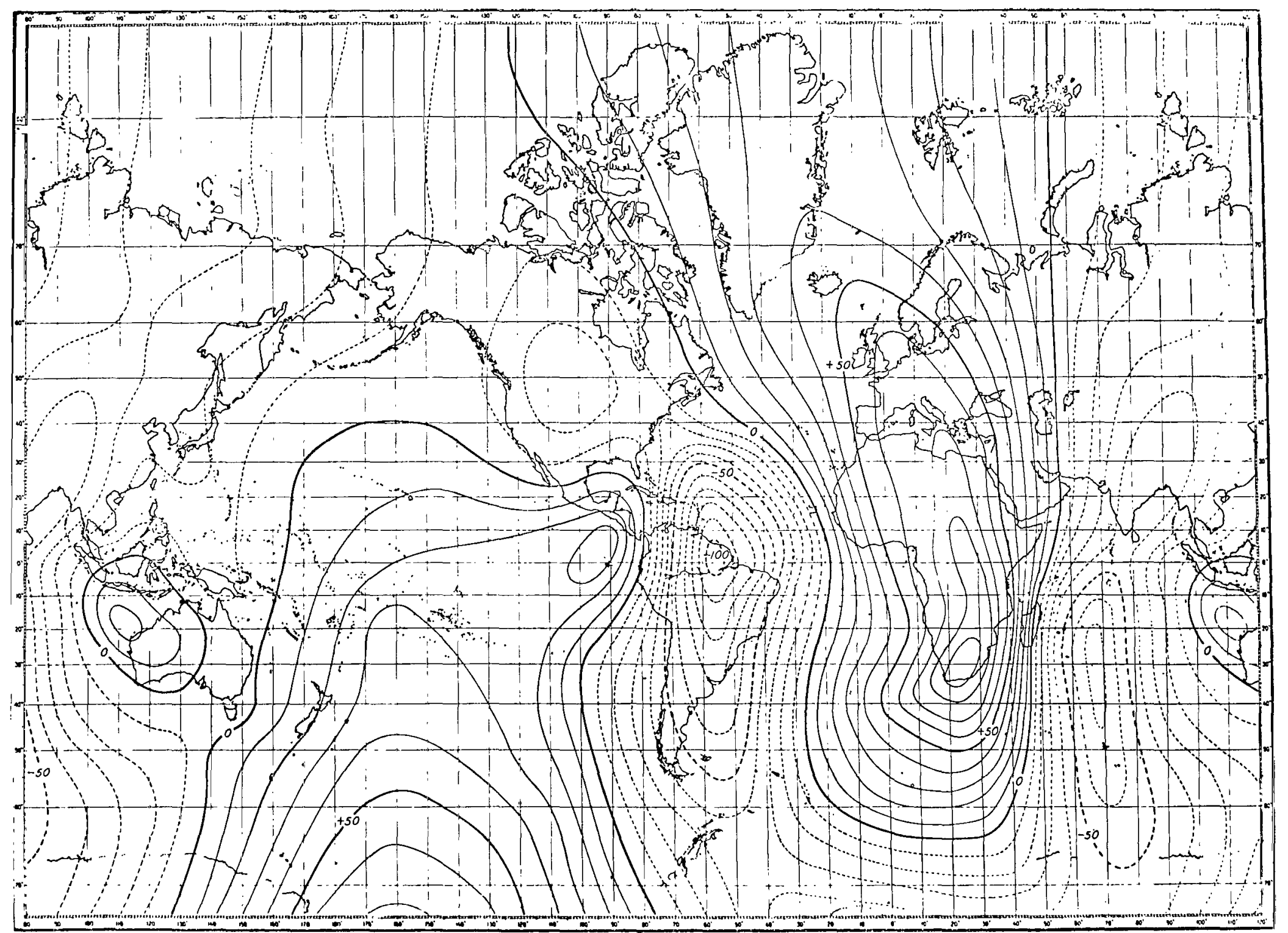

Figure B27-Geomagnetic secular change in gammas per year, east component, epoch 1922.5. Vestine et al. (1947). 


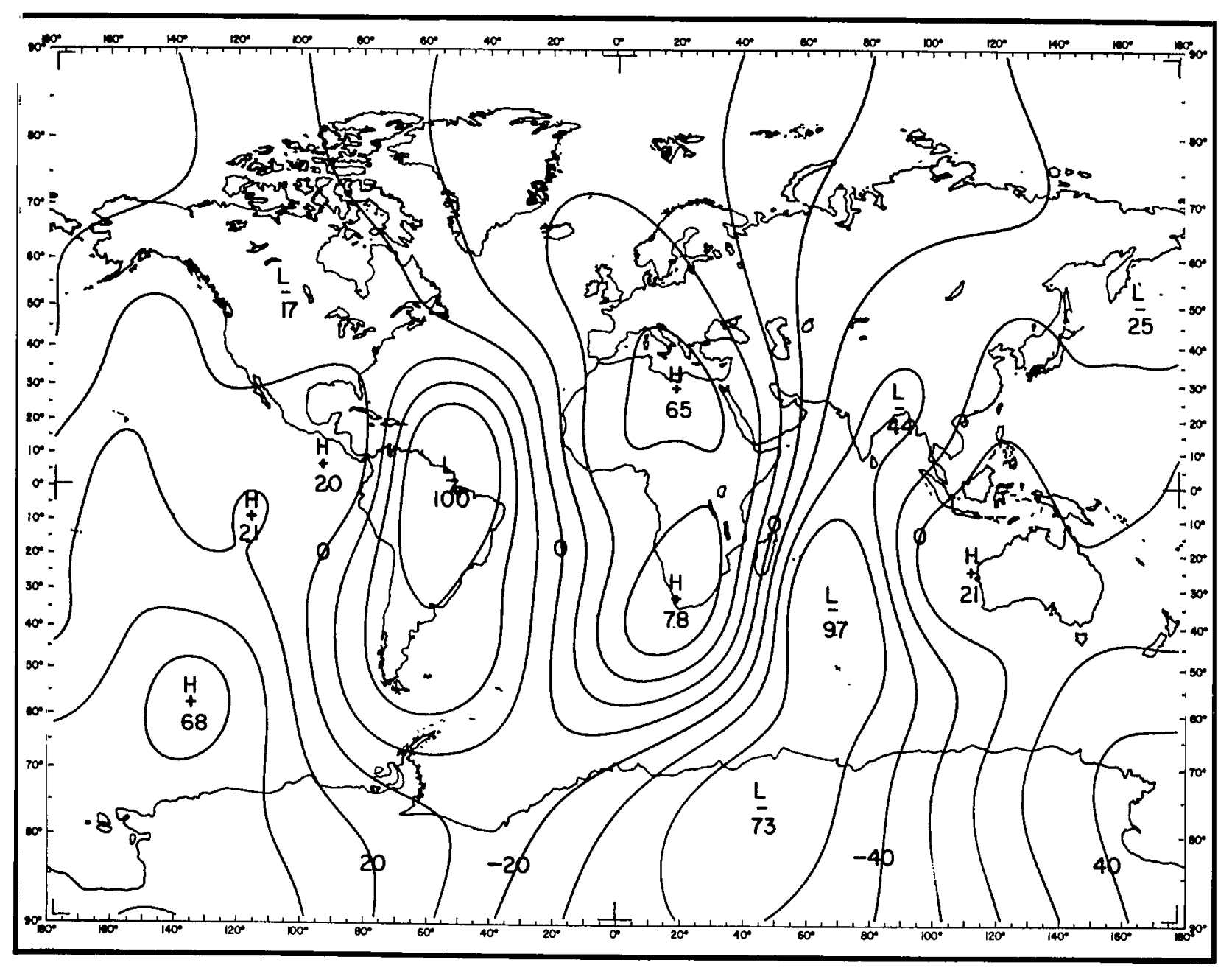

Figure B28-Geomagnetic secular change in gammas per year, east component, epoch 1922.5. GSFC $(12 / 66)$. 
品

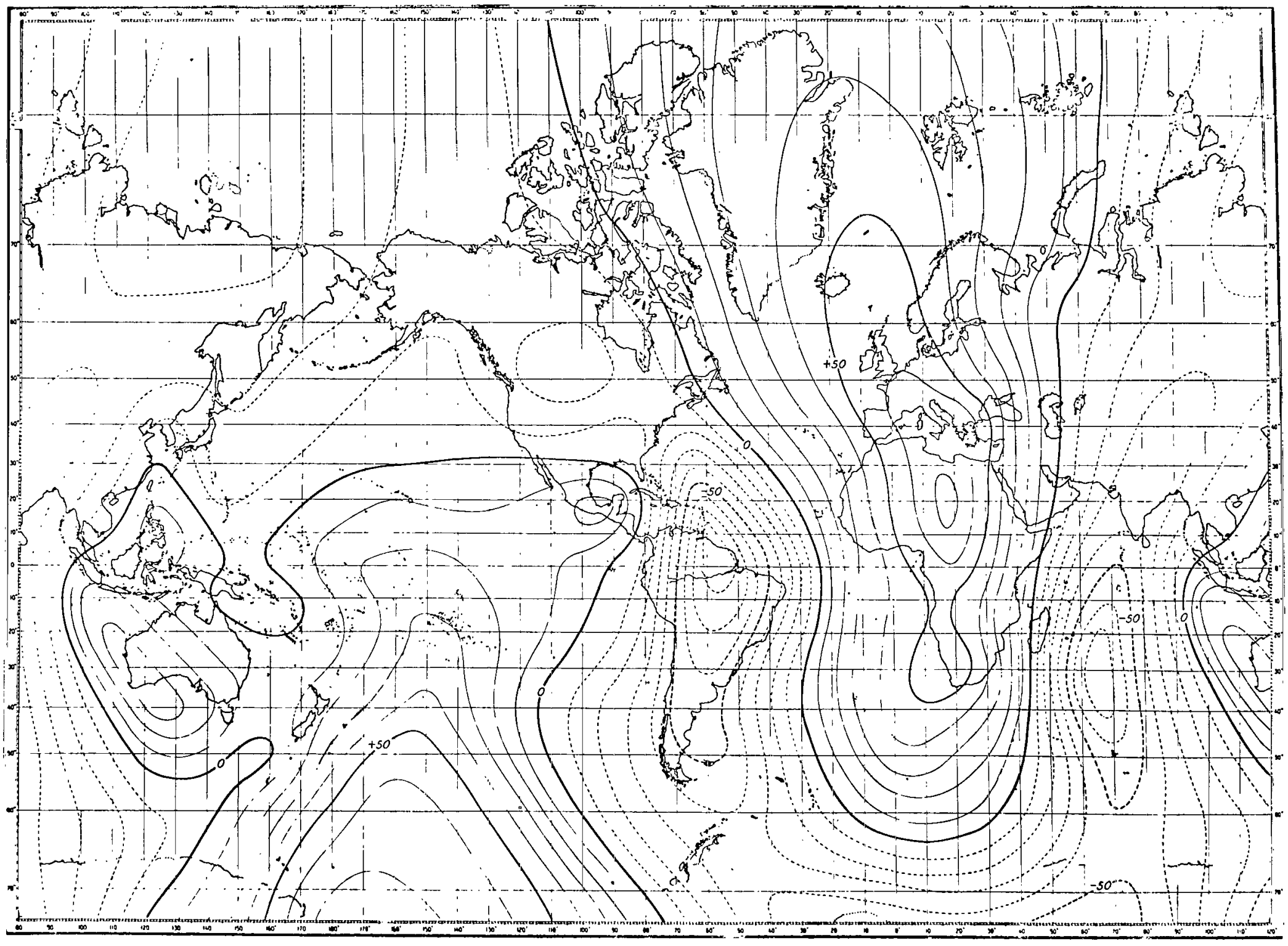

Figure B29-Geomagnetic secular change in gammas per year, east component, epoch 1932.5. Vestine et al. (1947). 

$\underset{\infty}{\infty}$

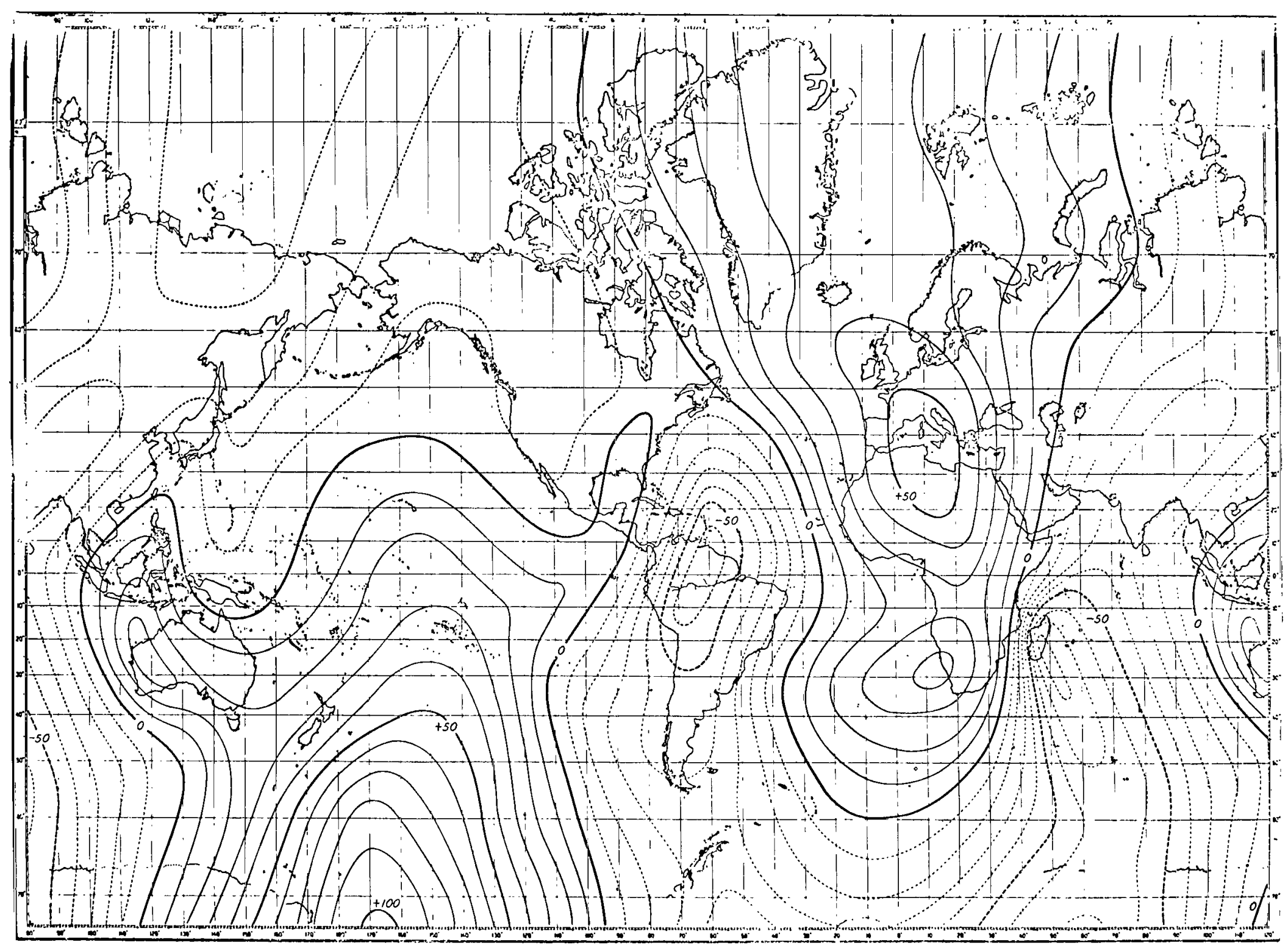

Figure B31-Geomagnetic secular change in gammas per year, east component, epoch 1942.5. Vestine et al. (1947). 


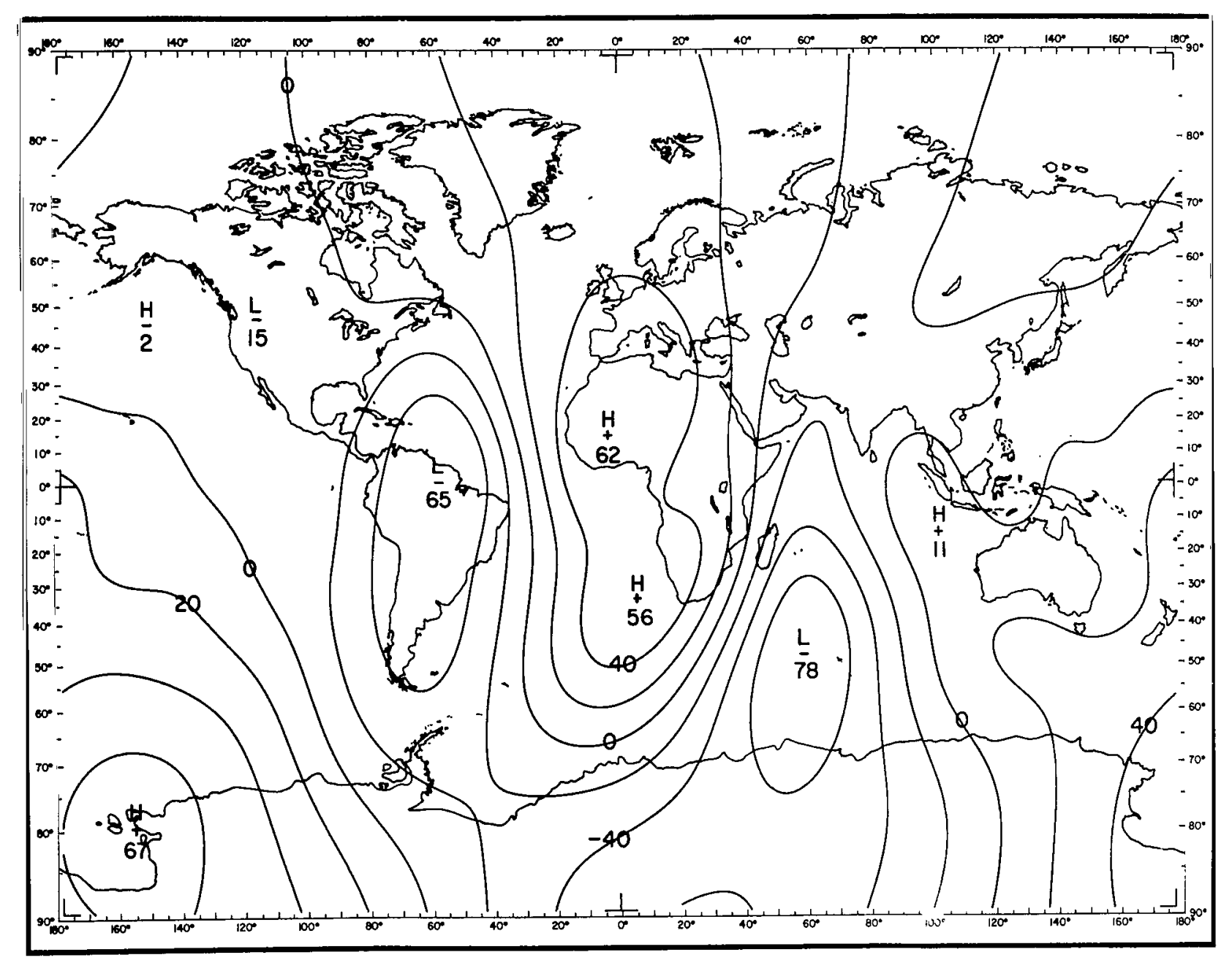

Figure B32-Geomagnetic secular change in gammas per year, east component, epoch 1942.5. GSFC (12/66). 


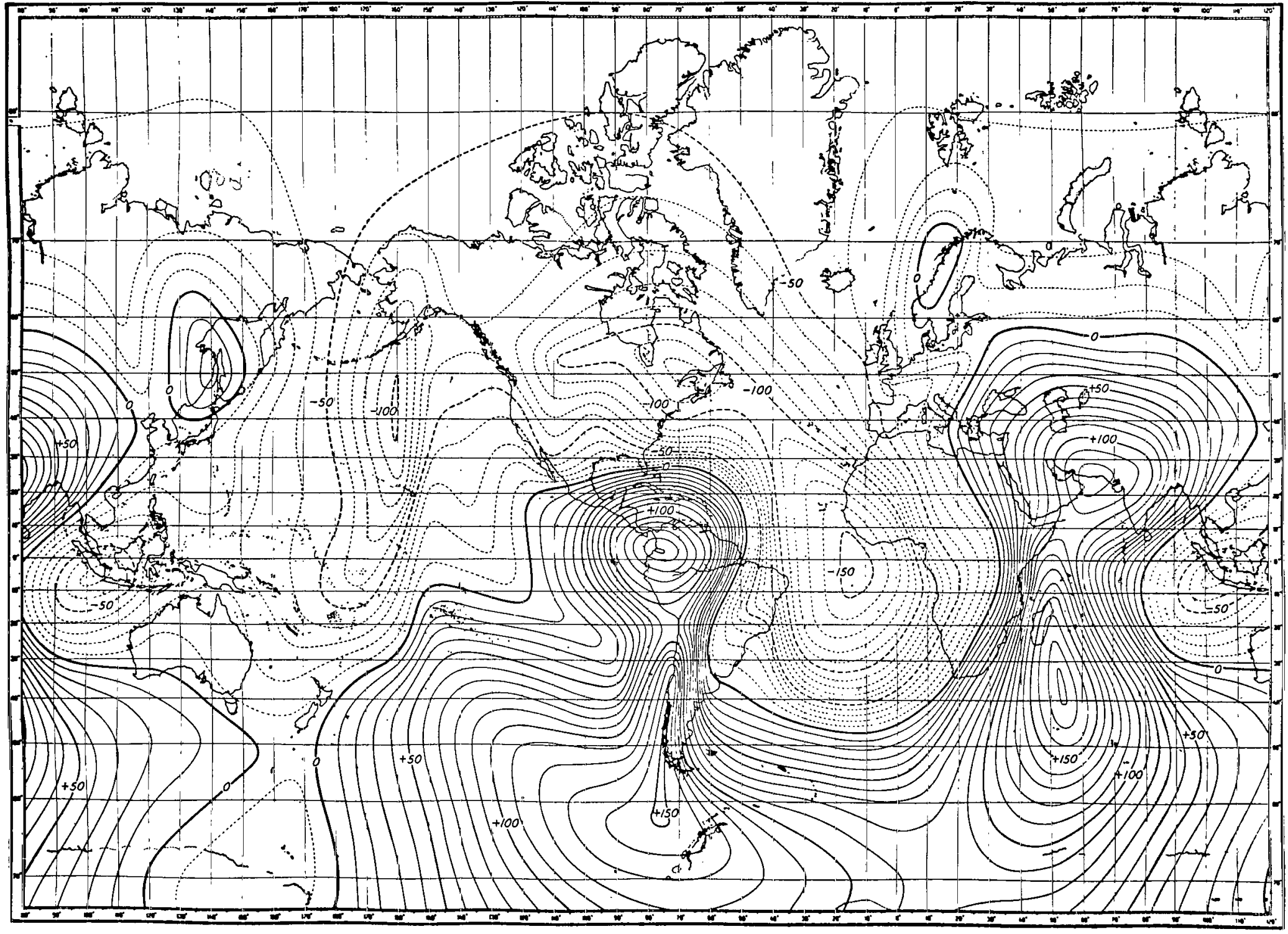

Figure B33-Geomagnetic secular change in gammas per year, vertical component, epoch 1912.5. Vestine et al. (1947). 


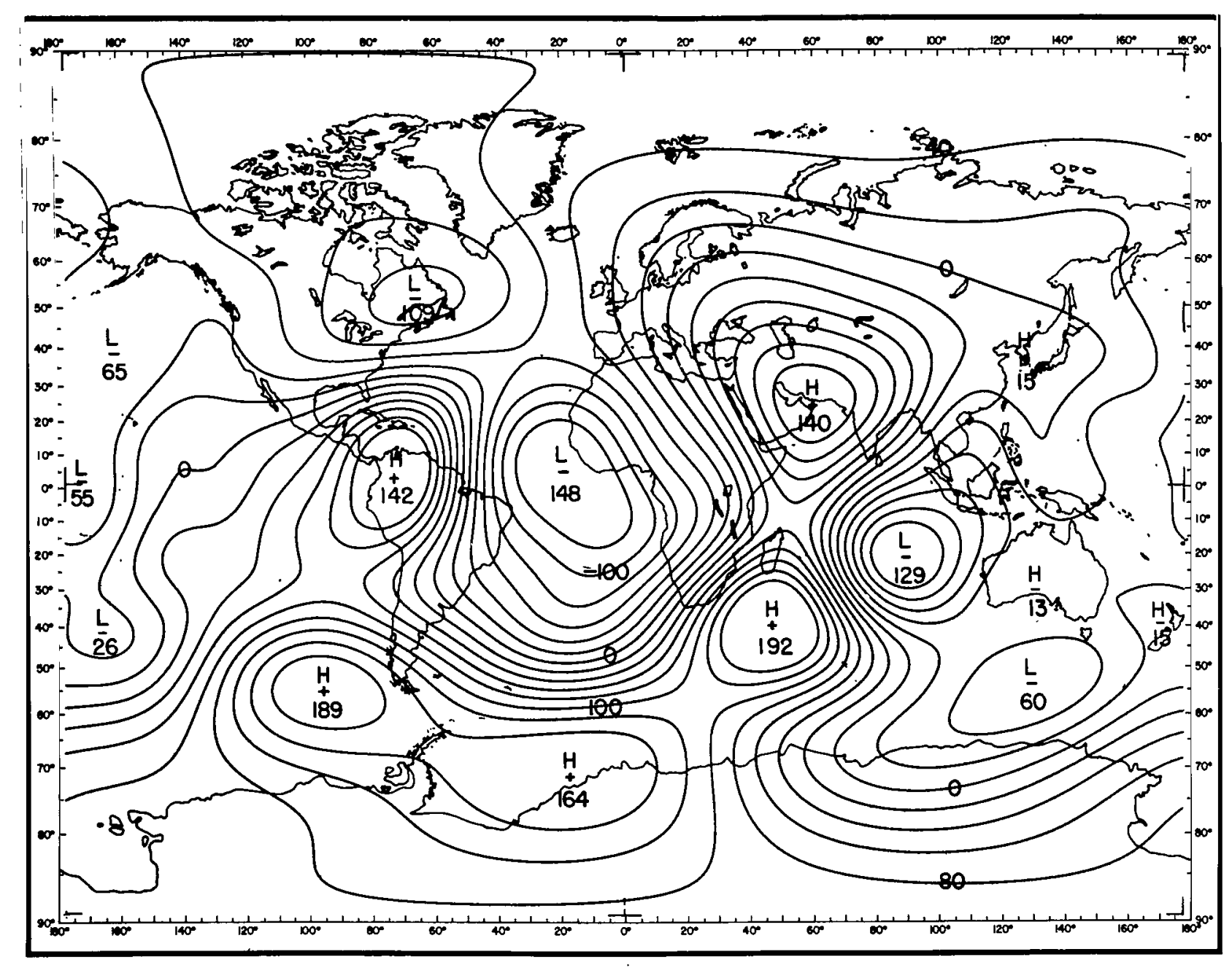

Figure B34-Geomagnetic secular change in gammas per year, vertical component, epoch 1912.5. GSFC (12/66). 


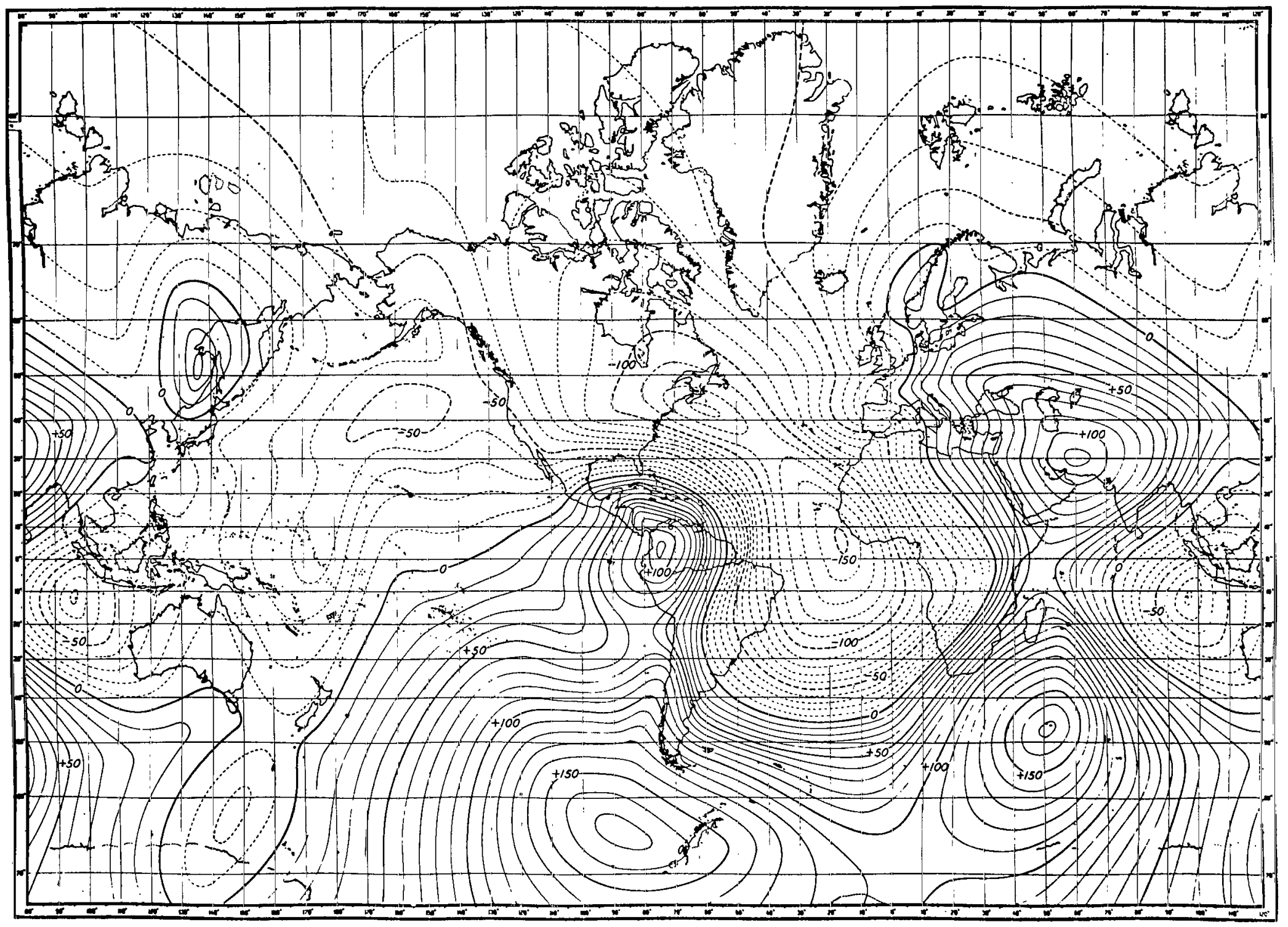

Figure B35-Geomagnetic secular change in gammos per year, vertical component, epoch 1922.5. Vestine et al. (1947). 


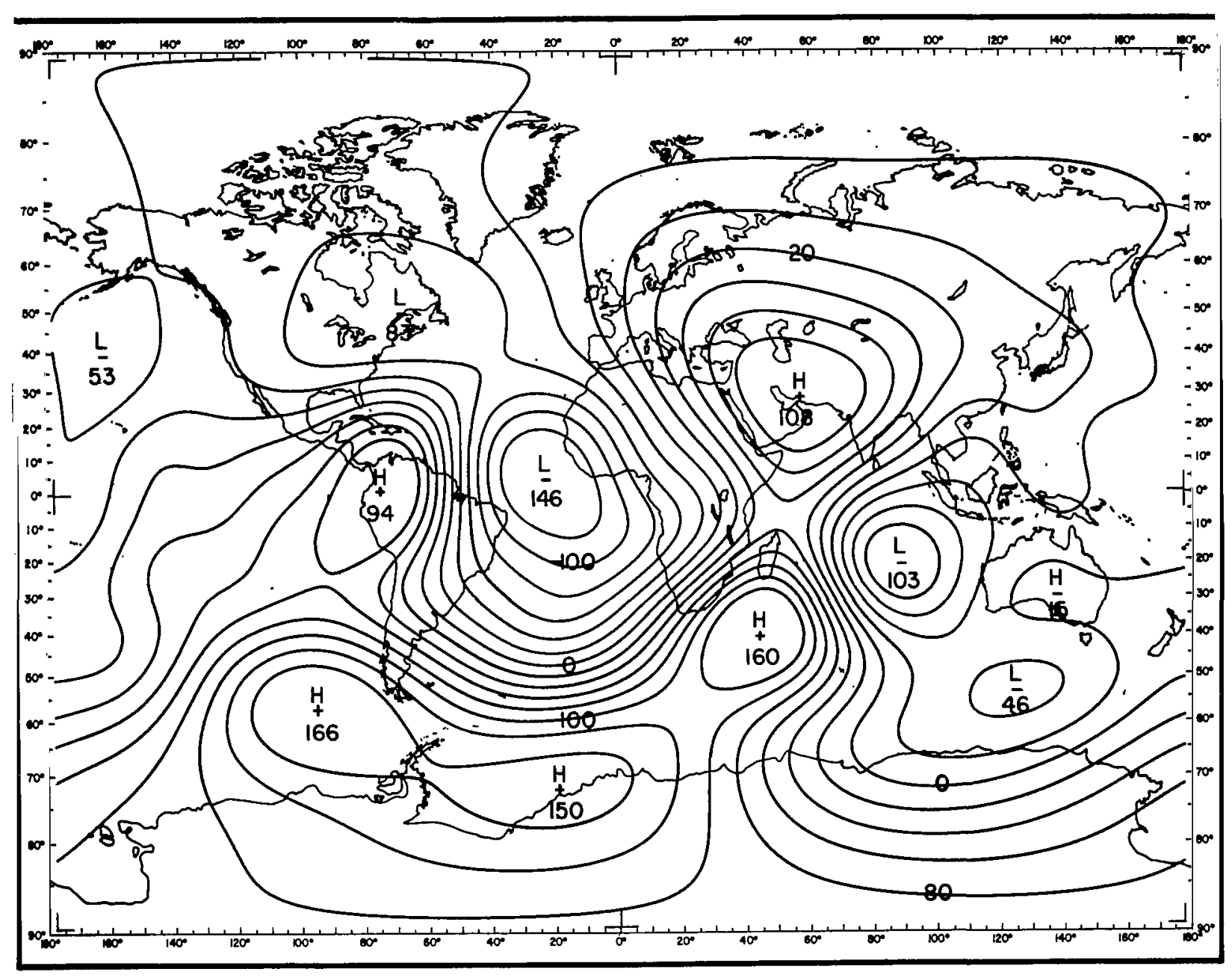

Figure B36-Geomagnetic secular change in gammas per year, vertical component, epoch 1922.5. GSFC $(12 / 66)$. 
$\ddot{\&}$

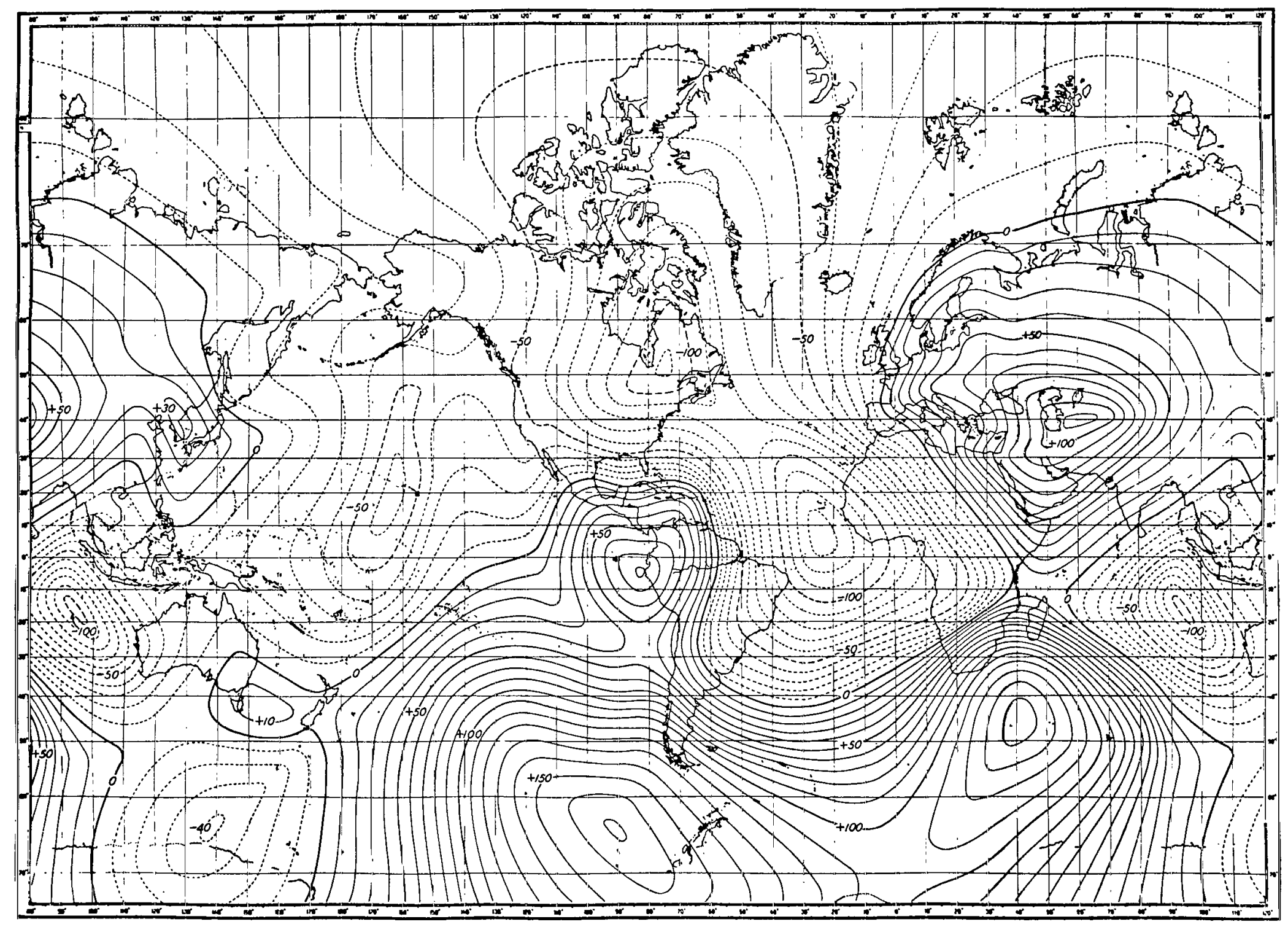

Figure B37-Geomagnetic secular change in gammas per year, vertical component, epoch 1932.5. Vestine et al. (1947). 


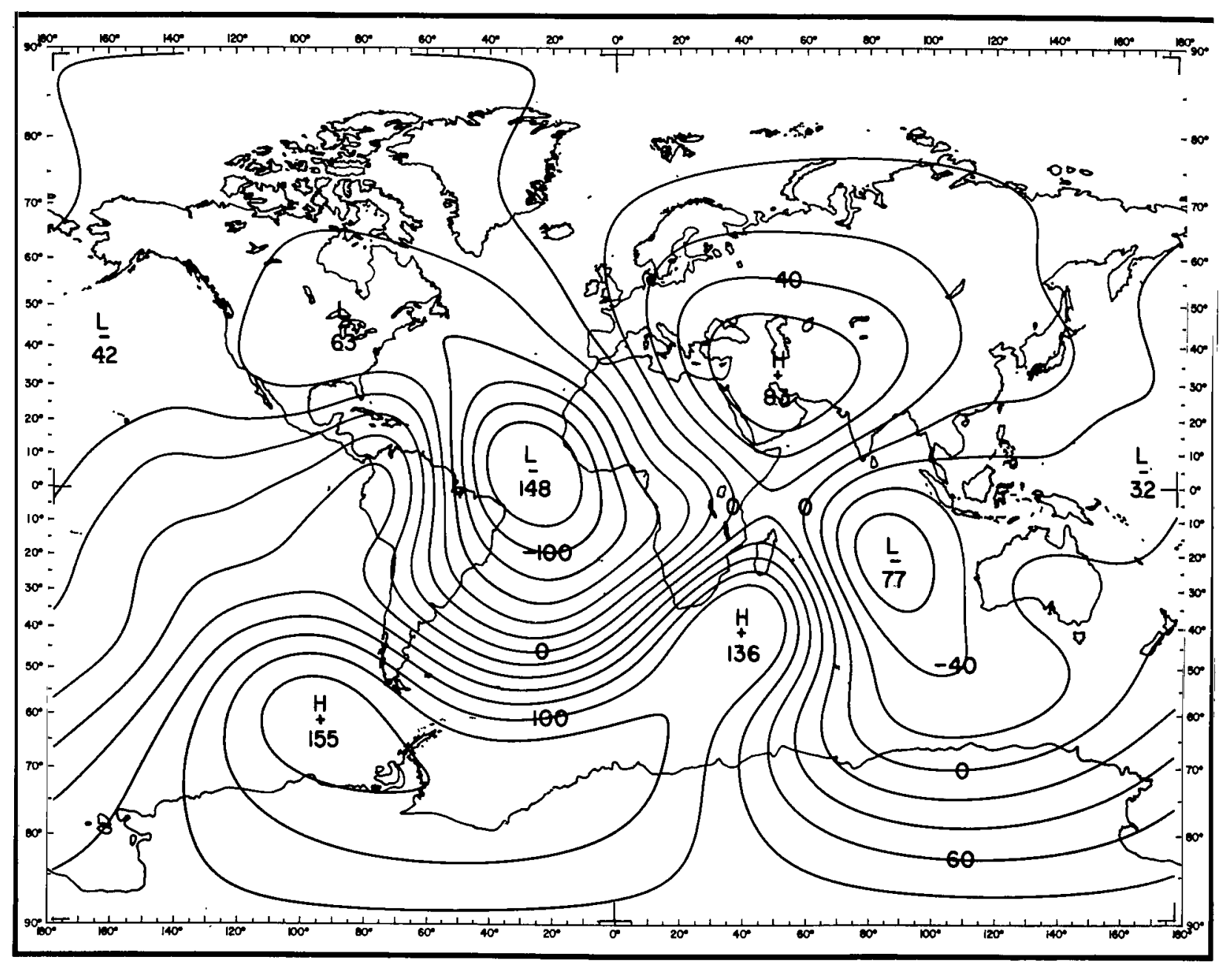

Figure B38-Geomagnetic secular change in gammas per year, vertical component, epoch 1932.5. GSFC (12/66). 



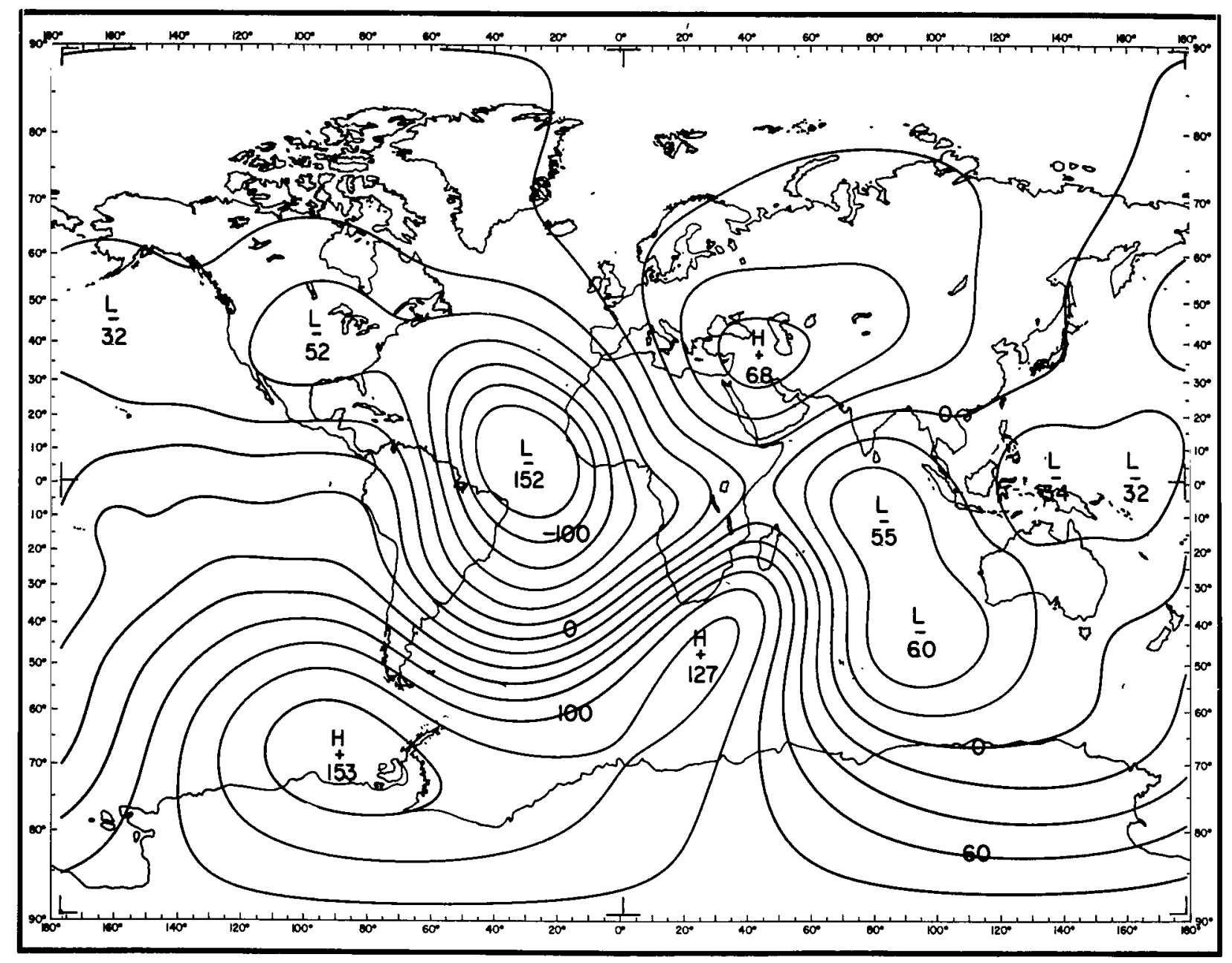

Figure B40-Geomagnetic secular change in gammas per year, vertical component, epoch 1942.5. GSFC (12/66). 


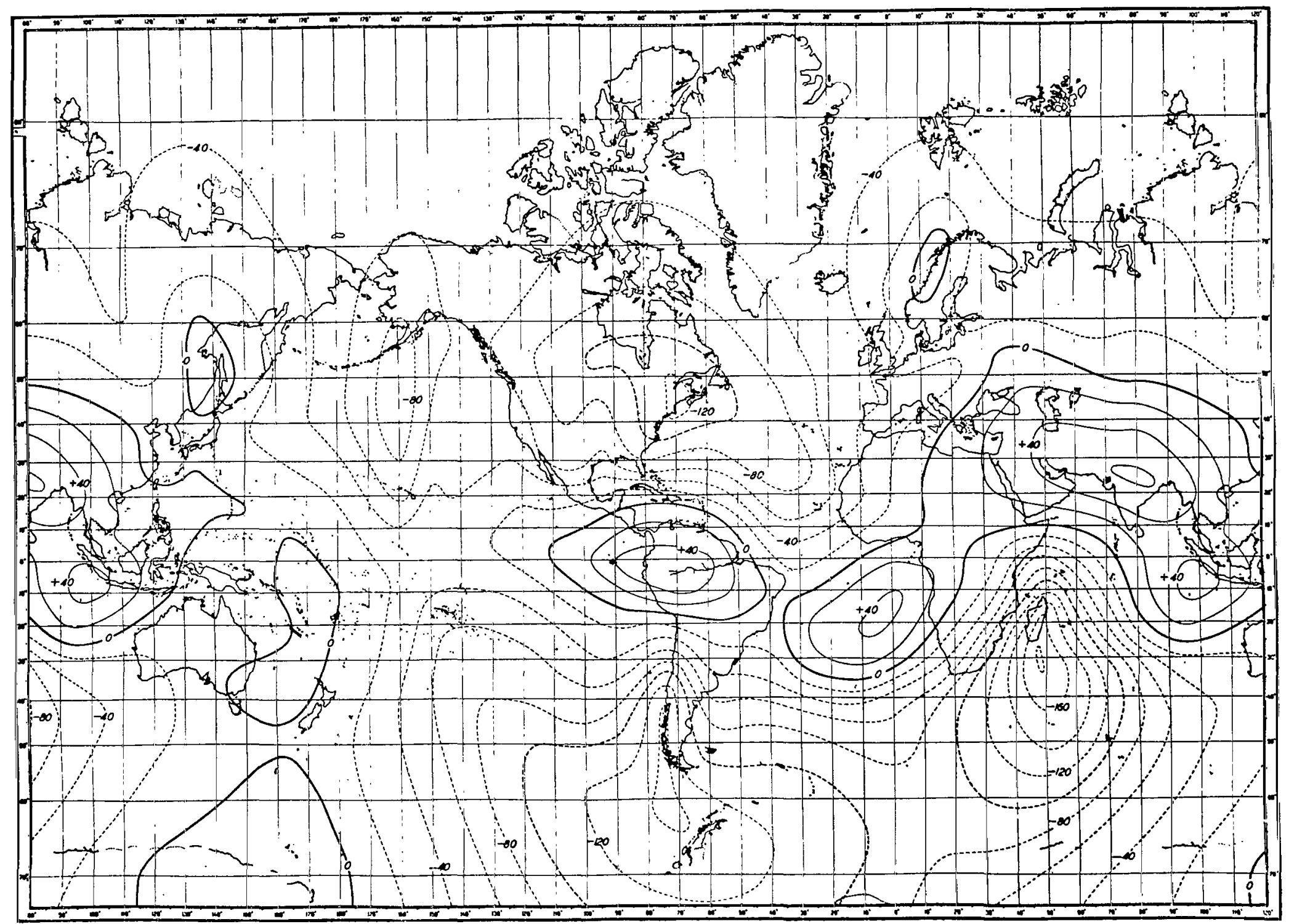

Figure B41-Geomagnetic secular change in gammas per year, total intensity, epoch 1912.5. Vestine et al. (1947). 


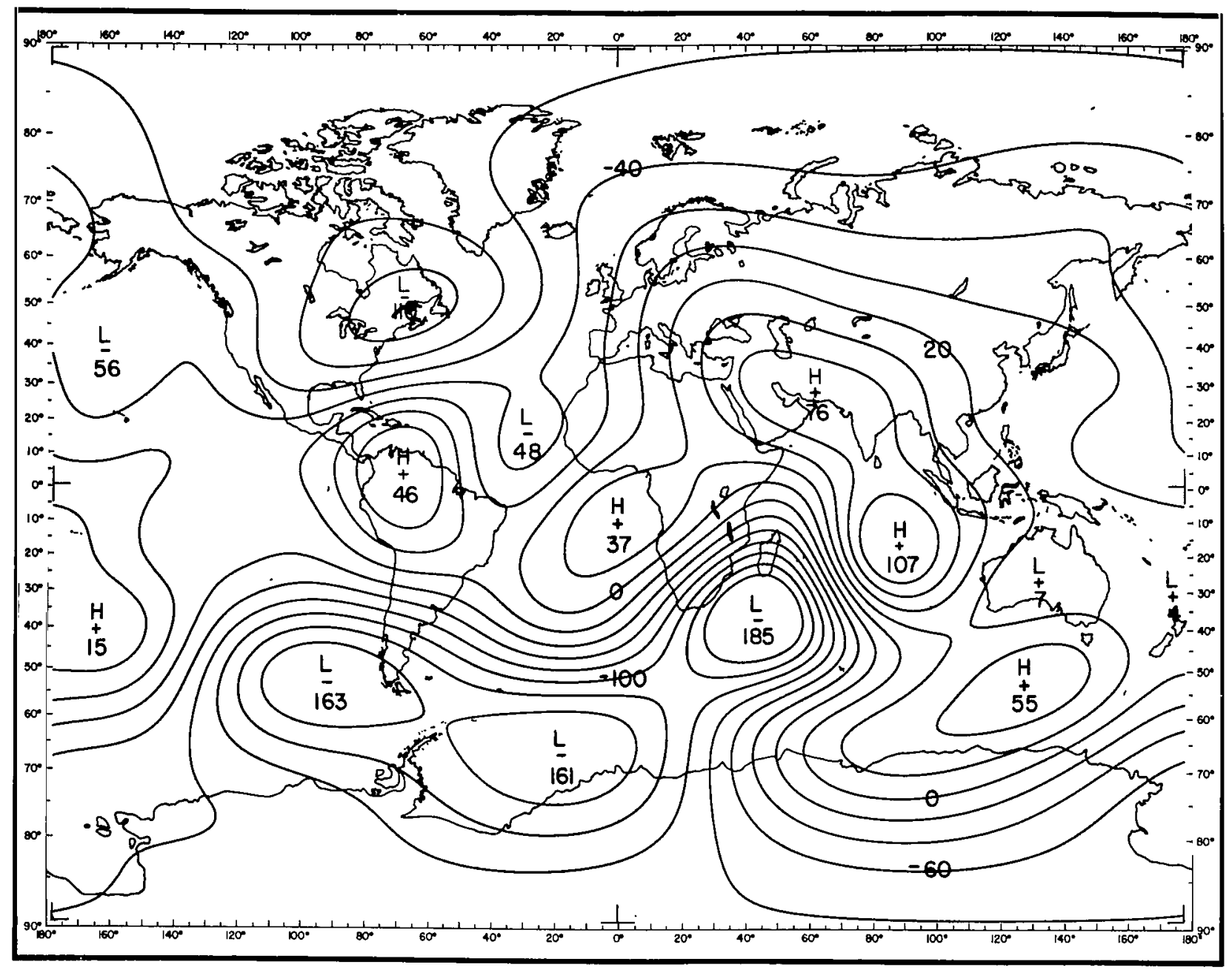

Figure B42-Geomagnetic secular change in gammas per year, total intensity, epoch 1912.5. GSFC (12/66). 


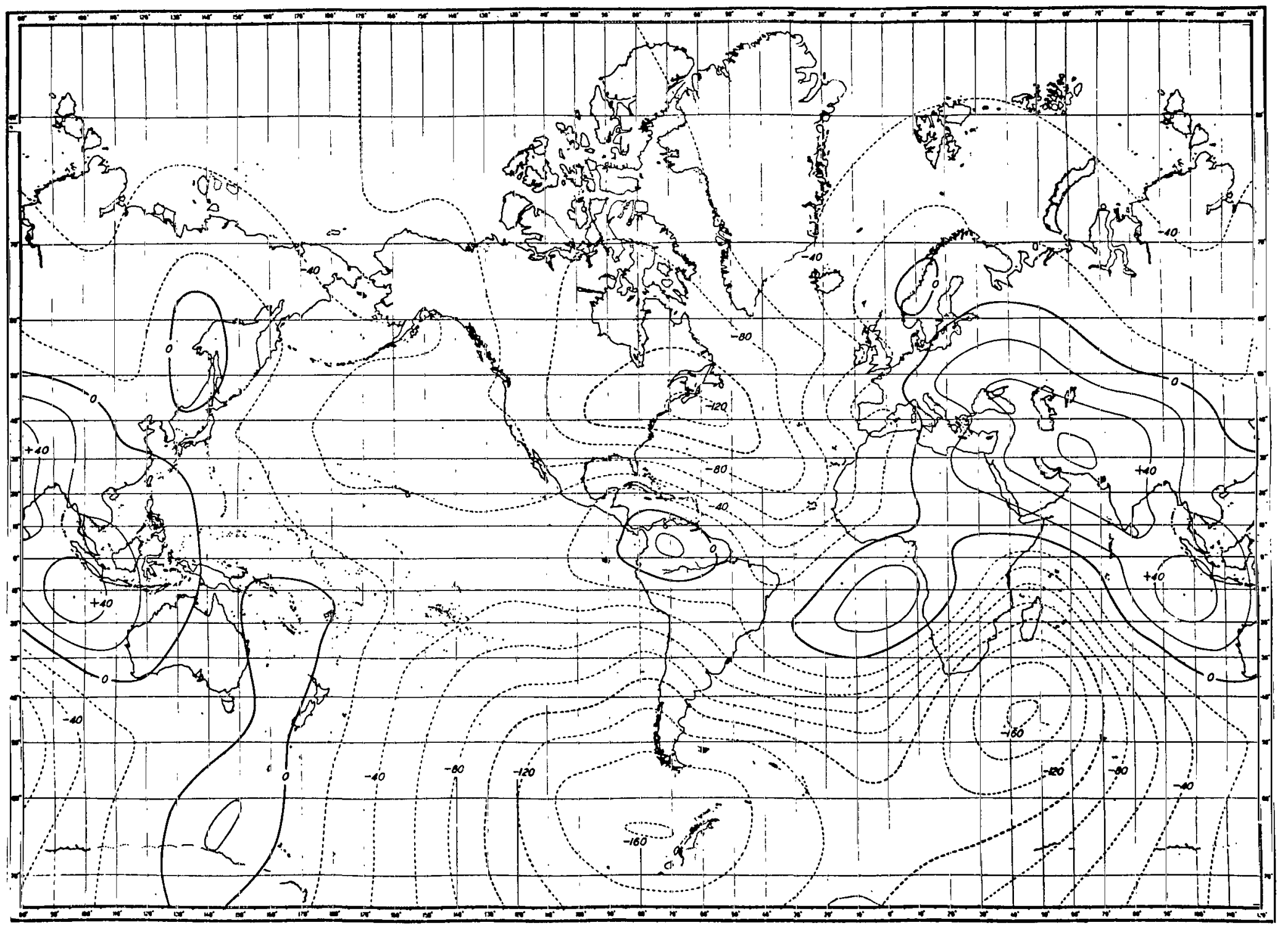

Figure B43-Geomagnetic secular change in gammas per year, total intensity, epoch 1922.5. Vestine et al. (1947). 


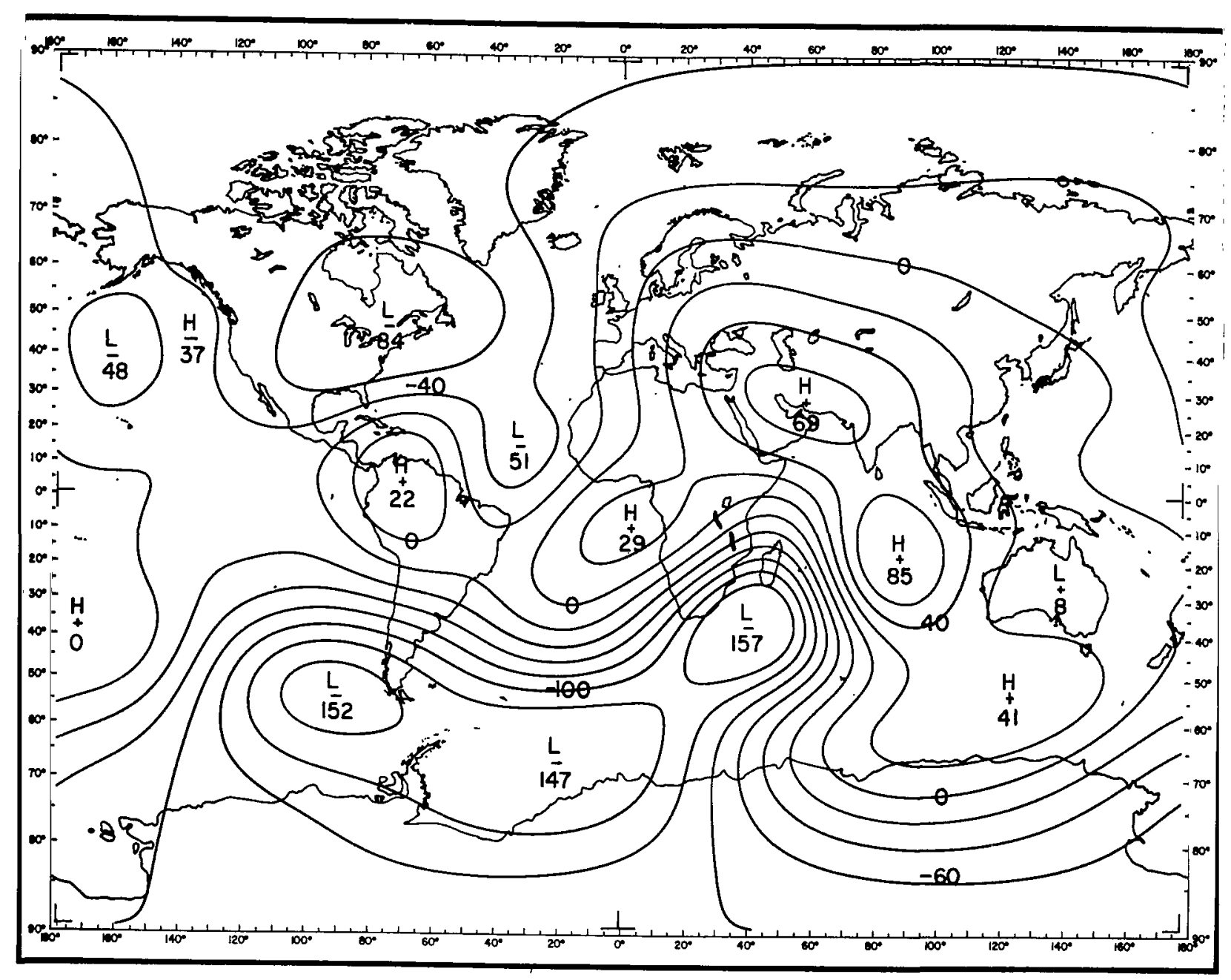

Figure B44-Geomagnetic secular change in gammas per year, total intensity, epoch 1922.5. GSFC (12/66). 


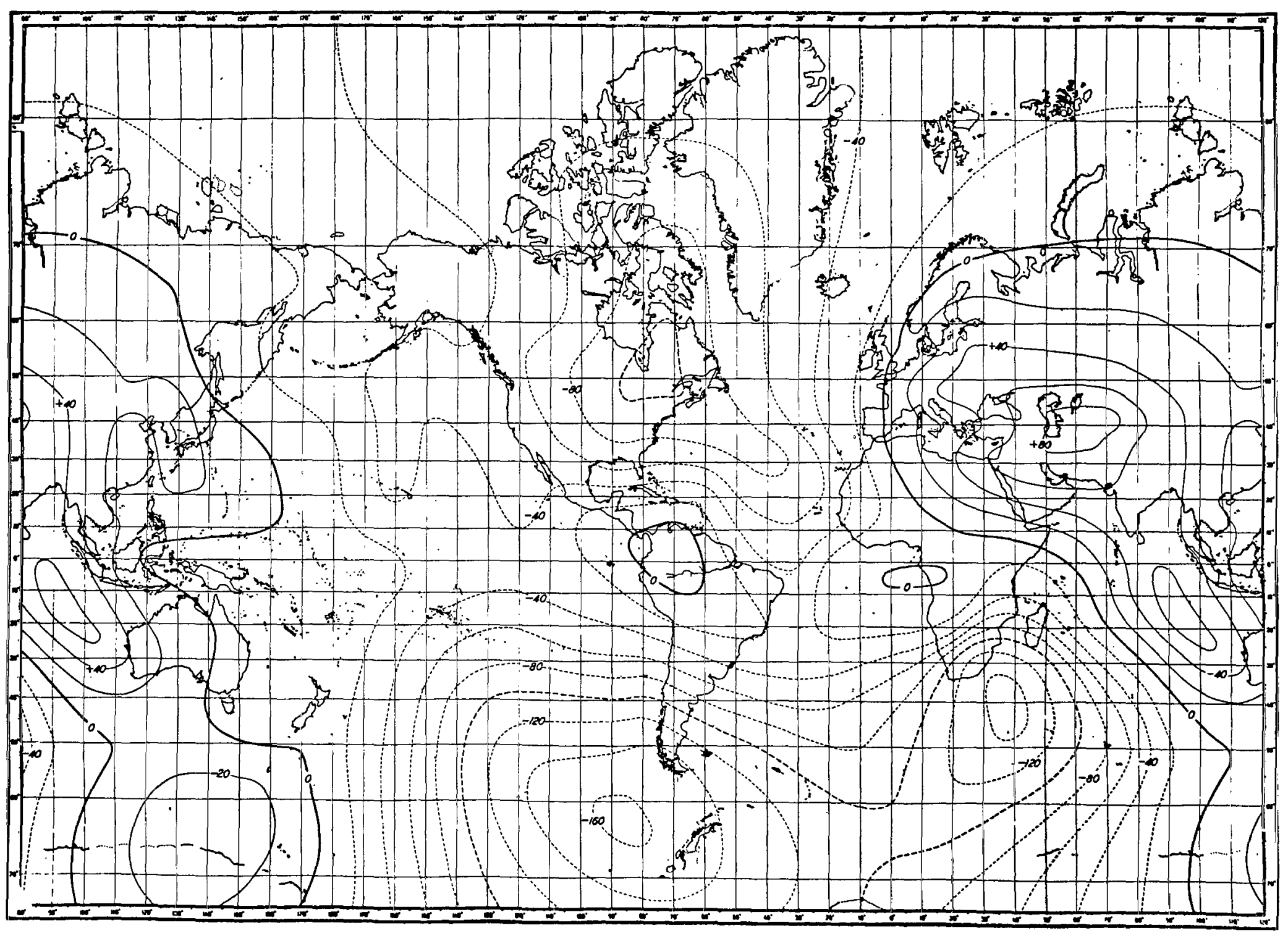

Figure B45-Geomagnetic secular change in gammas per year, total intensity, opoch 1932.5. Vestine et al. (1947). 


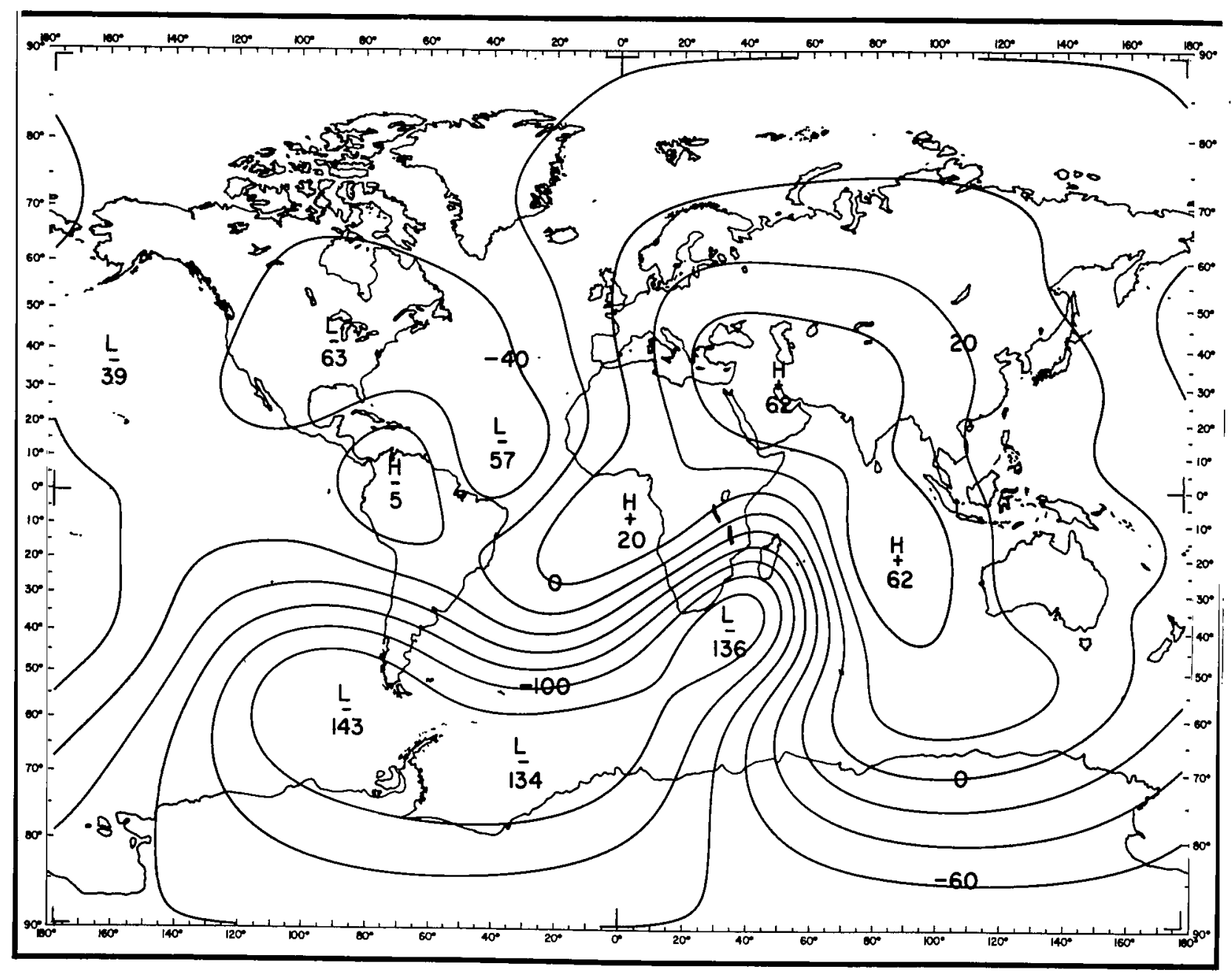

Figure B46-Geomagnetic secular change in gammas per year, total intensity, epoch 1932.5. GSFC $(12 / 66)$. 


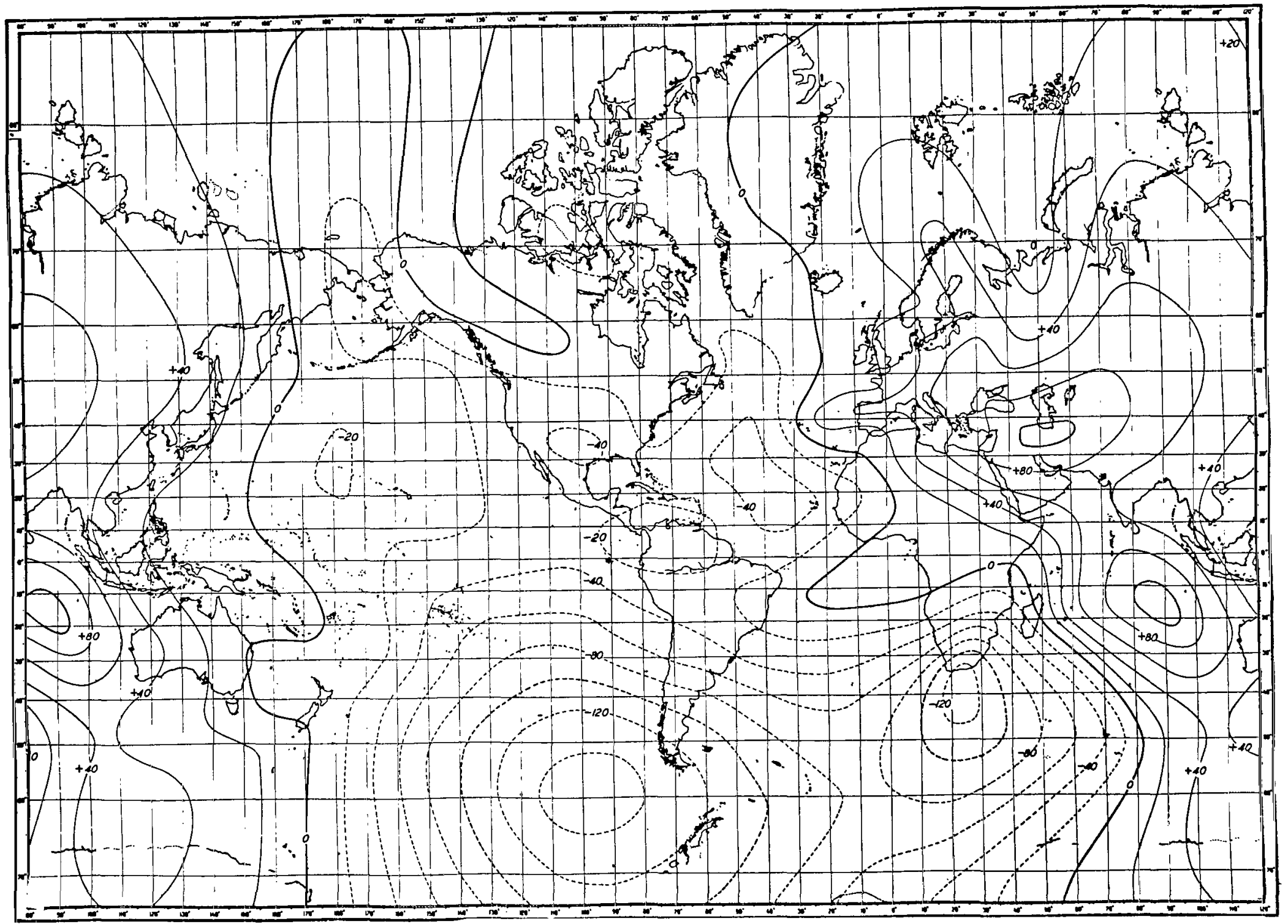

Figure B47-Geomagnetic secular change in gammas per year, total intensity, epoch 1942.5. Vestine et al. (1947). 


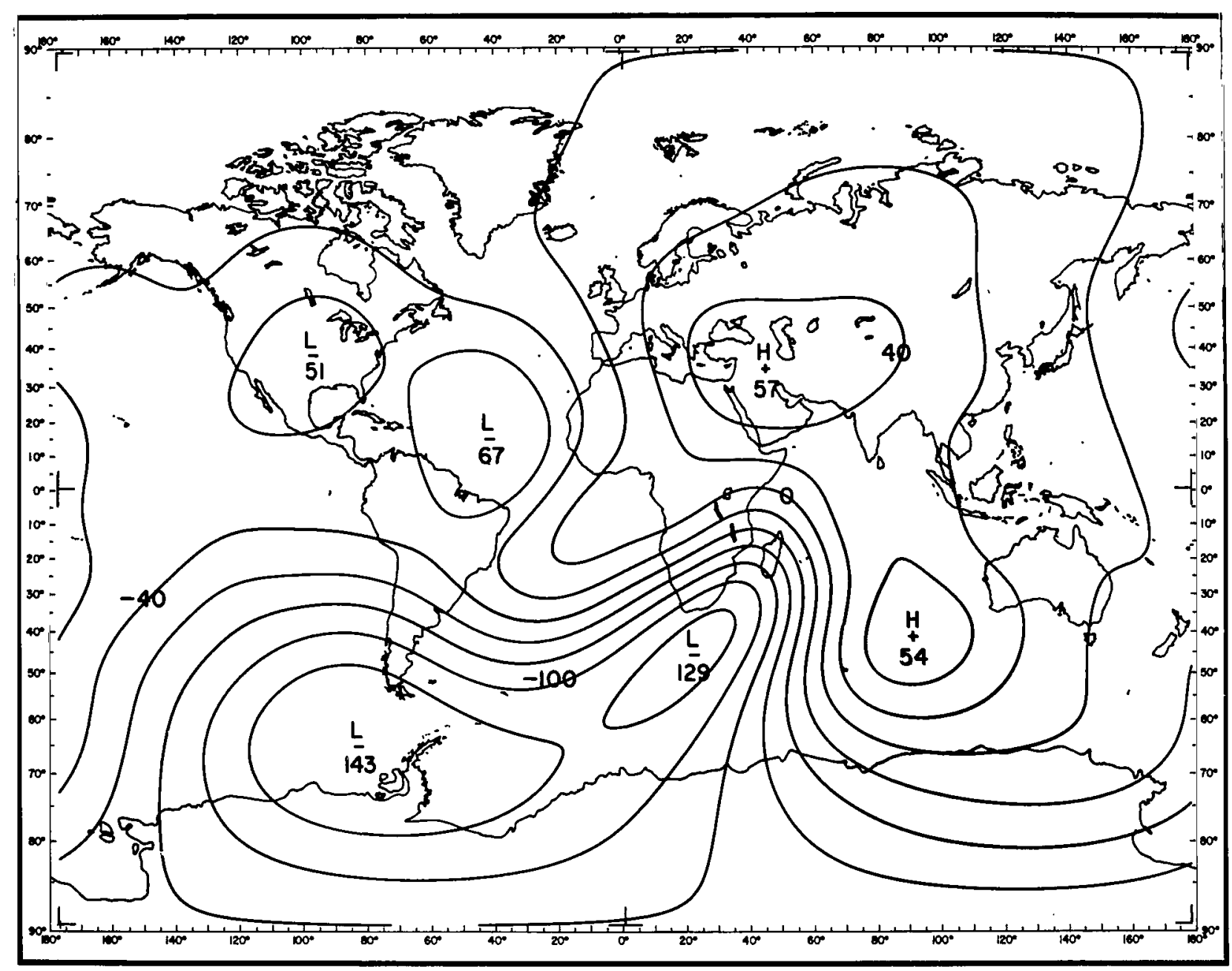

Figure B48-Geomagnetic secular change in gammas per year, total intensity, epoch 1942.5. GSFC (12/66). 
Appendix C

Main Field Component and Isoporic Charts Computed From GSFC $(12 / 66)$ for 1965.0 at the Earth's Surface 


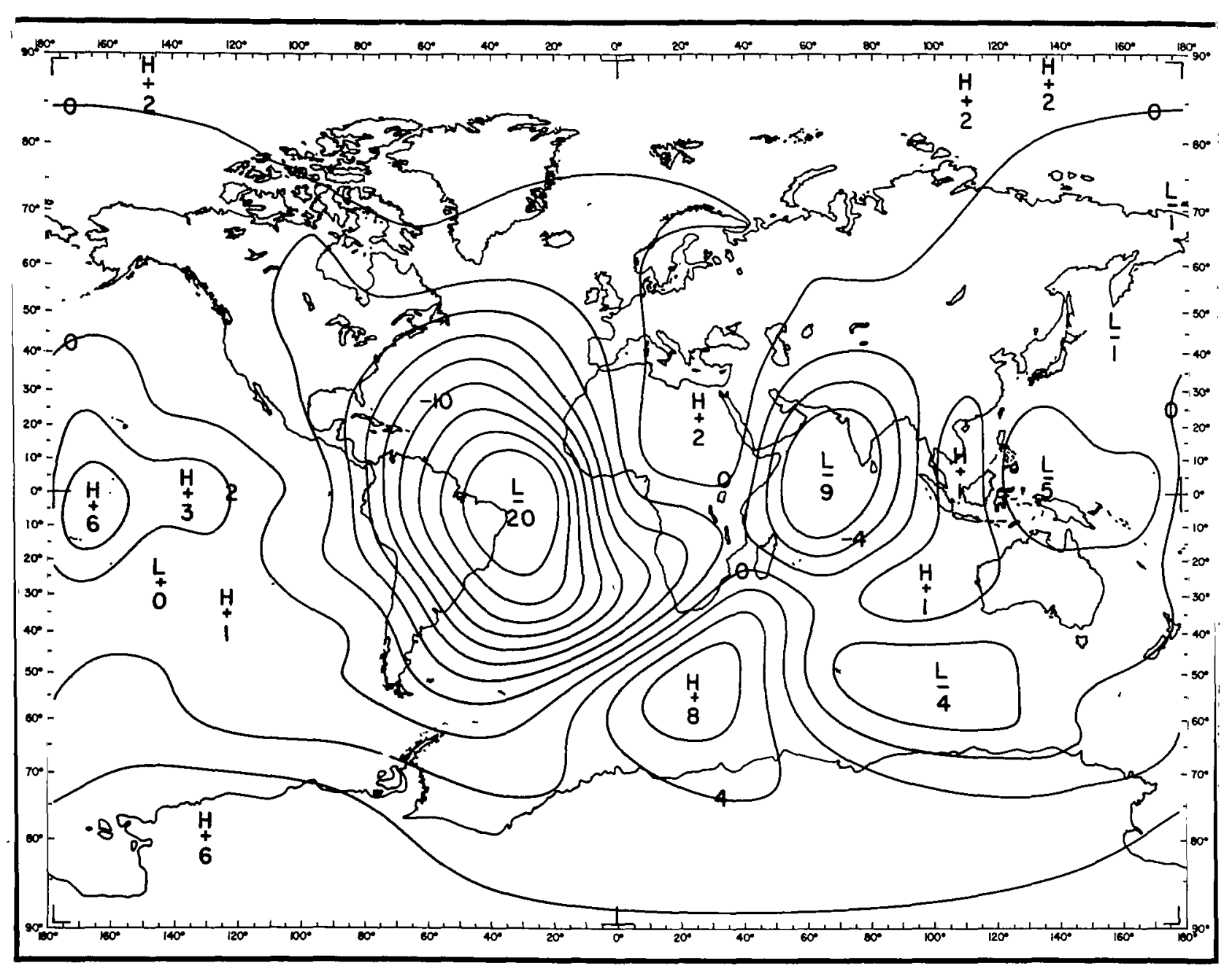

Figure $\mathrm{Cl}-$ Geomagnetic secular change in minutes per year, inclination, epoch 1965.0. GSFC $(12 / 66)$. 


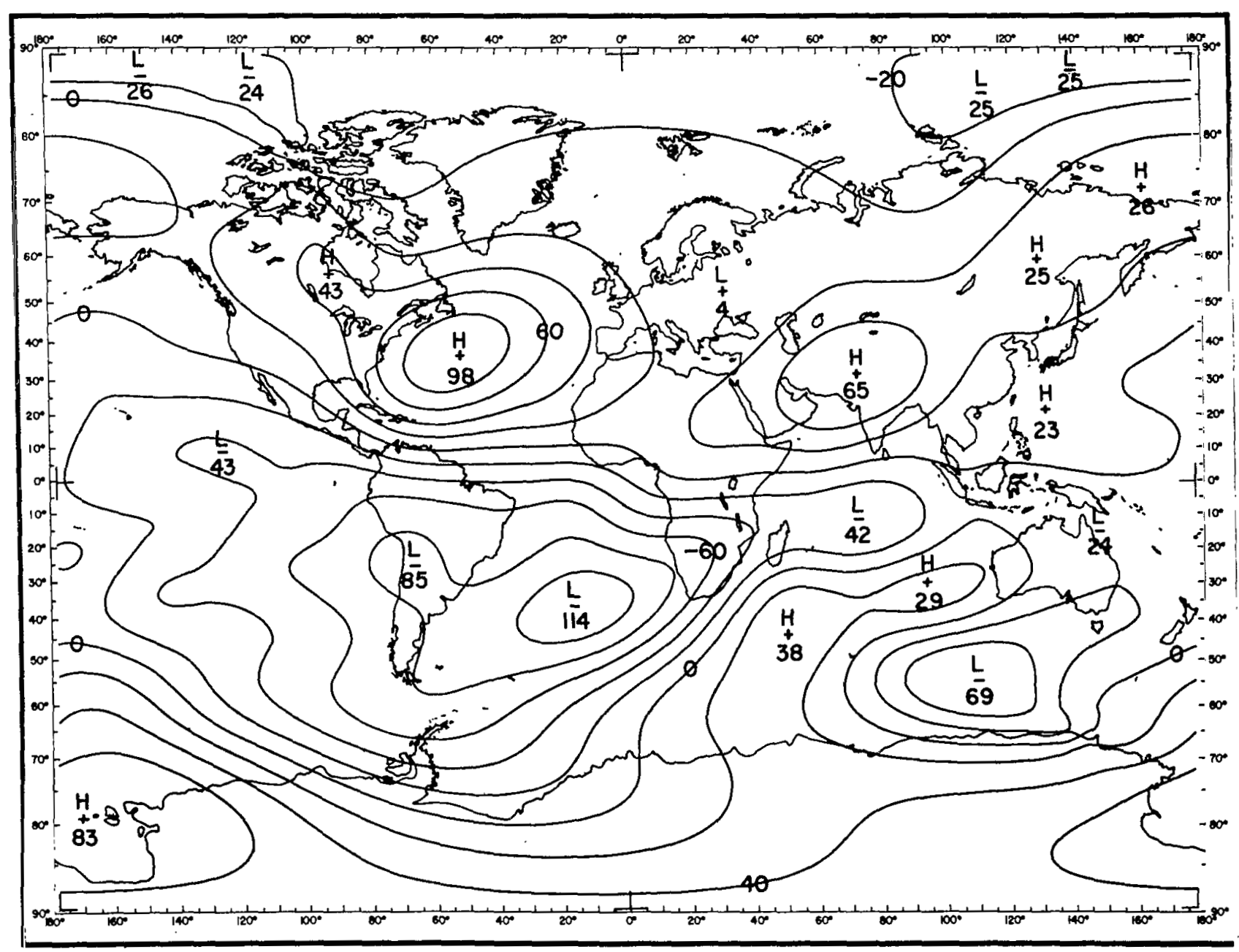

Figure C2-Geomagnetic secular change in gammas per year, horizontal component, epoch 1965.0. GSFC (12/66). 


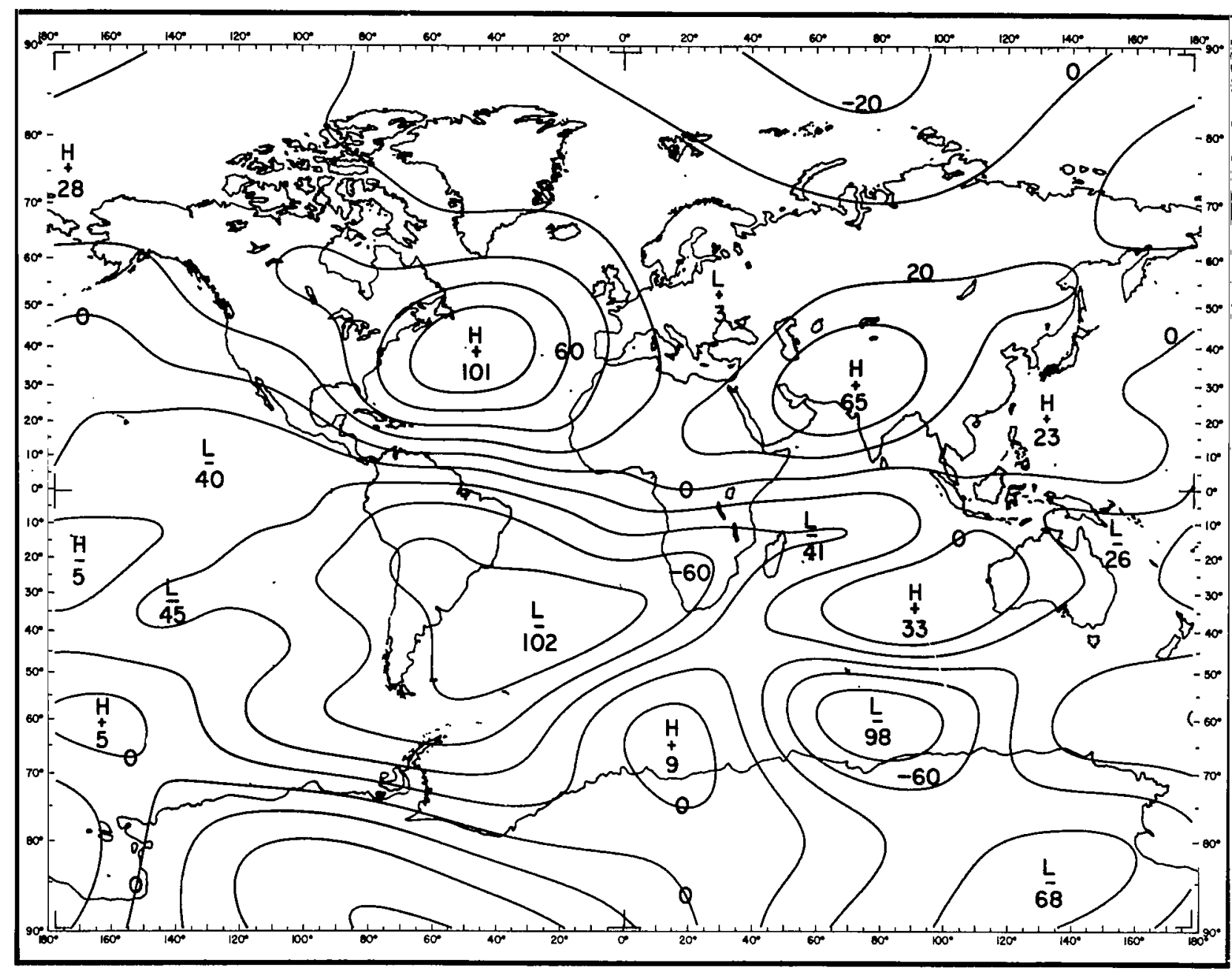

Figure C3-Geomagnetic secular change in gammas per year, north component, epoch 1965.0. GSFC (12/66). 


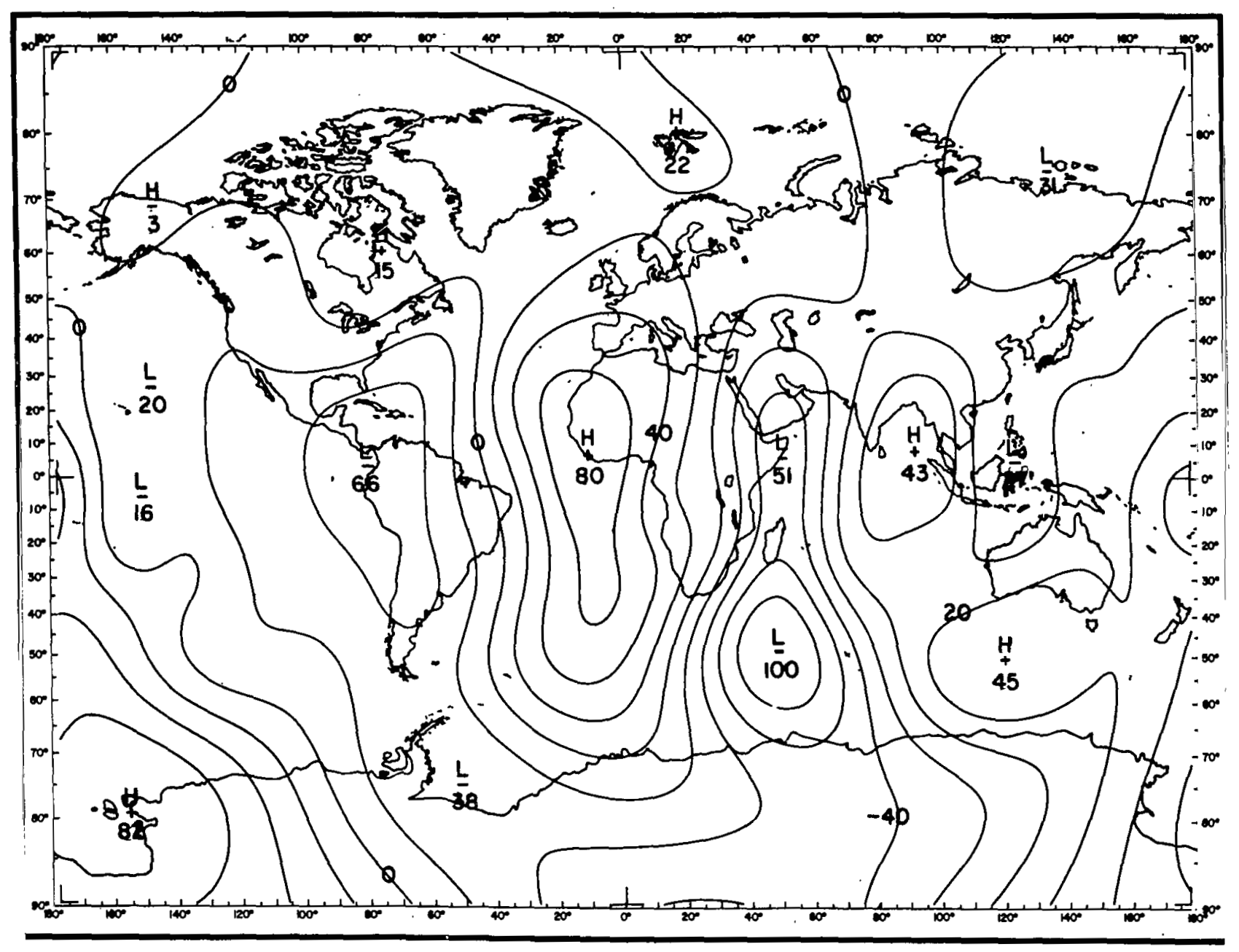

Figure C4-Geomagnetic secular change in gammas per year, east component, epoch 1965.0. GSFC $(12 / 66)$. 


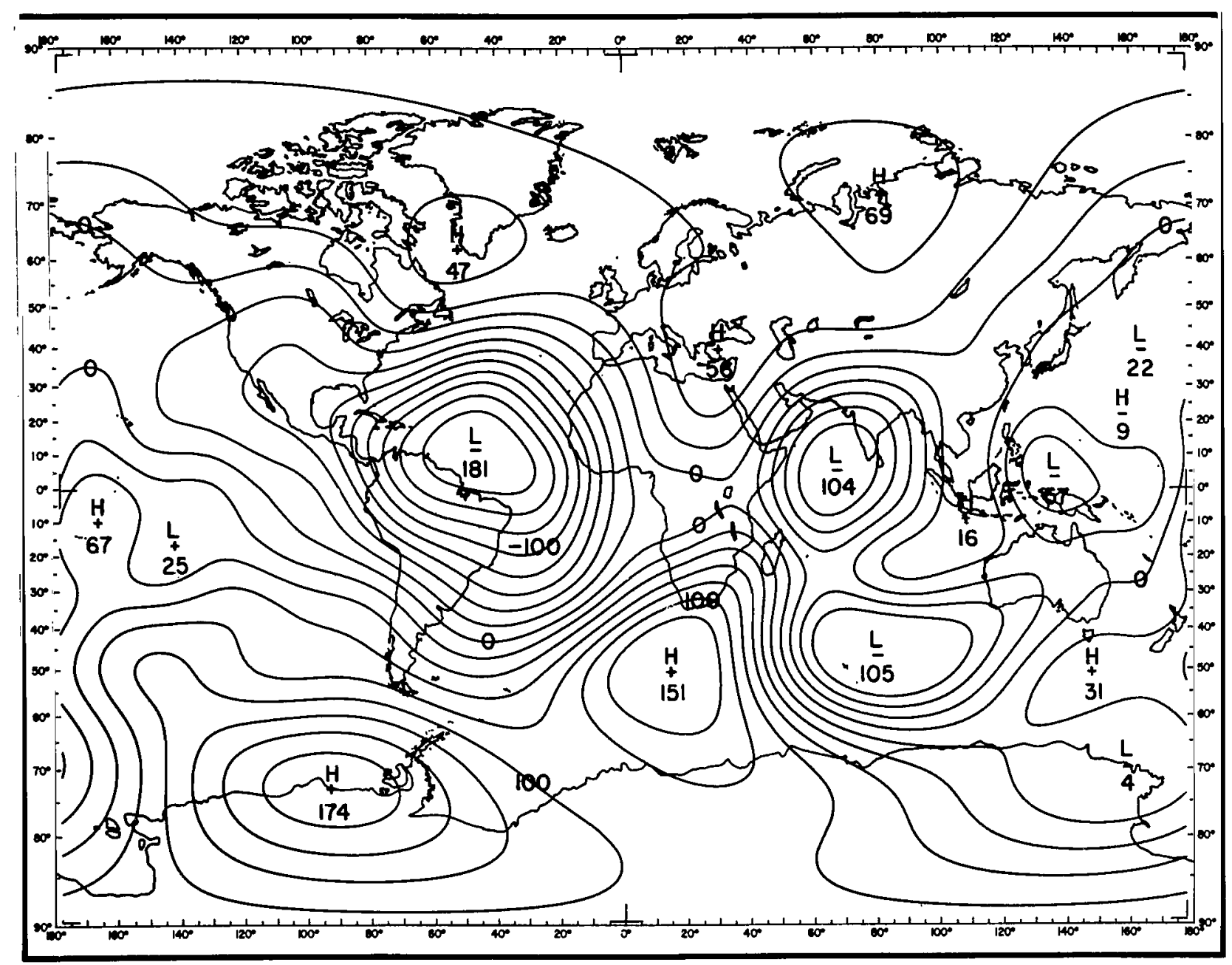

Figure C5-Geomagnetic secular change in gammas per year, vertical component, epoch 1965.0. GSFC (12/66). 


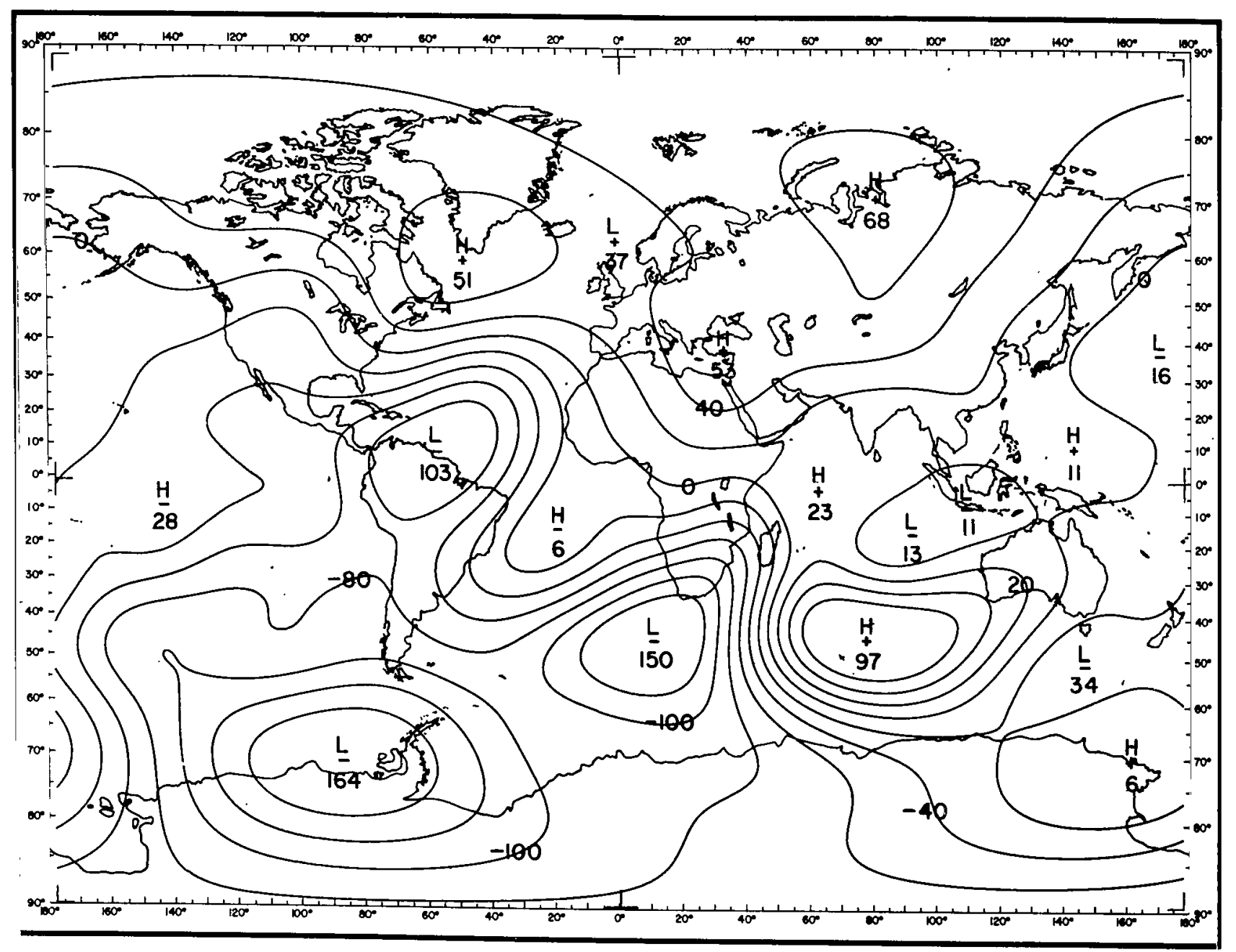

Figure C6-Geomagnetic secular change in gammas per year, total intensity, epoch 1965.0. GSFC (12/66). 


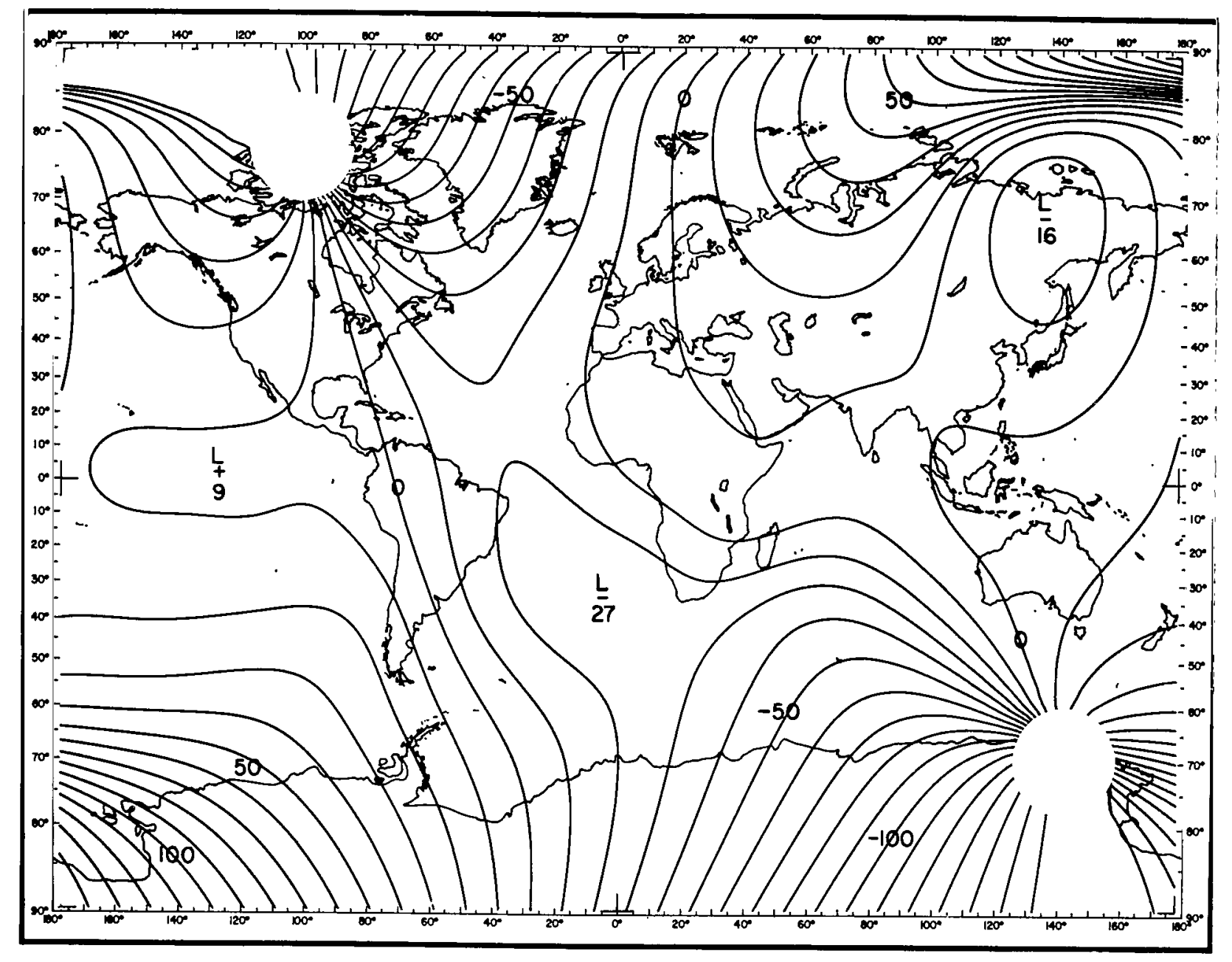

Figure C7-D in degrees, epoch 1965.0. GSFC (12/66). 


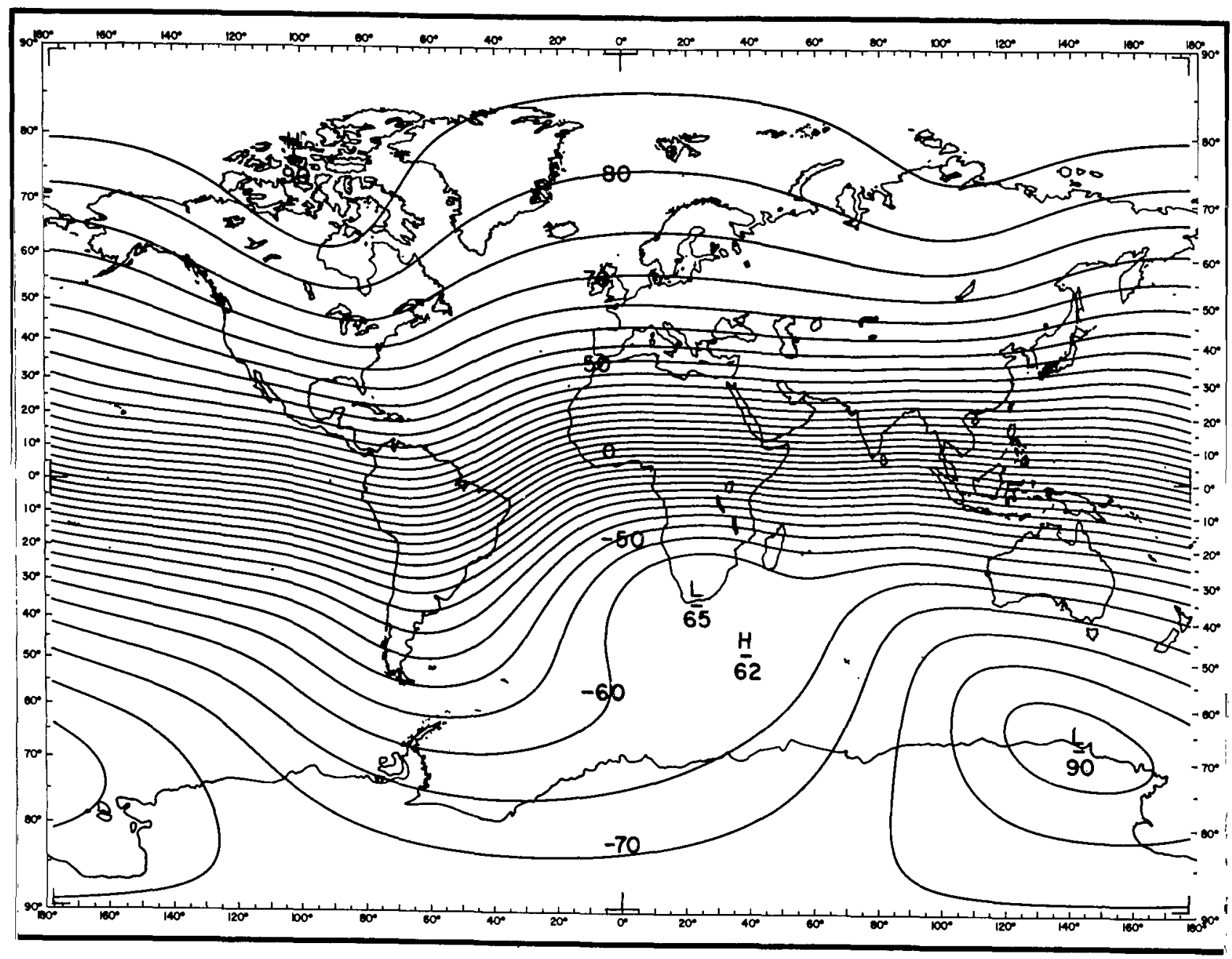

Figure C8-1 in degrees, epoch 1965.0. GSFC (12/66). 


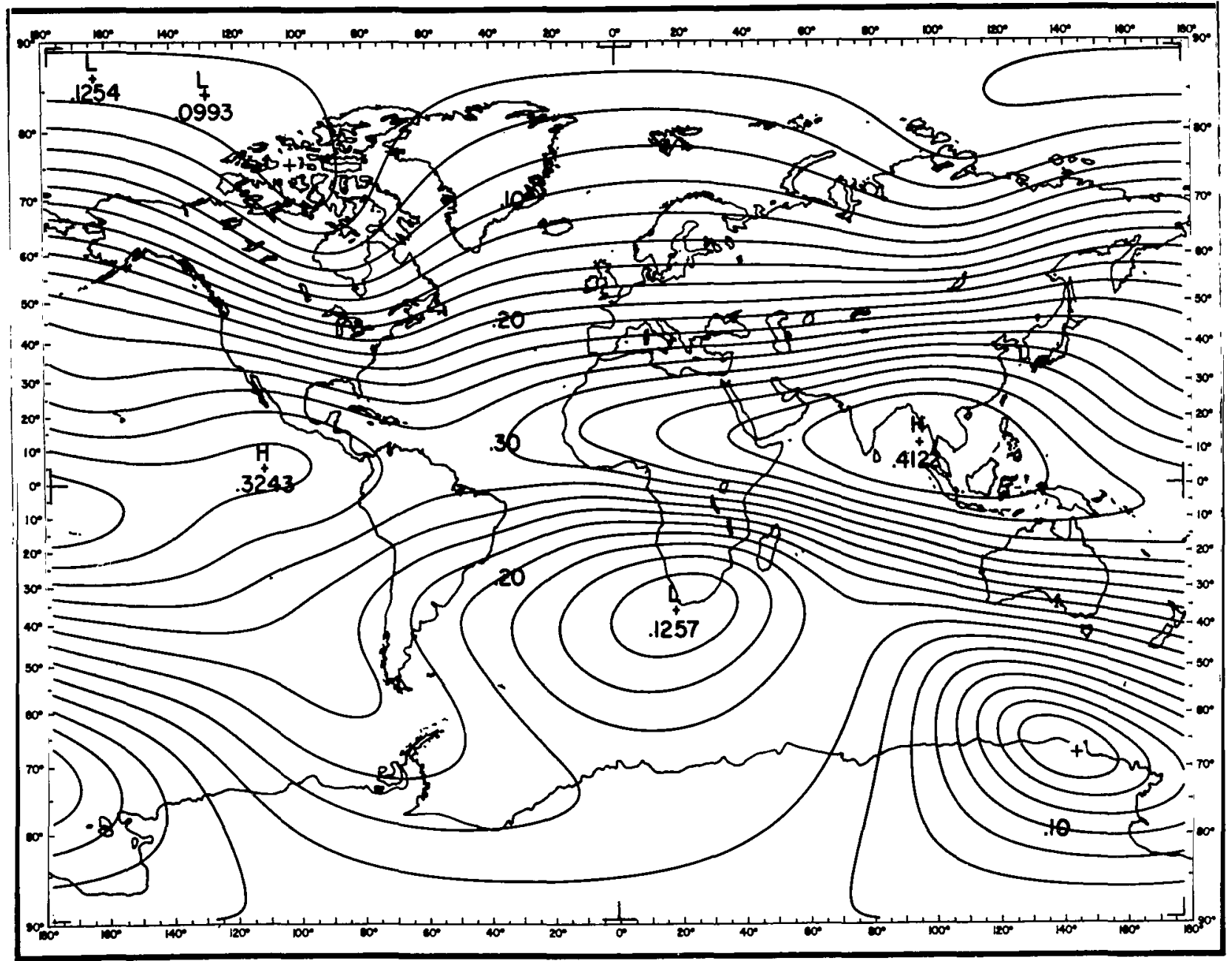

Figure $\mathrm{C} 9-\mathrm{H}$ in gauss, epoch 1965.0. GSFC (12/66). 


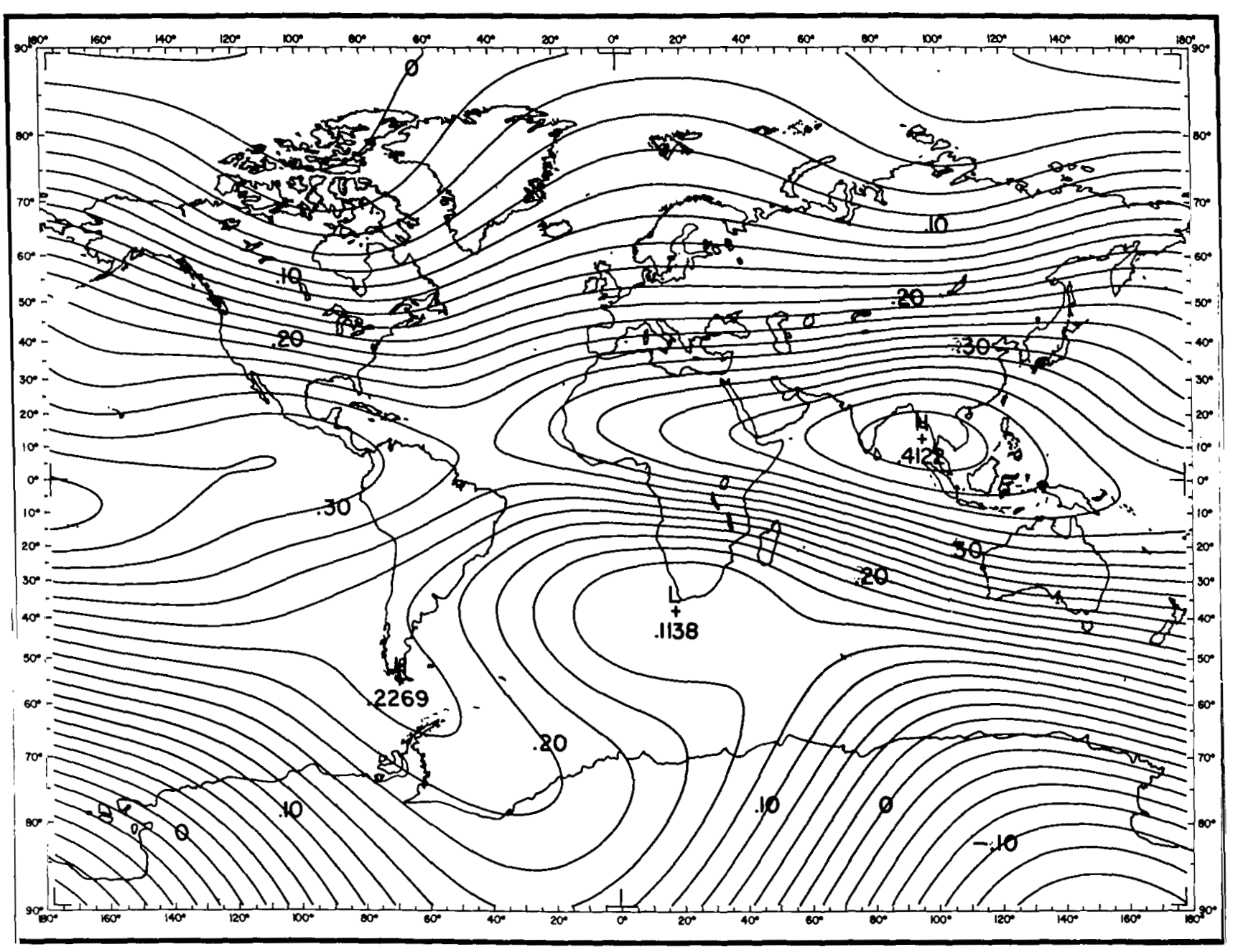

Figure C10-X in gauss, epoch 1965.0. GSFC (12/66). 


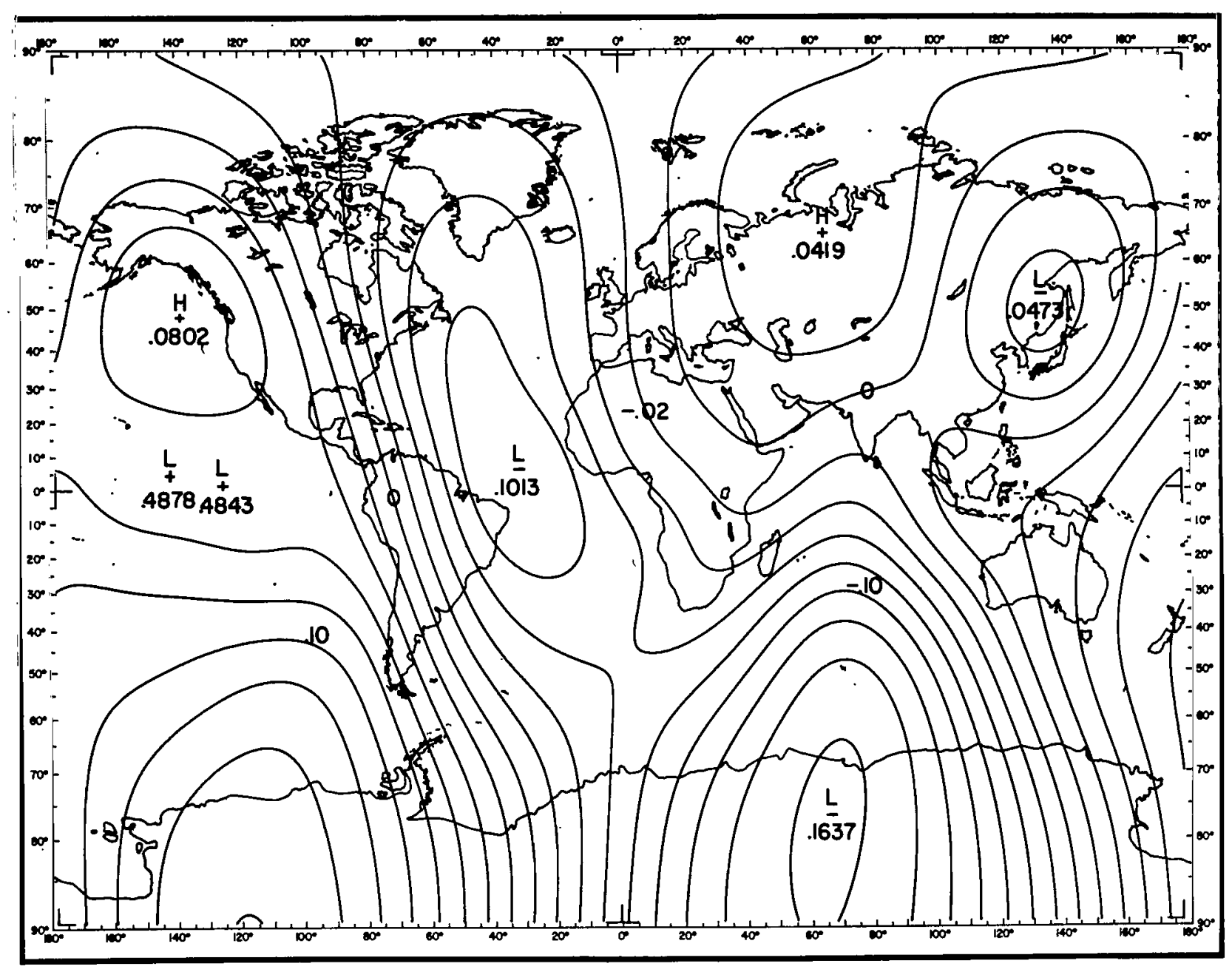

Figure C11-Y in gauss, epoch 1965.0. GSFC (12/66). 


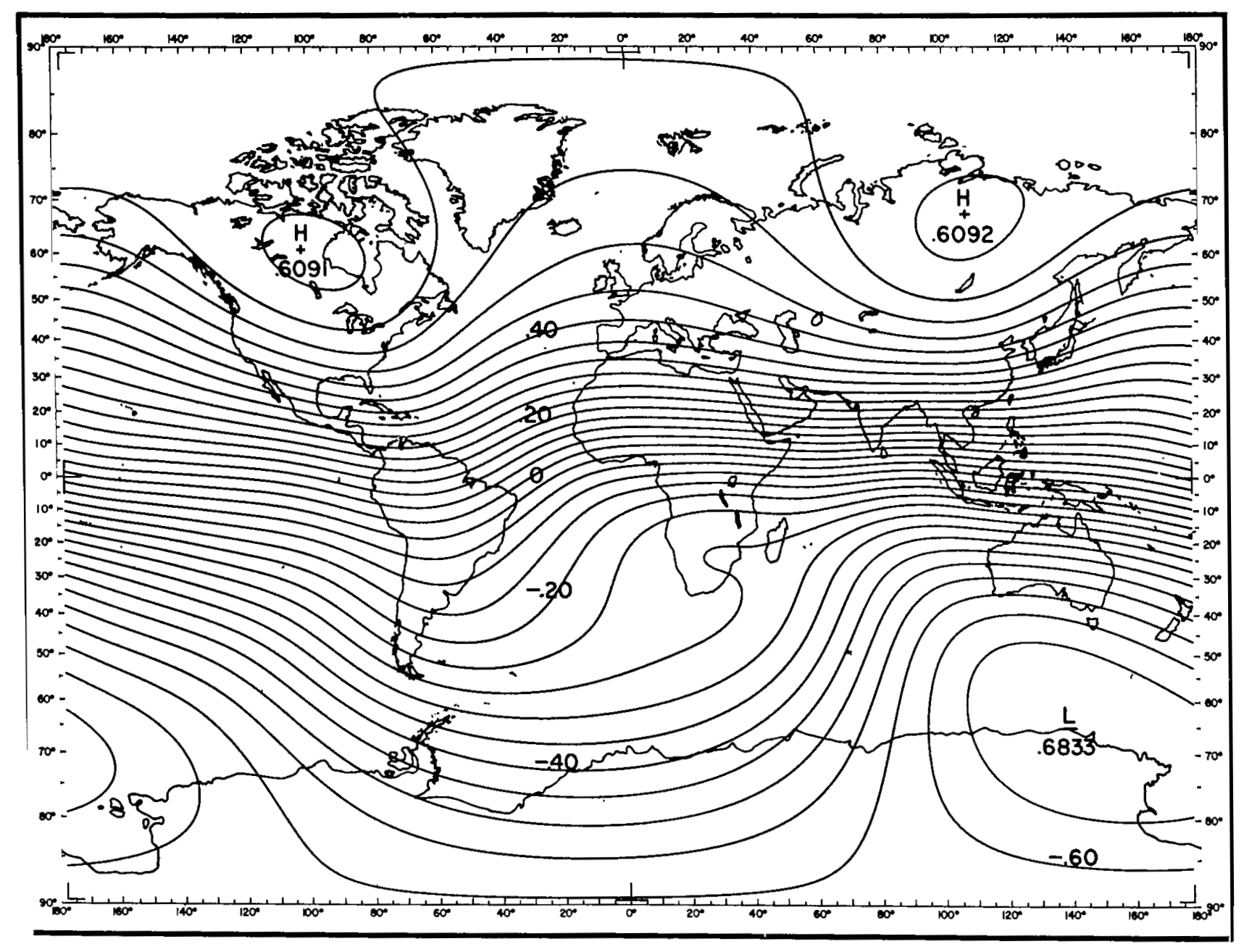

Figure $\mathrm{Cl} 2-\mathrm{Z}$ in gauss, epoch 1965.0. GSFC (12/66). 


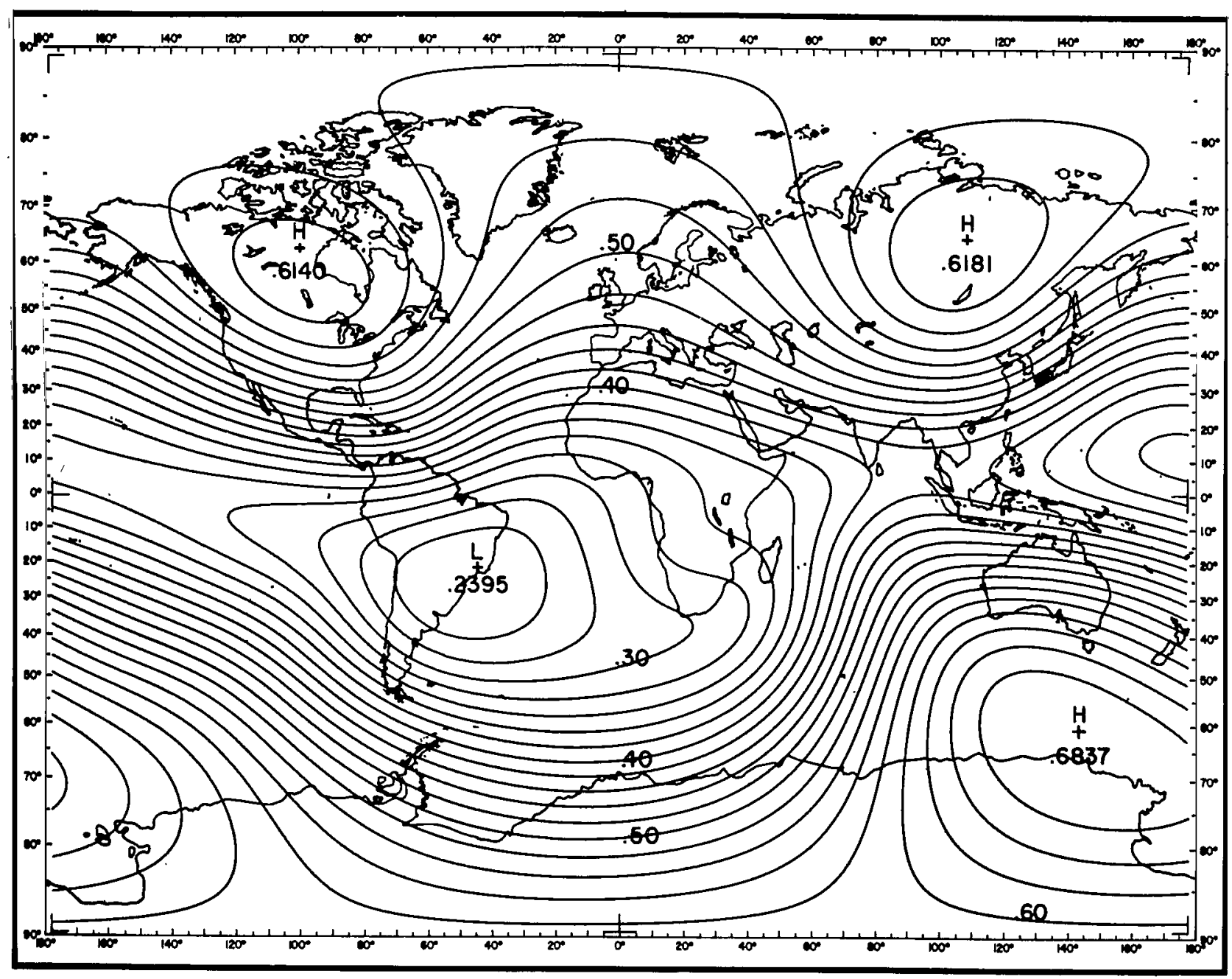

Figure $\mathrm{Cl} 3-\mathrm{F}$ in gauss, epoch 1965.0. GSFC (12/66). 
National Aeronaütics and Space Administration

WASHINGTON, D. :C.

OFFICIAL BUSINESS

$$
\begin{aligned}
& \text { ULU UO1 3E =1 3.55 6807400903 } \\
& \text { AI: HURCE WEATCHS LABURATURY/AFWL/ }
\end{aligned}
$$

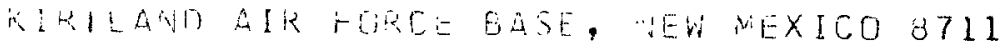

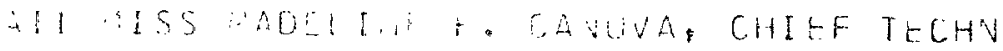

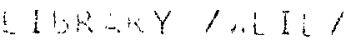

"The aeronautical and space activities of the United States shall be conducted so as to contribute . . to the expansion of buman knowledge of phenomena in the atmosphere and space. The Administration shall provide for the widest practicable and appropriate dissemination of information concerning its activities and the results thereof."

- National Aeronautics and Space Act of 1958

\section{NASA SCIENTIFIC AND TECHNICAL PUBLICATIONS}

TECHNICAL REPORTS: Scientific and technical information considered important, complete, and a lasting contribution to existing knowledge.

TECHNICAL NOTES: Information less broad in scope but nevertheless of importance as a contribution to existing knowledge.

TECHNICAL MEMORANDUMS: Information receiving limited distribution because of preliminary data, security classification, or other reasons.

CONTRACTOR REPORTS: Scientific and technical information generated under a NASA contract or grant and considered an important contribution to existing knowledge.

TECHNICAL TRANSLATIONS: Information published in a foreign language considered to merit NASA distribution in English.

SPECIAL PUBLICATIONS: Information derived from or of value to NASA activities. Publications include conference proceedings, monographs, data compilations, handbooks, sourcebooks, and special bibliographies.

TECHNOLOGY UTILIZATION PUBLICATIONS:; Information on technology used by NASA that may be of particular interest in commercial and other non-aerospace applications. Publications include Tech Briefs, Technology Utilization Reports and Notes, and Technology Surveys.

Details on the availability of these publications may be obtained from:

SCIENTIFIC AND TECHNICAL INFORMATION DIVISION 